\title{
Catalogue of Early Netherlandish Paintings with Devotional Portraits (1400-1550)
}

Cat. oo1-Type 6A

Anonymous Antwerp Master

Altarpiece of the Virgin (c. 1525)

Size unknown, oil on wood and carved piece Bocholt, church of St. Lawrence

BIBL.: BUYLE and VANTHILLO 2000, 134-35

(with bibl.); Exh. cat. Antwerp 1993, 133-34.

REMARK: The current shape and format of the altarpiece are not original. See BUYLE and VANTHILLO 2000.

Identity of the sitter(s): unknown

Provenance: Bocholt, church of St. Lawrence

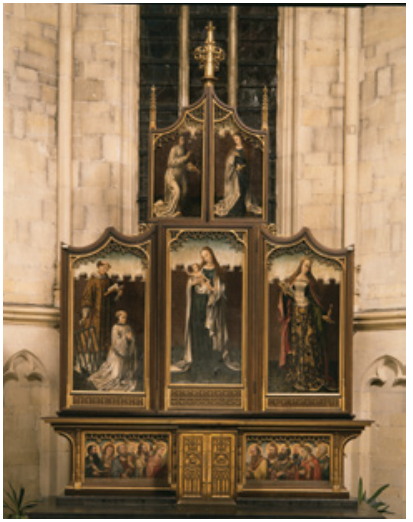

Number of portrait(s): 1

Type of person(s): religious (man alone: canon)

Attitude of the sitter(s): hands clasped

Representation of the sitter(s): full-length

Gaze of the sitter(s): indeterminate

Object(s): no

Coat(s) of arms: no

Environment: enclosed garden (incomplete)

Structuring of the pictorial space: indeterminate

Patron saint(s): Lawrence

Gesture of the patron saint(s): holding his/her attribute

Type of religious scene: hieratic

Religious scene(s) depicted: the Life of the Virgin, the Tree of Jesse, the Legend of St. Lawrence, the Annunciation, St. Catherine

Cat. oo2-Type $2 \mathrm{C}$

[R KD work no. 199623]

Anonymous Antwerp Master

Carved Triptych of the Adoration of the Magiwith a Family in Prayer (c.1500-1525)

$83.5 \times 72 \mathrm{~cm}$ (closed), oil on wood and carved piece

Brussels, sale Servarts (16 May 2006), lot no. 59 .

BIB L.: Sale cat. Servarts (Brussels, 16 May 2006), no. 59 . 
HISTORICAL INFORMATION: The coats of arms depicted on the wings are those of the Flemish family Dymudts (according the entry in the catalogue of the Servarts sale).

Identity of the sitter(s): members of the Dymudts family

Provenance: unknown

Number of portrait(s): 11

Type of person(s): mixed (family with children)

Attitude of the sitter(s): hands clasped

Representation of the sitter(s): full-length

Gaze of the sitter(s): towards the scene

Object(s): yes (rosary)

Coat(s) of arms: yes

Environment: landscape, no sacred connotation

Structuring of the pictorial space: distinct spaces (different techniques: painting/sculpture)

Patron saint(s): none

Gesture of the patron saint(s): not applicable

Type of religious scene: narrative

Religious scene(s) depicted: the Adoration of the Magi

\section{Cat. oo3-Type 6B}

Anonymous Antwerp Master

One Wing. Portrait of a Man in Prayer (c. 1525)

$34 \times 24.2 \mathrm{~cm}$

London, sale Sotheby's (14 April 2011), lot no. 43

Identity of the sitter(s): unknown

Provenance: unknown

Number of portrait(s): 1

Type of person(s): lay (man alone)

Attitude of the sitter(s): hands clasped

Representation of the sitter(s): half-length

Gaze of the sitter(s): indeterminate

Object(s): no

Coat(s) of arms: no

Environment: landscape, no sacred connotation (incomplete)

Structuring of the pictorial space: indeterminate

Type of religious scene: indeterminate

Patron saint(s): no 
Gesture of the patron saint(s): not applicable

Religious scene(s) depicted: none

\section{Cat. o04-Type 6A}

Anonymous Antwerp Master

One Wing. The Nativity; St. Paul and Five Men in Prayer (reverse) (dated 1516) $168 \times 114 \mathrm{~cm}$

Cologne, Wallraf-Richartz Museum, inv. nos. 592-593

BIB L.: Mus. cat. Cologne 1969, 14.

Identity of the sitter(s): unknown

Provenance: unknown

Number of portrait(s): 5

Type of person(s): lay (group: unidentified)

Attitude of the sitter(s): hands clasped

Representation of the sitter(s): full-length, small scale

Gaze of the sitter(s): indeterminate

Object(s): no

Coat(s) of arms: no

Environment: niche

Structuring of the pictorial space: indeterminate

Patron saint(s): none

Gesture of the patron saint(s): not applicable

Type of religious scene: hieratic

Religious scene(s) depicted: St. Paul, St. Nicholas

\section{Cat. 005 - Type ${ }_{3} \mathrm{C}$}

Anonymous Antwerp Master

The Seizing of St. Mark (c. 1520)

$37.1 \times 27.9 \mathrm{~cm}$

Philadelphia, Philadelphia Museum of Art, inv. no. $384 a$

BIB L.: Mus. cat. Philadelphia 1913 (vol. 2), no. 384(A); Mus. cat. Philadelphia 1994, 82.

HISTORICAL INFORMATION: The coat of arms painted in the upper part of the painting belongs to Marcus Cruyt, abbot of the Cistercian

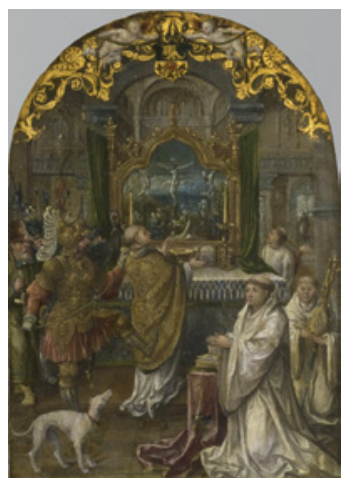
abbey of St. Bernard on the Scheldt in Hemiksem, between 1518 and 1536 . Soon after his entry into the abbey, Cruyt was sent to the Cistercian college 
in Paris. In 1518, he obtained the title of Licentiate of Theology from the University of Leuven and became abbot of Hemiksem. In 1519, he was appointed Vicar General of the Cistercian order of the Low Countries. In 1521, Charles v sent him with his embassy to Denmark. Cruyt died in 1536 (on the biography of Marcus Cruyt, see MOLHUYSEN and BLOK 1914, 270). The abbot is also known for his patronage: he commissioned to the scribe Francis Weert several manuscripts, including a book of Hours, illuminated in Antwerp c. 1525, which contained his portrait (Bornem, St. Bernard abbey, ms. 9) and the Arenberg Missal, illuminated by the Master of Cardinal Wolsey (whereabouts unknown). Cruyt also commissioned a Triptych of the Crucifixion (Springfield, Museum of Fine Arts) to Goswyn van der Weyden and a stained-glass window, also depicting the Crucifixion, for the church of St. Gummarus at Lier (c. 1535).

Identity of the sitter(s): Marcus Cruyt

Provenance: Hemiksem, abbey of St. Bernard on the Scheldt (?)

Number of portrait(s): 1

Type of person(s): religious (man alone: Cistercian abbot)

Attitude of the sitter(s): hands clasped

Representation of the sitter(s): full-length

Gaze of the sitter(s): into space

Object(s): yes (prie-dieu, book, dog)

Coat(s) of arms: yes

Environment: historical setting

Structuring of the pictorial space: not applicable

Patron saint(s): none

Gesture of the patron saint(s): not applicable

Type of religious scene: narrative

Religious scene(s) depicted: the Seizing of St. Mark

Cat. oo6-Type 2A

Anonymous Antwerp Master

Triptych of the Adoration of the Magi with a Family in Prayer and Patron

Saints (c. 1500-1525)

$99.7 \times 65.7 \mathrm{~cm}$ (centre panel) and

$99.7 \times 32.7 \mathrm{~cm}$ (wings)

New York, sale Sotheby's (6 June 2013), lot no. 5

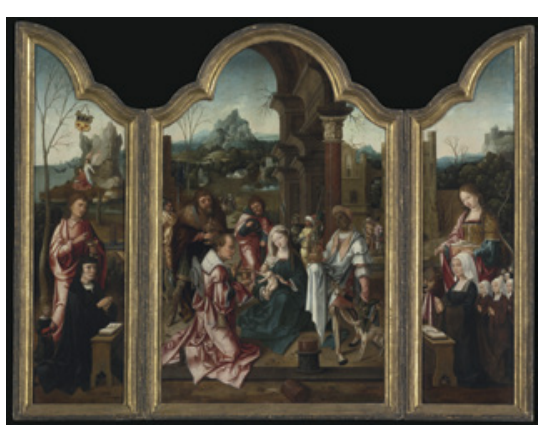

HISTORICAL INFORMATION: The coat of arms depicted on the left wing belongs to the Antwerp and Amsterdam family 'T Serwouters. The presence of 
St. John and St. Margaret introducing the couple suggests that the sitters were named Jan and Margriet. Unfortunately, no mention of the family has been traced back to the early sixteenth century.

Identity of the sitter(s): members of the 'T Serwouters family (?)

Provenance: unknown

Number of portrait(s): 10

Type of person(s): lay (family with children)

Attitude of the sitter(s): hands clasped, holding a small cross

Representation of the sitter(s): full-length

Gaze of the sitter(s): into space

Object(s): yes (prie-dieu, book, rosary, small cross)

Coat(s) of arms: yes

Environment: historical setting

Structuring of the pictorial space: unified space with discontinuities

Patron saint(s): John the Evangelist, Margaret

Gesture of the patron saint(s): holding his/her attribute

Type of religious scene: narrative

Religious scene(s) depicted: the Adoration of the Magi, St. Elizabeth and

St. Paul

\section{Cat. 007-Type 2A}

[RKD work no. 187411]

Anonymous Antwerp Master

Triptych of the Crucifixion with a Family in Prayer and Patron Saints

(c. 1525)

$88.5 \times 61 \mathrm{~cm}$ (centre panel) and $88.5 \times 25 \mathrm{~cm}$ (wings)

Nijmegen, church of St. Stephen

Identity of the sitter(s): unknown

Provenance: unknown

Number of portrait(s): 4

Type of person(s): lay (family)

Attitude of the sitter(s): hands clasped

Representation of the sitter(s): full-length

Gaze of the sitter(s): towards the scene

Object(s): no

Coat(s) of arms: no

Environment: historical setting

Structuring of the pictorial space: continuous space

Patron saint(s): a saint bishop, Catherine 
Gesture of the patron saint(s): holding his/her attribute

Type of religious scene: narrative

Religious scene(s) depicted: the Crucifixion, St. Christopher in a landscape

Cat. oo8-Type 2A

[RKD work no. 8839]

Anonymous Antwerp Master

Triptych of the Lamentation with Two Nuns in Prayer and Patron Saints (c. 1520)

$41.5 \times 27 \mathrm{~cm}$ (centre panel) and $41.5 \times 10 \mathrm{~cm}$ (wings)

Paris, sale Drouot Richelieu (18 December 1996), lot no. 1

Identity of the sitter(s): unknown

Provenance: unknown

Number of portrait(s): 2

Type of person(s): religious (group: Dominican nuns?)

Attitude of the sitter(s): hands clasped

Representation of the sitter(s): full-length

Gaze of the sitter(s): into space, towards the scene

Object(s): no

Coat(s) of arms: no

Environment: historical setting

Structuring of the pictorial space: continuous space

Patron saint(s): Bernard, a saint bishop

Gesture of the patron saint(s): introducing, holding his/her attribute

Type of religious scene: narrative

Religious scene(s) depicted: the Lamentation

Cat. oo9-Type 1 A

Anonymous Antwerp Master

Triptych of the Nativity (c. 1500-1510)

$106.5 \times 72 \mathrm{~cm}$ (centre panel) and $109 \times 3^{2} \mathrm{~cm}$ (wings)

Lille, Palais des Beaux-Arts, inv. no. P834

BIB L.: Repertory Nord-Pas-de-Calais II, no. $5^{8}$ (with bibl.).

Identity of the sitter(s): unknown

Provenance: unknown

Number of portrait(s): 2

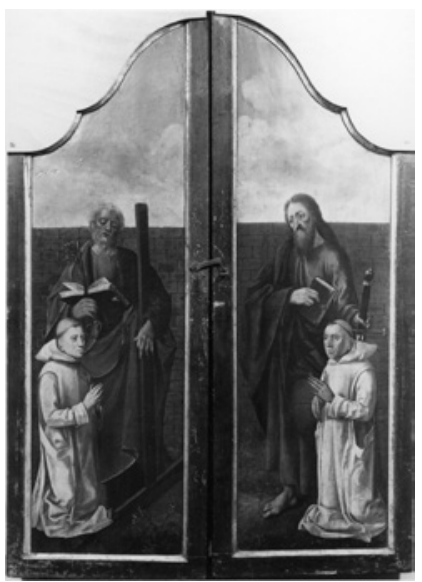


Type of person(s): religious (group: Carthusian monks)

Attitude of the sitter(s): hands clasped

Representation of the sitter(s): full-length

Gaze of the sitter(s): into space

Object(s): no

Coat(s) of arms: no

Environment: enclosed garden (incomplete)

Structuring of the pictorial space: distinct spaces

Patron saint(s): Peter, Paul

Gesture of the patron saint(s): holding his/her attribute

Type of religious scene: narrative

Religious scene(s) depicted: the Nativity, the Annunciation, the Massacre of the Innocents

\section{Cat. o10-Type 6A}

[RKD work no. 193333-193334]

Anonymous Antwerp Master

Two Wings. A Couple in Prayer (c. 1520)

$95.5 \times 32.5 \mathrm{~cm}$ (each wing)

Zurich, sale Koller (23 March 2007), lot no. 3004

REMARK: The religious scenes depicted in the background of the wings (the

Crucifixion on the left and the Discovery of the empty tomb on the right) suggest that the centre panel of the now dismembered triptych showed a Lamentation or a Descent from the Cross.

Identity of the sitter(s): unknown

Provenance: unknown

Number of portrait(s): 2

Type of person(s): lay (family)

Attitude of the sitter(s): hands clasped, holding a book

Representation of the sitter(s): half-length

Gaze of the sitter(s): indeterminate

Object(s): yes (prie-dieu, book, rosary)

Coat(s) of arms: no

Environment: historical setting

Structuring of the pictorial space: indeterminate

Patron saint(s): none

Gesture of the patron saint(s): not applicable

Type of religious scene: indeterminate

Religious scene(s) depicted: none 
Cat. o11-Type 2A

[RKD work no. 54593]

Anonymous Antwerp or Leiden Master

Triptych of the Descent of the Cross with a Family in Prayer and Patron Saints (c. 1520)

$119 \times 89 \mathrm{~cm}$ (centre panel), $119 \times 37 \mathrm{~cm}$ (left wing) and $119 \times 37.5 \mathrm{~cm}$ (right wing) Münster, Landesmuseum für Kunst und Kulturgeschichte, inv. no. 167 W KV BIB L.: GIBSON 1970, 111-15; Mus. cat. Münster 1986, 518-22.

HISTORICAL INFORMATION: The coats of arms of the family appear on the outer wings: on the left, the father's coat of arms is that of the Van Eck family, and that of the mother probably belongs to the Van Ockersum family. Both families came from the Northern Low Countries, but no trace of a marriage between their members in the early sixteenth century has been found.

Identity of the sitter(s): members of the families Van Eck and Van Ockersum Provenance: unknown

Number of portrait(s): 7

Type of person(s): lay (family with children)

Attitude of the sitter(s): hands clasped

Representation of the sitter(s): full-length

Gaze of the sitter(s): towards the scene

Object(s): no

Coat(s) of arms: yes (on the reverse)

Environment: historical setting

Structuring of the pictorial space: unified space with discontinuities

Patron saint(s): John the Baptist, Mary

Gesture of the patron saint(s): holding his/her attribute

Type of religious scene: narrative

Religious scene(s) depicted: the Descent from the Cross

Cat. 012-Type 2 B

Anonymous Artois Master

Triptych of the Virgin and Child ('Triptych of Jean Thorion') (c. 1500-1520)

$95 \times 63 \mathrm{~cm}$ (centre panel) and $95 \times 31.5 \mathrm{~cm}$ (wings)

Saint-Omer, church of Our Lady (loan of the Trésor de la Cathédrale, Arras), inv. no. 219

BIB L.: Repertory Nord-Pas-de-Calais II, no. 53 (with bibl.).

HISTORICAL INFORMATION: Jean Thorion was choirmaster and master of the Boys' Choir of the collegiate church of Saint-Omer. He is regularly cited between 1491-1492 and 1528 in the comptes de fabrique of this church. In 1517, he is 
mentioned as priest and vicar of the St. Catherine's chapel. According to Heck (Repertory Nord-Pas-de-Calais II), the triptych was a funerary work.

Identity of the sitter(s): Jean Thorion

Provenance: Saint-Omer, church of Our Lady, St. Nicholas' chapel, then chapel of Antoine Wissocq

Number of portrait(s): 1

Type of person(s): religious (man alone: canon)

Attitude of the sitter(s): hands clasped

Representation of the sitter(s): full-length

Gaze of the sitter(s): into space

Object(s): no

Coat(s) of arms: yes

Environment: landscape with sacred connotation

Structuring of the pictorial space: distinct spaces, religious scene in a cloud Patron saint(s): John the Baptist

Gesture of the patron saint(s): protecting

Type of religious scene: hieratic

Religious scene(s) depicted: Maria in Sole, St. Jerome in the wilderness, the Annunciation

\section{Cat. 013 - Type 2A}

Anonymous Brabant Master

Carved Altarpiece of the Assumption of the Virgin (the 'Ternant Altarpiece') (c. 1440-1455)

$15^{8} \times 315 \mathrm{~cm}$ (open), oil on wood and carved piece Ternant, church of St. Roch

BIB L.: JOURNET 1963; DIDIER 1967; GAUTHIER 1968; KAGAN et alii 2002.

HISTORICAL INFORMATION: Lord of Ternant, Thoisy and Boutevet, Philippe de Ternant was councillor and chamberlain of Philip the Good. He was also one of the first knights of the Order of the Golden Fleece in 1430. In 1431, he married Isabeau de Roye, daughter of Mathieu de Roye and Marguerite de Ghistelles. Philippe and Isabeau had one son, Charles de Ternant, who became a close friend of the future Charles the Bold. During his career, Philippe travelled several times to the Low Countries and thus may have

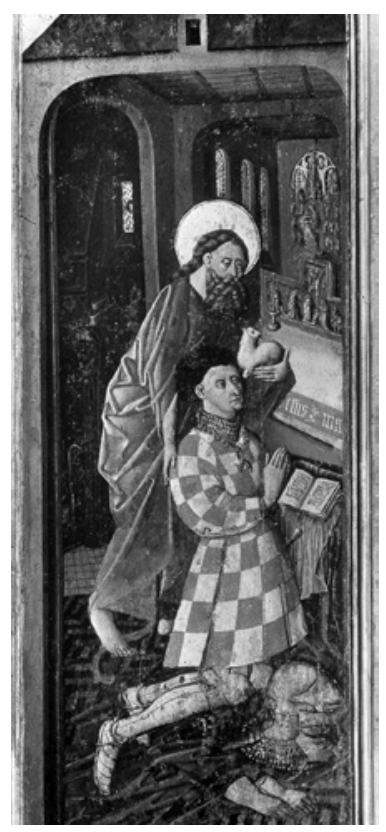


had several opportunities to commission his altarpiece. As both an ambassador and warrior, Philippe stayed in favour at the court until 1450. The following year, during the assembly of the Order of the Golden Fleece, he was accused of misappropriation of ducal funds and was obliged to undertake the pilgrimage to Santiago de Compostela. The commission of this altarpiece took place during the vast foundation of the chapel of the couple's castle, in the diocese of Autun. This chapel was dedicated to the Virgin and was founded in 1444. Four years later, Philippe de Ternant asked for authorisation to transform the chapel into a collegiate church. In April 1449, a papal bill authorised this transformation. Philippe de Ternant died in 1454, the very same year as the signature of the definitive foundation act.

Identity of the sitter(s): Philippe de Ternant and Isabeau de Roye

Provenance: Ternant, chapel of the castle

Number of portrait(s): 2

Type of person(s): lay (couple)

Attitude of the sitter(s): hands clasped

Representation of the sitter(s): full-length

Gaze of the sitter(s): towards the scene

Object(s): yes (prie-dieu, book, helmet, collar of the Order of the Golden Fleece)

Coat(s) of arms: yes

Environment: ecclesial space

Structuring of the pictorial space: distinct spaces (different techniques: painting/sculpture)

Patron saint(s): John the Baptist, Catherine

Gesture of the patron saint(s): introducing

Type of religious scene: narrative

Religious scene(s) depicted: the Life of the Virgin

Cat. 014-Type 3 B

Anonymous Brabant Master

Philippe de Hinckaert in Prayer in Front of the Virgin and Child (c. 1475-1500)

$66.2 \times 73 \mathrm{~cm}$

Cambridge, Fitzwilliam Museum, inv. no. PD.19-1961

BIBL.: VAN DEN BERGEN-PANTENS 1996; Exh. cat. Cambridge 1993, no. 4 (with bibl.).

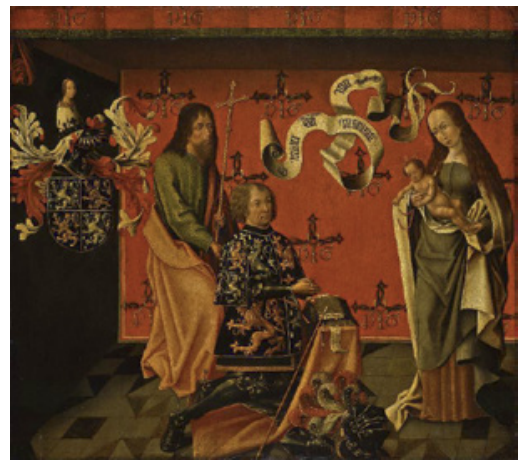


HISTORICAL INFORMATION: The painting includes the portrait of Philippe de Hinckaert, identified by his coat of arms. The man is cited until 1504 as Maitre d'hôtel of Philip the Fair. He is also mentioned as councillor of the Duke of Brabant. Philippe de Hinckaert died in 1505 and was buried in the choir of the Holy Sacrament in the church of Steenockerzeel, to which he made several gifts. He first married Hélène de Baronage, who regularly appears in archives as his wife between 1482 and 1493. In 1494, Philippe married Gertrude van de Vuecht, whose initials appear on the cloth in the background of the painting. The original location of the painting is unknown. Van den Bergen-Pantens suggests that this is a memorial piece mentioned in Philippe's will.

REMARK: According to several scholars, the work does not appear in its original shape, but would be a fragment of a bigger panel with the portrait of Hinckaert's wife, Gertrude van de Vuecht, on the right of the Virgin. Brine notably bases this hypothesis on the fact that Gertrude's initials appear in the background (BRINE 2008, 145-46). I could not examine the panel myself but its reproduction in Brine's article goes against this hypothesis. Indeed, four unpainted edges can be observed, suggesting that this is actually the original shape of the work.

Identity of the sitter(s): Philippe de Hinckaert

Provenance: unknown

Number of portrait(s): 1

Type of person(s): lay (man alone)

Attitude of the sitter(s): hands clasped

Representation of the sitter(s): full-length

Gaze of the sitter(s): towards the scene

Object(s): yes (prie-dieu, helmet, book, parchment, staff, banderole)

Coat(s) of arms: yes

Environment: architectural space with sacred connotation

Structuring of the pictorial space: not applicable

Patron saint(s): Philip

Gesture of the patron saint(s): introducing

Type of religious scene: hieratic

Religious scene(s) depicted: the Virgin and Child 
Cat. 015-Type $3 \mathrm{C}$

Anonymous Brabant Master

The Mass of St. Gregory with a Monk and Nuns in Prayer (c. 1475-1500)

$58.5 \times 54 \mathrm{~cm}$

Uden, Museum voor religieuze Kunst (loan of the Rijksmuseum, Amsterdam), inv. no. 34 BIBL.: Exh. cat. Den Bosch 1990, no. 93; Mus. cat. Amsterdam 2009 [online], https://www. rijksmuseum.nl/en/collection/SK-A-280o/ catalogue-entry (with bibl.).

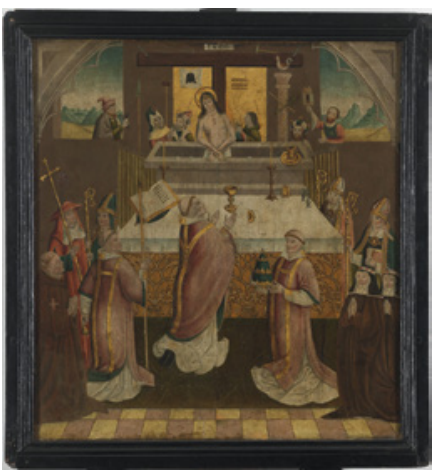
HISTORICAL INFORMATION: This panel comes from the Brigittine convent of Mariënwater in Koudewater. It depicts two Brigittine nuns and one Brigittine monk, who have not been identified. According to Filedt Kok (in Mus. cat. Amsterdam 2009 [online]), the panel probably comes from the cell of a nun and had a devotional function.

Identity of the sitter(s): Brigittine nuns and monk of Mariënwater

Provenance: Koudewater, Brigittine convent of Mariënwater

Number of portrait(s): 3

Type of person(s): religious (group: Brigittine nuns and a monk)

Attitude of the sitter(s): hands clasped

Representation of the sitter(s): full-length

Gaze of the sitter(s): into space, towards the scene

Object(s): no

Coat(s) of arms: no

Environment: historical setting

Structuring of the pictorial space: not applicable

Patron saint(s): none

Gesture of the patron saint(s): not applicable

Type of religious scene: narrative

Religious scene(s) depicted: the Mass of St. Gregory 
Cat. o16-Type $3 \mathrm{~A}$

Anonymous Bruges Master

Altarpiece of St. Michael (c. 1530)

$323 \times 235 \mathrm{~cm}$ (fully opened)

Bergara, church San Pedro

BIBL.: Exh. cat. Brussels 1985 (vol. 2), 500-03; MARTENS D. 2010, 215-17; FALQUE 2011, 291-92.

HISTORICAL INFORMATION: The altarpiece comes from the church of St. Peter at Bergara (in the Basque region), where it is still preserved today. The coat of arms painted on the prie-dieu is that of the city of Bergara, but the devotees cannot be identified. They could be members of the Ozaeta family, who occupied a prevailing position in the city during the sixteenth century. Nowadays, the altarpiece is located in the sacristy of the church, but this is not its original location. In Exh. cat. Brussels 1985 (vol. 2), Steppe mentions the existence of an altar dedicated to St. Michael, whose decoration was in the charge of the Flemish churchwarden Juan de Gante between 1525 and 1535, according to archival sources. Steppe considers, nonetheless, that the familial character of the altarpiece prevents a link to these documents. Rather, he believes that the work comes from the chapel of the Ozeata family, although he does not provide any supporting evidence. The iconography of the altarpiece and the coat of arms of the city nevertheless make the first hypothesis plausible.

Identity of the sitter(s): members of the Ozaeta family (?)

Provenance: Bergara, church of St. Peter

Number of portrait(s): 14

Type of person(s): lay (family with children)

Attitude of the sitter(s): hands clasped

Representation of the sitter(s): full-length

Gaze of the sitter(s): towards the scene

Object(s): yes (prie-dieu, book, helmet, rosary)

Coat(s) of arms: yes

Environment: landscape, no sacred connotation

Structuring of the pictorial space: fragmentation of the pictorial space

Patron saint(s): Gaspard (?), Mary

Gesture of the patron saint(s): holding his/her attribute, protecting

Type of religious scene: narrative

Religious scene(s) depicted: Apparitions of St. Michael, the Mass of St. Gregory, the Throne of Mercy, the Annunciation, the apostles, Christ as Salvator Mundi 
Cat. 017-Type 4B

Anonymous Bruges Master

Diptych of the Virgin and Child

('Diptych of Joos van der Burch')

(c. 1480 for the left wing and

c. 1490 for the right wing)

$56.6 \times 36.9 \mathrm{~cm}$ (left wing) and

$56.1 \times 35.7 \mathrm{~cm}$ (right wing)

Harvard, Fogg Art Museum, inv. no. $1906.6 \mathrm{a}-\mathrm{b}$

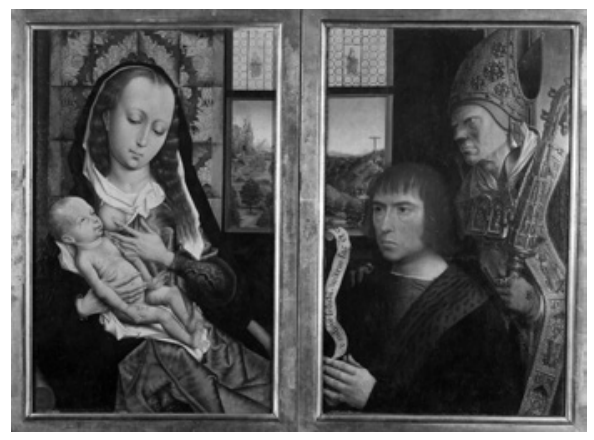

BIBL.: FRIEDLÄNDER II, no. 107c; Corpus New England, no. 64; Exh. cat. Antwerp and Washington 2006, no. 40 (with bibl.).

HISTORICAL INFORMATION: The two coats of arms and the epitaph inscribed on the reverse of the panels indicate that the portrayed man is Joos van de Burch: Hier voren ligghen begraven Joos van der Burch, wilen raed konijncx vanden rommschen Rijcke ende zijns zoons Philippus, erdshertogh van Oostrijcke, hertoghen van Bourgognen, graven van Vlanderen, etc., ende ghecommiteerd ontfanghere van Veurnambocht XXIX jaren, die starf den vierden dach van Sporkele int jare MCCCC zesendetneghentich JK [coat of arms] JK ende joncvrouwe Katheline vander Mersch, zijn eerSt. wijf, die starf den XX dach van maye int jaer MCCCC zesendetseventich. Bid over de zielen. Joos was receiver of the châtellenie of Veurne between 1465 and 1492 and also councillor of the city of Veurne. He first married Catheline van der Meersch, who died in 1476. They had several children. Afterwards, Joos married Isabelle de la Tour (or de la Torre). Technological investigation have revealed that the original portrait has been overpainted by the current one and that the coat of arms was modified at an early date. Initially, the diptych depicted Simon van der Burch-the third son of Joos-in prayer in front of the Virgin. Simon was bailiff of Veurne. He died in 1518. In all probability, the diptych was first conceived as a devotional piece for Simon. After his death, a member of the family probably inherited the work, changed the portrait and added the text on the reverse, in order to transform the work into a memorial work for his father, Joos and his mother, Catheline, with the work destined for the family chapel where his parents were buried.

Identity of the sitter(s): Joos van der Burch

Provenance: Veurne, church of St. Walburgis

Number of portrait(s): 1

Type of person(s): lay (man alone) 
Attitude of the sitter(s): holding a banderole

Representation of the sitter(s): half-length

Gaze of the sitter(s): into space

Object(s): yes (banderole)

Coat(s) of arms: yes

Environment: domestic setting

Structuring of the pictorial space: unified space with discontinuities

Patron saint(s): Simon (?)

Gesture of the patron saint(s): protecting

Type of religious scene: hieratic

Religious scene(s) depicted: the Virgin and Child

Cat. 018-Type $4 \mathrm{D}$

Anonymous Bruges Master

Diptych of the Virgin and Child with a Man in Prayer (c. 1490)

$37.2 \times 27.2 \mathrm{~cm}$ (left wing) and

$37.1 \times 26.9 \mathrm{~cm}$ (right wing)

London, Courtauld Institute of Art, inv. no. Lee bequest 1947

BIBL.: FRIEDLÄNDER VIa, no. 111;

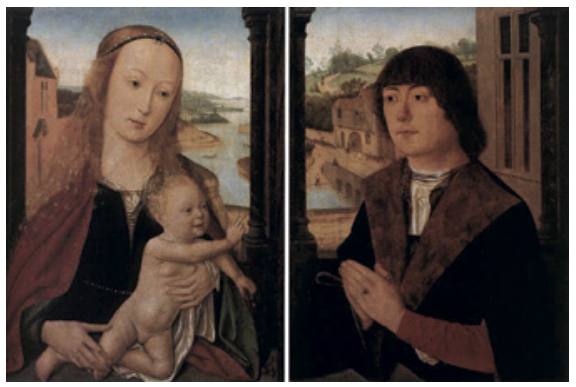

Exh. cat. Bruges 1994, no. 83 (with bibl.).

Identity of the sitter(s): unknown

Provenance: unknown

Number of portrait(s): 1

Type of person(s): lay (man alone)

Attitude of the sitter(s): hands clasped

Representation of the sitter(s): half-length

Gaze of the sitter(s): towards the scene

Object(s): no

Coat(s) of arms: no

Environment: domestic setting

Structuring of the pictorial space: continuous space

Patron saint(s): none

Gesture of the patron saint(s): not applicable

Type of religious scene: hieratic

Religious scene(s) depicted: the Virgin and Child 
Cat. 019-Type 5

Anonymous Bruges Master

Mary of Burgundy, Jan Crabbe and Pierre Vaillant in Front of the Nativity (opening panel of the Genealogy of Ten Duinen Abbey) (1480)

$136.5 \times 98 \mathrm{~cm}$

Bruges, Grootseminarie

BIBL.: JANSSENS DE BISTHOVEN 1984; Exh. cat. Bruges 1994, no. 65; Exh. cat. Mechelen 2005, no. 13 (with bibl.). HISTORICAL INFORMATION: This panel opens a cycle of seventeen panels tracing the genealogy of the Counts of Flanders and of the abbots of the Cistercian abbey of Ten Duinen in Koksijde. The inscrip-

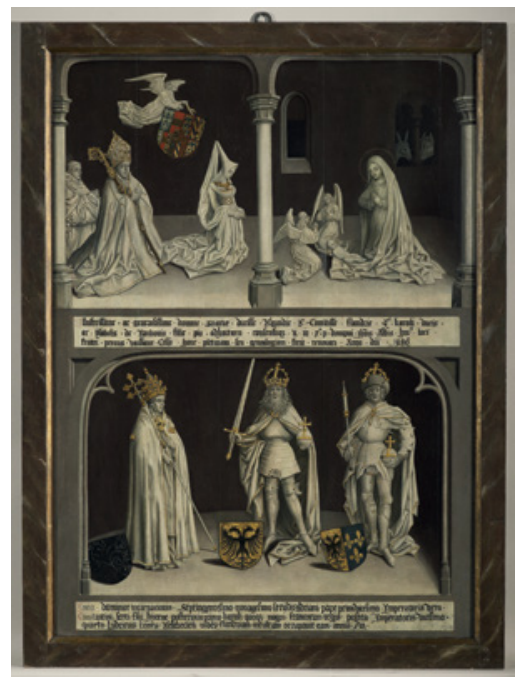
tion located in the lower part of the panel states that Pierre Vaillant, manager of Ten Duinen, commissioned the cycle at the request of the Duchess Mary of Burgundy and in agreement with the abbot Jan Crabbe in 1480: illustrissimae et generosissimae Dominae Mariae ducissae Burgundiae et comitissae Flandriae Karoli ducis / ac Ysabelis de Borbonio filiae pio adhortatu consensuque Reverendi in Christo Patris Domini Ioannis abbatis huius loci, / frater Petrus Vaillant cellerarius hanc picturam seu genealogiam fecit renovari. Anno Domini 1480 . The three sitters are depicted on the panel and the cycle was destined for the abbey. For another portrait of Jan Crabbe, see cat. 579.

Identity of the sitter(s): Mary of Burgundy, Jan Crabbe and Pierre Vaillant

Provenance: Koksijde, Cistercian abbey of Ten Duinen

Number of portrait(s): 3

Type of person(s): mixed (group)

Attitude of the sitter(s): hands clasped

Representation of the sitter(s): full-length

Gaze of the sitter(s): into space, towards the ground, towards the scene

Object(s): no

Coat(s) of arms: yes

Environment: niche

Structuring of the pictorial space: not applicable

Patron saint(s): none

Gesture of the patron saint(s): not applicable

Type of religious scene: narrative

Religious scene(s) depicted: the Nativity 
Cat. 020-Type 6B

Anonymous Bruges Master

Portrait of a Young Woman in Prayer (1519)

$51 \times 39 \mathrm{~cm}$

Merion, Barnes Foundation, inv. no. BF832 BIBL.: FRIEDLÄNDER VIa, no. 98; DE VOS 1994, no. B8 (with bibl.).

Identity of the sitter(s): unknown

Provenance: unknown

Number of portrait(s): 1

Type of person(s): lay (woman alone)

Attitude of the sitter(s): holding a rosary

Representation of the sitter(s): half-length

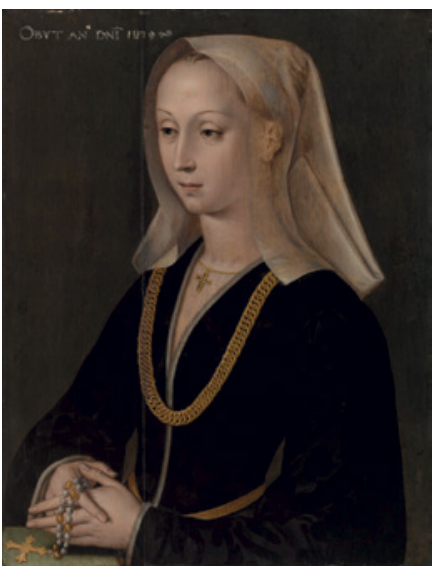

Gaze of the sitter(s): indeterminate

Object(s): yes (rosary)

Coat(s) of arms: no

Environment: neutral space (incomplete)

Structuring of the pictorial space: indeterminate

Patron saint(s): no

Gesture of the patron saint(s): not applicable

Type of religious scene: indeterminate

Religious scene(s) depicted: indeterminate

Cat. o21-Type 3 B

Anonymous Bruges Master

The Virgin and Child with a Couple in

Prayer and Patron Saints (c. 1475-1500)

$77 \times 84.6 \mathrm{~cm}$

Ghent, MSK, inv. no. 1969

BIBL.: MARTENS D. 1998b, 49-53 (with bibl.).

Identity of the sitter(s): unknown

Provenance: unknown

Number of portrait(s): 2

Type of person(s): lay (couple)

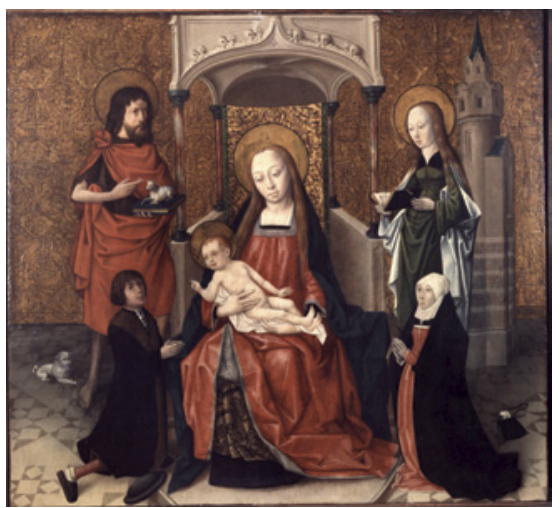

Attitude of the sitter(s): hands clasped 
Representation of the sitter(s): full-length, small scale

Gaze of the sitter(s): towards the scene

Object(s): yes (dog, hat, purse)

Coat(s) of arms: no

Environment: architectural space with sacred connotation

Structuring of the pictorial space: not applicable

Patron saint(s): John the Baptist, Barbara

Gesture of the patron saint(s): holding his/her attribute

Type of religious scene: hieratic

Religious scene(s) depicted: the Virgin and Child

Cat. o22-Type 2A

Anonymous Bruges Master

Triptych of the Lamentation with a Couple in Prayer and Patron Saints (c. 1500-1510) Size unknown

Hormaza, church San Esteban
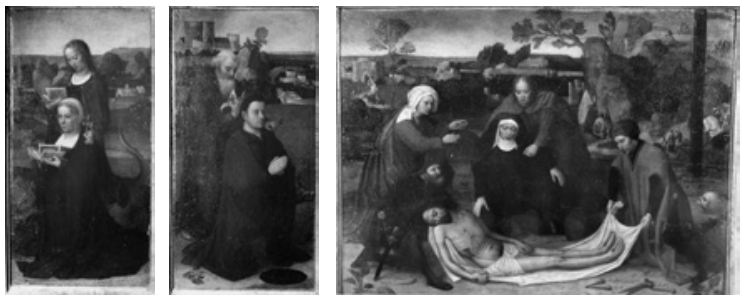

BIB L.: Repertory Spain II, no. 81 (with bibl.).

Identity of the sitter(s): unknown

Provenance: unknown

Number of portrait(s): 2

Type of person(s): lay (couple)

Attitude of the sitter(s): hands clasped, holding a book

Representation of the sitter(s): full-length

Gaze of the sitter(s): towards the scene

Object(s): yes (book, hat)

Coat(s) of arms: no

Environment: historical setting

Structuring of the pictorial space: unified space with discontinuities

Patron saint(s): Anthony, Margaret

Gesture of the patron saint(s): protecting, holding his/her attribute

Type of religious scene: narrative

Religious scene(s) depicted: the Lamentation 
Cat. 023-Type 2B

Anonymous Bruges Master

Triptych of the Virgin and

Child with a Priest in Prayer

(c. 1500-1550)

$55 \times 42 \mathrm{~cm}($ centre panel) and

$55 \times 18 \mathrm{~cm}$ (wings)

London, sale Sotheby's (7

December 2006), lot no. 112 BIBL.: GRÖSSINGER 1992,

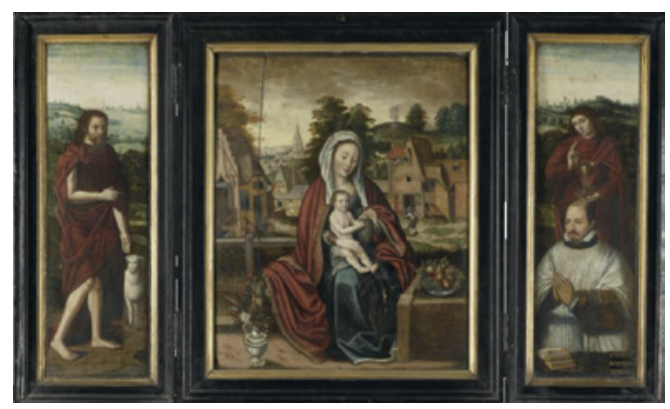

no. 40; Sale cat. Sotheby's (London, 7 December 2006), no. 112.

HISTORICAL INFORMATION: The coat of arms painted on the reverse of the wings is that of the Van Cuyck family. This lineage was nevertheless extinguished around 1400 . The same coat of arms - with some small changes-was also employed by the Van den Broeck family of Liège. The man portrayed on the right wing could thus be a man from this family, but he has not been identified precisely.

Identity of the sitter(s): unknown (member of the family Van der Broeck from Liège?)

Provenance: unknown

Number of portrait(s): 1

Type of person(s): religious (man alone: canon)

Attitude of the sitter(s): hands clasped

Representation of the sitter(s): half-length

Gaze of the sitter(s): into space

Object(s): yes (book, rosary)

Coat(s) of arms: yes

Environment: enclosed garden

Structuring of the pictorial space: unified space with discontinuities

Patron saint(s): John the Evangelist

Gesture of the patron saint(s): holding his/her attribute

Type of religious scene: hieratic

Religious scene(s) depicted: the Virgin and Child, St. John the Baptist, St. Nicholas, St. Jerome

\section{Cat. 024-Type $2 B$}

[Link to the museum website]

Anonymous Bruges Master

Triptych of the Virgin and Child with St. Anne with a Couple in Prayer and Patron Saints (dated 1488 on the frame) 
$67.5 \times 5^{1} \mathrm{~cm}$ (centre panel) and $68 \times 25.5 \mathrm{~cm}$ (wings)

Lübeck, Sankt-Annen-Museum, inv. no. 7429

BIB L.: MARTENS D. 1995, 99; HEISE and VOGELER 2008, 20-22 (with bibl.).

Identity of the sitter(s): unknown

Provenance: unknown

Number of portrait(s): 2

Type of person(s): lay (couple)

Attitude of the sitter(s): hands clasped

Representation of the sitter(s): full-length

Gaze of the sitter(s): towards the scene

Object(s): no

Coat(s) of arms: no

Environment: architectural space with sacred connotation

Structuring of the pictorial space: unified space with discontinuities

Patron saint(s): Peter, Barbara

Gesture of the patron saint(s): introducing

Type of religious scene: hieratic

Religious scene(s) depicted: the Virgin and Child with St. Anne, St. John the Evangelist, St. Peter

Cat. 025-Type 3 A

Anonymous Bruges Master (?)

The Crucifixion with a Nun in Prayer (c. 1500-1550)

Size unknown

Whereabouts unknown

Identity of the sitter(s): unknown

Provenance: unknown

Number of portrait(s): 1

Type of person(s): religious (woman alone: Augustinian canoness)

Attitude of the sitter(s): hands clasped

Representation of the sitter(s): full-length, small

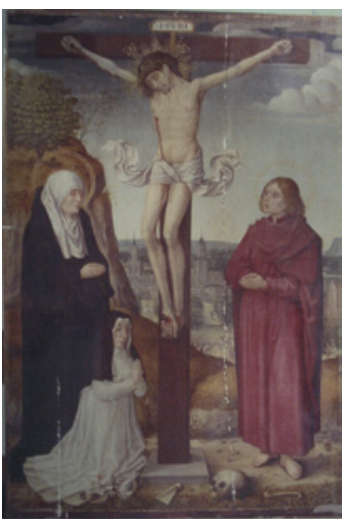

scale

Gaze of the sitter(s): into space

Object(s): no

Coat(s) of arms: yes (on the reverse)

Environment: historical setting

Structuring of the pictorial space: not applicable

Patron saint(s): none

Gesture of the patron saint(s): not applicable 
Type of religious scene: narrative

Religious scene(s) depicted: the Crucifixion

Cat. 026-Type 6A

Anonymous Bruges Master (Master of the Legend of St. Ursula?)

Two Wings. A Man in Prayer with St. Edward the Confessor; Four Saints

Standing in a Landscape (c. 1500)

$51 \times 20 \mathrm{~cm}$ (each wing)

Middlebury, Middlebury College Museum of Art, inv. no. MCMC 2011.001

Identity of the sitter(s): unknown

Provenance: unknown

Number of portrait(s): 1

Type of person(s): lay (man alone)

Attitude of the sitter(s): hands clasped

Representation of the sitter(s): full-length

Gaze of the sitter(s): indeterminate

Object(s): no

Coat(s) of arms: no

Environment: landscape, no sacred connotation (incomplete)

Structuring of the pictorial space: indeterminate

Patron saint(s): Edward or Henry

Gesture of the patron saint(s): introducing

Type of religious scene: indeterminate

Religious scene(s) depicted: St. Nicholas of Myra, St. Eloi, St. Blaise, a Bishop saint (in the background: the Martyrdom of St. Sebastian, the Beheading of St. Barbara, the Temptation of St. Anthony, and another saint)

Cat. 027-Type 6A

Anonymous Bruges or Brussels Master

Four Panels. The Legend of St. Anne (c. 1490)

$91 \times 53 \mathrm{~cm}$ (tempera on wood)

Frankfurt, Historisches Museum, inv. no. B 320-335

BIBL.: Mus. cat. Frankfurt 1957, 26-29; DE TERVARENT 1941, 35-46;

DHANENS 1998, 87-89.

HISTORICAL INFORMATION: The four panels (painted on both sides) come from an altarpiece dedicated to St. Anne, whose centre piece was carved and has not been preserved. The altarpiece was destined for the altar of the Brotherhood of St. Anne in the Carmelite church of Frankfurt. Several Flemish 
merchants were active in this brotherhood. A document dating from 1501 mentions the altarpiece on this altar. According to De Tervarent, the man with a hat and a cross, portrayed on the right, must be Rumold de Laubach, the Carmelite prior of Frankfurt between 1474 and 1496. Rumold was a fervent partisan of the cult of St. Anne and of the Immaculate Conception. He also acted as protector of the brotherhood. In his will, he stated that he wished to pay homage to the Virgin and her kinship through the commission of an altarpiece.

Identity of the sitter(s): members of the Brotherhood of St. Anne of Frankfurt Provenance: Frankfurt, Carmelite church

Number of portrait(s): 2

Type of person(s): religious (group: Carmelite monks)

Attitude of the sitter(s): hands clasped

Representation of the sitter(s): full-length

Gaze of the sitter(s): towards the scene

Object(s): no

Coat(s) of arms: no

Environment: ecclesial space

Structuring of the pictorial space: indeterminate

Patron saint(s): none

Gesture of the patron saint(s): not applicable

Type of religious scene: hieratic

Religious scene(s) depicted: the Legend of St. Anne

Cat. o28-Type 2A

Anonymous Bruges or Ghent Master

Triptych of the Lamentation with a Family in Prayer and Patron Saints (c. 1400-1500)

$71 \times 62 \mathrm{~cm}$ (centre panel) and $71 \times 26 \mathrm{~cm}$ (wings)

Vienna, sale Liebig (20 March 1934)

Identity of the sitter(s): unknown

Provenance: unknown

Number of portrait(s): 18

Type of person(s): mixed (family)

Attitude of the sitter(s): hands clasped

Representation of the sitter(s): full-length

Gaze of the sitter(s): towards the scene, towards the ground

Object(s): yes (rosary)

Coat(s) of arms: yes (on the reverse)

Environment: historical setting 
Structuring of the pictorial space: distinct spaces

Patron saint(s): Peter, James

Gesture of the patron saint(s): introducing, protecting

Type of religious scene: narrative

Religious scene(s) depicted: the Lamentation

\section{Cat. 029-Type 1D}

Anonymous Brussels Master

Carved Altarpiece of the Lamentation (c. 1490-1510)

Size unknown

Lille, Palais des Beaux-Arts, inv. no. A.267

Identity of the sitter(s): unknown

Provenance: unknown

Number of portrait(s): 1

Type of person(s): religious (man alone)

Attitude of the sitter(s): hands clasped

Representation of the sitter(s): full-length, small scale

Gaze of the sitter(s): towards the scene

Object(s): no

Coat(s) of arms: no

Environment: niche

Structuring of the pictorial space: continuous space

Patron saint(s): none

Gesture of the patron saint(s): not applicable

Type of religious scene: hieratic

Religious scene(s) depicted: the Lamentation, St. Elizabeth, St. Veronica, St. Barbara, St. Cecilia

\section{Cat. 03o-Type 24}

Anonymous Brussels Master

Carved Altarpiece of the Nativity

(c. 1490-1500)

$86 \times 151.5 \mathrm{~cm}$ (open), $86 \times 76 \mathrm{~cm}$

(closed), oil on wood and carved piece

Brussels, Musée du Centre public d'aide sociale (CPAs), inv. no. T 046

BIBL.: PERIER D'IETEREN and GESCHE-KONING 2000, 28-35.

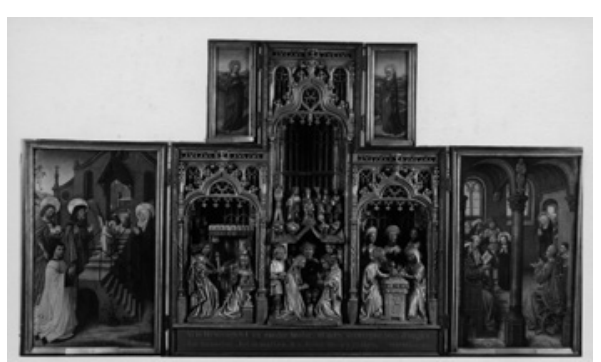


Identity of the sitter(s): unknown

Provenance: unknown

Number of portrait(s): 1

Type of person(s): religious (man alone: canon)

Attitude of the sitter(s): hands clasped

Representation of the sitter(s): full-length

Gaze of the sitter(s): into space

Object(s): no

Coat(s) of arms: no

Environment: historical setting

Structuring of the pictorial space: distinct spaces (different techniques: painting/sculpture)

Patron saint(s): John the Baptist

Gesture of the patron saint(s): introducing

Type of religious scene: narrative

Religious scene(s) depicted: the Annunciation, the Nativity, the Circumcision, the Presentation of the Virgin at the temple, Christ among the doctors, the Visitation

\section{Cat. o31-Type $4 \mathrm{D}$}

Anonymous Brussels Master

Diptych of the Pietà with Willem

Schouteet in Prayer (dated 1482

on the right wing)

$30 \times 24 \mathrm{~cm}$ (each wing)

Berlin, Staatliche Museen zu

Berlin, Gemäldegalerie (currently at the Bode Museum), inv. nos.

B.84-B.85

BIBL.: TOMBU and LEFFEVRE

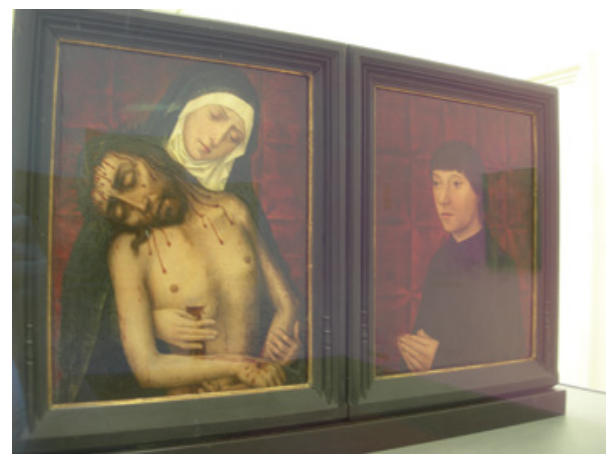

1930; Mus. cat. Berlin 1996, no. 787 .

HISTORICAL INFORMATION: An inscription identifying the sitter was formerly present on the diptych, but was erased during a restoration: Guillermus sculteti dictus de mechlinia fundator huius confrat portionar perpet ecclie bti Nicolai $9^{\circ}$ juny 1482 . The man is named as Willem Schouteet (or Guilelmus Scultetus). He was rector of the church of St. Nicholas in Brussels and was also one of the founders of the Brotherhood of the Holy Sacrament of this church. He died in 1492. According to Leffevre-who does not mention any source for this information - the diptych was destined for this church. 
Identity of the sitter(s): Willem Schouteet

Provenance: unknown

Number of portrait(s): 1

Type of person(s): religious (man alone: priest)

Attitude of the sitter(s): hands clasped

Representation of the sitter(s): half-length

Gaze of the sitter(s): towards the scene

Object(s): no

Coat(s) of arms: no

Environment: neutral space

Structuring of the pictorial space: continuous space

Patron saint(s): none

Gesture of the patron saint(s): not applicable

Type of religious scene: hieratic

Religious scene(s) depicted: the Pietà, Allegory of Death, Christ on the cross

Cat. o32-Type $3 \mathrm{C}$

Anonymous Brussels Master

The Rest on the Flight into Egypt with a Couple in Prayer (c. 1500)

$102 \times 78 \mathrm{~cm}$

Moravsky Sternberk Castle, inv. no. ST. 218 BIBL.: Repertory Czechoslovakia, no. 14 (with bibl.).

Identity of the sitter(s): unknown

Provenance: unknown

Number of portrait(s): 2

Type of person(s): lay (couple)

Attitude of the sitter(s): hands clasped

Representation of the sitter(s):

full-length

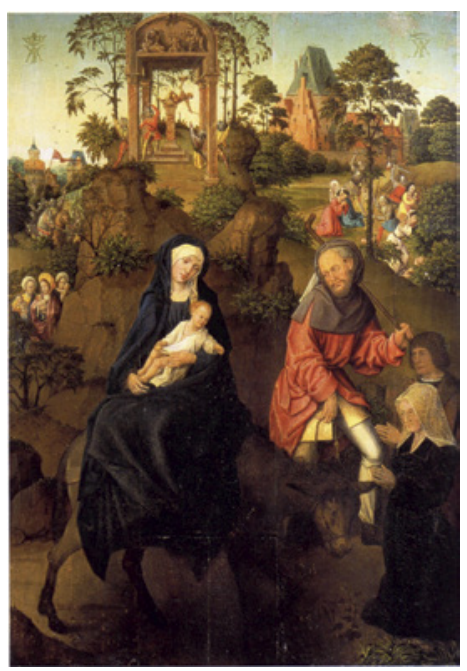

Gaze of the sitter(s): into space

Object(s): no

Coat(s) of arms: no

Environment: historical setting

Structuring of the pictorial space: not applicable

Patron saint(s): none

Gesture of the patron saint(s): not applicable

Type of religious scene: narrative

Religious scene(s) depicted: the Flight into Egypt 
Cat. 033-Type $3^{B}$

[Link to the Friedländer 3.o Database]

Anonymous Brussels Master

The Virgin and Child with St. Anne and a Monk in Prayer with Patron Saint (c. 1500$)$

$83 \times 67.5 \mathrm{~cm}$

Poznan, Museum Narodowe, inv. no. 211

BIBL.: FRIEDLÄNDER V, no. 38; MARTENS D. 1998a (with bibl.).

Identity of the sitter(s): unknown

Provenance: unknown

Number of portrait(s): 1

Type of person(s): religious (man alone: Carthusian monk)

Attitude of the sitter(s): hands clasped

Representation of the sitter(s): full-length

Gaze of the sitter(s): towards the scene

Object(s): no

Coat(s) of arms: no

Environment: architectural space, no sacred connotation

Structuring of the pictorial space: not applicable

Patron saint(s): James

Gesture of the patron saint(s): holding his/her attribute

Type of religious scene: hieratic

Religious scene(s) depicted: the Virgin and Child with St. Anne

\section{Cat. 034-Type 6A}

Anonymous Brussels Master

Two Wings. The Virgin and Child with a Canon in Prayer and St. Catherine (c. 1400-1500)

Size unknown

Whereabouts unknown (previously Madrid, Felix Labat collection)

Identity of the sitter(s): unknown

Provenance: unknown

Number of portrait(s): 1

Type of person(s): religious (man alone: canon)

Attitude of the sitter(s): hands clasped

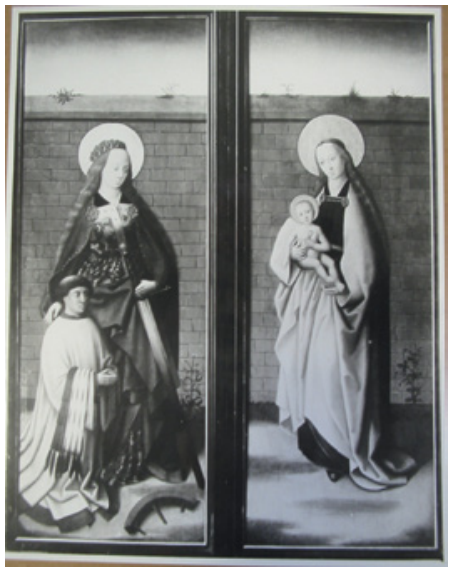

Representation of the sitter(s): full-length

Gaze of the sitter(s): indeterminate

Object(s): no 
Coat(s) of arms: no

Environment: enclosed garden (incomplete)

Structuring of the pictorial space: indeterminate

Patron saint(s): Catherine

Gesture of the patron saint(s): introducing

Type of religious scene: indeterminate

Religious scene(s) depicted: the Virgin and Child

\section{Cat. 035 - Type 2D}

Anonymous Brussels Master (previously attributed to the Master of the Embroidered Foliage)

Triptych of the Virgin and Child with Louis de Quarré and Barbe de Croesinck in Prayer (c. 1500)

$66 \times 57 \mathrm{~cm}$ (centre panel) and $75 \times 34$ $\mathrm{cm}$ (wings)

Lille, Palais des Beaux-Arts, inv. no. $\mathrm{P} 783$ BIBL.: FRIEDLÄNDER IV, no. 87; Exh. cat. Lille 2005, no. 10; Corpus Lille,

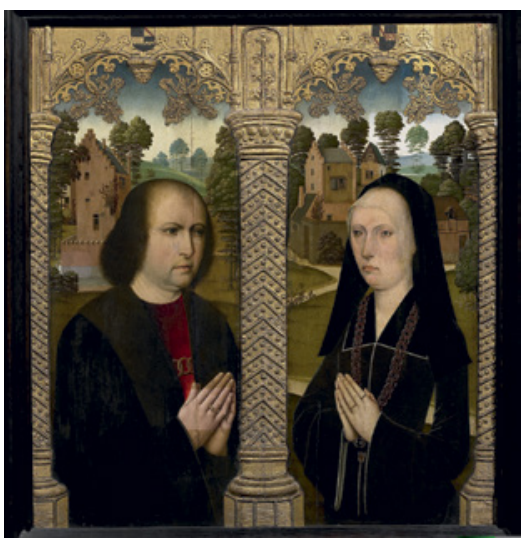
no. 229 (with bibl.).

HISTORICAL INFORMATION: Louis de Quarré was identified in 1938 as the male sitter in the painting, by Hulin de Loo, on the basis of his coat of arms (now overpainted). Lord of The Hague, he was the son of Simon de Quarré. He was appointed Receiver-general in 1482, then Treasurer of the Order of the Golden Fleece from 1486 onwards and Maitre des comptes of Luxembourg from 1491. In 1478, he married Barbe de Croesinck, who is also depicted in the triptych. The work could have been commissioned at the occasion of their marriage. Louis de Quarré died on 15 September 1520 and was buried at the church of St. Catherine in Mechelen. His wife died on 13 May 1531.

Identity of the sitter(s): Louis de Quarré and Barbe de Croesinck

Provenance: unknown

Number of portrait(s): 2

Type of person(s): lay (couple)

Attitude of the sitter(s): hands clasped

Representation of the sitter(s): half-length

Gaze of the sitter(s): into space

Object(s): no

Coat(s) of arms: yes 
Environment: landscape, no sacred connotation

Structuring of the pictorial space: distinct spaces

Patron saint(s): none

Gesture of the patron saint(s): not applicable

Type of religious scene: hieratic

Religious scene(s) depicted: the Virgin and Child

\section{Cat. 036-Type $3 \mathrm{D}$}

Anonymous Dordrecht Master

St. Agnes with Gertruy Haeck in Prayer

(c. 1475-1500)

$60.5 \times 46.4 \mathrm{~cm}$

Amsterdam, Rijksmuseum, inv. no. SK-A-3926

BIB L.: Mus. cat. Amsterdam 1976, 685;

Exh. cat. Utrecht 1999-2000, 243-44;

Mus. cat. Amsterdam 2009 [online], https://www.rijksmuseum.nl/nl/col lectie/SK-A-3926/catalogus-entry

(with bibl.).

HISTORICAL INFORMATION: On the basis of the coat of arms, the woman

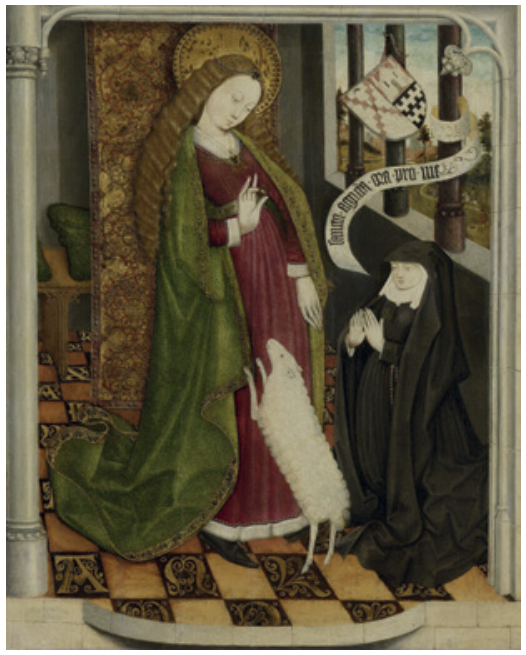
has been identified as Gertruy Haeckvan Slingelandt van der Tempel (c. 1425-1467). According to the exhibition catalogue Middeleeuwse kunst der noordelijke Nederlanden (Amsterdam, 1958), Gertruy came from Utrecht and married Adriaan Haeck from Dordrecht. Gertruy was thought to have entered the convent of St. Agnes (St. Agnesklooster) of Dordrecht after her husband's death in 1449, and the painting would commemorate this event. Nonetheless, a nineteenth-century genealogy informs us that Gertruy in fact married another man named Herman Haeck Hermansz. in 1441. According to this source, she passed away on 2 July 1467 and Herman in 1488. Scholars long believed that Gertruy is wearing a widow's dress in the painting but several other portraits of married women wearing that kind of dress do exist. Scholars usually affirm that the painting served as a memorial work at the convent of St. Agnes of Dordrecht or the one of Schoonhoven, where two of Gertruy's sisters (Catharina and Cornelia) were nuns, although no documents from the fifteenth century corroborate either of these two hypotheses.

Identity of the sitter(s): Gertruy Haeck-van Slingelandt van der Tempel 
Provenance: unknown

Number of portrait(s): 1

Type of person(s): lay (woman alone)

Attitude of the sitter(s): hands held up

Representation of the sitter(s): full-length

Gaze of the sitter(s): into space

Object(s): yes (banderole)

Coat(s) of arms: yes

Environment: architectural space with sacred connotation

Structuring of the pictorial space: not applicable

Patron saint(s): none

Gesture of the patron saint(s): not applicable

Type of religious scene: hieratic

Religious scene(s) depicted: St. Agnes

Cat. o37-Type 6A

Anonymous Douai Master (?)

One Wing. Portrait of Marie du Gardin with St. Bernard (before 1494)

$117 \times 39 \mathrm{~cm}$

Douai, Musée de la Chartreuse, inv. no. 1070

BIB L.: Repertory Nord-Pas-de-Calais II, no. 68 (with bibl.).

HISTORICAL INFORMATION: The inscription in the lower part of the panel and the coat of arms identify the nun as Marie du Gardin, abbess of the Cistercian abbey of Flines between 1480 and 1494: C'est la représentati(on) de vénérable et disc(rèt)e $n$ (otr)e dame marie dul gardin laquelle fut XIIII ans abbesse de cest église et trepassa l'an/IIIIcIIIIxxXIIII le XII de may Dieu doit avoir son âme. The wing most probably comes from a triptych with a Marian iconography, destined for the abbey of Flines, but this

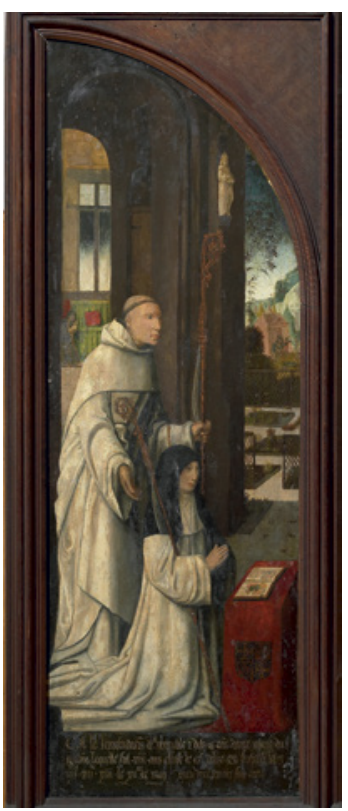
is not documented.

Identity of the sitter(s): Marie du Gardin

Provenance: Cistercian abbey of Flines (?)

Number of portrait(s): 1 
Type of person(s): religious (woman alone: Cistercian abbess)

Attitude of the sitter(s): hands clasped

Representation of the sitter(s): full-length

Gaze of the sitter(s): indeterminate

Object(s): yes (prie-dieu, book, crosier)

Coat(s) of arms: yes

Environment: domestic setting

Structuring of the pictorial space: indeterminate

Patron saint(s): Bernard

Gesture of the patron saint(s): introducing

Type of religious scene: indeterminate

Religious scene(s) depicted: none

Cat. 038-Type 5

Anonymous Douai Master (?)

The Virgin of the Cistercians;

The Last Judgment

(c. 1500-1510)

$91.5 \times 83.5 \mathrm{~cm}$

Douai, Musée de la

Chartreuse, inv. no. 408

BIBL.: FRIEDLÄNDER XII,

no. 130; Repertory Nord-Pas-
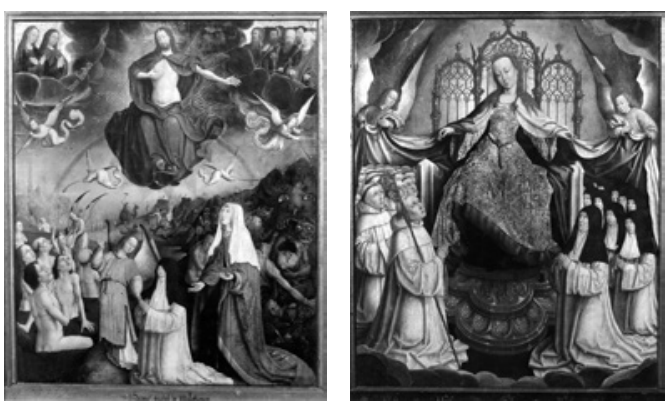
de-Calais I, no. 69 (with bibl.).

HISTORICAL INFORMATION: The nun depicted on the panel of the Last Judgement has been identified as Isabelle de Maléfiance, on the basis of an inscription on the lower part of the original frame (Dame Ysabel de Malefiance). Isabelle is mentioned at the Cistercian abbey of Flines as bursar from 1507 to 1529, that is during the abbacy of Jeanne de Boubais. The latter could be the person depicted as the first nun to the right of the Virgin on the other side of the panel. On Jeanne de Boubais, see cat. 228 and cat. 229.

Identity of the sitter(s): Isabelle de Maléfiance (and Jeanne de Boubais?)

Provenance: Cistercian abbey of Flines

Number of portrait(s): $1(2$ ?)

Type of person(s): religious (woman alone: Cistercian nun)

Attitude of the sitter(s): hands clasped

Representation of the sitter(s): full-length 
Gaze of the sitter(s): towards the scene

Object(s): yes (crosier)

Coat(s) of arms: no

Environment: celestial space

Structuring of the pictorial space: not applicable

Patron saint(s): Isabella of France

Gesture of the patron saint(s): introducing

Type of religious scene: narrative

Religious scene(s) depicted: the Virgin of the Cistercians, the Last Judgement

\section{Cat. 039-Type 5}

[Link to the museum website]

Anonymous Guelder Master

Triptych with Scenes of the Passion of Christ and the Life of St. Theodosia (c. 1545) $128 \times 130 \mathrm{~cm}$ (centre panel, gilded glass) and $128 \times 30 \mathrm{~cm}$ (wings)

Utrecht, Museum Catharijneconvent, inv. no. ABM s146 BIBL.: Mus. cat. Utrecht 2002, 102-06 (with bibl.).

HISTORICAL INFORMATION: The triptych is considered to come from the convent of St. Elizabeth in Huissen. Nonetheless, as mentioned in the MeMO database (entry no. 710), it contains portraits of tertiary nuns, but also of canons and canonesses regular. Its original place cannot be established with any certainty.

Identity of the sitter(s): unknown

Provenance: unknown

Number of portrait(s): several

Type of person(s): mixed (group: tertiary nuns, canon regular, canonesses regular)

Attitude of the sitter(s): hands clasped

Representation of the sitter(s): full-length

Gaze of the sitter(s): varied

Object(s): no

Coat(s) of arms: no

Environment: historical setting

Structuring of the pictorial space: fragmentation of the pictorial space

Patron saint(s): no

Gesture of the patron saint(s): not applicable

Type of religious scene: narrative

Religious scene(s) depicted: the Passion, the Life of St. Theodosia 
Cat. 040-Type ${ }_{3} \mathrm{C}$

Anonymous Haarlem Master

Christ Crowned with Thorns with Four Persons in Prayer (1475-1500)

$41 \times 38 \mathrm{~cm}$

Germany, private collection

BIB L.: CHÂTELET 1980, 231.

Identity of the sitter(s): unknown

Provenance: unknown

Number of portrait(s): 4

Type of person(s): religious (group: canon and canoness regular, unidentified)

Attitude of the sitter(s): hands clasped, holding a banderole

Representation of the sitter(s): full-length, small scale

Gaze of the sitter(s): into space, towards the scene

Object(s): yes (banderole, rosary)

Coat(s) of arms: no

Environment: historical setting

Structuring of the pictorial space: not applicable

Patron saint(s): none

Gesture of the patron saint(s): not applicable

Type of religious scene: narrative

Religious scene(s) depicted: Christ crowned with thorns

Cat. o41-Type ${ }_{3} \mathrm{C}$

Anonymous Haarlem Master

The Ecce Homo with a Woman in Prayer (c. 1490)

$89 \times 68 \mathrm{~cm}$

Whereabouts unknown

Identity of the sitter(s): unknown

Provenance: unknown

Number of portrait(s): 1

Type of person(s): lay (woman alone)

Attitude of the sitter(s): hands clasped

Representation of the sitter(s): full-length

Gaze of the sitter(s): into space

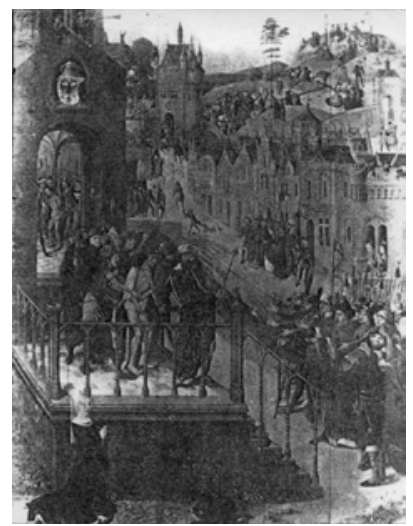

Object(s): no

Coat(s) of arms: no

Environment: historical setting

Structuring of the pictorial space: not applicable 
Patron saint(s): none

Gesture of the patron saint(s): not applicable

Type of religious scene: narrative

Religious scene(s) depicted: the Ecce homo

Cat. 042-Type ${ }_{3} \mathrm{C}$

Anonymous Haarlem Master (?)

The Crucifixion with a Monk in Prayer

(c. 1490-1500)

$71 \times 48 \mathrm{~cm}$

San Francisco, M. H. de Young Memorial Museum, inv. no. 52-6-8

BIBL.: CHÂTELET 1980, 230.

Identity of the sitter(s): unknown

Provenance: unknown

Number of portrait(s): 1

Type of person(s): religious (man alone:

Carthusian monk)

Attitude of the sitter(s): hands clasped

Representation of the sitter(s): full-length,

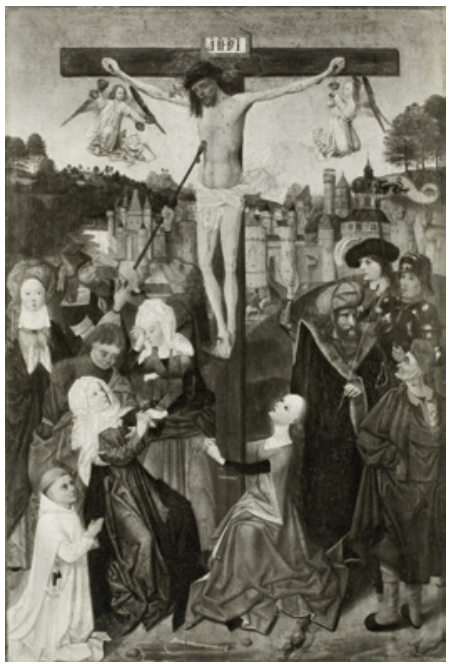

small scale

Gaze of the sitter(s): towards the scene

Object(s): no

Coat(s) of arms: no

Environment: historical setting

Structuring of the pictorial space: not applicable

Patron saint(s): none

Gesture of the patron saint(s): not applicable

Type of religious scene: narrative

Religious scene(s) depicted: the Crucifixion

Cat. 043-Type 2A

Anonymous Leiden Master

Triptych of the Ecce Homo with a Family in Prayer and Patron Saints (c. 1530-1540)

$106 \times 69.5 \mathrm{~cm}$ (centre panel) and $106 \times 32 \mathrm{~cm}$ (wings)

Highnam (Gloucestershire), Holy Innocents

BIBL.: GRÖSSINGER 1992, no. 28; Exh. cat. Leiden 2011, no. 27 (with bibl.). 
Identity of the sitter(s): unknown

Provenance: unknown

Number of portrait(s): 3

Type of person(s): lay (family with children)

Attitude of the sitter(s): hands clasped, holding a book

Representation of the sitter(s): full-length

Gaze of the sitter(s): into space

Object(s): yes (book, rosary)

Coat(s) of arms: no

Environment: historical setting

Structuring of the pictorial space: unified space with discontinuities

Patron saint(s): Peter, Mary Magdalen

Gesture of the patron saint(s): indicating, introducing

Type of religious scene: narrative

Religious scene(s) depicted: the Ecce Homo

\section{Cat. 044-Type 6A}

Anonymous Leiden Master

Two Wings. Portrait of the van Berendrecht Family in Prayer (c. 1537)

$85 \times 63.5 \mathrm{~cm}$ (each wing)

New York, sale Parke Bernet (23 March 1982), lot no. 56

BIBL.: PELINCK 1959, 100-02.

HISTORICAL INFORMATION: The coat of arms suspended above the devotees and the initials $I$ and $A$ have allowed the identification of the family of Jan van Berendrecht (1475/80-1536/7) and his wife Aechte Claesdr. van Poelgeest (1480-1527). They are accompanied by their children, Jan (born before 1513 and deceased after 1582), Adriana and Pieternella. The three youngest children in the centre of the composition are not documented and most probably died at a young age. Coming from Leiden, Jan van Berendrecht is mentioned in 1502 and 1504 as waagmeester, and as alderman several times. From 1523 onwards, he was appointed bailiff and dijkgraaf of Rijnland. He married Aechte in 1511. REMARK: In all likelihood, this panel was formerly two wings of a triptych. Once the centre panel had been lost, the wings were probably joined together in order to form one single work. The central section of the current work, showing a pillar with hanging crucifixes, is a later addition. Some other works of the corpus present similar additions (see cat. $33^{2}$ and 6o9).

Identity of the sitter(s): Jan van Berendrecht, Aechte Claesdr. van Poelgeest and their children

Provenance: unknown 
Number of portrait(s): 9

Type of person(s): lay (family with children)

Attitude of the sitter(s): hands clasped

Representation of the sitter(s): full-length

Gaze of the sitter(s): indeterminate

Object(s): yes (prie-dieu, helmet, book)

Coat(s) of arms: yes

Environment: architectural space, no sacred connotation (incomplete)

Structuring of the pictorial space: indeterminate

Patron saint(s): none

Gesture of the patron saint(s): not applicable

Type of religious scene: indeterminate

Religious scene(s) depicted: none

\section{Cat. 045-Type 2A}

Anonymous Leiden Master

(Aertgen van Leyden?)

Triptych of the Raising of

Lazarus with a Couple in Prayer

and Patron Saints (c. 1535)

$75.5 \times 78.5 \mathrm{~cm}$ (centre panel), $69.8 \times 28.2 \mathrm{~cm}$ (left wing) and $69.8 \times 27.9 \mathrm{~cm}$ (right wing)
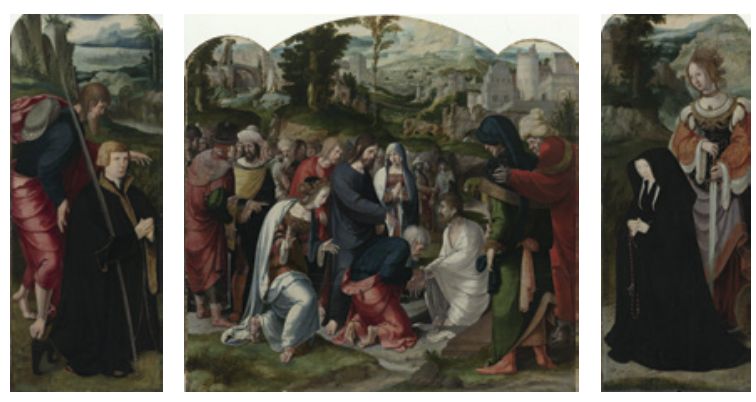

Amsterdam, Rijksmuseum, inv. nos. SK-A-3480, SK-A-4751a and SK-A-4751b

BIB L.: Exh. cat. Amsterdam 1986, no. 46; Mus. cat. Amsterdam 2009 [online], https://www.rijksmuseum.nl/nl/collectie/SK-A-348o/catalogus-entry; Exh. cat. Leiden 2011, no. 126 (with bibl.).

HISTORICAL INFORMATION: No element of the painting allows the identification of the sitters. Nevertheless, the palm leaf held by the man and the presence of St. James next to him seem to indicate that he was a member of a brotherhood of Jerusalem pilgrims. In 1986, Scholten proposed that the triptych could come from the chapel of the Jerusalem Pilgrims in the former Cellebroedersgracht (now the Keizerstraat) in Leiden.

Identity of the sitter(s): unknown

Provenance: unknown

Number of portrait(s): 2

Type of person(s): lay (couple) 
Attitude of the sitter(s): hands clasped

Representation of the sitter(s): full-length

Gaze of the sitter(s): into space

Object(s): yes (palm, rosary)

Coat(s) of arms: no

Environment: historical setting

Structuring of the pictorial space: distinct spaces

Patron saint(s): James, Catherine

Gesture of the patron saint(s): indicating, holding his/her attribute

Type of religious scene: narrative

Religious scene(s) depicted: the Resurrection of Lazarus

\section{Cat. 046-Type 6B}

Anonymous Liège Master

Portrait of Judoca Winnepenincx (c. 1547)

$35 \times 28 \mathrm{~cm}$

Liège, Musée Grand Curtius, inv. no. A5o

BIBL.: KOCKEROLS 2004, no. 218.

HISTORICAL INFORMATION: The

inscription identifies the woman as Judoca Winnepenincx, who died in 1547: Domicelle Judoca Winnepenincx alias Oudenhagen obyt anno XVc XIII april. We have no further information about this person.

Identity of the sitter(s): Judoca

Winnepenincx

Provenance: unknown

Number of portrait(s): 1

Type of person(s): lay (woman alone)

Attitude of the sitter(s): holding a rosary and a small cross

Representation of the sitter(s): half-length

Gaze of the sitter(s): indeterminate

Object(s): yes (rosary, small cross)

Coat(s) of arms: no

Environment: neutral space (incomplete)

Structuring of the pictorial space: indeterminate

Patron saint(s): none

Gesture of the patron saint(s): not applicable

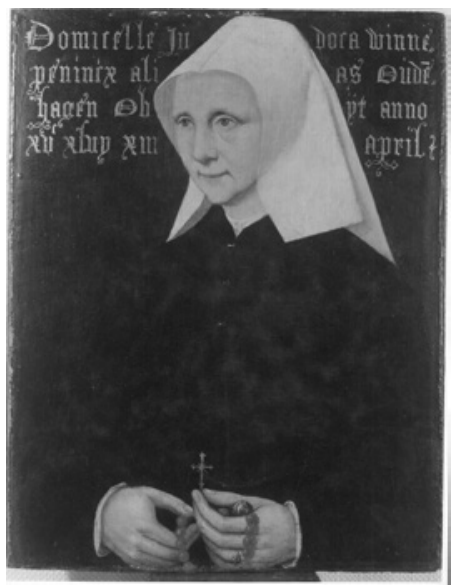


Type of religious scene: indeterminate

Religious scene(s) depicted: none

Cat. 047-Type $3 \mathrm{C}$

Anonymous Liège Master

The Martyrdom of St. Lambert with Renier van Hulsberg in Prayer (c. 1500-1550)

$66.5 \times 52.5 \mathrm{~cm}$

Liège, Musée Grand Curtius, inv. no. 80/76 BIB L.: KOCKEROLS 2004, no. 175; Repertory Liège, no. 25 (with bibl.).

HISTORICAL INFORMATION: The man portrayed in this painting is Renier van Hulsberg. Coming from Maastricht, he entered the priory of Ter Nood Gods in Tongeren in 1520 . He was a canon regular of the Congregation of Windesheim. He died

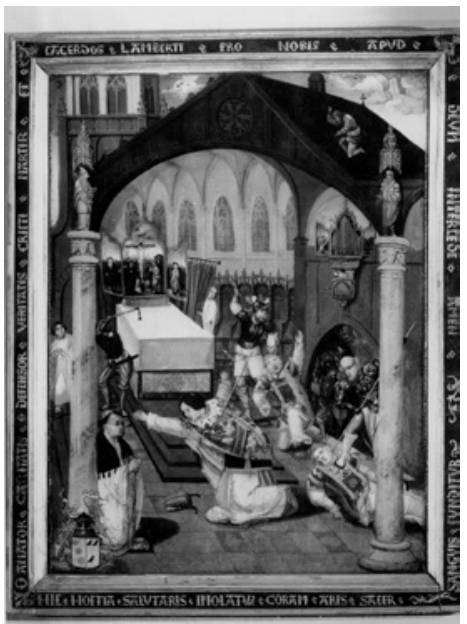
in 1544 in Oostrum.

Identity of the sitter(s): Renier van Hulsberg

Provenance: unknown

Number of portrait(s): 1

Type of person(s): religious (man alone: canon regular)

Attitude of the sitter(s): hands clasped

Representation of the sitter(s): full-length

Gaze of the sitter(s): into space

Object(s): no

Coat(s) of arms: yes

Environment: historical setting

Structuring of the pictorial space: not applicable

Patron saint(s): no

Gesture of the patron saint(s): not applicable

Type of religious scene: narrative

Religious scene(s) depicted: The Martyrdom of St. Lambert 
Cat. 048-Type 6A

Anonymous Liège Master (?)

The 'Palude Diptych'

(c. 1488-1515)

$38 \times 25 \mathrm{~cm}$ (each wing)

Liège, Musée Grand Curtius, inv.

no. A1o

BIBL.: KOCKEROLS 2004,

no. 159; Repertory Liège, no. 8 (with
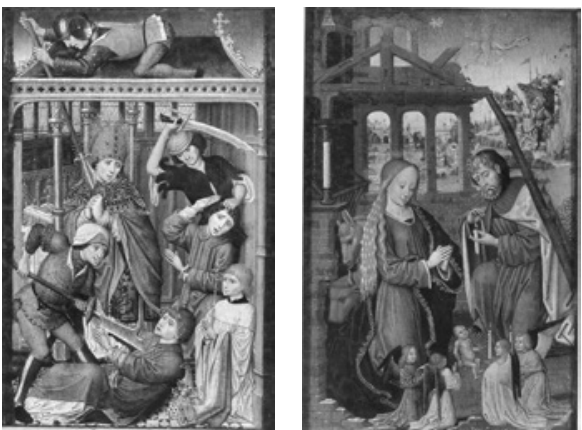

bibl.); BRUYERE 2012.

HISTORICAL INFORMATION: Henri ex Palude was an ecclesiastical leading figure in Liège at the end of the fifteenth century. He was a canon of the church of St. Lambert. In 1488, he was appointed cantor of the cathedral and received some associated benefits. He was notably authorised to occupy a personal stall in the choir. He is also well-known for receiving a gift of a choirmaster's baton in golden silver (now lost), which presented his coat of arms and the date 1495 . In the painting, Henri ex-Palude is portrayed with such a staff. He died on 24 March 1515 and was buried in the choir of the cathedral.

REMARK: It has long been assumed that the two panels formed a diptych, commissioned by the canon for the cathedral of Liège. Nonetheless, the compositional structure of the work (and more precisely the presence of two narrative scenes on the reverse), and the way the portrait is integrated into the work, strongly suggest that the panels were not conceived as a diptych but were wings of a small (possibly carved) altarpiece (see cat. 30 and 730 for a comparison).

Identity of the sitter(s): Henri ex Palude (or Desmarets)

Provenance: unknown

Number of portrait(s): 1

Type of person(s): religious (man alone: canon)

Attitude of the sitter(s): hands clasped

Representation of the sitter(s): full-length, small scale

Gaze of the sitter(s): towards the scene

Object(s): yes (staff)

Coat(s) of arms: yes

Environment: historical setting

Structuring of the pictorial space: distinct spaces

Patron saint(s): none

Gesture of the patron saint(s): not applicable

Type of religious scene: narrative

Religious scene(s) depicted: the Nativity, the Martyrdom of St. Lambert 
Cat. 049-Type 3D

Anonymous Liège Master (?)

The 'Virgin with the Butterfly' (before 1459)

$117 \times 111.5 \mathrm{~cm}$

Liège, Trésor de la cathédrale Saint-Paul BIBL.: BRINE 2006, 153-76; HEINS 2008; Repertory Liège, no. 1 (with bibl.); BRUYERE 2010.

HISTORICAL INFORMATION: The painting depicts Pieter van der Meulen (Petrus Molendino), dean of the collegiate church of St. Paul in Liège. As the

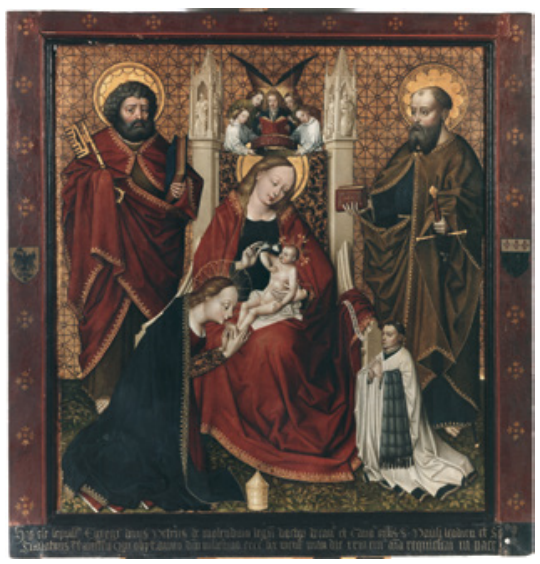
dean, Pieter supervised the extension work of the church and replaced several stained-glass windows. He also founded the construction of the new library of the chapter. He died in 1459. The painting was his epitaph, as confirmed by the inscription on the frame: Hic est sepult(us) egregi(us) $d$ (omi)nus petrus de molendino legu( $m$ ) doctor decan(us) et cano(nicus) eccl(esi)i(arum) s(ancti) pauli leodien(sis) et $s($ an $) c(t i) /$ salvatoris traiecten(sis) qui obyt anno d(om)ni millesimo $C C C C^{\circ}$ LIX mens(is) maii die XXIII cui $(u s)$ a $(n) i(m)$ a requiescat in pace. The painting was placed above his grave in the south apse of the church.

Identity of the sitter(s): Pieter van der Meulen (Petrus Molendino)

Provenance: Liège, church of St. Paul

Number of portrait(s): 1

Type of person(s): religious (man alone: canon)

Attitude of the sitter(s): hands clasped

Representation of the sitter(s): full-length, small scale

Gaze of the sitter(s): into space

Object(s): no

Coat(s) of arms: no

Environment: neutral space with sacred connotation

Structuring of the pictorial space: not applicable

Patron saint(s): none

Gesture of the patron saint(s): not applicable

Type of religious scene: hieratic

Religious scene(s) depicted: the Virgin and Child, St. Peter, St. Paul, St. Mary Magdalen 
Cat. 050-Type $2 B$

Anonymous Mechelen Master

Triptych of the Enclosed Garden with St. Ursula, St. Catherine and St. Elizabeth (c. 1513-1524)

$112 \times 194 \times 31 \mathrm{~cm}$ (open), oil on wood and polychromed wood, silk, paper, bone, wax, wire, and other materials in a wood case

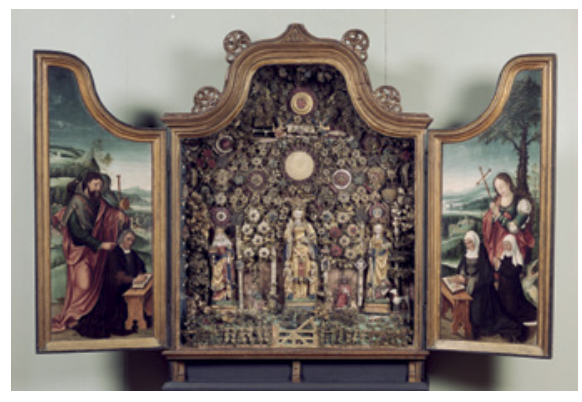

Mechelen, Museum Schepenhuis, inv. no. $\mathrm{BH} 2$

BIBL.: Exh. cat. Mechelen 1998, no. 49; Exh. cat. Mechelen 2005, no. 116; PEARSON 2017 (with bibl.).

HISTORICAL INFORMATION: in a recent article, Andrea Pearson has proposed convincingly the identification of the sitters as Jacob Van den Putte, his wife Margaretha Svos, and their daughter Maria Van den Putte, who was a nun at the Onze-Lieve-Vrouwegasthuis in Mechelen. Pearson's hypothesis is based on several archival documents. She argues that the couple commissioned the besloten hofje for the hospital. The pair lived in the centre of Mechelen. Jacob was the coadministrator of the Confraternity of the Holy Spirit (Heilige Geesttafel) at the priory of Hanswijk. Maria is mentioned as a professed sister at the Onze-Lieve-Vrouwegasthuis, in a document dating from 1524. In the triptych, Margaretha is depicted with her eyes closed and with what Pearson sees as "malformed ocular orbits, most likely to indicate that she is blind, or at the very least visually impaired".

Identity of the sitter(s): Jacob Van den Putte, Margaretha Svos and their daughter Maria Van den Putte

Provenance: Mechelen, Hospital of Our Lady (Onze-Lieve-Vrouwegasthuis)

Number of portrait(s): 3

Type of person(s): mixed (family)

Attitude of the sitter(s): hands clasped

Representation of the sitter(s): full-length

Gaze of the sitter(s): towards the ground, eyes closed

Object(s): yes (prie-dieu, book, rosary)

Coat(s) of arms: no

Environment: landscape, no sacred connotation

Structuring of the pictorial space: distinct spaces (different techniques: painting/enclosed garden)

Patron saint(s): John the Baptist, Margaret 
Gesture of the patron saint(s): holding his/her attribute, interceding Type of religious scene: hieratic

Religious scene(s) depicted: St. Ursula, St. Catherine, St. Elizabeth

Cat. 051-Type 5

Anonymous Mechelen Master

Triptych of the Enclosed Garden with

Christ on the Cross (c. 1525-1528)

$117 \times 94 \mathrm{~cm}$ (open), oil on wood and polychromed wood, silk, paper, bone, wax, wire, and other materials in a wood case

Mechelen, Museum Schepenhuis,

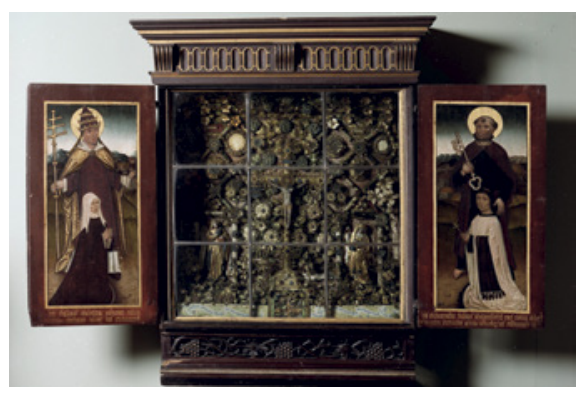
inv. no. MS $/ 8 \mathrm{C}$

BIBL.: Exh. cat. Brussels 1994, no. 116; Exh. cat. Mechelen 1998, no. $5^{2}$ (with bibl.); PEARSON 2017.

HISTORICAL INFORMATION: The triptych comes from the Hospital of Our Lady (Onze-Lieve-Vrouwegasthuis) in Mechelen. The devotees are identified by the inscriptions located on the frames. On the inner side of the wings are depicted Peeter van Steenwinckel (Heer Peeter van Steenwinckele vander reformatien die ierste rintmeester die gebuerde altera Innocentum anno $X V^{\circ}$ viii), who died in 1525 and Cornelia Andries (Suster cornelia andries vander reformatien der ierste moeder), who was the mother superior of the hospital. On the reverse are portrayed Marten Avonts (Heer Marten avonts priester vander reformatien die tweede rintmeestere) and Jozijne van Coolen (Suster sozijnen van coolen vander reformatien die ierste zuster). These devotees played an important role in the reforming of the hospital in the early sixteenth century.

Identity of the sitter(s): Peeter van Steenwinckel, Cornelia Andries, Jozijne van Coolen and Marten Avonts

Provenance: Mechelen, Hospital of Our Lady (Onze-Lieve-Vrouwegasthuis)

Number of portrait(s): 4

Type of person(s): religious (group: canon regular, Augustinian nuns)

Attitude of the sitter(s): hands clasped, holding a small cross

Representation of the sitter(s): full-length

Gaze of the sitter(s): into space, towards the scene

Object(s): yes (small cross)

Coat(s) of arms: no 
Environment: landscape, no sacred connotation

Structuring of the pictorial space: distinct spaces (different techniques: painting/enclosed garden)

Patron saint(s): Peter, Cornelius, Josse, Martin

Gesture of the patron saint(s): introducing, holding his/her attribute

Type of religious scene: narrative

Religious scene(s) depicted: the Crucifixion

\section{Cat. 052-Type $2 B$}

Anonymous Mechelen Master

Triptych of the Enclosed Garden with

the Virgin and Child with St. Anne

(c. 1500-1525)

$150 \times 120 \mathrm{~cm}$ (open), oil on wood

and polychromed wood, silk, paper, bone, wax, wire, and other materials in a wood case

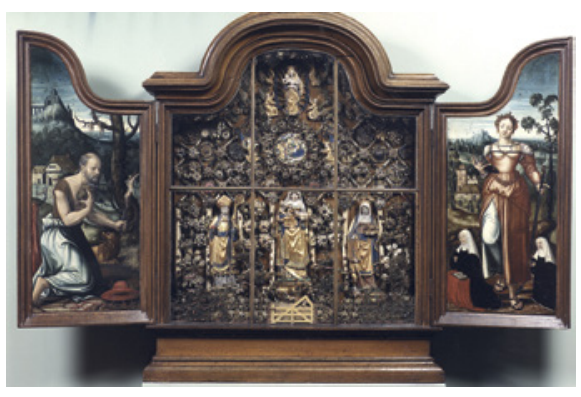

Mechelen, Museum Schepenhuis, inv. no. MS 8E

BIB L.: Exh. cat. Uden 1992, no. 118; Exh. cat. Mechelen 1998, no. 48 (with bibl.).

Identity of the sitter(s): unknown

Provenance: unknown

Number of portrait(s): 2

Type of person(s): religious (group: Augustinian nuns)

Attitude of the sitter(s): hands clasped

Representation of the sitter(s): full-length, small scale

Gaze of the sitter(s): into space

Object(s): yes (prie-dieu, book)

Coat(s) of arms: no

Environment: landscape, no sacred connotation

Structuring of the pictorial space: distinct spaces (different techniques: painting/enclosed garden)

Patron saint(s): Catherine

Gesture of the patron saint(s): holding his/her attribute

Type of religious scene: hieratic

Religious scene(s) depicted: the Virgin and Child with St. Anne, St. Augustine and St. Elizabeth, St. Jerome in the wilderness 
Cat. 053-Type $3^{B}$

Anonymous Mosan Master

Epitaph of the Canon Florentinus van Delft

(c. 1526-1536)

$89 \times 98 \mathrm{~cm}$

Tongeren, church of Our Lady

BIB L.: Exh. cat. Tongeren 1981, no. 43; BRINE 2008, 157 .

HISTORICAL INFORMATION: Florentinus van

Delft was a canon of the chapter of Our Lady in Tongeren. He died in 1536. As the Latin inscription indicates, the painting was his epitaph, located in the church of Our Lady in Tongeren: Vicesimo (or tricesimo): anno domini millesimo quingentesimo vicesimo sexton Hic jacet ... Cuius anima requiescat in sancta pace. Amen sicut lilium inter spinas Florentinus.

Identity of the sitter(s): Florentinus van Delft

Provenance: Tongeren, church of Our Lady

Number of portrait(s): 1

Type of person(s): religious (man alone: canon)

Attitude of the sitter(s): hands clasped

Representation of the sitter(s): full-length

Gaze of the sitter(s): towards the scene

Object(s): yes (prie-dieu, book)

Coat(s) of arms: yes

Environment: neutral space

Structuring of the pictorial space: religious scene in a cloud

Patron saint(s): Florentius

Gesture of the patron saint(s): protecting

Type of religious scene: hieratic

Religious scene(s) depicted: the Virgin of the Seven Sorrows 
Cat. 054-Type ${ }_{3}$ B

Anonymous Mosan Master (?)

The Virgin and Child with St. Anne,

St. Thomas, St. Bernard and a Woman

in Prayer (c. 1490-1500)

$5^{2} \times 45 \mathrm{~cm}$

Liège, Musée Grand Curtius, inv. no. Mx/2495

BIB L.: Repertory Liège, no. 24 (with bibl.).

Identity of the sitter(s): unknown

Provenance: unknown

Number of portrait(s): 1

Type of person(s): religious (woman alone:

Cistercian abbess)

Attitude of the sitter(s): holding a book

Representation of the sitter(s): full-length, small scale

Gaze of the sitter(s): into space

Object(s): yes (book, crosier)

Coat(s) of arms: no

Environment: architectural space with sacred connotation

Structuring of the pictorial space: not applicable

Patron saint(s): Bernard

Gesture of the patron saint(s): introducing

Type of religious scene: hieratic

Religious scene(s) depicted: the Virgin and Child with St. Anne, St. Thomas

\section{Cat. 055-Type 3 B}

Anonymous Namur Master

The Holy Trinity with a Couple in Prayer and Patron Saints (dated 1472 on the frame)

$75 \times 141 \mathrm{~cm}$

Brussels, private collection

BIB L.: Exh. cat. Namur 2001, 57-59; Exh. cat. Namur 2010, no. 52.

HISTORICAL INFORMATION: The inscription on the original frame identifies the portrayed couple:BertrandBorgois demeurand a Namur/Lan de grace LXXII fut fondé et benni et consacré cest hautel en lhonneur de Dieu et de Monseiagneur 
Saint Jaqes et de Monseiagnur Cristofles par Colart. Colard Bertrand was a rich patrician from Namur. His name notably appears in an extract from the Compte communal du magistrat of Namur dating from 1472-1473. The name of his wife is unknown. The painting was destined for an altar founded in 1472, according to the inscription, but its exact location is also unknown.

Identity of the sitter(s): Colard Bertrand and his wife

Provenance: unknown

Number of portrait(s): 2

Type of person(s): lay (couple)

Attitude of the sitter(s): hands clasped

Representation of the sitter(s): full-length

Gaze of the sitter(s): towards the scene

Object(s): no

Coat(s) of arms: no

Environment: architectural space with sacred connotation

Structuring of the pictorial space: not applicable

Patron saint(s): Peter, a saint bishop

Gesture of the patron saint(s): protecting, blessing

Type of religious scene: hieratic

Religious scene(s) depicted: the Holy Trinity, St. James, St. Christopher

Cat. 056-Type $3 \mathrm{D}$

Anonymous North Netherlandish Master (or German Master?)

A Friar in Prayer before St. Matthew (c. 1475)

$67.5 \times 54.2 \mathrm{~cm}$

Enschede, Rijksmuseum Twenthe, inv. no. 48

BIBL.: HOOGEWERFF II, 304-05; Mus. cat. Enschede, no. 23 (with bibl.).

Identity of the sitter(s): unknown

Provenance: unknown

Number of portrait(s): 1

Type of person(s): religious (man alone:

Franciscan friar)

Attitude of the sitter(s): hands clasped

Representation of the sitter(s): full-length

Gaze of the sitter(s): towards the scene

Object(s): yes (banderole)

Coat(s) of arms: no

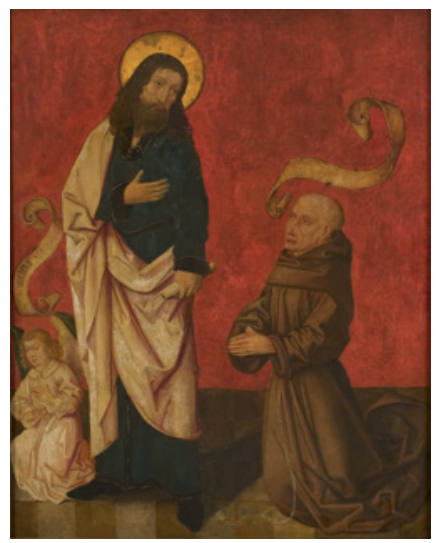


Environment: neutral space

Structuring of the pictorial space: not applicable

Patron saint(s): none

Gesture of the patron saint(s): not applicable

Type of religious scene: hieratic

Religious scene(s) depicted: St. Matthew

\section{Cat. 057-Type 3 B}

Anonymous North Netherlandish Master Christ Blessing a Family in Prayer ('Epitaph of the van Haamstede Family') (c. 1455) $63 \times 77 \mathrm{~cm}$

Utrecht, Centraal Museum, inv. no. 2482 BIBL.: FRIEDLÄNDER III, no. 41; HOOGEWERFF II, 23-27; Mus. cat. Utrecht 2011, no. 43 (with bibl.)

HISTORICAL INFORMATION: On the basis of the coats of arms, the devotees have been identified as Raas van

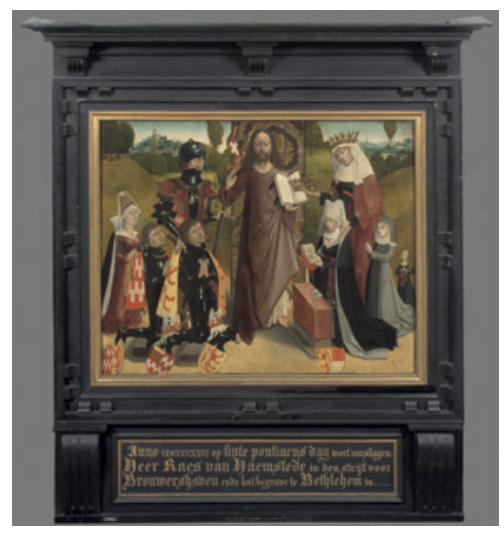
Haamstede, his wife Agnes de Vriese van Oostende and their three daughters. The oldest one, Maria, is depicted behind her father and with her husband Lodewijk Bloys van Treslong. Her two sisters are kneeling behind their mother. One of them, Goedela, wears a religious habit. She was a canoness of the convent of St. Elizabeth (St. Elisabethklooster) at Schoonhoven, before leaving the convent and marrying Willem van Noyts. The frame and the predella (including the inscription: Anno MCCCCXXVI op sinte pontiaens dag wort varslagen: // Heer Raes van Haemstede in den strijt voor // Brouwershaven ende leit begrave te Bethlehem in....) date back to the end of the eighteenth century. Nevertheless, the inscription is probably a copy of the original text. It recalls the events preceding the death of Raas van Haamstede. Lord of the island of Haamstede in Zeeland, Raas was a knight. He died on the battlefield of Brouwershaven in 1426, during a fight between the troops of Jacoba van Beieren and Philip the Good. He was buried in the Bethleem convent at Elkerzee. The last sentence of the predella is left unfinished, with the words ende leyt begraven te Bethleem in ... This suggests that the painting was not destined for Raas's burial place. It could have been commissioned for the convent of St. Elizabeth in Schoonhoven, where Goedela was canoness. She might, in fact, be the commissioner of the work. 
Identity of the sitter(s): Van Haamstede family

Provenance: Schoonhoven, convent of St. Elizabeth (?)

Number of portrait(s): 6

Type of person(s): lay (family with children)

Attitude of the sitter(s): hands clasped, holding a book

Representation of the sitter(s): full-length

Gaze of the sitter(s): towards the scene, reading a book, into space

Object(s): yes (prie-dieu, book, rosary)

Coat(s) of arms: yes

Environment: landscape with sacred connotation

Structuring of the pictorial space: not applicable

Patron saint(s): George, Elizabeth of Hungary

Gesture of the patron saint(s): protecting

Type of religious scene: hieratic

Religious scene(s) depicted: Christ blessing

Cat. 058 - Type ${ }_{3} \mathrm{C}$

Anonymous North Netherlandish Master

Christ Crowned with Thorns with a Family in

Prayer (c. 1400-1500)

Size unknown

Whereabouts unknown

Identity of the sitter(s): unknown

Provenance: unknown

Number of portrait(s): 12

Type of person(s): lay (family with children)

Attitude of the sitter(s): hands clasped

Representation of the sitter(s): full-length,

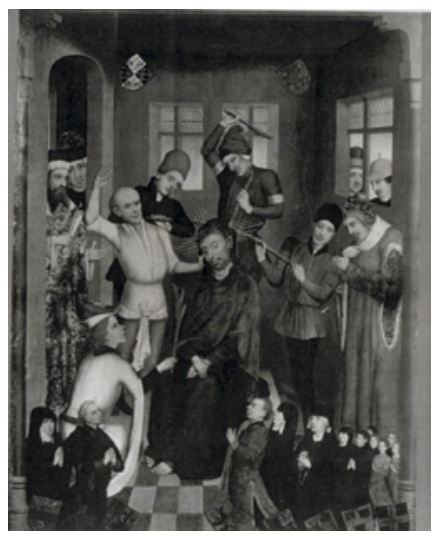

small scale

Gaze of the sitter(s): into space, towards the scene

Object(s): no

Coat(s) of arms: yes

Environment: historical setting

Structuring of the pictorial space: not applicable

Patron saint(s): none

Gesture of the patron saint(s): not applicable

Type of religious scene: narrative

Religious scene(s) depicted: Christ Crowned with Thorns 
Cat. 059-Type ${ }_{3} \mathrm{C}$

Anonymous North Netherlandish Master

Epitaph of Geertruivan Tetwijk and Geertrui de Ridder van Groenesteyn (c. 1530)

Size unknown

Germany, private collection

BIBL.: FRIEDRICHS 1970, 33 .

HISTORICAL INFORMATION: According to the inscription, this painting is a commemorative work made in honour of Geertrui van Tetwijk and her daughter Geertrui de Ridder van Groenesteyn: Int jaer ons here (n) XVc en (de) III op sunt Jelis dach sterf joffer ghertruyt va(n) groene(ste)yn vrou van desen cloester. re(qui)escat i(n) pace-Int jaer ons here(n) M CCCC en(de) LXXVI starf joffer gheertruit va $(n)$ tetwijck ja(n) de ridders wiif was. god heb har ziel. Geertrui de Ridder van Groenensteyn is mentioned as the prioress of the convent of Oostbroek in De Bilt, from 1456 up to her death in 1503 (on this family, see cat. 74). The painting was destined for this convent.

Identity of the sitter(s): Geertrui van Tetwijk and Geertrui de Ridder van Groenesteyn

Provenance: De Bilt, convent of Oostbroek

Number of portrait(s): 2

Type of person(s): mixed (family)

Attitude of the sitter(s): hands clasped

Representation of the sitter(s): full-length

Gaze of the sitter(s): into space

Object(s): no

Coat(s) of arms: yes

Environment: architectural space with sacred connotation

Structuring of the pictorial space: not applicable

Patron saint(s): John the Evangelist, an unidentified saint

Gesture of the patron saint(s): introducing

Type of religious scene: hieratic

Religious scene(s) depicted: Maria in Sole 
Cat. o6o-Type 3 B

Anonymous North

Netherlandish Master

Epitaph of JacobJan van

Assendelft and Haesgen van

Outshoorn (shortly after 1500)

$61 \times 91 \mathrm{~cm}$

Amsterdam, Rijksmuseum, inv.

no. SK-C-509

BIBL.: Mus. cat. Amsterdam

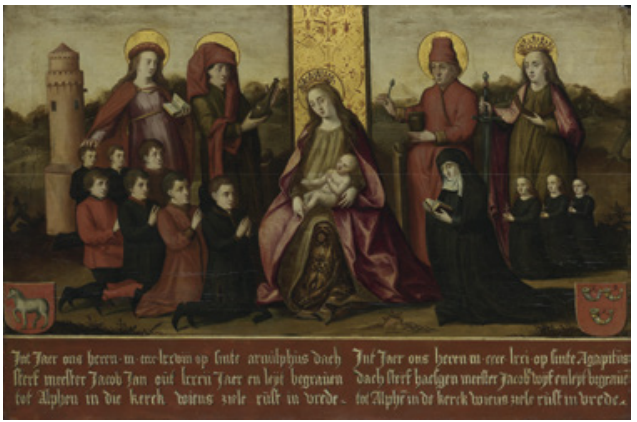

1976, 675; Mus. cat. Amsterdam

2009 [online], https://www.rijksmuseum.nl/nl/collectie/SK-C-509/catalogusentry (with bibl.).

HISTORICAL INFORMATION: The inscription on the lower part of the painting and the coats of arms indicate that the devotees are Jacob Jan van Assendelft (1396-1478), Haesgen van Outshoorn ( $\dagger$ 1471) and their children, and that the painting is their epitaph:IntJaer ons heren MCCCCLXXVIII op Sinte Arnulphus dach sterf meester Jan Jacob out LXXXI jaer en legt begraven tot Alphen in die kerck wiens ziele rust in vrede (on the left); Int Jaer ons heren MCCCCLXXI op sinte Agapitus dach sterf haesgen meester Jacobs wijf en legt begrave tot Alphe in de kerck wiens ziele rust in vrede (on the right). The inscription has been overpainted. According to the online catalogue of the Rijksmuseum, this could be a genealogical falsification from the seventeenth century. Although a lot of information is available about the Van Assendelft lineage, we do not know very much about Jacob Jan, except for the fact that he came from Alphen aan den Rijn, in the region of Leiden.

Identity of the sitter(s): Jacob Jan van Assendelft, Haesgen van Outshoorn and their children

Provenance: unknown

Number of portrait(s): 11

Type of person(s): lay (family with children)

Attitude of the sitter(s): hands clasped, holding a book

Representation of the sitter(s): full-length

Gaze of the sitter(s): towards the scene, reading a book

Object(s): yes (book, small cross)

Coat(s) of arms: yes

Environment: landscape with sacred connotation

Structuring of the pictorial space: not applicable

Patron saint(s): Barbara, Cosmas, Damian, Catherine 
Gesture of the patron saint(s): protecting

Type of religious scene: hieratic

Religious scene(s) depicted: the Virgin and Child

Cat. o61-Type 6A

[RKD work no. 148215]

Anonymous North Netherlandish Master

One Wing. A Couple in Prayer with Patron Saints (c. 1500-1525)

$62 \times 23 \mathrm{~cm}$

Loenen aan de Vecht, Stichting Teding van Berkhout, inv. no. 19

BIBL.: SCHMIDT C. 1986, 21.

historical information: The panel depicts Pieter Jansz. Berkhout $(1472 / 76-1558)$ and his wife Mary Heynes. Pieter Jansz. Berkhout was a wealthy patrician from the city of Hoorn. Several members of his family played an important role in the political life of the Low Countries. Several chronicles of the family-including Paulus Teding Berkhout's Memorie van het geslacht van Berckhout dating from the seventeenth century-have been preserved. Nevertheless, we do not know very much about Pieter. He was a merchant who held several important positions in the city of Hoorn. He acted as alderman seven times from 1523 onwards. He was also appointed burgomaster thirteen times, and was kerkmeester at the Grote Kerk and the Oosterkerk. Pieter and Mary had four sons and one daughter.

REMARK: Taking into account the fact that the couple is located on the right wing, one can assume that the left wing of the original triptych included the portraits of Pieter or Mary's parents. A similar case can be observed in Albrecht Bouts' Triptych of the Assumption of the Virgin (cat. 259).

Identity of the sitter(s): Pieter Jansz. Berkhout and Mary Heynes

Provenance: unknown

Number of portrait(s): 2

Type of person(s): lay (couple)

Attitude of the sitter(s): hands clasped

Representation of the sitter(s): full-length

Gaze of the sitter(s): indeterminate

Object(s): no

Coat(s) of arms: no

Environment: landscape, no sacred connotation (incomplete)

Structuring of the pictorial space: indeterminate

Patron saint(s): Paul (?) 
Gesture of the patron saint(s): protecting

Type of religious scene: indeterminate

Religious scene(s) depicted: none

Cat. o62-Type 6A

Anonymous North Netherlandish Master

One Wing. Hendrik de Pauw and his Sons in Prayer (c. 1500-1524)

$82.5 \times 30.5 \mathrm{~cm}$

The Netherlands, private collection

BIBL.: WOLLESWINKEL 1993, 149; WOLLESWINKEL 1994, 114-15.

HISTORICAL INFORMATION: On the basis of their coats of arms, the sitters have been identified as Hendrik de Pauw $(\dagger 1500)$ and his four sons: Reinier $(† 1541)$, Dirk (†1530), Gerard $(† 1567)$ and Frans. Hendrik de Pauw was a city councillor in Gouda. The original frame of the panel presents an epitaph: Hier leijt begraven Henrijck Pauw. die sterft. int jaer. ons heeren./.xv .c den eersten dach van. septe $[\mathrm{m}]$ ber. bidt voor de siel. It indicates that the panel was placed above the father's grave, which has not been located.

Identity of the sitter(s): Hendrik de Pauw and his sons

Provenance: unknown

Number of portrait(s): 5

Type of person(s): lay (family)

Attitude of the sitter(s): hands clasped, holding a book

Representation of the sitter(s): full-length

Gaze of the sitter(s): indeterminate

Object(s): yes (book, prie-dieu)

Coat(s) of arms: yes

Environment: architectural space, no sacred connotation (incomplete)

Structuring of the pictorial space: indeterminate

Patron saint(s): Andrew

Gesture of the patron saint(s): holding his/her attribute

Type of religious scene: indeterminate

Religious scene(s) depicted: none 


\section{Cat. 063-Type 6A}

[Link to the museum website]

Anonymous North Netherlandish Master

One Wing. Lambert Snoy and Emmerentiana Pauw in Prayer with Patron Saints (c. 1530)

$154.5 \times 87.8 \mathrm{~cm}$

Utrecht, Centraal Museum, inv. no. 6324

BIBL.: HOOGEWERFF III, 44-48; Mus. cat. Utrecht 1999, 1606-07; Mus. cat. Utrecht 2011, no. 49a-b (with bibl.).

HISTORICAL INFORMATION: The couple has been identified as Lambert Snoy $(\dagger 1529)$ and Emmerentiana Pauw (1510-1550), as the inscription indicates: $D($ OEN MEN) SCREF MVc (X)XIX DE(N) // (DACH) SE(PT)EM(bris) STERF LAM(BER)TSNOIE //D(IRCK)Z. (on the left) and D(OEN MEN) SCREF M $(V)$ cL (DEN)//(II DACH IN IVNIO) STE(RF)IOF(F)ER (EMM)E //RENCI(ANA) $\operatorname{LAMBER}(T)(H) V I S V R O V$ (on the right). The wing comes from a triptych whose centre panel is now lost. A copy of the left wing has been preserved and depicts Lambert's parents, Dirk Snoy and Margaretha van Drakenburg, with Lambert's sister, Balthasarine ( $† 1554)$. Lambert and Emmerentiana married in 1522. The triptych was thus produced after this date. When Lambert married Emmerentiana, she was only eleven years old and this union (arranged after the death of Emmerentiana's father, Ghijsbert de Pauw, in 1521) aroused much conflict among the members of the Pauw family. The marriage was finally confirmed in 1523. The couple then had two sons, Joos and Dirck, before Lambert died in 1529. The occasion for the commission of the triptych cannot be determined with certainty. Several hypotheses are plausible: this could be a commission made by Emmerentiana in 1529, to commemorate her late husband. The triptych could also have been commissioned by Lambert and his mother, Margaretha van Drakenburg, as a memorial work for his father and his brother Michael, both deceased in 1507. The most convincing hypothesis is, nevertheless, that Margaretha van Drakenburg and Emmerentiana commissioned the triptych together as a memorial work for their husbands. The triptych was destined for a small altar in the Brigittine church of Marienbaum.

Identity of the sitter(s): Lambert Snoy and Emmerentiana Pauw

Provenance: Marienbaum, Brigittine convent

Number of portrait(s): 2

Type of person(s): lay (couple)

Attitude of the sitter(s): hands clasped

Representation of the sitter(s): full-length 
Gaze of the sitter(s): indeterminate

Object(s): yes (helmet, prie-dieu, book)

Coat(s) of arms: yes

Environment: architectural space, no sacred connotation (incomplete)

Structuring of the pictorial space: indeterminate

Patron saint(s): Peter, Catherine

Gesture of the patron saint(s): introducing

Type of religious scene: indeterminate

Religious scene(s) depicted: the Flagellation of Christ

Cat. o64-Type 6B

Anonymous North Netherlandish Master

Portrait of Evert Zoudenbalch in Prayer

(c. 1491)

$45 \times 34.4 \mathrm{~cm}$

Utrecht, Centraal Museum, inv. no. $1845^{1}$

BIBL.: HOOGEWERFF I, 573; Mus. cat.

Utrecht 2011, no. 45 (with bibl.).

HISTORICAL INFORMATION: The

frame presents a nineteenth-century inscription, which identifies the sitter as Evert Zoudenbalch: HEER . EVERT . ZOVDENBALCH. PROEST. .//VAN.

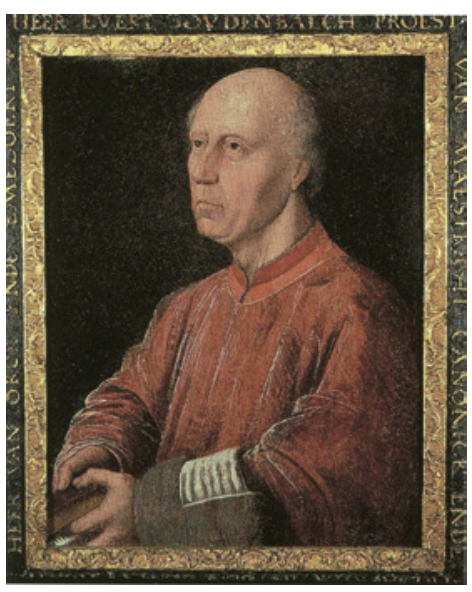

\section{MAESTRICHT.CANONICK.ENDE.}

//TRESAVRIER.IN.DEN.DOM.TVTRECHT.//HEER. VAN.ORCK.ENDE. EMELOERT. Born in 1423 or 1424, Evert Zoudenbalch came from one of the wealthiest families of Utrecht and made an ecclesiastical career. In 1441 , he is mentioned as a student at Leuven and then became provoost of the chapter of St. Servaas in Maastricht, canon and vice-dean of the Cathedral of Utrecht. In 1491, he founded the Hospital of St. Elizabeth (St. Elisabethsgasthuis) in Utrecht, the first actual orphanage of Holland. Evert died in 1503 and was buried in the chapel of the hospital. This portrait might come from this place.

Identity of the sitter(s): Evert Zoudenbalch

Provenance: Utrecht, St. Elizabeth's hospital (?)

Number of portrait(s): 1

Type of person(s): religious (man alone: canon)

Attitude of the sitter(s): holding a book

Representation of the sitter(s): half-length

Gaze of the sitter(s): indeterminate 
Object(s): yes (book)

Coat(s) of arms: no

Environment: neutral space (incomplete)

Structuring of the pictorial space: indeterminate

Patron saint(s): none

Gesture of the patron saint(s): indeterminate

Type of religious scene: indeterminate

Religious scene(s) depicted: none

\section{Cat. 065 - Type ${ }_{3} \mathrm{C}$}

Anonymous North Netherlandish Master The Agony in the Garden with a Couple in Prayer (dated 1489 on the frame)

$52.3 \times 43.4 \mathrm{~cm}$

New York, sale Sotheby's (8 June 2007), lot no. 230

BIB L.: Sale cat. Christie's (Amsterdam, 8 November 1999), no. 109; Sale cat.

Sotheby's (London, 8 June 2007), no. 230.

HISTORICAL INFORMATION: The frame of the painting bears the date 1489 and two coats of arms. According to the Christie's sale

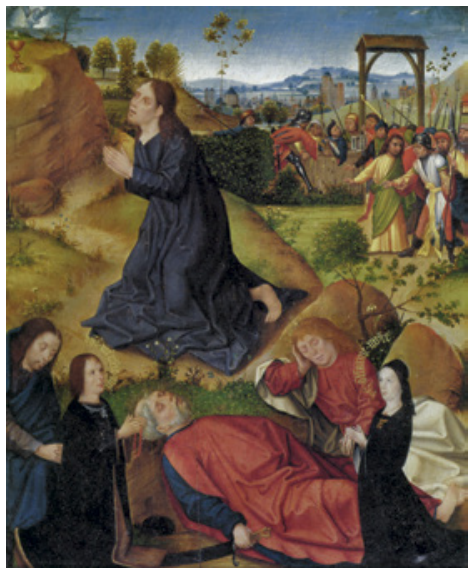
catalogue (8 November 1999), Wolleswinkel identified the man's coat of arms as that of the Jüdden family. According to the Sotheby's sale catalogue (8 June 2007), the coats of arms belong to the Juden (or Jüdden) and Zours (Seurs, Zoers, Soerse) families of Westphalia. The man wears a collar, but the insignia cannot be identified.

Identity of the sitter(s): unknown

Provenance: unknown

Number of portrait(s): 2

Type of person(s): lay (couple)

Attitude of the sitter(s): hands clasped

Representation of the sitter(s): full-length, small scale

Gaze of the sitter(s): into space, towards the viewer

Object(s): yes (banderole, rosary)

Coat(s) of arms: yes (on the frame)

Environment: historical setting

Structuring of the pictorial space: not applicable

Patron saint(s): none 
Gesture of the patron saint(s): not applicable

Type of religious scene: narrative

Religious scene(s) depicted: the Agony in the garden

Cat. o66-Type ${ }_{3} \mathrm{C}$

[Link to the museum website]

Anonymous North Netherlandish Master

The Crucifixion with a Couple in Prayer (c. 1530)

$66.5 \times 46.5 \mathrm{~cm}$

Utrecht, Museum Catharijneconvent, inv. no. ABM s99

BIB L.: Mus. cat. Utrecht 2002, 119 (with bibl.).

Identity of the sitter(s): unknown

Provenance: unknown

Number of portrait(s): 2

Type of person(s): lay (couple)

Attitude of the sitter(s): hands clasped

Representation of the sitter(s): full-length

Gaze of the sitter(s): towards the scene, towards the ground

Object(s): yes (banderole, rosary)

Coat(s) of arms: no

Environment: historical setting

Structuring of the pictorial space: not applicable

Patron saint(s): none

Gesture of the patron saint(s): not applicable

Type of religious scene: narrative

Religious scene(s) depicted: the Crucifixion

Cat. 067 - Type $3 \mathrm{~A}$

[RKD work no. 29702]

Anonymous North Netherlandish Master

The Crucifixion with a Couple in Prayer and Patron Saints (c. 1500)

$38 \times 28 \mathrm{~cm}$

Utrecht, Centraal Museum, inv. no. 14175

BIB L.: Mus. cat. Utrecht 1999, no. 751; Mus. cat. Utrecht 2011, no. 46 (with bibl.).

Identity of the sitter(s): unknown

Provenance: unknown

Number of portrait(s): 2

Type of person(s): lay (couple) 
Attitude of the sitter(s): hands clasped

Representation of the sitter(s): full-length

Gaze of the sitter(s): into space

Object(s): no

Coat(s) of arms: no

Environment: historical setting

Structuring of the pictorial space: not applicable

Patron saint(s): Peter, Gertrude of Nivelles

Gesture of the patron saint(s): introducing

Type of religious scene: narrative

Religious scene(s) depicted: the Crucifixion

\section{Cat. o68-Type 3 A}

Anonymous North Netherlandish Master

The Crucifixion with Hadewych van Hardenbroeck and Agnes van Ghent (c. 1540-1545)

$121.2 \times 70.6 \mathrm{~cm}$

Utrecht, Museum Catharijneconvent, inv. no. Авм s 194

BIBL.: HOOGEWERFF III, 50-52; Exh. cat. Utrecht 1999-2000, 218-19; Mus. cat. Utrecht 2002, 142-43 (with bibl.).

HISTORICAL INFORMATION: Hadewych van

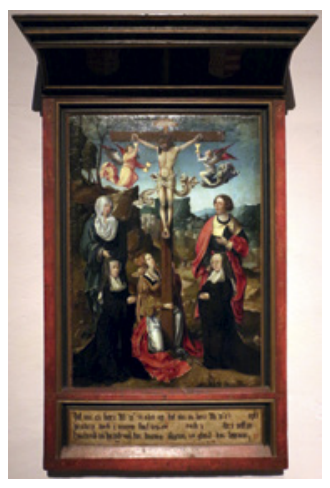
Hardenbroeck and Agnes van Ghent have been identified, on the basis of the inscriptions. The left part of the text relates to Hadewyck (Int jaer ons heren MVc ende XLIII op / Den Xden dach in iunyo stref iufrou / Hadwych van Hardenbroeck hier begraven / Bid voer die ziel) and the right part is dedicated to Agnes (Int jaer ons heeren MV c ende'opten / ... dach in ... sterf ioffrou / Agnes van Ghent hier begraven / Bid voer die ziel). The two women were nuns at the Benedictine convent of Oudwijk in Utrecht. The painting probably served as their epitaph and comes from this convent.

Identity of the sitter(s): Hadewych van Hardenbroeck and Agnes van Ghent Provenance: Benedictine convent of Oudwijk (?)

Number of portrait(s): 2

Type of person(s): religious (group: Benedictine nuns)

Attitude of the sitter(s): hands clasped

Representation of the sitter(s): full-length

Gaze of the sitter(s): into space

Object(s): no 
Coat(s) of arms: yes

Environment: historical setting

Structuring of the pictorial space: not applicable

Patron saint(s): Mary, John the Evangelist

Gesture of the patron saint(s): introducing

Type of religious scene: narrative

Religious scene(s) depicted: the Crucifixion

\section{Cat. o69-Type $3 \mathrm{C}$}

Anonymous North Netherlandish Master

The Ecce homo with a Nun in Prayer (c. 1520)

$59.5 \times 45 \mathrm{~cm}$

Uden, Museum voor religieuze Kunst

(loan of the Rijksmuseum, Amsterdam), inv. no. 238

BIB L.: Exh. cat. Den Bosch 1990, no. 95;

Mus. cat. Amsterdam 2009 [online], https:// www.rijksmuseum.nl/en/collection/SK-A4650/catalogue-entry (with bibl.).

HISTORICAL INFORMATION: This painting depicts a Brigittine nun in front of Christ and comes from the Brigittine convent of

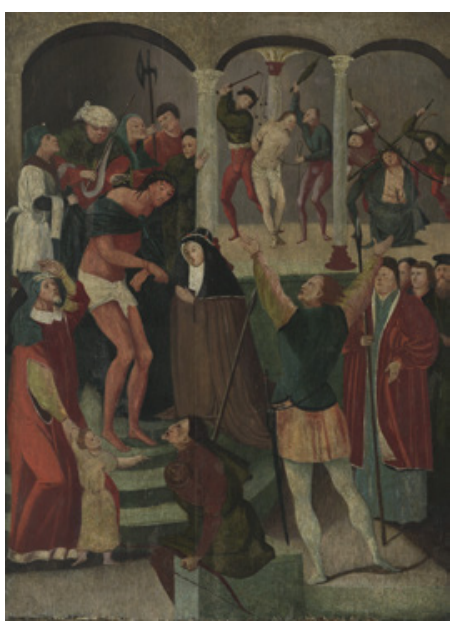
Mariënwater in Koudewater. According to Filedt Kok (Mus. cat. Amsterdam 2009), the panel probably comes from the cell of a nun and had a devotional function.

Identity of the sitter(s): unknown

Provenance: Koudewater, Brigittine convent of Mariënwater

Number of portrait(s): 1

Type of person(s): religious (woman alone: Brigittine nun)

Attitude of the sitter(s): hands clasped

Representation of the sitter(s): full-length

Gaze of the sitter(s): towards the ground

Object(s): no

Coat(s) of arms: no

Environment: historical setting

Structuring of the pictorial space: not applicable

Patron saint(s): none

Gesture of the patron saint(s): not applicable

Type of religious scene: narrative 
Religious scene(s) depicted: the Ecce Homo, the Flagellation of Christ, the Mocking of Christ

Cat. o7o-Type ${ }_{3} \mathrm{C}$

Anonymous North Netherlandish Master

The Lamentation with a Man in Prayer (c. 1540)

$131.1 \times 114.9 \mathrm{~cm}$

London, sale Christie's (8 July 2016), lot no. 109

REMARK: The composition of this panel is a free copy of cat. 719, but with another portrait.

Identity of the sitter(s): unknown

Provenance: unknown

Number of portrait(s): 1

Type of person(s): religious (man alone: Benedictine abbot)

Attitude of the sitter(s): hands clasped

Representation of the sitter(s): full-length

Gaze of the sitter(s): towards the scene

Object(s): yes (crosier)

Coat(s) of arms: no

Environment: historical setting

Structuring of the pictorial space: not applicable

Patron saint(s): none

Gesture of the patron saint(s): not applicable

Type of religious scene: narrative

Religious scene(s) depicted: the Lamentation

Cat. 071-Type $3 \mathrm{C}$

Anonymous North Netherlandish Master

The Resurrection with a Couple in Prayer (c. 15001550)

$73.5 \times 92 \mathrm{~cm}$

The Netherlands, private collection

Identity of the sitter(s): unknown

Provenance: unknown

Number of portrait(s): 2

Type of person(s): lay (couple)

Attitude of the sitter(s): hands clasped

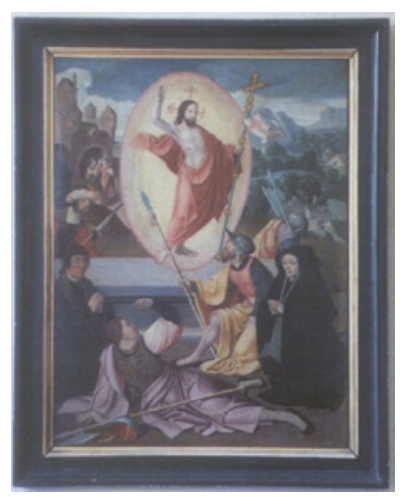

Representation of the sitter(s): full-length 
Gaze of the sitter(s): into space

Object(s): no

Coat(s) of arms: no

Environment: historical setting

Structuring of the pictorial space: not applicable

Patron saint(s): none

Gesture of the patron saint(s): not applicable

Type of religious scene: narrative

Religious scene(s) depicted: the Resurrection of Christ

Cat. o72-Type 5

[RKD work no. 29726]

Anonymous North Netherlandish Master

The Sacrament of Niervaart (c. 1535)

$167 \times 338 \mathrm{~cm}$

Breda, Breda's Museum, inv. nos. 1101 and 306

BIB L.: VAN WEZEL 2003, 224-34, no. 39 (with bibl.).

HISTORICAL INFORMATION: This incomplete (it was originally constituted of ten panels) polyptych illustrates the legend of the Sacrament of Niervaart, a sacred host discovered in 1300. The host had been held in Niervaart until 1449, when important flooding caused its transfer to the Grote Kerk of Breda. Soon after the installation of the sacred host in Breda, an altar aimed at receiving it was founded. In 1463, the Brotherhood of the Sacrament of Breda was created in order to promote this cult. The brotherhood was composed of men and women and they chose 24 June as their feast day. From 1500 onwards, the famous piece of the Sacrament of Niervaart was played each year at this date. Commissioned in 1535 by the brotherhood, the altarpiece was destined for the altar of its chapel at the Grote Kerk. Fourteen members of the brotherhood are depicted on the lower centre panel. The five men in the foreground are probably the masters. The portraits of Hendrik II I of Nassau and of his son René de Chalon can be seen on the panel representing the Corpus Christi procession.

Identity of the sitter(s): Members of the Brotherhood of the Sacrament of Niervaart

Provenance: Breda, Grote Kerk, Niervaart chapel

Number of portrait(s): mixed (group: association) 
Type of person(s): 13

Attitude of the sitter(s): hands clasped

Representation of the sitter(s): half-length

Gaze of the sitter(s): towards the viewer

Object(s): no

Coat(s) of arms: no

Environment: neutral space

Structuring of the pictorial space: distinct spaces

Patron saint(s): none

Gesture of the patron saint(s): not applicable

Type of religious scene: narrative

Religious scene(s) depicted: the Legend of the Sacrament of Niervaart

\section{Cat. 073-Type 5}

Anonymous North Netherlandish Master

Triptych of Christ Taking Leave of his Mother (c. 1500-1510)

$64.5 \times 36 \mathrm{~cm}$ (centre panel) and $63 \times 14.5 \mathrm{~cm}$ (wings)

London, sale Sotheby's (July 2012), lot no. 116

Identity of the sitter(s): unknown

Provenance: unknown

Number of portrait(s): 2

Type of person(s): religious (group: canons regular)

Attitude of the sitter(s): hands clasped

Representation of the sitter(s): full-length

Gaze of the sitter(s): into space, towards the scene

Object(s): no

Coat(s) of arms: no

Environment: historical setting

Structuring of the pictorial space: unified space with discontinuities

Patron saint(s): John the Baptist

Gesture of the patron saint(s): holding his/her attribute

Type of religious scene: narrative

Religious scene(s) depicted: Christ taking leave of his mother, the Mass of

St. Gregory 
Cat. o74-Type 2A

Anonymous North

Netherlandish Master

Triptych of the Crucifixion

with a Family and Patron

Saints ('Groenesteyn Triptych')

(c. 1530)

$70 \times 60 \mathrm{~cm}$ (centre panel) and

$70 \times 27 \mathrm{~cm}$ (wings)

Germany, private collection

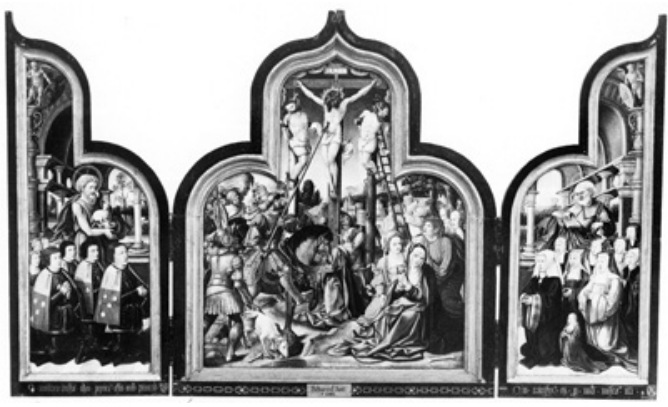

BIBL.: FRIEDRICHS 1970, 32-33.

HISTORICAL INFORMATION: On the basis of the coats of arms and the inscriptions on the frames (on the left: Anno $14473^{\circ} \mathrm{kal} .8 \mathrm{~B}$ mortuus Johannes de Ridder a Gruensteyn; on the right: Anno 1476 moritur domicella Gertrudis a Tetwijck), the devotees have been identified as Jan (IX) Jansz. de Ridder $(\dagger 1447)$, Gertruui van Tetwijk $(\dagger 1476)$ and their children. The triptych dates from the 1530 and is most probably a commission of the children. Jan de Ridder was Lord of Groenesteyn, in the surroundings of Utrecht. Between 1425 and 1445, he occupied the function of alderman in Utrecht. His wife, Gertruui van Tetwijk, was the daughter of Albert van Tetwijk and Isabella van Grijpestein. The names of five of their children are known: Jan, Hendrik, Willem, Gijsberte and Gertruui, who was a nun at Oostbroek. She is depicted with her mother in cat. 59 .

Identity of the sitter(s): Jan De Ridder van Groenesteyn, Gertruui van Tetwijk and their children

Provenance: unknown

Number of portrait(s): 16

Type of person(s): mixed (family with children)

Attitude of the sitter(s): hands clasped

Representation of the sitter(s): full-length

Gaze of the sitter(s): towards the scene

Object(s): no

Coat(s) of arms: yes

Environment: architectural space, no sacred connotation

Structuring of the pictorial space: distinct spaces

Patron saint(s): John the Baptist, Peter

Gesture of the patron saint(s): holding his/her attribute

Type of religious scene: narrative

Religious scene(s) depicted: the Crucifixion 
Cat. o75-Type $2 \mathrm{~A}$

[RKD work no. 31188]

Anonymous North Netherlandish Master

Triptych of the Crucifixion with a Family in Prayer and Patron Saints ('Kanis Triptych') (c. 1526-1530)

$96.5 \times 66.5 \mathrm{~cm}$ (centre panel), $96 \times 26.5 \mathrm{~cm}$ (wings) and $14.5 \times 53 \mathrm{~cm}$ (predella) Nijmegen, Museum Het Valkhof, inv. no. 1975.03.27

BIBL.: Exh. cat. Amsterdam 1986, no. 48; Exh. cat. Utrecht 1999-2000, 91, 115, 277; Exh. cat. Kevelaer 2000-2001, 149-50, no. III-56 (with bibl.).

HISTORICAL INFORMATION: The devotees have been identified as Jacob Kanis, Jeliske van Houweningen and their children. Born in Nijmegen in 1469, Jacob Kanis was adviser of the children of the Duke René II of Lotharingia. He also made a political career in Nijmegen. He first married, in 1518, Jeliske van Henegouwen, who died in 1526 . Their son, Peter Kanis (Petrus Casinius) was born in 1521. As a Jesuit, Jacob played a crucial role against Protestantism. In the triptych, his portrait has been overpainted by the effigy of his younger brother, Gerardt, when the latter was forty-nine years old. The triptych probably comes from the church of St. Stephen in Nijmegen.

Identity of the sitter(s): Jacob Kanis, Jeliske van Houweningen and their children

Provenance: Nijmegen, church of St. Stephen (?)

Number of portrait(s): 9

Type of person(s): lay (family with children)

Attitude of the sitter(s): hands clasped, holding a rosary

Representation of the sitter(s): full-length

Gaze of the sitter(s): into space, towards the ground

Object(s): yes (prie-dieu, rosary, hat)

Coat(s) of arms: yes

Environment: historical setting

Structuring of the pictorial space: continuous space

Patron saint(s): Jerome, Adrian

Gesture of the patron saint(s): introducing, holding his/her attribute

Type of religious scene: narrative

Religious scene(s) depicted: the Crucifixion 
Cat. o76-Type $1 \mathrm{~A}$

Anonymous North Netherlandish Master

Triptych of the Adoration of the Magi with a Couple in Prayer and Patron Saints (c. 1500-1525)

$55 \times 21.5 \mathrm{~cm}$ (wings)

Private collection

Identity of the sitter(s): unknown Provenance: unknown

Number of portrait(s): 2

Type of person(s): lay (couple)

Attitude of the sitter(s): hands clasped

Representation of the sitter(s):

full-length

Gaze of the sitter(s): into space

Object(s): no

Coat(s) of arms: no

Environment: landscape, no sacred connotation (incomplete)

Structuring of the pictorial space: distinct spaces

Patron saint(s): Andrew, John the Evangelist

Gesture of the patron saint(s): holding his/her attribute, protecting

Type of religious scene: narrative

Religious scene(s) depicted: the Adoration of the Magi, the Nativity, the Circumcision

Cat. 077-Type 2A

Anonymous North Netherlandish Master

Triptych of the Adoration of the Magi with a Couple in Prayer and Patron Saints (c. 1490)

$100 \times 87 \mathrm{~cm}$ (centre panel) and $100 \times 37 \mathrm{~cm}$ (wings)

Santo Domingo de la Calzada (La Rioja), cathedral

BIBL.: BERMEJO 1982, 103-04; Exh. cat. Leon and Palencia 1999, no. 45 (with bibl.).

Identity of the sitter(s): unknown

Provenance: unknown 
Number of portrait(s): 2

Type of person(s): lay (couple)

Attitude of the sitter(s): hands clasped, holding a book

Representation of the sitter(s): full-length

Gaze of the sitter(s): into space, reading a book

Object(s): yes (prie-dieu, book)

Coat(s) of arms: no

Environment: architectural space with sacred connotation

Structuring of the pictorial space: continuous space

Patron saint(s): Gabriel, Anne

Gesture of the patron saint(s): introducing, indicating

Type of religious scene: narrative

Religious scene(s) depicted: the Adoration of the Magi, the Baptism of Christ, the Transfiguration, the Annunciation

Cat. 078-Type 2A

Anonymous North Netherlandish Master

Triptych of the Adoration of the Magi with a Family in Prayer and Patron Saints (c. 1530)

$131 \times 96.5 \mathrm{~cm}$ (centre panel) and $131 \times 40.5 \mathrm{~cm}$ (wings)

Selborne, St. Mary

BIBL.: GRÖSSINGER 1992, no. 53 .

Identity of the sitter(s): unknown

Provenance: unknown

Number of portrait(s): 14 (13 devotional portraits and 1 hidden portrait)

Type of person(s): mixed (family with children)

Attitude of the sitter(s): hands clasped, holding a rosary

Representation of the sitter(s): full-length

Gaze of the sitter(s): into space, towards the ground

Object(s): yes (rosary)

Coat(s) of arms: yes

Environment: historical setting

Structuring of the pictorial space: distinct spaces

Patron saint(s): Andrew, George

Gesture of the patron saint(s): holding his/her attribute

Type of religious scene: narrative

Religious scene(s) depicted: the Adoration of the Magi 
Cat. o79-Type $2 \mathrm{~A}$

[RKD work no. 48195]

Anonymous North Netherlandish Master

Triptych of the Lamentation with a Couple in Prayer and Patron Saints (c. 1520)

$84 \times 60.4 \mathrm{~cm}$ (centre panel) and $84 \times 30.6 \mathrm{~cm}$ (wings)

London, sale Sotheby's (9 July 1998), lot no. $15^{2}$

Identity of the sitter(s): unknown

Provenance: unknown

Number of portrait(s): 2

Type of person(s): lay (couple)

Attitude of the sitter(s): hands clasped

Representation of the sitter(s): full-length

Gaze of the sitter(s): towards the scene

Object(s): no

Coat(s) of arms: no

Environment: historical setting

Structuring of the pictorial space: continuous space

Patron saint(s): Peter, Catherine

Gesture of the patron saint(s): introducing, holding his/her attribute

Type of religious scene: narrative

Religious scene(s) depicted: the Lamentation, St. Augustine, a female saint

Cat. o8o-Type 2A-2C

Anonymous North Netherlandish Master

Triptych of the Lamentation with a Family in Prayer (c. 1525-1550)

$72.7 \times 60.5 \mathrm{~cm}$ (centre panel) and $72.6 \times 30.7 \mathrm{~cm}$ (wings)

Amsterdam, sale Sotheby's (18 May 2010), lot no. 3

BIB L.: Sale cat. Sotheby's (Amsterdam, 18 May 2010), no. 3.

REMARK: The peculiarity of this triptych lies in the fact that the mother is introduced by her patron saint, while the men of the family are portrayed alone, without a saint. See a similar case in cat. 229.

Identity of the sitter(s): unknown

Provenance: unknown

Number of portrait(s): 7

Type of person(s): mixed (family)

Attitude of the sitter(s): hands clasped

Representation of the sitter(s): half-length

Gaze of the sitter(s): towards the scene

Object(s): yes (prie-dieu, book, rosary)

Coat(s) of arms: yes 
Environment: historical setting

Structuring of the pictorial space: continuous space

Patron saint(s): Barbara

Gesture of the patron saint(s): introducing

Type of religious scene: narrative

Religious scene(s) depicted: the Lamentation

Cat. 081-Type 2A

[Link to the museum website]

Anonymous North Netherlandish Master

Triptych of the Lamentation with Two Nuns in Prayer and Patrons Saints (c. 1535)

$60 \times 45 \mathrm{~cm}$ (centre panel) and $59 \times 18 \mathrm{~cm}$ (wings)

Utrecht, Museum Catharijneconvent, inv. no. ABM s108

вIBL.: Mus. cat. Utrecht 2002, 120-21 (with bibl.).

Identity of the sitter(s): unknown

Provenance: unknown

Number of portrait(s): 2

Type of person(s): religious (group: canonesses regular?)

Attitude of the sitter(s): hands clasped

Representation of the sitter(s): full-length

Gaze of the sitter(s): into space

Object(s): no

Coat(s) of arms: yes

Environment: historical setting

Structuring of the pictorial space: unified space with discontinuities

Patron saint(s): John the Evangelist, Catherine

Gesture of the patron saint(s): holding his/her attribute

Type of religious scene: narrative

Religious scene(s) depicted: the Lamentation

Cat. 082-Type 2A

Anonymous North

Netherlandish Master

Triptych of the Last Supper with

Carthusians Monks and a Nun

in Prayer (c. 1520-1521)

$149.5 \mathrm{~cm} \times 96.5 \mathrm{~cm}$ (centre

panel) and $149.5 \mathrm{~cm} \times 39 \mathrm{~cm}$

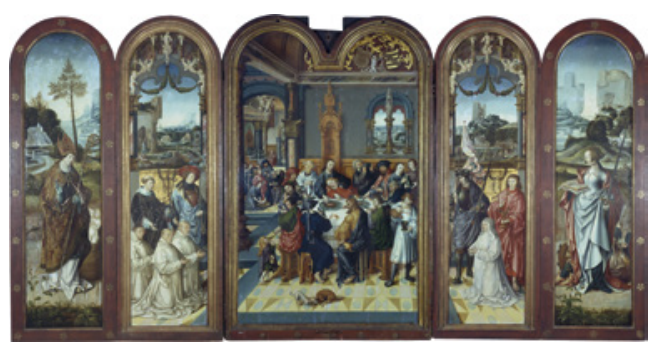

(wings) 
Utrecht, Centraal Museum, inv. no. 31199

BIBL.: VAN LUTTERVELD 1947; DEFOER 2011; Mus. cat. Utrecht 2011, no. 48 (with bibl.).

HISTORICAL INFORMATION: The triptych comes from the charterhouse of Nieuwlicht, in Utrecht. It contains the portraits of four Carthusian monks and a nun, from the Pauw and Sasz. families. Digna Sasz. is depicted on the right wing, while Pieter Sasz., Jacob and Vincent Pauw are portrayed on the left wing. The three men are the nephews of Digna: Pieter's father, Gerrit, was Digna's brother, and Jacob and Vincent's mother, Adriana, was her sister. Pieter entered the charterhouse of Nieuwlicht in 1512 and was its prior between 1525 and 1540. Vincent was, firstly, a monk in Nieuwlicht. He then moved to the charterhouse of Zonnenberg, before returning to Nieuwlicht a little while before his death in 1538. Jacob entered Nieuwlicht as a lay brother. In 1520, he became a novice and he was professed in 1521 . He died at Monnikhuizen in 1545. As one of the main benefactors of the charterhouse, Ghijsbert Pauw, the father of Jacob and Vincent, was buried at Nieuwlicht. Taking into account the fact that Jacob is depicted as a novice, the triptych can be dated to around $15^{21}$. It was probably destined for the altar of the Martyr Saints, which was located nearby Ghijsbert's grave.

Identity of the sitter(s): Jacob and Vincentius Pauw, Pieter and Digna Sasz.

Provenance: Utrecht, charterhouse of Nieuwlicht

Number of portrait(s): 4

Type of person(s): religious (group: Carthusian monks and a nun)

Attitude of the sitter(s): hands clasped

Representation of the sitter(s): full-length

Gaze of the sitter(s): into space

Object(s): no

Coat(s) of arms: yes

Environment: historical setting

Structuring of the pictorial space: unified space with discontinuities

Patron saint(s): Lawrence, Sebastian, George, John the Evangelist

Gesture of the patron saint(s): holding his/her attribute, introducing

Type of religious scene: narrative

Religious scene(s) depicted: the Last Supper, St. Nicholas, St. Catherine 
Cat. 083 - Type $2 B$

Anonymous North Netherlandish

Master

Triptych of the Maria in Sole with a Family in Prayer and Patron Saints (c. 1525)

$65.5 \times 46 \mathrm{~cm}$ (centre panel) and $68 \times$ $20 \mathrm{~cm}$ (wings)

Leiden, Stedelijk Museum de Lakenhal, inv. no. 246

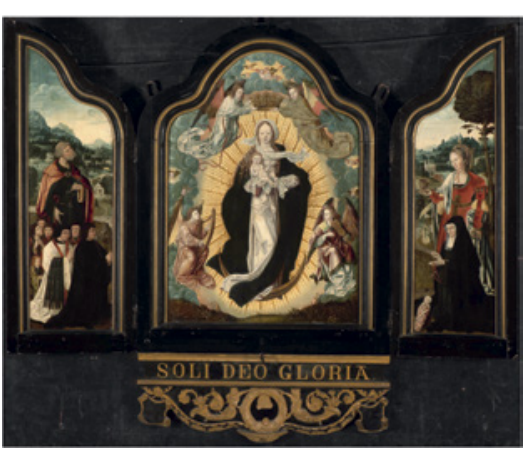

BIB L.: Mus. cat. Leiden 1983 , no. 246 (with bibl.).

HISTORICAL INFORMATION: The reverse of the wings contains the coat of arms of the city of Leiden, associated with that of the Van Hothorst family. In 1872, the triptych was located in the Hospital of St. Cecilia (St. Caeciliagasthuis) in Leiden. This could be its original destination.

Identity of the sitter(s): unknown

Provenance: Leiden, Hospital of St. Cecilia (?)

Number of portrait(s): 7

Type of person(s): mixed (family)

Attitude of the sitter(s): hands clasped

Representation of the sitter(s): full-length

Gaze of the sitter(s): towards the scene, into space, towards the viewer

Object(s): no

Coat(s) of arms: yes (on the reverse)

Environment: landscape with sacred connotation

Structuring of the pictorial space: distinct spaces, religious scene in a cloud

Patron saint(s): Peter, Mary Magdalen

Gesture of the patron saint(s): introducing, indicating

Type of religious scene: hieratic

Religious scene(s) depicted: Maria in sole, the Annunciation

Cat. 084-Type 2D

[RKD work no. 44084]

Anonymous North Netherlandish Master

Triptych of the Pietà with two Women in Prayer (c. 1500-1550)

$184 \times 94 \mathrm{~cm}$ (open)

Breda, Breda's Museum

BIBL.: PASSEMIERS 1987, 311-15, no. 37. 
HISTORICAL INFORMATION: The two women have been identified as Adriana Monincx (1470-1535) and her daughter Josyna († 1532). Originating from a wealthy family of s'Hertogenbosch, Adriana was the second daughter of Joost van Arkel, Lord of Dongen (1440-1525).

Identity of the sitter(s): Adriana Monincx and her daughter Josyna

Provenance: unknown

Number of portrait(s): 2

Type of person(s): lay (family)

Attitude of the sitter(s): hands clasped

Representation of the sitter(s): half-length

Gaze of the sitter(s): into space

Object(s): no

Coat(s) of arms: yes

Environment: landscape with sacred connotation

Structuring of the pictorial space: continuous space

Patron saint(s): none

Gesture of the patron saint(s): not applicable

Type of religious scene: hieratic

Religious scene(s) depicted: the Pietà

\section{Cat. 085-Type 2A}

[RKD work no. 28914]

Anonymous North Netherlandish Master

Triptych of the Raising of Lazarus with Jan Micault and Livina Cats van Welle (c. 1500-1510)

$61 \times 104.8 \mathrm{~cm}$ (centre panel) and $61.8 \times 47.3 \mathrm{~cm}$ (wings)

Oud-Zuilen (Maarssen), Zuylen Castle, inv. no. S 114

BIB L.: Exh. cat. Oud-Zuilen, no. 1.

HISTORICAL INFORMATION: Jan Micault and Livina Cats have been identified on the basis of the coats of arms and the inscription on the wings: MICAULT CONRO $[Y] / / L A B A M E N O R E V L X$ (on the left) and [CATS VAN WELLE] [BOTLANT] // CAMPE ALMONDE (on the right). The original location of the triptych remains unknown. On the sitters, see cat. 748. They also appear in cat. 341.

REMARK: the atypical format of the triptych is the result of a restoration made in 1912. Initially the panels were rectangular.

Identity of the sitter(s): Jan Micault and Livina Cats van Welle

Provenance: unknown

Number of portrait(s): 2

Type of person(s): lay (couple) 
Attitude of the sitter(s): hands clasped

Representation of the sitter(s): full-length

Gaze of the sitter(s): towards the scene

Object(s): yes (prie-dieu, book, dog)

Coat(s) of arms: yes

Environment: architectural space, no sacred connotation

Structuring of the pictorial space: distinct spaces

Patron saint(s): John the Baptist, Levinus

Gesture of the patron saint(s): introducing

Type of religious scene: narrative

Religious scene(s) depicted: the Raising of Lazarus

Cat. o86-Type 6A

[RKD work no. 38873]

Anonymous North Netherlandish Master

Two Wings. A Couple in Prayer with Patron Saints (c. 1500-1550)

$83 \times 27.5 \mathrm{~cm}$ (each wing)

Amsterdam, sale Sotheby's (5 November 2002), lot no. 266

BIBL.: BRUYN 1983, 119-20.

Identity of the sitter(s): unknown

Provenance: unknown

Number of portrait(s): 3

Type of person(s): lay (family with children)

Attitude of the sitter(s): hands clasped

Representation of the sitter(s): full-length, children in small scale

Gaze of the sitter(s): indeterminate

Object(s): yes (prie-dieu, book, rosary)

Coat(s) of arms: no

Environment: landscape, no sacred connotation (incomplete)

Structuring of the pictorial space: indeterminate

Patron saint(s): Mary Magdalen, Catherine

Gesture of the patron saint(s): holding his/her attribute

Type of religious scene: indeterminate

Religious scene(s) depicted: none

Cat. 087-Type 6A

Anonymous North Netherlandish Master

Two Wings. A Couple in Prayer with Patron Saints (c. 1500-1510)

Size unknown 
Poznan, Muzeum Narodowe, inv. no. Mo 128

Identity of the sitter(s): unknown

Provenance: unknown

Number of portrait(s): 2

Type of person(s): lay (couple)

Attitude of the sitter(s): hands clasped

Representation of the sitter(s): full-length

Gaze of the sitter(s): indeterminate

Object(s): yes (prie-dieu, book, dog)

Coat(s) of arms: yes

Environment: landscape with sacred connotation (incomplete)

Structuring of the pictorial space: indeterminate

Patron saint(s): Catherine, John the Baptist

Gesture of the patron saint(s): introducing, holding his/her attribute

Type of religious scene: indeterminate

Religious scene(s) depicted: none

Cat. 088-Type 6A

Anonymous North Netherlandish Master

Two Wings. A Family in Prayer with Patron Saints (c. 1515)

$105 \times 40 \mathrm{~cm}$ (each wing)

London, sale Sotheby's (26 April 1956), lot no. 67

Identity of the sitter(s): unknown

Provenance: unknown

Number of portrait(s): 17

Type of person(s): lay (family)

Attitude of the sitter(s): hands clasped

Representation of the sitter(s): full-length

Gaze of the sitter(s): indeterminate

Object(s): yes (rosary)

Coat(s) of arms: no

Environment: landscape, no sacred connotation (incomplete)

Structuring of the pictorial space: indeterminate

Patron saint(s): John the Evangelist, Barbara

Gesture of the patron saint(s): holding his/her attribute

Type of religious scene: indeterminate

Religious scene(s) depicted: none 
Cat. 089-Type 6A

[MEMO work no. 506]

Anonymous North Netherlandish Master

Two Wings. Arend van de Gruthuus and his Family in Prayer (c. 1550)

$5^{2.5} \times 82 \mathrm{~cm}$ (each panel)

Kampen, Stedelijk Museum, inv. no. 1319

BIB L.: Exh. cat. Utrecht 1999-2000, 98, 276.

HISTORICAL INFORMATION: The persons depicted on the panels are Arend van de Gruthuus, Betta van Ingen and their children. They came from Arnhem and Kampen. Arend died in 1545 and Betta in 1552. They are buried in the church of St. Eusebius in Arnhem. The epitaph on the lower part of the panels suggests that they were parts of a commemorative work destined for this church. As stated in the MeMO-database (work no. 506), the panels have a rounded shape, suggesting they were hung on a pillar.

Identity of the sitter(s): Arend van de Gruthuus, Betta van Ingen and their children

Provenance: Arnhem, church of St. Eusebius (Grote kerk)

Number of portrait(s): 18

Type of person(s): lay (family with children)

Attitude of the sitter(s): hands clasped, holding a book

Representation of the sitter(s): full-length

Gaze of the sitter(s): indeterminate

Object(s): yes (book)

Coat(s) of arms: yes

Environment: architectural space, no sacred connotation (incomplete)

Structuring of the pictorial space: indeterminate

Patron saint(s): John the Evangelist, Barbara

Gesture of the patron saint(s): indicating, holding his/her attribute

Type of religious scene: indeterminate

Religious scene(s) depicted: none

\section{Cat. ogo-Type 6A}

[RKD work no. 202210]

Anonymous North Netherlandish Master

Two Wings. St. Augustine and a Man in Prayer; St. Jerome (c. 1500-1550)

$45.2 \times 14.7 \mathrm{~cm}$ (each wing)

Paris, sale Eric Beaussant (2 December 2011), lot no. 1

Identity of the sitter(s): unknown

Provenance: unknown 
Number of portrait(s): 1

Type of person(s): religious (man alone: canon)

Attitude of the sitter(s): hands clasped

Representation of the sitter(s): full-length

Gaze of the sitter(s): indeterminate

Object(s): no

Coat(s) of arms: no

Environment: landscape, no sacred connotation (incomplete)

Structuring of the pictorial space: indeterminate

Patron saint(s): Augustine

Gesture of the patron saint(s): introducing

Type of religious scene: indeterminate

Religious scene(s) depicted: St. Jerome

\section{Cat. 091-Type 6A}

Anonymous North Netherlandish

Master

Two Wings. The Family Karre-Van

Groenewegen in Prayer (c. 1500-1550)

$90 \times 33 \mathrm{~cm}$ (each wing)

Rotterdam, Museum Rotterdam, inv.

nos. 10501-A.1-2

BIB L.: LIEBURG et alii 1996, 160-62. HISTORICAL INFORMATION: The family Karre-Van Groenewegen has been identified, on the basis of the coats of arms painted on the reverse of the panels. The father was named Pieter
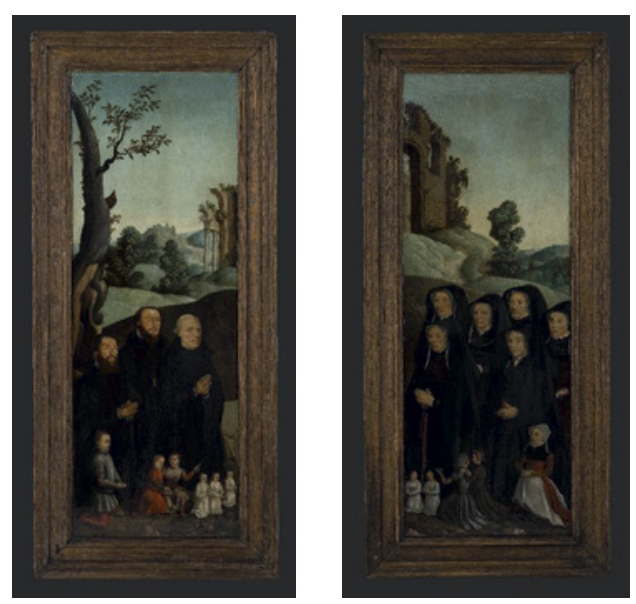
Adriaensz. Karre and the mother Maria

Dirksdr. van Groenewegen. They are depicted with their children (deceased and alive). Not long before 1516, Pieter and his mother founded a mass at the St. Jerome's altar of the church of St. Lawrence in Rotterdam. These panels might come from the altarpiece destined for this place.

Identity of the sitter(s): Karre-Van Groenewegen family

Provenance: Rotterdam, church of St. Lawrence, St. Jerome's altar (?)

Number of portrait(s): 20

Type of person(s): lay (family with children)

Attitude of the sitter(s): hands clasped, particular gesture

Representation of the sitter(s): full-length, children in small scale 
Gaze of the sitter(s): indeterminate

Object(s): no

Coat(s) of arms: yes (on the reverse)

Environment: landscape, no sacred connotation (incomplete)

Structuring of the pictorial space: indeterminate

Patron saint(s): none

Gesture of the patron saint(s): not applicable

Type of religious scene: indeterminate

Religious scene(s) depicted: none

Cat. 092-Type 6A

Anonymous North Netherlandish Master

Two Wings. The Lokhorst Family in Prayer (c. 1510)

$125.5 \times 94 \mathrm{~cm}$ (each wing)

Heeswijk-Dinther Castle

BIB L.: Exh. cat. Utrecht 1999-200o, no. 98 (with bibl.).

HISTORICAL INFORMATION: The two wings originate from a memorial work and present the portraits of six clergymen and five knights of the Lokhorst family from Utrecht. The knights are Adam ( $†$ 1103), Johannes ( $†$ 1223), Adam $(\dagger$ 1203) and Herman van Lokhorst van Wulven $(\dagger 1435)$ and Adam. The clergymen are Herman $(\dagger 1527)$ - who is probably the commissioner of the triptych—, Herman ( $† 1400)$, Werner ( $† 1430)$, Gijsbert ( $\left.1_{1454}\right)$, Herman $(\dagger 1456)$ and Jacobus $(\dagger 1463)$.

Identity of the sitter(s): family of Herman Lokhorst

Provenance: Utrecht, church of St. Gertrude

Number of portrait(s): 11

Type of person(s): mixed (family)

Attitude of the sitter(s): hands clasped

Representation of the sitter(s): full-length

Gaze of the sitter(s): indeterminate

Object(s): yes (helmet, sword)

Coat(s) of arms: no

Environment: ecclesial space, landscape, no sacred connotation (incomplete)

Structuring of the pictorial space: indeterminate

Patron saint(s): Martin, Adrien

Gesture of the patron saint(s): holding his/her attribute, protecting

Type of religious scene: indeterminate

Religious scene(s) depicted: none 
Cat. 093 - Type 6A

[Link to the museum website]

Anonymous North Netherlandish Master

Two Wings. Two Women in Prayer with St. Augustine and St. Gertrude (c. $\left.15^{25}-155^{0}\right)$

$65.3 \times 22.7 \mathrm{~cm}$ (each wing)

Chicago, Chicago Art Institute, inv. nos. 1933.1041-42

BIB L.: Mus. cat. Chicago 2008, 284-87 (with bibl.).

Identity of the sitter(s): unknown

Provenance: unknown

Number of portrait(s): 2

Type of person(s): religious (group: Augustinian canonesses)

Attitude of the sitter(s): hands clasped

Representation of the sitter(s): full-length

Gaze of the sitter(s): indeterminate

Object(s): no

Coat(s) of arms: no

Environment: landscape, no sacred connotation (incomplete)

Structuring of the pictorial space: indeterminate

Patron saint(s): Augustine, Gertrude

Gesture of the patron saint(s): holding his/her attribute

Type of religious scene: indeterminate

Religious scene(s) depicted: none

Cat. 094-Type ${ }_{3} \mathrm{C}$

Anonymous North Netherlandish Master

Four Scenes of the Legend of St. Elizabeth of Hungary (c. 1500)

$82.5 \times 61 \mathrm{~cm}$

Amsterdam, Rijksmuseum, inv. no. SK-A-2237 BIBL.: Mus. cat. Amsterdam 1976, 652; Mus. cat. Amsterdam 2009 [online], https://www .rijksmuseum.nl/nl/collectie/SK-A-2237/cat alogus-entry (with bibl.).

HISTORICAL INFORMATION: The coat of arms painted in the centre of the composition has not been identified. The text inscribed on

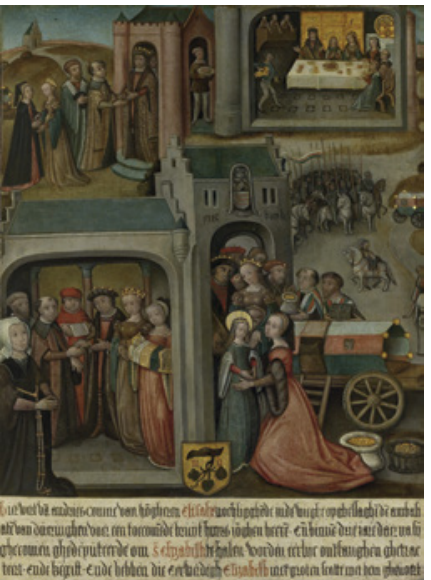
the lower part of the panel describes the depicted scenes. 
Identity of the sitter(s): unknown

Provenance: unknown

Number of portrait(s): 1

Type of person(s): lay (woman alone)

Attitude of the sitter(s): hands clasped

Representation of the sitter(s): full-length

Gaze of the sitter(s): towards the scene

Object(s): yes (rosary)

Coat(s) of arms: yes

Environment: historical setting

Structuring of the pictorial space: fragmentation of the pictorial space

Patron saint(s): none

Gesture of the patron saint(s): not applicable

Type of religious scene: narrative

Religious scene(s) depicted: the Legend of St. Elizabeth

Cat. 095-Type $3 \mathrm{C}$

Anonymous North Netherlandish

Master

The Roermond Passion (c. 1430-1440) $103 \times 167.5 \mathrm{~cm}$

Amsterdam, Rijksmuseum, inv. no. SK-A-1491

BIBL.: FRIEDLÄNDER III, no. 39;

Mus. cat. Amsterdam 1976, 674; Mus.

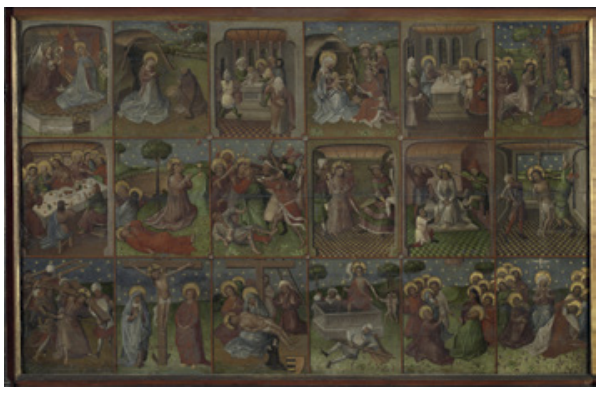
cat.Amsterdam2009[online],https://

www.rijksmuseum.nl/nl/collectie/SK-A-1491/catalogus-entry (with bibl.). HISTORICAL INFORMATION: The woman depicted as a widow in the panel of the Lamentation is Bela Scheiffart van Merode. In 1378, she married Johan van Mirlaer, Lord of Millendonck. They had a daughter, Bela van Mirlaer van Millendonck, who became a nun. In 1447, Bela is mentioned as the abbess of the Cistercian convent of Roermond. The original place and function of this panel are unknown.

Identity of the sitter(s): Bela Scheiffart van Merode

Provenance: unknown

Number of portrait(s): 1

Type of person(s): lay (woman alone)

Attitude of the sitter(s): hands clasped

Representation of the sitter(s): full-length, small scale 
Gaze of the sitter(s): towards the scene

Object(s): no

Coat(s) of arms: yes

Environment: historical setting

Structuring of the pictorial space: fragmentation of the pictorial space

Patron saint(s): none

Gesture of the patron saint(s): not applicable

Type of religious scene: narrative

Religious scene(s) depicted: scenes from the Passion

\section{Cat. o96-Type 2A}

[Link to the museum website]

Anonymous North Netherlandish Master

Triptych of the Crucifixion with Tieleman Oem van Wijngaarden and Dirk van Raaphorst in Prayer (c. 1525)

$122 \times 92 \mathrm{~cm}$ (centre panel) and $122 \times 41 \mathrm{~cm}$ (wings)

Utrecht, Museum Catharijneconvent, inv. no. RMCC s25

BIBL.: VAN BUEREN 1989, 133-37; Exh. cat. Utrecht 1999-2000, 217-18; Mus. cat. Utrecht 2002, 138-39 (with bibl.).

HISTORICAL INFORMATION: On the basis of an inventory dating from 1573, the man portrayed on the right wing has been identified as Tieleman Oem van Wingaerden, a priest of the Jansklooster of Haarlem, who died in 1518 . He was buried in the church of the Jansklooster. Originally, the reverse of the wings included coats of arms, but they have been overpainted. Nevertheless, the triptych had been described in 1913, before the alteration of these panels. This description allowed the identification of the man portrayed on the left as Dirk van Raaphorst (or Noordwijk) (†1504-1505). He was canon of the church of St. Pancras in Leiden and chaplain of the Holy Kinship's altar at the church of the Sts Sixtus and John the Baptist of Den Burg, on the island of Texel. Dirk had familial ties with Tieleman. In all likelihood, the triptych was meant to be the epitaph of both men, as suggested by the mention Epitaphium van wingaerden ons Hercn aent cruis, in the 1573 inventory.

Identity of the sitter(s): Tieleman Oem van Wijngaarden and Dirk van Raaphorst (or Noordwijk)

Provenance: Haarlem, Jansklooster (?)

Number of portrait(s): 2

Type of person(s): religious (group: priest and canon)

Attitude of the sitter(s): hands clasped

Representation of the sitter(s): full-length 
Gaze of the sitter(s): into space

Object(s): no

Coat(s) of arms: no

Environment: historical setting

Structuring of the pictorial space: unified space with discontinuities

Patron saint(s): Anthony (?), John the Baptist

Gesture of the patron saint(s): holding his/her attribute

Type of religious scene: narrative

Religious scene(s) depicted: the Crucifixion

\section{Cat. 097-Type 2A}

Anonymous North Netherlandish Master

Triptych of the Last Judgement with a Couple in Prayer and Patron Saints (c. 1540)

$58.5 \times 40.3 \mathrm{~cm}$ (centre panel) and $57.7 \times 25.9 \mathrm{~cm}$ (wings)

New York, sale Sotheby's (28 January 2011), lot no. 6

Identity of the sitter(s): unknown

Provenance: unknown

Number of portrait(s): 2

Type of person(s): lay (couple)

Attitude of the sitter(s): hands clasped

Representation of the sitter(s): full-length

Gaze of the sitter(s): towards the scene

Object(s): no

Coat(s) of arms: no

Environment: historical setting

Structuring of the pictorial space: continuous space

Patron saint(s): James, Anne

Gesture of the patron saint(s): introducing

Type of religious scene: narrative

Religious scene(s) depicted: the Last Judgement

Cat. o98-Type $3^{D}$

[RKD work no. 38816]

Anonymous North Netherlandish Master

The Virgin and Child with St. Anne and a Couple in Prayer (c. 1500-1525)

$97 \times 71 \mathrm{~cm}$

Previously Nederhemert Castle (destroyed)

BIBL.: HOOGEWERFF II, 380-84. 
Historical INFORMATION: The identification of the couple as Sander Bentinck and his wife comes from the RKD database. Hoogewerff had previously identified the couple as Willem van Zuylen and his wife. The painting was destroyed during a fire in Nederhemert Castle, where it had been preserved.

Identity of the sitter(s): Sander Bentinck tot Berencamp and Johanna van Zuylen van Anholt (or Willem van Zuylen Bentinck and Judith van Zuylen Nyevelt)

Provenance: unknown

Number of portrait(s): 2

Type of person(s): lay (couple)

Attitude of the sitter(s): hands clasped

Representation of the sitter(s): full-length

Gaze of the sitter(s): into space, towards the scene

Object(s): yes (prie-dieu, book, rosary)

Coat(s) of arms: yes

Environment: enclosed garden

Structuring of the pictorial space: not applicable

Patron saint(s): none

Gesture of the patron saint(s): not applicable

Type of religious scene: hieratic

Religious scene(s) depicted: the Virgin and Child with St. Anne

Cat. 099-Type 3 A

Anonymous North Netherlandish Master (?)

The Lamentation with a Man in Prayer and

Patron Saint (c. 1500)

$81 \times 57.5 \mathrm{~cm}$

Bonn, Rheinisches Landesmuseum, inv. no.

G. K. 1927

BIBL.: HOOGEWERFF II, 286; Mus. cat. Bonn 1927. no. 95.

Identity of the sitter(s): unknown

Provenance: unknown

Number of portrait(s): 1

Type of person(s): lay (man alone)

Attitude of the sitter(s): hands clasped

Representation of the sitter(s): full-length

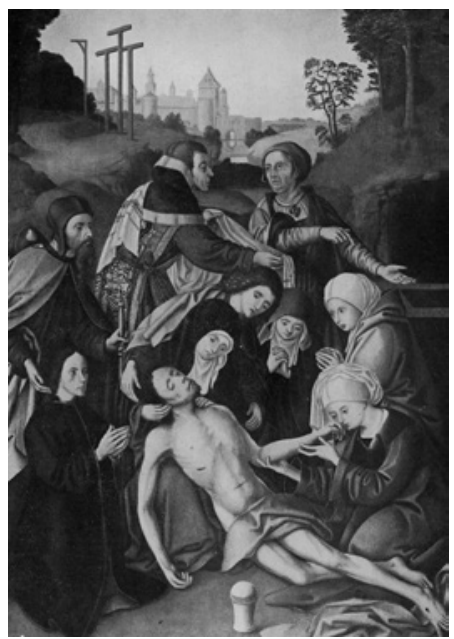

Gaze of the sitter(s): towards the scene

Object(s): no 
Coat(s) of arms: no

Environment: historical setting

Structuring of the pictorial space: not applicable

Patron saint(s): James

Gesture of the patron saint(s): introducing

Type of religious scene: narrative

Religious scene(s) depicted: the Lamentation

\section{Cat. 100-Type 3D}

[RKD work no. 13524]

Anonymous North Netherlandish Master (Amsterdam?)

The Jerusalem Brothers Jan Benningh Gerritsz., Wouter van Hoogesteyn, Meyndert Willemsz. (?) and Jacob Heyn Fransz. in Prayer before the Crypt of the Nativity of Christ in Bethlehem (c. 1520)

$79 \times 211.5 \mathrm{~cm}$

Utrecht, Museum Catharijneconvent, inv. no. ABM s104

BIB L.: Exh. cat. Utrecht 1999-2000, 166-67, no. 34; Mus. cat. Utrecht 2002, 13637 (with bibl.).

HISTORICAL INFORMATION: According to the inscription on the frame, the four men are Jerusalem Pilgrims (Jeruzalemvaarders), who made the pilgrimage to the Holy Land in 1519: Int jaer ons heeren XVc en XIX waren tesamen te Jerusalem broeder Wouter van Hoogesteyn Jan Benninck, Jacob Heyn en Meynnert Willems. From left to right, they are Jan Benninck, alderman of Amsterdam $(\dagger 1531)$, the Dominican Wouter van Hoogesteyn, Meyndert Willemsz. and Jacop Heyn, a nephew of Jan Benninck. The painting commemorates their pilgrimage and is evidence of their visit of the crypt of the Nativity of Christ, at Bethlehem, as the inscription at the centre of the panel indicates: Dit is die figuer vant Bethlehem van binnen daer god in gheboren is.

Identity of the sitter(s): Jan Benninck, Wouter van Hoogesteyn, Meyndert

Willemsz. and Jacop Heyn Fransz.

Provenance: Amsterdam, St. Olof's chapel, chapel of Jerusalem (?)

Number of portrait(s): 4

Type of persons: lay (group: association)

Attitude of the sitter(s): hands clasped

Representation of the sitter(s): full-length

Gaze of the sitter(s): into space

Object(s): yes (palms)

Coat(s) of arms: yes

Environment: actual setting 
Structuring of the pictorial space: not applicable

Patron saint(s): none

Gesture of the patron saint(s): not applicable

Type of religious scene: hieratic

Religious scene(s) depicted: Crypt of the Nativity of Christ, at Bethlehem

\section{Cat. 101-Type $\mathbf{3}^{\mathrm{B}}$}

Anonymous North Netherlandish Master (Guelder?)

The Virgin and Child with Catharina van Gelre Egmont in Prayer, St. Augustine and St. Mary Magdalen (c. 1500-1510)

$49 \times 57 \mathrm{~cm}$

Geldern, cathedral Pfarrgemeinde St. Maria Magdalena

BIB L.: Exh. cat. Kevelaer 2000-2001, no. III-12.

HISTORICAL INFORMATION: The inscription on the frame identifies the portrayed woman as Catharina van Gelre Egmont, daughter of the Duke Adolf van Gelre Egmont: Sr CATHANRINA DE GELDRIA PRIORISSA HVIVS DOMO / FILIA DVCIS GELDRIAE. Catharina was the prioress of the Augustinian convent of Nazareth in Geldern. The painting most probably comes from this convent.

Identity of the sitter(s): Catharina van Gelre Egmont

Provenance: Geldern, Augustinian convent of Nazareth (?)

Number of portrait(s): 1

Type of persons: religious (woman alone: Augustinian nun)

Attitude of the sitter(s): hands clasped

Representation of the sitter(s): full-length, small scale

Gaze of the sitter(s): towards the ground

Object(s): yes (banderole)

Coat(s) of arms: no

Environment: enclosed garden

Structuring of the pictorial space: not applicable

Patron saint(s): Augustine

Gesture of the patron saint(s): holding his/her attribute

Type of religious scene: hieratic

Religious scene(s) depicted: the Virgin and Child, Mary Magdalen

Cat. 102-Type ${ }_{3} \mathrm{C}$

[Link to the RMN Database]

Anonymous North Netherlandish Master (Master of the St. Elizabeth Panels?) 
Panorama of the Passion with a Couple in Prayer (c. 1450)

$94 \times 184 \mathrm{~cm}$

Pont-Saint-Esprit, Musée d'Art sacré du Gard (loan of the Musée du Louvre, Paris), inv. no. MNR971

BIBL.: HOOGEWERFF V, 29.

Identity of the sitter(s): unknown

Provenance: unknown

Number of portrait(s): 2

Type of persons: lay (couple)

Attitude of the sitter(s): hands clasped

Representation of the sitter(s): full-length

Gaze of the sitter(s): into space

Object(s): no

Coat(s) of arms: no

Environment: historical setting

Structuring of the pictorial space: fragmentation of the pictorial space

Patron saint(s): none

Gesture of the patron saint(s): not applicable

Type of religious scene: narrative

Religious scene(s) depicted: the Passion

Cat. 103-Type $2 B$

Anonymous North Netherlandish

Master (or Aert van Leyden)

Triptych of the Holy Family with

Henry III of Nassau (c. 1530-1535)

$73 \times 66 \mathrm{~cm}$ (centre panel) and $73 \times 29$

$\mathrm{cm}$ (wings)

Antwerp, KMSK, inv. nos. 977-979

BIB L.: Mus. cat. Antwerp 1998, 226-27;

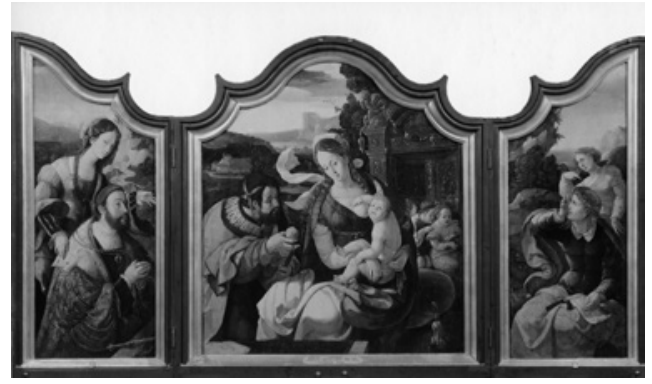

Exh. cat. Utrecht and Den Bosch 1993,

no. 180; Exh. cat. Leiden 2011, no. 122 (with bibl.).

HISTORICAL INFORMATION: Born in 1483, Henry III of Nassau was the oldest son of Jan V and the nephew of Englebert II of Nassau, from whom he inherited goods and seigneuries. After the death of Englebert in 1504, he became Count of Nassau-Dillenburg and of Vianden, Lord of Diest and of Breda. In 1505, he became knight of the Order of the Golden Fleece. He made a political career at the ducal court: he was chamberlain of Philip the Fair and of Maximilian of Austria, General Captain of the Duchy of Brabant in 1511, and Grand veneur of Brabant in 1532. He was member of the Conseil privé in 1507, 1515 and 1517, 
Governor of Zeeland and Friesland from 1515 to 1521 and finally chamberlain of Charles v from 1521 onwards. He died in 1538 .

Identity of the sitter(s): Henry III of Nassau

Provenance: unknown

Number of portrait(s): 1

Type of persons: lay (man alone)

Attitude of the sitter(s): hands clasped

Representation of the sitter(s): half-length

Gaze of the sitter(s): towards the scene

Object(s): yes (sceptre, collar of the Order of the Golden Fleece)

Coat(s) of arms: no

Environment: landscape, no sacred connotation

Structuring of the pictorial space: unified space with discontinuities

Patron saint(s): Tiburtine sibyl

Gesture of the patron saint(s): introducing

Type of religious scene: hieratic

Religious scene(s) depicted: the Holy Family, St. John the Evangelist, the Annunciation

\section{Cat. 104-Type $3 \mathrm{~A}$}

Anonymous North Netherlandish Master (or Anonymous Antwerp Master)

The Adoration of the Magi with the Van Schaik Family in Prayer and Patron Saints (c. 1540)

$120.7 \times 100 \mathrm{~cm}$

Amersfoort, Museum Flehite, inv. nos. 1993-222

BIBL.: DE MEYERE et alii 1995; Exh. cat. Utrecht 1999-2000, 207-09 (with bibl.).

HISTORICAL INFORMATION: The predella of the panel contains the coats of arms of Jacob and Alijd van Schaik and an epitaph divided into two columns: Int Jaer ons here-MIIIIc en- vijfennegentich de-XIIII dach van septe-ber sterff Alijt va-Scaijck. Jnt Jaer ons here- MVc en- dertich de-IIII dach va- juni sterff Jacop va-scaick. Jnt Jaer ons here-MVc en-veertich de-XII dach va de april sterff meister Are-t van scaijck. bidt voer die zielen (on the left); Int Jaer ons heere$M V$ c en $L V$ - de- tienden dach in november sterff Iacop Jacopsz. Jnt Jaer ons heere$M V c$ en- LIII opte- vijften dach in november sterff aeltge-van Scaeck. Jnt Jaere ons heere-MVc en (de) LVII den XXI in october Heer evert van scaick (on the right). Jacob and Alijd van Schaik came from Amsterfoort. Alijd died in 1495 and Jacob in 1530. Several archival documents give the names of their children 
(Arijs, Jacob, Aernt, Evert and Alijd). Arijs was burgomaster of Amersfoort, Evert was a priest and Aernt studied in Cologne. The painting and the predella constitute two distinct panels. While the painting dates from c. 1530, the text on the predella mentions dates up to 1557 . This has led some scholars to state that the painting was a commission of the Van Schaik children to commemorate their parents, while the predella was a later addition by the executors or some members of the family. It is often assumed that the panel was destined for the church of St. George in Amersfoort.

Identity of the sitter(s): Van Schaik family

Provenance: Amersfoort, church of St. George (?)

Number of portrait(s): 13

Type of persons: mixed (family with children)

Attitude of the sitter(s): hands clasped, holding a rosary

Representation of the sitter(s): full-length

Gaze of the sitter(s): into space

Object(s): yes (rosary)

Coat(s) of arms: yes

Environment: historical setting

Structuring of the pictorial space: not applicable

Patron saint(s): James, Barbara

Gesture of the patron saint(s): protecting

Type of religious scene: narrative

Religious scene(s) depicted: the Adoration of the Magi

Cat. 105-Type $3 \mathrm{D}$

Anonymous North Netherlandish Master (or circle of Jacob Cornelisz. van Oostsanen)

The Holy Kinship with a Nun in Prayer (c. 1520)

$71.3 \times 50.8 \mathrm{~cm}$

Vienna, sale Dorotheum (17 October 2007), lot no. 355

Identity of the sitter(s): unknown

Provenance: unknown

Number of portrait(s): 1

Type of persons: religious (woman alone: Poor Clare)

Attitude of the sitter(s): hands clasped

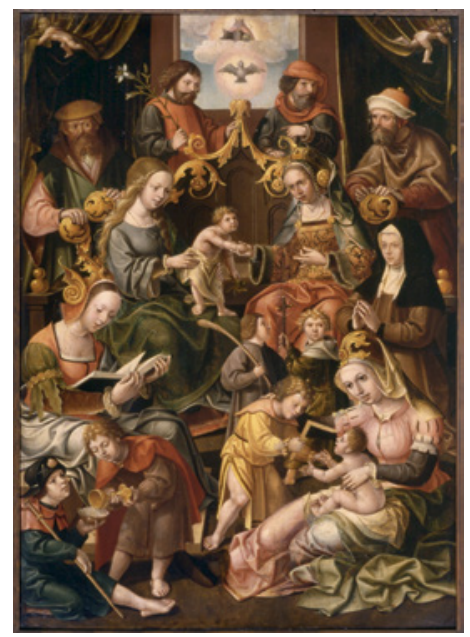


Representation of the sitter(s): full-length

Gaze of the sitter(s): into space

Object(s): no

Coat(s) of arms: no

Environment: architectural space with sacred connotation

Structuring of the pictorial space: not applicable

Patron saint(s): none

Gesture of the patron saint(s): not applicable

Type of religious scene: hieratic

Religious scene(s) depicted: the Holy kinship

Cat. 106-Type ${ }_{3}$ B

Anonymous South Netherlandish Master A Woman in Prayer with St. Jerome and St. Barbara before an Apparition of the Virgin and Child (c. 1500-1510)

$76.2 \times 78.7 \mathrm{~cm}$

New York, sale Sotheby's (5 October 2001), lot no. 21

Identity of the sitter(s): unknown

Provenance: unknown

Number of portrait(s): 1

Type of persons: lay (woman alone)

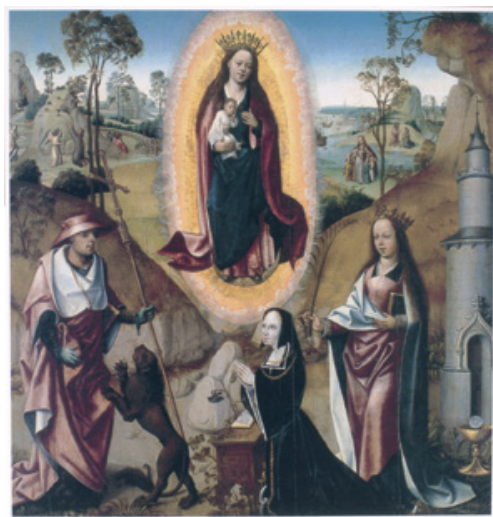

Attitude of the sitter(s): hands clasped

Representation of the sitter(s): full-length

Gaze of the sitter(s): towards the scene

Object(s): yes (prie-dieu, book)

Coat(s) of arms: no

Environment: landscape with sacred connotation

Structuring of the pictorial space: religious scene in a cloud

Patron saint(s): Barbara

Gesture of the patron saint(s): holding his/her attribute

Type of religious scene: hieratic

Religious scene(s) depicted: the Virgin and Child, St. Jerome 
Cat. 107-Type 3 A Anonymous South Netherlandish Master Antependium with Christ, the Arma Christi and Two Men in Prayer

(c. 1490-1500) $94 \times 194 \mathrm{~cm}$

Leuven, M Museum

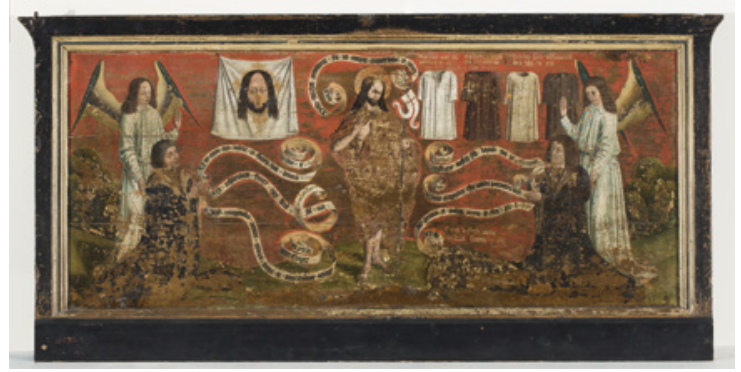

Leuven, inv. no. $\mathrm{S} / 2 / \mathrm{O}$

BIB L.: Exh. cat. Leuven 1975, no. B/43; Exh. cat. Leuven 1998, no. 86 (with bibl.). HISTORICAL INFORMATION: This panel served as an antependium in the chapel of the Holy Cross, in the church of St. James in Leuven. It might be a commission of the Brotherhood of the Holy Cross.

Identity of the sitter(s): unknown

Provenance: Leuven, church of St. James, chapel of the Holy Cross

Number of portrait(s): 2

Type of persons: lay (group: association?)

Attitude of the sitter(s): holding a banderole

Representation of the sitter(s): full-length

Gaze of the sitter(s): towards the scene

Object(s): yes (banderole)

Coat(s) of arms: no

Environment: neutral space with sacred connotation

Structuring of the pictorial space: not applicable

Patron saint(s): Angels

Gesture of the patron saint(s): presenting

Type of religious scene: hieratic

Religious scene(s) depicted: Christ, the arma Christi 
Cat. 108-Type ${ }_{3} \mathrm{C}$

Anonymous South Netherlandish Master

Christ Taking Leave of his Mother with a Young Man in Prayer (c. 1400-1500)

$63 \times 5^{1} \mathrm{~cm}$

Zürich, sale Koller (8 September 1999), lot no. 2

Identity of the sitter(s): unknown

Provenance: unknown

Number of portrait(s): 1

Type of persons: lay (man alone)

Attitude of the sitter(s): hands clasped

Representation of the sitter(s): full-length

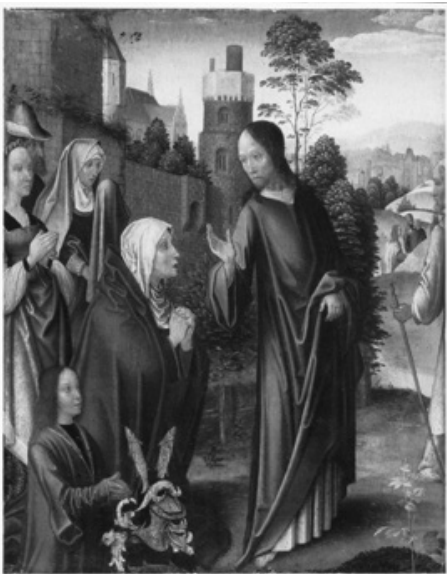

Gaze of the sitter(s): towards the scene

Object(s): no

Coat(s) of arms: yes

Environment: historical setting

Structuring of the pictorial space: not applicable

Patron saint(s): none

Gesture of the patron saint(s): not applicable

Type of religious scene: narrative

Religious scene(s) depicted: Christ taking leave of his mother

Cat. 109-Type 6A

Anonymous South Netherlandish

Master

Diptych (?) of St.John the Baptist

('Diptych of Jean de le Cambe')

(c. 1500-1550)

$46.5 \times 29.8 \mathrm{~cm}$ (each wing)

Lille, Musée de l'Hospice Comtesse, inv. no. D968.1

BIBL.: CORDONNIER 1994;

Repertory Nord-Pas-de-Calais II,

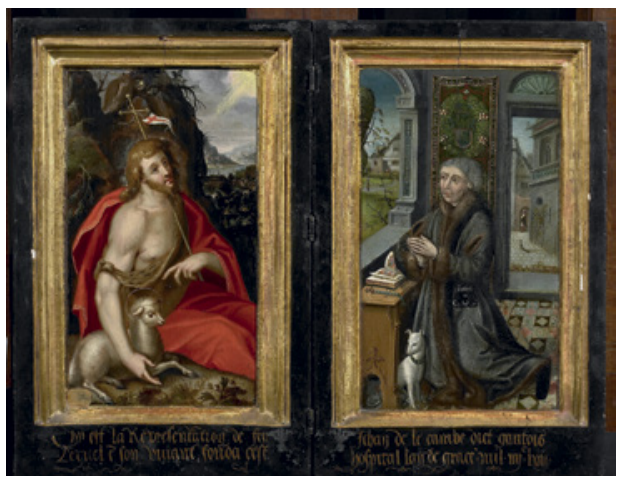
no. 94 (with bibl.).

REMARK: The current appearance of the work is most probably not its original one, as suggested by the stylistic differences between the two panels. The right wing can be dated to the late fifteenth century, while the left wing seems to have been produced at a later date. According to Heck (Repertory Nord-Pas-de-Calais 
II, 570-71), the left wing is typical of the Netherlandish mannerism, while the right wing is a late copy of an old composition, executed in the late sixteenth century. However, there is no evidence allowing us to confirm the hypothesis of a later copy. Nonetheless, the stylistic differences between the two panels strongly suggest that they were not produced together.

HISTORICAL INFORMATION: The inscription on the frame allowed the identification of the sitter as Jean de le Cambe, or Gantois (1410-1496): Chy est la représentation de feu Jehan de le Cambe dict gantois lequel de son vivant fonda cest hospital l'an de grace mil IIIIc LVII. He was a rich merchant of Lille. He was alderman of the city several times. He is also known as the founder of the Hospital of St. John the Baptist (also known as Hôpital Gantois) of Lille in 1462. According to the inscription, the work is a commemorative painting destined for the hospital.

Identity of the sitter(s): Jean de le Cambe

Provenance: Lille, Hospital of St. John the Baptist (Hôpital Gantois)

Number of portrait(s): 1

Type of persons: lay (man alone)

Attitude of the sitter(s): hands clasped

Representation of the sitter(s): full-length

Gaze of the sitter(s): towards the scene

Object(s): yes (dog, prie-dieu, book, rosary)

Coat(s) of arms: yes

Environment: domestic setting

Structuring of the pictorial space: distinct spaces

Patron saint(s): none

Gesture of the patron saint(s): not applicable

Type of religious scene: hieratic

Religious scene(s) depicted: St. John the Baptist

Cat. 110-Type $4 \mathrm{D}$

Anonymous South Netherlandish Master

Diptych of the Virgin and Child with a Couple in Prayer (c. 1460-1500) $35 \times 23.5 \mathrm{~cm}$ (each wing)

Antwerp, KMSK, inv. nos. 517-518 BIBL.: Mus. cat. Antwerp 1985, 42-43; Mus. cat. Antwerp 1998, 467; Exh. cat. Antwerp and Washington

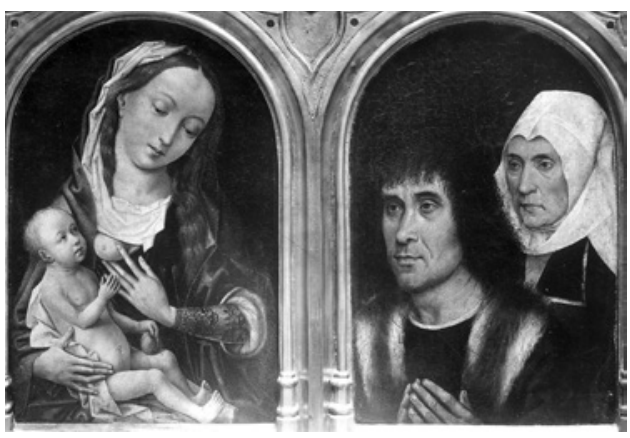
2006, no. 30 (with bibl.). 
Identity of the sitter(s): unknown

Provenance: unknown

Number of portrait(s): 2

Type of persons: lay (couple)

Attitude of the sitter(s): hands clasped

Representation of the sitter(s): half-length

Gaze of the sitter(s): into space

Object(s): no

Coat(s) of arms: no

Environment: neutral space

Structuring of the pictorial space: continuous space

Patron saint(s): none

Gesture of the patron saint(s): not applicable

Type of religious scene: hieratic

Religious scene(s) depicted: the Virgin and Child

Cat. 111-Type $3^{B}$

Anonymous South Netherlandish Master Epitaph of the Canon Aert van Pyringhen (c. 1497)

$57 \times 75 \mathrm{~cm}$

Tongeren, church of Our Lady

BIBL.: VEROUGSTRAETE and VAN SCHOUTE 1989, 322-23; Exh. cat. Brussels 1996, no. 3 .

HISTORICAL INFORMATION: Aert van Pyringhen $(\dagger 1497)$ was canon of the

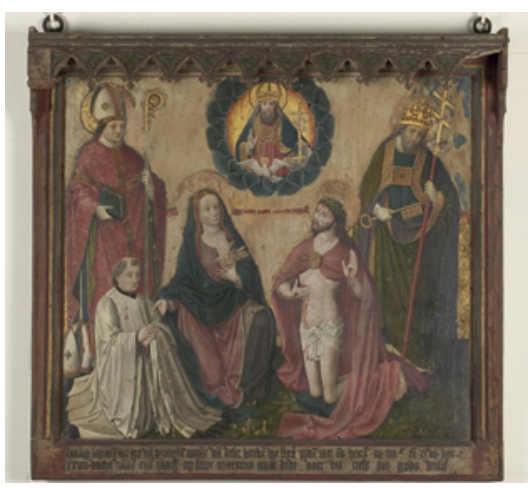
church of Our Lady in Tongeren, where he was buried. The inscription in the lower part confirms that the painting was his epitaph and that the work was placed above the grave of the canon: Hier ligt begraven ... inden jaer ons heeren M.IIIIc en XCVII des XXIIII dachs ... Bidt vor die ziele om gods wille.

Identity of the sitter(s): Aert van Pyringhen

Provenance: Tongeren, church of Our Lady

Number of portrait(s): 1

Type of persons: religious (man alone: canon)

Attitude of the sitter(s): hands clasped

Representation of the sitter(s): full-length

Gaze of the sitter(s): into space 
Object(s): no

Coat(s) of arms: no

Environment: neutral space with sacred connotation

Structuring of the pictorial space: not applicable

Patron saint(s): none

Gesture of the patron saint(s): not applicable

Type of religious scene: intercession

Religious scene(s) depicted: the Intercession of Christ and the Virgin

Cat. 112-Type 6A

[RKD work no. 48835]

Anonymous South Netherlandish Master

Fragment. A Family in Prayer (1500-1550)

$61 \times 45 \mathrm{~cm}$

Amsterdam, sale Brakke Grond (17 May 1904), lot no. 721

Identity of the sitter(s): unknown

Provenance: unknown

Number of portrait(s): 6

Type of persons: lay (family with children)

Attitude of the sitter(s): hands clasped, holding a hat

Representation of the sitter(s): full-length

Gaze of the sitter(s): indeterminate

Object(s): yes (rosary, hat, prie-dieu, book, dog)

Coat(s) of arms: no

Environment: landscape, no sacred connotation (incomplete)

Structuring of the pictorial space: indeterminate

Patron saint(s): none

Gesture of the patron saint(s): not applicable

Type of religious scene: indeterminate

Religious scene(s) depicted: none

Cat. 113-Type 6A

[RKD work no. 58921]

Anonymous South Netherlandish Master

Fragment. Portrait of a Man in Prayer (c. 1480-1500)

$32 \times 23.5 \mathrm{~cm}$

Hannover, Niedersächsisches Landesmuseum, inv. no. KM 119

BIB L.: FRIEDLÄNDER I, gob; Mus. cat. Hannover 1992, no. 93. 
Identity of the sitter(s): unknown

Provenance: unknown

Number of portrait(s): 1

Type of persons: religious (man alone)

Attitude of the sitter(s): hands clasped

Representation of the sitter(s): full-length

Gaze of the sitter(s): indeterminate

Object(s): no

Coat(s) of arms: no

Environment: neutral space (incomplete)

Structuring of the pictorial space: indeterminate

Patron saint(s): none

Gesture of the patron saint(s): not applicable

Type of religious scene: indeterminate

Religious scene(s) depicted: none

Cat. 114-Type $3 \mathrm{~A}$

Anonymous South Netherlandish Master

Noli me tangere with a Couple in Prayer and

Patron Saints (c. 1500-1510)

$74 \times 57 \mathrm{~cm}$

London, sale Sotheby's (17 May 1989), lot no. 89

Identity of the sitter(s): unknown

Provenance: unknown

Number of portrait(s): 2

Type of persons: lay (couple)

Attitude of the sitter(s): hands clasped

Representation of the sitter(s): full-length

Gaze of the sitter(s): into space

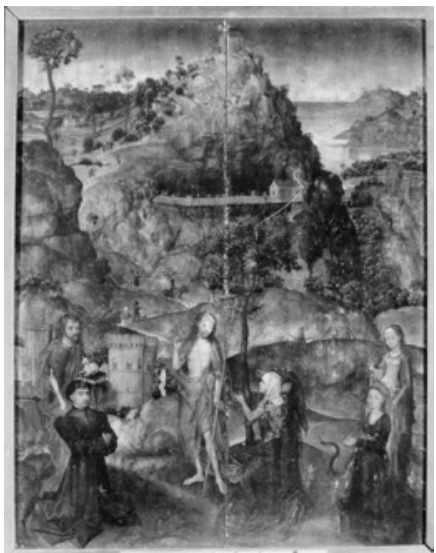

Object(s): no

Coat(s) of arms: no

Environment: historical setting

Structuring of the pictorial space: not applicable

Patron saint(s): John the Baptist, Margaret

Gesture of the patron saint(s): introducing

Type of religious scene: narrative

Religious scene(s) depicted: Noli me tangere 
Cat. 115-Type 6A

[Link to the museum website]

Anonymous South Netherlandish Master

One Wing. A Man in Prayer with Patron Saint (c. 1490-1510)

$40 \times 11.5 \mathrm{~cm}$

Bayonne, Musée Bonnat, inv. no. 1005

Identity of the sitter(s): unknown

Provenance: unknown

Number of portrait(s): 1

Type of persons: religious (man alone: canon regular)

Attitude of the sitter(s): hands clasped

Representation of the sitter(s): full-length

Gaze of the sitter(s): indeterminate

Object(s): no

Coat(s) of arms: no

Environment: architectural space, no sacred connotation (incomplete)

Structuring of the pictorial space: indeterminate

Patron saint(s): a saint bishop

Gesture of the patron saint(s): holding his/her attribute

Type of religious scene: indeterminate

Religious scene(s) depicted: none

Cat. 116-Type 6A

[RKD work no. 232635]

Anonymous South Netherlandish Master

One Wing. A Man in Prayer with St. James (c. 1510-1520)

$49.5 \times 20.3 \mathrm{~cm}$

New York, sale Sotheby's (9 June 2011), lot no. 58

Identity of the sitter(s): unknown

Provenance: unknown

Number of portrait(s): 1

Type of persons: lay (man alone)

Attitude of the sitter(s): hands clasped

Representation of the sitter(s): full-length

Gaze of the sitter(s): indeterminate

Object(s): no

Coat(s) of arms: no

Environment: landscape, no sacred connotation (incomplete) 
Structuring of the pictorial space: indeterminate

Patron saint(s): James

Gesture of the patron saint(s): introducing

Type of religious scene: indeterminate

Religious scene(s) depicted: none

Cat. 117-Type 6A

Anonymous South Netherlandish Master

One Wing. A Man in Prayer with St. Simon

(c. 1470-1475)

$16 \times 8 \mathrm{~cm}$

Antwerp, KMSK, inv. no. 542

BIBL.: Mus. cat. Antwerp 1985, 41 (with bibl.);

Mus. cat. Antwerp 1998, 466.

Identity of the sitter(s): unknown

Provenance: unknown

Number of portrait(s): 1

Type of persons: lay (man alone)

Attitude of the sitter(s): hands clasped

Representation of the sitter(s): full-length

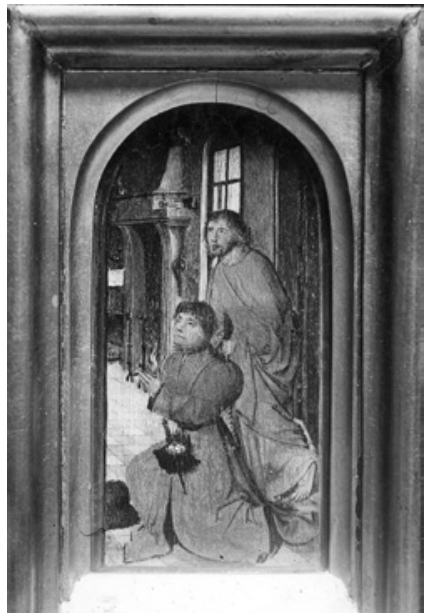

Gaze of the sitter(s): indeterminate

Object(s): yes (purse)

Coat(s) of arms: no

Environment: domestic setting

Structuring of the pictorial space: indeterminate

Patron saint(s): Simon

Gesture of the patron saint(s): introducing

Type of religious scene: indeterminate

Religious scene(s) depicted: none

Cat. 118-Type 6A

[R KD work no. 18643]

Anonymous South Netherlandish Master

One Wing. A Nun in Prayer with St. Catherine (c. 1500)

$46 \times 15.3 \mathrm{~cm}$

London, sale Christie's (18 April 1997), lot no. 144

Identity of the sitter(s): unknown

Provenance: unknown

Number of portrait(s): 1 
Type of persons: religious (woman alone: Carmelite nun)

Attitude of the sitter(s): holding a book

Representation of the sitter(s): full-length

Gaze of the sitter(s): reading a book

Object(s): yes (book)

Coat(s) of arms: no

Environment: neutral space (incomplete)

Structuring of the pictorial space: indeterminate

Patron saint(s): Catherine

Gesture of the patron saint(s): introducing

Type of religious scene: indeterminate

Religious scene(s) depicted: none

\section{Cat. 119-Type 6A}

[RKD work no. 235621]

Anonymous South Netherlandish Master

One Wing. Portrait of a Young Woman with St. Elizabeth (c. 1520)

$26.5 \times 19 \mathrm{~cm}$

London, sale Christie's (3 July 2012), lot no. 1

BIB L.: Sale cat. Christie's (London, 3 July 2012), no. 1.

HISTORICAL INFORMATION: Although no element of the work allows us to identify her with certainty, the sitter of this painting could be Isabella of Austria (1501-1526), the sister of Charles V and the wife of Christian II of Denmark. Indeed the sitter shares with Isabella some common physical features (see CAMPBELL 1985, nos. 24 and 68). The presence of St. Elizabeth of Hungary as patron saint reinforces this identification, for this saint was particularly venerated at the Brussels court at the beginning of the sixteenth century.

Identity of the sitter(s): Isabella of Austria (?)

Provenance: unknown

Number of portrait(s): 1

Type of persons: lay (woman alone)

Attitude of the sitter(s): holding a book

Representation of the sitter(s): half-length

Gaze of the sitter(s): indeterminate

Object(s): yes (book)

Coat(s) of arms: no

Environment: neutral space(incomplete)

Structuring of the pictorial space: indeterminate

Patron saint(s): Elizabeth of Hungary

Gesture of the patron saint(s): introducing 
Type of religious scene: indeterminate

Religious scene(s) depicted: none

Cat. 120-Type 6A

Anonymous South Netherlandish Master

One Wing. St. George Fighting the Dragon;

Two Men in Prayer with Patron Saints

(reverse) (c. 1540)

$107 \times 77 \mathrm{~cm}$

Brussels, MRBAB, inv. no. 691

BIB L.: Mus. cat. Brussels 1984, 397.

Identity of the sitter(s): unknown

Provenance: unknown

Number of portrait(s): 2

Type of persons: lay (group)

Attitude of the sitter(s): hands clasped, holding a small cross

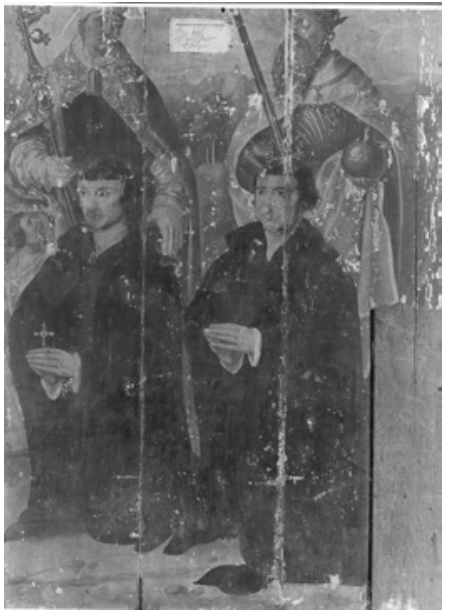

Representation of the sitter(s): full-length

Gaze of the sitter(s): indeterminate

Object(s): yes (small cross)

Coat(s) of arms: no

Environment: landscape, no sacred connotation (incomplete)

Structuring of the pictorial space: indeterminate

Patron saint(s): Odilon of Cluny, Charlemagne

Gesture of the patron saint(s): protecting, holding his/her attribute

Type of religious scene: indeterminate

Religious scene(s) depicted: St. George fighting the dragon

Cat. 121-Type $3 \mathrm{C}$

Anonymous South Netherlandish Master Panorama of the Passion (c. 1475-1500) $191 \times 203.5 \mathrm{~cm}$

Lisbon, Museo nacional do Azulejo, inv. no. 15

BIB L.: Corpus Lisbon I, no. 165 (with bibl.). HISTORICAL INFORMATION: In a manuscript dating from 1639 , and dedicated to the foundation of the convent of Madre Deus, a Poor Clare identified the kneeling woman as Queen Eleonore of Portugal and stated that

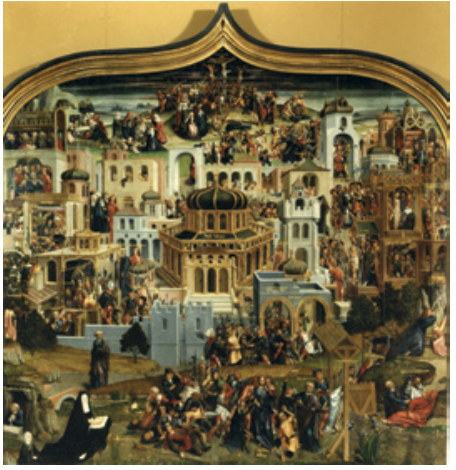


the painting was a gift from the queen to the convent of Xabregas. According to Frei Jeronymo de Belem (1755), the painting would have been offered to the queen by Maximilian I, but this information cannot be confirmed through any evidence. Born in 1458, Eleonore of Portugal married John II of Portugal in 1473. They had one son, who died accidently in 1491. After the death of her husband, Eleonore lived very piously and founded several convents, including the one of Madre Deus in Xabregas, in which she owned a private apartment and where she wanted to be buried. She died in 1525 . The identity of the woman portrayed next to Eleonore has not been confirmed with certainty. She wears a Portuguese headdress and she could be Eleonore's sister, Isabella of Bragance, who was buried next to her in the convent.

Identity of the sitter(s): Eleonore of Portugal and a lady (Isabelle of Bragance or Isabella of Aragon?)

Provenance: Xabregas, convent of Madre Deus

Number of portrait(s): 2

Type of persons: lay (group)

Attitude of the sitter(s): holding a book

Representation of the sitter(s): full-length

Gaze of the sitter(s): into space yes

Object(s): (prie-dieu, book)

Coat(s) of arms: no

Environment: historical setting

Structuring of the pictorial space: fragmentation of the pictorial space

Patron saint(s): none

Gesture of the patron saint(s): not applicable

Type of religious scene: narrative

Religious scene(s) depicted: the Passion

Cat. 122-Type 6B

Anonymous South Netherlandish Master

Portrait of a Canon in Prayer (c. 1475-1500)

$37 \times 26 \mathrm{~cm}$

Antwerp, KMSK, inv. no. 541

BIBL.: Mus. cat. Antwerp 1985, 34-35 (with bibl.);

Mus. cat. Antwerp 1998, 468.

Identity of the sitter(s): unknown

Provenance: unknown

Number of portrait(s): 1

Type of persons: religious (man alone: canon)

Attitude of the sitter(s): hands clasped

Representation of the sitter(s): half-length

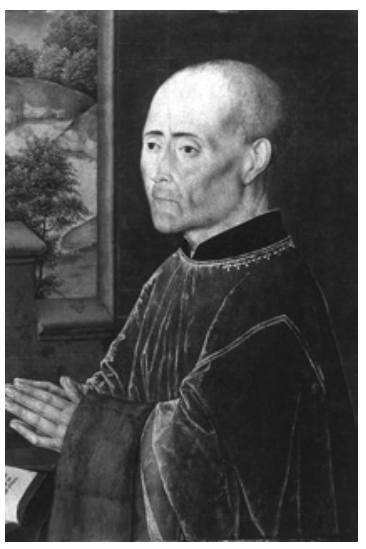


Gaze of the sitter(s): indeterminate

Object(s): yes (book)

Coat(s) of arms: no

Environment: domestic setting

Structuring of the pictorial space: indeterminate

Patron saint(s): none

Gesture of the patron saint(s): not applicable

Type of religious scene: indeterminate

Religious scene(s) depicted: none

Cat. 123-Type 6B

Anonymous South Netherlandish Master Portrait of a Carthusian Monk in Prayer with Two Saints (c. 1500-1510)

$33.7 \times 50.2 \mathrm{~cm}$

London, sale Phillips Son \& Neale

(13 December 1999), lot no. 56

BIB L.: Exh. cat. Roermond 2009, no. 35 . HISTORICAL INFORMATION: Despite the fact that the reverse of the panel presents a coat of arms and a motto, the identity of the Carthusian monk remains unknown.

Identity of the sitter(s): unknown

Provenance: unknown

Number of portrait(s): 1

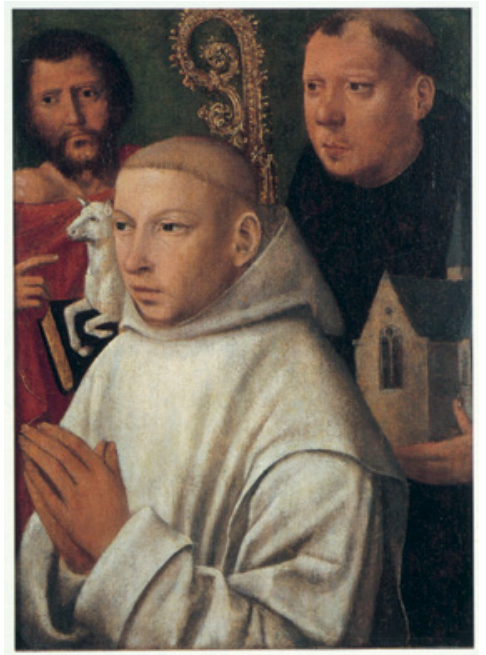

Type of persons: religious (man alone:

Carthusian monk)

Attitude of the sitter(s): hands clasped

Representation of the sitter(s): half-length

Gaze of the sitter(s): indeterminate

Object(s): no

Coat(s) of arms: yes

Environment: neutral space(incomplete)

Structuring of the pictorial space: indeterminate

Patron saint(s): John the Baptist, Robert of Molesme

Gesture of the patron saint(s): holding his/her attribute

Type of religious scene: indeterminate

Religious scene(s) depicted: none 
Cat. 124-Type 6B

Anonymous South Netherlandish Master

Portrait of a Man in Prayer (c. 1480)

$34 \times 25.5 \mathrm{~cm}$

Merion, Barnes Foundation, inv. no. BF440

Identity of the sitter(s): unknown

Provenance: unknown

Number of portrait(s): 1

Type of persons: lay (man alone)

Attitude of the sitter(s): hands clasped

Representation of the sitter(s):

half-length

Gaze of the sitter(s): indeterminate

Object(s): yes (hat)

Coat(s) of arms: no

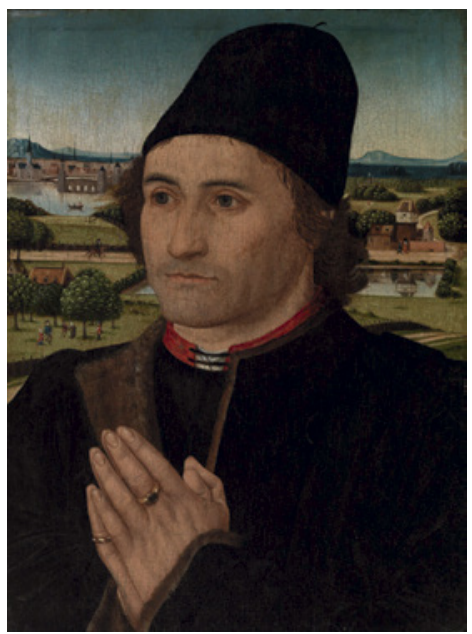

Environment: landscape, no sacred connotation (incomplete)

Structuring of the pictorial space: indeterminate

Patron saint(s): none

Gesture of the patron saint(s): not applicable

Type of religious scene: indeterminate

Religious scene(s) depicted: none

Cat. 125-Type 6B

Anonymous South Netherlandish Master

Portrait of a Man in Prayer (c. 1480)

$24.8 \times 20 \mathrm{~cm}$

Philadelphia, Philadelphia Museum of Art, inv. no. 1174

BIB L.: Mus. cat. Philadelphia 1994, 57.

Identity of the sitter(s): unknown

Provenance: unknown

Number of portrait(s): 1

Type of persons: lay (man alone)

Attitude of the sitter(s): hands clasped

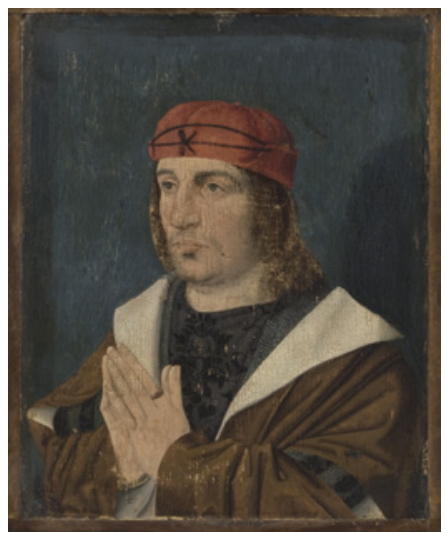

Representation of the sitter(s): half-length

Gaze of the sitter(s): indeterminate

Object(s): yes (hat)

Coat(s) of arms: no 
Environment: neutral space (incomplete)

Structuring of the pictorial space: indeterminate

Patron saint(s): none

Gesture of the patron saint(s): not applicable

Type of religious scene: indeterminate

Religious scene(s) depicted: none

Cat. 126-Type 6B

Anonymous South Netherlandish Master

Portrait of a Man in Prayer (Laurent Wouters?) (c. 1490-1500)

$21 \times 16.2 \mathrm{~cm}$

London, sale Christie's (5 July 1991), lot no. 60

BIBL.: VAN DEN BERGEN-PANTENS 1969.

HISTORICAL INFORMATION: Laurent Wouters was Lord of Vinderhoute and held several positions in the ducal administration under Charles the Bold. According to Christiane Van den Bergen-Pantens, this panel formed a pair with a portrait of Guarin de Beste and would have been an epitaph for both men, who were buried in the church of St. Martin of Ackerghem in Ghent. The tombstone of Laurent contains this inscription: hier licht begraven laureins wouters filius Thomas. In syn leven camerknape ende officier domesticq wylen des hertoghen carel van bourgoignen, wiens ziele goot ghenadigh sij. Die overleet dezer weirelt den III april $A^{\circ}$ MCCCCLXXVIII. Voor paeschen. Bidt over de ziele.

Identity of the sitter(s): Laurent Wouters?

Provenance: Ghent, church of St. Martin of Ackerghem (?)

Number of portrait(s): 1

Type of persons: lay (man alone)

Attitude of the sitter(s): hands clasped

Representation of the sitter(s): half-length

Gaze of the sitter(s): indeterminate

Object(s): no

Coat(s) of arms: yes

Environment: neutral space (incomplete)

Structuring of the pictorial space: indeterminate

Patron saint(s): none

Gesture of the patron saint(s): not applicable

Type of religious scene: indeterminate

Religious scene(s) depicted: none 
Cat. 127-Type 6B

[RKD work no. 64854]

Anonymous South Netherlandish Master

Portrait of a Woman in Prayer (c. 1500-1550)

Size unknown

Private collection

Identity of the sitter(s): unknown

Provenance: unknown

Number of portrait(s): 1

Type of persons: lay (woman alone)

Attitude of the sitter(s): hands clasped

Representation of the sitter(s): half-length

Gaze of the sitter(s): indeterminate

Object(s): no

Coat(s) of arms: no

Environment: landscape, no sacred connotation (incomplete)

Structuring of the pictorial space: indeterminate

Patron saint(s): none

Gesture of the patron saint(s): not applicable

Type of religious scene: indeterminate

Religious scene(s) depicted: none

Cat. 128-Type 6B

Anonymous South Netherlandish Master Portrait of a Young Man in Prayer

(c. 1490-1500)

$30.6 \times 39.6 \mathrm{~cm}$

San Diego, San Diego Museum of Art, inv. no. 1947.1

BIBL.: FRIEDLÄNDER VIb, supp. 233; DE VOS 1994, no. B7 (with bibl.).

Identity of the sitter(s): unknown

Provenance: unknown

Number of portrait(s): 1

Type of persons: lay (man alone)

Attitude of the sitter(s): hands clasped

Representation of the sitter(s): half-length

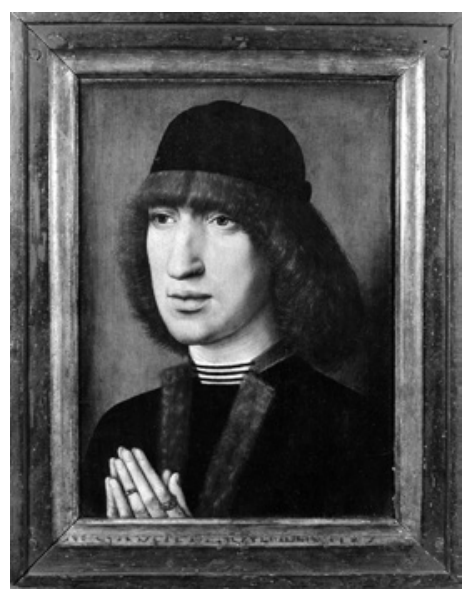


Gaze of the sitter(s): indeterminate

Object(s): no

Coat(s) of arms: no

Environment: neutral space (incomplete)

Structuring of the pictorial space: indeterminate

Patron saint(s): none

Gesture of the patron saint(s): not applicable

Type of religious scene: indeterminate

Religious scene(s) depicted: none

Cat. 129-Type 6A

Anonymous South Netherlandish Master

Portrait of Adolph of Clèves in Prayer (c. 1400-1500)

Size unknown

Anvaing, collection of the Count Philippe de Lannoy

HistoriCAL INFORMATION: Adoph of Clèves, Lord of Ravenstein, is the son of the Duke Adolph IV of Clèves, Count of la Mark, and of Mary of Burgundy. He was born in 1425 and died in 1492. He married Anne of Burgundy (on her, see cat. 215).

Identity of the sitter(s): Adolph of Clèves

Provenance: unknown

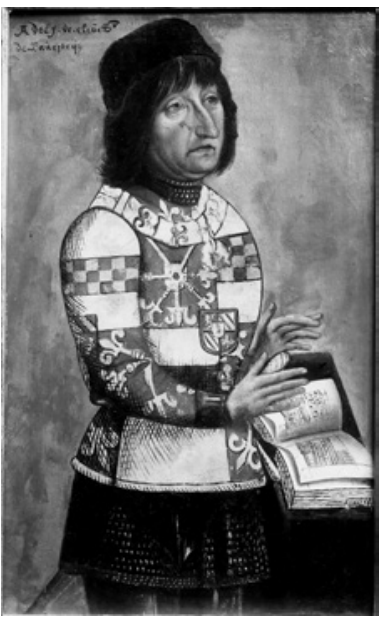

Number of portrait(s): 1

Type of persons: lay (man alone)

Attitude of the sitter(s): hands held up

Representation of the sitter(s): half-length

Gaze of the sitter(s): indeterminate

Object(s): yes (prie-dieu, book)

Coat(s) of arms: yes

Environment: neutral space (incomplete)

Structuring of the pictorial space: indeterminate

Patron saint(s): none

Gesture of the patron saint(s): not applicable

Type of religious scene: indeterminate

Religious scene(s) depicted: none 
Cat. 130-Type 6A

[RKD work no. 34515]

Anonymous South Netherlandish Master

Portrait of Jan III and Henri de Berghes in Prayer with Patron Saints (after 1481) $46.5 \times 41.5 \mathrm{~cm}$

Bergen op Zoom, Gemeentemuseum Het Markiezenhof

BIB L.: Exh. cat. Bruges 1962, no. 6o; Exh. cat. Den Bosch 1990, no. 61.

HISTORICAL INFORMATION: On the basis of their coats of arms, the two men have been identified as Jan III and Henry, sons of Jan II of Glymes-Bergen, Lord of Bergen-op-Zoom. They came from a wealthy and noble family of the Low Countries. Born in 1449, Henry made an ecclesiastical career. He studied in Leuven and Orléans, where he became doctor of Law. In 1478, he became Bishop of Cambrai and from 1487 onwards, he presided over the Grand conseil. Erasmus worked for a while with Henry as his secretary. In 1492, Henry was appointed chancellor of the Order of the Golden Fleece. Jan III was born in 1452. Lord of Bergen-op-Zoom, he made a military and political career at the Burgundian court. He was successively chamberlain of Charles the Bold and of Philip the Fair. In 1481, he became knight of the Order of the Golden Fleece and member of the Conseil des finances in 1487. On the basis of their economic activities in Bergen-op-Zoom, the brothers enjoyed excellent relations with British merchants. They recommended Philip the Fair to do the same and this created some tensions with Francophile members of the Burgundian court, notably the Croÿ family. In 1502, following these oppositions, the GlymesBergen brothers were dismissed from their political functions. Henry died a few months later, and Jan in 1532 (on this, see CoOLs 2001).

Identity of the sitter(s): Jan III and Henri de Glymes-Bergen

Provenance: unknown

Number of portrait(s): 2

Type of persons: mixed (family)

Attitude of the sitter(s): hands clasped

Representation of the sitter(s): full-length

Gaze of the sitter(s): indeterminate

Object(s): yes (prie-dieu, book, collar of the Order of the Golden Fleece)

Coat(s) of arms: yes

Environment: enclosed garden (incomplete)

Structuring of the pictorial space: indeterminate

Patron saint(s): John the Evangelist, Henry

Gesture of the patron saint(s): holding his/her attribute

Type of religious scene: indeterminate

Religious scene(s) depicted: none 
Cat. 131-Type 6B

Anonymous South Netherlandish Master

Portrait of Jeanne de Lannoy in Prayer (c. 1490-1500)

Size unknown

Previously Paris, Pelletier collection

HistoricAl information: The sitter has been identified as Jeanne de Lannoy, Lady of Brimeu, on the basis of the coat of arms. Born in 1414, she was the daughter of Jean III, Lord of Lannoy, and Jeanne Tyrel de Poix, Lady of Brimeu. She married Philippe de Hornes, Lord of Gaesbeeck, Viscount of Veurne and chamberlain of the Duke of Burgundy. They had four children: Arnold, Johann, Frans and Anton. Jeanne de Lannoy died in 1475.

Identity of the sitter(s): Jeanne de Lannoy

Provenance: unknown

Number of portrait(s): 1

Type of persons: lay (woman alone)

Attitude of the sitter(s): hands clasped

Representation of the sitter(s): half-length

Gaze of the sitter(s): indeterminate

Object(s): no

Coat(s) of arms: yes

Environment: neutral space (incomplete)

Structuring of the pictorial space: indeterminate

Patron saint(s): none

Gesture of the patron saint(s): not applicable

Type of religious scene: indeterminate

Religious scene(s) depicted: none

Cat. 132-Type 6B

[Link to the museum website]

Anonymous South Netherlandish Master

Portrait of Joris van Egmond in Prayer (c. 1530)

$105 \times 89.5 \mathrm{~cm}$

Ottawa, National Gallery of Canada, inv. no. 3701

BIBL.: Mus. cat. Ottawa 1987, 104-06.

HISTORICAL INFORMATION: Born in 1504, Joris van Egmond was appointed Bishop of Utrecht in 1534. He died in 1559. Taking into account the fact that he wears the canonical habit, the painting must have been commissioned before 1534 . 
Identity of the sitter(s): Joris van Egmond

Provenance: unknown

Number of portrait(s): 1

Type of persons: religious (man alone: canon)

Attitude of the sitter(s): hands clasped

Representation of the sitter(s): half-length

Gaze of the sitter(s): indeterminate

Object(s): no

Coat(s) of arms: no

Environment: architectural space, no sacred connotation (incomplete)

Structuring of the pictorial space: indeterminate

Patron saint(s): none

Gesture of the patron saint(s): not applicable

Type of religious scene: indeterminate

Religious scene(s) depicted: none

Cat. 133-Type 6A

[RKD work no. 36187]

Anonymous South Netherlandish Master

Six Panels. Six Saints and a Man in Prayer (c. 1500-1550)

$36.4 \times 11.9 \mathrm{~cm}$ (each panel)

Maastricht, Bonnefantenmuseum, inv. nos. 10-00907 (a-f)

BIB L.: Mus. cat. Maastricht 1958, 40.

Identity of the sitter(s): unknown

Provenance: unknown

Number of portrait(s): 1

Type of persons: religious (man alone: priest)

Attitude of the sitter(s): hands clasped

Representation of the sitter(s): full-length

Gaze of the sitter(s): into space

Object(s): yes (prie-dieu)

Coat(s) of arms: no

Environment: neutral space (incomplete)

Structuring of the pictorial space: indeterminate

Patron saint(s): none

Gesture of the patron saint(s): not applicable

Type of religious scene: indeterminate

Religious scene(s) depicted: St. John the Evangelist, St. Roch, St. Gregory,

St. Thomas, St. Anthony 
Cat. 134-Type $3 \mathrm{D}$

Anonymous South Netherlandish Master

St. Augustine with a Nun in Prayer (c. 1500-1510)

$90 \times 54 \mathrm{~cm}$

Bruges, Adornes collection

Identity of the sitter(s): unknown

Provenance: unknown

Number of portrait(s): 1

Type of persons: religious (woman alone)

Attitude of the sitter(s): holding a book

Representation of the sitter(s): full-length,

small scale

Gaze of the sitter(s): into space

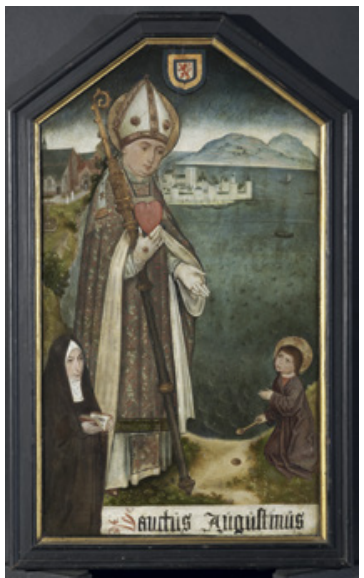

Object(s): yes (book)

Coat(s) of arms: yes

Environment: landscape, no sacred connotation

Structuring of the pictorial space: not applicable

Patron saint(s): none

Gesture of the patron saint(s): not applicable

Type of religious scene: hieratic

Religious scene(s) depicted: St. Augustine

Cat. 135-Type 3 D

Anonymous South Netherlandish Master

St. Jerome with a Man in Prayer (c. 1500)

$29 \times 19 \mathrm{~cm}$

Antwerp, KMSK, inv. no. 32

BIBL.: Mus. cat. Antwerp 1985, 42 (with bibl.);

Mus. cat. Antwerp 1998, 469.

Identity of the sitter(s): unknown

Provenance: unknown

Number of portrait(s): 1

Type of persons: lay (man alone)

Attitude of the sitter(s): holding a hat

Representation of the sitter(s): full-length

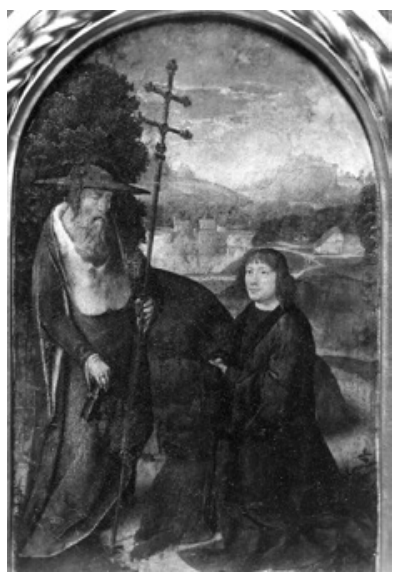

Gaze of the sitter(s): into space

Object(s): yes (hat)

Coat(s) of arms: no

Environment: landscape, no sacred connotation

Structuring of the pictorial space: not applicable 
Patron saint(s): none

Gesture of the patron saint(s): not applicable

Type of religious scene: hieratic

Religious scene(s) depicted: St. Jerome

Cat. 136-Type $3^{A}$

Anonymous South Netherlandish Master

The Ascension with a Couple in Prayer and

Patron Saints (c. 1450-1500)

$50 \times 36 \mathrm{~cm}$

Lille, Palais des Beaux-Arts, inv. no. P. 860

B I B L.: Corpus Lille, no. 233 (with bibl.).

Identity of the sitter(s): unknown

Provenance: unknown

Number of portrait(s): 2

Type of persons: lay (couple)

Attitude of the sitter(s): hands clasped,

particular gesture

Representation of the sitter(s): full-length

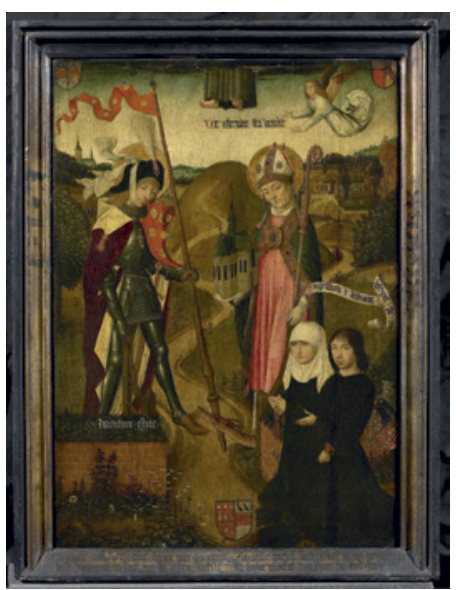

Gaze of the sitter(s): into space

Object(s): yes (gloves)

Coat(s) of arms: yes

Environment: landscape with sacred connotation

Structuring of the pictorial space: not applicable

Patron saint(s): Quirin of Neuss, Amand of Maastricht

Gesture of the patron saint(s): holding his/her attribute

Type of religious scene: narrative

Religious scene(s) depicted: the Ascension

\section{Cat. 137-Type 6A}

Anonymous South Netherlandish Master

The Baptism of Christ; St. Augustine, the Virgin and Child and a Canon in Prayer (reverse) (c. 1400-1500)

$54 \times 39 \mathrm{~cm}$

Marseille, Musée des Beaux-Arts, inv. no. 53.1.3

Identity of the sitter(s): unknown

Provenance: unknown

Number of portrait(s): 1

Type of persons: religious (man alone: canon regular) 
Attitude of the sitter(s): holding a banderole

Representation of the sitter(s): full-length

Gaze of the sitter(s): indeterminate

Object(s): yes (banderole)

Coat(s) of arms: no

Environment: enclosed garden (incomplete)

Structuring of the pictorial space: indeterminate

Patron saint(s): Augustine

Gesture of the patron saint(s): introducing

Type of religious scene: hieratic

Religious scene(s) depicted: the Virgin and Child, the Baptism of Christ

Cat. 138-Type $3^{\mathrm{A}}$

Anonymous South Netherlandish Master

The Coronation of the Virgin with a Nun in Prayer (c. 1500-1510)

$100 \times 95 \mathrm{~cm}$

Arras, Trésor de la Cathédrale-Musée des Beaux-Arts

B I в L.: Repertory Nord-Pas-de-Calais II, no. 76 (with bibl.).

HISTORICAL INFORMATION: The painting comes from the charterhouse of Gosnay. The identity of the sitter is unfortunately unknown. Taking into account the fact that she holds a crosier, she must be the prioress of the convent.

Identity of the sitter(s): nun from the charterhouse of Gosnay

Provenance: Gosnay, charterhouse of the Mont-Sainte-Marie

Number of portrait(s): 1

Type of persons: religious (woman alone: Carthusian nun)

Attitude of the sitter(s): hands clasped

Representation of the sitter(s): full-length

Gaze of the sitter(s): into space

Object(s): yes (crosier)

Coat(s) of arms: no

Environment: landscape with sacred connotation

Structuring of the pictorial space: fragmentation of the space, religious scene in a cloud

Patron saint(s): Bruno

Gesture of the patron saint(s): holding his/her attribute

Type of religious scene: narrative

Religious scene(s) depicted: the Coronation of the Virgin, the four evangelists, St. Thomas, St. Bartholomew 
Cat. 139-Type ${ }_{3} \mathrm{C}$

Anonymous South Netherlandish Master The Crucifixion with a Family in Prayer (c. 1500-1550) $121.5 \times 100 \mathrm{~cm}$

Tongeren, Begijnhof Sint-Catharina REMARK: one of the female devotees is depicted in the background with a patron saint, while the other sitters appear in the foreground, around the cross without patron saint.

Identity of the sitter(s): unknown

Provenance: unknown

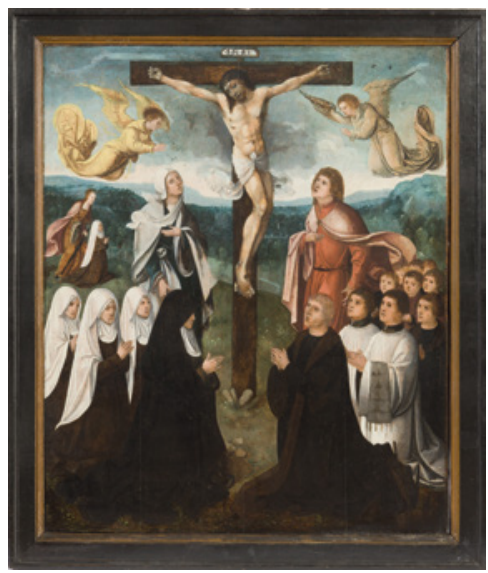

Number of portrait(s): 15

Type of persons: mixed (family)

Attitude of the sitter(s): hands clasped

Representation of the sitter(s): full-length

Gaze of the sitter(s): into space, towards the ground, towards the scene

Object(s): no

Coat(s) of arms: no

Environment: historical setting

Structuring of the pictorial space: historical setting

Patron saint(s): Catherine

Gesture of the patron saint(s): holding his/her attribute

Type of religious scene: narrative

Religious scene(s) depicted: the Crucifixion

Cat. 140-Type 3A

Anonymous South Netherlandish Master

The Crucifixion with a Group of Saints and a Nun in Prayer (c. 1400-1500) Size unknown

Previously Paris, Lemarre collection Identity of the sitter(s): unknown Provenance: unknown Number of portrait(s): 1

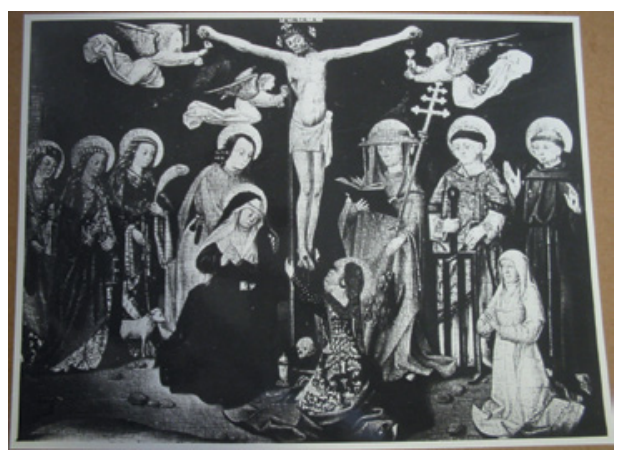


Type of persons: religious (woman alone: unidentified)

Attitude of the sitter(s): hands clasped

Representation of the sitter(s): full-length

Gaze of the sitter(s): towards the scene

Object(s): no

Coat(s) of arms: no

Environment: neutral space

Structuring of the pictorial space: not applicable

Patron saint(s): none

Gesture of the patron saint(s): not applicable

Type of religious scene: narrative

Religious scene(s) depicted: the Crucifixion

Cat. 141-Type $3 \mathrm{C}$

Anonymous South Netherlandish

Master

The Crucifixion with three Persons in Prayer (c. 1400-1500)

$20 \times 23.5 \mathrm{~cm}$

Previously Düsseldorf, Thomée collection

Identity of the sitter(s): unknown

Provenance: unknown

Number of portrait(s): 3

Type of persons: lay (family)

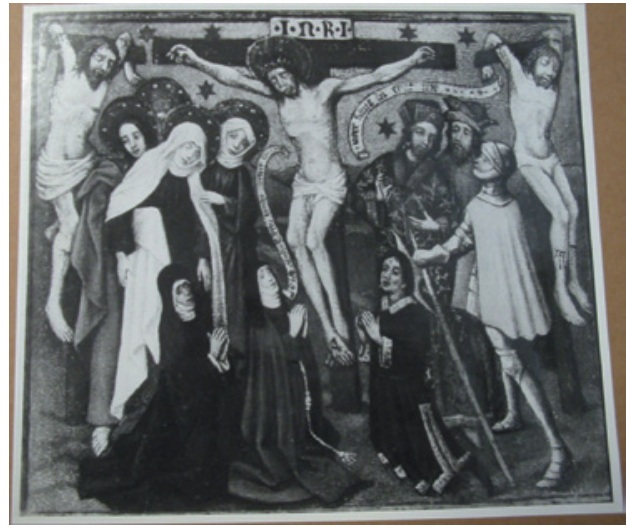

Attitude of the sitter(s): hands clasped

Representation of the sitter(s): full-length

Gaze of the sitter(s): towards the scene

Object(s): no

Coat(s) of arms: no

Environment: historical setting

Structuring of the pictorial space: not applicable

Patron saint(s): none

Gesture of the patron saint(s): not applicable

Type of religious scene: narrative

Religious scene(s) depicted: the Crucifixion 
Cat. 142-Type $3^{B}$

Anonymous South Netherlandish Master

The Ecce homo with a Nun in Prayer and St. Dominic (c. 1400-1500)

$34.3 \times 26.8 \mathrm{~cm}$

London, sale Christie's (7 July 2006), lot no. 120

Identity of the sitter(s): unknown

Provenance: unknown

Number of portrait(s): 1

Type of persons: religious (woman alone:

Dominican nun)

Attitude of the sitter(s): hands clasped

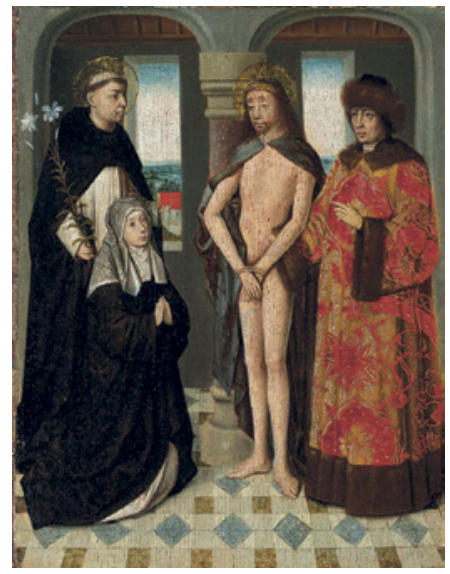

Representation of the sitter(s): full-length

Gaze of the sitter(s): towards the scene

Object(s): no

Coat(s) of arms: no

Environment: architectural space with sacred connotation

Structuring of the pictorial space: not applicable

Patron saint(s): Dominic

Gesture of the patron saint(s): introducing

Type of religious scene: hieratic

Religious scene(s) depicted: the Ecce homo

Cat. 143-Type $3^{D}$

Anonymous South Netherlandish Master (attributed to Colijn de Coter?)

The Fountain of Life with the Portuguese Royal Family in Prayer (c. 1519-1520)

$267 \times 210 \mathrm{~cm}$

Porto, Museu da Misericordia do Porto

BIBL.: PACULLY 1897; PERIER D'IETEREN 1985b, 155-56 (with bibl.).

HISTORICAL INFORMATION: The family of devotees has been identified as the royal family of Portugal: Manuel I of Portugal and Maria of Aragon, followed by their daughters Isabella of Portugal and Beatrice of Portugal,

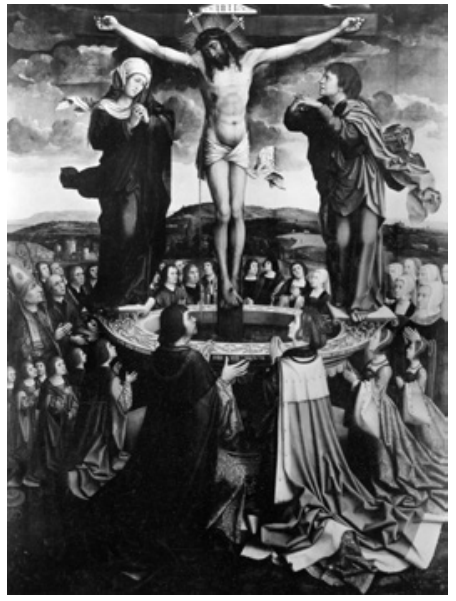


Duchess of Savoy and their sons. Nevertheless, no internal or external element allows us to confirm this hypothesis, which has been refuted by Pacully, but reaffirmed by Perier d'Ieteren.

Identity of the sitter(s): the king Manuel of Portugal, his wife Eléonore and their children (?)

Provenance: unknown

Number of portrait(s): 31 (at least)

Type of persons: mixed (family with children)

Attitude of the sitter(s): hands clasped, hands held up

Representation of the sitter(s): full-length

Gaze of the sitter(s): towards the scene

Object(s): no

Coat(s) of arms: no

Environment: landscape with sacred connotation

Structuring of the pictorial space: not applicable

Patron saint(s): none

Gesture of the patron saint(s): not applicable

Type of religious scene: hieratic

Religious scene(s) depicted: the Fountain of Life

\section{Cat. 144-Type $3^{B}$}

[RKD work no. 35980]

South Netherlandish Master

The Holy Trinity with a Nun in Prayer (dated 1545)

$94.5 \times 117.5 \mathrm{~cm}$

Maastricht, Bonnefantenmuseum, inv. no. 10-00180

вів L.: Mus. cat. Maastricht 1958, 62 (with bibl.).

HISTORICAL INFORMATION: The inscription on the banderole identifies the nun as Maria van Ree: suster.marie. van-ree-1545 $x$. Maria entered the Charterhouse of Sint-Anna-ter-Woestijne in Bruges on 8 December 1549 and took her vows in 1550 . She was appointed prioress in 1569 and died in 1589 .

Identity of the sitter(s): Maria van Ree

Provenance: unknown

Number of portrait(s): 1

Type of persons: religious (woman alone: Carthusian nun) 
Attitude of the sitter(s): hands clasped

Representation of the sitter(s): full-length

Gaze of the sitter(s): into space

Object(s): no

Coat(s) of arms: no

Environment: celestial space

Structuring of the pictorial space: religious scene in a cloud

Patron saint(s): Mary

Gesture of the patron saint(s): holding his/her attribute

Type of religious scene: hieratic

Religious scene(s) depicted: the Holy Trinity

\section{Cat. 145-Type $3^{B}$}

Anonymous South Netherlandish Master

The Intercession of Christ and the Virgin for a Couple in Prayer (c. 1490-1500)

$82 \times 68 \mathrm{~cm}$

Cologne, sale Lempertz (15 May 2010), lot no. 1528

BIB L.: Corpus Paris I, 92.

Identity of the sitter(s): unknown

Provenance: unknown

Number of portrait(s): 2

Type of persons: lay (couple)

Attitude of the sitter(s): hands clasped

Representation of the sitter(s): full-length

Gaze of the sitter(s): into space

Object(s): no

Coat(s) of arms: yes

Environment: landscape with sacred connotation

Structuring of the pictorial space: not applicable

Patron saint(s): Andrew, James

Gesture of the patron saint(s): introducing

Type of religious scene: intercession

Religious scene(s) depicted: the Intercession of Christ and the Virgin 
Cat. 146-Type $3 \mathrm{D}$

Anonymous South Netherlandish Master The Intercession of the Virgin for a Man in Prayer (c. 1420-1430)

$70.3 \times 71.6 \mathrm{~cm}$

Bruges, Treasure of St. Saviour's cathedral BIBL.: THÜRLEMANN 2002, no. III.G.3 (with bibl.).

Identity of the sitter(s): unknown

Provenance: unknown

Number of portrait(s): 1

Type of persons: lay (man alone)

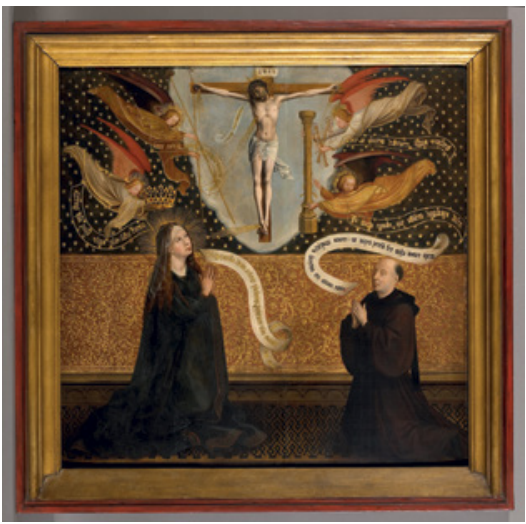

Attitude of the sitter(s): hands clasped

Representation of the sitter(s): full-length

Gaze of the sitter(s): towards the scene

Object(s): yes (banderole)

Coat(s) of arms: no

Environment: neutral space

Structuring of the pictorial space: not applicable

Patron saint(s): none

Gesture of the patron saint(s): not applicable

Type of religious scene: intercession

Religious scene(s) depicted: the Intercession of the Virgin

\section{Cat. 147-Type 3 B}

Anonymous South Netherlandish Master

The Lactation of St. Bernard with a Family in

Prayer (c. 1491-1500)

$44 \times 34 \mathrm{~cm}$

Antwerp, KMSK, inv. no. 976

BIBL.: VAN ROEY 1954-1960; Mus. cat. Antwerp 1985, 38-39 (with bibl.); Mus. cat. Antwerp 1998, 468.

HISTORICAL INFORMATION: On the basis of the coats of arms, two hypotheses have been formulated about the identity of the portrayed family. It could either be the De Waele family of Ghent or the Van Cottem family of Brussels. A Van Cottem genealogy

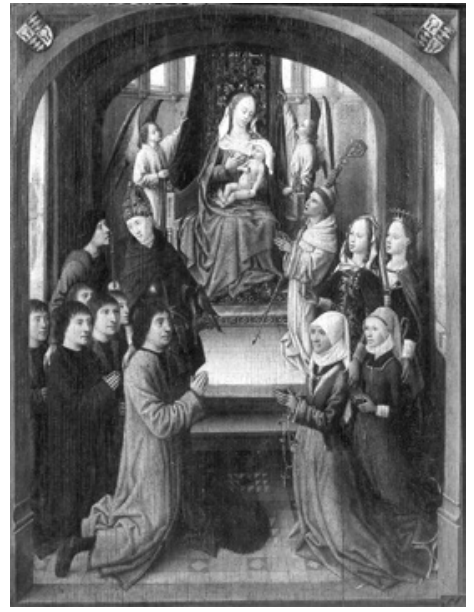


has been preserved. The presence of St. Rochus, St. Hubert, St. Mary Magdalen and St. Catherine as patron saints suggests that some family members portrayed in the painting bear their name. Yet, the Van Cottem genealogy does not mention any person bearing these names in the late fifteenth century. The De Waele hypothesis has been suggested with some reserve by Van Roey, who underlines the fact that the colours of the coats of arms are not clearly visible. As stated by Vandenbroeck, this identification is nevertheless more plausible than the first one.

Identity of the sitter(s): De Waele family or Van Cottem family

Provenance: unknown

Number of portrait(s): 8

Type of persons: lay (family)

Attitude of the sitter(s): hands clasped, holding a rosary

Representation of the sitter(s): full-length

Gaze of the sitter(s): into space

Object(s): yes (rosary)

Coat(s) of arms: yes

Environment: architectural space with sacred connotation

Structuring of the pictorial space: not applicable

Patron saint(s): Rochus, Hubert, Catherine, Mary Magdalene

Gesture of the patron saint(s): protecting

Type of religious scene: hieratic

Religious scene(s) depicted: the Lactation of St. Bernard

Cat. 148-Type $3 \mathrm{D}$

Anonymous South Netherlandish Master The Man of Sorrows with a Monk in Prayer (c. 1475-1500)

$45.3 \times 30.5 \mathrm{~cm}$

New York, MET, The Cloisters Collection, inv. no. 1974.392

BIBL.: VON SONNENBURG 1994;

AINSWORTH and CHRISTIANSEN 1998, 405; PYPAERT 2008, no. 140.

REMARK: the panel has been subjected to a hyper-restoration by Joseph van der Veken. Only the monk, Christ and the cross are authentic. See PYPAERT 2008.

Identity of the sitter(s): unknown

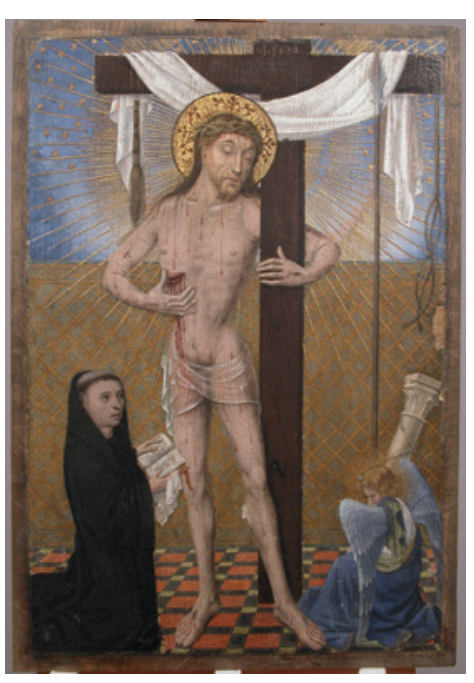


Provenance: unknown

Number of portrait(s): 1

Type of persons: religious (man alone: Benedictine monk)

Attitude of the sitter(s): holding a book

Representation of the sitter(s): full-length

Gaze of the sitter(s): into space

Object(s): yes (book)

Coat(s) of arms: no

Environment: neutral space

Structuring of the pictorial space: not applicable

Patron saint(s): none

Gesture of the patron saint(s): not applicable

Type of religious scene: hieratic

Religious scene(s) depicted: the Man of sorrows

Cat. 149-Type 3 A

Anonymous South Netherlandish Master The Mass of St. Gregory with a Family in Prayer and Patron Saints (c. 1400-1500) $74 \times 75 \mathrm{~cm}$

Previously Brussels, Joly collection

Identity of the sitter(s): unknown

Provenance: unknown

Number of portrait(s): 10

Type of persons: mixed (family)

Attitude of the sitter(s): hands clasped

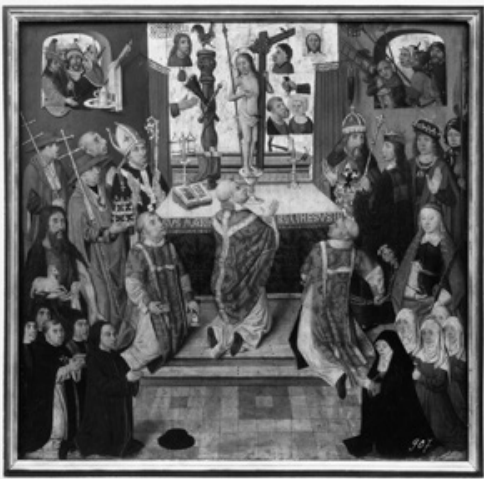

Representation of the sitter(s): full-

length, small scale

Gaze of the sitter(s): into space

Object(s): yes (hat)

Coat(s) of arms: no

Environment: historical setting

Structuring of the pictorial space: not applicable

Patron saint(s): John the Baptist, Agnes

Gesture of the patron saint(s): introducing

Type of religious scene: narrative

Religious scene(s) depicted: the Mass of St. Gregory 
Cat. 150-Type $3 \mathrm{C}$

Anonymous South Netherlandish Master

The Nativity with two Nuns in Prayer (c. 1500-1550)

$103 \times 99 \mathrm{~cm}$

Arras, Trésor de la Cathédrale-Musée des Beaux-Arts, inv. no. 424

BI B L.: Repertory Nord-Pas-de-Calais II, no. 85 (with bibl.).

HISTORICAL INFORMATION: The inscription identifies the two women as Marguerite de Houchin and Marie de la Cloÿe, who were nuns at the charterhouse of the Mont-Sainte-Marie in Gosnay. Marguerite was prioress of the convent.

Identity of the sitter(s): Marguerite de Houchin and Marie de la Cloÿe

Provenance: Gosnay, charterhouse of the Mont-Sainte-Marie

Number of portrait(s): 2

Type of persons: religious (group: Carthusian nuns)

Attitude of the sitter(s): hands clasped

Representation of the sitter(s): full-length

Gaze of the sitter(s): into space

Object(s): yes (cross, candle)

Coat(s) of arms: yes

Environment: historical setting

Structuring of the pictorial space: fragmentation of the pictorial space

Patron saint(s): none

Gesture of the patron saint(s): not applicable

Type of religious scene: narrative

Religious scene(s) depicted: the Nativity, the four Evangelists, the four Doctors of the Church, the Creation, Noah's sacrifice, Moses and the Burning bush, Aaron's rod, Gideon's Fleece, the Marriage of the Virgin, the Annunciation, the Visitation, St. Joseph's dream, August and the Tiburtine Sibyl, the Annunciation to the shepherds, the Circumcision, the Adoration of the Magi, the Presentation at the temple, the Massacre of the Innocents, the Flight into Egypt 
Cat. 151-Type $3^{B}$

Anonymous South Netherlandish Master

The Pietà with a Family in Prayer and Patron

Saints (c. 1490-1510)

$90 \times 90 \mathrm{~cm}$

Private collection

Identity of the sitter(s): unknown

Provenance: unknown

Number of portrait(s): 5

Type of persons: lay (family with children)

Attitude of the sitter(s): hands clasped

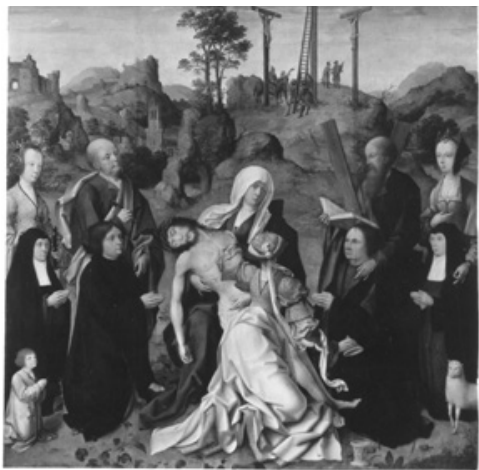

Representation of the sitter(s): full-length

Gaze of the sitter(s): towards the scene

Object(s): no

Coat(s) of arms: no

Environment: historical setting

Structuring of the pictorial space: not applicable

Patron saint(s): Catherine, Peter, Andrew, Agnes

Gesture of the patron saint(s): introducing, holding his/her attribute, protecting

Type of religious scene: hieratic

Religious scene(s) depicted: the Pietà

Cat. 152-Type ${ }_{3} \mathrm{D}$

Anonymous South Netherlandish Master

The Pietà with two Men in Prayer (c. 1400-1450)

$72 \times 62 \mathrm{~cm}$

Whereabouts unknown

Identity of the sitter(s): unknown

Provenance: unknown

Number of portrait(s): 2

Type of persons: religious (group: canons regular)

Attitude of the sitter(s): hands clasped

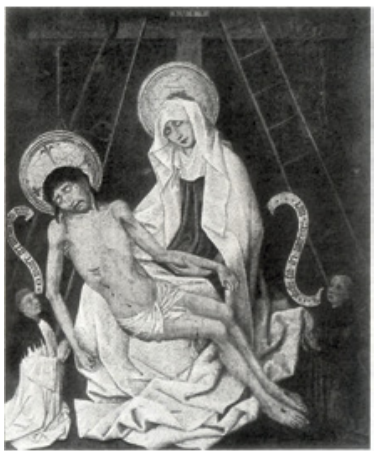

Representation of the sitter(s): full-length, small scale

Gaze of the sitter(s): towards the scene

Object(s): yes (banderole)

Coat(s) of arms: no

Environment: neutral space 
Structuring of the pictorial space: not applicable

Patron saint(s): none

Gesture of the patron saint(s): not applicable

Type of religious scene: hieratic

Religious scene(s) depicted: the Pietà

\section{Cat. 153-Type 6A}

Anonymous South Netherlandish Master (or André D'Ypres?)

Two Wings. The Betrayal of Christ with Two Men, The Resurrection with a Group of Women (c. 1475-1500)

$46 \times 28 \mathrm{~cm}$

Montpellier, Musée Fabre, inv. no. 892.4.7 and London, sale Sotheby's (5 December 2015), lot no. 5 .

BIB L.: Corpus Los Angeles, $245-58$ (with bibl.). HISTORICAL INFORMATION: The sitters have been identified by Sterling as Dreux I Budée, Jeanne Peschart and their children. He based this identification on the fact that the mother resembles the portrait of Jeanne Peschart on

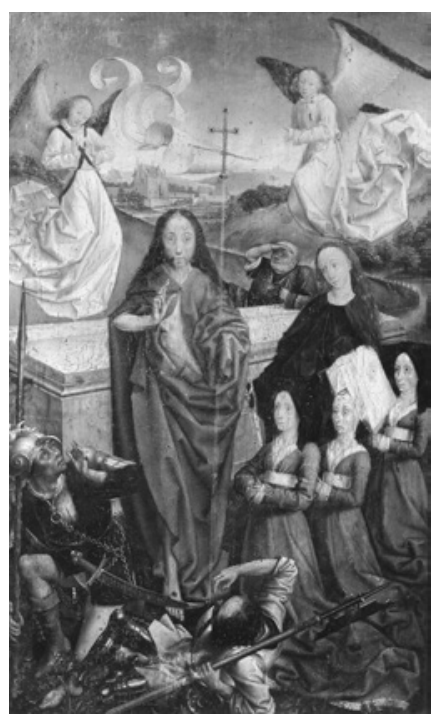
a panel now in a private collection, in which she is identified with certainty by her coat of arms. Dreux I Budée was a rich merchant, specialised in the wine trade in Paris in the mid-fifteenth century. He also worked as a high official at the royal French court, under Charles VII and Louis XI. He died in 1476 and was buried in the church of St. Gervais in Paris. His wife died in $145^{2}$.

REMARK: The panels could be the wings of a Triptych of the Crucifixion, whose centre panel is now held at the J. Paul Getty Museum in Los Angeles (inv. no. 79.PB.177). This hypothesis was first formulated by Burton Fredericksen, "A Parisian Triptych Reconstituted," The J. Paul Getty Museum Journal 11 (1983), $183^{-96 .}$

Identity of the sitter(s): Dreux I Budée, Jeanne Peschart and their children

Provenance: unknown

Number of portrait(s): 5

Type of persons: lay (family)

Attitude of the sitter(s): hands clasped

Representation of the sitter(s): full-length 
Gaze of the sitter(s): towards the scene

Object(s): no

Coat(s) of arms: no

Environment: historical setting

Structuring of the pictorial space: not applicable

Patron saint(s): Catherine, Christopher

Gesture of the patron saint(s): holding his/her attributes

Type of religious scene: narrative

Religious scene(s) depicted: the Betrayal of Christ, the Resurrection of Christ

Cat. 154-Type 3B

[RKD work no. 64422]

Anonymous South Netherlandish Master

The Salvator Mundi with a Family in Prayer and Patron Saints (1450-1500)

Size unknown

Amiens, Musée de Picardie

Identity of the sitter(s): unknown

Provenance: unknown

Number of portrait(s): 16

Type of persons: mixed (family with children)

Attitude of the sitter(s): hands clasped

Representation of the sitter(s): full-length, small scale

Gaze of the sitter(s): towards the scene, into space

Object(s): no

Coat(s) of arms: no

Environment: landscape with sacred connotation

Structuring of the pictorial space: not applicable

Patron saint(s): John the Baptist, Barbara

Gesture of the patron saint(s): introducing

Type of religious scene: hieratic

Religious scene(s) depicted: Christ blessing

Cat. 155-Type $3^{B}$

[Link to the museum website]

Anonymous South Netherlandish Master

The Virgin and Child with a Man in Prayer and St. Stephen (c. 1480)

$52.9 \mathrm{~cm} \times 62.6 \mathrm{~cm}$ 
London, Courtauld Institute of Art, inv. no. P.1947.LF.138

Identity of the sitter(s): unknown

Provenance: unknown

Number of portrait(s): 1

Type of persons: lay (man alone)

Attitude of the sitter(s): hands clasped

Representation of the sitter(s): half-length

Gaze of the sitter(s): into space

Object(s): no

Coat(s) of arms: no

Environment: domestic setting

Structuring of the pictorial space: not applicable

Patron saint(s): Stephen

Gesture of the patron saint(s): holding his/her attribute

Type of religious scene: hieratic

Religious scene(s) depicted: the Virgin and Child

Cat. ${ }_{156}$ - Type ${ }_{3} \mathrm{D}$

Anonymous South Netherlandish Master The Virgin and Child with St. Anne and a Woman in Prayer (c. 1415)

$158.7 \times 105.4 \mathrm{~cm}$

Neerlanden, church of St. Mary Magdalen BIBL.: DENEFFE and POSTEC 2004-2005; STROO 2009, 387-420 (with bibl.).

HISTORICAL INFORMATION: The kneeling woman on the left has not been identified. The man portrayed on the right was added at a later date and has been identified as Johannes Fredericus van Brackel, who was vicar of the church of Neerlanden. He acquired the painting in 1710.

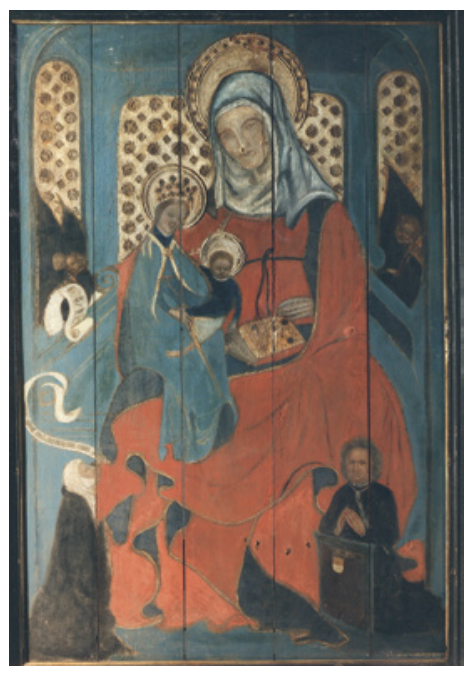

Identity of the sitter(s): unknown

Provenance: Neerlanden, church of St. Mary Magdalen (?)

Number of portrait(s): 1

Type of persons: religious (woman alone)

Attitude of the sitter(s): hands clasped

Representation of the sitter(s): full-length, small scale

Gaze of the sitter(s): towards the scene 
Object(s): yes (banderole)

Coat(s) of arms: no

Environment: architectural space with sacred connotation

Structuring of the pictorial space: not applicable

Patron saint(s): none

Gesture of the patron saint(s): not applicable

Type of religious scene: hieratic

Religious scene(s) depicted: the Virgin and Child with St. Anne

Cat. 157-Type 3 D

Anonymous South Netherlandish Master

The Virgin Interceding for a Woman in Prayer

(c. 1500-1510)

$78.5 \times 65 \mathrm{~cm}$

Madrid, Museo Lazaro Galdiano, inv. no. 3034

BIB L.: BERMEJO 1980, 94-95 (with bibl.).

Identity of the sitter(s): unknown

Provenance: unknown

Number of portrait(s): 1

Type of persons: lay (woman alone)

Attitude of the sitter(s): hands clasped

Representation of the sitter(s): full-length

Gaze of the sitter(s): towards the scene

Object(s): yes (banderole)

Coat(s) of arms: no

Environment: neutral space

Structuring of the pictorial space: not applicable

Patron saint(s): none

Gesture of the patron saint(s): not applicable

Type of religious scene: intercession

Religious scene(s) depicted: the Intercession of the Virgin 
Cat. 158-Type $1 \mathrm{~A}$

Anonymous South Netherlandish

Master

Triptych of St. Apollonia and St. Agatha

(c. $1535^{-1540)}$

$118.3 \times 160.8 \mathrm{~cm}$ (centre panel), $116.6 \times 78$

$\mathrm{cm}$ (left wing) and $117 \times 78.5 \mathrm{~cm}$ (right wing)

Turnhout, church of St. Peter

BIBL.: COENEN et alii 1984-85; VAN

BRUANE 2004 (online), http://www

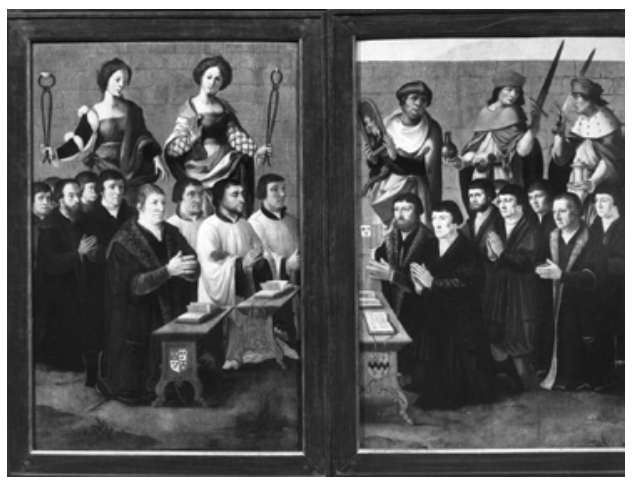

.dbnl.org/tekst/bruaoo2repe01_01/

bruaoo2repeo1_01_0145.php.

HISTORICAL INFORMATION: The men depicted on the reverse of this triptych are members of the rederijkkamer 'de Heibloem', whose patron saint was Apollonia. This chamber of rhetoric was active up to 1648. Its coat of arms, which is reproduced in a manuscript, contains the date 1538 . The triptych was destined for the St. Apollonia's chapel in the church of St. Peter in Turnhout.

Identity of the sitter(s): members of the rederijkers 'De Heibloem' from Turnhout

Provenance: Turnhout, church of St. Peter, St. Apollonia's altar

Number of portrait(s): 17

Type of persons: mixed (group: association)

Attitude of the sitter(s): hands clasped

Representation of the sitter(s): full-length

Gaze of the sitter(s): towards the centre

Object(s): yes (prie-dieu, book)

Coat(s) of arms: yes

Environment: architectural space, no sacred connotation

Structuring of the pictorial space: distinct spaces

Patron saint(s): Agatha, Apollonia, Luke, Cosmas, Damian

Gesture of the patron saint(s): holding his/her attribute

Type of religious scene: narrative

Religious scene(s) depicted: the Martyrdoms of St. Agatha and St. Apollonia 
Cat. 159-Type 2A

Anonymous South Netherlandish Master

Triptych of St. Colette's Vision of St. Anne with her Progeny with a Man in Prayer and Patron Saint (c. 1400-1500) $105 \times 190 \mathrm{~cm}$ (open)

Previously Paris, Bosse collection

Identity of the sitter(s): unknown

Provenance: unknown

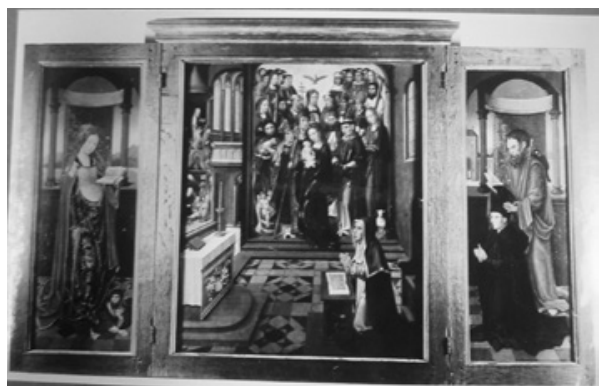

Number of portrait(s): 1

Type of persons: lay (man alone)

Attitude of the sitter(s): hands clasped

Representation of the sitter(s): full-length

Gaze of the sitter(s): towards the scene

Object(s): no

Coat(s) of arms: no

Environment: historical setting

Structuring of the pictorial space: distinct spaces

Patron saint(s): James

Gesture of the patron saint(s): holding his/her attribute

Type of religious scene: narrative

Religious scene(s) depicted: St. Catherine, St. Colette's Vision of St. Anne with her Progeny, the Annunciation

Cat. 16o-Type 5

Anonymous South Netherlandish Master

Triptych of the Crucifixion ('Triptych of Pietervan Woestijne') (c. 1475)

$37 \times 24 \mathrm{~cm}$ (centre panel) and $43 \times$ $15 \mathrm{~cm}$ (wings)

Berlin, Staatliche Museen zu Berlin, Gemäldegalerie, inv. no. $165^{8}$

BIBL.: Mus. cat. Berlin 1996, no. 786;

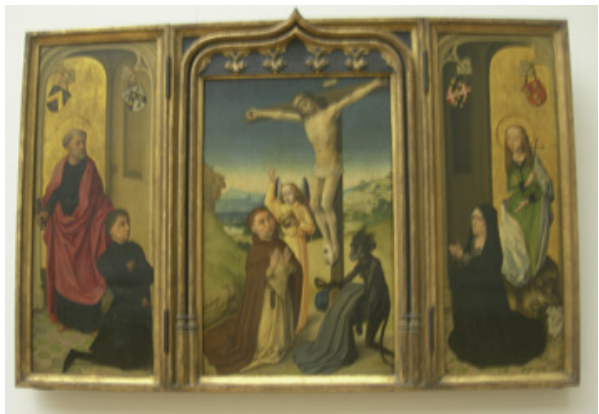

SCHADE 2001, 338-39 (with bibl.).

HISTORICAL INFORMATION: The devotees portrayed on the wings have been identified as Pieter van de Woestijne and his wife, Margaretha van Gruuthuse, called Margaretha of Bruges. She was the sister of Lodewijk of Gruuthuse (see 
cat. 539). The couple had one daughter, Anna, who married Jean du Cellier (see cat. 557). The monk portrayed on the centre panel has not been identified.

Identity of the sitter(s): Pieter van Woestijne and Margaretha van Gruuthuse, an anonymous monk

Provenance: unknown

Number of portrait(s): 3

Type of persons: mixed (unidentified group)

Attitude of the sitter(s): hands clasped, hands held up, particular gesture Representation of the sitter(s): full-length

Gaze of the sitter(s): towards the scene

Object(s): no

Coat(s) of arms: yes

Environment: architectural space, no sacred connotation

Structuring of the pictorial space: distinct spaces

Patron saint(s): Peter, Margaret

Gesture of the patron saint(s): holding his/her attribute

Type of religious scene: narrative

Religious scene(s) depicted: Christ on the cross

Cat. 161-Type $3^{A}$

Anonymous South Netherlandish Master

Triptych of the Crucifixion with a Family in Prayer and Patron Saints (c. 1500)

$235 \times 190 \mathrm{~cm}$ (centre panel) and $235 \times 94.5 \mathrm{~cm}$ (wings)

Zumaya, church of St. Peter BIB L.: Exh. cat. Leon and Palencia 1999, 107-08; MARTENS D. 2007a

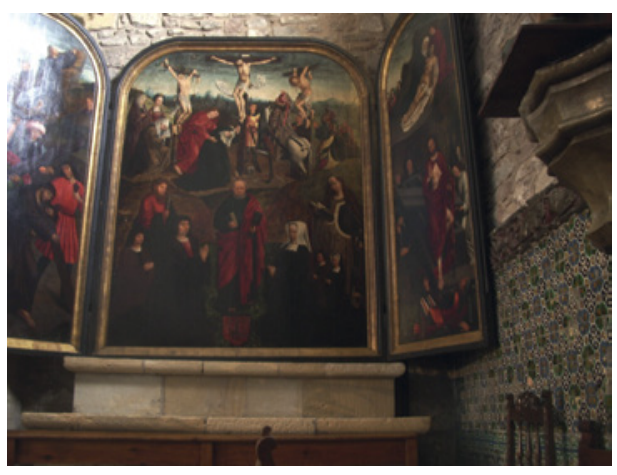
(with bibl.).

HISTORICAL INFORMATION: The triptych is nowadays preserved at its original location, namely the church of St. Peter at Zumaya. It was commissioned by the Basque family Elorriaga, as the coat of arms indicates.

Identity of the sitter(s): Elorriaga family

Provenance: Zumaya, church of St. Peter

Number of portrait(s): 5

Type of persons: lay (family with children)

Attitude of the sitter(s): hands clasped 
Representation of the sitter(s): full-length

Gaze of the sitter(s): into space

Object(s): no

Coat(s) of arms: yes

Environment: historical setting

Structuring of the pictorial space: not applicable

Patron saint(s): Barnabé, Catherine

Gesture of the patron saint(s): holding his/her attribute

Type of religious scene: narrative

Religious scene(s) depicted: the Crucifixion, St. Peter

Cat. 162-Type 2A

Anonymous South Netherlandish Master

Triptych of the Lamentation with a Couple in Prayer and Patron Saints (c. 1490)

Size unknown, oil on wood and carved piece

Baltimore, Walters Art Museum, inv. no. 37.242

Identity of the sitter(s): unknown

Provenance: unknown

Number of portrait(s): 2

Type of persons: lay (couple)

Attitude of the sitter(s): hands clasped

Representation of the sitter(s): half-length

Gaze of the sitter(s): towards the scene

Object(s): yes (prie-dieu, book)
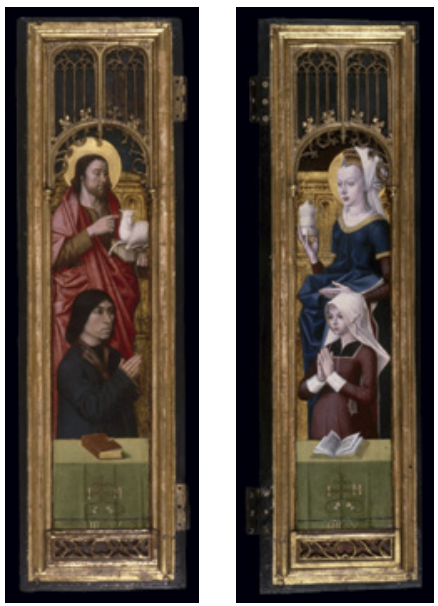

Coat(s) of arms: no

Environment: architectural space, no sacred connotation (incomplete)

Structuring of the pictorial space: distinct spaces (different techniques: painting/sculpture)

Patron saint(s): John the Baptist, Mary Magdalen

Gesture of the patron saint(s): holding his/her attribute

Type of religious scene: narrative

Religious scene(s) depicted: the Lamentation 
Cat. 163-Type 2B

Anonymous South Netherlandish Master

Triptych of the Calvary with Two Nuns in Prayer (c. 1500-1510)

$29.5 \times 18.5 \mathrm{~cm}$ (open)

Brussels, MRBAB, inv. no. 8734

BIB L.: Mus. cat. Brussels 1984, 388.

Identity of the sitter(s): unknown

Provenance: unknown

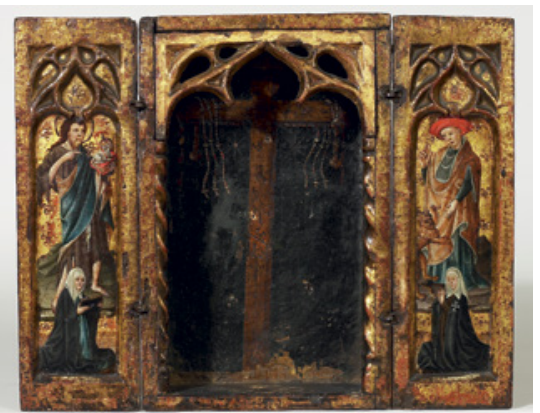

Number of portrait(s): 2

Type of persons: religious (group: unidentified)

Attitude of the sitter(s): hands clasped, holding a book

Representation of the sitter(s): full-length, small scale

Gaze of the sitter(s): into space, reading a book

Object(s): yes (book)

Coat(s) of arms: no

Environment: neutral space

Structuring of the pictorial space: distinct spaces

Patron saint(s): John the Baptist, Jerome

Gesture of the patron saint(s): holding his/her attribute

Type of religious scene: hieratic

Religious scene(s) depicted: the Cross

Cat. ${ }_{164}$-Type ${ }_{3} \mathrm{C}$

Anonymous South Netherlandish Master

Triptych of the Christ on the Cross with a Nun in Prayer and Saints (c. 1420)

$35.5 \times 28 \mathrm{~cm}$ (centre panel) and $35.5 \times 16 \mathrm{~cm}$ (wings)

Essen, Gallinat-Bank AG

BIB L.: Exh. cat. Bruges 2002, no. 2.

Identity of the sitter(s): unknown

Provenance: unknown

Number of portrait(s): 1

Type of persons: religious (woman alone: Augustinian canoness)

Attitude of the sitter(s): physical contact with the sacred person 
Representation of the sitter(s): full-length, small scale

Gaze of the sitter(s): into space

Object(s): no

Coat(s) of arms: no

Environment: neutral space

Structuring of the pictorial space: not applicable

Patron saint(s): none

Gesture of the patron saint(s): not applicable

Type of religious scene: narrative

Religious scene(s) depicted: the Crucifixion, a saint pope, St. Mary Magdalen,

St. Bernard, St. Francis

Cat. 165 -Type $3^{B}$

Anonymous South Netherlandish Master

Triptych of the Crucifixion and the Holy Trinity with a Man in Prayer (c.1400-1500)

Size unknown

Previously London, St. John's Wood E. Mutton collection

Identity of the sitter(s): unknown

Provenance: unknown

Number of portrait(s): 1

Type of persons: religious (man alone: unidentified)

Attitude of the sitter(s): hands clasped

Representation of the sitter(s): full-length

Gaze of the sitter(s): towards the scene

Object(s): yes (prie-dieu, book)

Coat(s) of arms: no

Environment: architectural space with sacred connotation

Structuring of the pictorial space: fragmentation of the pictorial space

Patron saint(s): Mary

Gesture of the patron saint(s): interceding

Type of religious scene: intercession

Religious scene(s) depicted: the Agony in the garden, the Crucifixion, the Entombment, the Annunciation, the Intercession of Christ and the Virgin, the Nativity

Cat. 166-Type $2 \mathrm{C}$

Anonymous South Netherlandish Master

Triptych of the Crucifixion with a Couple in Prayer (c. 1530-1550) 
$88.3 \times 60.5 \mathrm{~cm}$ (open)

Previously Leningrad, Bloudoff collection

BIBL.: MARLIER 1966, 192; MARTENS D. 1990.

Identity of the sitter(s): unknown

Provenance: unknown

Number of portrait(s): 2

Type of persons: lay (couple)

Attitude of the sitter(s): hands clasped

Representation of the sitter(s): full-length

Gaze of the sitter(s): into space

Object(s): yes (prie-dieu, book)

Coat(s) of arms: yes

Environment: historical setting

Structuring of the pictorial space: unified space with discontinuities

Patron saint(s): none

Gesture of the patron saint(s): not applicable

Type of religious scene: narrative

Religious scene(s) depicted: the Crucifixion

\section{Cat. 167-Type 2A}

Anonymous South Netherlandish Master

Triptych of the Crucifixion with a Couple in Prayer and Patron Saints (c. 1400-1500)

$86 \times 71 \mathrm{~cm}$ (centre panel) and $86 \times 32 \mathrm{~cm}$ (wings)

Whereabouts unknown (centre panel) and London, Sale Sotheby's (17 December 1998), lot no. 113 (wings)

BIB L.: Exh. cat. Cassel 2013, no. 21.

Identity of the sitter(s): unknown

Provenance: unknown

Number of portrait(s): 2

Type of persons: lay (couple)

Attitude of the sitter(s): hands clasped

Representation of the sitter(s): full-length

Gaze of the sitter(s): towards the scene

Object(s): yes (prie-dieu, book, dog)

Coat(s) of arms: no

Environment: landscape, no sacred connotation

Structuring of the pictorial space: distinct spaces

Patron saint(s): John the Baptist, Paul

Gesture of the patron saint(s): introducing, holding his/her attribute 
Type of religious scene: narrative

Religious scene(s) depicted: the Crucifixion

Cat. 168-Type 2A

Anonymous South Netherlandish Master

Triptych of the Crucifixion with a Couple in Prayer and Patron Saints (c. 1500-1550)

$5^{2.5} \times 3^{8} \mathrm{~cm}$ (centre panel) and 52.5 $\times 14.8 \mathrm{~cm}$ (wings)

Whereabouts unknown

Identity of the sitter(s): unknown

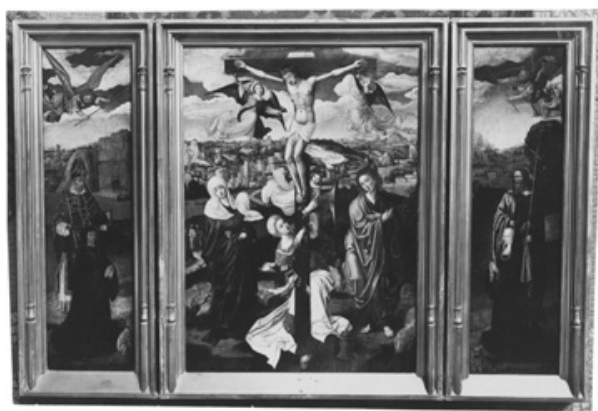

Provenance: unknown

Number of portrait(s): 2

Type of persons: lay (couple)

Attitude of the sitter(s): hands clasped

Representation of the sitter(s): full-length

Gaze of the sitter(s): indeterminate

Object(s): no

Coat(s) of arms: no

Environment: historical setting

Structuring of the pictorial space: unified space with discontinuities

Patron saint(s): a saint bishop, Philip

Gesture of the patron saint(s): indeterminate

Type of religious scene: narrative

Religious scene(s) depicted: the Crucifixion

Cat. 169-Type $3 \mathrm{C}$

[MEMO work no. 766]

Anonymous South Netherlandish Master

Triptych of the Crucifixion with a Monk in Prayer (c. 1500-1550)

$94.5 \times 90.2 \mathrm{~cm}$ (centre panel)

The Netherlands, private collection

Identity of the sitter(s): unknown

Provenance: unknown 
Number of portrait(s): 1

Type of persons: religious (man alone: Carthusian monk)

Attitude of the sitter(s): hands clasped

Representation of the sitter(s): full-length

Gaze of the sitter(s): towards the scene

Object(s): no

Coat(s) of arms: no

Environment: historical setting

Structuring of the pictorial space: continuous space

Patron saint(s): none

Gesture of the patron saint(s): not applicable

Type of religious scene: narrative

Religious scene(s) depicted: the Crucifixion, St. Bruno, St. Barbara, St. Catherine, the Virgin of the Seven Sorrows

Cat. 170-Type ${ }_{3} \mathrm{C}$

[RKD work no. 3997]

Anonymous South Netherlandish Master

Triptych of the Crucifixion with a Priest in Prayer (c. 1500-1510)

$75.3 \times 5^{2.2} \mathrm{~cm}$ (centre panel) and $73.5 \times 27 \mathrm{~cm}$ (wings)

London, sale Sotheby's (5 July 1995), lot no. 211

Identity of the sitter(s): unknown

Provenance: unknown

Number of portrait(s): 1

Type of persons: religious (man alone: priest)

Attitude of the sitter(s): holding a hat

Representation of the sitter(s): full-length

Gaze of the sitter(s): into space

Object(s): no

Coat(s) of arms: yes

Environment: historical setting

Structuring of the pictorial space: not applicable

Patron saint(s): none

Gesture of the patron saint(s): not applicable

Type of religious scene: narrative

Religious scene(s) depicted: the Crucifixion, St. Jerome, St. Francis 
Cat. 171-Type 2A

Anonymous South Netherlandish Master

Triptych of the Descent of the Holy Spirit with a Man in Prayer, St. John the Baptist and St. Peter (c. 1500-1510) Size unknown

Porto, Igreja de Miragaia BIBL.: CALVO et alii 2005.

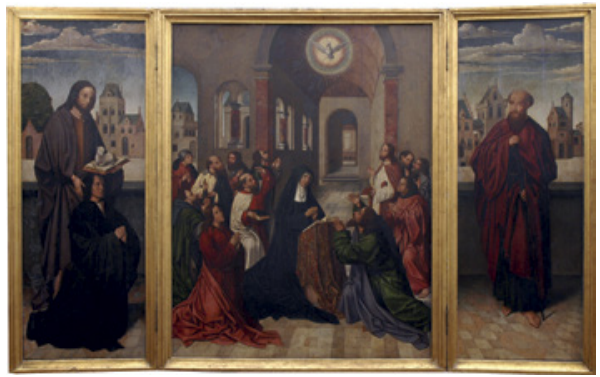

Identity of the sitter(s): unknown

Provenance: Porto, Hospital of the Holy Spirit of Miragaia, chapel of the Brotherhood of the mariners

Number of portrait(s): 1

Type of persons: lay (man alone)

Attitude of the sitter(s): hands clasped

Representation of the sitter(s): full-length

Gaze of the sitter(s): towards the scene

$\operatorname{Object}(\mathrm{s})$ : no

Coat(s) of arms: no

Environment: architectural space with sacred connotation

Structuring of the pictorial space: unified space with discontinuities

Patron saint(s): John the Baptist

Gesture of the patron saint(s): protecting

Type of religious scene: narrative

Religious scene(s) depicted: the Descent of the Holy Spirit, the Annunciation

Cat. 172-Type 2B

Anonymous South Netherlandish Master

Triptych of the Holy Face ('Epitaph of Christine Rupel') (c. 1548)

$44 \times 33.5 \mathrm{~cm}$ (centre panel), $42 \times 16 \mathrm{~cm}$ (left wing), $42 \times 17 \mathrm{~cm}$ (right wing) and $15 \times 31.5 \mathrm{~cm}$ (predella)

Prague, Narodni Galerie, inv. no. $\mathrm{O}_{16385}$

BIB L.: Mus. cat. Prague 1999, no. 99 (with bibl.).

HISTORICAL INFORMATION: The inscription on the predella states that the Cistercian nun depicted on the wing is called Christine Rupel and that she died on 3 November 1548, in terrible pain: Doodelijcke smerte midts ptysis bispien / Vrauwe christine Rupels portierighe eerbaer / Derden novembre XV'ç. xlviii voor complien / Met Christo moet zou Regneren eenpaer. No other information is known about this nun or the original location of the triptych.

Identity of the sitter(s): Christine Rupel 
Provenance: unknown

Number of portrait(s): 1

Type of persons: religious (woman alone: Cistercian nun)

Attitude of the sitter(s): hands clasped

Representation of the sitter(s): full-length and gisant

Gaze of the sitter(s): into space

Object(s): yes (prie-dieu, book)

Coat(s) of arms: no

Environment: landscape, no sacred connotation

Structuring of the pictorial space: distinct spaces

Patron saint(s): Christina

Gesture of the patron saint(s): introducing

Type of religious scene: hieratic

Religious scene(s) depicted: the Holy Face, St. Bernard, memento mori

\section{Cat. 173-Type 2B}

Anonymous South Netherlandish

Master

Triptych of the Holy Kinship with a Family in Prayer and Patron Saints ('Merode-Petershem Triptych') (c. 1510) $156 \times 160 \mathrm{~cm}$ (centre panel) and $108 \times$ $76 \mathrm{~cm}$ (wings)

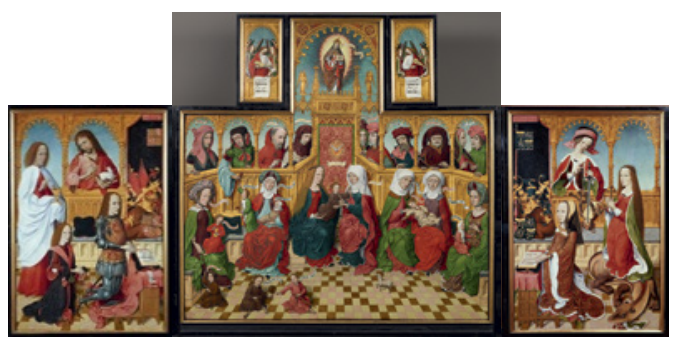

Cologne, Wallraf-Richartz Museum, inv. no. 416

BIB L.: Mus. cat. Cologne 1969, 128-31.

HISTORICAL INFORMATION: Johan VII von Merode was Lord of Merode, Petershem, Geel, Westerloo, Olen and Herselt. He died before 4 October 1497. Written on 8 July 1497, his will states that he wanted to be buried in the church of St. Dymphna at Geel. In the triptych, he is accompanied by his wife, Margaretha, and their son, Johan, who would become councillor of Charles v. According to Johan's appearance, the work can be dated c. 1510. The portrait of the father is thus posthumous. The triptych was most probably destined for the convent of Schwarzenbroich, near Düren, which had been founded in 1340 by Werner v and Werner viI von Merode. Furthermore, a manuscript coming from the convent and entitled Memoria generalis singularium benefactorum de familia merodana mentions a mass founded by Margaretha on 10 Augustus 1509 .

Identity of the sitter(s):Johann VII, Margarethe von Merode-Petershem and their son Johann viII

Provenance: Düren, convent of Schwarzenbroich (?) 
Number of portrait(s): 3

Type of persons: lay (family)

Attitude of the sitter(s): hands clasped

Representation of the sitter(s): full-length

Gaze of the sitter(s): towards the scene

Object(s): yes (prie-dieu, book, purse)

Coat(s) of arms: yes

Environment: architectural space with sacred connotation

Structuring of the pictorial space: unified space with discontinuities

Patron saint(s):John the Evangelist, John the Baptist, Dymphna (?), Margaret

Gesture of the patron saint(s): blessing

Type of religious scene: hieratic

Religious scene(s) depicted: the Holy kinship

Cat. 174-Type 2 B Anonymous South Netherlandish

Master

Triptych of the Holy Trinity with a Family in Prayer and Patron
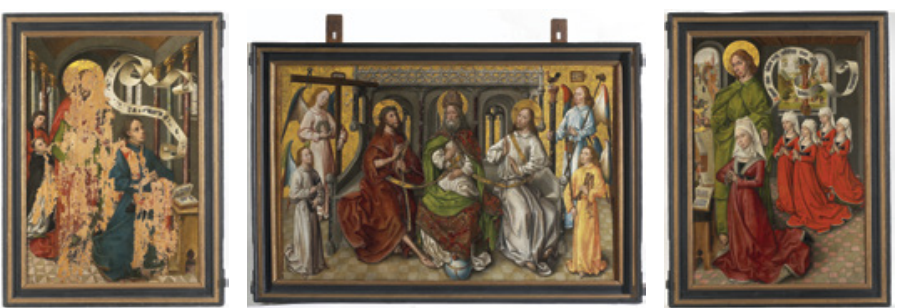

Saints (c. 1475-1500)

$112 \times 174 \mathrm{~cm}$ (centre panel) and $113.5 \times 79 \mathrm{~cm}$ (wings)

Berg, church of St. Servatius

BIBL.: VAN CAMP 1952; VRANCKX 1999.

Identity of the sitter(s): unknown

Provenance: unknown

Number of portrait(s): 7

Type of persons: lay (family)

Attitude of the sitter(s): hands clasped

Representation of the sitter(s): full-length

Gaze of the sitter(s): into space, towards the scene

Object(s): yes (prie-dieu, book, banderole)

Coat(s) of arms: no

Environment: architectural space with sacred connotation

Structuring of the pictorial space: distinct spaces

Patron saint(s): an unidentified saint, John the Evangelist

Gesture of the patron saint(s): introducing

Type of religious scene: hieratic

Religious scene(s) depicted: the Holy Trinity 
Cat. 175-Type $2 \mathrm{C}$

[Link to the Musénor Database]

Anonymous South Netherlandish Master

Triptych of the Lamentation with a Nun in Prayer (c. 1525-1550)

$49 \times 67 \mathrm{~cm}$ (open)

Arras, Musée des Beaux-Arts, inv. no. 896.5 (on deposit of the Musée du Louvre, no. R.F. 984)

BIB L.: Repertory Nord-Pas-de-Calais II, no. 90 (with bibl.).

Identity of the sitter(s): unknown

Provenance: unknown

Number of portrait(s): 1

Type of persons: religious (woman alone: Benedictine nun)

Attitude of the sitter(s): hands clasped

Representation of the sitter(s): full-length

Gaze of the sitter(s): into space

Object(s): yes (prie-dieu, book)

Coat(s) of arms: no

Environment: historical setting

Structuring of the pictorial space: continuous space

Patron saint(s): none

Gesture of the patron saint(s): not applicable

Type of religious scene: narrative

Religious scene(s) depicted: the Lamentation, St. Giles

Cat. 176-Type $1 \mathrm{~A}$

Anonymous South

Netherlandish Master

Triptych of the Legend of

St. Eustache (c. 1525-1550)

$92.2 \times 168 \mathrm{~cm}$ (open)

Brussels, MRBAB, inv. no. 331

вІв L.: Mus. cat. Brussels 1984,
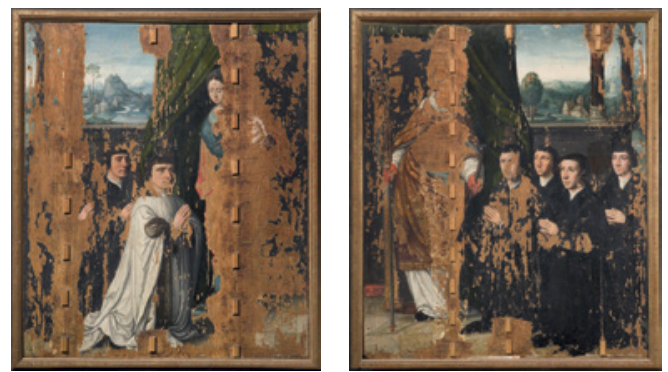
395 .

Identity of the sitter(s): unknown

Provenance: unknown

Number of portrait(s): 7

Type of persons: mixed (group: association)

Attitude of the sitter(s): hands clasped 
Representation of the sitter(s): full-length

Gaze of the sitter(s): towards the centre

Object(s): no

Coat(s) of arms: no

Environment: architectural space with sacred connotation

Structuring of the pictorial space: distinct spaces

Patron saint(s): an unidentified saint, Eligius

Gesture of the patron saint(s): holding his/her attribute

Type of religious scene: narrative

Religious scene(s) depicted: the Legend of St. Eustache

Cat. 177-Type 2B

Anonymous South Netherlandish Master

Triptych of the Monogram of Christ with a Family in Prayer and Patron Saints (c. 1490)

$59.5 \times 51.5 \mathrm{~cm}($ centre panel) and $55 \times 20 \mathrm{~cm}$ (wings)

Montgomery, Montgomery Museum of Fine Arts, inv. no. 1936.0008

вIB L.: VAN DEN BERGEN-PANTENS 1969; EISLER 1977, 69-71.

HISTORICAL INFORMATION: The centre panel of the triptych contains the coats of arms of the Wouters and Van Nieuwenhuyse families, as well as the mottos J'ay bien and A bien viengn and the initials MIM. The coat of arms depicted on the left wing belongs to the Wouters family. Together with the motto Plus est en Dieu, this allows the identification of the sitter as Jean Wouters $(\dagger$ 1516). His wife, Jossine de Beste $(\dagger 1505)$, is depicted on the right wing with her coat of arms and motto (ma fiance est telle). The couple is portrayed with their two children, Jean and Elisabeth. Jean Wouters was the son of Laurent and Anne Wouters. He was Lord of Hallebast and Broucke and made his career in the Burgundian administration, where he served Philip the Good, Charles the Bold, Mary of Burgundy and Philip the Fair.

Identity of the sitter(s): Jean Wouters, Jossine de Beste and their children

Provenance: unknown

Number of portrait(s): 4

Type of persons: lay (family with children)

Attitude of the sitter(s): hands clasped

Representation of the sitter(s): full-length 
Gaze of the sitter(s): towards the scene

Object(s): yes (prie-dieu, book)

Coat(s) of arms: yes

Environment: landscape with sacred connotation

Structuring of the pictorial space: distinct spaces

Patron saint(s): John the Baptist, Josse

Gesture of the patron saint(s): introducing, holding his/her attribute

Type of religious scene: hieratic

Religious scene(s) depicted: the Monogram of Christ

\section{Cat. 178-Type $2 \mathrm{~A}$}

[RKD work no. 255181]

Anonymous South Netherlandish Master

Triptych of the Nativity with a Couple in Prayer and Patron Saints (c. 1530)

$59 \times 44 \mathrm{~cm}$ (centre panel) and $63 \times 21.5 \mathrm{~cm}$ (wings)

London, sale Christie's (5 December 2012), lot no. 101

BIB L.: Sale cat. Christie's (London, 5 December 2012), no. 101.

HISTORICAL INFORMATION: According to the sale catalogue of 2012, the devotees are Jean Mercier d'Artois and Elisabeth Escobecque of Brabant, but the research on the coats of arms has not confirmed this hypothesis.

Identity of the sitter(s): unknown

Provenance: unknown

Number of portrait(s): 2

Type of persons: lay (couple)

Attitude of the sitter(s): hands clasped

Representation of the sitter(s): full-length

Gaze of the sitter(s): towards the scene

Object(s): yes (rosary)

Coat(s) of arms: yes (rosary)

Environment: historical setting

Structuring of the pictorial space: unified space with discontinuities

Patron saint(s): John the Evangelist, Elizabeth of Hungary

Gesture of the patron saint(s): holding his/her attribute

Type of religious scene: narrative

Religious scene(s) depicted: the Nativity, the Annunciation 
Cat. 179-Type 5

Anonymous South

Netherlandish Master

Triptych of the Nativity

(c. 1490-1500)

$69.5 \times 55 \mathrm{~cm}$ (centre panel) and $69.5 \times 27.5 \mathrm{~cm}$ (wings)

Antwerp, Mayer Van den

Bergh Museum, inv. no. 11

BIB L.: Corpus Antwerp, no.

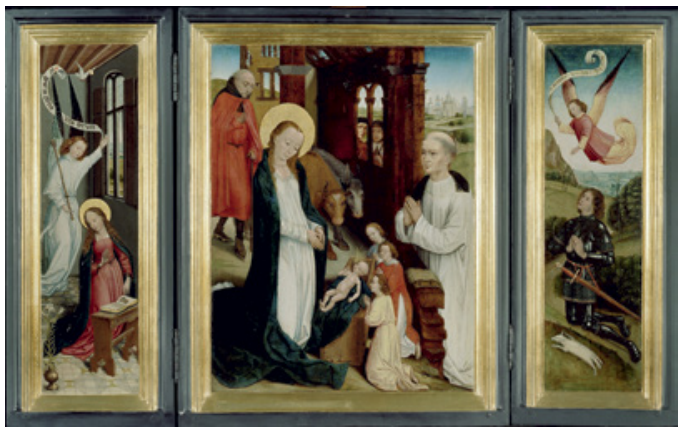

218 (with bibl.).

Identity of the sitter(s): unknown

Provenance: unknown

Number of portrait(s): 2

Type of persons: religious (group: canon, canon regular)

Attitude of the sitter(s): hands clasped

Representation of the sitter(s): full-length

Gaze of the sitter(s): into space, towards the scene

Object(s): no

Coat(s) of arms: no

Environment: historical setting

Structuring of the pictorial space: distinct spaces

Patron saint(s): Nicholas

Gesture of the patron saint(s): protecting

Type of religious scene: narrative

Religious scene(s) depicted: the Annunciation, the Nativity, St. Gideon

Cat. 180-Type 2B

Anonymous South Netherlandish

Master

Triptych of the Virgin and Child with a Couple in Prayer and Patron Saints (c. 1490-1500 for the centre panel and 1524 for the wings)

$48.5 \times 32 \mathrm{~cm}$ (centre panel) and $48.5 \times 15.5 \mathrm{~cm}$ (wings)

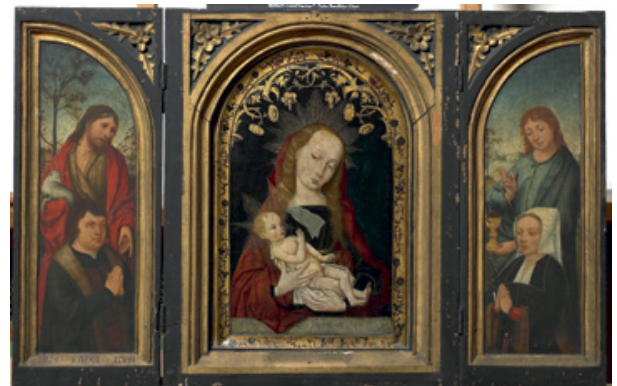

Douai, Musée de la Chartreuse, inv. nos. 420a-b

BIB L.: Repertory Nord-Pas-de-Calais II, no. 71 (with bibl.). 
Identity of the sitter(s): unknown

Provenance: unknown

Number of portrait(s): 2

Type of persons: lay (couple)

Attitude of the sitter(s): hands clasped

Representation of the sitter(s): half-length

Gaze of the sitter(s): into space

Object(s): yes (rosary)

Coat(s) of arms: no

Environment: landscape, no sacred connotation

Structuring of the pictorial space: distinct spaces

Patron saint(s): John the Baptist, John the Evangelist

Gesture of the patron saint(s): indicating, holding his/her attribute

Type of religious scene: hieratic

Religious scene(s) depicted: the Virgin and Child

Cat. 181-Type $2 B$

Anonymous South Netherlandish Master

Triptych of the Virgin and Child with a Man in Prayer and Two Saints (c. 1500-1550)

Size unknown

Private collection

Identity of the sitter(s): unknown

Provenance: unknown

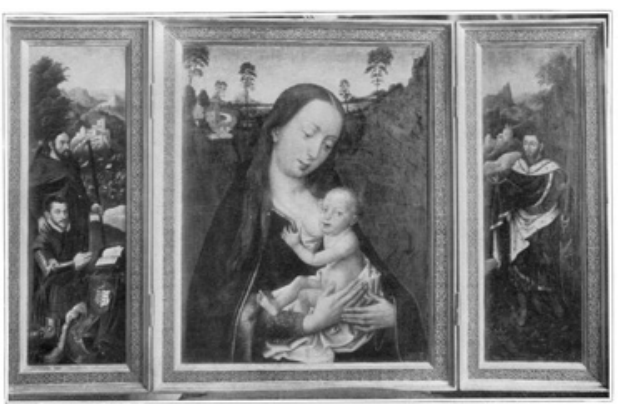

Number of portrait(s): 1

Type of persons: lay (man alone)

Attitude of the sitter(s): hands clasped

Representation of the sitter(s): full-length

Gaze of the sitter(s): towards the scene

Object(s): yes (prie-dieu, book, helmet)

Coat(s) of arms: yes

Environment: landscape, no sacred connotation

Structuring of the pictorial space: distinct spaces

Patron saint(s): John the Baptist

Gesture of the patron saint(s): protecting

Type of religious scene: hieratic

Religious scene(s) depicted: the Virgin and Child 
Cat. 182-Type 2 B

Anonymous South Netherlandish Master

Triptych of the Virgo inter Virgines ('Pardo Triptych') (c. 1490-1510) $72 \times 48.5$ (centre panel) and $72 \times$ $20.3 \mathrm{~cm}$ (wings)

Porto Rico, Museo de Arte Ponce BIBL.: DE VOS 1989-1991, 199.

HISTORICAL INFORMATION: Accor-

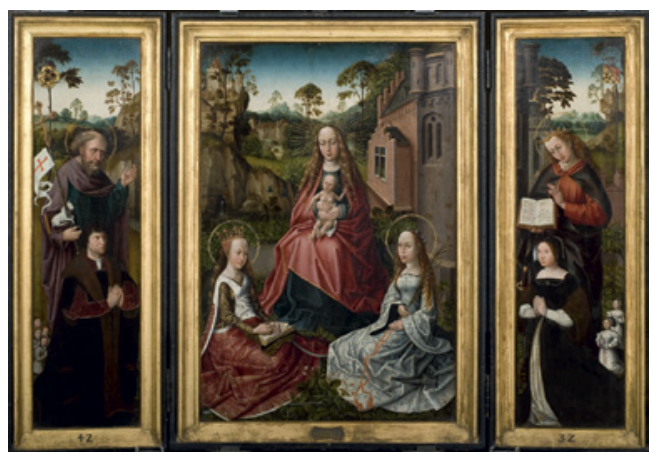
ding to De Vos, the triptych dates from the late fifteenth century and the portraits were added to the composition around $1535^{-1540 .}$. The devotees have been identified to the family of Jan I Pardo (1507-1549), from Burgos. Jan was a member of the Nation of Spain in Bruges. He was the youngest son of Silvester Pardo ( $\dagger 1538)$. He first married Cathelijne van Vlamijncpoorte (1508-1540). The couple is depicted with their children in the triptych. After Cathelijne's death, he married Godelieve de la Coste.

Identity of the sitter(s): Jan Pardo, Catharina van Vlamijncpoorte and their children

Provenance: unknown

Number of portrait(s): 8

Type of persons: lay (family with children)

Attitude of the sitter(s): hands clasped

Representation of the sitter(s): full-length, children in small scale

Gaze of the sitter(s): towards the scene

Object(s): no

Coat(s) of arms: no

Environment: landscape with sacred connotation

Structuring of the pictorial space: unified space with discontinuities

Patron saint(s): John the Baptist, Catherine

Gesture of the patron saint(s): holding his/her attribute

Type of religious scene: hieratic

Religious scene(s) depicted: the Virgin and Child with St.Barbara, St. Catherine, the Annunciation 
Cat. 183-Type 6A Anonymous South Netherlandish Master Two Wings (?). A Family in Prayer before an Apparition of the Holy Trinity

(c. 1480-1490) $38 \times 22 \mathrm{~cm}$ (each wing) Ghent, Msk, inv. nos. 1973-AE and $1973-\mathrm{AF}$

BIBL.: LEEFLANG and

MARTENS M. 2000.
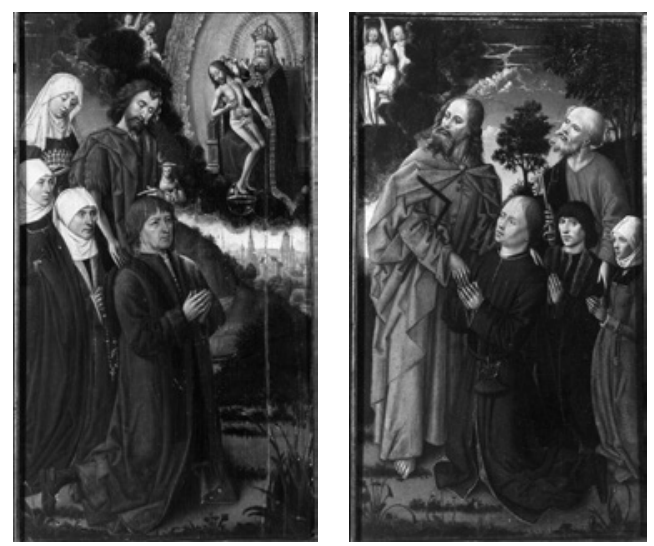

Identity of the sitter(s): unknown

Provenance: unknown

Number of portrait(s): 6

Type of persons: lay (family)

Attitude of the sitter(s): hands clasped

Representation of the sitter(s): full-length

Gaze of the sitter(s): into space, towards the scene, towards the viewer

Object(s): no

Coat(s) of arms: no

Environment: landscape with sacred connotation (incomplete)

Structuring of the pictorial space: continuous space, religious scene in a cloud

Patron saint(s): Elizabeth, John the Baptist, Peter, Thomas

Gesture of the patron saint(s): introducing, holding his/her attribute

Type of religious scene: hieratic

Religious scene(s) depicted: the Holy Trinity

Cat. 184-Type 6A

[RKD work no. 62420]

Anonymous South Netherlandish Master

Two Wings. A Couple in Prayer with Patron Saints (c. 1500-1550)

$49.4 \times 21.3 \mathrm{~cm}$ (each wing)

Amsterdam, sale Sotheby's (8 November 1999), lot no. 110

Identity of the sitter(s): unknown

Provenance: unknown 
Number of portrait(s): 2

Type of persons: lay (couple)

Attitude of the sitter(s): hands clasped

Representation of the sitter(s): full-length

Gaze of the sitter(s): indeterminate

Object(s): yes (rosary)

Coat(s) of arms: yes

Environment: landscape, no sacred connotation (incomplete)

Structuring of the pictorial space: indeterminate

Patron saint(s): Adrian, Anne

Gesture of the patron saint(s): protecting

Type of religious scene: indeterminate

Religious scene(s) depicted: none

Cat. 185-Type 6A

Anonymous South Netherlandish Master

Two Wings. A Couple in Prayer with Patron Saints (c. 1400-1500)

$69 \times 24 \mathrm{~cm}$ (each wing)

Cologne, sale Lempertz (17 November 1988), lot no. 16

Identity of the sitter(s): unknown

Provenance: unknown

Number of portrait(s): 2

Type of persons: lay (couple)

Attitude of the sitter(s): hands clasped, holding a book

Representation of the sitter(s): half-length

Gaze of the sitter(s): indeterminate

Object(s): yes (book)

Coat(s) of arms: yes

Environment: landscape, no sacred connotation (incomplete)

Structuring of the pictorial space: indeterminate

Patron saint(s): Matthew, Margaret (?)

Gesture of the patron saint(s): protecting

Type of religious scene: indeterminate

Religious scene(s) depicted: none

Cat. 186-Type 6A

Anonymous South Netherlandish Master

Two Wings. A Couple in Prayer with Patron Saints (c. 1500-1510) 
$56.2 \times 21.6 \mathrm{~cm}$ (each wing)

Paris, sale Christie's (16 December 2009), lot no. 332

Identity of the sitter(s): unknown

Provenance: unknown

Number of portrait(s): 2

Type of persons: lay (family with children)

Attitude of the sitter(s): hands clasped

Representation of the sitter(s): full-length, child in small scale

Gaze of the sitter(s): indeterminate

Object(s): no

Coat(s) of arms: no

Environment: landscape, no sacred connotation (incomplete)

Structuring of the pictorial space: indeterminate

Patron saint(s): Barbara, Augustine

Gesture of the patron saint(s): holding his/her attribute

Type of religious scene: indeterminate

Religious scene(s) depicted: none

Cat. 187-Type 6A

[RKD work no. $5^{8909]}$

Anonymous South Netherlandish Master

Two wings. A Couple in Prayer with Patron Saints (c. 1490-1510)

$50 \times 38.5 \mathrm{~cm}$ (each wing)

Whereabouts unknown

Identity of the sitter(s): unknown

Provenance: unknown

Number of portrait(s): 2

Type of persons: lay (couple)

Attitude of the sitter(s): hands clasped

Representation of the sitter(s): full-length

Gaze of the sitter(s): indeterminate

Object(s): no

Coat(s) of arms: no

Environment: landscape, no sacred connotation (incomplete)

Structuring of the pictorial space: indeterminate

Patron saint(s): James, Mary the Egyptian

Gesture of the patron saint(s): introducing, holding his/her attribute

Type of religious scene: indeterminate

Religious scene(s) depicted: none 
Cat. 188-Type 6A

Anonymous South Netherlandish Master

Two Wings. A Couple in Prayer; Christ on the Cross (c. 1500-1510)

$90 \times 34 \mathrm{~cm}$

Aengenesch, Katj. Pfarr-Rektorat 'Zur Schmerzensmutter'

BIB L.: Exh. cat. Kevelaer 2000-2001, no. $5^{8}$.

HistoriCAL INFORMATION: According to the Exh. cat. Kevelaer, 2000-2001, the persons portrayed could be Adriaen van Boedberg (owner of Haag Castle, near Gerldern) and his wife, but there is no evidence allowing to confirm this assumption.

Identity of the sitter(s): unknown

Provenance: unknown

Number of portrait(s): 2

Type of persons: lay (couple)

Attitude of the sitter(s): hands clasped

Representation of the sitter(s): full-length

Gaze of the sitter(s): indeterminate

Object(s): yes (rosary)

Coat(s) of arms: no

Environment: landscape, no sacred connotation (incomplete)

Structuring of the pictorial space: indeterminate

Patron saint(s): none

Gesture of the patron saint(s): not applicable

Type of religious scene: indeterminate

Religious scene(s) depicted: Christ on the cross, St. Catherine, St. Elizabeth, St. Adrian

Cat. 189-Type 6A

[R KD work no. 194833]

Anonymous South Netherlandish Master

Two Wings. A Family in Prayer with Patron Saints

(c. 1520-1530)

$62 \times 28 \mathrm{~cm}$ (each wing)

the Netherlands, private collection

Identity of the sitter(s): unknown

Provenance: unknown 
Number of portrait(s): 3

Type of persons: lay (family with children)

Attitude of the sitter(s): hands clasped

Representation of the sitter(s): full-length

Gaze of the sitter(s): indeterminate

Object(s): yes (rosary)

Coat(s) of arms: no

Environment: landscape, no sacred connotation (incomplete)

Structuring of the pictorial space: indeterminate

Patron saint(s): Eustache or Hubert, Catherine

Gesture of the patron saint(s): introducing

Type of religious scene: indeterminate

Religious scene(s) depicted: none

\section{Cat. 190-Type 6A}

\section{Anonymous South Netherlandish Master}

Two Wings. A Family in Prayer with St. John the Baptist and St. Elizabeth of

Hungary (c. 1500-1550)

$74 \times 24.4 \mathrm{~cm}$ (each wing)

Amsterdam, sale Sotheby's (29 October 2007), lot no. 1

Identity of the sitter(s): unknown

Provenance: unknown

Number of portrait(s): 5

Type of persons: lay (family with children)

Attitude of the sitter(s): hands clasped

Representation of the sitter(s): full-length

Gaze of the sitter(s): indeterminate

Object(s): yes (rosary, hat)

Coat(s) of arms: no

Environment: architectural space, no sacred connotation (incomplete)

Structuring of the pictorial space: indeterminate

Patron saint(s): John the Baptist, Elizabeth of Hungary

Gesture of the patron saint(s): holding his/her attribute

Type of religious scene: indeterminate

Religious scene(s) depicted: none 
Cat. 191-Type 6A

[RKD work no. 46918]

Anonymous South Netherlandish Master

Two Wings. A Man in Prayer with St. John the Baptist and St. Mary Magdalen

(c. 1500-1550)

$108.6 \times 83.7 \mathrm{~cm}$ (each wing)

Liverpool, Walker Art Gallery, inv. no. 1192

BIB L.: Mus. cat. Liverpool 1963, 145, no. 1192.

Identity of the sitter(s): unknown

Provenance: unknown

Number of portrait(s): 1

Type of persons: lay (man alone)

Attitude of the sitter(s): hands clasped

Representation of the sitter(s): full-length

Gaze of the sitter(s): indeterminate

Object(s): yes (prie-dieu, book)

Coat(s) of arms: no

Environment: landscape, no sacred connotation (incomplete)

Structuring of the pictorial space: indeterminate

Patron saint(s): John the Baptist

Gesture of the patron saint(s): protecting

Type of religious scene: indeterminate

Religious scene(s) depicted: St. Mary Magdalen

Cat. 192-Type 6A

Anonymous South

Netherlandish Master

Two Wings. A Monk in Prayer with

St. Hubert, The Virgin and Child with St. Elizabeth of Hungary (c. 1450-1500)

$22 \times 15.5 \mathrm{~cm}$ (each wing)

Liège, Musée Grand Curtius, inv. no. A11

BIBL.: KOCKEROLS 2004, no.

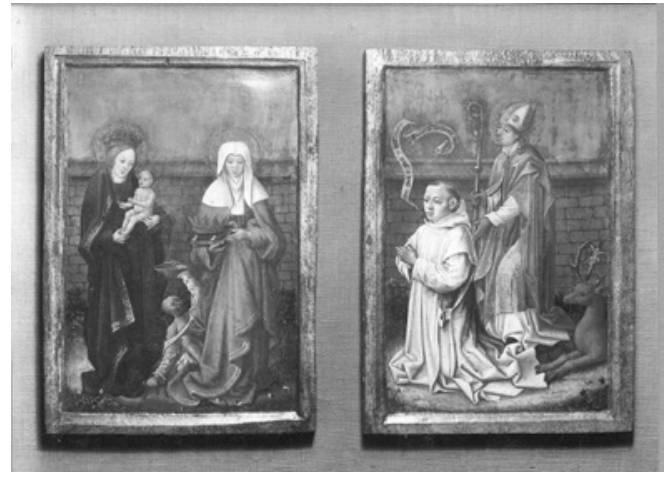
142; Repertory Liège, no. 18 (with bibl.).

REMARK: It has long been argued that the two panels constitute a diptych, but their compositional and iconographical features nonetheless strongly suggest 
that they were part of a triptych (or maybe a polyptych): saints standing before a brick wall are indeed more typical of outer wings of triptychs than of diptychs (for other examples, see cat. 9, 34, 488). Unfortunately, the original frames of the two panels have not been preserved and the technical examination of the works did not deliver any additional information.

Identity of the sitter(s): unknown

Provenance: unknown

Number of portrait(s): 1

Type of persons: religious (man alone: Carthusian monk)

Attitude of the sitter(s): hands clasped

Representation of the sitter(s): full-length

Gaze of the sitter(s): towards the scene

Object(s): yes (banderole)

Coat(s) of arms: no

Environment: enclosed garden (incomplete)

Structuring of the pictorial space: indeterminate

Patron saint(s): Hubert

Gesture of the patron saint(s): introducing

Type of religious scene: indeterminate

Religious scene(s) depicted: the Virgin and Child, St. Elizabeth of Hungary

\section{Cat. 193-Type 6A}

[Link to the Musenor Database]

Anonymous South Netherlandish Master

Two Wings. Nicaise Ladam and his Family in Prayer (c. 1550)

$79.5 \times 25.5 \mathrm{~cm}$ (each wing)

Arras, Musée des Beaux-Arts (loan of the Musée de la Chartreuse de Douai), inv. no. 24

BIB L.: Repertory Nord-Pas-de-Calais II, no. 92 (with bibl.).

HISTORICAL INFORMATION: Born in Béthune in 1466, Nicaise Ladam was a poet and a chronicler. From 1516 onwards, he worked for Charles $v$ and became one of his Kings of Arms, under the name of 'Grenade'. Ladam also made a political career in Arras, where he became mayor in 1535. He died on 28 September 1547 and was buried in the church of Saint-Jean-en-Ronville. These wings come from the triptych destined to decorate his tombstone. He is depicted with his first wife, Jeanne Ricquart, and their son.

Identity of the sitter(s): Nicaise Ladam, Jeanne Ricquart and their son

Provenance: Arras, church of Saint-Jean-en-Ronville

Number of portrait(s): 3 
Type of persons: lay (family)

Attitude of the sitter(s): hands clasped

Representation of the sitter(s): half-length

Gaze of the sitter(s): indeterminate

Object(s): yes (book, rosary)

Coat(s) of arms: yes

Environment: landscape, no sacred connotation (incomplete)

Structuring of the pictorial space: indeterminate

Patron saint(s): Nicasius, John the Evangelist, Clare

Gesture of the patron saint(s): holding his/her attribute

Type of religious scene: indeterminate

Religious scene(s) depicted: Death

\section{Cat. 194-Type 6A}

Anonymous South Netherlandish Master Two wings. The Crucifixion with a Man in Prayer and Patron Saint; The Resurrection with a Woman in Prayer and Patron Saint (c. 1550) $91 \times 29 \mathrm{~cm}$ (each wing)

Douai, Musée de la Chartreuse, inv. no. 283 BIBL.: Repertory Nord-Pas-de-Calais, no. 93 (with bibl.).

Identity of the sitter(s): unknown

Provenance: unknown

Number of portrait(s): 2

Type of persons: lay (couple)

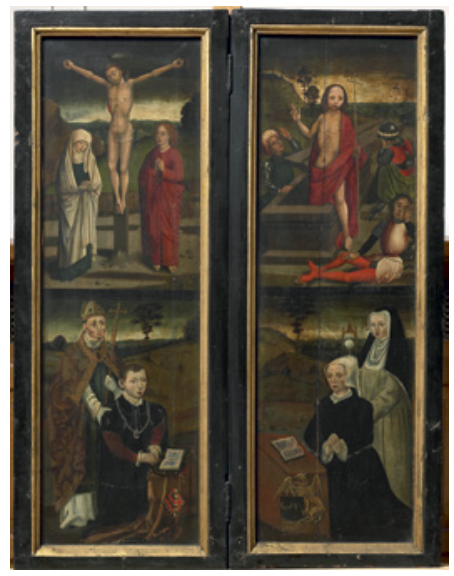

Attitude of the sitter(s): hands clasped, holding a hat

Representation of the sitter(s): full-length

Gaze of the sitter(s): indeterminate

Object(s): yes (prie-dieu, book, hat)

Coat(s) of arms: yes

Environment: landscape, no sacred connotation (incomplete)

Structuring of the pictorial space: indeterminate

Patron saint(s): a saint bishop, Clare

Gesture of the patron saint(s): introducing

Type of religious scene: narrative

Religious scene(s) depicted: the Crucifixion, the Resurrection 
Cat. 195-Type 6A

[KIK-IRPA work no. 20013754]

Anonymous South Netherlandish Master

Two Wings. The Ecce Homo with a Monk in Prayer and St. Bruno (c. 1515-1535)

$74.5 \mathrm{~cm} \times 29.5 \mathrm{~cm}$

Brussels, MRBAB, inv. nos. 4706-4709

BIB L.: Mus. cat. Brussels 1984, 399 .

Identity of the sitter(s): unknown

Provenance: unknown

Number of portrait(s): 1

Type of persons: religious (man alone: Carthusian monk)

Attitude of the sitter(s): hands clasped

Representation of the sitter(s): full-length

Gaze of the sitter(s): indeterminate

Object(s): no

Coat(s) of arms: yes

Environment: architectural space with sacred connotation (incomplete)

Structuring of the pictorial space: indeterminate

Patron saint(s): Bruno

Gesture of the patron saint(s): introducing

Type of religious scene: hieratic

Religious scene(s) depicted: the Ecce homo, St. Jerome in the wilderness, the Temptation of St. Anthony

Cat. 196-Type 3 A

Anonymous South Netherlandish Master

Votive Panel with Philip the Good and Isabella of Portugal. The Annunciation, the Descent of the Holy Ghost, the Coronation of the Virgin (c. 1500-1510) $72 \times 151 \mathrm{~cm}$

Arras, Trésor de la Cathédrale-Musée des Beaux-Arts, inv. no. 201

BIB L.: Repertory Nord-Pas-de-Calais II, no. 73 (with bibl.).

HISTORICAL INFORMATION: The painting is probably a votive panel, commissioned by the charterhouse of Gosnay, in order to commemorate the pious memory of their benefactors, the Duke Philip the Good and the Duchess Isabella of Portugal. Their portraits seem to have been executed after those painted by Rogier van der Weyden. 
Identity of the sitter(s): Philip the Good and Isabel of Portugal

Provenance: Gosnay, charterhouse of the Val-Saint-Esprit

Number of portrait(s): 2

Type of persons: lay (couple)

Attitude of the sitter(s): hands clasped

Representation of the sitter(s): full-length

Gaze of the sitter(s): into space

Object(s): yes (prie-dieu, book, collar of the Order of the Golden Fleece)

Coat(s) of arms: yes

Environment: landscape, no sacred connotation

Structuring of the pictorial space: fragmentation of the pictorial space

Patron saint(s): Andrew, Elizabeth of Hungary

Gesture of the patron saint(s): guiding

Type of religious scene: narrative

Religious scene(s) depicted: the Annunciation, the Descent of the Holy Spirit, the Coronation of the Virgin

\section{Cat. 197-Type $3 \mathrm{D}$}

Anonymous South Netherlandish Master Votive Panel. The Life of Christ and the Virgin (c. 1490-1500) $90.4 \times 51.5 \mathrm{~cm}$

Bruges, Museum van het Heilig Bloed BIBL.: MADOU 2002; URBACH 2015 (vol. 2), 112. HISTORICAL INFORMATION: The coats of arms depicted on the frame belong to the Van Themseke family of Bruges. The woman, who wears the Benedictine habit, most probably belongs to this family but has not been identified precisely.

Identity of the sitter(s): member of the Van

Themseke family (?)

Provenance: unknown

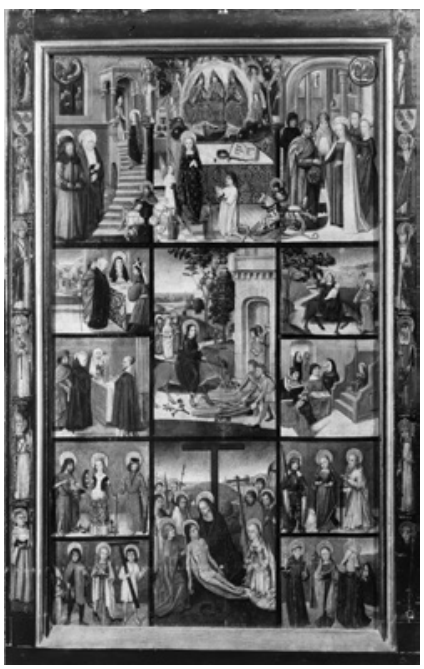

Number of portrait(s): 1

Type of persons: religious (woman alone: Benedictine nun)

Attitude of the sitter(s): hands clasped

Representation of the sitter(s): full-length

Gaze of the sitter(s): towards the scene

Object(s): no 
Coat(s) of arms: yes

Environment: neutral space

Structuring of the pictorial space: fragmentation of the pictorial space

Patron saint(s): none

Gesture of the patron saint(s): not applicable

Type of religious scene: hieratic

Religious scene(s) depicted: the Holy Trinity, the Marriage of the Virgin, the Presentation of the Virgin in the temple, the Circumcision, the Flight into Egypt, the Presentation in the temple, St. Nicholas, St. Medard of Soissons, St. George, St. Dorothea, St. Cecilia, St. John the Baptist, St. Catherine, St. Margaret, St. Sebastian, St. Rochus, St. Philip, St. Adrian, St. Agnes, St. Paul, St. Barbara, St. Elizabeth of Hungary, St. Brendanus of Ireland, St. Gislenus, St. Hubert, St. Thomas Becket, St. Augustine, St. Gregory the Great, St. Ambrose, St. Martin

\section{Cat. 198-Type 3B}

Anonymous South Netherlandish Master

Votive Panel. The Virgin and Child enthroned with a Man in Prayer with St. Peter and St. Catherine (1475)

Size unknown

Zumaya, church

BIB L.: Exh. cat. Leon and Palencia 1999, 105.

Identity of the sitter(s): unknown

Provenance: unknown

Number of portrait(s): 1

Type of persons: lay (man alone)

Attitude of the sitter(s): hands clasped

Representation of the sitter(s): full-length, small scale

Gaze of the sitter(s): towards the scene

Object(s): no

Coat(s) of arms: no

Environment: enclosed garden

Structuring of the pictorial space: not applicable

Patron saint(s): Peter

Gesture of the patron saint(s): holding his/her attribute

Type of religious scene: hieratic

Religious scene(s) depicted: the Virgin and Child 
Cat. 199-Type 6A

[RKD work no. 43526]

Anonymous South Netherlandish Master

One Wing. A Bishop in Prayer with Patron Saint (dated 1520)

$50 \times 37 \mathrm{~cm}$

Germany, private collection

Identity of the sitter(s): unknown

Provenance: unknown

Number of portrait(s): 1

Type of persons: religious (man alone: bishop)

Attitude of the sitter(s): hands clasped

Representation of the sitter(s): full-length

Gaze of the sitter(s): indeterminate

Object(s): yes (prie-dieu, crosier, mitre)

Coat(s) of arms: yes

Environment: architectural space, no sacred connotation (incomplete)

Structuring of the pictorial space: indeterminate

Patron saint(s): Stephen

Gesture of the patron saint(s): holding his/her attribute

Type of religious scene: indeterminate

Religious scene(s) depicted: St. John the Baptist

Cat. 20o-Type 6B

Anonymous South Netherlandish Master

Portrait of a Young Man in Prayer (c. 1520)

$30 \times 21 \mathrm{~cm}$

Kromeriz Castle, inv. no. $0-326$

BIB L.: Repertory Czechoslovakia, no. 46 (with bibl.).

Identity of the sitter(s): unknown

Provenance: unknown

Number of portrait(s): 1

Type of person(s): lay (man alone)

Attitude of the sitter(s): hands clasped

Representation of the sitter(s): half-length

Gaze of the sitter(s): indeterminate

Object(s): no

Coat(s) of arms: no

Environment: neutral space (incomplete)

Structuring of the pictorial space: indeterminate 
Patron saint(s): none

Gesture of the patron saint(s): not applicable

Type of religious scene: indeterminate

Religious scene(s) depicted: none

Cat. 201-Type $3^{B}$

Anonymous South Netherlandish Master

The Holy Family with a Man in Prayer

(c. 1500-1550)

$49 \times 32 \mathrm{~cm}$

Private collection

Identity of the sitter(s): unknown

Provenance: unknown

Number of portrait(s): 1

Type of person(s): lay (man alone)

Attitude of the sitter(s): physical contact with the sacred person

Representation of the sitter(s): full-length

Gaze of the sitter(s): towards the scene

Object(s): yes (hat)

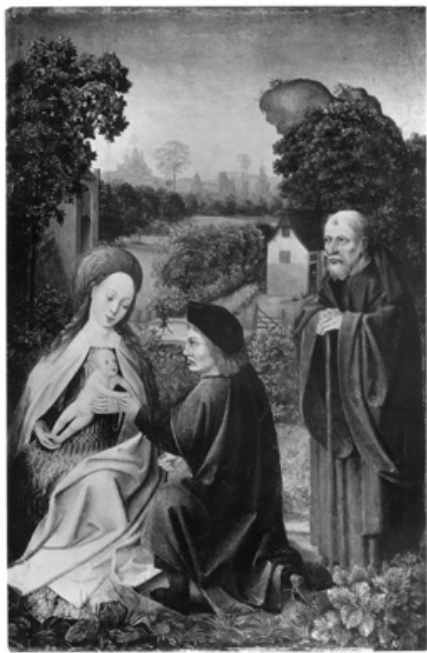

Coat(s) of arms: no

Environment: enclosed garden

Structuring of the pictorial space: not applicable

Patron saint(s): none

Gesture of the patron saint(s): not applicable

Type of religious scene: hieratic

Religious scene(s) depicted: the Holy family

Cat. 202-Type ${ }_{3} \mathrm{C}$

[RKD work no. 54986]

Anonymous South Netherlandish Master

The Meeting of Anne and Joachim at the Golden Door with a Man in Prayer (c. 1500-1525)

Size unknown

Whereabouts unknown

Identity of the sitter(s): unknown

Provenance: unknown

Number of portrait(s): 1 
Type of person(s): lay (man alone)

Attitude of the sitter(s): hands clasped

Representation of the sitter(s): full-length

Gaze of the sitter(s): into space

Object(s): yes (prie-dieu, book)

Coat(s) of arms: yes

Environment: historical setting

Structuring of the pictorial space: not applicable

Patron saint(s): none

Gesture of the patron saint(s): not applicable

Type of religious scene: narrative

Religious scene(s) depicted: the Meeting of Anne and Joachim at the Golden door

Cat. 203-Type $3 \mathrm{C}$

Anonymous South Netherlandish Master

The Nativity with a Woman in Prayer (c. 1480) $123 \times 96 \mathrm{~cm}$

Munich, sale Hampel (4 April 2008), lot no. 412 Identity of the sitter(s): unknown

Provenance: unknown

Number of portrait(s): 1

Type of person(s): lay (woman alone)

Attitude of the sitter(s): hands clasped

Representation of the sitter(s): full-length, small scale

Gaze of the sitter(s): towards the scene

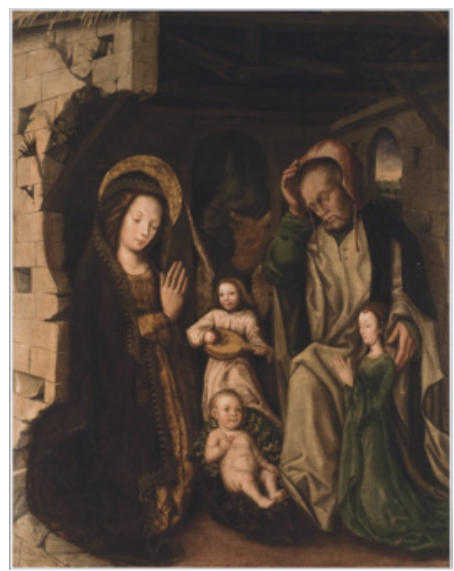

Object(s): no

Coat(s) of arms: no

Environment: historical setting

Structuring of the pictorial space: not applicable

Patron saint(s): none

Gesture of the patron saint(s): not applicable

Type of religious scene: narrative

Religious scene(s) depicted: the Nativity 
Cat. 204-Type $3^{B}$

Anonymous South Netherlandish Master The Pietà with Philip the Good, Isabella of Portugal and their Children (c. 1478) $138 \times 205 \mathrm{~cm}$

Montmirey-la-Ville, castle HISTORICAL INFORMATION: The coats of arms and the motto (aultre naray) identify the sitters as Philip the Good,

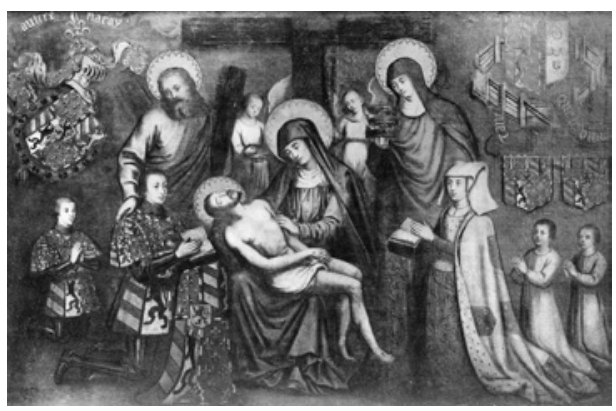
Isabella of Portugal and their children.

The original location and function of this panel are unknown.

Identity of the sitter(s): Philip the Good, Isabel of Portugal and their children

Provenance: unknown

Number of portrait(s): 5

Type of person(s): lay (family with children)

Attitude of the sitter(s): hands clasped

Representation of the sitter(s): full-length

Gaze of the sitter(s): into space

Object(s): yes (prie-dieu, book)

Coat(s) of arms: yes

Environment: neutral space

Structuring of the pictorial space: not applicable

Patron saint(s): Andrew, Elizabeth of Hungary

Gesture of the patron saint(s): protecting, holding his/her attribute

Type of religious scene: hieratic

Religious scene(s) depicted: the Pietà

\section{Cat. 205-Type $3^{B}$}

Anonymous South Netherlandish Master

The Virgin and Child with a Man in Prayer and St. Jerome (c. 1490-1500)

$31 \times 33.5 \mathrm{~cm}$

Amsterdam, sale P. de Boer (1930)

Identity of the sitter(s): unknown

Provenance: unknown

Number of portrait(s): 1

Type of person(s): lay (man alone)

Attitude of the sitter(s): hands clasped

Representation of the sitter(s): half-length 
Gaze of the sitter(s): towards the scene

Object(s): no

Coat(s) of arms: no

Environment: landscape with sacred connotation

Structuring of the pictorial space: not applicable

Patron saint(s): Jerome

Gesture of the patron saint(s): protecting

Type of religious scene: hieratic

Religious scene(s) depicted: the Virgin and Child

\section{Cat. 206-Type 3B}

Anonymous South Netherlandish Master

The Virgin and Child with St. Thomas, St. Andrew and a Family in Prayer (c. 1490-1500)

Size unknown

Previously Madrid, Conde de San Clemente collection

Identity of the sitter(s): unknown

Provenance: unknown

Number of portrait(s): 4

Type of person(s): lay (family with children)

Attitude of the sitter(s): hands clasped

Representation of the sitter(s): full-length, small scale

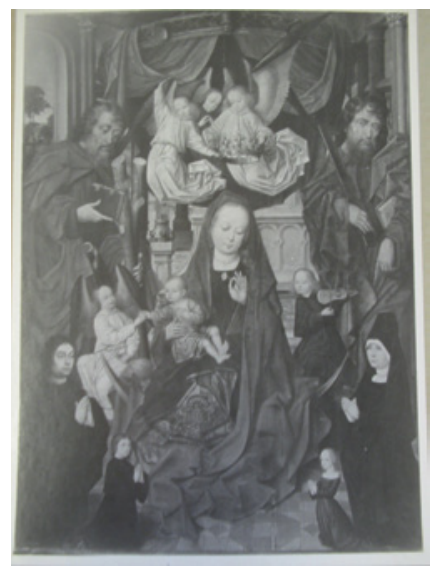

Gaze of the sitter(s): into space

Object(s): no

Coat(s) of arms: no

Environment: architectural space with sacred connotation

Structuring of the pictorial space: not applicable

Patron saint(s): Andrew, Thomas

Gesture of the patron saint(s): indicating, holding his/her attribute

Type of religious scene: hieratic

Religious scene(s) depicted: the Virgin and Child

\section{Cat. 207-Type 2B}

Anonymous South Netherlandish Master

Triptych of the Virgin and Child with a Couple in Prayer and Patron Saints (c. 1480-1490) 
$5^{2} \times 73 \mathrm{~cm}$ (open)

Whereabouts unknown

BIB L.: SCHADE 2001, 184-85.

Identity of the sitter(s): unknown

Provenance: unknown

Number of portrait(s): 2

Type of person(s): lay (couple)

Attitude of the sitter(s): hands clasped

Representation of the sitter(s): full-length, small scale

Gaze of the sitter(s): towards the scene

Object(s): no

Coat(s) of arms: no

Environment: landscape, no sacred connotation

Structuring of the pictorial space: distinct spaces

Patron saint(s): Christopher or Philip (?), Barbara (?)

Gesture of the patron saint(s): introducing

Type of religious scene: hieratic

Religious scene(s) depicted: the Virgin and Child

Cat. 208-Type $2 B$

[R KD work no. 243419]

Anonymous South Netherlandish Master

Triptych of the Virgin and Child with St. Anne, a Nun in Prayer and Patron Saint (c. $1500-1550)$

$45.5 \times 35 \mathrm{~cm}$ (centre panel) and $49 \times 15.5 \mathrm{~cm}$ (wings)

Luzern, sale Fischer (16 June 2010), lot no. 1006

Identity of the sitter(s): unknown

Provenance: unknown

Number of portrait(s): 1

Type of person(s): religious (woman alone: Benedictine nun?)

Attitude of the sitter(s): hands clasped

Representation of the sitter(s): full-length

Gaze of the sitter(s): towards the scene

Object(s): no

Coat(s) of arms: no

Environment: enclosed garden

Structuring of the pictorial space: continuous space 
Patron saint(s): Walburga

Gesture of the patron saint(s): holding his/her attribute

Type of religious scene: hieratic

Religious scene(s) depicted: the Virgin and Child with St. Anne, St. Corona

Cat. 209-Type 6A

[R KD work no. 45977]

Anonymous South Netherlandish Master

Two Wings. A Family in Prayer (c. 1550)

$78 \times 22 \mathrm{~cm}$ (each wing)

Amsterdam, sale Sotheby's (6 May 1998), lot no. 68

Identity of the sitter(s): unknown

Provenance: unknown

Number of portrait(s): 5

Type of person(s): mixed (family)

Attitude of the sitter(s): hands clasped

Representation of the sitter(s): full-length

Gaze of the sitter(s): indeterminate

Object(s): yes (prie-dieu, book, small cross)

Coat(s) of arms: no

Environment: neutral space (incomplete)

Structuring of the pictorial space: indeterminate

Patron saint(s): none

Gesture of the patron saint(s): not applicable

Type of religious scene: indeterminate

Religious scene(s) depicted: none

Cat. 210-Type 6A

[RKD work no. 236117]

Anonymous South Netherlandish Master

Two Wings. A Family in Prayer with Patron Saints (c. 1500-1550)

$80 \times 25 \mathrm{~cm}$ (each wing)

London, sale Bonhams (27 October 2010) lot no. 28

Identity of the sitter(s): unknown

Provenance: unknown 
Number of portrait(s): 22

Type of person(s): lay (family with children)

Attitude of the sitter(s): hands clasped

Representation of the sitter(s): full-length

Gaze of the sitter(s): indeterminate

Object(s): yes (prie-dieu, book)

Coat(s) of arms: yes

Environment: landscape, no sacred connotation (incomplete)

Structuring of the pictorial space: indeterminate

Patron saint(s): Irmgard and Denis

Gesture of the patron saint(s): holding his/her attribute

Type of religious scene: indeterminate

Religious scene(s) depicted: none

\section{Cat. 211-Type 6A}

\section{Anonymous South Netherlandish Master}

Two Wings. Portraits of Willem van Overbeke and Johanna de Keysere in Prayer

(c. 1500-1510)

$25.5 \times 8.5 \mathrm{~cm}$ (each wing)

Whereabouts unknown

HISTORICAL INFORMATION: On the sitters, see cat. 647 .

Identity of the sitter(s): Willem van Overbeke and Johanna de Keysere

Provenance: unknown

Number of portrait(s): 2

Type of person(s): lay (couple)

Attitude of the sitter(s): hands clasped

Representation of the sitter(s): half-length

Gaze of the sitter(s): indeterminate

Object(s): no

Coat(s) of arms: yes

Environment: neutral space (incomplete)

Structuring of the pictorial space: indeterminate

Patron saint(s): none

Gesture of the patron saint(s): not applicable

Type of religious scene: indeterminate

Religious scene(s) depicted: none 
Cat. 212-Type $3 \mathrm{C}$

Anonymous South Netherlandish Master (workshop of Rogier van der Weyden?)

The Crucifixion with a Monk in Prayer (c. 1470) $38.4 \times 29.2 \mathrm{~cm}$

Cleveland, Cleveland Museum of Art, inv. no.

31.449

BIB L.: Mus. cat. Cleveland 1978, 76; STROO and SYFER D'OLNE 1996, 147.

Identity of the sitter(s): unknown

Provenance: unknown

Number of portrait(s): 1

Type of person(s): religious (man alone:

Carthusian monk)

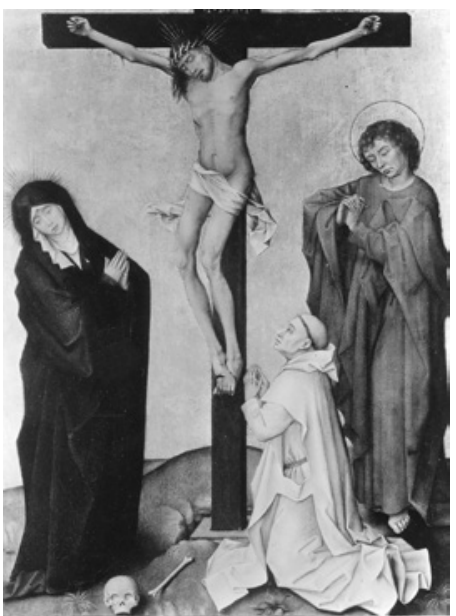

Attitude of the sitter(s): hands clasped

Representation of the sitter(s): full-length

Gaze of the sitter(s): towards the scene

Object(s): no

Coat(s) of arms: no

Environment: neutral space

Structuring of the pictorial space: not applicable

Patron saint(s): none

Gesture of the patron saint(s): not applicable

Type of religious scene: narrative

Religious scene(s) depicted: the Crucifixion

Cat. 213-Type 3A

Anonymous South Netherlandish

Master (Hainaut?)

The Sacrilege of Cambron with a Man

in Prayer (c. 1530-1550)

$36 \times 31 \mathrm{~cm}$

Tournai, Musée des Beaux-Arts,

inv. no. 347

BIB L.: MARTENS D. 2007 b (with bibl.). HISTORICAL INFORMATION: The theme of the painting and the presence of St. Bernard strongly suggest that the monk comes from the Cistercian abbey of Cambron.

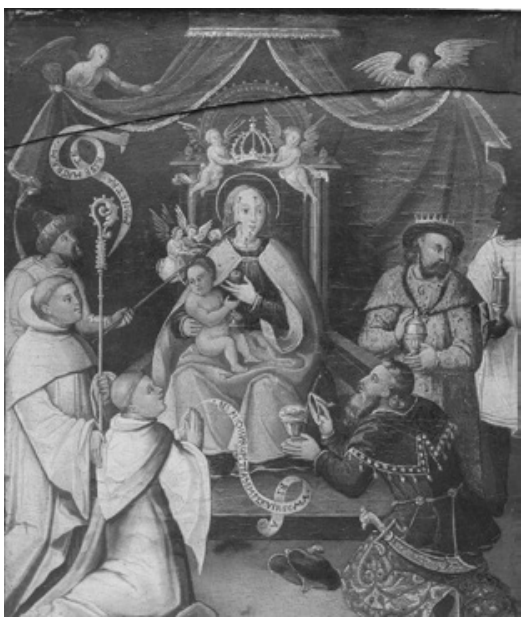


Identity of the sitter(s): unknown

Provenance: unknown

Number of portrait(s): 1

Type of person(s): religious (man alone: Cistercian monk)

Attitude of the sitter(s): holding a banderole

Representation of the sitter(s): full-length

Gaze of the sitter(s): towards the scene

Object(s): yes (banderole)

Coat(s) of arms: no

Environment: historical setting

Structuring of the pictorial space: not applicable

Patron saint(s): Bernard

Gesture of the patron saint(s): introducing

Type of religious scene: narrative

Religious scene(s) depicted: the Sacrilege of Cambron

Cat. 214-Type 6A

Anonymous South Netherlandish Master (or Albrecht Bouts and workshop)

Ambrosius van Engelen (?) with St. Ambrose (c. 1520)

$72.4 \times 22.9 \mathrm{~cm}$

London, NG, inv. no. NG 264

BIBL.: CAMPBELL 2014, 164-70.

HISTORICAL INFORMATION: Ambrosius van Engelen (1481-1543) was the abbot of the Premonstratensian abbey of Parc, in the surroundings of Leuven, from 1515 to 1543 . He has been identified, on the basis of his motto (NE QVID NIMIS), which comes from Terence's play Andria. As Campbell notes, this motto was quite popular at that time. It appears on other works commissioned by Ambrosius (stained-glass windows and manuscripts). Ambrosius was born in 1481 and came from Brabant. He took his vows at Parc c. 1504 and was ordained in 1506. In 1514 he was made coadjutor of Parc, and then abbot in 1515. Ambrosius is

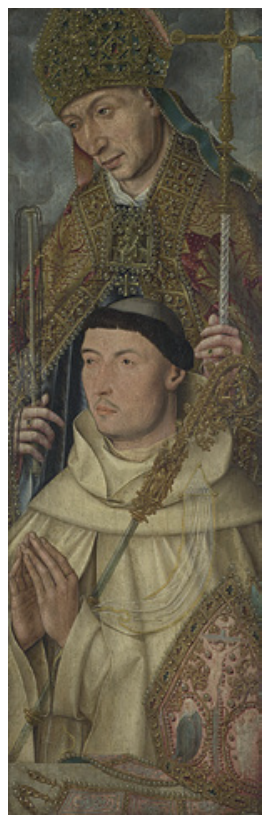
also known for his activity as an embroiderer and for his patronage of the abbey of Parc, but also of the Franciscan church in Leuven and the convent of Premonstatensian canonesses Sint-Catharinadal at Breda. He died on 16 March 1543 and was buried in the chapel of the Virgin in the abbey church of Parc. This wing comes from a triptych of the Virgin and Child, with St. Augustine on the left wing and St. Ambrose and the abbot on the right 
wing. In the seventeenth century, the triptych was still located at Parc, as a description made by the abbot Libert de Paepe testifies. The abbot mentioned the date 1520 on the triptych and corrected a note previously written by the abbot Jan Maes, who stipulated that the work contained an inscription stating the age of the sitter (29). According to De Paepe, Maes misread 29 for 39.

Identity of the sitter(s): Ambrosius van Engelen (?)

Provenance: Premonstrian abbey of Parc (?)

Number of portrait(s): 1

Type of person(s): religious (man alone: Premonstratensian abbot)

Attitude of the sitter(s): hands clasped

Representation of the sitter(s): half-length

Gaze of the sitter(s): indeterminate

Object(s): yes (crosier, mitre)

Coat(s) of arms: no

Environment: neutral space (incomplete)

Structuring of the pictorial space: indeterminate

Patron saint(s): Ambrose

Gesture of the patron saint(s): holding his/her attribute

Type of religious scene: indeterminate (probably hieratic)

Religious scene(s) depicted: none

Cat. 215-Type $3 \mathrm{C}$

Anonymous South Netherlandish Master (or Anonymous North of France Master)

The Mass of St. Gregory with Anne of Burgundy in Prayer (c. 1500-1510)

$47 \times 38 \mathrm{~cm}$

Calais, Musée des Beaux-Arts et de la Dentelle, inv. no. 951.41.1

BIBL.: Repertory Nord-Pas-de-Calais II, no. 72 (with bibl.).

HISTORICAL INFORMATION: The wOMan has been identified as Anne of Burgundy, on the basis of the coat of arms and the initials on the prie-dieu. Anne was the illegitimate daughter of Philip the Good

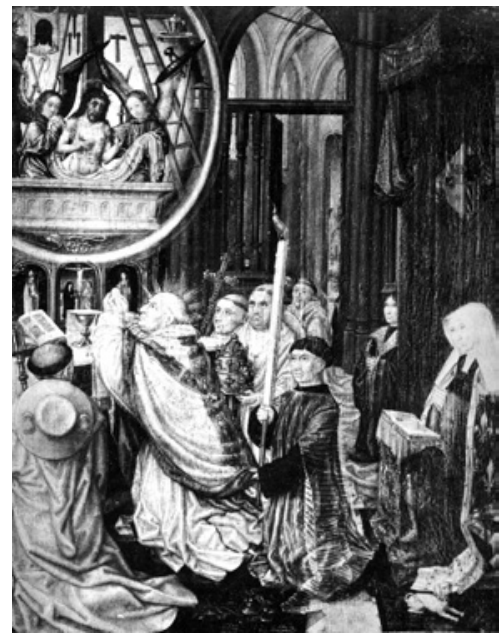
and the second wife of Adolph of Clèves (see cat. 129), whose coat of arms and initials appear in the painting. Anne was buried with her husband in the Dominican church of Brussels. 
Identity of the sitter(s): Anne of Burgundy

Provenance: unknown

Number of portrait(s): 1

Type of person(s): lay (woman alone)

Attitude of the sitter(s): hands clasped

Representation of the sitter(s): full-length

Gaze of the sitter(s): towards the scene

Object(s): yes (prie-dieu, book, dog)

Coat(s) of arms: yes

Environment: historical setting

Structuring of the pictorial space: not applicable

Patron saint(s): none

Gesture of the patron saint(s): not applicable

Type of religious scene: narrative

Religious scene(s) depicted: the Mass of St. Gregory

Cat. 216-Type 4A

Anonymous South

Netherlandish Master

(or anonymous Savoy

Master)

Diptych of Charlotte of

Savoy (c. 1472)

$36 \times 27 \mathrm{~cm}$ (each wing)

Paris, sale Cornette de saint Cyr $(25$ October

2013), lot no. 8
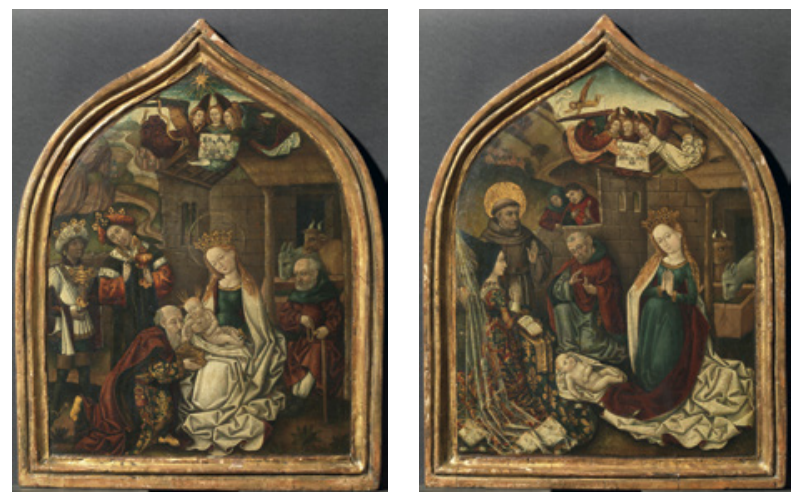

BIBL.: STERLING 1978,

334-37; Sale cat. Cornette de Saint Cyr (Paris, 25 October 2013), no. 8 (with bibl.).

HISTORICAL INFORMATION: The woman depicted on the right wing has been identified as Charlotte of Savoy, Queen of France (c. 1441-1483), on the basis of the coats of arms painted on the reverse of the panels. The diptych is mentioned in the inventory of her goods, drawn up after her death. Charlotte was the daughter of Louis of Savoy and Anne de Chypre-Lusignan. First betrothed to Frederic of Saxony in 1443, she finally married the dauphin Louis, future King Louis XI in 1451. Louis then came into conflict with his father, Charles VII, and the couple found refuge in Genappe, with the help of Philip the Good. Charlotte gave birth to eight children, of whom only three 
survived: Charles VIII, Anne of Beaujeu and Jeanne of France, who would later marry the future Louis XII and who is portrayed in a similar diptych (cat. 677). Charlotte possessed an important library. She died in 1483, a few months after her husband. According to Sterling, the presence of St. Francis on the diptych alludes to the birth of her son François in 1472. The hennin she wears follows the fashion of the years 1470-1475.

Identity of the sitter(s): Charlotte of Savoy

Provenance: unknown

Number of portrait(s): 1

Type of person(s): lay (woman alone)

Attitude of the sitter(s): hands clasped

Representation of the sitter(s): full-length

Gaze of the sitter(s): towards the scene

Object(s): yes (prie-dieu, book)

Coat(s) of arms: yes (on the reverse)

Environment: historical setting

Structuring of the pictorial space: not applicable

Patron saint(s): Francis

Gesture of the patron saint(s): holding his/her attribute

Type of religious scene: narrative

Religious scene(s) depicted: the Adoration of the Magi, the Nativity

Cat. 217-Type $3 \mathrm{C}$

Anonymous South Netherlandish Master (or attributed to Jan Provoost)

The Nativity with a Monk in Prayer (c. 1500)

$22 \times 14 \mathrm{~cm}$

Philadelphia, Lasalle University Art Museum

Identity of the sitter(s): unknown

Provenance: unknown

Number of portrait(s): 1

Type of person(s): religious (man alone: Carthusian monk)

Attitude of the sitter(s): hands clasped Representation of the sitter(s): full-length Gaze of the sitter(s): towards the ground Object(s): yes (banderole)

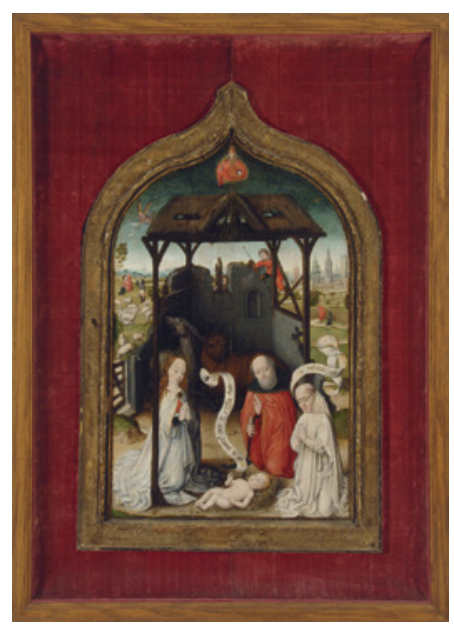


Coat(s) of arms: no

Environment: historical setting

Structuring of the pictorial space: not applicable

Patron saint(s): none

Gesture of the patron saint(s): not applicable

Type of religious scene: narrative

Religious scene(s) depicted: the Nativity, the Annunciation to the Shepherds

\section{Cat. 218-Type 2A}

[Link to the museum website]

Anonymous South Netherlandish Master (or attributed to Jan Provoost)

Triptych of the Adoration of the Magi with a Couple in Prayer and Patron Saints

(c. 1400-1500)

$100 \times 75 \mathrm{~cm}$ (open)

Durham, Barnard Castle, Bowes Museum, inv. no. 1980.14.2/B.M

HISTORICAL INFORMATION: It has not been possible to relate the coats of arms to any fifteenth- or sixteenth-century Flemish family. They might have been added later (source: The Bowes Museum, following a letter of $\mathrm{F}$. Kertschmar of the Stichting Iconographisch Bureau in The Hague).

Identity of the sitter(s): unknown

Provenance: unknown

Number of portrait(s): 2

Type of person(s): lay (couple)

Attitude of the sitter(s): hands clasped

Representation of the sitter(s): full-length

Gaze of the sitter(s): towards the scene

Object(s): yes (rosary)

Coat(s) of arms: yes

Environment: historical setting

Structuring of the pictorial space: unified space with discontinuities

Patron saint(s): John the Baptist, Anne

Gesture of the patron saint(s): protecting

Type of religious scene: narrative

Religious scene(s) depicted: the Adoration of the Magi 
Cat. 219-Type ${ }_{3} \mathrm{C}$

Anonymous South Netherlandish Master (or attributed to Juan des Flandes)

The Crucifixion with a Man in Prayer

(c. 1500-1550)

$27.5 \times 19.1 \mathrm{~cm}$

Merion, Barnes Foundation, inv. no. BF791

Identity of the sitter(s): unknown

Provenance: unknown

Number of portrait(s): 1

Type of person(s): lay (man alone)

Attitude of the sitter(s): hands clasped

Representation of the sitter(s): full-length

Gaze of the sitter(s): towards the scene

Object(s): no

Coat(s) of arms: no

Environment: historical setting

Structuring of the pictorial space: not applicable

Patron saint(s): none

Gesture of the patron saint(s): not applicable

Type of religious scene: narrative

Religious scene(s) depicted: the Crucifixion

\section{Cat. 220-Type $2 B$}

[RKD work no. 261868]

Anonymous South Netherlandish Master (or Master of 1999)

Triptych of the Virgin and Child with Angels Carrying the Arma Christi and A

Canon in Prayer (c. 1500)

$117.5 \times 170 \mathrm{~cm}$ (fully opened)

London, art dealer Sam Fogg (in 2015)

BIBL.: GUISLAIN-WITTERMANN et alii 1980-81.

REMARK: Several modifications of the composition occurred in the late sixteenth century, especially on the right inner wing. The original kneeling figure was completely overpainted and replaced by another portrait. This man was dressed corresponding to the fashion of the 1570s. The coat of arms located on the consoles of the Annunciation on the reverse were also overpainted on that occasion. The late sixteenth-century kneeling figure and the new coat of arms were removed during a programme of conservation undertaken at KIK/ IRPA from 1979-1981, in order to reveal the original motifs. Unfortunately, the original coat of arms has not been identified. 
Identity of the sitter(s): unknown

Provenance: unknown

Number of portrait(s): 1

Type of person(s): religious (man alone: canon)

Attitude of the sitter(s): hands clasped

Representation of the sitter(s): full-length

Gaze of the sitter(s): towards the scene

Object(s): no

Coat(s) of arms: yes (on the outer wings)

Environment: ecclesial space

Structuring of the pictorial space: distinct spaces

Patron saint(s): Peter

Gesture of the patron saint(s): holding his/her attribute

Type of religious scene: hieratic

Religious scene(s) depicted: the Virgin and Child with Angels Carrying the Arma Christi, the Nativity, St. Mary Magdalene, St. Nicholas, St. Jerome, the Annunciation

\section{Cat. 221-Type $3 \mathrm{D}$}

Anonymous South Netherlandish Master (or Master of Alkmaar)

The Virgin and Child with St. Anne and two Persons in Prayer (c. 1480)

$61 \times 47.5 \mathrm{~cm}$

Cologne, sale Lempertz (14-17 November 1956), lot no. 99

Identity of the sitter(s): unknown

Provenance: unknown

Number of portrait(s): 2

Type of person(s): religious (group: canon, canoness regular?)

Attitude of the sitter(s): hands clasped

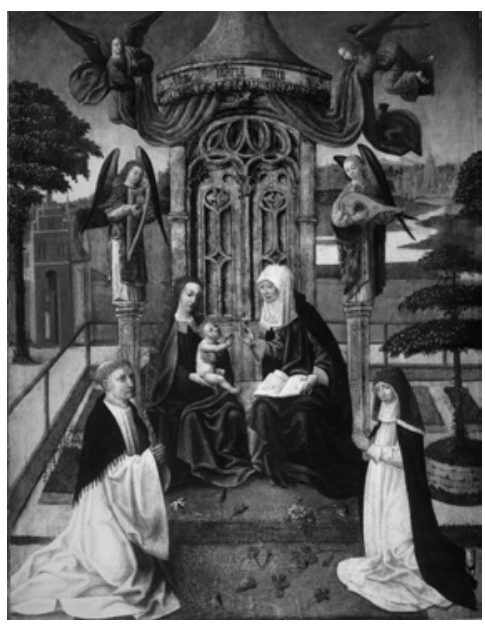

Representation of the sitter(s): full-length

Gaze of the sitter(s): towards the scene, towards the ground

Object(s): no

Coat(s) of arms: no

Environment: enclosed garden

Structuring of the pictorial space: not applicable

Patron saint(s): none

Gesture of the patron saint(s): not applicable 
Type of religious scene: hieratic

Religious scene(s) depicted: the Virgin and Child with St. Anne

Cat. 222-Type 6B

Anonymous South Netherlandish Master (or Master of the Legend of St. Catherine)

Portrait of a Woman in Prayer (c. 1490-1500)

$29 \times 19 \mathrm{~cm}$

Previously Brussels, Seyffers collection

Identity of the sitter(s): unknown

Provenance: unknown

Number of portrait(s): 1

Type of person(s): lay (woman alone)

Attitude of the sitter(s): hands clasped

Representation of the sitter(s): half-length

Gaze of the sitter(s): indeterminate

Object(s): no

Coat(s) of arms: no

Environment: neutral space (incomplete)

Structuring of the pictorial space: indeterminate

Patron saint(s): none

Gesture of the patron saint(s): not applicable

Type of religious scene: indeterminate

Religious scene(s) depicted: none

Cat. 223-Type 6B

Anonymous South Netherlandish Master (or Master of the Portraits of Princes)

Portrait of Margaret of York in Prayer (c. 1468)

$20.5 \times 12 \mathrm{~cm}$

Paris, Musée du Louvre, inv. no. RF 1938-17

BIBL.: Corpus Paris I, no. 79; Exh. cat. Mechelen 2005, no. 1; Exh. cat. Brussels 2013, no. 48 (with bibl.).

HISTORICAL INFORMATION: Born in 1446, Margaret of York was the daughter of Richard Plantagenet, Duke of York, and Cécile de Neville. She was also the sister of the kings Edward IV and Richard III. She married Charles the Bold in 1468.

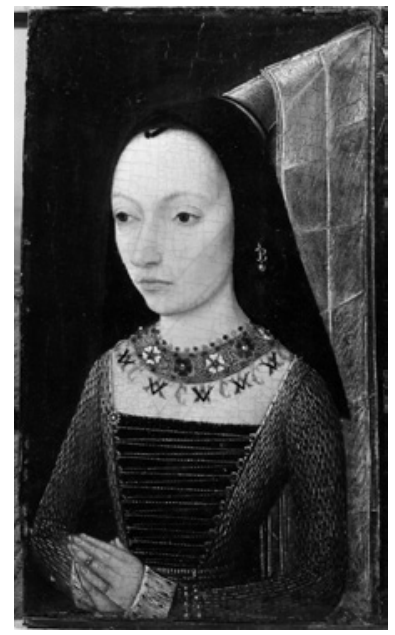


The painting must have been commissioned after their union, for the initial "C" (for Charles) appears on her necklace.

Identity of the sitter(s): Margaret of York

Provenance: unknown

Number of portrait(s): 1

Type of person(s): lay (woman alone)

Attitude of the sitter(s): hands clasped

Representation of the sitter(s): half-length

Gaze of the sitter(s): indeterminate

Object(s): no

Coat(s) of arms: no

Environment: neutral space (incomplete)

Structuring of the pictorial space: indeterminate

Patron saint(s): none

Gesture of the patron saint(s): not applicable

Type of religious scene: indeterminate

Religious scene(s) depicted: none

Cat. 224-Type $2 \mathrm{C}$

Anonymous South

Netherlandish Master (or workshop of Pieter Coecke van Aelst) Triptych of the Crucifixion with a Couple in Prayer (c. 1530-1550) $72.5 \times 50 \mathrm{~cm}$ (open)

London, NG, inv. no. NG 1088 BIBL.: MARLIER 1966, 192; MARTENS D. 1990; CAMPBELL
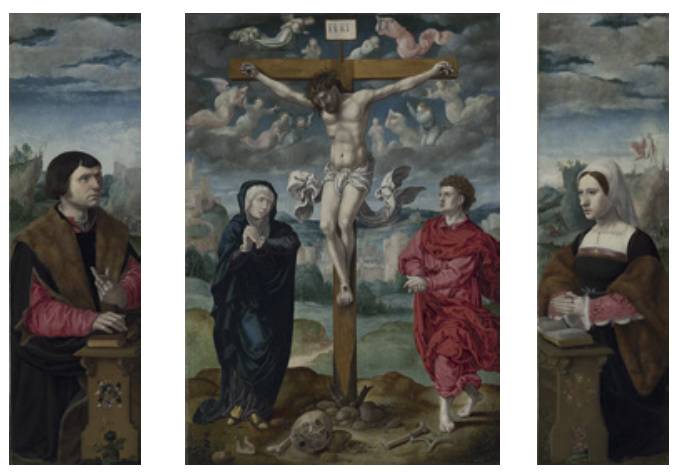
2014, 250-57.

HISTORICAL INFORMATION: The coat of arms of the man has not been identified with certainty, for it was used by several families, including the Bollis. The letters $W B$, inscribed above the helm, are probably the man's initials. Accordingly, the man might be a member of the Bollis family of Sint-Truiden. A Willem Bollis is mentioned in 1519, as member of the court of the PrinceBishop of Liège in Sint-Truiden. The coat of arms of the woman is not readable.

Identity of the sitter(s): Willem Bollis and his wife (?)

Provenance: unknown

Number of portrait(s): 2

Type of person(s): lay (couple)

Attitude of the sitter(s): hands clasped, particular gesture 
Representation of the sitter(s): full-length

Gaze of the sitter(s): into space, towards the scene

Object(s): yes (prie-dieu, book)

Coat(s) of arms: yes

Environment: historical setting

Structuring of the pictorial space: unified space with discontinuities

Patron saint(s): none

Gesture of the patron saint(s): not applicable

Type of religious scene: narrative

Religious scene(s) depicted: the Crucifixion, the Annunciation

Cat. 225-Type 2B

Anonymous South Netherlandish Master and circle of Pieter Coecke van Aelst

Triptych of the Holy Family with a Man in Prayer (c. 1525)

$94.4 \times 60.8 \mathrm{~cm}$ (centre panel) and $91.8 \times 32.3 \mathrm{~cm}$ (wings)

Cologne, sale Van Ham (14 May 2010), lot no. 105

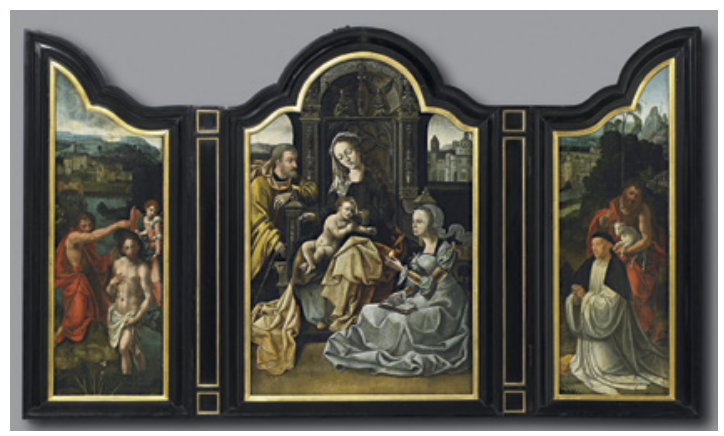

Identity of the sitter(s): unknown

Provenance: unknown

Number of portrait(s): 1

Type of person(s): religious (man alone: canon regular)

Attitude of the sitter(s): hands clasped

Representation of the sitter(s): full-length

Gaze of the sitter(s): towards the scene

Object(s): no

Coat(s) of arms: no

Environment: architectural space with sacred connotation

Structuring of the pictorial space: distinct spaces

Patron saint(s): John the Baptist

Gesture of the patron saint(s): holding his/her attribute

Type of religious scene: hieratic

Religious scene(s) depicted: the Holy Family, St. John the Baptist, the Baptism of Christ, St. Augustine, St. Monica 
Cat. 226-Type $3 \mathrm{D}$

Anonymous Tournai Master

Triptych of the Pietà with a Monk in Prayer (c. 1420-1430)

$51.5 \times 39.5 \mathrm{~cm}$ (centre panel) and $51.5 \times 19.5 \mathrm{~cm}$ (wings)

Cologne, Wallraf-Richartz Museum, inv. no. WRM 533

BIB L.: Mus. cat. Cologne 1969, 107; Exh. cat. Rotterdam 2012, no. 60 (with bibl.).

Identity of the sitter(s): unknown

Provenance: unknown

Number of portrait(s): 1

Type of person(s): religious (man alone: Carthusian monk)

Attitude of the sitter(s): hands clasped

Representation of the sitter(s): full-length

Gaze of the sitter(s): towards the scene

Object(s): yes (banderole)

Coat(s) of arms: no

Environment: historical setting

Structuring of the pictorial space: not applicable

Patron saint(s): none

Gesture of the patron saint(s): not applicable

Type of religious scene: hieratic

Religious scene(s) depicted: the Pietà

Cat. 227-Type 5

Anonymous Utrecht Master (?)

Epitaph of Elisabeth van Culemborg

(after 1530)

$110 \times 156 \mathrm{~cm}$

Culemborg, Museum

Elisabethweeshuis, inv. no. MEW 212

BIBL.: HOOGEWERFF III, 477-80;

Exh. cat. Utrecht 1999-2000, no. 99

(with bibl.).

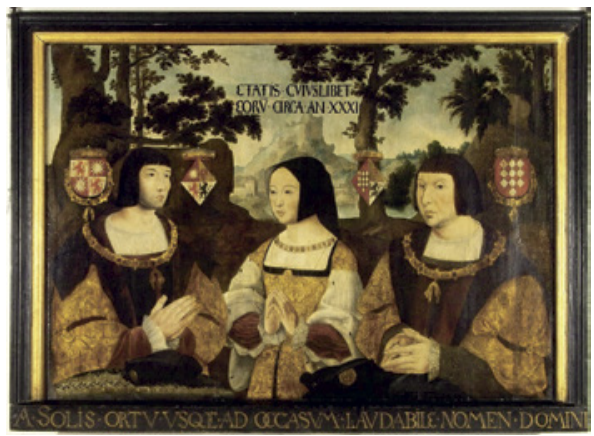

HISTORICAL INFORMATION: Elisabeth van Culemborg († 1555) is accompanied by her two successive husbands: John of Luxembourg ( $† 1508)$, on the left, and Antoine de Lalaing ( $† 1540)$, on the right. The work is considered as her epitaph.

REMARK: The painting does not include a religious scene. 
Identity of the sitter(s): Elisabeth van Culemborg, Jean de Luxembourg and Antoine de Lalaing

Provenance: unknown

Number of portrait(s): 3

Type of person(s): lay (family)

Attitude of the sitter(s): hands clasped

Representation of the sitter(s): half-length

Gaze of the sitter(s): into space, towards the viewer

Object(s): yes (collar of the Order of the Golden Fleece, hat)

Coat(s) of arms: yes

Environment: landscape, no sacred connotation

Structuring of the pictorial space: not applicable

Patron saint(s): none

Gesture of the patron saint(s): not applicable

Type of religious scene: absent

Religious scene(s) depicted: none

Cat. 228 - Type 4B (5)

[RKD work no. 32511]

BELLEGAMBE, Jean

Diptych of the Virgin and Child with a Monk in Prayer ('Diptych of Jeanne de Boubais') (c. 1507-1533)

$43 \times 28 \mathrm{~cm}$ (each wing)

Pittsburgh, Frick Art and Historical Center, inv. no. 1970.063

BIB L.: FRIEDLÄNDER XII, no. 123; PEARSON 2001; PEARSON 2005a, 136-61; Exh. cat. Antwerp and Washington 2006, no. 1 (with bibl.); KOOPSTRA 2016, $145^{-59}$.

HISTORICAL INFORMATION: The identity of the Cistercian monk portrayed on the inner right wing is unknown. Pearson suggests that he could be Guillaume of Brussels, the confessor of the Cistercian nuns of the convent of Flines in the early sixteenth century (see cat. 232 and cat. 294). Koopstra does not follow this identification and considers the monk unidentified. The nun depicted on the reverse can be identified as Jeanne de Boubais, abbess of the convent of Flines from 1507 to 1533 . The portrait and the coat of arms are indeed similar to those of Jeanne in the Le Cellier Triptych (cat. 229). Jeanne also appears in cat. 38. Taking into consideration the stylistic discrepancy between the interior and the exterior of the diptych, Koopstra argues that Jeanne the Boubais received the diptych from the unidentified monk and added her own portrait 
on the exterior at a later date. This cannot be confirmed by any other visual or textual evidence.

Identity of the sitter(s):Jeanne de Boubais and an unknown man (Guillaume of Brussels?)

Provenance: unknown

Number of portrait(s): 2

Type of person(s): religious (group: Cistercian monk, Cistercian abbess)

Attitude of the sitter(s): hands clasped

Representation of the sitter(s): half-length

Gaze of the sitter(s): towards the scene, reading a book

Object(s): yes (book, crosier)

Coat(s) of arms: yes

Environment: architectural space, no sacred connotation, domestic setting

Structuring of the pictorial space: continuous space

Patron saint(s): Bernard

Gesture of the patron saint(s): indicating, introducing

Type of religious scene: hieratic

Religious scene(s) depicted: the Virgin and Child

\section{Cat. 229-Type 5}

BELLEGAMBE, Jean

Le Cellier Triptych (1509)

$101.6 \times 61 \mathrm{~cm}$ (open)

New York, MET, inv. no. 32.100.102

BIBL.: FRIEDLÄNDER XII, no. 119; AINSWORTH and

CHRISTIANSEN 1998, no. 87

(with bibl.); PEARSON 2000;

KOOPSTRA 2016, 111-44.

HISTORICAL INFORMATION: This

triptych owes its current name to its

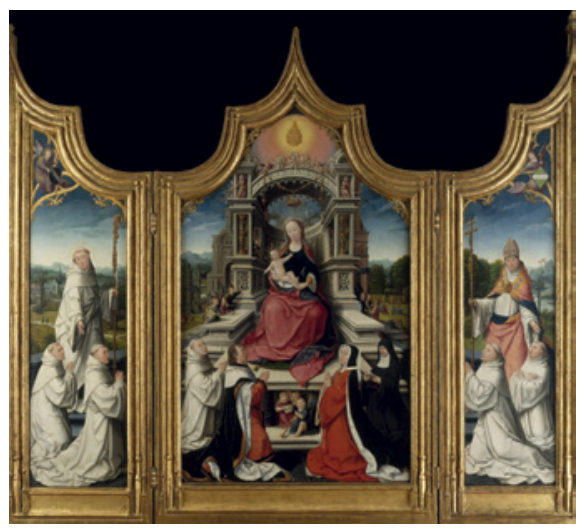

discovery in 1861 at the Le Cellier farm, which previously served as a barn for the monastery of Clairvaux. The triptych presents the coat of arms and the portrait of Jeanne de Boubais, the abbess of the Cistercian convent of Flines from 1507 up to 1533 (see cat. 228). She is most probably the patron of the triptych. It is usually assumed that Jeanne is depicted in the centre panel, reading a book and wearing the Benedictine habit, while the convent of Flines appears in the background of the left wing (next to the four towers of the monastery of Anchin). According to Koopstra, who made a technical investigation of the 
triptych, the light underdrawing in this figure does not support its identification with the abbess. The similarities between her face and Jeanne's effigy in the Frick diptych (cat. 228) is nonetheless striking enough to support this hypothesis. The iconography of the triptych is quite complex. It represents the family of St. Bernard in adoration before the Virgin and Child. In this context, Jeanne is depicted as Humbeline, St. Bernard's sister. According to Pearson, the triptych could be a gift of the abbess to the monastery of Clairvaux (whose coat of arms appears on the left wing), and more precisely to the prior Jean Foucault, who initiated the reform of the convent of Flines. More recently, Koopstra has underlined the peculiarity of the iconography and its close relationship with the Cistercian Order and the convent of Flines, arguing that the triptych was an altarpiece with liturgical functions, destined for the convent of Flines. In her analysis of the triptych, she mentions an archival document that attests the presence of a work of art depicting the Virgin and Child with the family of St. Bernard at the gatehouse of the monastery of Clairvaux. This document relates the visit of Philippe de Gueldre and the queen of Sicily to the abbey in 1517. The document describes the whole abbey and mentions the existence in the porterie of a "representation of Our Lady, Monseigneur saint Bernard and his father and mother, brothers and sister, below which gate one finds a beautiful chapel where Mass is celebrated every day". This archival document mentioned by Koopstra could reinforce Pearson's hypothesis of the gift of Jeanne to Foucault, although Koopstra does not make the link between the document and the painting.

Identity of the sitter(s): Jeanne de Boubais and unidentified persons

Provenance: Benedictine abbey of Clairvaux (?)

Number of portrait(s): 8

Type of person(s): mixed (group: unidentified)

Attitude of the sitter(s): hands clasped, holding a book, hands crossed over the chest

Representation of the sitter(s): full-length

Gaze of the sitter(s): towards the scene, reading a book

Object(s): yes (book)

Coat(s) of arms: yes

Environment: landscape with sacred connotation

Structuring of the pictorial space: continuous space

Patron saint(s): Bernard, Malachy

Gesture of the patron saint(s): introducing

Type of religious scene: hieratic 
Religious scene(s) depicted: the Virgin and Child, the Family of St. Bernard, the Lactation of St. Bernard

Cat. 230-Type 6A

BELLEGAMBE, Jean

One Wing. Charles Coguin in Prayer (c. 1509-1513) $67.9 \times 28.9 \mathrm{~cm}$

New York, MET, inv. no. 32.100.125

BIB L.: FRIEDLÄNDER XII, no. 137; AINSWORTH and CHRISTIANSEN 1998, 184 (with bibl.); KOOPSTRA 2016, 68-69.

HISTORICAL INFORMATION: This wing depicts Charles Coguin, abbot of the Benedictine abbey of Anchin. This portrait seems to be a replica of his effigy in the Polyptych of Anchin (cat. 231). The wing can be related to another wing panel, executed by Bellegambe and depicting St. Barbara in semigrisaille (Douai, Musée de la Chartreuse, inv. no. 2011.1.1). The two wings measure approximately the same size and have the same provenance in the early twentieth century.

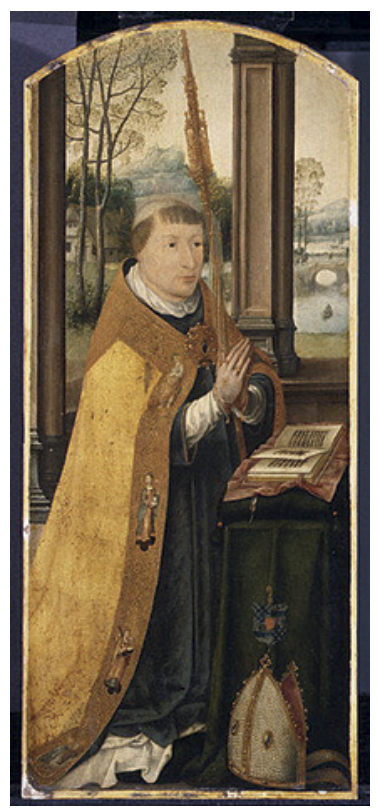

Identity of the sitter(s): Charles Coguin

Provenance: Benedictine abbey of Anchin

Number of portrait(s): 1

Type of person(s): religious (man alone: Benedictine abbot)

Attitude of the sitter(s): hands clasped

Representation of the sitter(s): full-length

Gaze of the sitter(s): indeterminate

Object(s): yes (prie-dieu, book, mitre, crosier)

Coat(s) of arms: no

Environment: architectural space, no sacred connotation (incomplete)

Structuring of the pictorial space: indeterminate

Patron saint(s): none

Gesture of the patron saint(s): not applicable

Type of religious scene: indeterminate

Religious scene(s) depicted: none 
Cat. 231-Type $1 B$

BELLEGAMBE, Jean

Polyptych of Anchin (c.1511-1520)

$177.5 \times 90 \mathrm{~cm}$ (centre panel), 177 $\times 136.2 \mathrm{~cm}$ (inner wings) and 162 $\times 78 \mathrm{~cm}$ (outer wings)

Douai, Musée de la Chartreuse, inv. no. 2175

BIBL.: FRIEDLÄNDER XII, no.
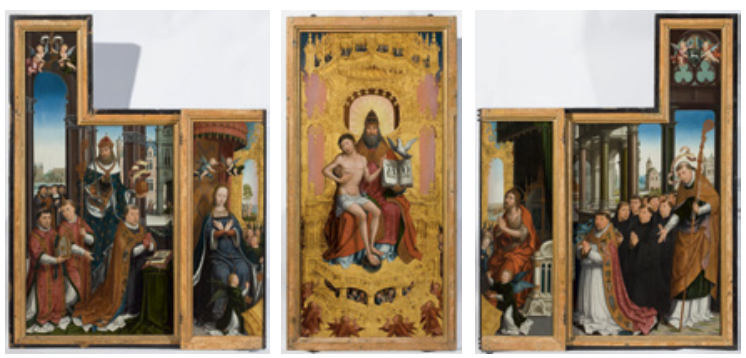

114; Repertory Nord-Pas-de-Calais I, no. 3 (with bibl.). HISTORICAL INFORMATION: The polyptych was destined for the high altar of the abbey church of Anchin. Originally, a thirteenth-century reliquary was placed at its centre. The altarpiece was commissioned by Charles Coguin, abbot of Anchin from 1511 to 1546, the year of his death. His coat of arms and his motto are painted above his portrait. Coguin also commissioned to Bellegambe a Triptych of the Mystic Bath (Lille, Palais des Beaux-Arts) and appears in cat. 230 as well. Furthermore, his motto (Favente deo) appears in four manuscripts commissioned for the library of the abbey of Anchin (Douai, Bibliothèque municipale, mss 91, 101, 102 and 124).

Identity of the sitter(s): Charles Coguin and monks of Anchin

Provenance: Benedictine abbey of Anchin, high altar of the church

Number of portrait(s): 2 (at least)

Type of person(s): religious (group: Cistercian abbot and monks)

Attitude of the sitter(s): hands clasped, particular gesture

Representation of the sitter(s): full-length

Gaze of the sitter(s): towards the scene

Object(s): yes (prie-dieu, book, mitre, crosier)

Coat(s) of arms: yes

Environment: architectural space with sacred connotation

Structuring of the pictorial space: distinct spaces

Patron saint(s): Charlemagne, Benedict

Gesture of the patron saint(s): holding his/her attribute, introducing

Type of religious scene: hieratic

Religious scene(s) depicted: the Holy Trinity with the Virgin and St. John the Baptist, St. Peter, St. Paul, St. Andrew, St. Stephen, St. Catherine, St. Barbara, Christ and the Virgin interceding 
Cat. 232-Type $3^{A}$

BELLEGAMBE, Jean

Triptych of the Annunciation with Guillaume of Brussels in Prayer (c. 1516-1517) $109 \times 80 \mathrm{~cm}$ (centre panel) and $103 \times 33 \mathrm{~cm}$ (wings) Saint Petersburg, Hermitage Museum, inv. nos.

5575-5025-5227

вIBL.: GENAILLE 1976, no.

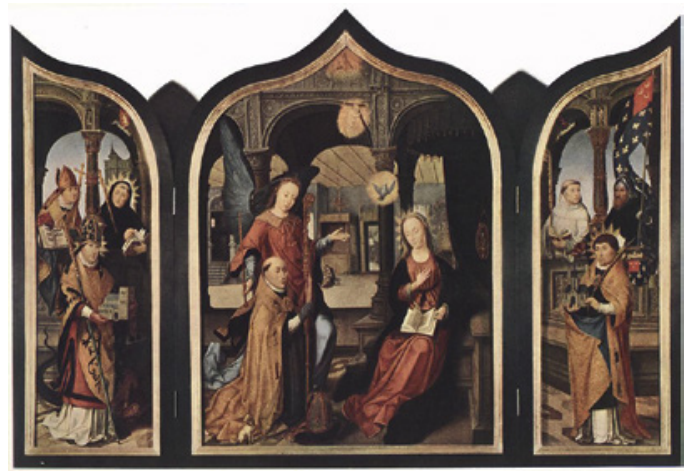

17; NICOULINE 1987, no.

81-89 (with bibl.); KOOPSTRA 2016, 160-86.

HISTORICAL INFORMATION: The man portrayed on the centre panel is usually identified as Guillaume (Bollart) of Brussels, although the resemblance of the monk's face to Guillaume's attested effigy, in a painting executed by Pieter Coecke van Aelst (cat. 294), is not that obvious. The identity of the saints and scenes depicted in the triptych nonetheless plead in favour of this identification. Born in the city of Brabant around 1470, Guillaume Bollart of Brussels made a successful ecclesiastic and diplomatic career. He first worked in the 1490 s for Hendrik van Bergen, who was Bishop of Cambrai between 1480 and 1502. This appointment led Bollart to join his patron in diplomatic missions abroad and to visit Erasmus, who was secretary to the bishop from 1493 onwards. Their relationship is attested by three letters written in 1517-1518. Following the death of Van Bergen in 1502, Guillaume entered the Cistercian Order in Clairvaux, before becoming father confessor of the female convent of Flines, where he established a much-needed monastic reform. In 1513, he left the Cistercian Order and became abbot of the Benedictine abbey of Saint-Amand, before being appointed abbot of Sint-Truiden on 17 September 1516. At Sint-Truiden, Guillaume of Brussels continued the reform initiated by Nicholas of Cusa and the reconstruction of the abbey. He also commissioned several precious artworks for the monastery (see HERMAND 2002) and other institutions. He notably commissioned stainedglass windows with his own portrait and the Annunciation, for the charterhouse of Scheut and the Augustinian priory of Sint-Maartensdal, near Leuven. During his abbacy at Sint-Truiden, Guillaume experienced some health issues that forced him to reside for much of the time in Leuven, where he had the opportunity to gravitate in university and humanistic circles. He also acted for some time as counsellor of Maximilian of Austria, as several archival documents attest. Guillaume died in Leuven on 14 November 1532. His heart and entrails were buried in the Carthusian monastery of Scheut, while the rest of his body was buried 
in a funerary chapel at Sint-Truiden. Both funerary monuments are unfortunately lost, but we know that his epitaph was composed by the Benedictine Pascal de Bierset (Berselius). Little is known about this Triptych of the Annunciation, its function or location. Taking into account the size of the work and the absence of a coat of arms, it is generally assumed that the painting was meant for personal devotion. The presence of saints related to the Cistercian (Bernard) and Benedictine (Benedict) orders, as well as to the two patron saints of the monastery, where Guillaume acted as abbot (Trudo and Amand), suggests that the painting was commissioned after 1516 . Koopstra dates the triptych to around 1525. Guillaume of Brussels also appears in cat. 232 and cat. 294.

Identity of the sitter(s): Guillaume (Bollart) of Brussels

Provenance: unknown

Number of portrait(s): 1

Type of person(s): religious (man alone: Cistercian abbot)

Attitude of the sitter(s): hands clasped

Representation of the sitter(s): full-length

Gaze of the sitter(s): into space

Object(s): yes (crosier, mitre, dog)

Coat(s) of arms: no

Environment: historical setting (domestic setting)

Structuring of the pictorial space: not applicable

Patron saint(s): none

Gesture of the patron saint(s): not applicable

Type of religious scene: narrative

Religious scene(s) depicted: the Annunciation, St. Amand, St. Trudo

\section{Cat. 233-Type 5}

BELLEGAMBE, Jean

Triptych of the Lamentation

(c. 1495-1500)

$130 \times 80 \mathrm{~cm}$ (centre panel) and

$130 \times 40 \mathrm{~cm}$ (wings)

Warsaw, Muzeum Norodowe, inv. no. M.Ob.15

BIBL.: FRIEDLÄNDER XII, no. 118; GENAILLE 1963;

GENAILLE 1976, no. 1.

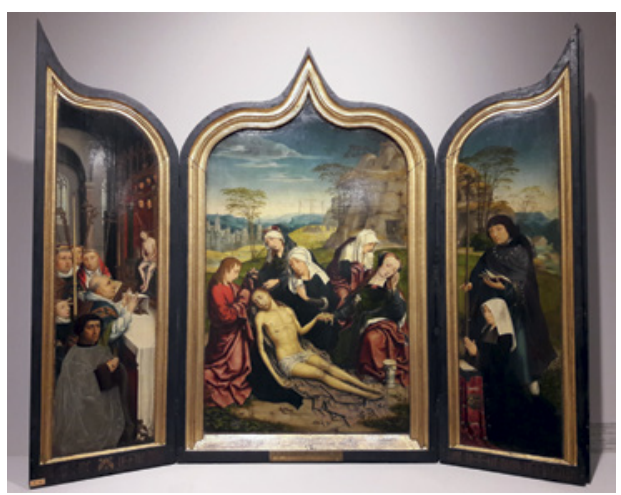

HISTORICAL INFORMATION: The coats of arms on the wings seem to be those of the Mouscron family, but their state of preservation is not very good, 
thereby preventing any further identification. The iconography of these panels led Genaille to claim that the portrayed persons were called Grégoire and Jossine. In the early sixteenth century, the Mouscron family was constituted of two branches, one from Bruges and the other from Hainaut. The first one is well-documented, the latter a little less so, but we know that its members had relations with the abbey of Marchiennes, for which Jean Bellegambe produced several paintings.

REMARK: A peculiarity of this triptych lies in the fact that the woman portrayed on the left wing is introduced by her patron saint and is directing her prayers towards the scene of the centre panel, while the man is depicted alone before the Mass of St. Gregory on the right wing. See a similar case in cat. 229.

Identity of the sitter(s): members of the Mouscron family

Provenance: unknown

Number of portrait(s): 2

Type of person(s): mixed (group)

Attitude of the sitter(s): hands clasped

Representation of the sitter(s): full-length

Gaze of the sitter(s): into space

Object(s): yes (prie-dieu, book)

Coat(s) of arms: yes

Environment: historical setting

Structuring of the pictorial space: particular case (see the 'Remark' section)

Patron saint(s): Josse

Gesture of the patron saint(s): holding his/her attribute

Type of religious scene: narrative

Religious scene(s) depicted: the Lamentation, the Mass of St. Gregory

Cat. 234-Type 2B

BELLEGAMBE, Jean

Triptych of the Trinity of

Marchiennes (c. 1520)

$105 \times 69 \mathrm{~cm}$ (centre panel) and

$108 \times 30 \mathrm{~cm}$ (wings)

Lille, Palais des Beaux-Arts,

inv. no. P833

BIBL.: FRIEDLÄNDER XII, no. 120;

Repertory Nord-Pas-de-Calais I,

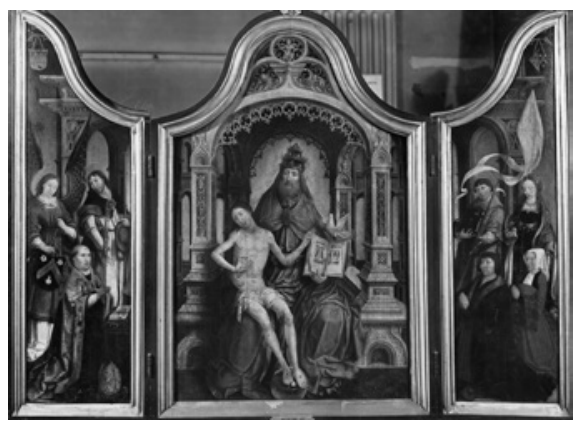

no. 4 (with bibl.). 
HISTORICAL INFORMATION: The abbot portrayed on the left wing is Jacques Coëne. Born in 1468 or 1469, he was abbot of the Benedictine abbey of Marchiennes from 1501 until his death in 1542. Jacques Coëne is well-known for his patronage of several Netherlandish painters, including Anthonis Mor, Bernard van Orley and Jan van Scorel. His portrait can also be found in several paintings executed by Van Orley and Van Scorel (cat. 720, cat. 721, cat. 741). The identity of the couple depicted on the right wing cannot be established with certainty. The coat of arms indicates that the man is a member of the Ocoche de Manchicourt family. Several members of this noble family were monks at Marchiennes. The woman could be Catherine Coëne, the niece or sister of Jacques, and the man Léonard Ocoche de Manchicourt.

REMAR K: The triptych is closely related to the Anchin Polyptych, for the centre panel echoes the Anchin composition.

Identity of the sitter(s): Jacques Coëne, Catherine Coëne (?) and a member of the Ocoche de Manchicourt family

Provenance: Benedictine abbey of Marchiennes (?)

Number of portrait(s): 3

Type of person(s): mixed (family)

Attitude of the sitter(s): hands clasped

Representation of the sitter(s): full-length

Gaze of the sitter(s): into space

Object(s): yes (prie-dieu, book, mitre, crosier, rosary)

Coat(s) of arms: yes

Environment: architectural space with sacred connotation

Structuring of the pictorial space: continuous space

Patron saint(s): an angel, James, Catherine, an unidentified saint

Gesture of the patron saint(s): holding his/her attribute, indicating

Type of religious scene: hieratic

Religious scene(s) depicted: the Holy Trinity, the Annunciation

\section{Cat. 235-Type 2D}

BELLEGAMBE, Jean

Triptych of the Virgin and Child ('Triptych of the Abbot of Anchin') (c. 1500-1505) $42 \times 30 \mathrm{~cm}$ (centre panel) and $22 \times 13 \mathrm{~cm}$ (wings)

Angers, Musée des Beaux-Arts, inv. no. MA III R 389 BIBL.: GENAILLE 1976, no. 3; SCHADE 2001, 198-99 (with bibl.). HISTORICAL INFORMATION: According to Genaille, the abbot portrayed on the right wing is an abbot of Anchin. The buildings in the background would 
therefore be those of the abbey. This identification cannot be confirmed with certainty.

Identity of the sitter(s): an abbot of Anchin (?)

Provenance: unknown

Number of portrait(s): 1

Type of person(s): religious (man alone: Cistercian abbot)

Attitude of the sitter(s): hands clasped

Representation of the sitter(s): half-length

Gaze of the sitter(s): towards the scene

Object(s): yes (crosier)

Coat(s) of arms: yes

Environment: landscape, no sacred connotation

Structuring of the pictorial space: distinct spaces

Patron saint(s): none

Gesture of the patron saint(s): not applicable

Type of religious scene: hieratic

Religious scene(s) depicted: the Virgin and Child, St. William of Maleval

\section{Cat. 236-Type 6A}

[RKD work no. 32510]

BELLEGAMBE, Jean

Two Wings. A Family in Prayer with Patron Saints (c. 1500-1520)

$102 \times 33 \mathrm{~cm}$ (each wing)

Chaalis, Musée Jacquemart-André

BIB L.: FRIEDLÄNDER XII, no. 125; GENAILLE 1961; GENAILLE 1976, no. 5 . REMARK: Genaille suggested that these wings formed initially a triptych with the Virgin of the Litanies of the Musée de la Chartreuse de Douai (inv. no. 2313), which is nowadays considered as a painting executed after an original of Bellegambe. Although the sizes of the different panels are quite similar, they nonetheless do not have the same format and thus probably come from two distinct triptychs.

Identity of the sitter(s): unknown

Provenance: unknown

Number of portrait(s): 9

Type of person(s): mixed (family)

Attitude of the sitter(s): hands clasped

Representation of the sitter(s): full-length, child in small scale

Gaze of the sitter(s): indeterminate

Object(s): yes (book) 
Coat(s) of arms: no

Environment: landscape, no sacred connotation (incomplete)

Structuring of the pictorial space: indeterminate

Patron saint(s): William of Maleval, Francis

Gesture of the patron saint(s): introducing

Type of religious scene: indeterminate

Religious scene(s) depicted: none

Cat. 237-Type 6A

BELLEGAMBE, Jean

Two Wings. The Pottier Family in

Prayer (c. 1522-1526)

$224 \times 93 \mathrm{~cm}$ (each wing)

Douai, Musée de la Chartreuse,

inv. no. 23

BIBL.: FRIEDLÄNDER XII, no. 124;

Repertory Nord-Pas-de-Calais I,

no. 5 (with bibl.); KOOPSTRA 2016,

207-35.

HISTORICAL INFORMATION: The his-

tory of the triptych from which these

wings come is well-documented.
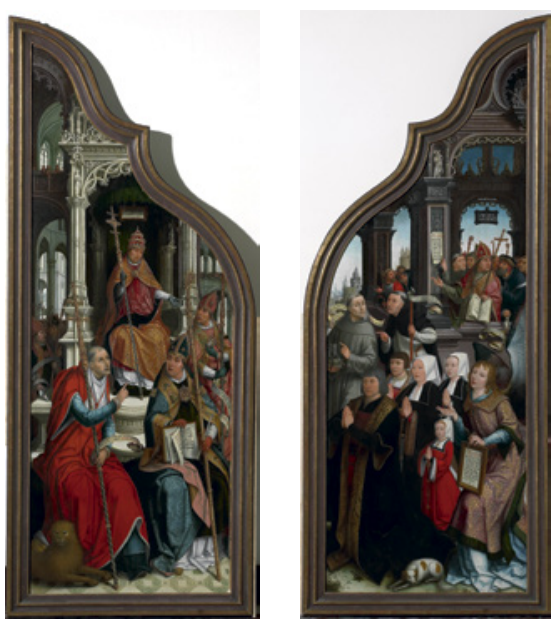

According to a now lost inscription

on the work, the painting was commissioned by Jean Pottier and Marguerite Muret in 1521. In commissioning this work, they were following the last wishes of their daughter, Marguerite, who would pass away that year. Marguerite wanted the triptych to serve as the altarpiece for the chapel of the Immaculate Conception in the Franciscan church of Douai, where she would be buried. The triptych was finished in 1526 . On the right wing, Jean Pottier is accompanied by his wife and his three children, Jean, Marguerite and Catherine, while the left wing depicts an assembly of ecclesiastics and theologians. Jean Pottier and Marguerite Muret married in 1495. The Pottier family held a prominent position in Douai in the early sixteenth century. Several men of the family were aldermen of the city. Jean notably occupied several important roles in the city magistrate in the 1510 and 1520 . In her dissertation, Koopstra has undertaken archival research on the family and discovered the marriage agreement made between the couple's daughter Marguerite and Anthoine Le Moisne, three months before her death. It reveals that she was Jean Pottier's natural daughter. Marguerite Muret was thus not her actual mother. 
Identity of the sitter(s): Jean Pottier, Marguerite Muret and their family Provenance: Douai, convent of the Wallonese Recollects

Number of portrait(s): 5

Type of person(s): lay (family)

Attitude of the sitter(s): hands clasped

Representation of the sitter(s): full-length

Gaze of the sitter(s): indeterminate

Object(s): yes (dog, rosary)

Coat(s) of arms: no

Environment: architectural space with sacred connotation (incomplete)

Structuring of the pictorial space: indeterminate

Patron saint(s): none

Gesture of the patron saint(s): not applicable

Type of religious scene: indeterminate

Religious scene(s) depicted: Assembly of theologians defending the doctrine of the Immaculate conception, episodes of the Life of St. Anne

\section{Cat. 238-Type ${ }_{3} \mathrm{C}$}

BELLEGAMBE, Martin (?)

The Meeting of St. Peter and Christ Carrying his Cross with a Nun in Prayer (dated 1539 on the frame)

$47 \times 33 \mathrm{~cm}$

Douai, Musée de la Chartreuse, inv. no. 421 BIB L.: Repertory Nord-Pas-de-Calais I, no. 10 (with bibl.).

HISTORICAL INFORMATION: An inscription on the frame identifies the nun as Jacqueline de Lalaing, who was the abbess of the convent of Flines from 1533 up to 1561: Ce tabelet fust donné à madame humble et / abesse de Flines Dame Jacqueline /

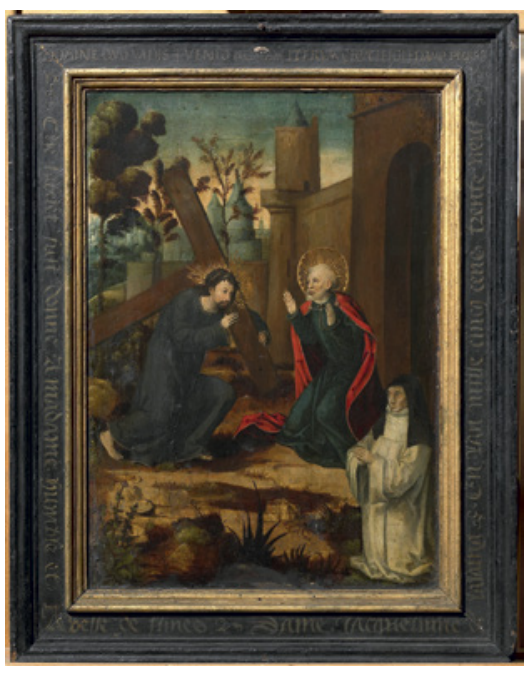
de Lalaing en l'an mille cinq cent trente neuf.

Identity of the sitter(s): Jacqueline de Lalaing

Provenance: unknown

Number of portrait(s): 1

Type of person(s): religious (woman alone: Cistercian abbess)

Attitude of the sitter(s): hands clasped

Representation of the sitter(s): full-length 
Gaze of the sitter(s): towards the scene

Object(s): no

Coat(s) of arms: no

Environment: historical setting

Structuring of the pictorial space: not applicable

Patron saint(s): none

Gesture of the patron saint(s): not applicable

Type of religious scene: narrative

Religious scene(s) depicted: The Meeting of St. Peter and Christ carrying his cross

\section{Cat. 239-Type 6A}

BENSON, Ambrosius

Five Panels. Scenes of the Life of Christ and St. Anne (c. 1540)

$115 \times 60 \mathrm{~cm}$ (the three first panels), $124 \times 60 \mathrm{~cm}$ (fourth panel), $125 \times 90 \mathrm{~cm}$ (fifth panel) and $104 \times$ $57 \mathrm{~cm}$ (sixth and seventh panels)

Madrid, Museo Nacional del Prado, inv. nos. 2197-2198-2199-2200-2200a-2201a-2201b BIBL.: FRIEDLÄNDER XI, no. 239; MARLIER 1957, no. 1; MARTENS D. 2010, 149-54 (with bibl.).

Identity of the sitter(s): unknown

Provenance: Segovia, Dominican convent of Santa Cruz

Number of portrait(s): 1

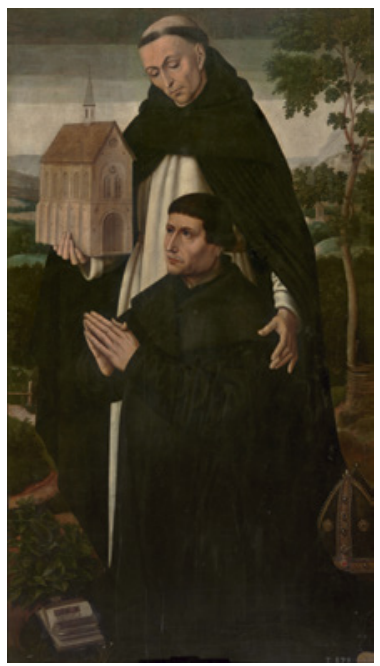

Type of person(s): lay (man alone)

Attitude of the sitter(s): hands clasped

Representation of the sitter(s): full-length

Gaze of the sitter(s): indeterminate

Object(s): yes (book)

Coat(s) of arms: no

Environment: landscape, no sacred connotation (incomplete)

Structuring of the pictorial space: indeterminate

Patron saint(s): Thomas

Gesture of the patron saint(s): protecting

Type of religious scene: indeterminate

Religious scene(s) depicted: the Meeting of Anne and Joachim at the Golden gate, the Birth of the Virgin, the Lamentation, the Entombment, the Virgin and Child with St. Anne, St. Dominic 
Cat. 240-Type 6A

[RKD work no. 207017]

BENSON, Ambrosius

One Wing. Four Women in Prayer with St. Peter (c. 1500-1550)

$76.4 \times 28.3 \mathrm{~cm}$

Amsterdam, sale Christie's (10 November 2008), lot no. 24

Identity of the sitter(s): unknown

Provenance: unknown

Number of portrait(s): 4

Type of person(s): lay (family with children)

Attitude of the sitter(s): hands clasped

Representation of the sitter(s): full-length, child in small scale

Gaze of the sitter(s): indeterminate

Object(s): yes (rosary, small cross)

Coat(s) of arms: no

Environment: landscape with sacred connotation (incomplete)

Structuring of the pictorial space: indeterminate

Patron saint(s): Peter

Gesture of the patron saint(s): holding his/her attribute

Type of religious scene: indeterminate

Religious scene(s) depicted: none

Cat. 241-Type 6A

[RKD work no. 64439]

BENSON, Ambrosius

One Wing. Portrait of a Man in Prayer (c. 1500-1550)

Size unknown

Whereabouts unknown

Identity of the sitter(s): unknown

Provenance: unknown

Number of portrait(s): 1

Type of person(s): lay (man alone)

Attitude of the sitter(s): hands clasped

Representation of the sitter(s): half-length

Gaze of the sitter(s): indeterminate

Object(s): no

Coat(s) of arms: no

Environment: landscape, no sacred connotation (incomplete)

Structuring of the pictorial space: indeterminate

Patron saint(s): none 
Gesture of the patron saint(s): not applicable

Type of religious scene: indeterminate

Religious scene(s) depicted: none

Cat. 242-Type 6B

BENSON, Ambrosius

Portrait of a Man in Prayer (c. 1520-1525)

$35.5 \times 26 \mathrm{~cm}$

Madrid, Fundacion Coleccion Thyssen-

Bornemisza, inv. no. 1934.3

BIBL.: FRIEDLÄNDER XI, no. 289;

MARLIER 1957, no. 126; EISLER 1989, no. 34;

Exh. cat. Bruges 1998 (vol. 2), no. 54 (with bibl.).

Identity of the sitter(s): unknown

Provenance: unknown

Number of portrait(s): 1

Type of person(s): lay (man alone)

Attitude of the sitter(s): hands clasped

Representation of the sitter(s): half-length

Gaze of the sitter(s): indeterminate

Object(s): no

Coat(s) of arms: no

Environment: landscape, no sacred connotation (incomplete)

Structuring of the pictorial space: indeterminate

Patron saint(s): none

Gesture of the patron saint(s): not applicable

Type of religious scene: indeterminate

Religious scene(s) depicted: none

Cat. 243-Type 6B

[RKD work no. 64182]

BENSON, Ambrosius

Portrait of a Man in Prayer (c. 1520-1525)

$36 \times 24 \mathrm{~cm}$

New York, sale Sotheby's Parke Bernet (22 January 1976), lot no. 32

BIBL.: FRIEDLÄNDER XI, no. 287; MARLIER 1957, no. 125.

Identity of the sitter(s): unknown 
Provenance: unknown

Number of portrait(s): 1

Type of person(s): lay (man alone)

Attitude of the sitter(s): hands clasped

Representation of the sitter(s): half-length

Gaze of the sitter(s): indeterminate

Object(s): no

Coat(s) of arms: no

Environment: landscape, no sacred connotation (incomplete)

Structuring of the pictorial space: indeterminate

Patron saint(s): none

Gesture of the patron saint(s): not applicable

Type of religious scene: indeterminate

Religious scene(s) depicted: none

Cat. 244-Type 6B

[RKD work no. 64842]

BENSON, Ambrosius

Portrait of a Woman in Prayer (c. 1500-1550)

$40 \times 27 \mathrm{~cm}$

Toledo (Ohio), Toledo Museum of Art, inv. no. 50.239

BIBL.: FRIEDLÄNDER XI, no. 293; MARLIER 1957, no. 128; Mus. cat. Toledo 1976, 21-22.

Identity of the sitter(s): unknown

Provenance: unknown

Number of portrait(s): 1

Type of person(s): lay (woman alone)

Attitude of the sitter(s): hands clasped

Representation of the sitter(s): half-length

Gaze of the sitter(s): indeterminate

Object(s): no

Coat(s) of arms: no

Environment: landscape, no sacred connotation (incomplete)

Structuring of the pictorial space: indeterminate

Patron saint(s): none

Gesture of the patron saint(s): not applicable

Type of religious scene: indeterminate

Religious scene(s) depicted: none 
Cat. 245-Type 2A

[Link to the Friedländer 3.o Database]

BENSON, Ambrosius

Triptych of the Assumption of the Virgin with two Men in Prayer and Patron Saints (c. 1500-1550)

$182 \times 109 \mathrm{~cm}$ (centre panel) and $193 \times 5^{2} \mathrm{~cm}($ wings $)$

Navarrete, church of Our Lady

BIB L.: FRIEDLÄNDER XI, no. 233; Exh. cat. Brussels 1985 (vol. 2), 474; Exh. cat.

Leon and Palencia 1999, no. 40.

Identity of the sitter(s): unknown

Provenance: unknown

Number of portrait(s): 2

Type of person(s): lay (group)

Attitude of the sitter(s): hands clasped

Representation of the sitter(s): full-length

Gaze of the sitter(s): towards the scene

Object(s): no

Coat(s) of arms: yes

Environment: architectural space, no sacred connotation

Structuring of the pictorial space: distinct spaces

Patron saint(s): Peter, John the Evangelist

Gesture of the patron saint(s): introducing, holding his/her attribute

Type of religious scene: narrative

Religious scene(s) depicted: the Assumption of the Virgin

Cat. 246-Type $2 \mathrm{C}$

BENSON, Ambrosius

Triptych of the Lamentation with a Couple in Prayer (dated 1538)

$48.2 \times 31.6 \mathrm{~cm}$ (centre panel) and 61 $\times 89 \mathrm{~cm}$ (wings)

Private collection

BIB L.: FRIEDLÄNDER XI, no. 297.

REMARK: According to the RDK (work no. 626o8), the triptych has been dismembered c. 1930.

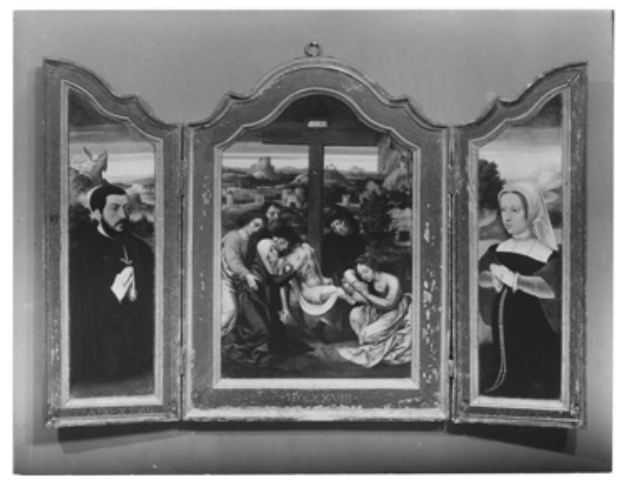

Identity of the sitter(s): unknown

Provenance: unknown 
Number of portrait(s): 2

Type of person(s): lay (couple)

Attitude of the sitter(s): hands clasped

Representation of the sitter(s): half-length

Gaze of the sitter(s): towards the scene

Object(s): yes (rosary)

Coat(s) of arms: no

Environment: historical setting

Structuring of the pictorial space: distinct spaces

Patron saint(s): none

Gesture of the patron saint(s): not applicable

Type of religious scene: narrative

Religious scene(s) depicted: the Lamentation

Cat. 247-Type 2A

BENSON, Ambrosius

Triptych of the Lamentation with a Couple in Prayer and Patron Saints (c. 1535)

$146 \times 107 \mathrm{~cm}$ (centre panel) and $146 \times 47 \mathrm{~cm}$ (wings)

London, sale Sotheby's (9 July 2008), lot no. 9 BIB L.: FRIEDLÄNDER XI, no. 235; MARLIER 1957, no. 6; Sale cat. Sotheby's (London, 9 July

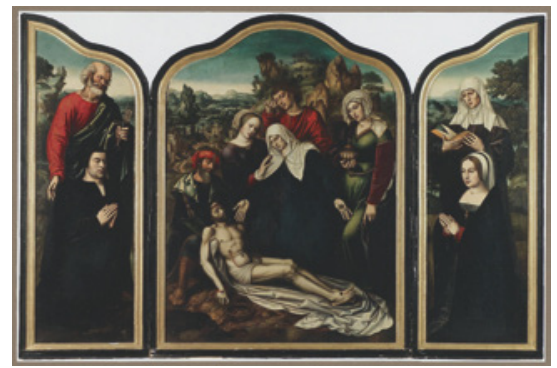
2008), no. 9 (with bibl.).

Identity of the sitter(s): unknown

Provenance: unknown

Number of portrait(s): 2

Type of person(s): lay (couple)

Attitude of the sitter(s): hands clasped

Representation of the sitter(s): full-length

Gaze of the sitter(s): towards the scene

Object(s): no

Coat(s) of arms: no

Environment: historical setting

Structuring of the pictorial space: unified space with discontinuities

Patron saint(s): Peter, Anne

Gesture of the patron saint(s): introducing, holding his/her attribute

Type of religious scene: narrative

Religious scene(s) depicted: the Lamentation, Adam and Eve 
Cat. 248-Type 6A

[RKD work no. 132711]

BENSON, Ambrosius

Two Wings. A Couple in Prayer (c. 1525-1550)

$50 \times 16.5 \mathrm{~cm}$ (each wing)

Paris, art dealer Jean Max Tassel

Identity of the sitter(s): unknown

Provenance: unknown

Number of portrait(s): 2

Type of person(s): lay (couple)

Attitude of the sitter(s): hands clasped

Representation of the sitter(s): full-length

Gaze of the sitter(s): indeterminate

Object(s): no

Coat(s) of arms: no

Environment: landscape, no sacred connotation (incomplete)

Structuring of the pictorial space: indeterminate

Patron saint(s): none

Gesture of the patron saint(s): not applicable

Type of religious scene: indeterminate

Religious scene(s) depicted: none

Cat. 249-Type 6A

[R KD work no. 64434]

BENSON, Ambrosius

Two Wings. A Man in Prayer with St. John the Baptist (c. 1500-1550)

$46.5 \times 26.5 \mathrm{~cm}$ (each wing)

Brussels, MRBAB, inv. no. 4026

BIBL.: FRIEDLÄNDER XI, no. 241; MARLIER 1957, no. $10 B$.

Identity of the sitter(s): unknown

Provenance: unknown

Number of portrait(s): 1

Type of person(s): lay (man alone)

Attitude of the sitter(s): hands clasped

Representation of the sitter(s): half-length

Gaze of the sitter(s): indeterminate

Object(s): no 
Coat(s) of arms: no

Environment: landscape, no sacred connotation (incomplete)

Structuring of the pictorial space: indeterminate

Patron saint(s): none

Gesture of the patron saint(s): not applicable

Type of religious scene: indeterminate

Religious scene(s) depicted: St. John the Baptist

\section{Cat. 250-Type $2 \mathrm{C}$}

BENSON, Ambrosius (attributed to)

Triptych of St. Jerome in the

Wilderness with a Man in Prayer

(c. 1525)

$43.7 \times 36.5 \mathrm{~cm}$ (centre panel),

$46.3 \times 18.4 \mathrm{~cm}$ (left wing) and

$46.3 \times 18.1 \mathrm{~cm}$ (right wing)

Philadelphia, Philadelphia Museum

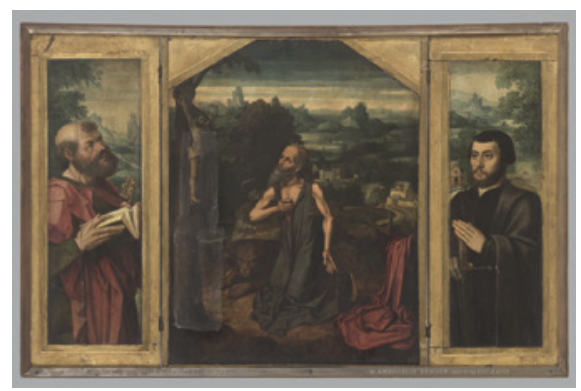

of Art, inv. no. 359

BIBL.: FRIEDLÄNDER XI, no. 238; MARLIER 1957, no. 12; Mus. cat. Philadelphia 1994, 33 .

Identity of the sitter(s): unknown

Provenance: unknown

Number of portrait(s): 1

Type of person(s): lay (man alone)

Attitude of the sitter(s): particular gesture

Representation of the sitter(s): half-length

Gaze of the sitter(s): into space

Object(s): yes (sword)

Coat(s) of arms: no

Environment: historical setting

Structuring of the pictorial space: unified space with discontinuities

Patron saint(s): none

Gesture of the patron saint(s): not applicable

Type of religious scene: narrative

Religious scene(s) depicted: St. Jerome in the wilderness, St. Peter 
Cat. 251-Type 2A

BENSON, Ambrosius (centre panel) and VAN UTRECHT, Jacob (wings) Triptych of the Crucifixion with a Couple in Prayer and Patron Saints (c. 1500-1550)

Size unknown

Copenhagen, church of Noddebo BIB L.: FRIEDLÄNDER XI, no. 249.

Identity of the sitter(s): unknown

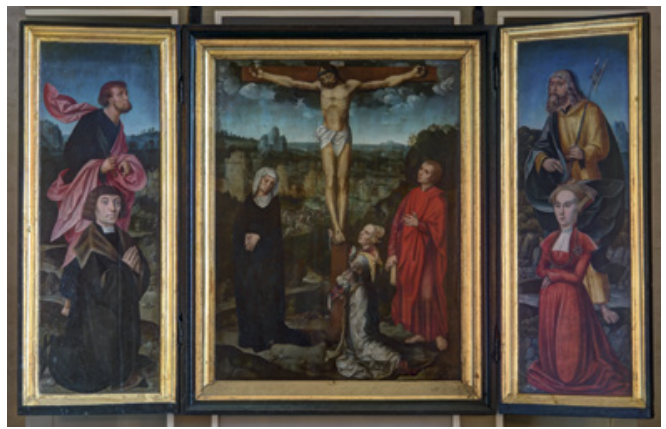

Provenance: unknown

Number of portrait(s): 2

Type of person(s): lay (couple)

Attitude of the sitter(s): hands clasped

Representation of the sitter(s): full-length

Gaze of the sitter(s): into space

Object(s): no

Coat(s) of arms: no

Environment: historical setting

Structuring of the pictorial space: continuous space

Patron saint(s): Peter, Paul

Gesture of the patron saint(s): holding his/her attribute

Type of religious scene: narrative

Religious scene(s) depicted: the Crucifixion

Cat. 252-Type $3^{\mathrm{D}}$

BENSON, Ambrosius (circle of)

A Man in Prayer before St. Peter (c. 1500-1550)

$44 \times 28 \mathrm{~cm}$

Whereabouts unknown

Identity of the sitter(s): unknown

Provenance: unknown

Number of portrait(s): 1

Type of person(s): lay (man alone)

Attitude of the sitter(s): hands clasped

Representation of the sitter(s): full-length

Gaze of the sitter(s): into space

Object(s): no

Coat(s) of arms: no

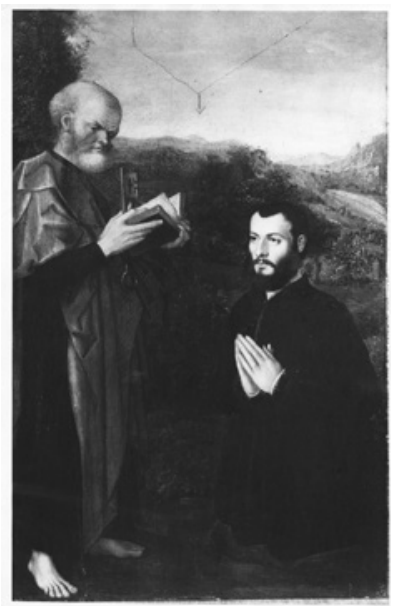


Environment: landscape, no sacred connotation

Structuring of the pictorial space: not applicable

Patron saint(s): none

Gesture of the patron saint(s): not applicable

Type of religious scene: hieratic

Religious scene(s) depicted: St. Peter

\section{Cat. 253-Type 6B}

[Link to the Friedländer 3.o Database]

BENSON, Ambrosius (circle of)

Portrait of a Man in Prayer with St. Michael (c. 1500-1550)

$38 \times 30 \mathrm{~cm}$

Whereabouts unknown

BIBL.: FRIEDLÄNDER XI, no. 276; MARLIER 1957, no. 169.

Identity of the sitter(s): unknown

Provenance: unknown

Number of portrait(s): 1

Type of person(s): lay (man alone)

Attitude of the sitter(s): hands clasped

Representation of the sitter(s): half-length

Gaze of the sitter(s): indeterminate

Object(s): no

Coat(s) of arms: no

Environment: neutral space (incomplete)

Structuring of the pictorial space: indeterminate

Patron saint(s): Michael

Gesture of the patron saint(s): protecting

Type of religious scene: indeterminate

Religious scene(s) depicted: none

\section{Cat. 254-Type 2A}

BENSON, Ambrosius (circle of)

Triptych of the Lamentation with a Man in Prayer and Patron Saint (c. 1500-1550) $81 \times 5^{6} \mathrm{~cm}$ (centre panel) and $81 \times 22 \mathrm{~cm}$ (wings)

London, sale Bonhams (3 December

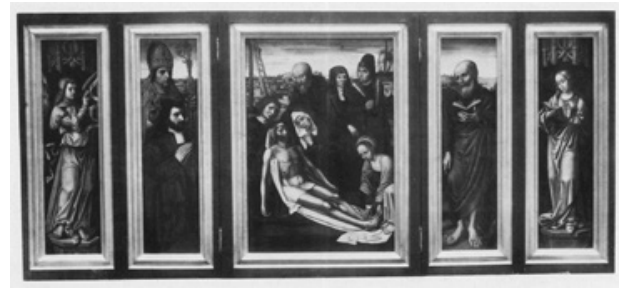
2008), lot no. 16 
BIBL.: FRIEDLÄNDER XI, no. 234; MARLIER 1957, no. 4.

Identity of the sitter(s): unknown

Provenance: unknown

Number of portrait(s): 1

Type of person(s): lay (man alone)

Attitude of the sitter(s): hands clasped

Representation of the sitter(s): full-length

Gaze of the sitter(s): towards the scene

Object(s): no

Coat(s) of arms: no

Environment: historical setting

Structuring of the pictorial space: unified space with discontinuities

Patron saint(s): a saint bishop (Bavo?)

Gesture of the patron saint(s): holding his/her attribute

Type of religious scene: narrative

Religious scene(s) depicted: the Lamentation, the Annunciation

Cat. 255-Type 6A

BENSON, Ambrosius (circle of)

Two wings. A Couple in Prayer (c. 1500-1550)

$23.75 \times 18.75 \mathrm{~cm}$ (left wing) and $25 \times 19 \mathrm{~cm}$ (right wing)

London, sale Sotheby's (5 April 1990), lot no. 3

Identity of the sitter(s): unknown

Provenance: unknown

Number of portrait(s): 2

Type of person(s): lay (couple)

Attitude of the sitter(s): hands clasped

Representation of the sitter(s): half-length

Gaze of the sitter(s): indeterminate

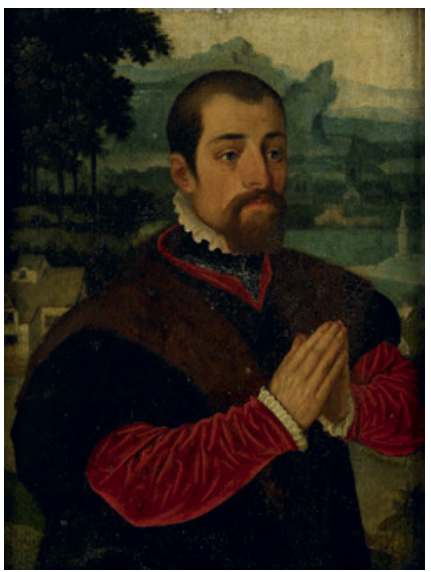

Object(s): no

Coat(s) of arms: no

Environment: landscape, no sacred connotation (incomplete)

Structuring of the pictorial space: indeterminate

Patron saint(s): none

Gesture of the patron saint(s): not applicable 
Type of religious scene: indeterminate

Religious scene(s) depicted: none

Cat. 256-Type $2 \mathrm{~A}$

BENSON, Ambrosius (follower of) Triptych of the Crucifixion with a Family in Prayer (c. 1500-1550)

$69 \times 49 \mathrm{~cm}$ (centre panel) and $72 \times$ $21 \mathrm{~cm}$ (wings)

Bruges, Adornes collection, inv. no. AD 08013 BIBL.: ZDANOV 2015 (with bibl.).

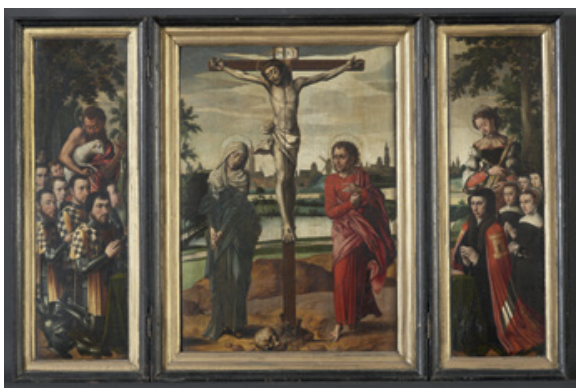
HistoriCAL INFORMATION: The triptych depicts Jean de la Coste Adornes, his wife Catherine de Metteneye and their children (including Marguerite, Catherine, Jeanne, Marie, Jérôme, Gabriel, Josse, Karel, Pieter and Pierkin). Jean was the son of André de la Coste and Agnès Adornes. He was born on 8 October 1494 and died in 1538. Jean and Catherine married in 1520. Catherine died in 1547. The work was obviously destined for the Jeruzalemkerk in Bruges, where it is still preserved today and where the family Adornes is buried. According to several scholars, the painting was commissioned as a memorial work after the death of Catherine in 1547, but this cannot be confirmed. In a recent article, Sacha Zdanov states, without being totally convincing, that the triptych can be dated from $153^{1-1532}$, by analysing the portraits of the sons on the left wing.

Identity of the sitter(s): Jean de la Coste, Catherine de Metteneye and their children

Provenance: Bruges, Jeruzalemkerk

Number of portrait(s): 13

Type of person(s): mixed (family with children)

Attitude of the sitter(s): hands clasped

Representation of the sitter(s): full-length

Gaze of the sitter(s): towards the scene, into space, towards the viewer

Object(s): yes (helmet, book, prie-dieu, gloves)

Coat(s) of arms: yes

Environment: historical setting

Structuring of the pictorial space: continuous space 
Patron saint(s): John the Baptist, Catherine

Gesture of the patron saint(s): holding his/her attribute

Type of religious scene: narrative

Religious scene(s) depicted: the Crucifixion

\section{Cat. 257-Type 6A}

[RKD work no. 219055]

BLONDEEL, Lancelot (circle of)

Marguerite de Metteneye in Prayer with St. Margaret (dated 1523 on the frame) $29.7 \times 25.5 \mathrm{~cm}$

Bruges, Groeningemuseum, inv. no. 94.16.

BIB L.: Exh. cat. Bruges 1998 (vol. 2), no. 92 (with bibl.).

historical information: Marguerite de Metteneye has been identified, on the basis of her coat of arms. She was the fourth child of Claire Losschaert and Louis de Baenst, knight of the Order of Jerusalem and Provoost of the Brotherhood of the Holy Blood. Marguerite married Pierre Metteneye, Lord of Marcke. According to De Vos, the memento mori on the reverse of the panel indicates a funerary context for the work, which would have been commissioned to commemorate Marguerite's late husband.

Identity of the sitter(s): Marguerite de Metteneye and her son

Provenance: unknown

Number of portrait(s): 2

Type of person(s): lay (family with children)

Attitude of the sitter(s): hands clasped

Representation of the sitter(s): full-length

Gaze of the sitter(s): indeterminate

Object(s): yes (prie-dieu, book, small cross)

Coat(s) of arms: yes

Environment: architectural space, no sacred connotation (incomplete)

Structuring of the pictorial space: indeterminate

Patron saint(s): Margaret

Gesture of the patron saint(s): holding his/her attribute

Type of religious scene: indeterminate

Religious scene(s) depicted: memento mori 
Cat. 258-Type $3^{A}$

BOSCH, Hieronymus

The Crucifixion with a Man in Prayer

(c. 1495-1500)

$74.7 \times 61 \mathrm{~cm}$

Brussels, MRBAB, inv. no. 6639

BIBL.: FRIEDLÄNDER V, no. 84; STROO et alii 2001, 70-83; VAN WAMEL 2016, 41619; ILSINK et alii 2016, no. 15 (with bibl.); HOOGSTEDE et alii 2016, no. 15 .

Identity of the sitter(s): unknown

Provenance: unknown

Number of portrait(s): 1

Type of person(s): lay (man alone)

Attitude of the sitter(s): hands clasped

Representation of the sitter(s): full-length

Gaze of the sitter(s): into space

Object(s): yes (sword)

Coat(s) of arms: no

Environment: historical setting

Structuring of the pictorial space: not applicable

Patron saint(s): Peter

Gesture of the patron saint(s): interceding

Type of religious scene: narrative

Religious scene(s) depicted: the Crucifixion

Cat. 259-Type 5

BOSCH, Hieronymus

Triptych of the Adoration of the Magi with a Couple in Prayerand Patron Saints (1492-1498) $138 \times 72 \mathrm{~cm}$ (centre panel) and $138 \times 33 \mathrm{~cm}$ (wings)

Madrid, Museo Nacional del Prado, inv. no. 2048

BIBL.: FRIEDLÄNDER V, no. 68; RENSON 2001; SILVER 2006, 164-68; DUQUENNE 2009; ILSINK et alii 2016 (with bibl.), no. 9 ;

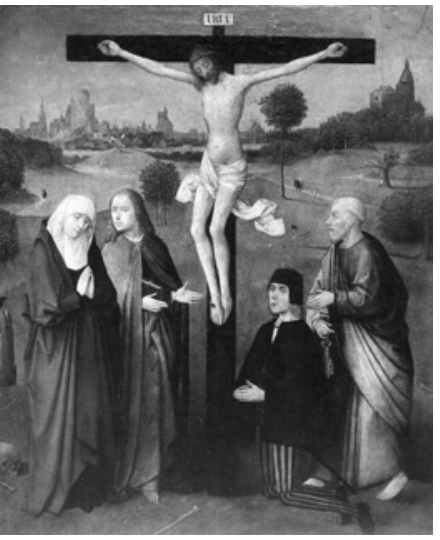

HOOGSTEDE et alii 2016, no. 9 .

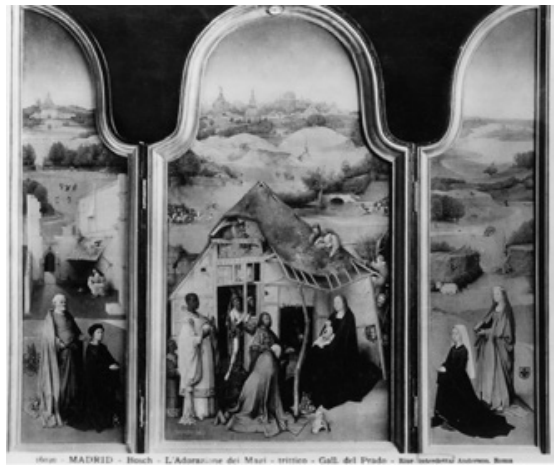


HISTORICAL INFORMATION: Until recently, the triptych was linked to an entry in Jan van Casembroot's inventory, dated to 1567 . This entry describes a triptych of the Adoration of the Magi, executed by Bosch, which includes the coats of arms of the Bronchorst and Bosshuyse families: Ung tableau des trois roix faicts par Jeronimus bossche serrant a deux huys ayans par dehors les armes de bronchorst et bosshuyse. Because of the presence of St. Peter and St. Agnes, the devotees have been identified as Pieter van Bronchorst and Agnes van Boschuysen. Nevertheless, the coats of arms appear on the inner side of the triptych and not on its outer side. Furthermore, they do not match those of the Bronchorst or Bosshuyse families. In 2009, Duquenne identified correctly the coats of arms and recognised the inscription een voer al as the motto of Peter Scheyfve. An Antwerp merchant, Peter married Agnes de Gramme. He appears in archival documents as a draper from 1494 onwards. He also made a political career in Antwerp. From 1495 to 1505 , he is mentioned as a collector and then as burgomaster, in 1505. Peter first married Barbe van Woelputte, with whom he had three daughters and one son. After the death of Barbe in 1492, he married Agnes de Gramme, who died in 1497. The triptych can thus be dated from 1492-1498. Peter passed away in 1506.

REMARK: According to Duquenne, the young boy and the old man depicted on the outer wings are also portraits. They could be Jan, Peter's son from his first marriage, and his tutor, or Peter de Gramme, Agnes' father. According to the technical investigation led in the framework of the Bosch project, they were integral part of the original composition. ILSINK et alii 2016 identifies these two men as Nicolaas and Jan Scheyfve, the father and son of Peter.

Identity of the sitter(s): Peter Scheyfve and Agnes de Gramme, Nicolaas and Jan Scheyfve

Provenance: unknown

Number of portrait(s): 4

Type of person(s): lay (couple)

Attitude of the sitter(s): hands clasped

Representation of the sitter(s): full-length

Gaze of the sitter(s): into space

Object(s): no

Coat(s) of arms: no

Environment: historical setting

Structuring of the pictorial space: continuous space

Patron saint(s): Peter, Agnes

Gesture of the patron saint(s): introducing

Type of religious scene: narrative

Religious scene(s) depicted: the Adoration of the Magi, the Mass of St. Gregory 
Cat. 260-Type 5

BOSCH, Hieronymus (workshop)

Triptych of the Ecce Homo

(c. 1495-1503)

$85.1 \times 71.7 \mathrm{~cm}$ (open)

Boston, Museum of Fine Arts, inv.

no. $5^{2.2027}$

BIBL.: FRIEDLÄNDER V, add. 149;

Corpus New England, no. 66; VAN

DIJCK 1998; ILSINK et alii 2016, no.

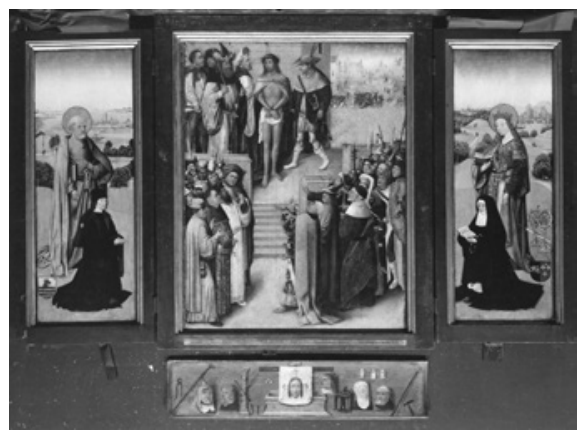

24 (with bibl.); HOOGSTEDE et alii

2016, no. 24.

HISTORICAL INFORMATION: The man portrayed on the inner left wing has been identified by his coat of arms as Pieter van Os Pietersz. $(\dagger 1542)$. He wears a mantle with the insignia of the Brotherhood of Our Lady of s'Hertogenbosch. The Van Os family occupied an important position in this brotherhood and in the city during the sixteenth century. Pieter is mentioned as Zwanebroeder (a title given to the brotherhood masters). Besides his activity in the brotherhood, Pieter was also alderman and gasthuismeester of the Hospital of St. Elizabeth in s'Hertogenbosch, where the brotherhood members carried out charitable activities. Pieter is also the author of a chronicle of the city and of Brabant. He is portrayed in the triptych with his first wife, Henricxken van Langel, who was also a member of the brotherhood. The swaddled baby lying on her robe could be a symbol of her charitable activities at the hospital. It could also be an allusion to their stillborn baby. Henricxken died in 1500 and Pieter married again in 1502 or 1503, this time to Henricxken Jacobs van der Heze, with whom he had five children. The persons portrayed on the outer wings are members of the Van Langel family. The frontman on the left is Franco van Langel († 1497), Henricxken's father and alderman of s'Hertogenbosch. He also wears the insignia of the brotherhood. He is accompanied by his sons, Franco and Jan (firstly monk and then prior of the monastery of Mariënkroon in Heusden). Henricxken's mother, Heylwich Henricx van der Rullen, is kneeling on the right wing with her daughters. One of them, Lysbeth, was a nun at the Bethaniën convent, whose patron saint was Mary Magdalen. The original location of the triptych remains unknown, but it seems to be a memorial work for the Van Langel family, commissioned by Pieter around 1500.

Identity of the sitter(s): Pieter van Os, Henricxken van Langel and their family

Provenance: unknown

Number of portrait(s): 15

Type of person(s): mixed (family) 
Attitude of the sitter(s): hands clasped, holding a book

Representation of the sitter(s): full-length

Gaze of the sitter(s): into space, towards the ground, reading a book

Object(s): yes (book, hat, rosary)

Coat(s) of arms: yes

Environment: historical setting

Structuring of the pictorial space: distinct spaces

Patron saint(s): Peter, Catherine, John the Evangelist, Mary Magdalen

Gesture of the patron saint(s): holding his/her attribute

Type of religious scene: narrative

Religious scene(s) depicted: the Ecce Homo

Cat. 261-Type 6A

BOSCH, Hieronymus (follower of)

Two Wings. The Flagellation with a Man in Prayer, Christ Bearing the Cross (c. 1505-1510) $106.8 \times 33.5 \mathrm{~cm}$

Philadelphia, Philadelphia Museum of Art, inv. no. 408

BIBL.: UNVEFEHRT 1975, 139-41; Mus. cat. Philadelphia 1994, 81.

Identity of the sitter(s): unknown

Provenance: unknown

Number of portrait(s): 1

Type of person(s): religious (man alone)

Attitude of the sitter(s): hands clasped

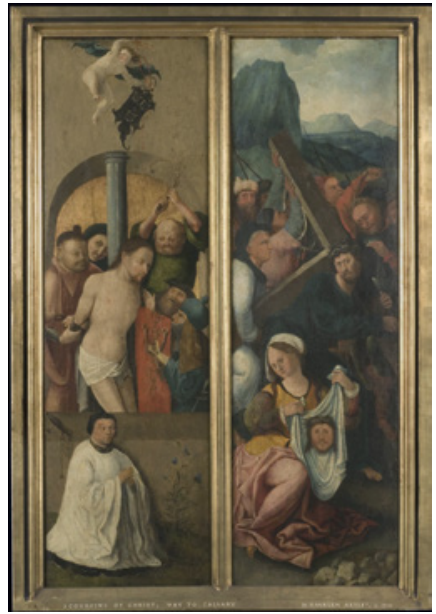

Representation of the sitter(s): full-length, small scale

Gaze of the sitter(s): indeterminate

Object(s): no

Coat(s) of arms: yes

Environment: historical setting

Structuring of the pictorial space: indeterminate

Patron saint(s): none

Gesture of the patron saint(s): not applicable

Type of religious scene: narrative

Religious scene(s) depicted: the Flagellation, Christ bearing the cross 
Cat. 262-Type ${ }_{3} \mathrm{C}$

BOSCH, Hieronymus (follower of) (or circle of Jan van Scorel)

Christ Crowned with Thorns with a Man in

Prayer (c. 1500-1550)

$83 \times 68 \mathrm{~cm}$

Antwerp, KMSK, inv. no. 840

BIBL.: FRIEDLÄNDER V, no. 8oa;

UNVEFEHRT 1975, 129-30; Mus. cat.

Antwerp 1985, 56-59 (with bibl.); Mus. cat.

Antwerp 1998, 49 .

Identity of the sitter(s): unknown

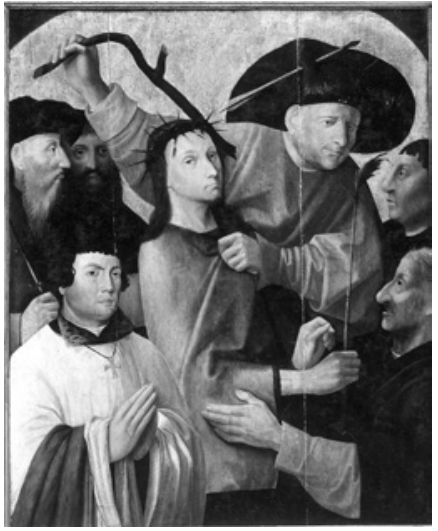

Provenance: unknown

Number of portrait(s): 1

Type of person(s): religious (man alone: canon)

Attitude of the sitter(s): hands clasped

Representation of the sitter(s): half-length

Gaze of the sitter(s): into space

Object(s): no

Coat(s) of arms: no

Environment: neutral space

Structuring of the pictorial space: not applicable

Patron saint(s): none

Gesture of the patron saint(s): not applicable

Type of religious scene: narrative

Religious scene(s) depicted: Christ crowned with thorns

Cat. 263-Type $3^{B}$

[RKD work no. 102526]

BOUTS, Albrecht

St. Augustine with a Canon in Prayer and St. John the Baptist (c. 1475)

$61 \times 44 \mathrm{~cm}$

Berlin, Staatliche Museen zu Berlin, Gemäldegalerie, inv. no. 540

BIB L.: FRIEDLÄNDER III, no. 69; Mus. cat. Berlin 1996, no. 620;

HENDERIKS 2011, 78-85, no. 2 (with bibl.). 
REMARK: Technical investigation has shown that the figure of St. John the Baptist is not original, but hides the actual patron saint of the canon, which has been identified as William of Maleval. See HENDERIKS 2011.

Identity of the sitter(s): unknown

Provenance: unknown

Number of portrait(s): 1

Type of person(s): religious (man alone: canon regular)

Attitude of the sitter(s): hands clasped

Representation of the sitter(s): full-length

Gaze of the sitter(s): towards the scene

Object(s): no

Coat(s) of arms: no

Environment: architectural space with sacred connotation

Structuring of the pictorial space: not applicable

Patron saint(s): John the Baptist (previously William of Maleval)

Gesture of the patron saint(s): introducing

Type of religious scene: hieratic

Religious scene(s) depicted: St. Augustine

Cat. 264-Type 2A

BOUTS, Albrecht

Triptych of the Assumption of the Virgin (c. 1495-1500) $206.7 \times 135.2 \mathrm{~cm}$ (centre panel), $205.1 \times 67.2 \mathrm{~cm}$ (left wing) and 205 $\times 67.6 \mathrm{~cm}$ (right wing)

Brussels, MRBAB, inv. no. 574

BIBL.: FRIEDLÄNDER III, no. 57; WERA 1951; STROO et alii 2001, 134-55; HENDERIKS 2011, 46-71,

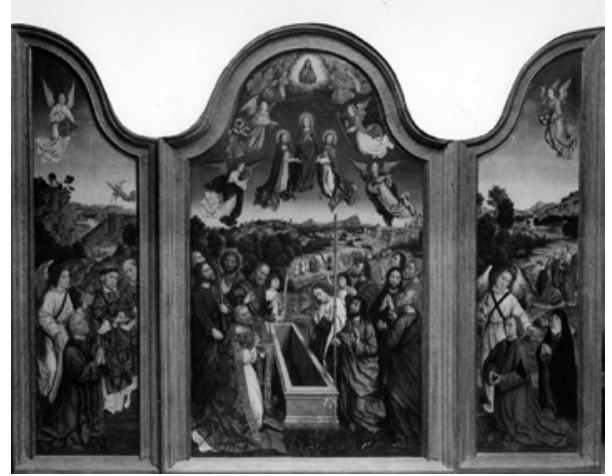
no. 13 (with bibl.).

HISTORICAL INFORMATION: Hulin de Loo identified the couple portrayed on the right panel as the painter Albrecht Bouts and his wife Elisabeth de Nausnydere. Several archival documents, discovered by Wéra, show that the triptych was placed in the chapel Onze-Lieve-Vrouw-van-Ginderbuiten at Leuven and that Albrecht Bouts lived in a house adjacent to this chapel for several years. The man depicted on the left panel is likely to be either Henri Ter Brugghe or Christian Nausnydere. 
Identity of the sitter(s): Albrecht Bouts, Elisabeth de Nausnydere and Henri Ter Brugghe (or Christian Nausnydere)

Provenance: Leuven, chapel Onze-Lieve-Vrouw-van-Ginderbuiten

Number of portrait(s): 3

Type of person(s): lay (family)

Attitude of the sitter(s): hands clasped

Representation of the sitter(s): full-length

Gaze of the sitter(s): into space, towards the scene

Object(s): no

Coat(s) of arms: yes

Environment: historical setting

Structuring of the pictorial space: unified space with discontinuities

Patron saint(s): Angels

Gesture of the patron saint(s): introducing

Type of religious scene: narrative

Religious scene(s) depicted: the Assumption of the Virgin

\section{Cat. 265 - Type 6A}

BOUTS, Albrecht

Two Wings. Moses and the Burning Bush, Gideon's Fleece (after 1485)

$74.6 \times 41.9 \mathrm{~cm}$

San Antonio, Mc Nay Art Museum, inv. no. 1955.9

BIBL.: FRIEDLÄNDER III, no. 42; HENDERIKS 2011, 98-104, no. 6 (with bibl.).

Identity of the sitter(s): unknown

Provenance: unknown

Number of portrait(s): 1

Type of person(s): religious (man alone: Franciscan friar)

Attitude of the sitter(s): hands clasped

Representation of the sitter(s): full-length

Gaze of the sitter(s): indeterminate

Object(s): no

Coat(s) of arms: no

Environment: landscape, no sacred connotation (incomplete)

Structuring of the pictorial space: indeterminate

Patron saint(s): none

Gesture of the patron saint(s): not applicable

Type of religious scene: indeterminate

Religious scene(s) depicted: Moses and the Burning bush, Gideon's Fleece 
Cat. 266-Type 6A

BOUTS, Albrecht (and workshop)

Two Wings. A Couple in Prayer with

Patron Saints (c. 1510-1520)

$43.5 \times 35.2 \mathrm{~cm}$ (right wing) and

$43.5 \times 35.4 \mathrm{~cm}$ (left wing)

Brussels, MRBAB, inv. nos. 402-403 BIBL.: FRIEDLÄNDER III,

no. 59; STROO et alii 2001, 176-87;
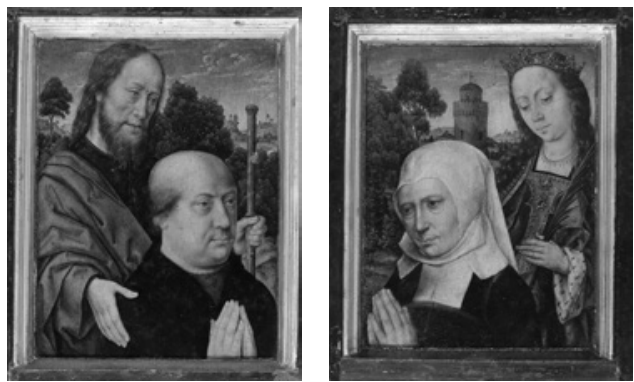

HENDERIKS 2011, 197-201, no. 40

(with bibl.).

Identity of the sitter(s): unknown

Provenance: unknown

Number of portrait(s): 2

Type of person(s): lay (couple)

Attitude of the sitter(s): hands clasped

Representation of the sitter(s): half-length

Gaze of the sitter(s): indeterminate

Object(s): no

Coat(s) of arms: no

Environment: landscape, no sacred connotation (incomplete)

Structuring of the pictorial space: indeterminate

Patron saint(s): James, Barbara

Gesture of the patron saint(s): protecting, holding his/her attribute

Type of religious scene: indeterminate

Religious scene(s) depicted: none

Cat. 267 -Type $3 \mathrm{C}$

BOUTS, Albrecht (previously attributed to)

The Crucifixion with a Nun in Prayer

(c. 1490-1500)

$70 \times 59 \mathrm{~cm}$ (open)

Paris, sale Schiff (1905)

BIBL.: FRIEDLÄNDER III, no. 52;

HENDERIKS 2011, no. 48.

Identity of the sitter(s): unknown

Provenance: unknown

Number of portrait(s): 1

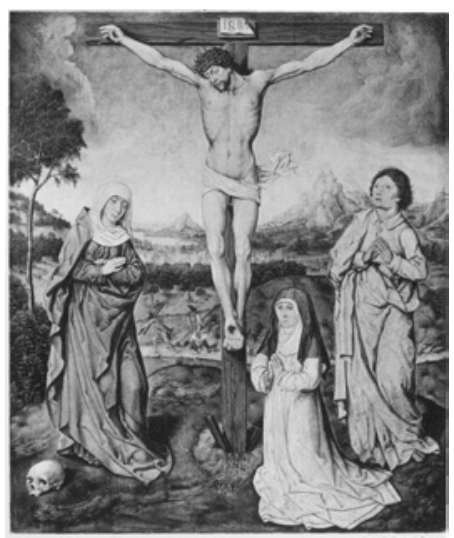


Type of person(s): religious (woman alone: Augustinian canoness)

Attitude of the sitter(s): hands clasped

Representation of the sitter(s): full-length

Gaze of the sitter(s): into space

Object(s): no

Coat(s) of arms: no

Environment: historical setting

Structuring of the pictorial space: not applicable

Patron saint(s): none

Gesture of the patron saint(s): not applicable

Type of religious scene: narrative

Religious scene(s) depicted: the Crucifixion

\section{Cat. 268-Type 6A}

BOUTS, Albrecht (workshop of)

Fragment. A Man in Prayerwith St. Peter (c.1530-1540) $30 \times 17.5 \mathrm{~cm}$

Basel, Wocher collection

BIB L.: FRIEDLÄNDER III, supp. 112; HENDERIKS 2011, no. 36 .

Identity of the sitter(s): unknown

Provenance: unknown

Number of portrait(s): 1

Type of person(s): lay (man alone)

Attitude of the sitter(s): indeterminate

Representation of the sitter(s): indeterminate

Gaze of the sitter(s): indeterminate

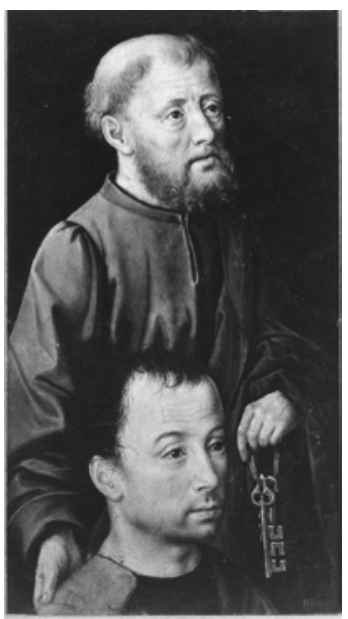

Object(s): no

Coat(s) of arms: no

Environment: neutral space (incomplete)

Structuring of the pictorial space: indeterminate

Patron saint(s): Peter

Gesture of the patron saint(s): holding his/her attribute

Type of religious scene: indeterminate

Religious scene(s) depicted: none 
Cat. 269-Type 6A

BOUTS, Albrecht (workshop of)

One Wing. A Woman in Prayer with St. Elizabeth (c. 1500-1525)

$49.5 \times 18 \mathrm{~cm}$

Belgium, private collection

BIB L.: HENDERIKS 2011, 163-65, no. 25.

Identity of the sitter(s): unknown

Provenance: unknown

Number of portrait(s): 1

Type of person(s): lay (woman alone)

Attitude of the sitter(s): holding a book

Representation of the sitter(s): full-length

Gaze of the sitter(s): reading a book

Object(s): yes (book, rosary)

Coat(s) of arms: no

Environment: enclosed garden (incomplete)

Structuring of the pictorial space: indeterminate

Patron saint(s): Elizabeth of Hungary

Gesture of the patron saint(s): holding his/her attribute

Type of religious scene: indeterminate

Religious scene(s) depicted: none

Cat. 270-Type 6A

BOUTS, Albrecht (workshop of)

Two Wings. Two Men in Prayer with Patron

Saints (c. 1530)

$56 \times 22.5 \mathrm{~cm}$ (each wing)

Bonn, Rheinisches Landesmuseum, inv.

nos. 1935/258-259

BIB L.: FRIEDLÄNDER III, no. 6o;

HENDERIKS 2011, 182-85, no. 34 (with bibl.).

Identity of the sitter(s): unknown

Provenance: unknown

Number of portrait(s): 2

Type of person(s): religious (group)

Attitude of the sitter(s): hands clasped

Representation of the sitter(s): full-length

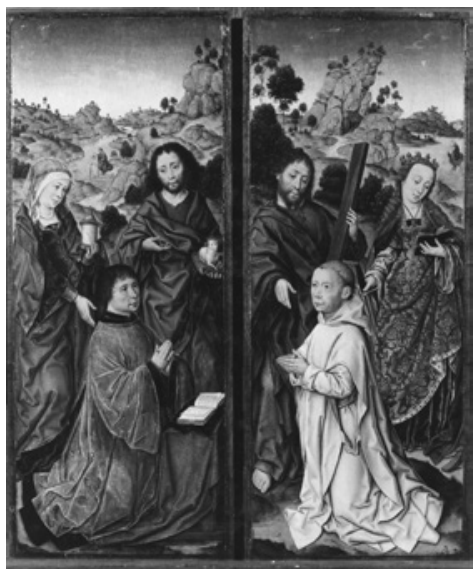


Gaze of the sitter(s): indeterminate

Object(s): yes (prie-dieu, book)

Coat(s) of arms: no

Environment: landscape with sacred connotation (incomplete)

Structuring of the pictorial space: indeterminate

Patron saint(s): Barbara, John the Baptist, Andrew, Catherine

Gesture of the patron saint(s): introducing, holding his/her attribute

Type of religious scene: indeterminate

Religious scene(s) depicted: none

Cat. 271-Type ${ }_{3} \mathrm{C}$

BOUTS, Dirk

Christ in the House of Simon with a Monk in

Prayer (c. 1446-1454)

$41 \times 61 \mathrm{~cm}$

Berlin, Staatliche Museen zu Berlin, Gemäldegalerie, inv. no. IV 557

BIBL.: FRIEDLÄNDER III, no. 16; PERIER

D'IETEREN 2005, no. 1 (with bibl.).

Identity of the sitter(s): unknown

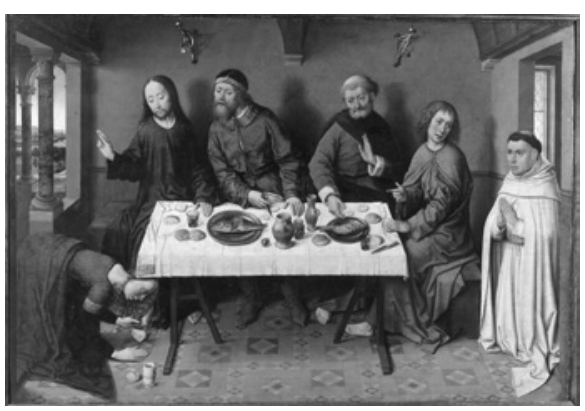

Provenance: unknown

Number of portrait(s): 1

Type of person(s): religious (man alone)

Attitude of the sitter(s): hands clasped

Representation of the sitter(s): full-length

Gaze of the sitter(s): towards the scene

Object(s): no

Coat(s) of arms: no

Environment: historical setting

Structuring of the pictorial space: not applicable

Patron saint(s): none

Gesture of the patron saint(s): not applicable

Type of religious scene: narrative

Religious scene(s) depicted: Christ in the House of Simon 
Cat. 272-Type $3^{B}$

BOUTS, Dirk

The Ecce Agnus Dei with a Man in Prayer

(c. 1469)

$53.7 \times 41.4 \mathrm{~cm}$

Munich, Alte Pinakothek, inv. no. 15192

BIBL.: FRIEDLÄNDER III, no. 22; PERIER

D'IETEREN 2005, no. 21 (with bibl.); Mus. cat.

Munich 2006, 298-99 (with bibl.).

Identity of the sitter(s): unknown

Provenance: unknown

Number of portrait(s): 1

Type of person(s): lay (man alone)

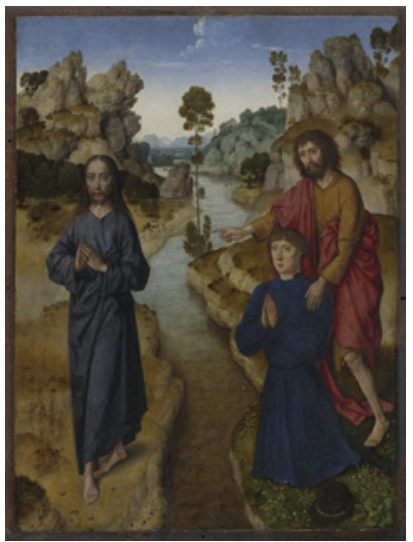

Attitude of the sitter(s): hands clasped

Representation of the sitter(s): full-length

Gaze of the sitter(s): into space

Object(s): yes (hat)

Coat(s) of arms: no

Environment: landscape, no sacred connotation

Structuring of the pictorial space: not applicable

Patron saint(s): John the Baptist

Gesture of the patron saint(s): protecting, indicating

Type of religious scene: hieratic

Religious scene(s) depicted: Ecce Agnus Dei

Cat. 273-Type 6A

BOUTS, Dirk

Fragment. Portrait of a Man in Prayer (c. 1470)

$29.5 \times 20.6 \mathrm{~cm}$

New York, MET, inv. no. 1913 (14.40.644)

BIB L.: FRIEDLÄNDER III, no. 32;

AINSWORTH and CHRISTIANSEN 1998, 160-61; PERIER D'IETEREN 2005, no. 23

(with bibl.).

Identity of the sitter(s): unknown

Provenance: unknown

Number of portrait(s): 1

Type of person(s): lay (man alone)

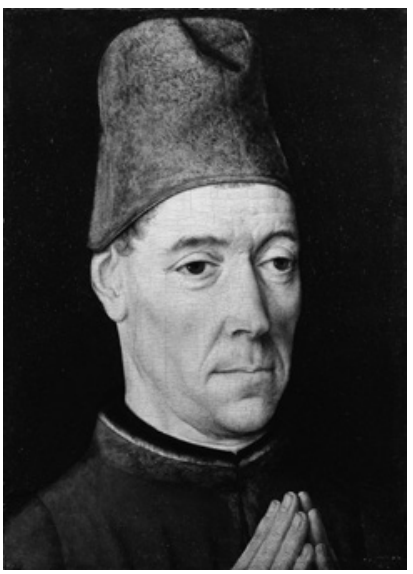

Attitude of the sitter(s): hands clasped 
Representation of the sitter(s): indeterminate

Gaze of the sitter(s): indeterminate

Object(s): no

Coat(s) of arms: no

Environment: neutral space (incomplete)

Structuring of the pictorial space: indeterminate

Patron saint(s): none

Gesture of the patron saint(s): not applicable

Type of religious scene: indeterminate

Religious scene(s) depicted: none

Cat. 274-Type 6A

BOUTS, Dirk

Fragment. Portrait of a Man in Prayer

(c. 1470-1475)

$25.6 \times 20.6 \mathrm{~cm}$

Washington, National Gallery of Art, inv. no. 1961.9.66 (1618)

BIBL.: FRIEDLÄNDER III, no. 7; Mus. cat. Washington 1986, 24-26; PERIER D'IETEREN 2005, no. B6 (with bibl.).

Identity of the sitter(s): unknown

Provenance: unknown

Number of portrait(s): 1

Type of person(s): lay (man alone)

Attitude of the sitter(s): hands clasped

Representation of the sitter(s): indeterminate

Gaze of the sitter(s): indeterminate

Object(s): no

Coat(s) of arms: no

Environment: neutral space (incomplete)

Structuring of the pictorial space: indeterminate

Patron saint(s): none

Gesture of the patron saint(s): not applicable

Type of religious scene: indeterminate

Religious scene(s) depicted: none 
Cat. 275-Type 6B

BOUTS, Dirk (attributed to)

Portrait of a Monk in Prayer (c. 1475-1500)

$39 \times 23 \mathrm{~cm}$

Antwerp, KMSK, inv. no. 253

BIBL.: FRIEDLÄNDER III, no. 27; Mus. cat. Antwerp 1985, 32-34; Mus. cat. Antwerp 1998, 466; BRUYN 1998; PERIER D'IETEREN 2005, no. B3 (with bibl.).

Identity of the sitter(s): unknown

Provenance: unknown

Number of portrait(s): 1

Type of person(s): religious (man alone:

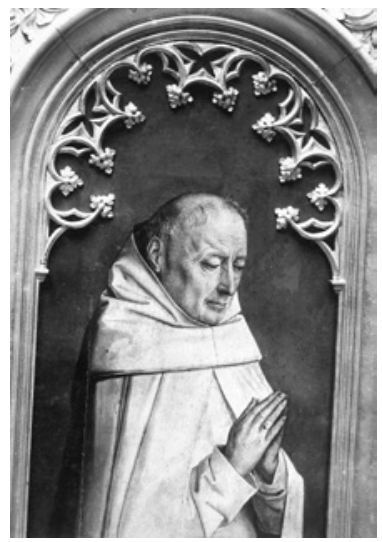

Premonstrian or Carthusian monk)

Attitude of the sitter(s): hands clasped

Representation of the sitter(s): half-length

Gaze of the sitter(s): towards the ground

Object(s): no

Coat(s) of arms: no

Environment: neutral space (incomplete)

Structuring of the pictorial space: indeterminate

Patron saint(s): none

Gesture of the patron saint(s): not applicable

Type of religious scene: indeterminate

Religious scene(s) depicted: none

Cat. 276-Type 6A

BOUTS, Dirk (circle of)

Fragment. Portrait of a Man in Prayer with

Patron Saint (c. 1460-1465)

$22.2 \times 17.8 \mathrm{~cm}$

New York, MET, inv. no. 1931 32.100.41

BIBL.: FRIEDLÄNDER III, no. 10;

AINSWORTH and CHRISTIANSEN 1998, 156-57; PERIER D'IETEREN 2005, no. A6 (with bibl.).

Identity of the sitter(s): unknown

Provenance: unknown

Number of portrait(s): 1

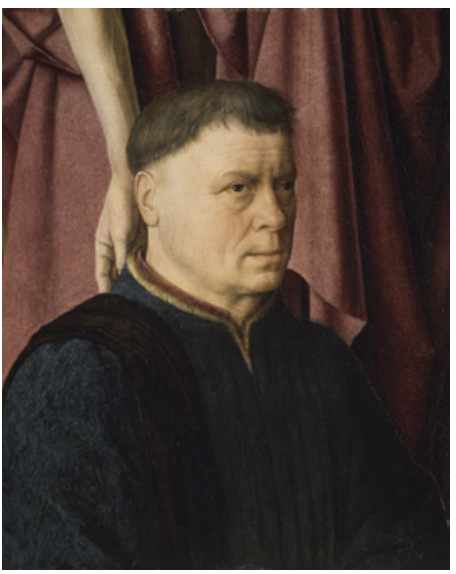


Type of person(s): lay (man alone)

Attitude of the sitter(s): indeterminate

Representation of the sitter(s): indeterminate

Gaze of the sitter(s): indeterminate

Object(s): no

Coat(s) of arms: no

Environment: indeterminate

Structuring of the pictorial space: indeterminate

Patron saint(s): an unidentified saint

Gesture of the patron saint(s): introducing

Type of religious scene: indeterminate

Religious scene(s) depicted: none

Cat. 277-Type $3 \mathrm{C}$

[MEMO work no. 688]

BOUTS, Dirk (follower of) (or Anonymous Haarlem Master)

The Visitation with Jan Willem Jansz. in Prayer (before 1500)

$72 \times 50 \mathrm{~cm}$

Weimar, Staatliche Museen, inv. no. G1221

BIBL.: VAN BUEREN 1989, 125-29; VAN BUEREN 1993, 284-88 (with bibl.); BRUYN 2009, 93-97.

HISTORICAL INFORMATION: The sitter wears the habit of the Jansheren of Haarlem. On the basis of his coat of arms and his motto (trahit sua quemque voluptas, an excerpt of Virgil), he has been identified as Jan Willem Jansz., commander of the Jansklooster in Haarlem between 1484 and 1514. Born c. 1451, Jan came from a noble family. Before entering the Jansklooster, he had been deacon in Zoeterwoude and a priest. In several archival documents, he is mentioned as a magister, indicating that he studied at the university. His ex-libris appears in several manuscripts that have been preserved. He died in 1514 .

Identity of the sitter(s): Jan Willem Jansz.

Provenance: Haarlem, Jansklooster

Number of portrait(s): 1

Type of person(s): religious (man alone:Jansheer)

Attitude of the sitter(s): hands clasped

Representation of the sitter(s): full-length

Gaze of the sitter(s): towards the scene

Object(s): yes (hat)

Coat(s) of arms: yes

Environment: historical setting 
Structuring of the pictorial space: not applicable

Patron saint(s): none

Gesture of the patron saint(s): not applicable

Type of religious scene: narrative

Religious scene(s) depicted: the Visitation

Cat. 278-Type $2 \mathrm{C}$

BOUTS, Dirk and VAN DER GOES, Hugo

Triptych of the Martyrdom of St.

Hippolytus ('Triptych Berthoz')

(c. 1470-75 for the centre panel and right

wing and c. 1475-79 for the left wing)

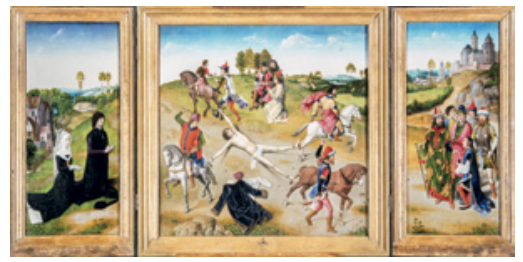

$91 \times 91 \mathrm{~cm}$ (centre panel) and $91 \times 40 \mathrm{~cm}$ (wings)

Bruges, St. Saviour's Cathedral

BIBL.: FRIEDLÄNDER III, no. 29; VAN DEN BERGEN-PANTENS 2001; PERIER D'IETEREN 2005, no. A7 (with bibl.).

HISTORICAL INFORMATION: The triptych was commissioned by Hippolyte Berthoz ( $† 1503)$ and his wife Isabelle Huygheins. Begun by Dirk Bouts, the work was finished by Hugo van der Goes. The reverse of the wings includes the figures of St. Charlemagne, St. Hippolytus, St. Elizabeth of Hungary and St. Margaret, and were added by Hippolyte's son, Charles, at a later date. The outer wings bear Charles' coat of arms and those of his wife, Marguerite le Mutre. Coming from Poligny, Hippolyte Berthoz made a financial career at the Burgundian court. He successively held the positions of Trésorier des guerres and registrar under Charles the Bold, Argentier of Margaret of York and Maître des comptes. Isabelle Huygheins came from a wealthy family of Bruges. Hippolyte and Isabelle had four children. In 1502, their son Charles offered the triptych to the lime carriers' Guild, which placed it on the altar of their chapel at the church of St. Saviour at Bruges.

Identity of the sitter(s): Hippolyte Berthoz and Isabelle Huygheins

Provenance: Bruges, church of St. Saviour, chapel of the lime carriers' Guild

(from 1502 onwards)

Number of portrait(s): 2

Type of person(s): lay (couple)

Attitude of the sitter(s): hands clasped

Representation of the sitter(s): full-length

Gaze of the sitter(s): towards the scene 
Object(s): no

Coat(s) of arms: yes

Environment: historical setting

Structuring of the pictorial space: continuous space

Patron saint(s): none

Gesture of the patron saint(s): not applicable

Type of religious scene: narrative

Religious scene(s) depicted: the Martyrdom of St. Hippolytus, St. Elizabeth of Hungary, St. Margaret, St. Hippolytus, St. Charlemagne

Cat. 279-Type 2A

BUYS II, Cornelis (attributed to) Triptych of the Lamentation with two Persons in Prayer and Patron Saints (c. 1530 for the centre panel and c. 1540-1554 for the wings) $46.5 \times 40 \mathrm{~cm}$ (centre panel) and $48.5 \times 18.5 \mathrm{~cm}$ (wings)

Amsterdam, Rijksmuseum, inv.

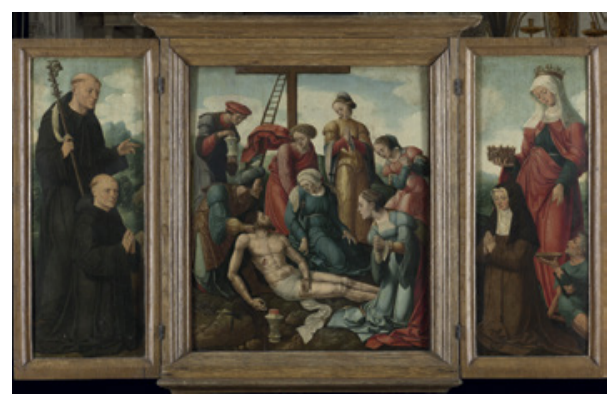
no. SK-A-2392

BIBL.: Mus. cat. Amsterdam 1976, 158; Mus. cat. Amsterdam 2009 [online], https://www.rijksmuseum.nl/nl/collectie/SK-A-2392/catalogus-entry (with bibl.).

Identity of the sitter(s): unknown

Provenance: unknown

Number of portrait(s): 2

Type of person(s): religious (group)

Attitude of the sitter(s): hands clasped

Representation of the sitter(s): full-length

Gaze of the sitter(s): into space, towards the ground

Object(s): no

Coat(s) of arms: no

Environment: historical setting

Structuring of the pictorial space: continuous space

Patron saint(s): Benedict, Elizabeth of Hungary

Gesture of the patron saint(s): holding his/her attribute

Type of religious scene: narrative

Religious scene(s) depicted: the Lamentation 
Cat. 280-Type 6A

CHRISTUS, Petrus

One Wing. A Man in Prayer with St. Anthony (c. 1450)

$57.4 \times 31 \mathrm{~cm}$

Copenhagen, Statens Museum for Kunst, inv. no.

KMSspi62

BIB L.: Exh. cat. Bruges 2002, no. 11 (with bibl.). HISTORICAL INFORMATION: It has not been possible to identify the coat of arms of the devotee.

Identity of the sitter(s): unknown

Provenance: unknown

Number of portrait(s): 1

Type of person(s): lay (man alone)

Attitude of the sitter(s): hands clasped

Representation of the sitter(s): full-length

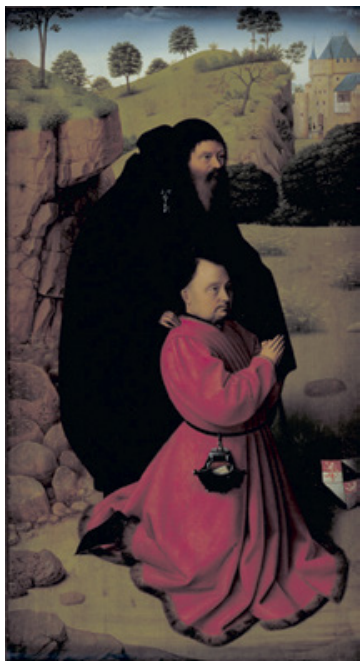

Gaze of the sitter(s): indeterminate

Object(s): yes (purse)

Coat(s) of arms: yes

Environment: landscape, no sacred connotation (incomplete)

Structuring of the pictorial space: indeterminate

Patron saint(s): Anthony

Gesture of the patron saint(s): protecting

Type of religious scene: indeterminate

Religious scene(s) depicted: none

Cat. 281-Type 6B

CHRISTUS, Petrus

Portrait of a Young Man in Prayer (c. 1450-146o) $35.4 \times 26 \mathrm{~cm}$

London, NG, inv. no. NG 2593

BIBL.: FRIEDLÄNDER I, pl. 91; Corpus London I, no. 37 (with bibl.); CAMPBELL 1998, 104-09 (with bibl.).

Identity of the sitter(s): unknown

Provenance: unknown

Number of portrait(s): 1

Type of person(s): lay (man alone)

Attitude of the sitter(s): holding a book

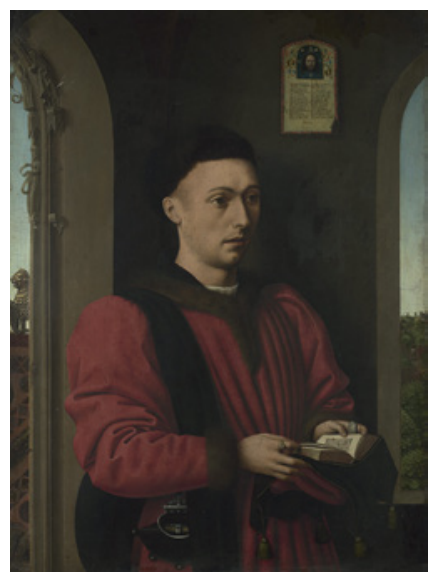

Representation of the sitter(s): half-length 
Gaze of the sitter(s): indeterminate

Object(s): yes (book, purse)

Coat(s) of arms: no

Environment: domestic setting

Structuring of the pictorial space: indeterminate

Patron saint(s): none

Gesture of the patron saint(s): not applicable

Type of religious scene: indeterminate

Religious scene(s) depicted: none

Cat. 282-Type ${ }_{3}$ B

\section{CHRISTUS, Petrus}

The Virgin and Child with Jan Vos and St. Barbara (the 'Exeter Madonna') (c. 1450)

$19.5 \times 14 \mathrm{~cm}$

Berlin, Staatliche Museen zu Berlin, Gemäldegalerie, inv. no. $523 \mathrm{~B}$

BIBL.: FRIEDLÄNDER I, pl. 86; Exh. cat. New York 1994, no. 7 (with bibl.).

HISTORICAL INFORMATION: The Carthusian monk is Jan Vos, as a comparison with his portrait in Van Eyck's Virgin ofJan Vos (cat. 695) indicates. Jan Vos was first a member of the Teutonic Order,

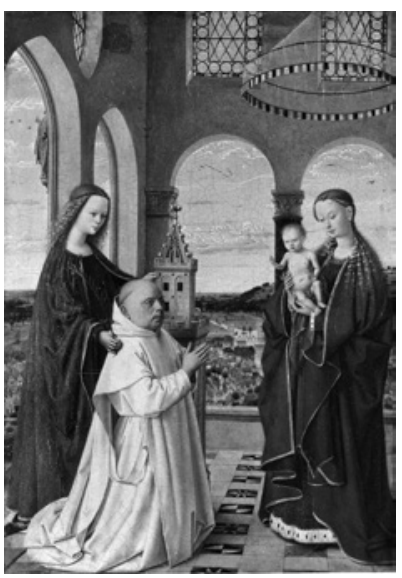
before entering the charterhouse of Nieuwlicht, in Utrecht, in 1431. After a few years spent in this monastery, he moved to the charterhouse of Genadedal in Bruges, to serve as prior. He stayed nine years in Bruges before returning to Nieuwlicht in 1450. In all likelihood, Jan Vos commissioned this small painting for his personal use while he was in Bruges and he took it with him when he returned to Nieuwlicht.

Identity of the sitter(s): Jan Vos

Provenance: Bruges, charterhouse of Genadedal, then Utrecht, charterhouse of Nieuwlicht (?)

Number of portrait(s): 1

Type of person(s): religious (man alone: Carthusian monk)

Attitude of the sitter(s): hands clasped

Representation of the sitter(s): full-length

Gaze of the sitter(s): towards the scene

Object(s): no

Coat(s) of arms: no 
Environment: architectural space with sacred connotation

Structuring of the pictorial space: not applicable

Patron saint(s): Barbara

Gesture of the patron saint(s): protecting

Type of religious scene: hieratic

Religious scene(s) depicted: the Virgin and Child

Cat. 283-Type 2D

CHRISTUS, Petrus

Triptych of the Virgin and Child with a Couple in Prayer (c. 1450)

$46.7 \times 44.6 \mathrm{~cm}$ (centre panel), $42 \times 21.2$ $\mathrm{cm}$ (left wing) and $41.8 \times 21.6 \mathrm{~cm}$ (right wing)

Washington, National Gallery of Art, inv. no. 1961.9.10-11 (wings) and Frankfurt, Städelsches Kunstinstitut, inv. no. 920 (centre panel)

BIB L.: FRIEDLÄNDER I, pl. 104; Mus. cat. Washington 1986, 49-55; Mus. cat. Frankfurt 1993, 154-74 (with bibl.); LANE 1970; Exh. cat. New York 1994, no. 12; Exh. cat. Bruges 2002, no. 12 (with bibl.).

HISTORICAL INFORMATION: In all likelihood, the portrayed couple comes from Italy, and more precisely from Genoa: the coat of arms of the woman corresponds to that of the Vivaldi family, which belongs to the Genovese aristocracy. The man's coat of arms is similar to that of the Lomellini family.

REMARK: The reconstruction of the triptych was proposed by Lane (1970). Although criticised by several art historians, this proposition has been confirmed by a dendrochronological analysis.

Identity of the sitter(s): unknown

Provenance: unknown

Number of portrait(s): 2

Type of person(s): lay (couple)

Attitude of the sitter(s): hands clasped

Representation of the sitter(s): full-length

Gaze of the sitter(s): into space

Object(s): yes (prie-dieu, book)

Coat(s) of arms: yes

Environment: architectural space with sacred connotation 
Structuring of the pictorial space: unified space with discontinuities

Patron saint(s): none

Gesture of the patron saint(s): not applicable

Type of religious scene: hieratic

Religious scene(s) depicted: the Virgin and Child

Cat. 284-Type 6A

CHRISTUS, Petrus (follower of)

One Wing. Isabella of Portugal in Prayer with St.

Elizabeth (after 1457)

$59 \times 33 \mathrm{~cm}$

Bruges, Groeningemuseum, inv. no. 0.1614.I BIBL.: FRIEDLÄNDER I, pl. 110; Corpus Bruges I, no. 138; Exh. cat. Bruges, Bern and Vienna 2009, no. 2 (with bibl.).

historical information: Presumably, this wing belonged to a triptych mentioned in the 1516 inventory of Margaret of Austria: ung grant tableau dune Nostre Dame de pityé, à deux feulletz, deans l'ung y a une saincte Elizabeth et Madame Ysabeau de Portugal, et en l'autre une saincte Katherine, et au dehors une annonciade de blanc

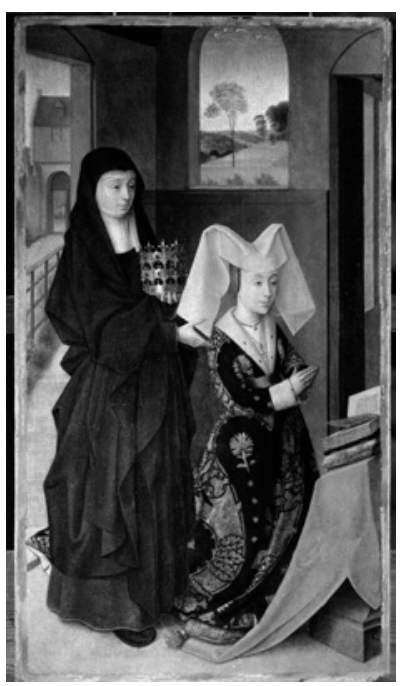
et de noir, qui aesté donné à Madame par Katheline du Buisson (EICHBERGER 2002, 207). Katheline du Buisson was the abbess of the convent of St. Elizabeth in Quesnoy. She is also mentioned in several archival documents as demoiselle d'atour of Margaret of Austria (see Corpus Bruges I, 90). On this panel, the duchess seems quite old. The work is thus probably later than her installation in la Motte-au-Bois near Nieppe in 1457. This residence was the living place of the Franciscan 'soeurs grises'. The triptych might have been destined for this place.

Identity of the sitter(s): Isabella of Portugal

Provenance: Convent of la Motte-au-Bois (?)

Number of portrait(s): 1

Type of person(s): lay (woman alone)

Attitude of the sitter(s): hands clasped

Representation of the sitter(s): full-length

Gaze of the sitter(s): indeterminate

Object(s): yes (prie-dieu, book)

Coat(s) of arms: no 
Environment: architectural space, no sacred connotation (incomplete)

Structuring of the pictorial space: indeterminate

Patron saint(s): Elizabeth of Hungary

Gesture of the patron saint(s): introducing

Type of religious scene: indeterminate

Religious scene(s) depicted: none

Cat. 285-Type 2A

COCK Jan Wellens de (attributed to)

Triptych of the Crucifixion with a

Couple in Prayer and Patron Saints

(c. 1506-1527)

$37 \times 25.5 \mathrm{~cm}$ (centre panel) and

$32.5 \times 10 \mathrm{~cm}$ (wings)

Maastricht, Bonnefantenmuseum(loan

of the Rijksmuseum, Amsterdam), inv.

no. SK-A-1598

BIBL.: FRIEDLÄNDER XI, no. 112; Mus. cat. Amsterdam 1976, 170; Exh. cat. Antwerp and Maastricht 2005, no. 93; Mus. cat. Amsterdam 2009 [online], https:// www.rijksmuseum.nl/nl/collectie/SK-A-1598/catalogus-entry (with bibl.); Exh. cat. Leiden 2011, no. 23 (with bibl.).

HISTORICAL INFORMATION: It has not been possible to identify the coats of arms painted on the inner wings.

Identity of the sitter(s): unknown

Provenance: unknown

Number of portrait(s): 2

Type of person(s): lay (couple)

Attitude of the sitter(s): hands clasped, holding a rosary

Representation of the sitter(s): full-length

Gaze of the sitter(s): towards the scene

Object(s): yes (rosary)

Coat(s) of arms: yes

Environment: historical setting

Structuring of the pictorial space: unified space with discontinuities

Patron saint(s): Peter, James

Gesture of the patron saint(s): introducing, protecting

Type of religious scene: narrative

Religious scene(s) depicted: the Crucifixion, St. Christopher, the Christ

Child on the Road of Life 
Cat. 286-Type 6A

COCK, Jan Wellens de (attributed to)

Two Wings. A Couple in Prayer with Patron Saints

(c. 1500-1550)

Size unknown

Whereabouts unknown

Identity of the sitter(s): unknown

Provenance: unknown

Number of portrait(s): 2

Type of person(s): lay (couple)

Attitude of the sitter(s): hands clasped

Representation of the sitter(s): full-length

Gaze of the sitter(s): indeterminate

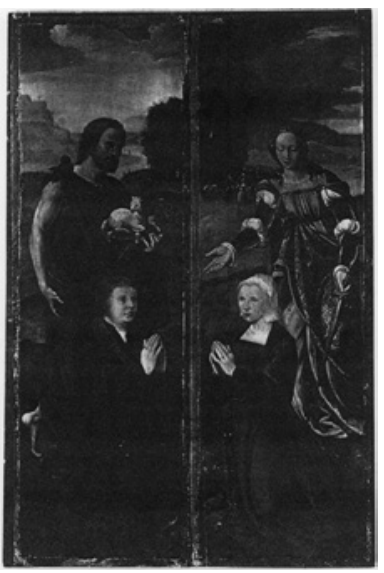

Object(s): no

Coat(s) of arms: no

Environment: landscape, no sacred connotation (incomplete)

Structuring of the pictorial space: indeterminate

Patron saint(s): John the Baptist, Catherine

Gesture of the patron saint(s): holding his/her attribute, introducing

Type of religious scene: indeterminate

Religious scene(s) depicted: none

Cat. 287-Type 2A (?)

COCK, Jan Wellens de (attributed to) (or Lucas Cornelisz. Kunst)

Triptych of the Temptation of St. Anthony with a Couple in Prayer and Patron Saints (c. 1500-1550) $50 \times 35 \mathrm{~cm}$ (centre panel) and $5^{0} \times$ $22 \mathrm{~cm}$ (wings)

Tiel, Flipje en Streekmuseum

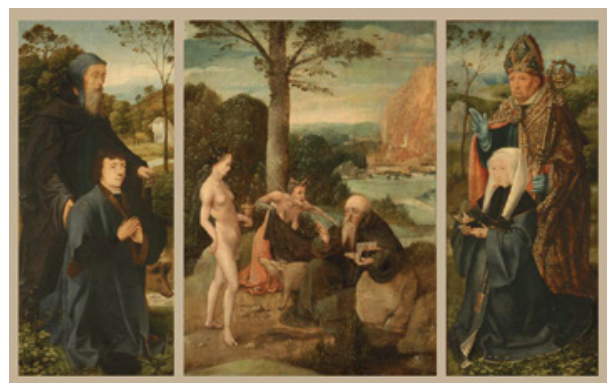

BIB L.: Exh. cat. Kevelaer 2000-2001, 146, no. III-53.

REMARK: St. Anthony is depicted twice in the work: once as the main character of the centre panel and once as the patron saint of the man on the left wing. This situation is quite unusual and suggests that the current state of the work is not original.

Identity of the sitter(s): unknown

Provenance: Tiel, church of St. Martin, altar of the Brotherhood of St. Anthony (?) 
Number of portrait(s): 2

Type of person(s): lay (couple)

Attitude of the sitter(s): hands clasped, holding a book

Representation of the sitter(s): full-length

Gaze of the sitter(s): into space

Object(s): yes (book)

Coat(s) of arms: no

Environment: historical setting

Structuring of the pictorial space: distinct spaces

Patron saint(s): Anthony, Donatian (?)

Gesture of the patron saint(s): introducing, holding his/her attribute

Type of religious scene: narrative

Religious scene(s) depicted: the Temptation of St. Anthony

Cat. 288-Type $3 \mathrm{~A}$

COCK, Jan Wellens de (workshop of)

The Crucifixion with Two Persons in Prayer

(c. 1500-1525)

$52.5 \times 42 \mathrm{~cm}$

London, sale Phillips (2 December 1997), lot no. 7

Identity of the sitter(s): unknown

Provenance: unknown

Number of portrait(s): 2

Type of person(s): mixed (group)

Attitude of the sitter(s): hands clasped

Representation of the sitter(s): full-length

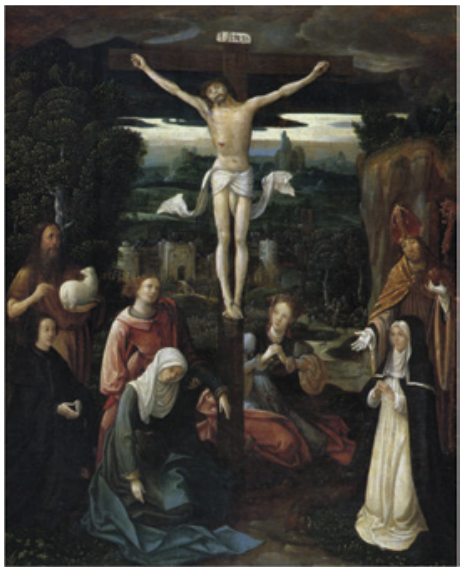

Gaze of the sitter(s): into space

Object(s): no

Coat(s) of arms: no

Environment: historical setting

Structuring of the pictorial space: not applicable

Patron saint(s): John the Baptist, Augustine

Gesture of the patron saint(s): introducing, holding his/her attribute

Type of religious scene: narrative

Religious scene(s) depicted: the Crucifixion 
Cat. 289 - Type $2 \mathrm{D}$

COECKE VAN AELST, Pieter

Triptych of St. Philip and St. James the Lesser with a Family in Prayer (1527-1531)

Size unknown

Funchal, church of Socorro, inv. no. $\mathrm{MASF}_{40 \mathrm{O}}$

BIBL.: MARLIER 1966, 261-62.

HISTORICAL INFORMATION: The triptych was discovered by Cayola Zagallo

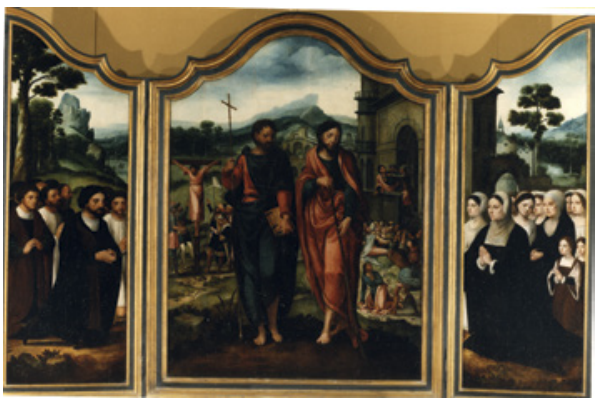
in the vestry of the church of Socorro (previously known as the church of St. James the Lesser), in Funchal. He identified the father of the family as Simão Gonçalves da Câmara, who is accompanied by his first wife Joana Castelo Branco, or his second wife Isabel Silva, and his children. According to Zagallo, the triptych can be dated around 1527-1531 and was destined for the altar of the church of Socorro, which had been build a few years before the execution of the triptych. St. James the Lesser is the patron saint of Funchal since 1521.

Identity of the sitter(s): Simão Gonçalves da Câmara, Joana Castelo Branco or Isabel da Silva (?) and their children

Provenance: unknown

Number of portrait(s): 14 (at least)

Type of person(s): lay (family with children)

Attitude of the sitter(s): hands clasped

Representation of the sitter(s): full-length

Gaze of the sitter(s): into space, towards the scene

Object(s): no

Coat(s) of arms: no

Environment: historical setting

Structuring of the pictorial space: unified space with discontinuities

Patron saint(s): none

Gesture of the patron saint(s): not applicable

Type of religious scene: hieratic

Religious scene(s) depicted: St. Philip, St. James the Lesser, the Annunciation 
Cat. 290-Type 2A

COECKE VAN AELST, Pieter

Triptych of the Crucifixion ('Triptych of Paul Robyns') (after 1532)

$122 \times 81.5 \mathrm{~cm}$ (centre panel) and $123 \times$ $36 \mathrm{~cm}$ (wings)

Amsterdam, sale Frederik Muller (4June 1929)

BIBL.: FRIEDLÄNDER XII, no. 143; MARLIER 1966, 189-92.

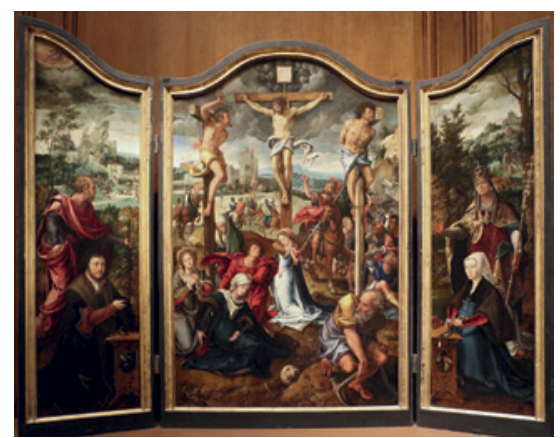

HistoricAl information: The man portrayed on the left wing is Paul Robyns, as the coat of arms on the prie-dieu indicates. His wife, portrayed on the right wing, is Cornelia Losschaert. Coming from Antwerp, Paul Robyns is mentioned as almoner in 1532. Taking into account the fact that he wears his almoner costume in the triptych, the work can be dated to after 1532. He died in 1540. The Antwerp almonry was a charitable institution founded in the fifteenth century, and was managed by ten almoners, appointed by the magistrate for five-year periods. The almoners were responsible for the administration of the goods of the charitable institutions of the city. They organised quests, distributed food and clothes and managed the hospices. On this topic, see ROBIJNS DE SCHEIDAUER 1955 .

Identity of the sitter(s): Paul Robyns and Cornelia Losschaert

Provenance: unknown

Number of portrait(s): 2

Type of person(s): lay (couple)

Attitude of the sitter(s): holding a hat, holding a rosary

Representation of the sitter(s): full-length

Gaze of the sitter(s): into space

Object(s): yes (prie-dieu, hat, rosary)

Coat(s) of arms: yes

Environment: historical setting

Structuring of the pictorial space: unified space with discontinuities

Patron saint(s): Paul, Cornelius

Gesture of the patron saint(s): introducing

Type of religious scene: narrative

Religious scene(s) depicted: the Crucifixion 
Cat. 291-Type 2A

COECKE VAN AELST, Pieter

Triptych of the Crucifixion with a Family in Prayer and Patron Saints (c. 1535)

$150 \times 100 \mathrm{~cm}$ (centre panel)

Dublin, National Gallery of Ireland, inv. no. L14168.

BIBL.: MARLIER 1966, 192-94.

Identity of the sitter(s): unknown

Provenance: unknown

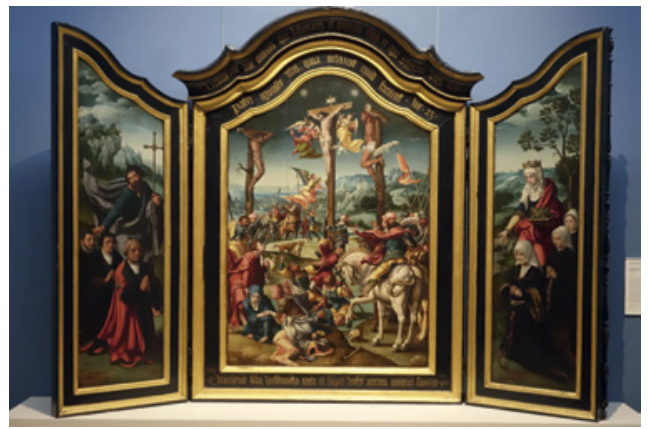

Number of portrait(s): 6

Type of person(s): lay (family)

Attitude of the sitter(s): hands clasped

Representation of the sitter(s): full-length

Gaze of the sitter(s): into space, towards the ground

Object(s): yes (rosary)

Coat(s) of arms: no

Environment: historical setting

Structuring of the pictorial space: distinct spaces

Patron saint(s): Philip, Elizabeth of Hungary

Gesture of the patron saint(s): introducing, indicating

Type of religious scene: narrative

Religious scene(s) depicted: the Crucifixion

Cat. 292-Type 2D

COECKE VAN AELST, Pieter

Triptych of the Virgin Immaculate with a

Man in Prayer (c. 1500-1550)

$106 \times 70.5 \mathrm{~cm}$ (centre panel) and $106 \times$

$30 \mathrm{~cm}$ (wings)

London, sale Sotheby's (21 February 1962), lot no. 139

BIB L.: MARLIER 1966, 180-82.

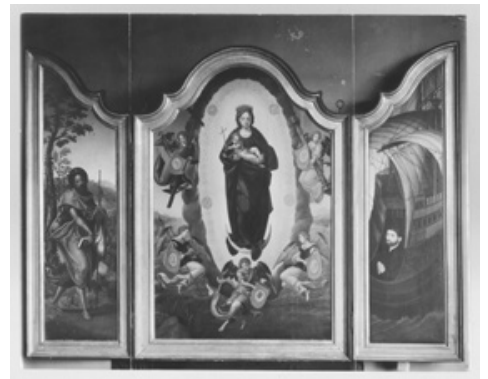

REMARK: The sitter is depicted in a boat.

Identity of the sitter(s): unknown

Provenance: unknown

Number of portrait(s): 1

Type of person(s): lay (man alone) 
Attitude of the sitter(s): hands clasped

Representation of the sitter(s): full-length

Gaze of the sitter(s): towards the scene

Object(s): no

Coat(s) of arms: no

Environment: landscape with sacred connotation

Structuring of the pictorial space: distinct spaces

Patron saint(s): none

Gesture of the patron saint(s): not applicable

Type of religious scene: hieratic

Religious scene(s) depicted: the Virgin immaculate, St. John the Baptist

Cat. 293-Type 6A

COECKE VAN AELST, Pieter

Two Wings. A Family in Prayer with Patron Saints

(c. 1500-1550)

$112 \times 44 \mathrm{~cm}$ (each wing)

Madrid, Museo Nacional del Prado, inv. nos. 1609-1610 BIBL.: FRIEDLÄNDER XII, no. 146; Mus. cat. Madrid 1991, nos. 306o-61.

REMARK: The iconography of the scenes depicted in the background of the wings suggests that the now lost centre panel showed the Last Judgement.

Identity of the sitter(s): unknown

Provenance: unknown

Number of portrait(s): 15

Type of person(s): mixed (family with children)

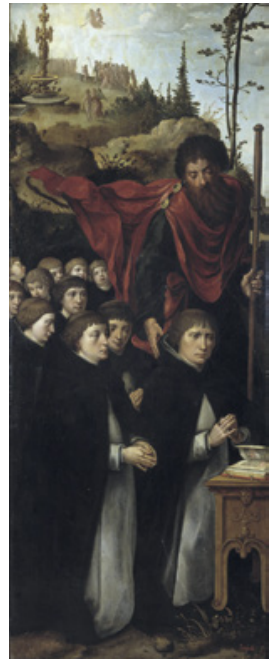

Attitude of the sitter(s): hands clasped

Representation of the sitter(s): full-length

Gaze of the sitter(s): indeterminate

Object(s): yes (prie-dieu, book, rosary, dog)

Coat(s) of arms: no

Environment: landscape with sacred connotation (incomplete)

Structuring of the pictorial space: indeterminate

Patron saint(s): James, John the Evangelist

Gesture of the patron saint(s): introducing, holding his/her attribute

Type of religious scene: indeterminate

Religious scene(s) depicted: none 
Cat. 294-Type $3 \mathrm{~A}$

COECKE VAN AELST, Pieter

The Annunciation with an Abbot in Prayer (c. 1530) $130 \times 93 \mathrm{~cm}$

Sint-Truiden, Klein Seminarie

BIB L.: Exh. cat. Brussels 1996, no. 6.

HISTORICAL INFORMATION: The abbot has been identified as Guillaume of Brussels, on the basis of his coat of arms and his motto (RVRSVM POST. TENEBRAS SEPRO LUCEM). Guillaume of Brussels also appears in cat. 228 (see this entry for a

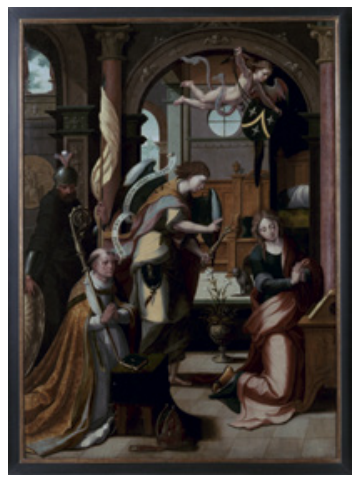
biography of the sitter)

Identity of the sitter(s): Guillaume (Bollart) of Brussels

Provenance: unknown

Number of portrait(s): 1

Type of person(s): religious (man alone: Cistercian abbot)

Attitude of the sitter(s): hands clasped

Representation of the sitter(s): full-length

Gaze of the sitter(s): into space

Object(s): yes (prie-dieu, book, mitre, crosier)

Coat(s) of arms: yes

Environment: historical setting (domestic setting)

Structuring of the pictorial space: not applicable

Patron saint(s): William of Aquitaine

Gesture of the patron saint(s): holding his/her attribute

Type of religious scene: narrative

Religious scene(s) depicted: the Annunciation, the Intercession of Christ and the Virgin

\section{Cat. 295-Type 6A}

[RKD work no. 38867]

COECKE VAN AELST, Pieter (circle of)

Two Wings. A Family in Prayer with Patron Saints (c. 1525-1550)

Size unknown

Whereabouts unknown

Identity of the sitter(s): unknown

Provenance: unknown

Number of portrait(s): 8

Type of person(s): lay (family with children) 
Attitude of the sitter(s): hands clasped

Representation of the sitter(s): full-length

Gaze of the sitter(s): indeterminate

Object(s): yes (dog, prie-dieu, book)

Coat(s) of arms: no

Environment: ecclesial space

Structuring of the pictorial space: indeterminate

Patron saint(s): Peter, Barbara

Gesture of the patron saint(s): introducing

Type of religious scene: indeterminate

Religious scene(s) depicted: none

Cat. 296-Type 6A

[RKD work no. 38870]

COECKE VAN AELST, Pieter (circle of)

Two Wings. Two Women in Prayer with Patron Saints (c. 1525-1550)

$49 \times 40 \mathrm{~cm}$ (each wing)

Berlin, sale Rudolph Lepke (19 March 1918), lot no. 5

Identity of the sitter(s): unknown

Provenance: unknown

Number of portrait(s): 2

Type of person(s): religious (group)

Attitude of the sitter(s): hands clasped, holding a book

Representation of the sitter(s): full-length

Gaze of the sitter(s): indeterminate

Object(s): yes (crosier, book)

Coat(s) of arms: no

Environment: architectural space, no sacred connotation (incomplete)

Structuring of the pictorial space: indeterminate

Patron saint(s): Benedict, Servatius (?)

Gesture of the patron saint(s): introducing

Type of religious scene: indeterminate

Religious scene(s) depicted: none 
Cat. 297-Type 2A

COECKE VAN AELST, Pieter (workshop of)

Triptych of the Adoration of the Magi with Two Men in Prayer (c. 1530)

$102 \times 71 \mathrm{~cm}$ (centre panel) and $102 \times 30.2 \mathrm{~cm}$ (wings)

London, sale Sotheby's (7 December 2006), lot no. 113

BIB L.: GRÖSSINGER 1992, no. 39.

Identity of the sitter(s): unknown

Provenance: unknown

Number of portrait(s): 2

Type of person(s): religious (group: unidentified)

Attitude of the sitter(s): hands clasped, holding a book

Representation of the sitter(s): half-length

Gaze of the sitter(s): into space

Object(s): yes (book)

Coat(s) of arms: no

Environment: historical setting

Structuring of the pictorial space: unified space with discontinuities

Patron saint(s): Melchior, Joseph

Gesture of the patron saint(s): holding his/her attribute

Type of religious scene: narrative

Religious scene(s) depicted: the Adoration of the Magi, St. Ambrose,

St. Augustine

Cat. 298-Type ${ }_{3} \mathrm{C}$

CORNELISZ. VAN OOSTSANEN, Jacob

The Crucifixion with a Monk in Prayer (c. 1500-1550)

$62 \times 43 \mathrm{~cm}$

Antwerp, KMSK, inv. no. $5^{073}$

BIBL.: FRIEDLÄNDER XII, no. 265; Mus. cat.

Antwerp 1998, 93 .

Identity of the sitter(s): unknown

Provenance: unknown

Number of portrait(s): 1

Type of person(s): religious (man alone:

Carthusian monk)

Attitude of the sitter(s): holding a rosary

Representation of the sitter(s): full-length

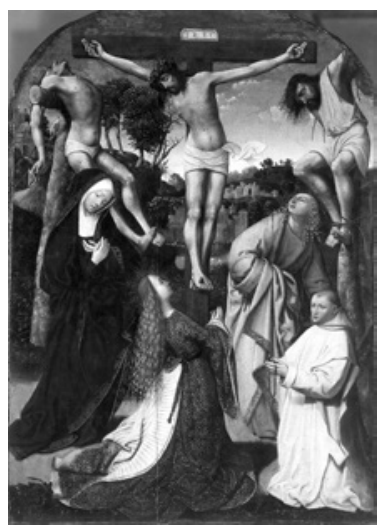


Gaze of the sitter(s): into space

Object(s): yes (rosary)

Coat(s) of arms: no

Environment: historical setting

Structuring of the pictorial space: not applicable

Patron saint(s): none

Gesture of the patron saint(s): not applicable

Type of religious scene: narrative

Religious scene(s) depicted: the Crucifixion

Cat. 299-Type $3 \mathrm{~A}$

CORNELISZ. VAN OOSTSANEN, Jacob

The Nativity with the Family Boelen in

Prayer (1512)

$128 \times 177 \mathrm{~cm}$

Naples, Museo di Capodimonte, inv. no. 3

BIBL.: FRIEDLÄNDER XII, no. 253; SCHOLTENS 1958; CARROLL 1987,

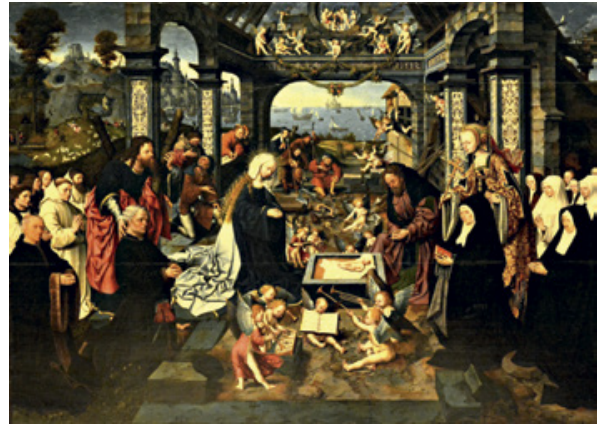
107-12 (with bibl.); Exh. cat. Oostzaan 2000, no. 7; Exh. cat. Alkmaar 2014, no. 13. HISTORICAL INFORMATION: The painting was commissioned by Margriet Boelen in 1512. She is depicted with her family. Her parents, Margriet Claas Heijnensdr. ( $† 1459)$ and Dirk Boel Heinricksz. $(\dagger 1459)$ are portrayed at the place of honour, presented by their patron saints. Margriet Boelen appears on the right, behind her mother. Behind Dirk Boel appears his son Vechter Dirk Boelensz., the only brother of Margriet who was still alive in 1512. The other persons are her brothers and sisters. The two women wearing the brown habit are Agnes and Duife, who were nuns at the convent of St. Lucy in Amsterdam. The work is mentioned in the register of donations of the charterhouse of SintAndries-ter-Zaliger-Haven, in the surroundings of Amsterdam, which indicates that it was destined for this monastery where two brothers of Margriet were monks: Hillebrant ( $† 1501)$ and Jacob ( $† 1508)$. They also appear in the painting.

Identity of the sitter(s): Jan and Margriet Boelen and their children

Provenance: Amsterdam, Charterhouse of Sint-Andries-ter-Zaliger-Haven

Number of portrait(s): 15

Type of person(s): mixed (family)

Attitude of the sitter(s): hands clasped, holding a book 
Representation of the sitter(s): full-length

Gaze of the sitter(s): into space

Object(s): no

Coat(s) of arms: no

Environment: historical setting

Structuring of the pictorial space: not applicable

Patron saint(s): Andrew, Margaret

Gesture of the patron saint(s): introducing

Type of religious scene: narrative

Religious scene(s) depicted: the Nativity

Cat. 30o-Type ${ }_{3} \mathrm{C}$

CORNELISZ. VAN OOSTSANEN, Jacob

The Resurrection with Four Persons in

Prayer (c. 1500-1510)

$114 \times 86 \mathrm{~cm}$

Whereabouts unknown

BIB L.: FRIEDLÄNDER XX, no. 268.

REMARK: The nun depicted on the far right looks like Neel Claes Basgensdr., whose portrait appears in an Adoration of the Magi, attributed to a follower of Cornelisz. van Oostsanen (cat. 306).

Identity of the sitter(s): unknown

Provenance: unknown

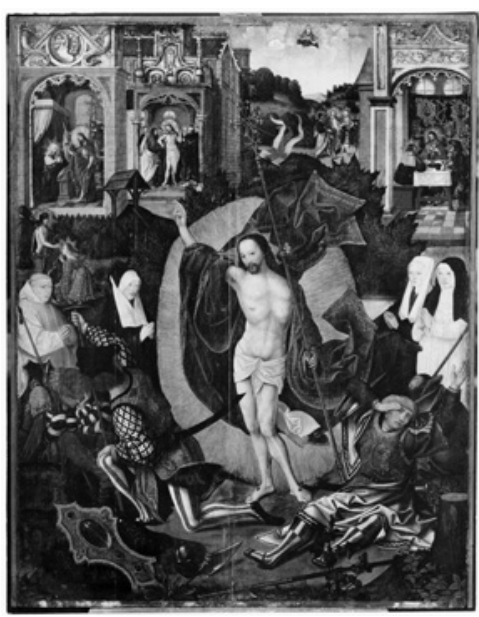

Number of portrait(s): 4

Type of person(s): mixed (unidentified group)

Attitude of the sitter(s): hands clasped

Representation of the sitter(s): full-length

Gaze of the sitter(s): towards the scene

Object(s): no

Coat(s) of arms: no

Environment: historical setting

Structuring of the pictorial space: not applicable

Patron saint(s): none

Gesture of the patron saint(s): not applicable

Type of religious scene: narrative

Religious scene(s) depicted: the Resurrection of Christ 
Cat. 301-Type $2 B$

[R KD work no. 21967]

CORNELISZ. VAN OOSTSANEN, Jacob

Triptych of the Virgin and Child with a Family in Prayer and Patron Saints (before 1518)

$66 \times 57.4 \mathrm{~cm}$ (centre panel) and $65 \times 23.5 \mathrm{~cm}$ (wings)

Rotterdam, Museum Boijmans van Beuningen, inv. no. 3170 (centre panel), Düsseldorf, Kunstmuseum, inv. no. M 1970 13a (inner wings) and private collection (outer wings)

BIB L.:FRIEDLÄNDER XII, no. 240; CARROLL 1987, no. 8; Exh. cat. Rotterdam 1994, no. 68 (with bibl.); Exh. cat. Oostzaan 2000, no. 9.

Identity of the sitter(s): unknown

Provenance: unknown

Number of portrait(s): 6

Type of person(s): lay (family with children)

Attitude of the sitter(s): hands clasped

Representation of the sitter(s): half-length, child in small scale

Gaze of the sitter(s): into space, towards the scene

Object(s): no

Coat(s) of arms: no

Environment: landscape with sacred connotation

Structuring of the pictorial space: distinct spaces

Patron saint(s): Peter, Mary Magdalen

Gesture of the patron saint(s): introducing, indicating

Type of religious scene: hieratic

Religious scene(s) depicted: the Virgin and Child, St. John the Evangelist, St. Peter

Cat. 302-Type 5

[RKD work no. 22594]

CORNELISZ. VAN OOSTSANEN, Jacob

Triptych of St.Jerome (dated 1511 on the centre panel)

$176 \times 113 \mathrm{~cm}$ (centre panel) and $175 \times 44.5 \mathrm{~cm}$ (wings)

Vienna, Kunsthistorisches Museum, inv. no. 646

BIB L.: FRIEDLÄNDER XII, no. 244; HOOGEWERFF III, 103-07; CARROLL 1987, 229-37; Exh. cat. Alkmaar 2014, no. 10.

HISTORICAL INFORMATION: The identity of the portrayed family remains unknown. It has been suggested that the triptych was destined for the high altar of the Hieronymushuis of the Brethren of the Common Life in Utrecht. It has 
also recently been discovered that the embroidered motif of the throne in the centre panel is similar to the motif of the paintings of the pillars at the Oude Kerk in Amsterdam.

Identity of the sitter(s): unknown

Provenance: unknown

Number of portrait(s): 5

Type of person(s): lay (family with children)

Attitude of the sitter(s): hands clasped

Representation of the sitter(s): full-length

Gaze of the sitter(s): into space

Object(s): yes (hat)

Coat(s) of arms: no

Environment: architectural space with sacred connotation

Structuring of the pictorial space: not applicable

Patron saint(s): none

Gesture of the patron saint(s): not applicable

Type of religious scene: hieratic

Religious scene(s) depicted: St. Jerome, St. Ambrose, St. Augustine, St. Gregory,

St. Thomas, St. Andrew, St. Bartholomew, St. Joseph, St. Willibrod, St. Henry,

St. Elizabeth of Hungary, St. Martin, St. Elizabeth of Portugal, St. Catherine,

St. Ursula, the Mass of St. Gregory

Cat. 303-Type $2 \mathrm{~A}$

CORNELISZ.VAN

OOSTSANEN, Jacob

Triptych of the Adoration of the

Magi with a Family in Prayer and

Patron Saints (dated 1517 on the centre panel)

$83 \times 56 \mathrm{~cm}$ (centre panel) and $83 \times 24 \mathrm{~cm}$ (wings)

Amsterdam, Rijksmuseum, inv. no. SK-C-1554

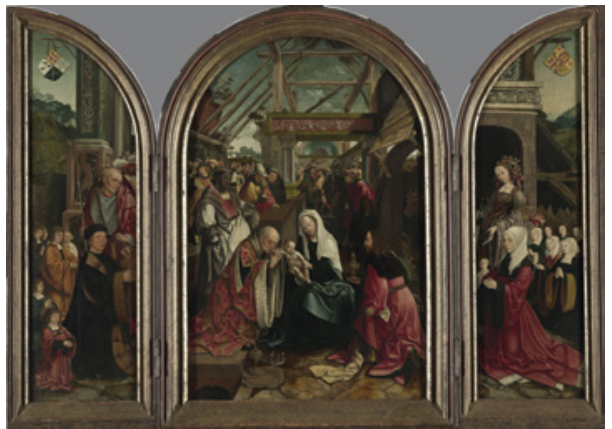

вIBL.: FRIEDLÄNDER XII, no. 239; DUDOK VAN HEEL 1996; Exh. cat. Oostzaan 2000, no. 13; Exh. cat. Rotterdam 1992, no. 32; Mus. cat. Amsterdam 2009 [online], https://www.rijksmuseum.nl/nl/collectie/SK-A-4706/catalogusentry (with bibl.); Exh. cat. Alkmaar 2014, no. 29.

HISTORICAL INFORMATION: The triptych presents two coats of arms on the outer wings and two others on the inner wings, which have been overpainted 
(probably in the seventeenth or eighteenth century). This caused many problems in the process of identifying the portrayed family. In their current state, the coats of arms on the inner wings are those of the Heereman and Ramp families. The coats of arms of the reverse are those of the Heereman and of an unknown family. In 1996, Dudok van Heel claimed that the devotees were Claes Bouwensz., an apothecary from Amsterdam, deceased in 1536, and his second wife Volsckgen Jansdr. A study of the underdrawing nevertheless revealed that the original coat of arms on the right was close to its current state. This suggests that the devotees are members of the Heereman family. The man could be Peter Ghijsbertsz Heereman (1469-1539/41).

Identity of the sitter(s): members of the Heereman family

Provenance: unknown

Number of portrait(s): 15

Type of person(s): lay (family with children)

Attitude of the sitter(s): hands clasped

Representation of the sitter(s): full-length

Gaze of the sitter(s): into space

Object(s): no

Coat(s) of arms: yes (overpainted in the seventeenth or eighteenth century)

Environment: historical setting

Structuring of the pictorial space: unified space with discontinuities

Patron saint(s): Jerome, Catherine

Gesture of the patron saint(s): introducing

Type of religious scene: narrative

Religious scene(s) depicted: the Adoration of the Magi, St. Christopher, St. Anthony

Cat. 304-Type 2A

CORNELISZ. VAN OOSTSANEN, Jacob

Triptych of the Crucifixion with a

Family in Prayer and Patron Saints

(c. 1510-1515)

$30,2 \times 19.8 \mathrm{~cm}$ (centre panel) and

$33.5 \times 10.5 \mathrm{~cm}$ (wings)

Amsterdam, sale Sotheby's

(14 May 2002), lot no. 32

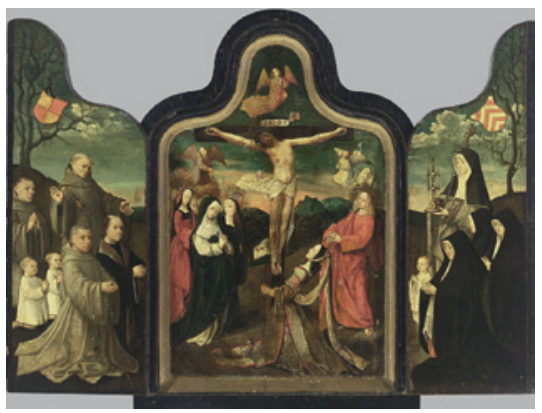

Sale cat. Sotheby's (Amsterdam, 14 May 2002), no. 32.

Identity of the sitter(s): unknown

Provenance: unknown 
Number of portrait(s): 8

Type of person(s): mixed (family with children)

Attitude of the sitter(s): hands clasped

Representation of the sitter(s): full-length

Gaze of the sitter(s): towards the scene

Object(s): no

Coat(s) of arms: yes

Environment: historical setting

Structuring of the pictorial space: continuous space

Patron saint(s): Francis, Barbara

Gesture of the patron saint(s): holding his/her attribute

Type of religious scene: narrative

Religious scene(s) depicted: the Crucifixion

Cat. 305-Type 2 B

[RKD work no. 126739]

CORNELISZ. VAN OOSTSANEN, Jacob

Triptych of the Virgin and Child ('Teylingen Triptych') (c. 1515)

$42 \times 3^{2} \mathrm{~cm}$ (centre panel) and $50 \times 17 \mathrm{~cm}$ (wings)

Berlin, Staatliche Museen zu Berlin, Gemäldegalerie, inv. no. 607

BIB L.: FRIEDLÄNDER XII, no. 241; CARROLL 1987, 152-55; Exh. cat. Oostzaan 2000, no. 12 (with bibl.); Exh. cat. Alkmaar 2014, no. 26.

HISTORICAL INFORMATION: Augustijn van Teylingen (1474-1533), burgomaster of Alkmaar, and his wife Judoca van Nijenburg (1484-1554) have been identified, on the basis of a comparison with their double portraits (Rotterdam, Museum Boijmans van Beuningen, inv. no. 1625-1626).

Identity of the sitter(s): Augustijn van Teylingen and Justina van Egmond

Provenance: unknown

Number of portrait(s): 2

Type of person(s): lay (couple)

Attitude of the sitter(s): hands clasped, holding a book

Representation of the sitter(s): half-length

Gaze of the sitter(s): into space

Object(s): yes (book, rosary)

Coat(s) of arms: no

Environment: landscape with sacred connotation

Structuring of the pictorial space: unified space with discontinuities

Patron saint(s): Augustine, Barbara, the Virgin and Child

Gesture of the patron saint(s): protecting, holding his/her attribute

Type of religious scene: narrative 
Religious scene(s) depicted: the Virgin and Child with St. Anne, St. Elizabeth of Hungary

Cat. 306-Type 2 B

CORNELISZ. VAN OOSTSANEN, Jacob Triptych of the Virgin and Child ('Triptych of Pompejus Occo') (dated 1515 on the frame) $107 \times 72 \mathrm{~cm}($ centre panel) and $107 \times 30 \mathrm{~cm}$ (wings)

Antwerp, KMSK, inv. nos. 523-525

BIBL.: FRIEDLÄNDER XII, no. 242; HAAK 1958, 27-32; CARROLL 1987, 55-57, 157-62;

Exh. cat. Alkmaar 2014, no. 21.

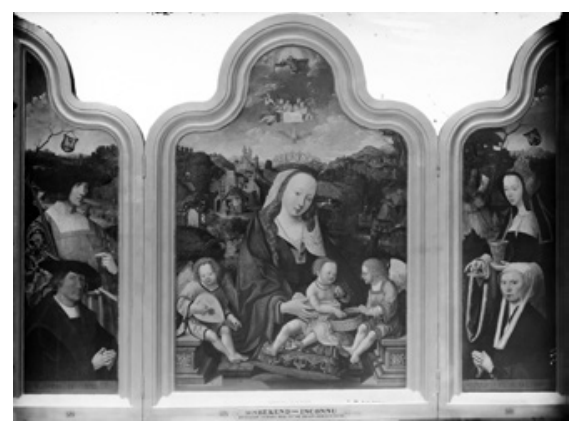

Historical Information: Pompejus Occo (c. 1483-1537) has been identified by his coat of arms. The inscription on the frame also gives the date of commission: Adi 15 iunii $32 a^{\circ} 1515$. Coming from Friesland, Occo spent a few years in Augsburg, before moving to Amsterdam in 1510 and settling into a house in the Kalverstraat, named 'het paradijs'. In Amsterdam, he worked for the Fugger company, in which he was in charge of the commercial interests of German bankers and merchants. His activity led him to accumulate important wealth quite quickly. Occo lent money to the city of Amsterdam and to Margaret of Parma. Between 1505 and 1507, he married Gerbrich Claes, the daughter of Claes Jacob Maetgensz. They had six children. In Amsterdam, Pompejus Occo gravitated in the circles of scholars and humanists. He had close contacts with Alard of Amsterdam and Nicolas Cannius. He rapidly became one of the leading figures of Netherlandish humanism. He possessed one of the biggest libraries of the city. His uncle, Adolf, had a close relationship with Agricola, who bequeathed to him his library. Adolf then gave the books to Pompejus.

Identity of the sitter(s): Pompejus Occo and Gerbrich Claesdr.

Provenance: unknown

Number of portrait(s): 2

Type of person(s): lay (couple)

Attitude of the sitter(s): hands clasped

Representation of the sitter(s): half-length

Gaze of the sitter(s): towards the viewer

Object(s): no

Coat(s) of arms: yes

Environment: landscape with sacred connotation 
Structuring of the pictorial space: unified space with discontinuities

Patron saint(s): Sebastian, Mary Magdalen

Gesture of the patron saint(s): holding his/her attribute

Type of religious scene: hieratic

Religious scene(s) depicted: the Virgin and Child, Adam and Eve

\section{Cat. 307-Type 2B}

CORNELISZ. VAN OOSTSANEN, Jacob (after)

Triptych of the Virgin and Child ('Triptych of the Sampson Family') (dated 1518 on the frame)

$118.5 \times 83.5 \mathrm{~cm}$ (centre panel) and $118.5 \times 41.5 \mathrm{~cm}($ wings $)$

Uden, Museum voor Religieuze Kunst, inv. no. 1754

BIB L.: Exh. cat. Den Bosch 1990, no. 124; Exh. cat. Oostzaan 2000, no. 10; Exh. cat. Alkmaar 2014, no. 25b.

HistoricAl information: The devotees are Joris Sampson, Engelken Coolen and their children. This family came from s'Hertogenbosch, where Joris acted as burgomaster. From 1505-1506, he was juror of the Brotherhood of Our Lady and then Provoost from 1525-1527. He died from the plague in 1532 . His wife passed away shortly before 1540 . In the triptych, which is dated 1518 , Joris is depicted at the age of thirty-seven and Engelken at thirty-five, as the inscriptions on the prie-dieu indicate: ano $d m i{ }_{1518}-37-\left(\right.$ on the left); $A^{\circ} d m i .1518-$ 35 - (on the right). The reverse of the wings contains the couple's motto (Spe vivo cum timore) and sixteen depictions of their initials. This must be related to the fact that Joris and Engelken celebrated their sixteenth wedding anniversary in 1518. In all likelihood, they commissioned the triptych on that occasion.

Identity of the sitter(s): Joris Sampson, Engelken Coolen and their children

Provenance: Aarle-Rixtel (Laarbeek), church of Our Lady (?)

Number of portrait(s): 9

Attitude of the sitter(s): hands clasped

Type of person(s): mixed (family with children)

Representation of the sitter(s): full-length, small scale

Gaze of the sitter(s): towards the scene

Object(s): yes (prie-dieu, book)

Coat(s) of arms: yes

Environment: landscape with sacred connotation

Structuring of the pictorial space: continuous space

Patron saint(s): George, Anne

Gesture of the patron saint(s): introducing, holding his/her attribute

Type of religious scene: hieratic

Religious scene(s) depicted: the Virgin and Child 
Cat. 3o8-Type ${ }_{3} \mathrm{C}$

CORNELISZ. VAN OOSTSANEN, Jacob (after) The Nativity with a Family in Prayer (dated 1526) $75 \times 55 \mathrm{~cm}$

Spain, private collection

Identity of the sitter(s): unknown

Provenance: unknown

Number of portrait(s): 8

Type of person(s): mixed (family with children)

Attitude of the sitter(s): hands clasped

Representation of the sitter(s): full-length

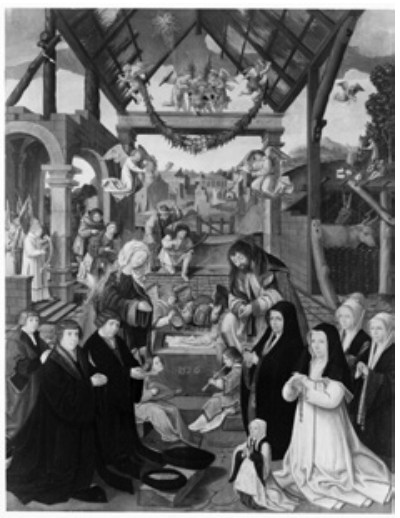

Gaze of the sitter(s): into space, towards the ground

Object(s): yes (rosary)

Coat(s) of arms: no

Environment: historical setting

Structuring of the pictorial space: not applicable

Patron saint(s): none

Gesture of the patron saint(s): not applicable

Type of religious scene: narrative

Religious scene(s) depicted: the Nativity

Cat. 309-Type 6A

CORNELISZ. VAN OOSTSANEN, Jacob (attributed to)

Fragments. Portrait of the Family Elbertsz.-

Schellingh in Prayer (c. 1500-1525)

$90 \times 57 \mathrm{~cm}$ (each panel)

Amsterdam, Amsterdam Museum, SA

8173 and SA 7304

BIB L.: FRIEDLÄNDER XII, no. 287;

CARROLL 1987, no. 31; Mus. cat.
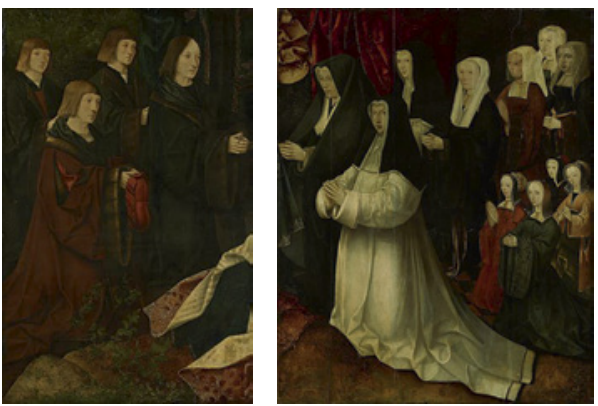

Amsterdam 1976, 177; Exh. cat. Alkmaar 2014, no. 16 (with bibl.).

HISTORICAL INFORMATION: These panels are fragments of a memorial painting commissioned by Margriet Corsgendr. (c. 1480-1556) to honour the memory of her parents, Corgsen and Geertruyt Elbertsz., as indicated by the inscription: Item in't iaer ons here MCCCCC ende III two dagen voer Korsdach starf korsgen Elbertsen myn lieve ... et in't iaer ons heren MCCCC ende ses op sinte 
Ceciliendach starf Gheerte Kortens myn lieve.... In all likelihood, the religious theme of the painting was the Crucifixion. The piece of embroidered cloth at the feet of the men could indeed be a part of the dress of Mary Magdalen, kneeling next to the cross. The memorial work was destined for the Convent of the Sisters of St. Agnes (Agnietenklooster) of Amsterdam, where Margriet was a nun. The Elbertsz. were a rich family of Amsterdam, where they played an active role in the religious life of the city. The sons of Corgsen and Geertruyt held important political positions in the city council.

Identity of the sitter(s): Corgsen Elbertsz., Geertruyt van der Schellingh Hendricksdr. and their children

Provenance: Amsterdam, Convent of the Sisters of St. Agnes (Agnietenklooster), refectory

Number of portrait(s): 15

Type of person(s): mixed (family with children)

Attitude of the sitter(s): hands clasped, holding a hat

Representation of the sitter(s): full-length

Gaze of the sitter(s): indeterminate

Object(s): yes (hat)

Coat(s) of arms: no

Environment: indeterminate

Structuring of the pictorial space: indeterminate

Patron saint(s): none

Gesture of the patron saint(s): not applicable

Type of religious scene: indeterminate

Religious scene(s) depicted: none

Cat. 310-Type 2A

CORNELISZ. VAN OOSTSANEN, Jacob (attributed to)

Triptych of Christ and the Woman Taken in Adultery with a Couple in Prayer and Patron Saints (dated 1526 on the centre panel)

$114 \times 68 \mathrm{~cm}$ (centre panel) and $119 \times 28$ $\mathrm{cm}$ (wings)

Brussels, MRBAB, inv. no. 2590

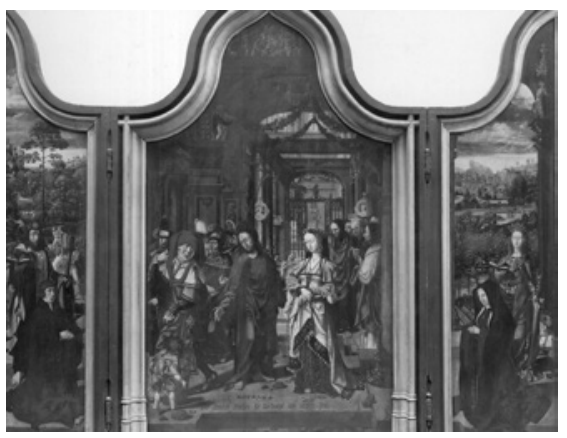

BIB L.: Mus. cat. Brussels 1984, 215.

Identity of the sitter(s): unknown

Provenance: unknown 
Number of portrait(s): 2

Type of person(s): lay (couple)

Attitude of the sitter(s): hands clasped

Representation of the sitter(s): full-length

Gaze of the sitter(s): into space

Object(s): no

Coat(s) of arms: no

Environment: historical setting

Structuring of the pictorial space: distinct spaces

Patron saint(s): James (?), Catherine

Gesture of the patron saint(s): holding his/her attribute

Type of religious scene: narrative

Religious scene(s) depicted: Christ and the woman taken in adultery,

St. Cornelius, St. Wilgeforte

Cat. 311-Type ${ }_{3} \mathrm{C}$

CORNELISZ. VAN OOSTSANEN, Jacob (circle of)

The Adoration of the Magi with Two Persons in Prayer (c. 1545)

$79.4 \times 65.4 \mathrm{~cm}$

New York, sale Sotheby's (12 January 1995), lot no. 12

BIB L.: DUDOK VAN HEEL 1995.

HISTORICAL INFORMATION: Claes Hendriksz. Basgen (1488-1563) was a wealthy merchant, who acted as burgomaster and city councillor of Amsterdam.

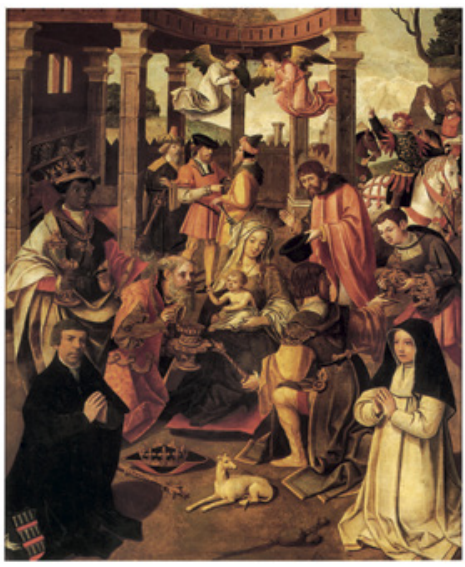
$\mathrm{He}$ is depicted with his daughter from his first marriage, Neel Claes Basgensdr. (1528-1594). Neel entered the Oudenonnenklooster (Mariënveld) of Amsterdam c. 1545 as an Augustinian canoness. In 1573, she is mentioned as the prior (mater). Claes and Neel have been identified, on the basis of Neel's will, dating from 21 July 1582 , which mentions a painting of the Adoration of the Magi with the portrait of her father that was to be bequeathed to her half-brother, Jacob Claeszn. Bas (1536-1589): een bordt van de drie coningen daer haer vaders figuer in staet. The coat of arms in the painting belongs to the Bas family and was added in the seventeenth century. According to Dudok van Heel, the painting could have been commissioned on 
the occasion of the entry of Neel in the Oudenonnenklooster, but there is no evidence allowing to justify this assertion.

Identity of the sitter(s): Claes Hendriksz. Basgen and Neel Claes Basgensdr.

Provenance: Amsterdam, Oudenonnenklooster (Mariënveld) (?)

Number of portrait(s): 2

Type of person(s): mixed (family)

Attitude of the sitter(s): hands clasped

Representation of the sitter(s): full-length

Gaze of the sitter(s): into space

Object(s): no

Coat(s) of arms: yes (dating from the seventeenth century)

Environment: historical setting

Structuring of the pictorial space: not applicable

Patron saint(s): none

Gesture of the patron saint(s): not applicable

Type of religious scene: narrative

Religious scene(s) depicted: the Adoration of the Magi

\section{Cat. 312-Type $3 \mathrm{~A}$}

CORNELISZ.VAN OOSTSANEN, Jacob (circle of) The Lamentation with two Men in Prayer and Patron Saints (after 1516)

$69.7 \times 53 \mathrm{~cm}$

Amsterdam, Museum Ons' Lieve Heer op Solder, inv. no. Br. 254

BIB L.: Exh. cat. Utrecht 1999-2000, no. 85 .

Identity of the sitter(s): unknown

Provenance: unknown

Number of portrait(s): 2

Type of person(s): lay (group indeterminate)

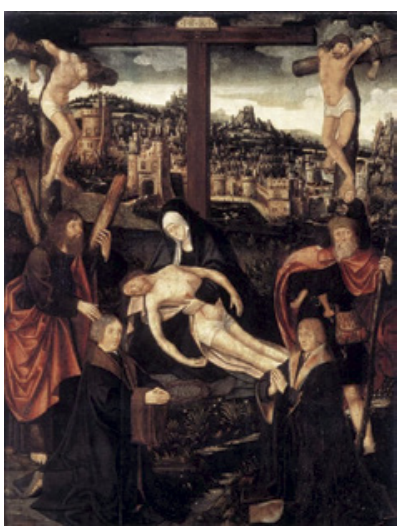

Attitude of the sitter(s): hands clasped

Representation of the sitter(s): full-length

Gaze of the sitter(s): into space

Object(s): no

Coat(s) of arms: no

Environment: historical setting

Structuring of the pictorial space: not applicable

Patron saint(s): Andrew, Christopher 
Gesture of the patron saint(s): protecting, holding his/her attribute Type of religious scene: narrative

Religious scene(s) depicted: the Lamentation

Cat. 313-Type ${ }_{3} \mathrm{C}$

CORNELISZ. VAN OOSTSANEN, Jacob (follower of)

The Crucifixion with two Women in Prayer (c. 1480-1530)

Size unknown

France, private collection

Identity of the sitter(s): unknown

Provenance: unknown

Number of portrait(s): 2

Type of person(s): lay (group indeterminate)

Attitude of the sitter(s): hands clasped

Representation of the sitter(s): full-length

Gaze of the sitter(s): into space

Object(s): no

Coat(s) of arms: no

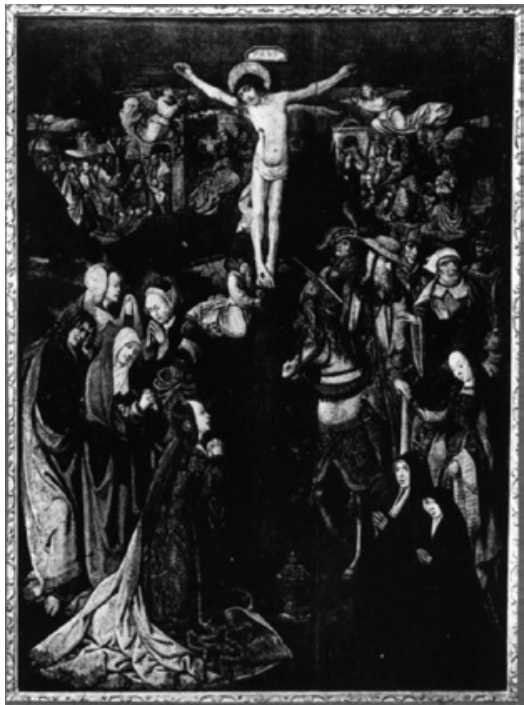

Environment: historical setting

Structuring of the pictorial space: not applicable

Patron saint(s): none

Gesture of the patron saint(s): not applicable

Type of religious scene: narrative

Religious scene(s) depicted: the Crucifixion

Cat. 314-Type $2 A$

CORNELISZ. VAN OOSTSANEN, Jacob (follower of)

Triptych of the Nativity with a Family in Prayer and Patron Saints (c. 1525-1550)

$89 \times 136 \mathrm{~cm}$ (open)

Whereabouts unknown

Identity of the sitter(s): unknown

Provenance: unknown

Number of portrait(s): 12

Type of person(s): mixed (family with children)

Attitude of the sitter(s): hands clasped 
Representation of the sitter(s): half-length, children in small scale

Gaze of the sitter(s): into space, towards the viewer

Object(s): yes (hat)

Coat(s) of arms: no

Environment: historical setting

Structuring of the pictorial space: unified space with discontinuities

Patron saint(s): John the Evangelist, Ursula

Gesture of the patron saint(s): introducing

Type of religious scene: narrative

Religious scene(s) depicted: the Nativity

Cat. 315-Type ${ }_{3} \mathrm{C}$

CORNELISZ. VAN OOSTSANEN, Jacob (workshop of?)

Triptych of the Last Judgement with the Danish Royal Family in Prayer

(c. 1515-1526)

$233.5 \times 155 \mathrm{~cm}$ (open)

Copenhagen, Statens Museum for Kunst, inv. no. 7278

BIBL.: HOOGEWERFF III, 124; HENDRIKMAN 2005, 192-94; MEUWISSEN and VAN LEERDAM 2011.

Historical INFORMATION: The triptych shows Christian II, King of Denmark, with his wife Isabella of Austria. Born in 1481, Christian II acceded to the throne in 1513 and had a troubled reign. Well-known for his long-term adulterous relationship with Duveke Nicolaasdr. ( $\dagger 1517)$, he married Isabella of Austria, sister of Charles v and niece of Margaret of Austria, in 1515. They had six children, three of them deceased at a young age. Isabella passed away in ${ }^{1526}$. The original location of the triptych cannot be determined with certainty. The work might come from the Carmelite priory of Helsingör, which had close ties with the Danish royal family. Two hypotheses have been formulated with regard to its dating: the triptych might have been commissioned for the wedding of the king in 1515 (according to Hendrikman, who attributes the work to Jan Mostaert). Another possibility would be a commission around 1521, during the diplomatic journey of Christian II through the Low Countries. At this time, the king was seeking the support of his family-in-law after his invasion of Sweden in 1520. This hypothesis was made by Meuwissen and Van Leerman, who also state that the triptych could have been commissioned in 1526 to commemorate the deceased queen. During his trip in 1521, Christian II visited Charles v's court in Brussels and went twice to Amsterdam, where he was welcomed by Pompejus Occo (see cat. 306). He met there several humanists and artists, including Jacob 
Cornelisz. van Oostsanen. After his return to Denmark, the political situation deteriorated. In 1523 the royal couple was forced to go into exile in the Low Countries, where the queen died. In 1531, Christian returned to Denmark and tried vainly to recover his territory. He was captured and held in jail until his death in 1559 .

Identity of the sitter(s): the Danish royal family

Provenance: Helsingör, Carmelite priory (?)

Number of portrait(s): 2

Type of person(s): lay (couple)

Attitude of the sitter(s): hands clasped

Representation of the sitter(s): full-length

Gaze of the sitter(s): towards the viewer

Object(s): yes (prie-dieu, book, helmet, dog)

Coat(s) of arms: yes

Environment: historical setting

Structuring of the pictorial space: not applicable

Patron saint(s): none

Gesture of the patron saint(s): not applicable

Type of religious scene: narrative

Religious scene(s) depicted: the Last Judgement

Cat. 316-Type ${ }_{3} \mathrm{C}$

[Link to the Friedländer 3.o Database]

CORNELISZ. VAN OOSTSANEN, Jacob (workshop of)

Landscape with the Legends of St. Roch, St. Christopher and St. Anthony with a Couple in Prayer (c. 1525-1550)

$5^{6} \times 84 \mathrm{~cm}$

Esztergom, Kereszteny Muzeum, inv. no. 55.325

BIB L.: FRIEDLÄNDER XII, no. 280.

Identity of the sitter(s): unknown

Provenance: unknown

Number of portrait(s): 2

Type of person(s): lay (couple)

Attitude of the sitter(s): holding a rosary

Representation of the sitter(s): full-length

Gaze of the sitter(s): into space

Object(s): yes (rosary)

Coat(s) of arms: no

Environment: historical setting 
Structuring of the pictorial space: not applicable

Patron saint(s): none

Gesture of the patron saint(s): not applicable

Type of religious scene: narrative

Religious scene(s) depicted: the legends of St. Roch, St. Christopher and St. Anthony

\section{Cat. 317-Type 6A}

[RKD work no. 22689]

CORNELISZ. VAN OOSTSANEN, Jacob (workshop of)

Two Wings. A Man with St. Christopher; St. Catherine (c. 1516)

$70 \times 26.5 \mathrm{~cm}$ (each wing)

Rotterdam, Museum Boijmans van Beuningen, inv. nos. 3378-3379

BIBL.: FRIEDLÄNDER XII, no. 247; CARROLL 1987, 320-22, 325; Exh. cat. Rotterdam 1994, no. 71-72 (with bibl.); Exh. cat. Alkmaar 2014, no. 27.

HistoriCAL INFORMATION: The coat of arms located at the feet of the canon is that of the Van Rietwijk family from Alkmaar. The only member of this family who was canon in the early sixteenth century is Dirk Willemsz. van Rietwijk. He was priest and canon of the St. Catherine's chapter of the slotkapel at Egmond. The presence of St. Catherine on the right wing confirms this identification. Dirk Willemsz. was born c. 1480 and studied at the University of Leuven. He became priest in 1504 and joined the St. Catherine's chapter in 1507. He died in 1516 .

Identity of the sitter(s): Dirk Willemsz. van Rietwijk

Provenance: unknown

Number of portrait(s): 1

Type of person(s): religious (man alone: canon)

Attitude of the sitter(s): hands clasped

Representation of the sitter(s): full-length

Gaze of the sitter(s): indeterminate

Object(s): no

Coat(s) of arms: yes

Environment: landscape, no sacred connotation (incomplete)

Structuring of the pictorial space: indeterminate

Patron saint(s): Christopher

Gesture of the patron saint(s): introducing

Type of religious scene: indeterminate

Religious scene(s) depicted: St. Catherine, St. Adalbert, St. Jeroen van Noordwijk 
Cat. 318-Type 6A

[RKD work no. 22693]

CORNELISZ. VAN OOSTSANEN, Jacob (workshop of)

Two Wings. Two Persons in Prayer with Patron Saints (c. 1520-1525)

$50.8 \times 20.4 \mathrm{~cm}$ (each wing)

Chicago, Chicago Art Institute, inv. nos. 36240-41

BIBL.: CARROLL 1987, 320-22, 325-26; Mus. cat. Chicago 2008, 180-84 (with bibl.).

Identity of the sitter(s): unknown

Provenance: unknown

Number of portrait(s): 2

Type of person(s): religious (group)

Attitude of the sitter(s): hands clasped

Representation of the sitter(s): full-length

Gaze of the sitter(s): indeterminate

Object(s): no

Coat(s) of arms: no

Environment: architectural space, no sacred connotation (incomplete)

Structuring of the pictorial space: indeterminate

Patron saint(s): Matthias (?), Peter

Gesture of the patron saint(s): holding his/her attribute, introducing

Type of religious scene: indeterminate

Religious scene(s) depicted: St. Andrew, St. Thomas

Cat. 319-Type 6A

[RKD work no. 46804]

COXCIE, Michiel (attributed to)

Two Wings. A Couple in Prayer with Patron Saints (c. 1500-1550)

$82 \times 25 \mathrm{~cm}$ (each wing)

New York, sale Christie's (6 April 2006), lot no. 21

BIB L.: Sale cat. Christie's (New York, 6 April 2006), no. 21.

Historical information: The Count Guillaume de Bourgoing, Lord of Poissons, and his wife Philippa le Clerc du Tremblay, have been identified by a comparison with their portraits in a double portrait made by Michiel Coxcie in 1536 (Paris, collection de Bourgoing; see Burlington Magazine 631 (1955), 317). Another double portrait of the couple, produced by an anonymous Netherlandish artist active in France is preserved in a private collection (see: exh. cat. Paris 2017, no. 144). Guillaume de Bourgoing was lieutenant-général in the bailiwick of Saint-Pierre-le-Moustier (in the region of Nevers) and 
councillor at the Parliament of Paris from 1523 onwards. He married Philippa in 1525 .

Identity of the sitter(s): Guillaume de Bourgoing and Philippa le Clerc du Tremblay (?)

Provenance: unknown

Number of portrait(s): 2

Type of person(s): lay (couple)

Attitude of the sitter(s): hands clasped

Representation of the sitter(s): half-length

Gaze of the sitter(s): indeterminate

Object(s): no

Coat(s) of arms: no

Environment: neutral space (incomplete)

Structuring of the pictorial space: indeterminate

Patron saint(s): Charlemagne, Elizabeth of Hungary

Gesture of the patron saint(s): holding his/her attribute

Type of religious scene: indeterminate

Religious scene(s) depicted: none

Cat. 320-Type 5

CRUPERS, Willem (painted parts) and VAN COTHEM, Jacob (carved parts)

Altarpiece of the Averbode Passion

(c. 1514)

$161 \times 170 \mathrm{~cm}$ (open)

Antwerp, Museum Vleeshuis, inv. no. II $25 \mathrm{~A} 1$

BIBL.: MARIJNISSEN 1961; BUYLE

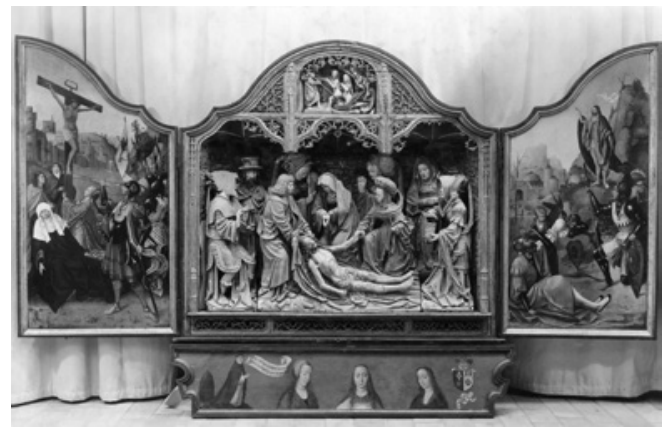
and VANTHILLO 2000, 122-23.

HISTORICAL INFORMATION: The triptych comes from the Premonstratensian abbey of Averbode, as an archival document held at the abbey testifies. According to this source, the triptych was bought in Antwerp in 1514 by Jan van Cothem through the painter Willem Cruypers. The sum of thirty-nine guilders was paid by Nicolaas Huybs, a lay brother who entered the abbey in 1510 and died in 1528. Nicolaas Huybs was the doorman of the abbey and was also in charge of the beekeeping work. It was precisely this activity that allowed him to pay the cost of the commission, as stated in the document. The lay brother is depicted on the predella, next to a banderole with the inscription: Frater 
Nicolaus de Poppel, conversus et portarius averbodiensis per apes me quesivit. The coat of arms painted on the predella belongs to the abbot Gérard van der Scaeft. The triptych was destined for the altar of the Holy Confessors.

Identity of the sitter(s): Nicolaas Huybs

Provenance: Premonstratensian abbey of Averbode, altar of the Holy Confessors

Number of portrait(s): 1

Type of person(s): religious (man alone: Premonstratensian brother)

Attitude of the sitter(s): hands clasped

Representation of the sitter(s): full-length, small scale

Gaze of the sitter(s): into space

Object(s): yes (banderole)

Coat(s) of arms: yes

Environment: neutral space

Structuring of the pictorial space: distinct spaces

Patron saint(s): none

Gesture of the patron saint(s): not applicable

Type of religious scene: narrative

Religious scene(s) depicted: the Crucifixion, the Resurrection of Christ, the Ecce Homo, Christ bearing the cross, the Lamentation, personifications of Faith, Belief and Love

Cat. 321-Type 6A

DARET, Jacques

Four Panels of the 'Altarpiece of St. Vaast' (c. 1460$)$

$57 \times 5^{2} \mathrm{~cm}$ (each wing)

Berlin, Staatliche Museen zu Berlin, Gemäldegalerie, inv. no. 542 et 527 (panel 1 and 3), Madrid, Fundación Colección Thyssen-Bornemisza, inv. no. 1935.17 (panel 2), Paris, Petit Palais (panel 4) BIB L.:FRIEDLÄNDER II, no. 78-81; EISLER 1989, no. 6; THÜRLEMANN 2002, no. III.A

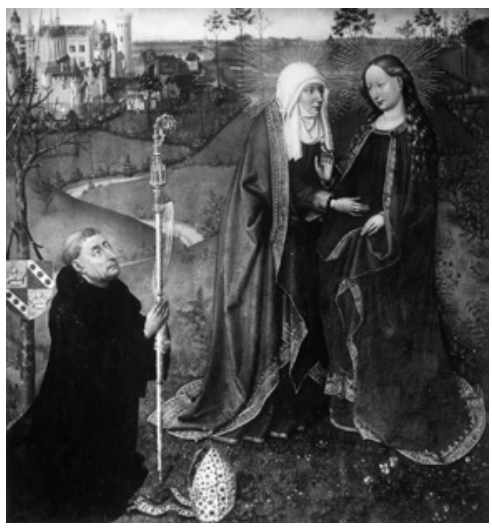
(with bibl.); Exh. cat. Frankfurt and Berlin 2009, no. 13 (with bibl.). HISTORICAL INFORMATION: The four panels were parts of a Marian altarpiece, commissioned by Jean du Clercq (1376-1462), abbot of the Benedictine abbey of St. Vaast in Arras. Jean du Clercq entered the abbey in 1391 and 
became abbot in 1428. During his abbacy, he completed refurbishment works of the abbey, started in the thirteenth century. In 1433-1434, he commissioned the Altarpiece of the Virgin from Jacques Daret. The work was destined for his funerary chapel, which was dedicated to the Virgin and which was located in the great choir of the church. The dedication of the altarpiece took place on 8 September 1435 (feast of the birth of the Virgin), in the presence of Philip the Good. A few weeks earlier, prestigious visitors, including the cardinal Albergati and Heinrich von Werl, had been invited in St. Vaast to see the altarpiece.

Identity of the sitter(s): Jean du Clercq

Provenance: Benedictine abbey of St. Vaast, high choir

Number of portrait(s): 1

Type of person(s): religious (man alone: Benedictine abbot)

Attitude of the sitter(s): hands clasped

Representation of the sitter(s): full-length

Gaze of the sitter(s): towards the scene

Object(s): yes (crosier, mitre)

Coat(s) of arms: no

Environment: historical setting

Structuring of the pictorial space: indeterminate

Patron saint(s): none

Gesture of the patron saint(s): not applicable

Type of religious scene: narrative

Religious scene(s) depicted: the Visitation, the Adoration of the Magi, the Presentation at the temple, the Nativity

Cat. 322-Type $4 \mathrm{~A}$

DAVID, Gerard

Diptych of the Crucifixion ('Diptych of Bernardijn de Salviati') (c. 1501)

$104.5 \times 94.3 \mathrm{~cm}$ (each wing)

London, NG, inv. no. NG 1045 (left wing) and Berlin, Staatliche Museen zu Berlin, Gemäldegalerie, inv. no. 573 (right wing) BIBL.: FRIEDLÄNDER VIb, no. 185, 219; Corpus London I, no. 40;VAN MIEGROET 1989, no. 16, 22 (with bibl.); CAMPBELL 1998, 122-33 (with bibl.); VAN DER VELDEN 2006.

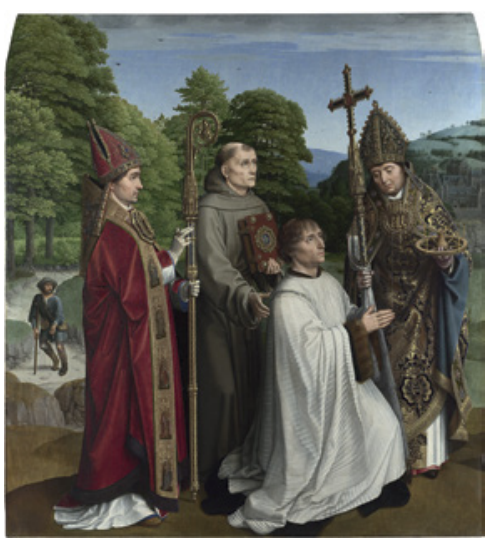


HISTORICAL INFORMATION: Bernardijn Salviati is the illegitimate child of Borromeo Salviati (a Florentine merchant established in Bruges) and Christine van Rossem. He was canon of the collegiate church of St. Donatian in Bruges from 1498 up to 1519 . Born in the 146os, Bernardijn studied in Leuven. In September 1502, he obtained letters of legitimation. In 1510, he became sacristan of the church of Sint-Kruis, whose priest was Richard Visch van de Capelle (see cat. 325). Bernardijn died in 1519 and was buried next to his mother in a chapel he founded at the church of St. Donatian and in which he founded several anniversary masses for his mother.

Identity of the sitter(s): Bernardijn de Salviati

Provenance: Bruges, church of St. Donatian

Number of portrait(s): 1

Type of person(s): religious (man alone: canon)

Attitude of the sitter(s): hands clasped

Representation of the sitter(s): full-length

Gaze of the sitter(s): towards the scene

Object(s): no

Coat(s) of arms: no

Environment: historical setting

Structuring of the pictorial space: continuous space

Patron saint(s): Donatian, Martin, Bernardino

Gesture of the patron saint(s): introducing

Type of religious scene: narrative

Religious scene(s) depicted: the Crucifixion

\section{Cat. 323-Type 6B}

DAVID, Gerard

Portrait of an Augustinian Friar in Prayer (c. 1515)

$35.9 \times 28.6 \mathrm{~cm}$

London, NG, inv. no. NG 710

BIB L.: FRIEDLÄNDER VIb, no. 223;

Corpus London I, no. 39; VAN MIEGROET

1989, no. 34; CAMPBELL 1998, 116-21

(with bibl.).

Identity of the sitter(s): unknown

Provenance: unknown

Number of portrait(s): 1

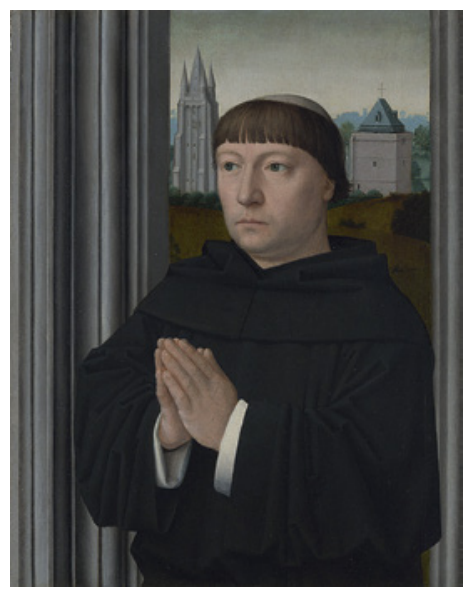


Type of person(s): religious (man alone: Augustinian friar)

Attitude of the sitter(s): hands clasped

Representation of the sitter(s): half-length

Gaze of the sitter(s): indeterminate

Object(s): no

Coat(s) of arms: no

Environment: architectural space, no sacred connotation (incomplete)

Structuring of the pictorial space: indeterminate

Patron saint(s): none

Gesture of the patron saint(s): not applicable

Type of religious scene: indeterminate

Religious scene(s) depicted: none

\section{Cat. 324-Type 3 B}

DAVID, Gerard

The Tree ofJesse with two Men in Prayer

(c. 1490)

$118 \times 69 \mathrm{~cm}$

Lyon, Musée des Beaux-Arts, inv. no. 89.70

BIB L.: FRIEDLÄNDER VIb, no. 196; VAN MIEGROET 1989, no. 46; Exh. cat. Bruges 1998 (vol. 2), no. 9 (with bibl.).

Identity of the sitter(s): unknown

Provenance: unknown

Number of portrait(s): 2

Type of person(s): lay (group)

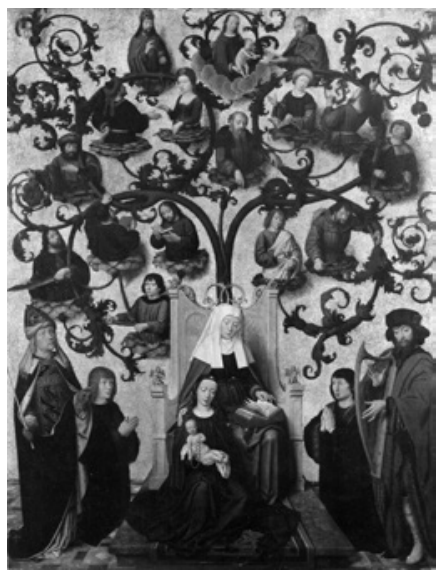

Attitude of the sitter(s): hands clasped

Representation of the sitter(s): full-length

Gaze of the sitter(s): towards the scene

Object(s): no

Coat(s) of arms: no

Environment: neutral space

Structuring of the pictorial space: not applicable

Patron saint(s): Aaron, David

Gesture of the patron saint(s): holding his/her attribute

Type of religious scene: hieratic

Religious scene(s) depicted: the Virgin and Child with St. Anne, the Tree of Jesse 
Cat. 325 - Type $3 \mathrm{D}$

DAVID, Gerard

The Virgin and Child with Saints and Richard de Visch van der Capelle in Prayer (c. 1510) $107.7 \times 146.5 \mathrm{~cm}$

London, NG, inv. no. NG 1432

BIBL.: FRIEDLÄNDER VIb, no. 216; Corpus London I, no. 43; VAN MIEGROET 1989, no. 24; CAMPBELL 1998, 146-57

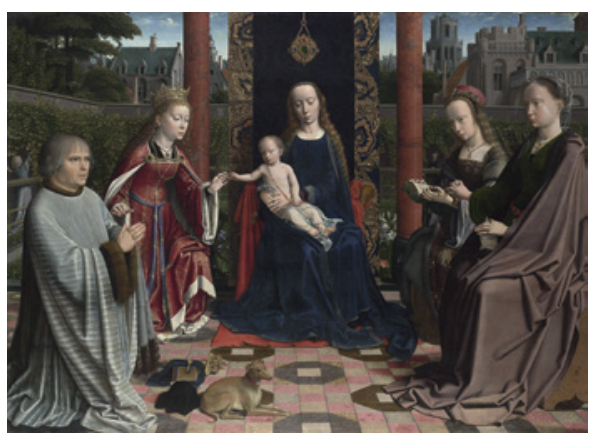
(with bibl.).

historical information: Richard de Visch van der Capelle has been identified, on the basis of the small coat of arms painted on the dog's collar. Richard was the illegitimate son of Richard van der Capelle and Jacqueline van Zijl. After studying canon law, he made a long ecclesiastical career in Bruges. He entered the chapter of St. Donatian in 1457, and became cantor in 1463. He also made a political career at the Burgundian court: he was notably advisor of the Council of State and ecclesiastical councillor for the Grand conseil in Mechelen. Richard de Visch acted as a benefactor for the church of St. Donatian: he founded several masses and an altar dedicated to St. Catherine in the St. Anthony's chapel, which belonged to his family. In all likelihood, the painting was destined for this altar, under which he was buried.

Identity of the sitter(s): Richard de Visch van der Capelle

Provenance: Bruges, church of St. Donatian (St. Catherine's altar?)

Number of portrait(s): 1

Type of person(s): religious (man alone: canon)

Attitude of the sitter(s): hands clasped

Representation of the sitter(s): full-length

Gaze of the sitter(s): towards the scene

Object(s): yes (dog, book, hat, staff)

Coat(s) of arms: yes (on the collar of the dog)

Environment: enclosed garden

Structuring of the pictorial space: not applicable

Patron saint(s): none

Gesture of the patron saint(s): not applicable

Type of religious scene: hieratic

Religious scene(s) depicted: the Virgin and Child with St. Catherine, St. Barbara, St. Mary Magdalen 
Cat. 326-Type 3D

DAVID, Gerard

The Virgo inter Virgines with a Couple in Prayer (1509)

$118 \times 212 \mathrm{~cm}$

Rouen, Musée des Beaux-Arts, inv. no. D.803

BIBL.: FRIEDLÄNDER VIb, no. 215;

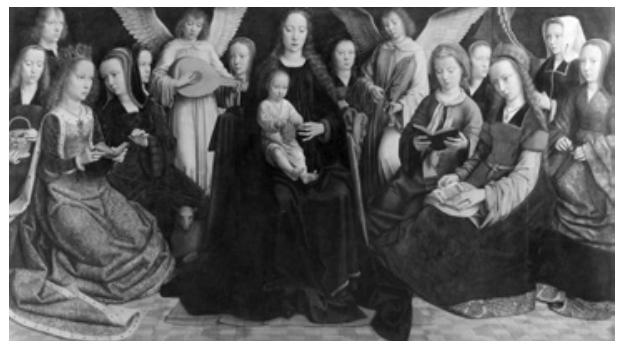
VAN MIEGROET 1989, no. 29.

HISTORICAL INFORMATION: On the basis of a drawing of the Recueil d'Arras, the portrayed couple has been identified by Weale as the painter Gerard David and his wife Cornelia Cnoop. David offered the painting to the Carmelite convent of Sion in Bruges in 1509. It was destined for the high altar of its church, as an inventory of 1537 indicates: item een schoon tafele van olywarwe staende upden / hooghen autaer Maria met haer kindekin in zijn hande / kins hebbendeeen druve daer bij twee inghelkins / ende vele heleghe maechdekins ghemaect ende ghe / ghevene bij Meestre gheraert david procuresse / daen ter tijt onsen eerweerdeghe vader broeder ysenbaert de bru / prioresse sustere lisbette vander panneelleanno XVC ix / thont daer de vorseide beelde upghemaakt es / betaelde de huusvrauwe van lambijn / die hier begraven es men noumde haer ghemeenlic / packette in mijns heeren hof zij dedeonse gasthuuse / vele diversche aalmoesenen sij ghaf oocvoortijts / een groot arduinsteene wijwater vat dat daer staet / in de voorkercke bij de sepulture van haren man / de dueren vander vaste tafele waren buuten on / gheschildert ende ooc binnen ende als nu anno xvc xxxvij / afghedaen om te schilderen ende te warken / de cost daer of gheghevene bij diversche personen / ter procuratie van sustere jacqmine bernaerts. This document reveals that the wooden panel was not paid by David himself but by a woman called Packette. She was the housekeeper of a man called Lambijn and was buried in the church. Gerard David and his wife are thus not the only donors of this painting.

Identity of the sitter(s): Gerard David and Cornelia Cnoop

Provenance: Bruges, Carmelite Convent of Sion

Number of portrait(s): 2

Type of person(s): lay (couple)

Attitude of the sitter(s): hands clasped

Representation of the sitter(s): full-length

Gaze of the sitter(s): towards the scene

Object(s): no 
Coat(s) of arms: no

Environment: neutral space

Structuring of the pictorial space: not applicable

Patron saint(s): none

Gesture of the patron saint(s): not applicable

Type of religious scene: hieratic

Religious scene(s) depicted: the Virgin and Child, St. Cecilia, St. Agnes, St. Lucy, St. Catherine, St. Barbara, St. Apollonia, St. Fausta, St. Godelieve

Cat. 327-Type ${ }_{3} \mathrm{C}$

DAVID, Gerard

The Wedding at Cana with Jean de Sedano and his Family (c. 1501-1518)

$100 \times 128 \mathrm{~cm}$

Paris, Musée du Louvre, inv. no. 1995

BIBL.: FRIEDLÄNDER VIb, no. 183; Corpus Paris I, no. 90; VAN MIEGROET 1989, no. 42 (with bibl.).

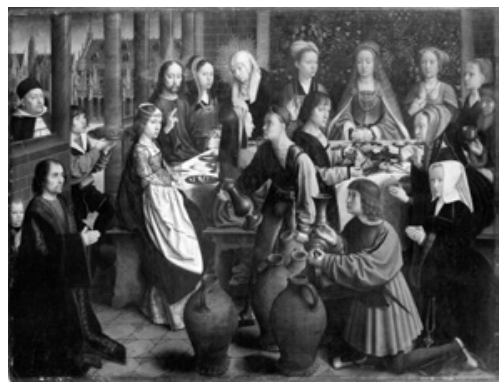
HISTORICAL INFORMATION: Jean de Sedano was a Spanish merchant from Santa Maria del Campo in the surrounding of Burgos. He was established in Bruges. In 1486, he married Marie Caignet, the daughter of a Bruges merchant. Jean and Marie had one son. From 1501 up to his death in 1518, Jean de Sedano was a member of the Brotherhood of the Holy Blood, whose tabaert he is wearing in the painting. This clothing can be identified by the embroidered border with the motif of a pelican feeding its babies with its own blood. The painting most probably comes from the chapel of the brotherhood. The Sedanos are also portrayed in cat 330.

Identity of the sitter(s): Jean de Sedano, Marie Caignet and their son

Provenance: Bruges, chapel of the Holy Blood

Number of portrait(s): 3

Type of person(s): lay (family with children)

Attitude of the sitter(s): hands clasped

Representation of the sitter(s): full-length

Gaze of the sitter(s): into space

Object(s): no

Coat(s) of arms: no

Environment: historical setting

Structuring of the pictorial space: not applicable

Patron saint(s): none 
Gesture of the patron saint(s): not applicable

Type of religious scene: narrative

Religious scene(s) depicted: the Wedding at Cana

Cat. 328-Type 5

DAVID, Gerard

Triptych of the Baptism of Christ ('Triptych of Jean des Trompes') (c. 1502-1508) $132 \times 96.6 \mathrm{~cm}$ (centre panel) and $132 \times 42.2 \mathrm{~cm}$ (wings)

Bruges, Groeningemuseum, inv. no. 0.35

BIBL.: FRIEDLÄNDER VIb,

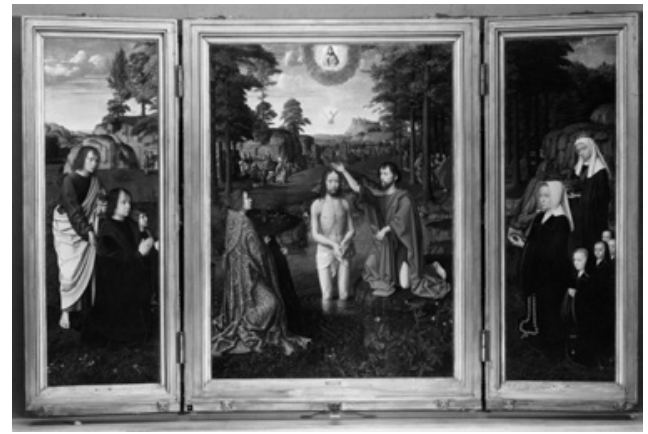
no. 161; Corpus Bruges I, no. 6; VAN MIEGROET 1989, no. 23; Exh. cat. Bruges 1998 (vol. 2), no. 13 (with bibl.). HISTORICAL INFORMATION: This triptych is a commission of Jean des Trompes, made c. 1502. Jean is portrayed on the left inner wing with his son Philip. His first wife, Elisabeth van der Meersch (†1502), appears with their four daughters (Adewijc, Anna, Johanna and Agnes) on the inner right wing. The reverse of the wings show the second wife of Jean, Magdalena Cordier, and their first daughter, Cornelia. The original location of the triptych remains unknown. In 1520, the work was donated by the heirs of Jean des Trompes to the Brotherhood of the Sworn Clerks of the Tribunal. They placed the triptych on their altar in the lower church of St. Basil at Bruges. The foundation act and other archival documents have been preserved (see Corpus Bruges I, 40). Jean des Tromps was Baillif of Oostende in 1498 and 1499, and he then made a political career in Bruges. He notably became burgomaster in 1507. Between 1509 and 1512, he acted as Extraordinary Receiver-general of Flanders. He passed away in 1516 .

Identity of the sitter(s): Jean des Trompes, Elisabeth van der Meersch, Magdalena Cordier and their children

Provenance: Bruges, church of St. Basil, St. Lawrence's chapel (altar of the Brotherhood of the Sworn Clerks), from 1520 onwards

Number of portrait(s): 9

Type of person(s): lay (family with children)

Attitude of the sitter(s): hands clasped, holding a book

Representation of the sitter(s): full-length

Gaze of the sitter(s): towards the scene 
Object(s): yes (book, rosary)

Coat(s) of arms: no

Environment: historical setting

Structuring of the pictorial space: continuous space

Patron saint(s): John the Evangelist, Elisabeth of Hungary, Mary Magdalen

Gesture of the patron saint(s): introducing, holding his/her attribute, protecting

Type of religious scene: narrative

Religious scene(s) depicted: the Baptism of Christ, the Virgin and Child

Cat. 329-Type 2A

DAVID, Gerard

Triptych of the Nativity with a

Couple in Prayer and Patron

Saints (after 1510)

$89.6 \times 71.1 \mathrm{~cm}($ centre panel $)$ and

$89.6 \times 31.4 \mathrm{~cm}$ (wings)

New York, MET, inv. no.

49.7.2Oa-b-c (inner wings and

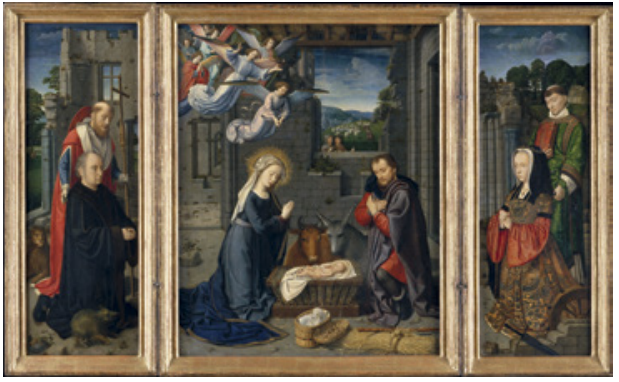

centre panel) and The Hague,

Mauritshuis, inv. no. 843 (outer wings)

BIBL.: FRIEDLÄNDER VIb, no. 16o; VAN MIEGROET 1989, no. 30; VAN SUCHTELEN et alii 1997; AINSWORTH and CHRISTIANSEN 1998, 302-05 (with bibl.).

Identity of the sitter(s): unknown

Provenance: unknown

Number of portrait(s): 2

Type of person(s): lay (couple)

Attitude of the sitter(s): hands clasped

Representation of the sitter(s): full-length

Gaze of the sitter(s): towards the scene

Object(s): no

Coat(s) of arms: no

Environment: historical setting

Structuring of the pictorial space: unified space with discontinuities

Patron saint(s): Jerome, Vincent

Gesture of the patron saint(s): introducing

Type of religious scene: narrative

Religious scene(s) depicted: the Nativity 
Cat. 330-Type $2 B$

DAVID, Gerard

Triptych of the Virgin and Child

('Sedano Triptych') (c. 1490)

$97.1 \times 71.5 \mathrm{~cm}$ (centre panel) and $91 \times 30 \mathrm{~cm}$ (wings)

Paris, Musée du Louvre, inv. no.

RF 588

BIBL.: FRIEDLÄNDER VIb, no. 165;

Corpus Paris I, no. 89 (with bibl.);

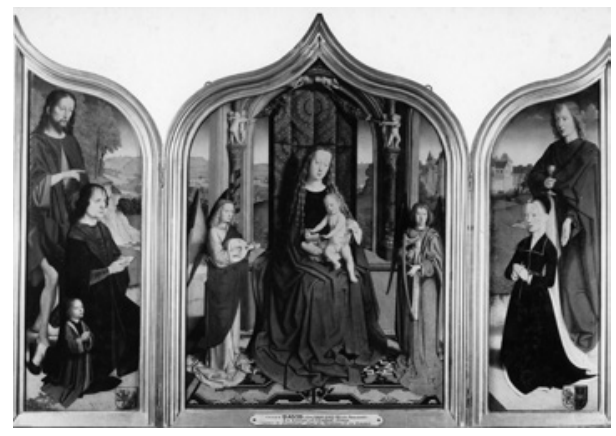

VAN MIEGROET 1989, no. 9 .

HistoriCAl INFORMATION: Jean de Sedano and Marie Caignet can be identified by their coats of arms. On these persons, see cat. 327. The original destination of the triptych remains unknown.

Identity of the sitter(s): Jean de Sedano, Marie Caignet and their son

Provenance: unknown

Number of portrait(s): 3

Type of person(s): lay (family with children)

Attitude of the sitter(s): hands clasped, holding a book

Representation of the sitter(s): full-length

Gaze of the sitter(s): towards the scene

Object(s): yes (book, small cross)

Coat(s) of arms: yes

Environment: landscape with sacred connotation

Structuring of the pictorial space: continuous space

Patron saint(s): John the Baptist, John the Evangelist

Gesture of the patron saint(s): introducing, holding his/her attribute

Type of religious scene: hieratic

Religious scene(s) depicted: the Virgin and Child, Adam and Eve

\section{Cat. 331-Type 6B}

DAVID, Gerard (?)

Portrait of a Man in Prayer (c. 1490-1500)

$28.9 \times 21 \mathrm{~cm}$

Denver, Denver Art Museum, inv. no. E-955

BIB L.: DÜLBERG 1990, no. 12 (with bibl.); PYPAERT 2008, no. 190.

Identity of the sitter(s): unknown

Number of portrait(s): 1

Type of person(s): lay (man alone)

Attitude of the sitter(s): hands clasped 
Representation of the sitter(s): half-length

Gaze of the sitter(s): indeterminate

Object(s): no

Coat(s) of arms: yes (on the reverse)

Environment: neutral space (incomplete)

Structuring of the pictorial space: indeterminate

Patron saint(s): none

Gesture of the patron saint(s): not applicable

Type of religious scene: indeterminate

Religious scene(s) depicted: none

\section{Cat. 332-Type 6B}

[RKD work no. 248295]

DAVID, Gerard (circle of)

Portrait of a Friar in Prayer (c. 1500)

$37.5 \times 32 \mathrm{~cm}$

Cleveland, Cleveland Museum of Art, inv. no. 1942.632

BIB L.: Mus. cat. Cleveland 1978, 83; VAN MIEGROET 1989, 303.

Identity of the sitter(s): unknown

Provenance: unknown

Number of portrait(s): 1

Type of person(s): religious (man alone)

Attitude of the sitter(s): hands clasped

Representation of the sitter(s): half-length

Gaze of the sitter(s): indeterminate

Object(s): yes (book)

Coat(s) of arms: no

Environment: architectural space, no sacred connotation (incomplete)

Structuring of the pictorial space: indeterminate

Patron saint(s): none

Gesture of the patron saint(s): not applicable

Type of religious scene: indeterminate

Religious scene(s) depicted: none

\section{Cat. 333-Type $3 \mathrm{D}$}

[RKD work no. 50109]

DAVID, Gerard (follower of)

The Lamentation with a Monk in Prayer (c. 1500-1525) 
$21.6 \times 27.8 \mathrm{~cm}$

Edinburgh, National Gallery of Scotland, inv. no. 1642 BIB L.: FRIEDLÄNDER VIb, no. 197a; Mus. cat. Edinburgh 1997, 254.

Identity of the sitter(s): unknown

Provenance: unknown

Number of portrait(s): 1

Type of person(s): religious (man alone)

Attitude of the sitter(s): hands clasped

Representation of the sitter(s): full-length

Gaze of the sitter(s): towards the scene

Object(s): no

Coat(s) of arms: no

Environment: historical setting

Structuring of the pictorial space: not applicable

Patron saint(s): none

Gesture of the patron saint(s): not applicable

Type of religious scene: hieratic

Religious scene(s) depicted: the Lamentation

Cat. 334-Type $2 \mathrm{~A}$

DAVID, Gerard (follower of)

Triptych of the Descent from the

Cross with a Couple in Prayer and

Patron Saints (c. 1500-1550)

$203 \times 125 \mathrm{~cm}$ (centre panel) and

$203 \times 56 \mathrm{~cm}$ (wings)

Funchal, Museu de Arte Sacra, inv. no. MASF 20

BIB L.: FRIEDLÄNDER VIb, supp. 253; COUTO 1955, 1-3; VAN

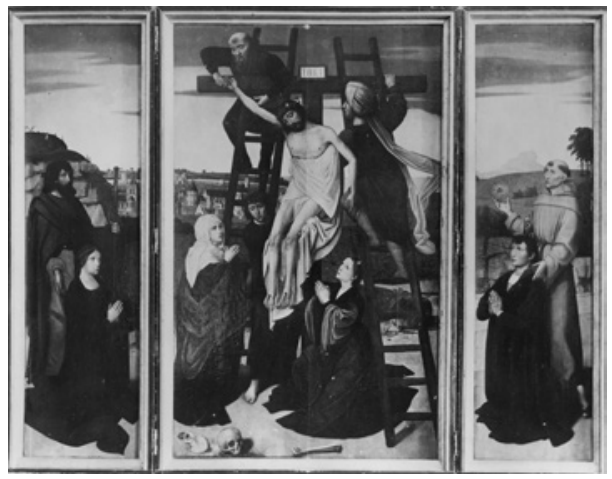
MIEGROET 1989, no. 72.

REMARK: The traditional heraldic disposition (men on the left and women on the right) is not respected in this triptych.

HISTORICAL INFORMATION: According to the notice of the artwork on the museum website, the triptych comes from the (now destroyed) Franciscan convent of Our Lady of Piety in Santa Cruz, Madeira. This convent was founded in 1527 by Jorge Lomelina, who was respecting the will of his uncle Urbano Lomelino. It has thus been argued that the sitters are Jorge Lomelino and his wife Maria Adão. Taking into consideration the fact that the woman is 
depicted on the left wing (à dextre, the position of honour), one might question this assumption and argue that the woman is, in fact, the commissioner of the artwork.

Identity of the sitter(s): Jorge Lomelino and Maria Adão (?)

Provenance: Franciscan convent of Our Lady of Piety in Santa Cruz in

Madeira (?)

Number of portrait(s): 2

Type of person(s): lay (couple)

Attitude of the sitter(s): hands clasped

Representation of the sitter(s): full-length

Gaze of the sitter(s): towards the scene

Object(s): no

Coat(s) of arms: no

Environment: historical setting

Structuring of the pictorial space: continuous space

Patron saint(s): James the Greater, Bernardino of Siena

Gesture of the patron saint(s): introducing

Type of religious scene: narrative

Religious scene(s) depicted: the Descent from the cross, St. James the Lesser, St. Lucia

Cat. 335-Type 6A

DAVID, Gerard (follower of)

Two Wings. A Couple in Prayer with Patron

Saints (c. 1515)

$83.4 \times 28.6 \mathrm{~cm}$ (left wing) and $83.5 \times 28.5 \mathrm{~cm}$ (right wing)

London, NG, inv. nos. NG 657.1-NG 657.2 BIB L.: Corpus London I, no. 38; CAMPBELL 1998, 167-73 (with bibl.).

Identity of the sitter(s): unknown

Provenance: unknown

Number of portrait(s): 2

Type of person(s): lay (couple)

Attitude of the sitter(s): hands clasped
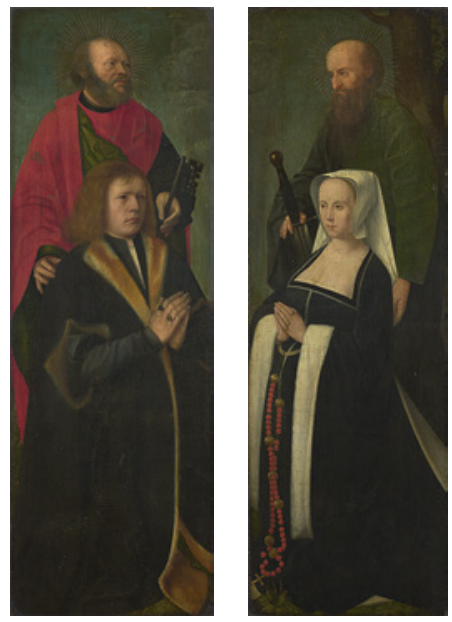

Representation of the sitter(s): full-length

Gaze of the sitter(s): indeterminate

Object(s): yes (rosary)

Coat(s) of arms: no 
Environment: neutral space (incomplete)

Structuring of the pictorial space: indeterminate

Patron saint(s): Peter, Paul

Gesture of the patron saint(s): protecting

Type of religious scene: indeterminate

Religious scene(s) depicted: St. Jerome, St. Nicholas

Cat. 336-Type ${ }_{3} B$

DE BEER, Jan

The Holy Kinship with a Man in Prayer (c.1505-1510) $5^{2} \times 36 \mathrm{~cm}$

Bourg-en-Bresse, Musée de l'Ain, inv. no. 978.7 A.D BIB L.: FRIEDLÄNDER XI, no. 26; Exh. cat. Bourgen-Bresse 1981, no. 16; EWING 1984; EWING 2016, 200-04, no. 13 (with bibl.).

Identity of the sitter(s): unknown

Provenance: unknown

Number of portrait(s): 1

Type of person(s): lay (man alone)

Attitude of the sitter(s): hands clasped

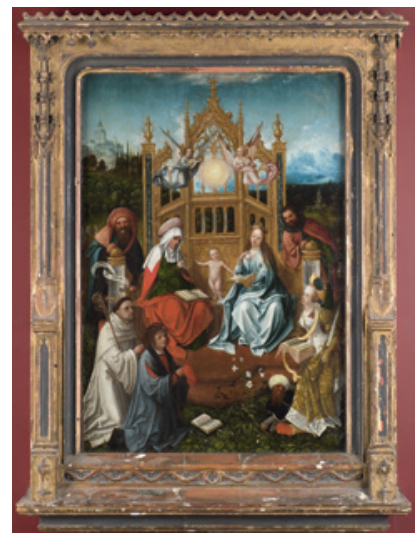

Representation of the sitter(s): full-length

Gaze of the sitter(s): towards the scene

Object(s): yes (book)

Coat(s) of arms: no

Environment: landscape with sacred connotation

Structuring of the pictorial space: not applicable

Patron saint(s): Bernard

Gesture of the patron saint(s): introducing

Type of religious scene: hieratic

Religious scene(s) depicted: the Holy kinship, St. Catherine

Cat. 337-Type 6A

DE COTER, Colijn

A Couple in Prayer with St. John the Baptist and St. Barbara before a Crucifix

(c. 1500-1510)

$90 \times 75 \mathrm{~cm}$

Bratislava, cathedral St. Martin

вівL.: Repertory Czechoslovakia, no. 38 (with bibl.); CIULISOVA 2009a;

CIULISOVA 2009b; Exh. cat. Brussels 2013, no. 87 . 
REMARK: The central section of the current work, showing a crucifix, is a later addition. In all likelihood, this panel was formerly two wings of a triptych. Once the centre panel was lost, the wings were probably joined together in order to form one single work. Other works of the corpus present similar additions (cat. 44 and 6o9).

Identity of the sitter(s): unknown

Provenance: unknown

Number of portrait(s): 2

Type of person(s): lay (couple)

Attitude of the sitter(s): hands clasped

Representation of the sitter(s): half-length

Gaze of the sitter(s): into space

Object(s): no

Coat(s) of arms: no

Environment: landscape, no sacred connotation (incomplete)

Structuring of the pictorial space: not applicable

Patron saint(s): John the Baptist, Barbara

Gesture of the patron saint(s): protecting

Type of religious scene: hieratic

Religious scene(s) depicted: none

Cat. 338-Type $1 \mathrm{D}$

DE COTER, Colijn

Altarpiece of the Descent from the Cross ('Triptych of Johanna van Maerke') (dated 1522)

$190.2 \times 165.2 \mathrm{~cm}($ centre panel $)$ and $163.5 \times 78.5$ $\mathrm{cm}$ (wings)

Brussels, MRBAB, inv. no. 355

BIBL.: STROO et alii 2001, 306-31 (with bibl.); RIMMELE 2014.

HISTORICAL INFORMATION: The inscription in the lower part of the reverse of the wings iden-

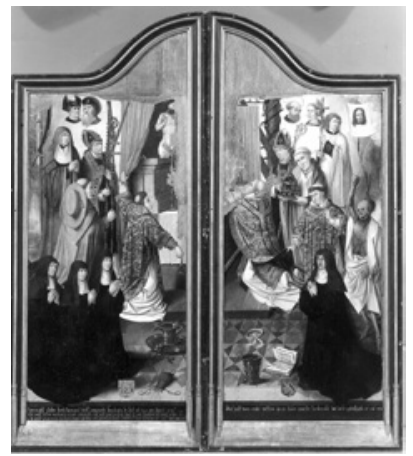
tifies the four nuns portrayed on these panels.

They are four Benedictine nuns of the abbey of Voorst: Hier in dese $(n)$ closter leeyt begraven Joffr magriete boeckaers sij sterf int Jaer ons heere(n) XIIIIc. [...] / En(de)Joffr lijsbet bockaers groot. canter [e]sse va(n) dese (n) godshuyse. sy sterf de(n) xiiii septe $(m)$ ber : $A^{\circ}$ XIIIIcXCVII: / En(de) Joffr Ermgaers Boeckaer groot $p\left(\right.$ ri)eryn (n)e va(n) dese (n) godshuyse sy st (e)rf de(n) VIII septe $(m)$ ber $A^{\circ} \mathrm{XVc}$ 
byt voer zyele. (on the left), Dit heeft doen make(n)JoffrouJanne Wa(n)de Maerke borsierresse wa(n) dese $(n)$ godshuyse $A^{\circ} . X V c . X X I I$. The three nuns portrayed on the left wing are Margareta, Elisabeth and Ermgardis Bockaerts. The nun depicted on the right wing is Johanna van Maerke. She commissioned the triptych in 1522. By that time, the three Bockaerts sisters were already deceased. The triptych was most probably destined for the abbey church of Voorst.

Identity of the sitter(s): Margareta, Elisabeth and Ermgardis Bockaerts and Jeanne van Maerke

Provenance: Benedictine abbey of Voorst

Number of portrait(s): 4

Type of person(s): religious (group: Benedictine nuns)

Attitude of the sitter(s): hands clasped

Representation of the sitter(s): full-length

Gaze of the sitter(s): into space

Object(s): yes (purse, book)

Coat(s) of arms: yes

Environment: historical setting

Structuring of the pictorial space: continuous space

Patron saint(s): none

Gesture of the patron saint(s): not applicable

Type of religious scene: narrative

Religious scene(s) depicted: the Descent from the cross, the Arrest of Christ, the Resurrection of Christ, the Mass of St. Gregory

Cat. 339-Type 6A

DE COTER, Colijn

Fragments. Philip the Fair and his Suite with Christ, Joanna of Castile and her Suite with the Virgin (c. 1500) $110 \times 74 \mathrm{~cm}$ (each wing)

Paris, Musée du Louvre, inv. nos. M.N.R. $375^{-M}$-N.R. 376 BIBL.: FRIEDLÄNDER IV, no. 93; Corpus Paris I, no. 88
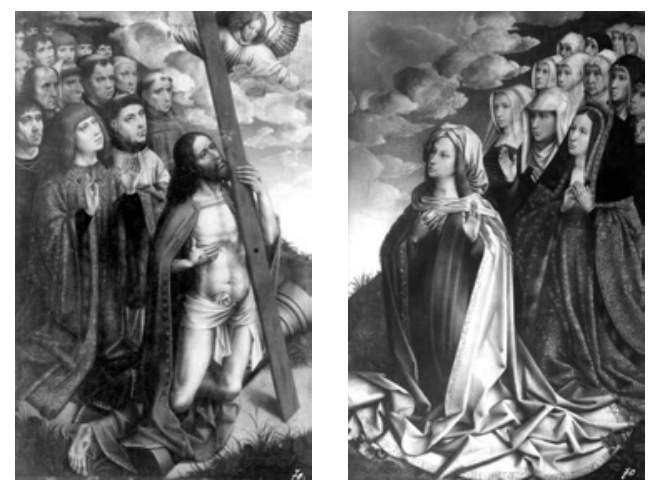
(with bibl.); PERIER-D'IETEREN 1985b, 87-89, 146.

HISTORICAL INFORMATION: These two fragments come from one single panel depicting Christ and the Virgin interceding for Philip the Fair and his 
wife Joanna of Castile. The sitters have been identified, on the basis of a comparison with their portraits in the Zierikzee Triptych kept in Bergen-op-Zoom. We know nothing about the original location of the painting.

Identity of the sitter(s): Philip the Fair and Joanna of Castile

Provenance: unknown

Number of portrait(s): 29

Type of person(s): mixed (unidentified group)

Attitude of the sitter(s): hands clasped, hands held up

Representation of the sitter(s): full-length

Gaze of the sitter(s): indeterminate

Object(s): no

Coat(s) of arms: no

Environment: landscape, no sacred connotation (incomplete)

Structuring of the pictorial space: indeterminate

Patron saint(s): none

Gesture of the patron saint(s): not applicable

Type of religious scene: intercession

Religious scene(s) depicted: the Intercession of Christ and the Virgin

\section{Cat. 340-Type 6A}

[RKD work no. 43036]

DE COTER, Colijn (attributed to)

Portrait of a Couple in Prayer

(c. 1490-1510)

$39.2 \times 24.2 \mathrm{~cm}$ (left wing) and

$39.1 \times 24 \mathrm{~cm}$ (right wing)

Brunswick, Herzog Anton

Ulrich-Museum, inv. no. 9

Identity of the sitter(s): unknown

Provenance: unknown

Number of portrait(s): 2

Type of person(s): lay (couple)

Attitude of the sitter(s): hands clasped

Representation of the sitter(s): half-length

Gaze of the sitter(s): indeterminate

Object(s): no

Coat(s) of arms: no

Environment: neutral space (incomplete)

Structuring of the pictorial space: indeterminate 
Patron saint(s): none

Gesture of the patron saint(s): not applicable

Type of religious scene: indeterminate

Religious scene(s) depicted: none

Cat. 341-Type 5

DE COTER, Colijn, Master of the Guild of Saint

George, Master of the Magdalen Legend and various anonymous masters

The Legend and Miracles of St. Rombouts

(c. 1480-1510)

$140 \times 70 \mathrm{~cm}$ (each panel)

Mechelen, St. Rombouts' Cathedral

BIB L.: FRIEDLÄNDER IV, no. 106;

FRIEDLÄNDER XII, no. 25; PERIER D'IETEREN

1975b; PERIER D'IETEREN 1975c; PERIER

D'IETEREN 1976; PERIER D'IETEREN 1985b,

79-84, 143-45 (with bibl.).

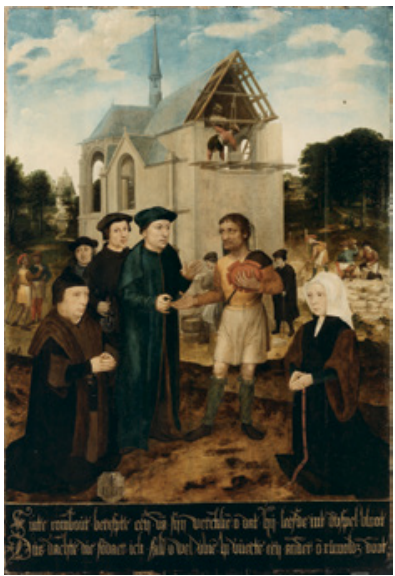

HISTORICAL INFORMATION: The suite of twenty-seven panels was destined for the St. Rombouts' chapel in the cathedral of Mechelen. Most of the coats of arms painted on the panels have not been identified. Only the sitters of panels no. 25 and no. 17 are known. They are Jan Micault and his wife, on the one hand (see cat. 748 and cat. 85), and Peter van Steynemolen and his family, on the other.

Identity of the sitter(s): unknown for most of them, except Jan Micault and his wife and Peter van Steynemolen and his family

Provenance: Mechelen, St. Rombouts' Cathedral, St. Rombouts' chapel

Number of portrait(s): at least 47

Type of person(s): mixed (unidentified group)

Attitude of the sitter(s): hands clasped

Representation of the sitter(s): full-length

Gaze of the sitter(s): varied

Object(s): yes (books, rosary, small cross, prie-dieu)

Coat(s) of arms: yes

Environment: historical setting

Structuring of the pictorial space: not applicable

Patron saint(s): none

Gesture of the patron saint(s): not applicable

Type of religious scene: narrative

Religious scene(s) depicted: the Legend of St. Rombouts 
Cat. 342-Type 5

ENGEBRECHTSZ., Cornelis

Triptych of the Crucifixion

(c. 1515-1517)

$180 \times 146 \mathrm{~cm}$ (centre panel),

$180 \times 63.5 \mathrm{~cm}$ (wings) and

$16.5 \times 146 \mathrm{~cm}$ (predella)

Leiden, Stedelijk Museum de

Lakenhal, inv. no. 93

BIBL.: FRIEDLÄNDER $x$,

no. 71; Mus. cat. Leiden 1983 ,

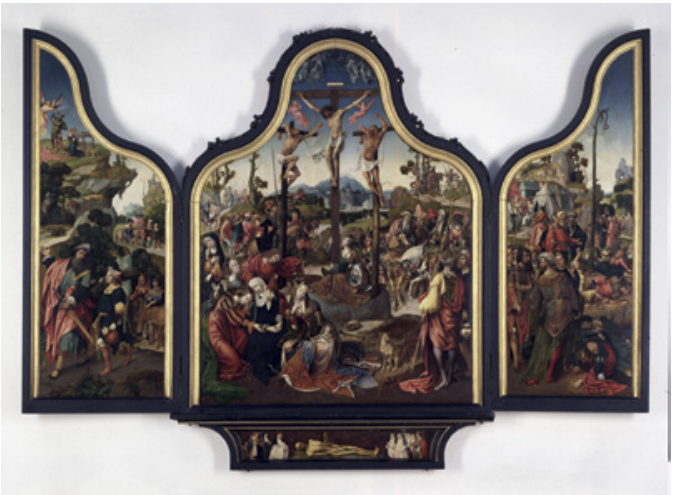

134-36; Exh. cat. Leiden 2011,

no. 2; FILEDT KOK et alii 2014, no. 19 (with bibl.).

HistoriCAL INFORMATION: This triptych comes from the Augustinian convent of Mariënpoel in Leiden (on the convent, see cat. 343) and includes the portraits of six nuns and one canon on its predella. The canon has been identified as Jacob Martensz. Schout, rector and then chaplain of Mariënpoel (see cat. 343). The Franciscan nun kneeling behind him could be either his sister, Margaretha, or his mother. The five Augustinian nuns have not been identified. They are probably the prioress and four other nuns. The triptych was presumably destined for the high altar of the convent church or to the chapel of the Holy Cross (as suggested by its iconography). A recent study of the underdrawing revealed that the canon's figure hides the head of a much older man. It has been argued that this underdrawn portrait is that of Jacob at the time of the commission and that it was overpainted by a younger effigy of himself, at his request.

Identity of the sitter(s): Jacob Martensz. Schout and unidentified nuns

Provenance: Leiden, convent of Mariënpoel

Number of portrait(s): 7

Type of person(s): religious (group: Augustinian canon, Augustinian nuns,

Franciscan tertiary nun)

Attitude of the sitter(s): hands clasped

Representation of the sitter(s): half-length, small scale

Gaze of the sitter(s): into space, towards the ground

Object(s): no

Coat(s) of arms: no

Environment: neutral space

Structuring of the pictorial space: distinct spaces

Patron saint(s): Augustine, Martin 
Gesture of the patron saint(s): holding his/her attribute

Type of religious scene: narrative

Religious scene(s) depicted: the Crucifixion, the Sacrifice of Isaac, the Adoration of the brazen serpent, the Mocking of Christ, Christ on the cold stone, the Body of Adam

\section{Cat. 343-Type $2 \mathrm{~A}$}

ENGEBRECHTSZ., Cornelis

Triptych of the Lamentation with two Persons in Prayer and Patron

Saints (c. 1508-1510)

$124.5 \times 122.5 \mathrm{~cm}$ (centre panel) and $124.5 \times 55.5 \mathrm{~cm}$ (wings)

Leiden, Stedelijk Museum de

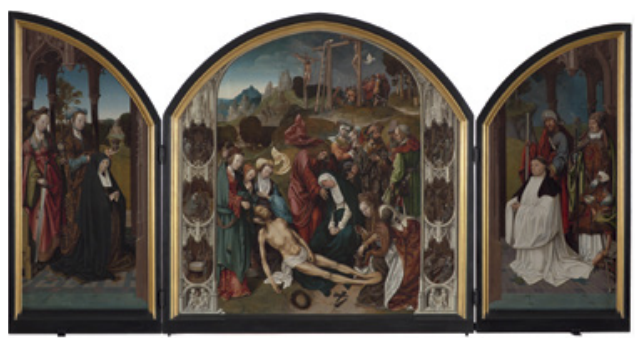

Lakenhal, inv. no. 94

BIB L.: FRIEDLÄNDER X, no. 74; Mus. cat. Leiden 1983, 136-37; Exh. cat. Leiden 2011, no. 1; FILEDT KOK et alii 2014, no. 34 (with bibl.).

HISTORICAL INFORMATION: The triptych comes from the convent of Mariënpoel in Leiden. Founded in 1428 by Boudewijn van Swieten (a nobleman from the city, treasurer of the Counts of Holland), Mariënpoel was placed under the Augustinian rule. The convent welcomed mostly women stemming from wealthy families from Holland (such as the Van Poelgeests, the Van Alkemades and the Van Duivenvoordes). The convent thus benefited from many donations. The triptych was certainly located on one of the four altars open to the public in the nave of the church. Jacob Martensz. Schout $\left(147^{6-1526)}\right.$ is portrayed on the right wing. Initially a canon regular in the Augustinian monastery of St. Willibrod in Heiloo, Jacob was then appointed rector of Mariënpoel in 1508 (the triptych might have been commissioned on that occasion). He held this position until 1522, when he became chaplain of the convent. He died in 1526. The identity of the Franciscan tertiary nun on the left wing cannot be established with certainty, but she could be Margaretha Martensdr., Jacob's sister. Margaretha entered the convent of Mariënpoel, like many other Franciscan nuns seeking a more severe way of life. The themes of the Lamentation and the Virgin of the Seven Sorrows were probably chosen by Jacob, for Heiloo was a pilgrimage site dedicated to the Sorrows of the Virgin.

Identity of the sitter(s): Jacob Martensz. Schout and a nun (Margaretha Martensdr?)

Provenance: Leiden, convent of Mariënpoel (St. Barbara's chapel?) 
Number of portrait(s): 2

Type of person(s): religious (group: canon regular, Franciscan tertiary nun) Attitude of the sitter(s): hands clasped

Representation of the sitter(s): full-length

Gaze of the sitter(s): towards the scene

Object(s): no

Coat(s) of arms: no

Environment: architectural space, no sacred connotation

Structuring of the pictorial space: distinct spaces

Patron saint(s): Cecilia, Mary Magdalen, James, Martin

Gesture of the patron saint(s): protecting, holding his/her attribute

Type of religious scene: narrative

Religious scene(s) depicted: the Lamentation, St. Apollonia, St. Gertrude, St. Agatha, St. Agnes

\section{Cat. 344-Type 6A}

ENGEBRECHTSZ., Cornelis

Two Wings. The Family Van der Does-Van

Poelgeest in Prayer with Patron Saints

(c. 1517-1519)

$162.5 \times 55.5 \mathrm{~cm}$ (each wing)

Leiden, Stedelijk Museum de Lakenhal, inv. no. 622

BIB L.: FRIEDLÄNDER X, no. 75; Exh. cat. Leiden 2011, no. 3a; FILEDT KOK et alii 2014, no. 53 (with bibl.).

HISTORICAL INFORMATION: These wings come from a triptych that was located in the Van Lockhorst chapel in the church of

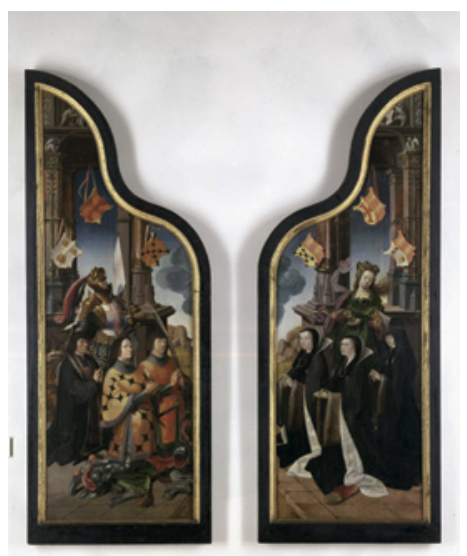

St. Peter in Leiden and whose centre panel (which depicted a scene from St. John's Revelavations) caught fire and burned in 1837. The work is mentioned by Karel van Mander in his Schilder-Boek. The three women on the left are the daughters of Willem van der Does and Hendrica van Poelgeest: Adriana, Henrica and Margaretha. Their husbands are Jan Gertsz. van Lockhorst, Jacob Gerytsz. Heerman (depicted holding a palm leaf, witness to his pilgrimage in the Holy Land in 1491) and Willem Jan Kerstansz. Stoop. They are depicted on the left wing. Jan Gertsz. and Jacob Gerytsz. were members of the high nobility of Leiden, while Willem Jan Kerstansz. was a rich merchant. It is for this reason 
that he does not bear an armorial mantle. The coats of arms of Willem van der Does and of Hendrica van Poelgeest are painted on the reverse. One can thus assume that their portraits were located on the centre panel. A similar distribution of portraits can be observed in Mostaert's Triptych of the Last Judgement (cat. 597).

Identity of the sitter(s): Willem Jan Kerstantsz. Stoop, Jan van Lochorst, Jacob Heerman Gerritsz., Adriana, Hendrika and Margaretha van der Does Provenance: Leiden, church of St. Peter, Van Lockhorst chapel

Number of portrait(s): 6

Type of person(s): lay (family)

Attitude of the sitter(s): hands clasped

Representation of the sitter(s): full-length

Gaze of the sitter(s): indeterminate

Object(s): yes (helmet, sword)

Coat(s) of arms: yes

Environment: architectural space, no sacred connotation (incomplete)

Structuring of the pictorial space: indeterminate

Patron saint(s): George, Mary Magdalen

Gesture of the patron saint(s): introducing, holding his/her attribute

Type of religious scene: indeterminate

Religious scene(s) depicted: none

Cat. 345-Type $3 \mathrm{~A}$

ENGEBRECHTSZ., Cornelis (and workshop)

The Lamentation with a Nun, St. Augustine and

St. Cecilia (c. 1510-1515)

$80 \times 65 \mathrm{~cm}$

London, archbishopric of Southwark

BIBL.: FRIEDLÄNDER X, no. 97; GIBSON 1977, 245-46; Exh. cat. Leiden 2011, no. 8; FILEDT KOK et alii 2014, no. 36 (with bibl.).

HISTORICAL INFORMATION: The nun presented by St. Augustine is an Augustinian nun, as her habit testifies. Taking into account the fact that Cornelis Engebrechtsz. had close links with the convent of Mariënpoel, the painting

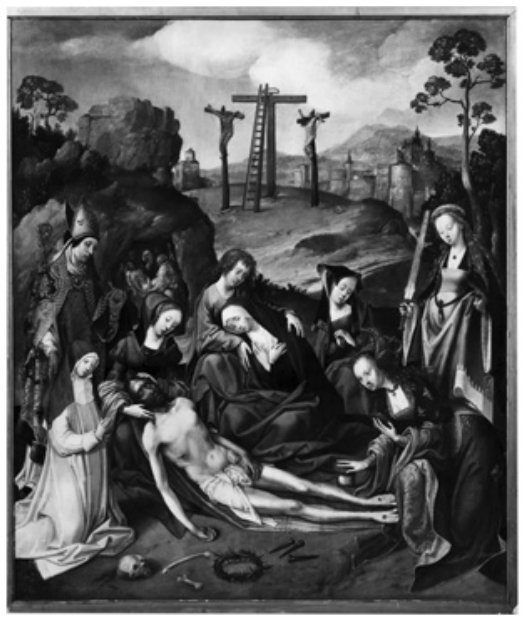
could come from this place. On Mariënpoel, see cat. 343 . 
Identity of the sitter(s): nun of the convent of Mariënpoel (?)

Provenance: Leiden, convent of Mariënpoel (?)

Number of portrait(s): 1

Type of person(s): religious (woman alone: Augustinian nun)

Attitude of the sitter(s): hands clasped

Representation of the sitter(s): full-length

Gaze of the sitter(s): towards the scene

Object(s): no

Coat(s) of arms: no

Environment: historical setting

Structuring of the pictorial space: not applicable

Patron saint(s): Augustine, Cecilia

Gesture of the patron saint(s): introducing, holding his/her attribute

Type of religious scene: narrative

Religious scene(s) depicted: the Lamentation

Cat. 346-Type 3 A

ENGEBRECHTSZ., Cornelis (follower of)

The Crucifixion with a Man in Prayer

(c. 1500-1550)

Size unknown

Private collection

Identity of the sitter(s): unknown

Provenance: unknown

Number of portrait(s): 1

Type of person(s): religious (man alone)

Attitude of the sitter(s): hands clasped

Representation of the sitter(s): full-length

Gaze of the sitter(s): into space

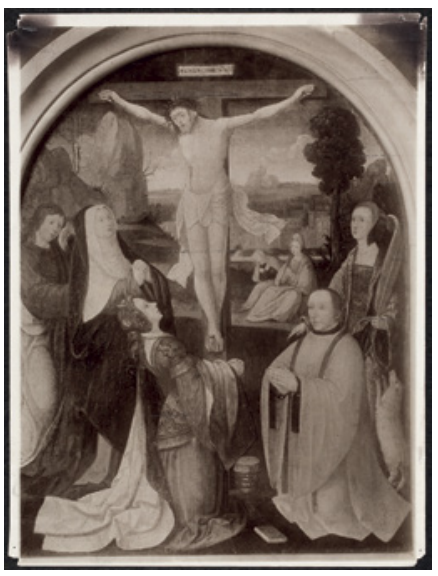

Object(s): yes (book)

Coat(s) of arms: no

Environment: historical setting

Structuring of the pictorial space: not applicable

Patron saint(s): Agnes

Gesture of the patron saint(s): introducing

Type of religious scene: narrative

Religious scene(s) depicted: the Crucifixion 
Cat. 347-Type 2A

ENGEBRECHTSZ. Cornelis (workshop of?)

Triptych of the Adoration of the Magi with a Man in Prayer (c. 1520)

$41.3 \times 27.3 \mathrm{~cm}$ (centre panel) and $41.3 \times 11.4 \mathrm{~cm}$ (wings)

Pasadena, Norton Simon Museum, inv. no. F.1968.11.5.P

BIBL.: GIBSON 1977, no. 35; SCHADE 2001, 296-97; FILEDT KOK et alii 2014, no. 4 (with bibl.).

Identity of the sitter(s): unknown

Provenance: unknown

Number of portrait(s): 1

Type of person(s): religious (man alone)

Attitude of the sitter(s): hands clasped

Representation of the sitter(s): half-length

Gaze of the sitter(s): into space

Object(s): no

Coat(s) of arms: no

Environment: historical setting

Structuring of the pictorial space: distinct spaces

Patron saint(s): Bartholomew

Gesture of the patron saint(s): holding his/her attribute

Type of religious scene: narrative

Religious scene(s) depicted: he Adoration of the Magi, St. Ursula, St. Peter, St. Paul

Cat. 348-Type $3 \mathrm{~A}$

ENGEBRECHTSZ., Cornelis (workshop of)

Christ Crowned with Thorns with a Nun in Prayer (c. 1510)

$38 \times 41 \mathrm{~cm}$

Berlin, Staatliche Museen zu Berlin, Gemäldegalerie, inv. no. 1212

BIBL.: FRIEDLÄNDER X, no. 85; GIBSON 1977, 168-69; Exh. cat. Leiden 2011, no. 12; FILEDT KOK et alii 2014, no. 11 (with bibl.).

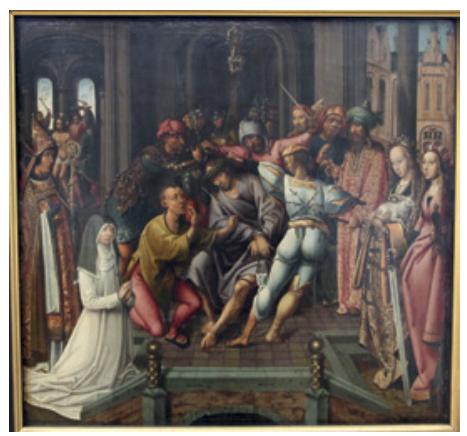
HISTORICAL INFORMATION: The nun presented by St. Augustine is an Augustinian nun, as her habit testifies. Taking into account the fact that Cornelis Engebrechtsz. had close links with the convent 
of Mariënpoel, the painting could come from this place. On Mariënpoel, see cat. 343 .

Identity of the sitter(s): sister of the convent of Mariënpoel (?)

Provenance: Leiden, convent of Mariënpoel (?)

Number of portrait(s): 1

Type of person(s): religious (woman alone: Augustinian nun)

Attitude of the sitter(s): hands clasped

Representation of the sitter(s): full-length

Gaze of the sitter(s): into space

Object(s): no

Coat(s) of arms: no

Environment: historical setting

Structuring of the pictorial space: not applicable

Patron saint(s): Augustine

Gesture of the patron saint(s): holding his/her attribute

Type of religious scene: narrative

Religious scene(s) depicted: Christ crowned with thorns

\section{Cat. 349-Type $3 \mathrm{~A}$}

ENGEBRECHTSZ., Cornelis (workshop of) The Crucifixion with a Couple in Prayer and Patron Saints (c. 1525)

$61.5 \times 89.5 \mathrm{~cm}$

New York, MET, inv. no. 88.3.88

BIBL.: FRIEDLÄNDER X, no. 90; GIBSON 1977, 151-52; AINSWORTH and CHRISTIANSEN 1998, 352-53; Exh. cat.

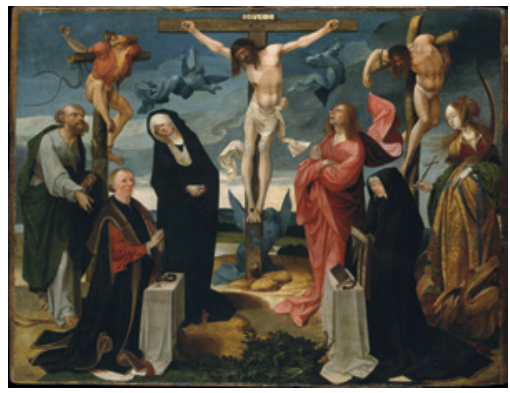

Leiden 2011, no. 10; FILEDT KOK et alii 2014, no. 25 (with bibl.).

Identity of the sitter(s): unknown

Provenance: unknown

Number of portrait(s): 2

Type of person(s): lay (couple)

Attitude of the sitter(s): hands clasped

Representation of the sitter(s): full-length

Gaze of the sitter(s): towards the scene, towards the ground

Object(s): yes (prie-dieu, book)

Coat(s) of arms: no 
Environment: historical setting

Structuring of the pictorial space: not applicable

Patron saint(s): Peter, Margaret

Gesture of the patron saint(s): introducing, holding his/her attribute

Type of religious scene: narrative

Religious scene(s) depicted: the Crucifixion

Cat. 350-Type $3 \mathrm{~A}$

ENGEBRECHTSZ., Cornelis (workshop of)

The Lamentation with a Family in Prayer and

Patron Saints (c. 1500-1550)

$115 \times 124 \mathrm{~cm}$

Munich, Alte Pinakothek, inv. no. 1468 BIBL.: FRIEDLÄNDER X, no. 94; GIBSON 1977, 133-34, 266; Mus. cat. Munich 2006, 312; FILEDT KOK et alii 2014, no. 36 (with bibl.).

REMARK: The format of the panel in not

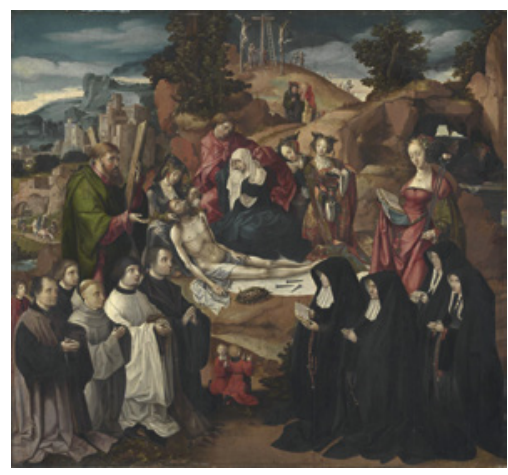
original. Its top was initially terminated in a triple arch. This could suggest that the panel was originally the centre piece of a triptych.

Identity of the sitter(s): unknown

Provenance: unknown

Number of portrait(s): 12

Type of person(s): mixed (family)

Attitude of the sitter(s): hands clasped, holding a book

Representation of the sitter(s): full-length

Gaze of the sitter(s): into space, towards the scene

Object(s): yes (book, rosary)

Coat(s) of arms: no

Environment: historical setting

Structuring of the pictorial space: not applicable

Patron saint(s): Andrew, Lucy

Gesture of the patron saint(s): introducing, holding his/her attribute

Type of religious scene: narrative

Religious scene(s) depicted: the Lamentation 
Cat. 351-Type $3^{A}$

ENGEBRECHTSZ., Cornelis (workshop of)

The Mocking of Christ with a Nun in Prayer

(c. 1500)

$52 \times 41 \mathrm{~cm}$

Antwerp, KMSK, inv. no. 532

BIBL.: FRIEDLÄNDER X, no. 87; GIBSON 1977, 168-69; FILEDT KOK et alii 2014, no. 17 (with bibl.).

HISTORICAL INFORMATION: The nun presented by St. Augustine is an Augustinian nun, as her habit testifies. Taking into account the fact that Cornelis Engebrechtsz.

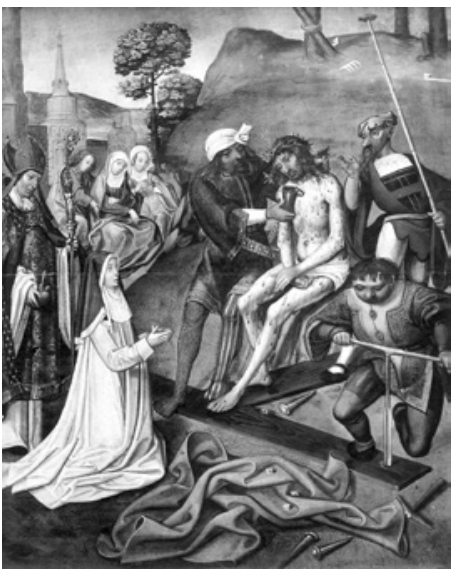
had close links with the convent of

Mariënpoel and executed several paintings for the nuns, the painting could come from this place. On Mariënpoel, see cat. 343 .

Identity of the sitter(s): sister from the Mariënpoel convent (?)

Provenance: Leiden, convent of Mariënpoel (?)

Number of portrait(s): 1

Type of person(s): religious (woman alone: Augustinian nun)

Attitude of the sitter(s): hands clasped

Representation of the sitter(s): full-length

Gaze of the sitter(s): towards the scene

Object(s): no

Coat(s) of arms: no

Environment: historical setting

Structuring of the pictorial space: not applicable

Patron saint(s): Augustine

Gesture of the patron saint(s): holding his/her attribute

Type of religious scene: narrative

Religious scene(s) depicted: the Mocking of Christ

Cat. 352-Type 2A

[RKD work no. 19573]

ENGEBRECHTSZ., Cornelis (workshop of)

Triptych of the Feeding of the Five Thousand with a Family in Prayer and Patron Saints ('Triptych of the Paedts-van Raephorst Family') (c. 1500-1550)

$115 \times 64 \mathrm{~cm}$ (centre panel) and $115 \times 51 \mathrm{~cm}$ (wings)

Berlin, Staatliche Museen zu Berlin, Gemäldegalerie (destroyed in 1945) 
BIBL.: FRIEDLÄNDER X, no. 69; HOOGEWERFF III, 188-92; GIBSON 1977, 192-91, no. 2; FILEDT KOK et alii 2014, no. 5 (with bibl.).

HISTORICAL INFORMATION: The persons portrayed in this triptych have not been identified with certainty. The coat of arms on the left wing belongs to the Paeds family from Leiden. The one on the right wing belongs to the Paeds family impaled with those of the Raephorst or Pynssens family. Unfortunately, no archival document allows us to establish a link between these families.

Identity of the sitter(s): members of the Paedts-van Raephorst family (?)

Provenance: unknown

Number of portrait(s): 14

Type of person(s): mixed (family)

Attitude of the sitter(s): hands clasped, holding a book

Representation of the sitter(s): full-length

Gaze of the sitter(s): into space, towards the scene

Object(s): yes (rosary, palm)

Coat(s) of arms: yes

Environment: niche

Structuring of the pictorial space: distinct spaces

Patron saint(s): Paul, Barbara

Gesture of the patron saint(s): introducing, holding his/her attribute

Type of religious scene: narrative

Religious scene(s) depicted: the Feeding of the five thousand

Cat. 353-Type ${ }_{3} \mathrm{C}$

GEERTGEN TOT SINT JANS

The Raising of Lazarus with a Family in Prayer

(c. 1485)

$127 \times 97 \mathrm{~cm}$

Paris, Musée du Louvre, inv. no. RF 1285

BIBL.:FRIEDLÄNDER V, no.5; HOOGEWERFF

II, 156-58; Exh. cat. Rotterdam 1992, no. 3 (with bibl.).

Identity of the sitter(s): unknown

Provenance: unknown

Number of portrait(s): 2

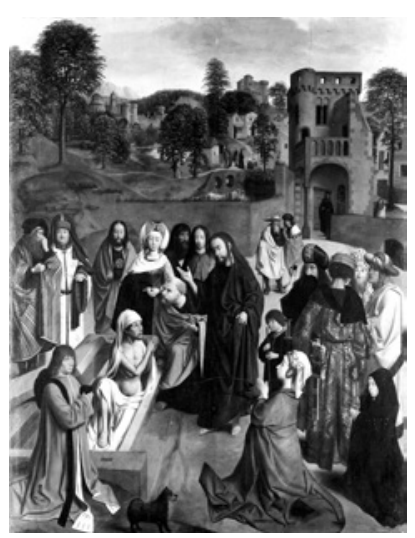

Type of person(s): lay (couple)

Attitude of the sitter(s): hands clasped

Representation of the sitter(s): full-length

Gaze of the sitter(s): into space, towards the scene 
Object(s): no

Coat(s) of arms: no

Environment: historical setting

Structuring of the pictorial space: not applicable

Patron saint(s): none

Gesture of the patron saint(s): not applicable

Type of religious scene: narrative

Religious scene(s) depicted: the Resurrection of Lazarus

Cat. 354-Type $3 \mathrm{D}$

GEERTGEN TOT SINT JANS

The Tree of Jesse with a Nun in Prayer (c. 1500)

$89 \times 59 \mathrm{~cm}$

Amsterdam, Rijksmuseum, inv. no. SK-A-3901

BIB L.: FRIEDLÄNDER X, no. 23; Mus. cat.

Amsterdam 1976, 401; Exh. cat. Rotterdam 1992, no. 13; Mus. cat. Amsterdam 2009 [online], https:// www.rijksmuseum.nl/nl/collectie/SK-A-3901/cata logus-entry (with bibl.).

HISTORICAL INFORMATION: The white habit of the nun and the provenance of the painting (it is mentioned in the 1572 inventory of the Jansklooster of Haarlem) suggest that the work comes from the

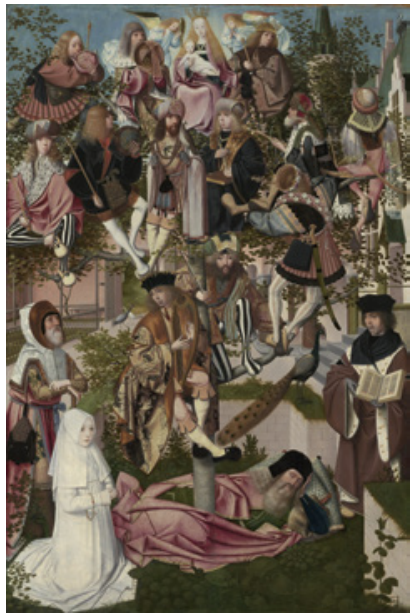
Wittevrouwenklooster in Haarlem. Nonetheless, the nun cannot be identified.

Identity of the sitter(s): unknown

Provenance: Haarlem, Wittevrouwenklooster or convent of St. Mary

Magdalen (?)

Number of portrait(s): 1

Type of person(s): religious (woman alone: Cistercian nun?)

Attitude of the sitter(s): hands clasped

Representation of the sitter(s): full-length

Gaze of the sitter(s): into space

Object(s): yes (rosary)

Coat(s) of arms: no

Environment: cloister

Structuring of the pictorial space: not applicable

Patron saint(s): none

Gesture of the patron saint(s): not applicable 
Type of religious scene: narrative

Religious scene(s) depicted: the Tree of Jesse

Cat. 355-Type $2 \mathrm{~A}$

GEERTGEN TOT SINT JANS

Triptych of the Adoration of the Magi with a Couple in Prayer and Patron Saints (c. 1485-1490)

$111 \times 69.5 \mathrm{~cm}$ (centre panel), $71 \times$ $38.7 \mathrm{~cm}$ (left wing) and $70.8 \times 38.8$ $\mathrm{cm}$ (right wing)

Prague, Narodni Galerie, inv. nos. HS $236-237-238$

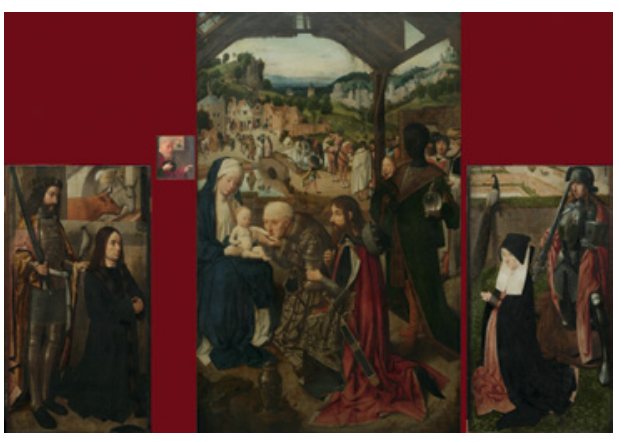

BIBL.: FRIEDLÄNDER V, no. 4; SIP 1963; Mus. cat. Prague 1999, no. 36; Exh. cat. Rotterdam 1992, no. 10 (with bibl.); KYZOUROVA et alii 2010.

REMARK: The triptych is only partially preserved, the upper part $(\mathrm{c} .40 \mathrm{~cm})$ of the wings being missing. The centre panel has been shrunk by $20-25 \mathrm{~cm}$ on the left and by $3 \mathrm{~cm}$ on the right. Dendrochronological and stylistic analyses made on a small panel $(11.4 \times 9.8 \mathrm{~cm})$ showing St. Joseph, now held in the Historisches Museum of Frankfurt, have proven that it was formerly part of the centre panel of the triptych.

Identity of the sitter(s): unknown

Provenance: unknown

Number of portrait(s): 2

Type of person(s): lay (couple)

Attitude of the sitter(s): hands clasped

Representation of the sitter(s): full-length

Gaze of the sitter(s): into space

Object(s): no

Coat(s) of arms: no

Environment: historical setting

Structuring of the pictorial space: unified space with discontinuities

Patron saint(s): Bavo, Adrian

Gesture of the patron saint(s): holding his/her attribute

Type of religious scene: narrative

Religious scene(s) depicted: the Adoration of the Magi 
Cat. 356-Type $4 \mathrm{D}$

[RKD work no. 189449]

GOSSART, Jan

Diptych of Don Juan Zúñiga y Avellaneda (after 1532)

Size unknown

Previously Barcelona, Capilla Real, el Palau (destroyed)

BIBL.: FRIEDLÄNDER VIII, add. 162; MARCH 1948; AINSWORTH 2010, no. $62 \mathrm{~A}-\mathrm{B}$ (with bibl.).

HISTORICAL INFORMATION: Don Juan Zúñiga y Avellaneda (1488-1546) was a Spanish nobleman, who spent his whole career at the Spanish royal court. During his youth, Don Juan Zúñiga spent some time in the Low Countries, working for Charles v. In Spain, he worked for Mencia de Mendoza. He accompanied her to the Low Countries in 1530, where she married Henry III of Nassau-Breda. After the death of her husband, Mencia went back to Spain in 1538 and Don Juan Zúñiga joined her. On the diptych, Don Juan Zúñiga is wearing the insignia of the Castilian Grand Commander of the Order of Santiago, an insignia he received on 2 March 1532. The work must thus have been commissioned after that date.

Identity of the sitter(s): Don Juan Zúñiga y Avellaneda

Provenance: unknown

Number of portrait(s): 1

Type of person(s): lay (man alone)

Attitude of the sitter(s): hands clasped

Representation of the sitter(s): half-length

Gaze of the sitter(s): into space

Object(s): no

Coat(s) of arms: no

Environment: neutral space

Structuring of the pictorial space: continuous space

Patron saint(s): none

Gesture of the patron saint(s): not applicable

Type of religious scene: hieratic

Religious scene(s) depicted: the Virgin and Child 
Cat. 357-Type $4 \mathrm{D}$

GOSSART, Jan

Diptych of Jean Carondelet (dated 1517 on the frame) $42 \times 27 \mathrm{~cm}$ (each wing) Paris, Musée du Louvre, inv. nos. 1442-1443 BIBL.: FRIEDLÄNDER VIII, no. 4; Exh. cat. Bruges and Rotterdam 1965, no. 11; GELFAND
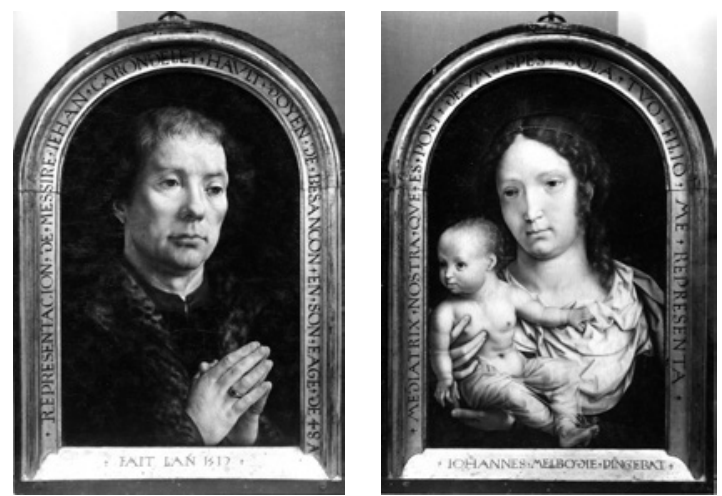
1994, 133-36; AINSWORTH 2010, no. 40 (with bibl.). HISTORICAL INFORMATION: The inscription on the frame identifies the sitter as Jean Carondelet: REPRESENTACION'DE'MESSIRE IEHAN CARONDELE $T \cdot H A V L T \cdot D O Y E N \cdot D E \cdot B E S A N C O N \cdot E N \cdot S O N \cdot A E G E \cdot D E \cdot 48 \cdot A$. His coat of arms, his initials and his motto (MATVRA) are also painted on the reverse of the panels. Born in Dôle in 1469, Jean Carondelet was the son of Jean Carondelet and Marguerite de Chassey. He studied Law and made a brilliant ecclesiastical and political career. He was first canon of St. Peter at Anderlecht, and then canon of the church of St. Donatian in Bruges in 1485. Soon afterwards, he became Provoost of St. Piat in Seclin and of St. Walburgis in Veurne, before being appointed dean of the cathedral of Besançon in 1493. In 1497, Jean Carondelet was appointed by Philip the Fair, member of the Grand conseil of the Low Countries and in 1508, he became member of the Conseil privé in Mechelen. In 1517-1519, he travelled with Charles V to Spain and, when he returned, on 28 November 1520 , he was elected Provoost of St. Donatian at Bruges. His ecclesiastical career was crowned a few years later by his election as Archdeacon of Palerma and Primate of Sicily. Jean Carondelet died in Mechelen in 1545 and was buried in his funerary chapel in the church of St. Donatian. He is also portrayed in cat. 362 .

Identity of the sitter(s): Jean Carondelet

Provenance: unknown

Number of portrait(s): 1

Type of person(s): religious (man alone: canon)

Attitude of the sitter(s): hands clasped

Representation of the sitter(s): half-length

Gaze of the sitter(s): into space 
Object(s): no

Coat(s) of arms: yes

Environment: neutral space

Structuring of the pictorial space: continuous space

Patron saint(s): none

Gesture of the patron saint(s): not applicable

Type of religious scene: hieratic

Religious scene(s) depicted: the Virgin and Child, memento mori

Cat. 358-Type 6B

GOSSART, Jan

Portrait of a Man in Prayer (c. 1520)

$69 \times 49.1 \mathrm{~cm}$

London, NG, inv. no. NG656

BIBL.: FRIEDLÄNDER VIII, no. 71; AINSWORTH 2010, no. 54 (with bibl.); CAMPBELL 2014, 312-18. HISTORICAL INFORMATION: The man is wearing unusual clothes, similar to those worn by the sitters of two portraits attributed to Jan Mostaert (cat. 593 and Brussels, mRBAB, inv. no. 2935). This suggests that this is an official form of costume, perhaps of the officials of the Court of Holland. Indeed, Thierry de Bye Dolleman proposed the identification of the

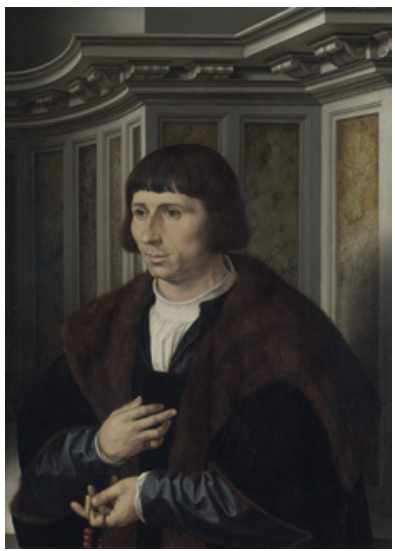
sitter as Abel van Coulster (1477-1548), councillor at the Court of Holland, Zeeland and West Friesland from 1506 onwards.

Identity of the sitter(s): Abel van Coulster (?)

Provenance: unknown

Number of portrait(s): 1

Type of person(s): lay (man alone)

Attitude of the sitter(s): particular gesture

Representation of the sitter(s): half-length

Gaze of the sitter(s): indeterminate

Object(s): yes (rosary)

Coat(s) of arms: no

Environment: architectural space, no sacred connotation (incomplete)

Structuring of the pictorial space: indeterminate

Patron saint(s): none

Gesture of the patron saint(s): not applicable

Type of religious scene: indeterminate

Religious scene(s) depicted: none 
Cat. 359-Type 6B

GOSSART, Jan

Portrait of a Monk in Prayer (1526)

$37 \times 25 \mathrm{~cm}$

Paris, Musée du Louvre, inv. no. R.F. 23

вIBL.: FRIEDLÄNDER VIII, no. 72; AINSWORTH 2010, no. 50 (with bibl.). REMARK: The signature on the right of the sitter's head is not authentic, but it might nonetheless be a transcription of the painter's signature, which would have been located on the original frame.

Identity of the sitter(s): unknown

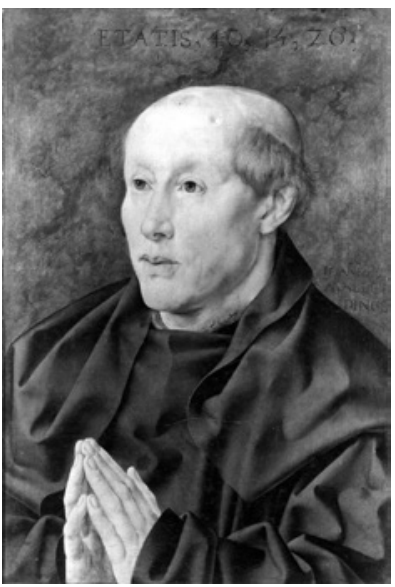

Provenance: unknown

Number of portrait(s): 1

Type of person(s): religious (man alone: Benedictine monk)

Attitude of the sitter(s): hands clasped

Representation of the sitter(s): half-length

Gaze of the sitter(s): indeterminate

Object(s): no

Coat(s) of arms: no

Environment: neutral space (incomplete)

Structuring of the pictorial space: indeterminate

Patron saint(s): none

Gesture of the patron saint(s): not applicable

Type of religious scene: indeterminate

Religious scene(s) depicted: none

Cat. 36o-Type 6A

GOSSART, Jan

Triptych of the Virgin and Child with

a Couple in Prayer (c. 1525-1530)

$47.6 \times 36.8 \mathrm{~cm}$ (centre panel) and

$70 \times 23.5 \mathrm{~cm}$ (each wing)

Norfolk, Chrysler Museum of Art, inv. no. 71.491 (centre panel) and Brussels, MRBAB, inv. no. 4740 (wings) BIBL.: FRIEDLÄNDER VIII, no. 6; HARRISON 1994; AINSWORTH 2010,

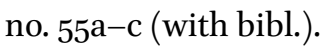
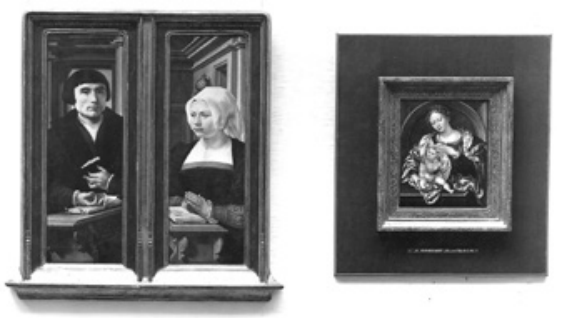
Identity of the sitter(s): unknown

Provenance: unknown

Number of portrait(s): 2

Type of person(s): lay (couple)

Attitude of the sitter(s): particular gesture

Representation of the sitter(s): half-length

Gaze of the sitter(s): towards the viewer, towards the scene

Object(s): yes (prie-dieu, book)

Coat(s) of arms: no

Environment: domestic setting

Structuring of the pictorial space: unified space with discontinuities

Patron saint(s): none

Gesture of the patron saint(s): not applicable

Type of religious scene: hieratic

Religious scene(s) depicted: the Virgin and Child

Cat. 361 -Type $3^{D}$

GOSSART, Jan (attributed to)

The Virgin and Child with a Man in Prayer

(c. 1525-1535)

$27 \times 22 \mathrm{~cm}$

Copenhagen, Statens Museum for Kunst, inv. no. KMS1859

BIB L.: FRIEDLÄNDER VIII, no. 41; Mus. cat.

Copenhagen 1951, no. 270.

Identity of the sitter(s): unknown

Provenance: unknown

Number of portrait(s):

Type of person(s): lay (man alone)

Attitude of the sitter(s): particular gesture

Representation of the sitter(s): half-length

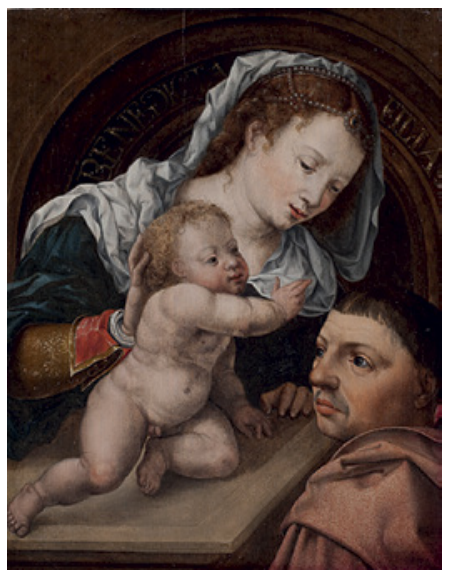

Gaze of the sitter(s): towards the scene

Object(s): no

Coat(s) of arms: no

Environment: neutral space

Structuring of the pictorial space: not applicable

Patron saint(s): none

Gesture of the patron saint(s): not applicable

Type of religious scene: hieratic

Religious scene(s) depicted: the Virgin and Child 
Cat. 362-Type 6A

GOSSART, Jan (attributed

to) (or Jan Vermeyen)

Diptych (?) of Jean

Carondelet with

St. Donatian (c. 1525-1530)

$43 \times 34 \mathrm{~cm}$ (each wing)

Tournai, Musée des Beaux-

Arts, inv. no. 370 (left wing)

and Kansas City, Nelson-
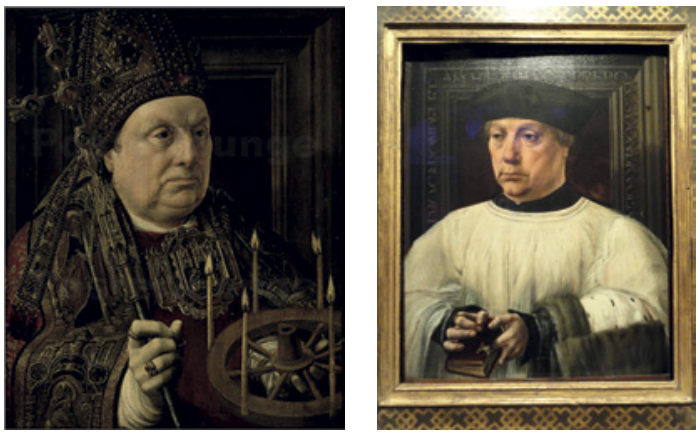

Atkins Museum of Art, inv. no. 63-17 (right wing)

BIBL.: FRIEDLÄNDER VIII, no. 5; WEALE 1910; Mus. cat. Kansas City 2005, no. 17; AINSWORTH 2010, 305 (with bibl.).

REMARK: Max Friedländer suggested in 1902 that these two wings formed initially a diptych, taking into account their similar size and composition, and the presence of Carondelet's coat of arms on the reverse of St. Donatian's panel. Nonetheless, by comparison with other diptychs, this one presents a surprising iconography. Not only is the devotee not portrayed in prayer, but he is also facing a saint (and not the Virgin, Christ or a narrative scene). According to Nicole Verhaegen, the panels were initially the wings of a triptych, whose centre piece was Gossart's Virgin and Child, now at the Gemäldegalerie in Berlin. The three panels do indeed have a similar size, and the attitude of the Virgin suggests that the panel had a pendant. Several triptychs of this kind have been preserved, and that makes this second hypothesis more plausible than the first (notably, cat. 585).

HISTORICAL INFORMATION: Jean Carondelet has been identified by the inscriptions and other portraits. On him, see cat. 357.

Identity of the sitter(s): Jean Carondelet

Provenance: unknown

Number of portrait(s): 1

Type of person(s): religious (man alone: canon)

Attitude of the sitter(s): holding a book

Representation of the sitter(s): half-length

Gaze of the sitter(s): into space

Object(s): yes (book)

Coat(s) of arms: yes

Environment: neutral space (incomplete)

Structuring of the pictorial space: indeterminate

Patron saint(s): none

Gesture of the patron saint(s): not applicable

Type of religious scene: hieratic

Religious scene(s) depicted: St. Donatian 
Cat. 363-Type 6B

[Link to the Friedländer 3.o Database]

GOSSART, Jan (follower of)

Portrait of a Young Man in Prayer (c. 1500-1550)

$33 \times 31 \mathrm{~cm}$

Geneva, Musée d'Art et d'Histoire, inv. no. 1872-4

BIB L.: FRIEDLÄNDER VIII, no. 81; AINSWORTH 2010, 306 (with bibl.).

Identity of the sitter(s): unknown

Provenance: unknown

Number of portrait(s): 1

Type of person(s): lay (man alone)

Attitude of the sitter(s): hands clasped

Representation of the sitter(s): half-length

Gaze of the sitter(s): indeterminate

Object(s): no

Coat(s) of arms: no

Environment: neutral space (incomplete)

Structuring of the pictorial space: indeterminate

Patron saint(s): none

Gesture of the patron saint(s): not applicable

Type of religious scene: indeterminate

Religious scene(s) depicted: none

Cat. 364-Type 4 B

GOSSART, Jan (with the collaboration of Gerard David and Simon Bening?)

Diptych of Antonio Siciliano

('Doria Diptych') (c. 1510-1514)

$41 \times 24 \mathrm{~cm}$ (each wing)

Rome, Galleria Doria Pamphili BIB L.: FRIEDLÄNDER VIII, no. 3; Exh. cat. Antwerp and
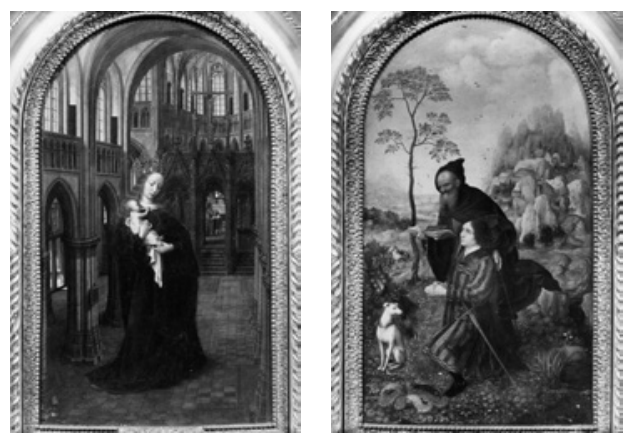

Washington 2006, no. 13;

AINSWORTH 2010, no. 7a-b (with bibl.). 
HISTORICAL INFORMATION: The man portrayed on the right wing is Antonio Siciliano, who served as chamberlain and secretary of the Duke of Milan, Massimiliano Sforza. In 1513-1514, Siciliano travelled at the request of his master to the Low Countries to meet Margaret of Austria (for the archival documents related to this trip, see WEIDEMA and KOOPSTRA 2012, 12-13). During this trip, he commissioned the Grimani Breviary, a precious manuscript produced by several artists (including Gerard David and Simon Bening). Until very recently, it was believed that Siciliano commissioned this diptych to Gossart in Mechelen, for the painter was working there on the Altarpiece of St. Luke drawing the Virgin (Vienna, Kunsthistorisches Museum) destined for the altar of the Guild of St. Luke in 1513-1514. The two men might indeed have met in Mechelen. Nevertheless, technical investigations have shown that the left wing was not painted by Gossart, but by Gerard David (probably c. 1510). According to Ainsworth, Siciliano bought David's Virgin and Child in Church when he was in Bruges for the commission of the Grimani Breviary. He then asked Gossart to paint his portrait on another panel to form a diptych. The landscape seems to have been executed by another painter, perhaps Simon Bening.

Identity of the sitter(s): Antonio Siciliano

Provenance: most probably in the property of Antonio Siciliano, and then of Gabriel Vendramin

Number of portrait(s): 1

Type of person(s): lay (man alone)

Attitude of the sitter(s): hands clasped

Representation of the sitter(s): full-length

Gaze of the sitter(s): towards the scene

Object(s): yes (sword, dog, helmet, book, rosary)

Coat(s) of arms: yes

Environment: landscape, no sacred connotation, ecclesial space

Structuring of the pictorial space: distinct space

Patron saint(s): Anthony

Gesture of the patron saint(s): introducing

Type of religious scene: hieratic

Religious scene(s) depicted: the Virgin and Child 
Cat. 365-Type 6A

HORENBOUT, Gerard

Two Wings. Portraits of Lieven

van Pottelsberghe and Livina van

Steeland and their Children in

Prayer (c. 1524-1531)

$43 \times 33.5 \mathrm{~cm}$ (each wing)

Ghent, MSK, inv. nos. 1932-A and

1937-A

BIBL.: HULIN DE LOO 1939;

MARTENS M. 2000; BORN et
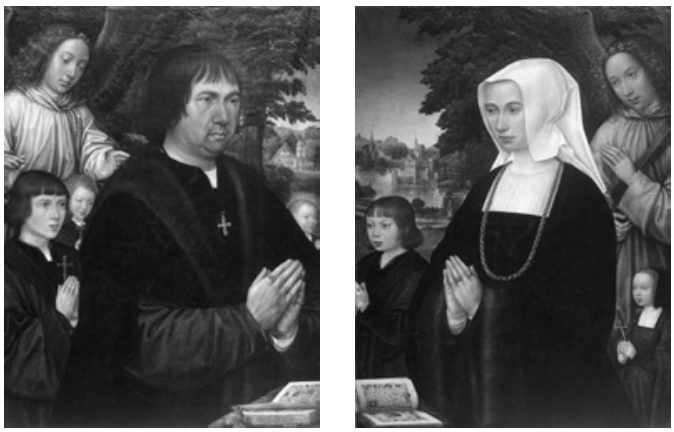

alii 2014 (with bibl.).

HISTORICAL INFORMATION: Lord of Vinderhoute, Meerendree and Wissekerke, Lieven van Pottelsberghe is the son of Lieven van Pottelsberghe and Livina Snibbels. He was a member of the Council of Flanders and of the Conseil privé. He was also Advisor of the Council of State and Receiver-general of Flanders. He resigned from his offices in 1522 and died in 1531. With his wife Livina van Steeland ( $\uparrow 1563)$, he had five children. All of them died at a young age, except Frans (1516-1545), who is depicted next to his mother and without a small cross in his hands. On the left wing appear Florens ( $\dagger$ 1517), Antoon $(\dagger 1524)$ and another unknown son. The daughter on the right is also unknown. In 1513, the couple initiated the construction of the Alynshospitaal in Ghent. In 1521, they also founded a bursary for ten schoolchildren at the school of the Brethren of the Common Life, in memory of their son Florens. Lievin was also one of the founders of the Brotherhood 'De Zoete Naam Jezus', which used to meet in his family chapel in the church of St. Michael. In 1525 , he founded an altar in this chapel, where he has also been buried. On the panels, the husband and wife are kneeling on a prie-dieu, on which is displayed an illuminated book of hours. Lievin's books shows a Crucifixion and Livina's book a Virgin and Child. Their mottos (Plus est en luy for him and Ma foy est telle for her) are inscribed on the pages. In a recent study (BORN et alii 2014), a group of scholars has argued that the panels formed a memorial to the family, together with a panel depicting St. Livinus (Aachen, Suermondt-Ludwig Museum, inv. no. GK 0317) and another, now lost, panel with the Virgin and Child. This memorial was probably destined for the family chapel in the Ghent church of St. Michael.

Identity of the sitter(s): Lieven van Pottelsberghe, Livina van Steeland and their children

Provenance: Ghent, church of St. Michael or Vinderhout, chapel of the castle (?) 
Number of portrait(s): 7

Type of person(s): lay (family with children)

Attitude of the sitter(s): hands clasped, holding a small cross

Representation of the sitter(s): half-length

Gaze of the sitter(s): indeterminate

Object(s): yes (prie-dieu, book, small cross)

Coat(s) of arms: yes

Environment: landscape, no sacred connotation (incomplete)

Structuring of the pictorial space: indeterminate

Patron saint(s): Angels

Gesture of the patron saint(s): introducing, holding his/her attribute

Type of religious scene: indeterminate

Religious scene(s) depicted: St. Livinus (?), the Virgin and Child

\section{Cat. 366-Type 4 B}

Isenbrant, Adrien (attributed to)

Diptych of Our Lady of the Seven Sorrows ('Van de Velde Diptych') (1521) $144 \times 143 \mathrm{~cm}$ (left wing with frame) and $138 \times 138 \mathrm{~cm}$ (right wing)

Brussels, MRBAB, inv. no. 2592 (left wing) and Bruges, church of Our Lady (right wing)

BIBL.: FRIEDLÄNDER XI, no. 138; Exh. cat. Bruges 1998 (vol. 2), no. 40 (with bibl.); VAN DER VELDEN 2006.

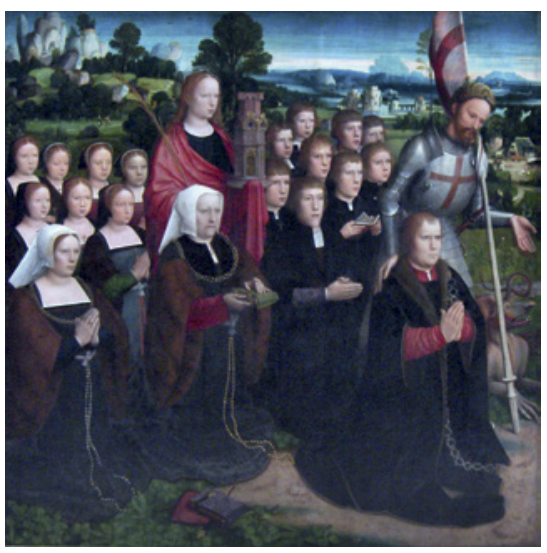

HISTORICAL INFORMATION: This imposing diptych was destined for the chapel of the Van de Velde family, at the church of Our Lady in Bruges. The left wing includes the portraits of Joris van de Velde, his wife Barbara le Maire and their children. The work was most probably commissioned by Barbara, after the death of her husband in 1528. At this time, she instituted a foundation in memory of Joris and she also tried to establish the cult of the Seven Sorrows of the Virgin in this church. Joris van de Velde was a member of the Bruges elite. He made a long and brilliant political career: in 1517, he was appointed burgomaster and Provoost of the Brotherhood of the Holy Blood, whose insignias he is wearing in the diptych.

Identity of the sitter(s): Joris van de Velde, Barbara le Maire and their children

Provenance: Bruges, church of Our Lady 
Number of portrait(s): 18

Type of person(s): lay (family with children)

Attitude of the sitter(s): hands clasped, holding a book

Representation of the sitter(s): full-length, small scale

Gaze of the sitter(s): into space

Object(s): yes (rosary, book)

Coat(s) of arms: yes

Environment: landscape, no sacred connotation; architectural space with sacred connotation

Structuring of the pictorial space: distinct spaces

Patron saint(s): Barbara, George

Gesture of the patron saint(s): introducing, holding his/her attribute

Type of religious scene: hieratic

Religious scene(s) depicted: the Virgin of the Seven Sorrows

Cat. 367 -Type $4 \mathrm{D}$

ISENBRANT, Adrien (attributed to)

Diptych of the Virgin and Child with a Member of the Hillenberger Family in Prayer (dated 1513 on the frame)

$31.7 \times 22.2 \mathrm{~cm}$ (each wing)

Miami, Coral Gables, Lowe Art Museum

вIB L.: FRIEDLÄNDER I, 43; EISLER 1977, 73-74; DÜLLBERG 1990, no. 15. HISTORICAL INFORMATION: The coat of arms painted on the reverse of the right wing belongs to the Hillenberger family. The original frame includes an inscription giving the age of the sitter: DO ICK HABDE DISSE GHESTALT / WAS ICK 32 IAER ALT A 1513 O I FEBRVARII.

Identity of the sitter(s): Member of the Hillenberger family

Provenance: unknown

Number of portrait(s): 1

Type of person(s): lay (man alone)

Attitude of the sitter(s): hands clasped

Representation of the sitter(s): half-length

Gaze of the sitter(s): towards the scene

Object(s): no

Coat(s) of arms: yes (on the reverse) 
Environment: domestic setting

Structuring of the pictorial space: continuous space

Patron saint(s): none

Gesture of the patron saint(s): not applicable

Type of religious scene: hieratic

Religious scene(s) depicted: the Virgin and Child

Cat. 368-Type 6A

[RKD work no. 46426]

ISENBRANT, Adrien (attributed to)

Fragment. A Man in Prayer (c. 1500-1550)

$25 \times 18 \mathrm{~cm}$ (each wing)

Whereabouts unknown

вIB L.: FRIEDLÄNDER XI, no. 226.

Identity of the sitter(s): unknown

Provenance: unknown

Number of portrait(s): 1

Type of person(s): lay (man alone)

Attitude of the sitter(s): hands clasped

Representation of the sitter(s): half-length

Gaze of the sitter(s): indeterminate

Object(s): yes (sword)

Coat(s) of arms: no

Environment: landscape, no sacred connotation (incomplete)

Structuring of the pictorial space: indeterminate

Patron saint(s): none

Gesture of the patron saint(s): not applicable

Type of religious scene: indeterminate

Religious scene(s) depicted: none

Cat. 369-Type 6B

[Link to the Friedländer 3.o Database]

ISENBRANT, Adrien (attributed to)

Portrait of a Man in Prayer with St. Paul and St. Peter (c. 1530)

$46.7 \times 36.8 \mathrm{~cm}$

London, private collection

BIB L.: FRIEDLÄNDER XI, no. 215; Exh. cat. Bruges 1998 (vol. 2), no. 49 (with bibl.). 
Identity of the sitter(s): unknown

Provenance: unknown

Number of portrait(s): 1

Type of person(s): lay (man alone)

Attitude of the sitter(s): hands clasped

Representation of the sitter(s): half-length

Gaze of the sitter(s): indeterminate

Object(s): no

Coat(s) of arms: no

Environment: neutral space (incomplete)

Structuring of the pictorial space: indeterminate

Patron saint(s): Peter, Paul

Gesture of the patron saint(s): introducing, holding his/her attribute

Type of religious scene: indeterminate

Religious scene(s) depicted: none

Cat. 370-Type 6B

[R KD work no. 46398]

ISENBRANT, Adrien (attributed to)

Portrait of a Man in Prayer with St. Peter (c. 1500-1550)

$28.3 \times 22.2 \mathrm{~cm}$

Berlin, Staatliche Museen zu Berlin, Gemäldegalerie, inv. no. 2084

B IB L.: FRIEDLÄNDER XI, no. 144; Mus. cat. Berlin 1996, no. 718.

Identity of the sitter(s): unknown

Provenance: unknown

Number of portrait(s): 1

Type of person(s): lay (man alone)

Representation of the sitter(s): half-length

Attitude of the sitter(s): hands clasped

Gaze of the sitter(s): indeterminate

Object(s): no

Coat(s) of arms: yes

Environment: landscape, no sacred connotation (incomplete)

Structuring of the pictorial space: indeterminate

Patron saint(s): Peter

Gesture of the patron saint(s): blessing 
Type of religious scene: indeterminate

Religious scene(s) depicted: none

Cat. 371-Type 6B

ISENBRANT, Adrien (attributed to)

Portrait of Paul de Nigro in Prayer (dated 1518)

$34.5 \times 27.5 \mathrm{~cm}$

Bruges, Groeningemuseum, inv. no. 1280 BIBL.: FRIEDLÄNDER XI, no. 227; Exh. cat. Bruges 1998 (vol. 2), no. 36 (with bibl.). HISTORICAL INFORMATION: A native of Genoa, Paul de Nigro went to Flanders for commercial reasons. His presence in Bruges is attested from 1512 onwards, when he is mentioned as a shipping broker. In 1525, he moved to Antwerp and joined

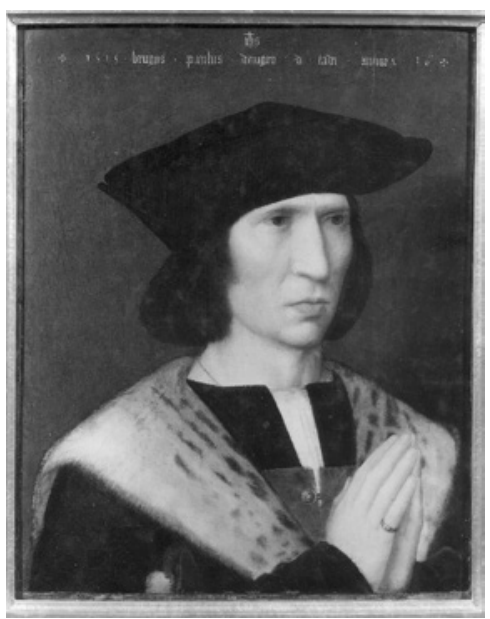
the Nation of Genoa. The inscription located on the upper part of the panel indicates that the painting was executed in Bruges: IHS 1518 . brugys . paulus .denigro.

Identity of the sitter(s): Paul de Nigro

Provenance: unknown

Number of portrait(s): 1

Type of person(s): lay (man alone)

Attitude of the sitter(s): hands clasped

Representation of the sitter(s): half-length

Gaze of the sitter(s): indeterminate

Object(s): no

Coat(s) of arms: no

Environment: neutral space (incomplete)

Structuring of the pictorial space: indeterminate

Patron saint(s): none

Gesture of the patron saint(s): not applicable

Type of religious scene: indeterminate

Religious scene(s) depicted: none 
Cat. 372-Type $3 \mathrm{D}$

ISENBRANT, Adrien (attributed to)

St. John the Baptist with a Couple in Prayer

(c. 1500-1550)

$56 \times 41 \mathrm{~cm}$

New York, sale Parke-Bernet (15 November 1945)

BIB L.: FRIEDLÄNDER XI, no. 207.

Identity of the sitter(s): unknown

Provenance: unknown

Number of portrait(s): 2

Type of person(s): lay (couple)

Attitude of the sitter(s): hands clasped

Representation of the sitter(s): full-length

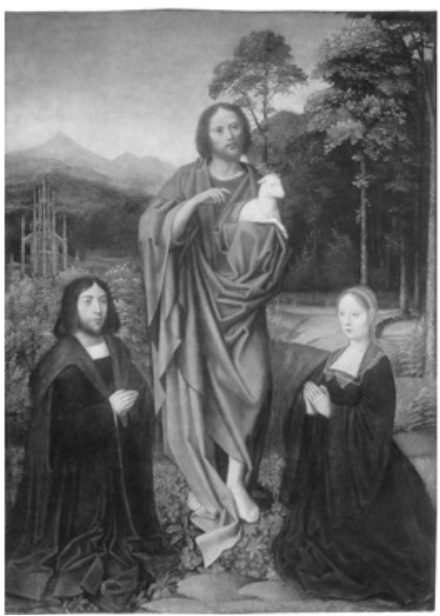

Gaze of the sitter(s): into space

Object(s): no

Coat(s) of arms: no

Environment: landscape with sacred connotation

Structuring of the pictorial space: not applicable

Patron saint(s): none

Gesture of the patron saint(s): not applicable

Type of religious scene: hieratic

Religious scene(s) depicted: St. John the Baptist

Cat. 373-Type $3 \mathrm{D}$

ISENBRANT, Adrien (attributed to)

The Virgin and Child Enthroned with a

Family in Prayer (c. 1500-1550)

$65 \times 62.5 \mathrm{~cm}$

Whereabouts unknown

BIB L.: FRIEDLÄNDER XI, no. 186.

Identity of the sitter(s): unknown

Provenance: unknown

Number of portrait(s): 6

Type of person(s): lay (family with children)

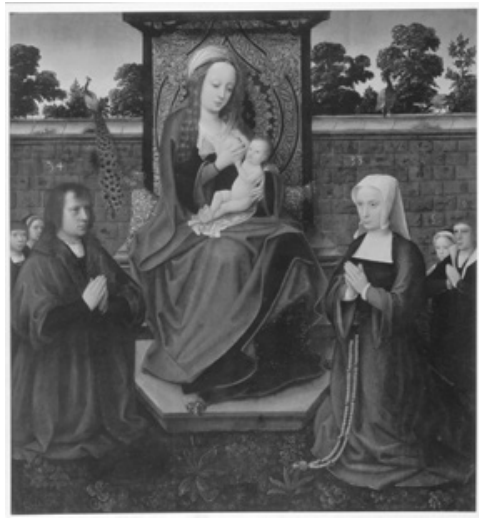

Attitude of the sitter(s): hands clasped

Representation of the sitter(s): full-length

Gaze of the sitter(s): into space 
Object(s): yes (rosary)

Coat(s) of arms: no

Environment: enclosed garden

Structuring of the pictorial space: not applicable

Patron saint(s): none

Gesture of the patron saint(s): not applicable

Type of religious scene: hieratic

Religious scene(s) depicted: the Virgin and Child

Cat. 374-Type 2A

[RKD work no. 60304]

ISENBRANT, Adrien (attributed to)

Triptych of the Crucifixion with two Women in Prayer and Patron Saints (c. 1500-1550)

$59.6 \times 38.3 \mathrm{~cm}$ (centre panel) and $60.5 \times 16.5 \mathrm{~cm}$ (wings)

London, sale Sotheby's (8 July 1999), lot no. 48

BIBL.: FRIEDLÄNDER XI, no. 130; Sale cat. Sotheby's (London, 8 July 1999),

no. 48 (with bibl.); SCHADE 2001, 356-57.

Identity of the sitter(s): unknown

Provenance: unknown

Number of portrait(s): 2

Type of person(s): mixed (unidentified group)

Attitude of the sitter(s): hands clasped

Representation of the sitter(s): full-length

Gaze of the sitter(s): into space

Object(s): no

Coat(s) of arms: no

Environment: historical setting

Structuring of the pictorial space: unified space with discontinuities

Patron saint(s): James (?), Catherine

Gesture of the patron saint(s): introducing, holding his/her attribute

Type of religious scene: narrative

Religious scene(s) depicted: the Crucifixion, the Annunciation

Cat. 375-Type $3 \mathrm{~A}$

ISENBRANT, Adrien (attributed to)

Triptych of the Mass of St. Gregory with a Man in Prayer (c. 1490)

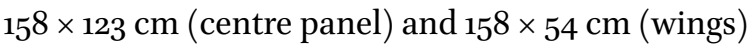


Santo Domingo de la Calzada (La Rioja), cathedral

BIBL.: BERMEJO 1982, 103-04 (with bibl.); Exh. cat. Leon and Palencia 1999, no. $5^{2}$ (with bibl.).

Identity of the sitter(s): unknown

Provenance: unknown

Number of portrait(s): 1

Type of person(s): lay (man alone)

Attitude of the sitter(s): hands clasped

Representation of the sitter(s): full-length

Gaze of the sitter(s): towards the scene

Object(s): no

Coat(s) of arms: no

Environment: historical setting

Structuring of the pictorial space: not applicable

Patron saint(s): Francis (?)

Gesture of the patron saint(s): indicating

Type of religious scene: narrative

Religious scene(s) depicted: the Mass of St. Gregory, St. Anthony, St. Dominic, the Annunciation

Cat. 376 - Type 5

ISENBRANT, Adrien (attributed to)

Triptych of the Presentation at the Temple with a Couple in Prayer and Patron Saints (c. 1510-1511)

$60.5 \times 42.6 \mathrm{~cm}$ (centre panel) and $60.5 \times 15 \mathrm{~cm}$ (wings)

Bruges, Treasure of the St. Saviour's Cathedral

BIB L.: FRIEDLÄNDER XI, no. 128; Exh. cat. Bruges 1998 (vol. 2), no. 35 (with bibl.).

HISTORICAL INFORMATION: Weale identified the persons portrayed on the wings as Philippe Wielant, a Bruges jurist († 1521), and his wife Johanna van Halewijn ( $\dagger 1510$ ), on the basis of their coats of arms. The centre panel contains a third coat of arms, located right above the portrait of a nun, who appears to be Philippine de Gros. This portrait and the coat of arms were added at a 
later date. According to Janssens de Bisthoven, the triptych was commissioned in 1510, right after the death of Johanna, in order to perpetuate her memory. In 1521, Philippe died, as well as his daughter Philippine Wielant, who had married Ferry de Gros. Their daughter, Philippine de Gros, who was then a nun at the Augustinian convent of Bruges, inherited the triptych and added her own portrait and coat of arms on the centre panel.

Identity of the sitter(s): Philippe Wielant, Johanna van Halewijn and Philippine de Gros

Provenance: unknown

Number of portrait(s): 3

Type of person(s): lay (family)

Attitude of the sitter(s): hands clasped

Representation of the sitter(s): full-length

Gaze of the sitter(s): towards the scene

Object(s): no

Coat(s) of arms: yes

Environment: historical setting

Structuring of the pictorial space: unified space with discontinuities

Patron saint(s): Philip, John the Evangelist

Gesture of the patron saint(s): introducing, holding his/her attribute Type of religious scene: narrative

Religious scene(s) depicted: the Presentation at the temple

\section{Cat. 377-Type 6A}

ISENBRANT, Adrien (attributed to)

Two wings. A couple in prayer (c. 1500-1550) $73 \times 27 \mathrm{~cm}$ (each wing)

Lyon, Musée des Beaux-Arts, inv. no. E. $538.93 / 4$

BIBL.: FRIEDLÄNDER XI, supp. 307.

Identity of the sitter(s): unknown

Provenance: unknown

Number of portrait(s): 2

Type of person(s): lay (couple)

Attitude of the sitter(s): hands clasped

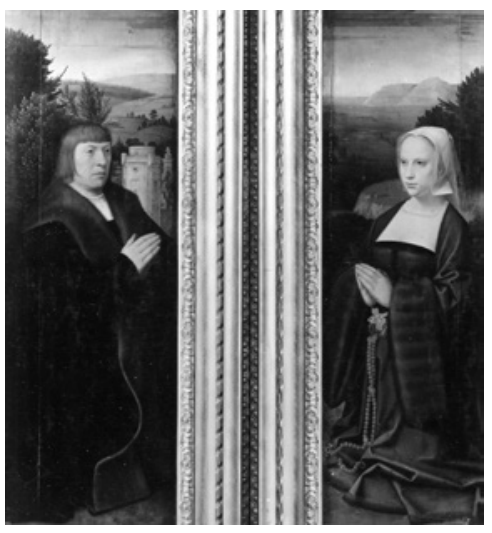

Representation of the sitter(s): full-length

Gaze of the sitter(s): indeterminate 
Object(s): yes (rosary)

Coat(s) of arms: no

Environment: landscape, no sacred connotation (incomplete)

Structuring of the pictorial space: indeterminate

Patron saint(s): none

Gesture of the patron saint(s): not applicable

Type of religious scene: indeterminate

Religious scene(s) depicted: none

Cat. 378-Type 6A

[RKD work no. 45442]

ISENBRANT, Adrien (attributed to)

Two Wings. A Family in Prayer with Patron Saints (c. 1500-1550)

$86 \times 28 \mathrm{~cm}$ (each wing)

Private collection

BIBL.: FRIEDLÄNDER XI, no. 141.

Identity of the sitter(s): unknown

Provenance: unknown

Number of portrait(s): 6

Type of person(s): lay (family with children)

Attitude of the sitter(s): hands clasped

Representation of the sitter(s): full-length

Gaze of the sitter(s): indeterminate

Object(s): yes (rosary)

Coat(s) of arms: no

Environment: landscape, no sacred connotation (incomplete)

Structuring of the pictorial space: indeterminate

Patron saint(s): John the Evangelist, Catherine

Gesture of the patron saint(s): holding his/her attribute

Type of religious scene: indeterminate

Religious scene(s) depicted: none 
Cat. 379-Type 6A

ISENBRANT, Adrien (attributed to)

Two Wings. Three Persons in Prayer with Patron

Saints (c. 1500-1550)

$73 \times 22 \mathrm{~cm}$ (each wing)

Whereabouts unknown

BIB L.: FRIEDLÄNDER XI, no. 143.

Identity of the sitter(s): unknown

Provenance: unknown

Number of portrait(s): 3

Type of person(s): lay (family)

Attitude of the sitter(s): hands clasped

Representation of the sitter(s): full-length

Gaze of the sitter(s): indeterminate
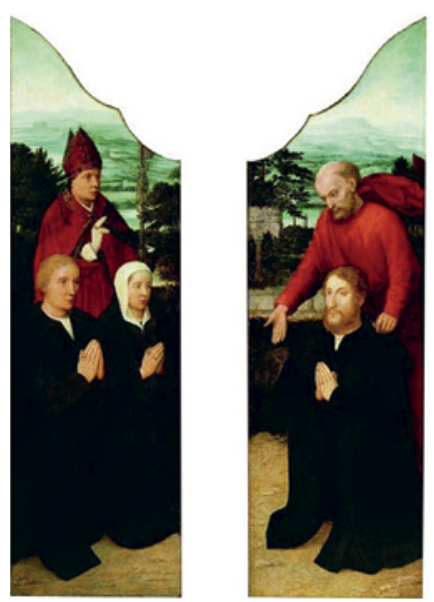

Object(s): no

Coat(s) of arms: no

Environment: landscape, no sacred connotation (incomplete)

Structuring of the pictorial space: indeterminate

Patron saint(s): Peter, Nicholas

Gesture of the patron saint(s): introducing, holding his/her attribute

Type of religious scene: indeterminate

Religious scene(s) depicted: none

\section{Cat. 380-Type 6A}

[RKD work no. 45445]

ISENBRANT, Adrien (attributed to) and Anonymous South Netherlandish Master

Two Wings. Christ Bearing the Cross with a Man in Prayer and St. James (c. 1500-1550)

$46 \times 13.5 \mathrm{~cm}$ (each wing)

Whereabouts unknown

BIB L.: FRIEDLÄNDER XI, no. 142.

Identity of the sitter(s): unknown

Provenance: unknown

Number of portrait(s): 1

Type of person(s): lay (man alone)

Attitude of the sitter(s): hands clasped

Representation of the sitter(s): full-length 
Gaze of the sitter(s): indeterminate

$\operatorname{Object}(\mathrm{s})$ : no

Coat(s) of arms: no

Environment: landscape, no sacred connotation (incomplete)

Structuring of the pictorial space: indeterminate

Patron saint(s): James

Gesture of the patron saint(s): introducing

Type of religious scene: indeterminate

Religious scene(s) depicted: Christ bearing the cross

Cat. 381-Type 2D

ISENBRANT, Adrien (attributed to) and POURBUS, Pieter

Triptych of the Virgin and Child Enthroned with a Man in Prayer and St. Andrew (c. 1500-1550) $38 \times 30 \mathrm{~cm}$ (centre panel) and $38 \times$ $9 \mathrm{~cm}$ (wings)

Whereabouts unknown BIB L.: FRIEDLÄNDER XI, no. 134; SCHADE 2001, 156-57 (with bibl.).

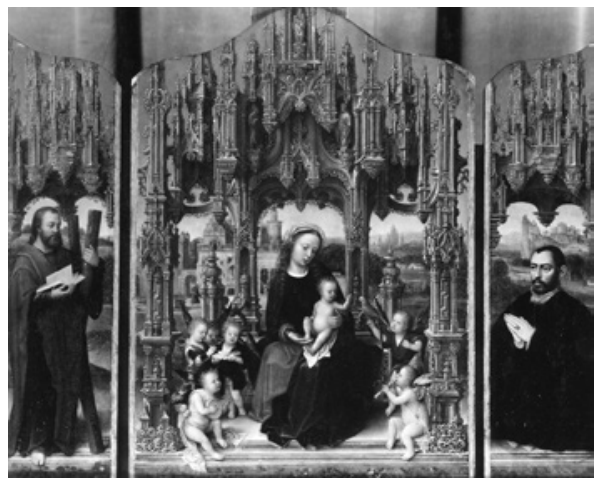

Identity of the sitter(s): unknown

Provenance: unknown

Number of portrait(s): 1

Type of person(s): lay (man alone)

Attitude of the sitter(s): hands clasped

Representation of the sitter(s): half-length

Gaze of the sitter(s): into space

Object(s): no

Coat(s) of arms: no

Environment: architectural space with sacred connotation

Structuring of the pictorial space: continuous space

Patron saint(s): none

Gesture of the patron saint(s): not applicable

Type of religious scene: hieratic

Religious scene(s) depicted: the Virgin and Child, St. Andrew 
Cat. 382 -Type ${ }_{3} \mathrm{C}$ (then 5 )

ISENBRANT, Adrien (circle of)

Triptych of the Crucifixion with a Man

in Prayer (c. 1500-1550)

$171 \times 171 \mathrm{~cm}$ (centre panel) and $171 \times$

$82 \mathrm{~cm}$ (wings)

Tallinn, Niguliste Museum, inv. no.

EKM M 5172/1-3

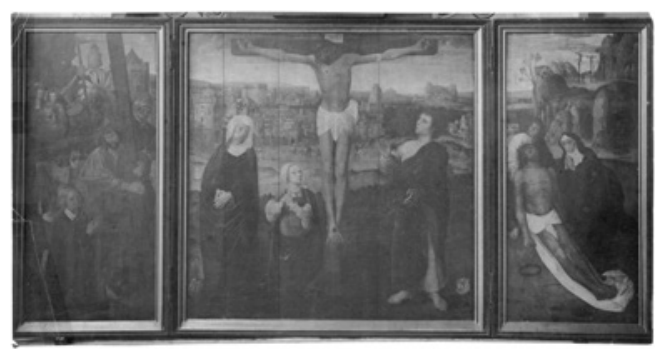

BIBL.: MÄND and NURKSE 2013 (with bibl.)

HISTORICAL INFORMATION: The triptych was produced in Bruges in the early sixteenth century and was overpainted and modified several times. The identity of the first commissioner and the original location of the triptych remains unknown. Taking into consideration the original presence of four Franciscan saints on the outer wings, the triptych might have been commissioned for a Franciscan friary (in the Low Countries or in the region of Tallinn). After 1516, Victor van der Lippe and his wife Gertrud van Grest commissioned a drastic alteration of the outer wings of the work. In their actual state, the coats of arms on the reverse are those of Euert van der Lippe and Johan van Grest, the fathers of the couple, who were important political figures in Tallinn in the fifteenth century. Victor and Gertrud probably placed the triptych on the Lippe family altar in the Dominican friary of Tallinn. Around 1550, the triptych came into the possession of Urban Dene, the mint-master of Tallinn who was related to the Lippe family. He commissioned the addition of two portraits on the centre panel and placed the altarpiece in the church of St. Nicholas, where it served as a memorial work. On the basis of the accompanying coats of arms, the sitters of the centre panel have been identified as Urban Dene and Heinrich Bock. Urban was a wealthy merchant who belonged to the social elite of Tallinn. Heinrich was a cleric and superintendent in Tallinn between 1540 and 1549, year of his death. Finally, a third portrait was added on the left wing in 1654 by the grandson of Urban Dene. This portrait might cover an initial portrait of the merchant Dirick Dornemann, also painted in the mid-sixteenth century.

Identity of the sitter(s): unknown

Provenance: unknown

Number of portrait(s): 1

Type of person(s): lay (group: unidentified)

Attitude of the sitter(s): hands clasped

Representation of the sitter(s): full-length

Gaze of the sitter(s): towards the scene 
Object(s): no

Coat(s) of arms: yes (overpainted)

Environment: historical setting

Structuring of the pictorial space: continuous space

Patron saint(s): none

Gesture of the patron saint(s): not applicable

Type of religious scene: narrative

Religious scene(s) depicted: the Crucifixion, the Lamentation, Christ bearing the cross, St. James (initially St. Francis), the Virgin and Child (initially St. Anthony of Padova), St. Adrian (initially St. Louis of Toulouse), St. Anthony (initially St. Bernardino of Siena)

Cat. 383 - Type $2 \mathrm{D}$

ISENBRANT, Adrien (circle of)

Triptych of the Holy Family with a Couple in Prayer (c. 1500-1550) $70 \times 5^{2} \mathrm{~cm}($ centre panel) and $70 \times$ $21 \mathrm{~cm}$ (wings)

Previously Brussels, collection of the Baron Peñaranda BIB L.: FRIEDLÄNDER XI, no. 133.

Identity of the sitter(s): unknown

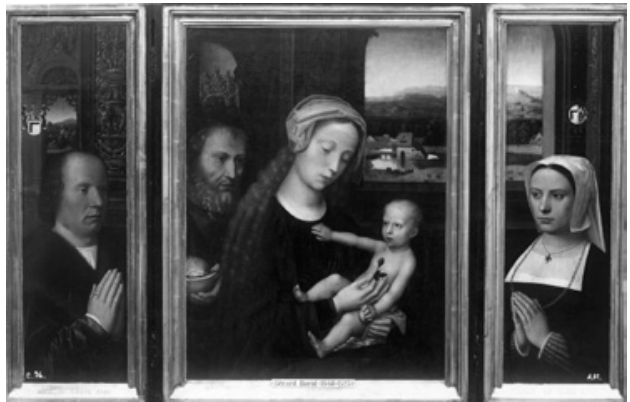

Provenance: unknown

Number of portrait(s): 2

Type of person(s): lay (couple)

Attitude of the sitter(s): hands clasped

Representation of the sitter(s): half-length

Gaze of the sitter(s): into space, towards the scene

Object(s): no

Coat(s) of arms: yes

Environment: domestic setting

Structuring of the pictorial space: continuous space

Patron saint(s): none

Gesture of the patron saint(s): not applicable

Type of religious scene: hieratic

Religious scene(s) depicted: the Holy family 
Cat. 384-Type 2D

ISENBRANT, Adrien (circle of)

Triptych of the Virgin of the Immaculate Conception with a Couple in Prayer (c. 1500-1550)

$112 \times 72 \mathrm{~cm}$ (centre panel) and $113 \times 31.5 \mathrm{~cm}$ (wings)

Warsaw, Muzeum Narodowe, inv. no. M.Ob.16

BIBL.: Mus. cat. Warsaw 1967, vol. 2, no.

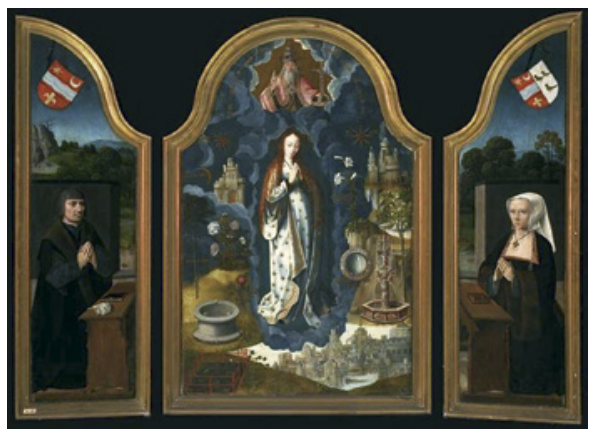
1573 (not consulted).

Historical INFORMATion: According to the RKD database entry (no. 45339), the sitters are Mathias Laurin (Lauwerin) and Françoise Ruffault.

Identity of the sitter(s): unknown

Provenance: unknown

Number of portrait(s): 2

Type of person(s): lay (couple)

Attitude of the sitter(s): hands clasped

Representation of the sitter(s): full-length

Gaze of the sitter(s): towards the scene

Object(s): yes (prie-dieu, book)

Coat(s) of arms: yes

Environment: enclosed garden

Structuring of the pictorial space: distinct spaces

Patron saint(s): none

Gesture of the patron saint(s): not applicable

Type of religious scene: hieratic

Religious scene(s) depicted:Virgin of the Immaculate Conception

Cat. 385 - Type $2 \mathrm{D}$

JACOBSZ., Dirck (wings) and workshop of Pieter Coecke van Aelst (centre panel)

Triptych of the Holy Family with a Couple in Prayer (c. 1535)

$103 \times 71 \mathrm{~cm}($ centre panel $)$ and $105 \times$ $29.5 \mathrm{~cm}$ (wings)

Utrecht, Museum Catharijneconvent, inv. no. ABM s 67

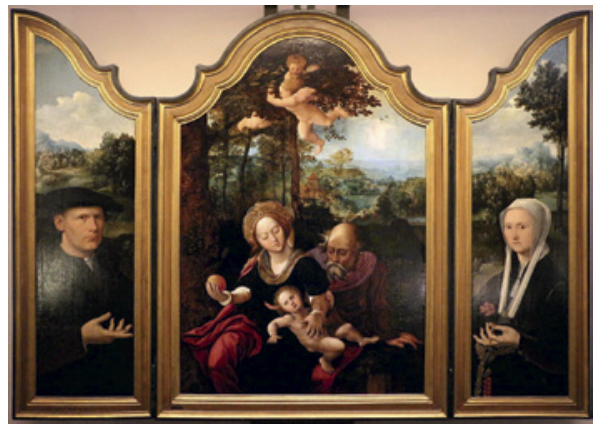


BIBL.: FRIEDLÄNDER XII, no. 242; HOOGEWERFF III, 529-30; Mus. cat. Utrecht 2002, 40-41 (with bibl.).

Identity of the sitter(s): unknown

Provenance: unknown

Number of portrait(s): 2

Type of person(s): lay (couple)

Attitude of the sitter(s): particular gesture

Representation of the sitter(s): half-length

Gaze of the sitter(s): towards the viewer

Object(s): yes (carnation, rosary)

Coat(s) of arms: no

Environment: landscape, no sacred connotation

Structuring of the pictorial space: unified space with discontinuities

Patron saint(s): none

Gesture of the patron saint(s): not applicable

Type of religious scene: hieratic

Religious scene(s) depicted: the Holy family

\section{Cat. 386-Type $2 \mathrm{C}$}

[RKD work no. 25828]

JACOBSZ., Dirck and CORNELISZ. VAN OOSTSANEN, Jacob

Triptych of the Virgin and Child with a Couple in Prayer (centre panel dated 1526 and wings dated 1530 )

$111.5 \times 70.5 \mathrm{~cm}$ (centre panel) and $110 \times 30.5 \mathrm{~cm}$ (wings)

Stuttgart, Staatsgalerie, inv. no. GVL 61

BIBL.: FRIEDLÄNDER XII, no. 243; Mus. cat. Stuttgart 1992, 90-91; Exh. cat.

Alkmaar 2014, no. 56 .

Identity of the sitter(s): unknown

Provenance: unknown

Number of portrait(s): 2

Type of person(s): lay (couple)

Attitude of the sitter(s): particular gesture

Representation of the sitter(s): half-length

Gaze of the sitter(s): towards the viewer

Object(s): yes (prie-dieu, book, parchment)

Coat(s) of arms: no

Environment: landscape with sacred connotation

Structuring of the pictorial space: continuous space

Patron saint(s): none 
Gesture of the patron saint(s): not applicable

Type of religious scene: hieratic

Religious scene(s) depicted: the Virgin and Child

Cat. 387-Type $2 \mathrm{~A}$

JOEST van Kalkaar, Jan (wings) and Brabender, Heinrich (centre piece)

Altarpiece of the Crucifixion ('Brömse Altarpiece') (c. 1512)

Size unknown; oil on wood and sandstone relief Lübeck, church of St. James

BIBL.: FRIEDLÄNDER IXa, 48; D'HAENENS 1984, 73, 294; WOLFF-THOMSEN 1997.

HISTORICAL INFORMATION: Heinrich Brömse, merchant and burgomaster of Lübeck, is depicted

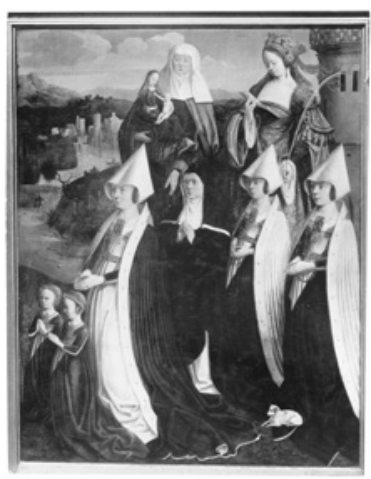
with his wife Elisabeth Westfal and their eleven children. These two wings come from an altarpiece, whose centre piece is a sandstone relief, executed by Heinrich Brabender. Dated c. 1512, the altarpiece was destined for their family chapel in the church of St. James (Jacobikirche), in Lübeck. Taking into account the fact that Heinrich died in 1502, the work was probably commissioned by his son Nikolaus, who also appears on the left wing.

Identity of the sitter(s): Heinrich Brömse, Elisabeth Westfal and their eleven children

Provenance: Lübeck, church of St. James

Number of portrait(s): 13

Type of person(s): mixed (family with children)

Attitude of the sitter(s): hands clasped, holding a book

Representation of the sitter(s): full-length

Gaze of the sitter(s): indeterminate

Object(s): yes (prie-dieu, book)

Coat(s) of arms: yes (on the predella)

Environment: landscape, no sacred connotation

Structuring of the pictorial space: distinct spaces (different techniques: painting/sandstone relief)

Patron saint(s): George, Anne, Barbara, an unidentified saint

Gesture of the patron saint(s): introducing, holding his/her attribute

Type of religious scene: narrative

Religious scene(s) depicted: the Crucifixion, St. James, St. Nicholas 
Cat. 388 - Type $3^{\mathrm{D}}$

JOEST van Kalkaar, Jan

Altarpiece of Our Lady of the Seven

Sorrows (1505)

$200 \times 140 \mathrm{~cm}$

Palencia, St. Antolin's Cathedral

BIBL.: FRIEDLÄNDER IXa, no. 2;

Exh. cat. Brussels 1985 (vol. 1), 254;

MARTENS D. 2010, 220-21, 224;

KASL 2014, 11-13.

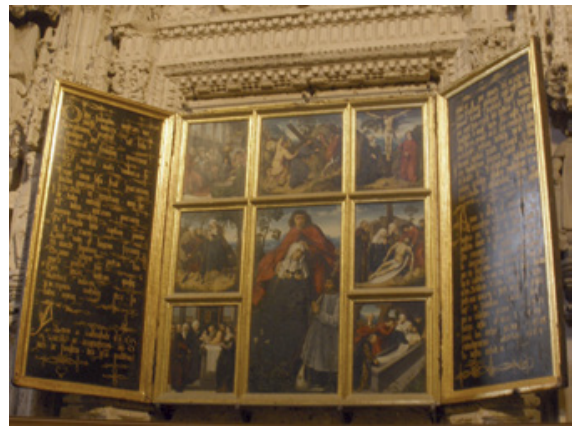

HISTORICAL INFORMATION: This altarpiece was commissioned by don Juan Rodriguez de Fonseca, a wealthy ecclesiastic who worked for Ferdinand of Aragon. During his long career, don Juan Rodriguez de Fonseca was sent three times to the Netherlands (in 1499, 1501 and 1504). In Brussels, he was in charge of documenting the marriage of Philip the Fair and Joanna of Castile. During these trips, he became a member of the Brotherhood of the Seven Sorrows of the Virgin, at the church of St. Gery. This led him to commission this altarpiece for the cathedral of Palencia. An entry of the Libro de Acuerdos of the cathedral indicates that the altarpiece was the work of the painter Juan de Holand, who has been identified with Jan Joest van Kalkar. From 1513 onwards, the altarpiece was located on an altar of the trascoro of the cathedral carved by Juan de Ruesga and Pedro de Paredes.

Identity of the sitter(s): Don Juan Rodriguez de Fonseca

Provenance: Palencia, St. Antolin's Cathedral, high altar

Number of portrait(s): 1

Type of person(s): religious (man alone: ecclesiastic)

Attitude of the sitter(s): hands clasped

Representation of the sitter(s): full-length

Gaze of the sitter(s): towards the scene

Object(s): yes (crosier, mitre)

Coat(s) of arms: no

Environment: landscape, no sacred connotation

Structuring of the pictorial space: fragmentation of the pictorial space

Patron saint(s): none

Gesture of the patron saint(s): not applicable

Type of religious scene: hieratic

Religious scene(s) depicted: the Virgin of the Seven Sorrows, the Presentation at the Temple, the Flight into Egypt, Christ among the Doctors, Christ Bearing the cross, the Crucifixion, the Lamentation, the Entombment 
Cat. 389-Type $3 \mathrm{~A}$

[Link to the Friedländer 3.o Database]

JOOS VAN GHENT (attributed to)

The Crucifixion with a Family in Prayer and Patron Saints (c. 1490-1500)

$122 \times 134 \mathrm{~cm}$

Madrid, Herreros de Tejada collection

BIB L.: FRIEDLÄNDER III, add. 132; PAUWELS 1959; BERMEJO 1982, 65-66 (with bibl.).

Identity of the sitter(s): unknown

Provenance: unknown

Number of portrait(s): 8

Type of person(s): mixed (family)

Attitude of the sitter(s): hands clasped, holding a book, holding a parchment Representation of the sitter(s): full-length

Gaze of the sitter(s): towards the scene, towards the ground, into space

Object(s): yes (book, parchment)

Coat(s) of arms: no

Environment: historical setting

Structuring of the pictorial space: not applicable

Patron saint(s): Jerome, James, Mary Magdalen, Catherine

Gesture of the patron saint(s): introducing, protecting

Type of religious scene: narrative

Religious scene(s) depicted: the Crucifixion

Cat. 390-Type $4 B$

LEYDE de, Lucas

The Virgin and Child with a Man in Prayer and St. Mary Magdalen (dated 1522)

$50 \times 68 \mathrm{~cm}$ and $42 \times 29 \mathrm{~cm}$

Munich, Alte pinakothek, inv. nos. 148-149

BIBL.: FRIEDLÄNDER X, no. 114; FILEDT KOK et alii 1975; Mus. cat. Munich 2006, 320-21 (with bibl.).

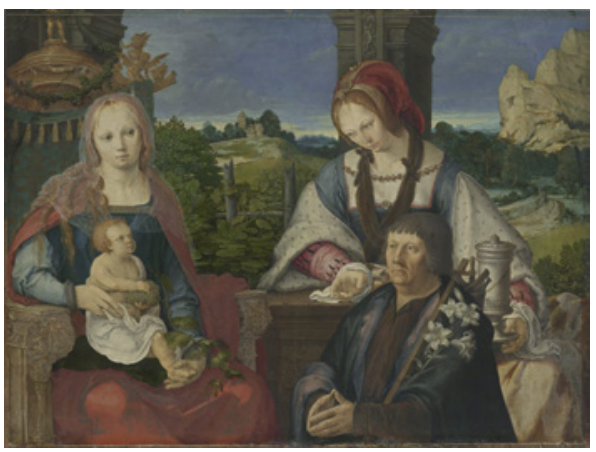
REMARK: This work was formerly a diptych, whose panels were joined at a later date. See FILEDT KOK et alii 1975.

Identity of the sitter(s): unknown 
Provenance: unknown

Number of portrait(s): 1

Type of person(s): lay (man alone)

Attitude of the sitter(s): hands clasped

Representation of the sitter(s): half-length

Gaze of the sitter(s): towards the scene

Object(s): yes (lily, staff)

Coat(s) of arms: no

Environment: architectural space with sacred connotation

Structuring of the pictorial space: continuous space

Patron saint(s): Mary Magdalen

Gesture of the patron saint(s): indicating

Type of religious scene: hieratic

Religious scene(s) depicted: the Virgin and Child, the Annunciation

\section{Cat. 391-Type $1 B$}

[RKD work no. 23910]

LEYDE de, Lucas (or Anonymous North Netherlandish Master)

Triptych of the Multiplication of Loaves (c. 1500-1550)

$74 \times 43 \mathrm{~cm}$ (centre panel) and $74 \times 16.5 \mathrm{~cm}$ (wings)

Greenville, The Bob Jones University Museum and Gallery

вIв L.: FRIEDLÄNDER X, suppl. 167; HOOGEWERFF III, 377-79.

Identity of the sitter(s): unknown

Provenance: unknown

Number of portrait(s): 1

Type of person(s): religious (man alone: canon)

Attitude of the sitter(s): hands clasped

Representation of the sitter(s): full-length

Gaze of the sitter(s): into space

Object(s): no

Coat(s) of arms: no

Environment: landscape, no sacred connotation

Structuring of the pictorial space: distinct spaces

Patron saint(s): Anthony

Gesture of the patron saint(s): holding his/her attribute

Type of religious scene: hieratic

Religious scene(s) depicted: the Multiplication of Loaves, the Ecce Homo 
Cat. 392-Type $3^{\mathrm{A}}$

[RKD work no. 210638]

LOMBARD, Lambert (circle of)

The Beheading of St. John the Baptist with a Priest in Prayer (c. 1540)

$66 \times 54 \mathrm{~cm}$

Zurich, sale Koller (14-19 September 2010), lot no. 3011

Identity of the sitter(s): unknown

Provenance: unknown

Number of portrait(s): 1

Type of person(s): religious (man alone: priest)

Attitude of the sitter(s): hands clasped

Representation of the sitter(s): full-length

Gaze of the sitter(s): eyes closed

Object(s): no

Coat(s) of arms: no

Environment: historical setting

Structuring of the pictorial space: not applicable

Patron saint(s): John the Baptist

Gesture of the patron saint(s): holding his/her attribute

Type of religious scene: narrative

Religious scene(s) depicted: the Beheading of John the Baptist

Cat. 393-Type 6A

[RKD work no. 107659]

LOMBARD, Lambert (follower of)

One Wing. The Deposition, A Woman in Prayer with St. Lawrence and St. Elizabeth

of Hungary (c. 1525-1550)

$72.2 \times 28.2 \mathrm{~cm}$

Amsterdam, sale Christie's (3 September 2002), lot no. 14

Identity of the sitter(s): unknown

Provenance: unknown

Number of portrait(s): 1

Type of person(s): religious (woman alone)

Attitude of the sitter(s): hands clasped

Representation of the sitter(s): full-length

Gaze of the sitter(s): indeterminate

Object(s): no 
Coat(s) of arms: no

Environment: niche

Structuring of the pictorial space: indeterminate

Patron saint(s): Lawrence, Elizabeth of Hungary

Gesture of the patron saint(s): holding his/her attribute

Type of religious scene: indeterminate

Religious scene(s) depicted: the Deposition

\section{Cat. 394-Type 6B}

MARMION, Simon

One Wing. A Canon in Prayer with

St.Jerome (c. 1475-1480)

$65.1 \times 48.9 \mathrm{~cm}$

Philadelphia, Philadelphia Museum of

Art, inv. no. 1329

BIB L.: Mus. cat. Philadelphia 1994, 71;

Exh. cat. London and Los Angeles 2003, no. 46 (with bibl.).

HISTORICAL INFORMATION: The stained-glass window behind the devotee contains an unknown coat of arms (with a cardinal hat on top of it, despite the fact that the sitter is wearing

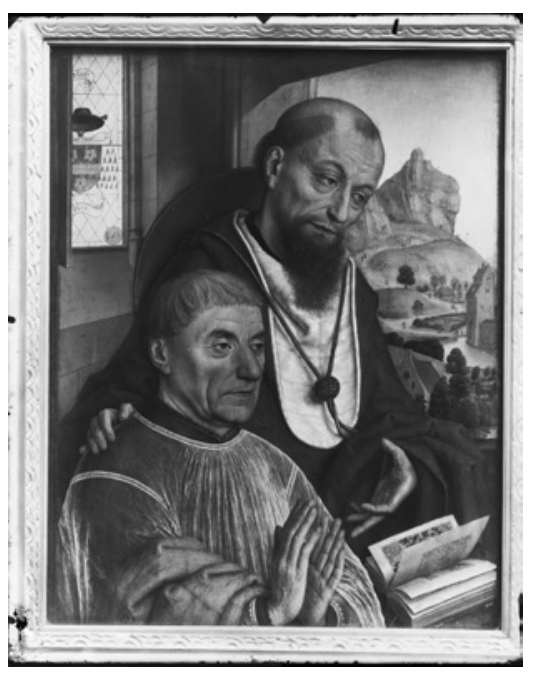
a canon's habit), the motto placet and the initials $J B$. Several hypotheses have been formulated regarding the identity of the sitter. The name of the Vierling family from Holland has been proposed, but no cardinal has been identified as coming from this family. Taking into account the small number of cardinals coming from the Low Countries, Châtelet argued that the sitter is Philibert Hugonet, Bishop of Mâcon, who was appointed cardinal in 1473. However, the coat of arms does not match. The portrait has also been linked to an extract from the will of Pierre Dewez, who was chaplain of the cathedral of Cambrai. This document dating from 1484 states: A Symon Marmion demorant a Valenchiennes ad cause de reste de son mestier de pointerie, pour ung tablet de Nostre-Dame a II feulles en maniere de ung epitaphe, paye pour l'aportage et a la demande du deffunct xiij l. The lack of other information prevents the confirmation of this identification.

Identity of the sitter(s): unknown

Provenance: unknown 
Number of portrait(s): 1

Type of person(s): religious (man alone: canon)

Attitude of the sitter(s): hands held up

Representation of the sitter(s): half-length

Gaze of the sitter(s): indeterminate

Object(s): yes (book)

Coat(s) of arms: yes

Environment: domestic setting

Structuring of the pictorial space: indeterminate

Patron saint(s): Jerome

Gesture of the patron saint(s): protecting

Type of religious scene: indeterminate

Religious scene(s) depicted: none

\section{Cat. 395-Type 6A}

[R KD work no. 64429]

MARMION, Simon (circle of) (or anonymous South Netherlandish Master)

Portrait of a Monk in Prayer with Patron Saint (c. 1450-1500)

$50 \times 32 \mathrm{~cm}$

Mainz, Landesmuseum Mainz, inv. no. 1181

Identity of the sitter(s): unknown

Provenance: unknown

Number of portrait(s): 1

Type of person(s): religious (man alone: monk)

Attitude of the sitter(s): hands clasped

Representation of the sitter(s): half-length

Gaze of the sitter(s): indeterminate

Object(s): no

Coat(s) of arms: no

Environment: landscape, no sacred connotation (incomplete)

Structuring of the pictorial space: indeterminate

Patron saint(s): a saint bishop

Gesture of the patron saint(s): holding his/her attribute

Type of religious scene: indeterminate

Religious scene(s) depicted: none 
Cat. 396-Type $2 B$

MARMION, Simon (follower of) Triptych of the Virgin and Child with a Couple in Prayer and Patron Saints (c. 1480)

$52.3 \times 38.8 \mathrm{~cm}$ (left wing) and 50.2 $\times 36.8 \mathrm{~cm}$ (right wing and centre panel together)
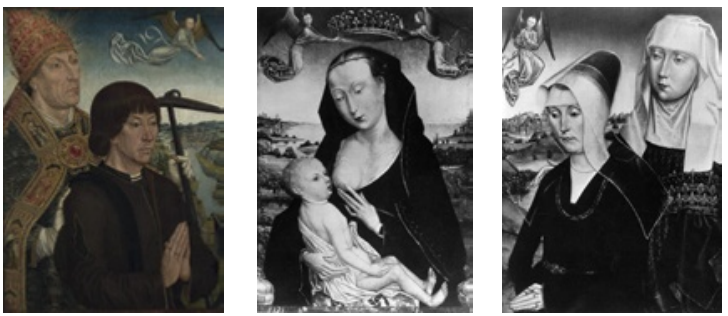

London, NG, inv. no. NG 1669

(left wing), New York, sale Sotheby's (22 May 1992), lot no. 64 (right wing) and London, sale Christie's (7 July 2006), lot no. 111 (centre panel)

BIBL.: CAMPBELL 1998, 310-15 (with bibl.); Sale cat. Christie's (London, 7 July 2006), no. 111.

Identity of the sitter(s): unknown

Provenance: unknown

Number of portrait(s): 2

Type of person(s): lay (couple)

Attitude of the sitter(s): hands clasped

Representation of the sitter(s): half-length

Gaze of the sitter(s): into space

Object(s): no

Coat(s) of arms: no

Environment: landscape, no sacred connotation

Structuring of the pictorial space: continuous space

Patron saint(s): Clement, Elizabeth of Hungary

Gesture of the patron saint(s): holding his/her attribute

Type of religious scene: hieratic

Religious scene(s) depicted: the Virgin and Child

Cat. 397-Type $2 \mathrm{C}$

MASSYS, Quinten

Triptych of the Crucifixion with a Family in Prayer (c. 1500-1550)

$95 \times 59.5 \mathrm{~cm}$ (centre panel), $94.5 \times 25 \mathrm{~cm}$ (left wing) and $95 \times 24.5 \mathrm{~cm}$ (right wing) Brussels, MRBAB, inv. no. 1236

BIBL.: FRIEDLÄNDER VII, no. 58; DE BOSQUE 1975, 198; Mus. cat. Brussels

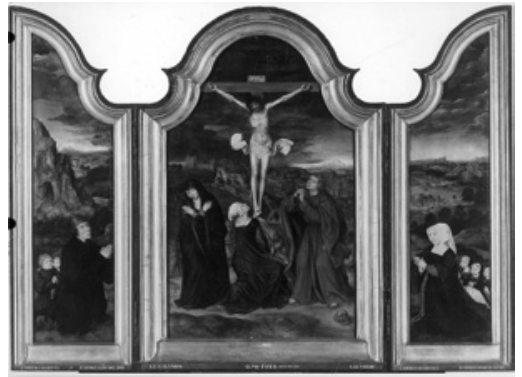
1984, 187 . 
Identity of the sitter(s): unknown

Provenance: unknown

Number of portrait(s): 7

Type of person(s): lay (family with children)

Attitude of the sitter(s): hands clasped

Representation of the sitter(s): full-length

Gaze of the sitter(s): into space, towards the scene

Object(s): yes (rosary)

Coat(s) of arms: yes (on the reverse)

Environment: historical setting

Structuring of the pictorial space: continuous space

Patron saint(s): none

Gesture of the patron saint(s): not applicable

Type of religious scene: narrative

Religious scene(s) depicted: the Crucifixion, St. Adrian, the Virgin and Child with St. Anne

\section{Cat. 398-Type 6A}

MASSYS, Quinten (?)

Fragment. A Man in Prayer (c. 1500-1550)

$68.5 \times 33 \mathrm{~cm}$

London, NG, inv. no. NG 1081

BIBL.: FRIEDLÄNDER VII, no. 75; CAMPBELL 2014, 480 (with bibl.).

Identity of the sitter(s): unknown

Provenance: unknown

Number of portrait(s): 1

Type of person(s): lay (man alone)

Attitude of the sitter(s): hands clasped

Representation of the sitter(s): full-length

Gaze of the sitter(s): indeterminate

Object(s): yes (prie-dieu, book)

Coat(s) of arms: no

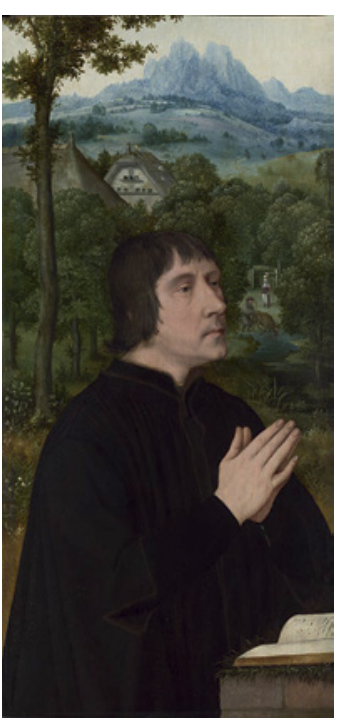

Environment: landscape, no sacred connotation

(incomplete)

Structuring of the pictorial space: indeterminate

Patron saint(s): none

Gesture of the patron saint(s): not applicable

Type of religious scene: indeterminate

Religious scene(s) depicted: none 
Cat. 399-Type 2A

MASSYS, Quinten (and workshop) Triptych of the Crucifixion with a Couple in Prayer and Patron Saints (c. 1520)

$156 \times 92.7 \mathrm{~cm}$ (centre panel) and $158.8 \times 42.2 \mathrm{~cm}$ (wings)

Antwerp, Museum Mayer van den Bergh, inv. no. 362

BIBL.: FRIEDLÄNDER VII, no. 56; DE BOSQUE 1975, 188-91; Mus. cat.

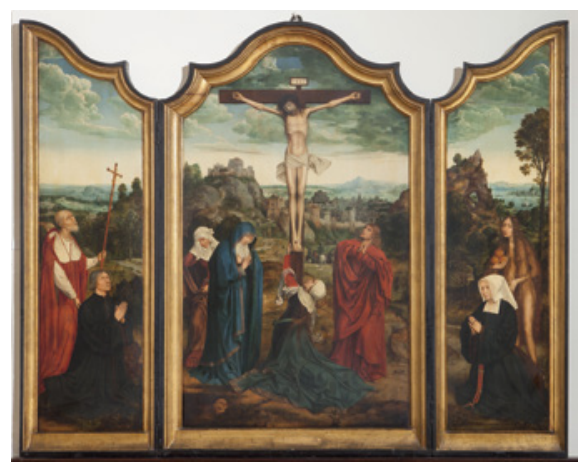

Antwerp 1978, 107-09; SILVER 1984, $97,179,215$, no. 22 (with bibl.).

Identity of the sitter(s): unknown

Provenance: unknown

Number of portrait(s): 2

Type of person(s): lay (couple)

Attitude of the sitter(s): hands clasped

Representation of the sitter(s): full-length

Gaze of the sitter(s): into space, towards the scene

Object(s): yes (rosary)

Coat(s) of arms: no

Environment: historical setting

Structuring of the pictorial space: continuous space

Patron saint(s): Jerome, Mary the Egyptian

Gesture of the patron saint(s): introducing

Type of religious scene: narrative

Religious scene(s) depicted: the Crucifixion

Cat. 400-Type 6A

[RKD work no. 55365]

MASSYS, Quinten (circle of)

Portrait of a Man in Prayer (c. 1500-1550)

Size unknown

London, collection of Edward Speelman

Identity of the sitter(s): unknown

Provenance: unknown

Number of portrait(s): 1 
Type of person(s): lay (man alone)

Attitude of the sitter(s): hands clasped

Representation of the sitter(s): full-length

Gaze of the sitter(s): indeterminate

Object(s): no

Coat(s) of arms: no

Environment: neutral space (incomplete)

Structuring of the pictorial space: indeterminate

Patron saint(s): none

Gesture of the patron saint(s): not applicable

Type of religious scene: indeterminate

Religious scene(s) depicted: none

\section{Cat. 401-Type 2D}

Master Johannes

Triptych of the Family of St. Anne

(c. 1513-1515)

$246 \times 349.5 \mathrm{~cm}$ (open)

Maria-ter-Heide (Brasschaat), church Onze-lieve-Vrouw

Onbevlekt Ontvagen

BIBL.: PASSEMIERS 1987, 16583, no. 6; Exh. cat. Brussels 1996,

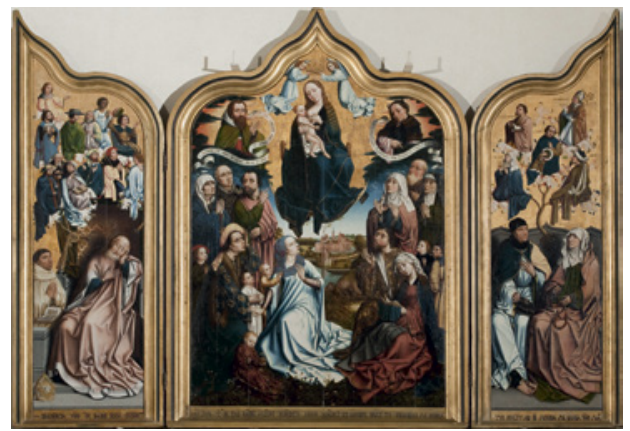
no. 6; MARTENS D. 2000 (with bibl.).

HistoricAl INFORMATION: The coat of arms of the Premonstratensian abbey of Tongerloo, depicted on the abbot's cross, led Martens to determine the identity of the sitter and the original location of the triptych. He also discovered an archival document containing information about the painter and the payment made for the work: the abbey paid on several occasions a certain 'Master Johannes' between 1513 and 1515 for the execution of a painting portraying the Legend of St. Anne. Taking into consideration this information, the abbot depicted on the left wing must be Antonius Tsgrooten. The triptych was most probably destined for the abbey church of Tongerloo. The description of an altarpiece located in the abbey church does indeed fit with the triptych:Hier onder staet een autear, daer een geschilderde taeffel op staet met deuren open ende toegaende, wesende een oude seer perfecte schilderij van den boom Jesse in de eene deure, ende in d'andere de generatie van Elisabeth ende Zacharias, int midden tafle (sic) de generatie van Joachim ende S(int) Anna, ons L(ieve) 
vrouw int midde (see MARTENS D. 2000, 81-82 for the quotations). Born in 1460 in Oosterwijk, Antonius Tsgrooten entered the Premonstratensian abbey of Tongerloo on 11 July 1482. After the death of Johannes Matthei in 1488, he became Provoost of St. Sulpicius in Diest, before becoming abbot of Tongerloo on 28 August 1504. He held this position until his death in 1530 . As the abbot, he managed construction works in the abbey and acted as an important patron for artists. Tsgrooten also appears in cat. 659 .

Identity of the sitter(s): Antonius Tsgrooten

Provenance: Premonstratensian abbey of Tongerloo

Number of portrait(s): 1

Type of person(s): religious (man alone: Premonstratensian abbot)

Attitude of the sitter(s): hands clasped

Representation of the sitter(s): full-length

Gaze of the sitter(s): towards the scene

Object(s): yes (prie-dieu, book)

Coat(s) of arms: yes (on the cross)

Environment: architectural space with sacred connotation

Structuring of the pictorial space: distinct spaces

Patron saint(s): none

Gesture of the patron saint(s): not applicable

Type of religious scene: hieratic

Religious scene(s) depicted: the Family of St. Anne

Cat. 402-Type $3^{B}$

Master of 1420 (copy after?)

The Brid-Belle Madonna (c. 1420)

$62 \times 117 \mathrm{~cm}$

Ieper, Museum Belle Godshuis, inv. no. 12

BIBL.: MARIJNISSEN 1985, 354-63; NYS 2001, 47-48; BRINE 2008, 146-47.

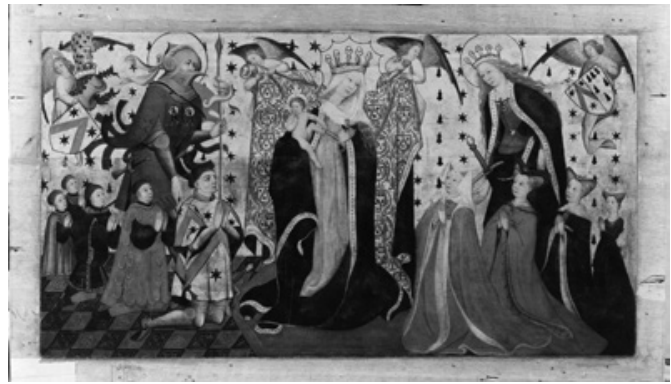

HISTORICAL INFORMATION: This panel is the epitaph of Yolande Belle, as the inscription indicates: HIER VOOREN LIGHT BEGRAVEN VRAWE YOLENTE BELLE DOCHTERE MER IAN BELLES RUDDERE HEERE VAN BOESINGHE IOOS BRIDS WYF WAS DIE STARF DEN EERSTEN DACH VAN SPORKEL 1420. The Belle family was an important family in Ieper. In its current state, it is difficult to assert whether the panel shows the original epitaph (largely 
overpainted in the late sixteenth or early seventeenth century) or a copy after the original. In any case, the original panel was placed in the chapel of the Belle Hospital, which had been founded in 1276 by Christine of Ghines in homage to her husband, Salomon Belle.

Identity of the sitter(s): Joos Brid, Yolande Belle and their children

Provenance: Ieper, Belle Hospital

Number of portrait(s): 9

Type of person(s): lay (family with children)

Attitude of the sitter(s): hands clasped

Representation of the sitter(s): full-length

Gaze of the sitter(s): towards the scene

Object(s): no

Coat(s) of arms: yes

Environment: architectural space with sacred connotation

Structuring of the pictorial space: not applicable

Patron saint(s): George, Catherine

Gesture of the patron saint(s): introducing

Type of religious scene: hieratic

Religious scene(s) depicted: the Virgin and Child

Cat. 403-Type 2D

Master of 1473

Triptych of the Virgin and Child

('Triptych of Jan de Witte') (dated 1473 on the frame)

$74.5 \times 38.7 \mathrm{~cm}$ (centre panel), 74.5

$\times 38.5 \mathrm{~cm}$ (left wing) and $74.5 \times$

$38.5 \mathrm{~cm}$ (right wing)

Brussels, MRBAB, inv. no. 7007

BIB L.: FRIEDLÄNDER VIa, no. 112; DE VOS 1970; STROO et alii 2006, 392-413 (with bibl.).

Historical INFORMATION: Weale has identified the sitters as Jan de Witte and his wife Maria Hoose, on the basis of their coats of arms. Born in 1443, Jan de Witte was councillor of Charles the Bold, but also alderman and then burgomaster of Bruges in 1482. He first married Margareta Bornuydt, who died in 1469, and then married Maria Hoose. Scholars often assume that the triptych commemorates their marriage, as the precise date inscribed on the frame could suggest: Etatis. XXX.anom / hoc opus pfectu a ${ }^{\circ}$ m. iiijc. LXXiii. XXVII / die 
julii. etatis. XVI. anom. This inscription also informs us about their age: Jan was thirty and Maria was sixteen. They had several children. Jan died in 1486-87 and Maria before 1518 .

Identity of the sitter(s): Jan de Witte and Maria Hoose

Provenance: unknown

Number of portrait(s): 2

Type of person(s): lay (couple)

Attitude of the sitter(s): hands clasped

Representation of the sitter(s): full-length

Gaze of the sitter(s): towards the scene, towards the ground

Object(s): yes (dog)

Coat(s) of arms: yes

Environment: enclosed garden

Structuring of the pictorial space: continuous space

Patron saint(s): none

Gesture of the patron saint(s): not applicable

Type of religious scene: hieratic

Religious scene(s) depicted: the Virgin and Child

Cat. 404-Type $4 \mathrm{D}$ (then 5)

Master of 1499

Diptych of Christiaan de Hondt (1499)

$31 \times 14.5 \mathrm{~cm}$ (each wing)

Antwerp, KMSK, inv. nos. $255^{-256}$

BIBL.: FRIEDLÄNDER IV, no. 37; Mus. cat. Antwerp 1985, 125-29; Mus. cat. Antwerp 1998, 503-04; TESTA 1986; Exh. cat. Antwerp and Washington 2006,
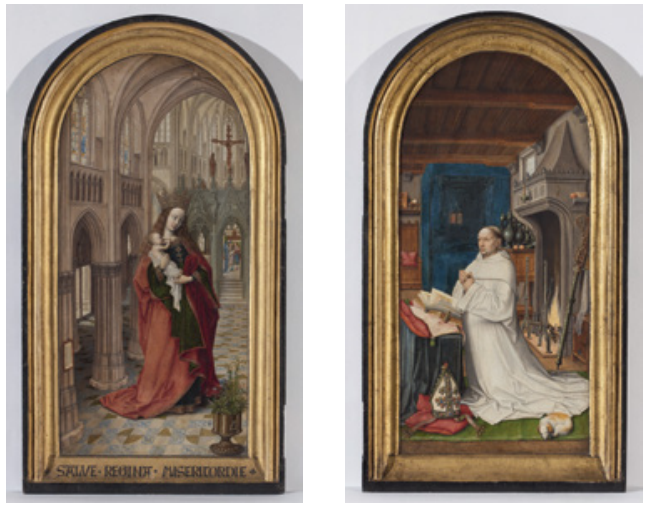
no. 21 (with bibl.).

HISTORICAL INFORMATION: On the basis of the coat of arms, the man portrayed on the inner right wing has been identified as Christiaan de Hondt, abbot of the Cistercian abbey of Ten Duinen in Koksijde from 1495 to 1509. His successor, Robrecht de Clercq, is depicted on the outer left wing. This is a later addition, suggesting that he inherited the diptych after Christiaan de Hondt's death. De Hondt also appears in cat. 589 . 
Identity of the sitter(s): Christiaan de Hondt (and Robrecht de Clercq on the reverse of the right wing)

Provenance: Koksijde, Cistercian abbey of Ten Duinen (?)

Number of portrait(s): $1(2)$

Type of person(s): religious (man alone: Cistercian abbot)

Attitude of the sitter(s): hands clasped

Representation of the sitter(s): full-length

Gaze of the sitter(s): towards the scene

Object(s): yes (prie-dieu, book, dog, mitre, crosier)

Coat(s) of arms: yes

Environment: domestic setting, ecclesial space

Structuring of the pictorial space: distinct spaces

Patron saint(s): none

Gesture of the patron saint(s): not applicable

Type of religious scene: hieratic

Religious scene(s) depicted: the Virgin and Child, Christ blessing

Cat. 405 - Type $4 \mathrm{D}$

Master of 1499

Diptych of Margaret of Austria (c. 1501-1507)

$30.6 \times 14.6 \mathrm{~cm}$ (left wing) and $30.6 \times 14.8 \mathrm{~cm}$ (right wing)

Ghent, M SK, inv. no. 1973-A

BIBL.: EECKHOUT 1985-1988;

PEARSON 2001-2002; Exh. cat.

Mechelen 2005, no. 95 (with bibl.); FALQUE 2012, 112-13.

HISTORICAL INFORMATION:

Born in 1480, Margaret of

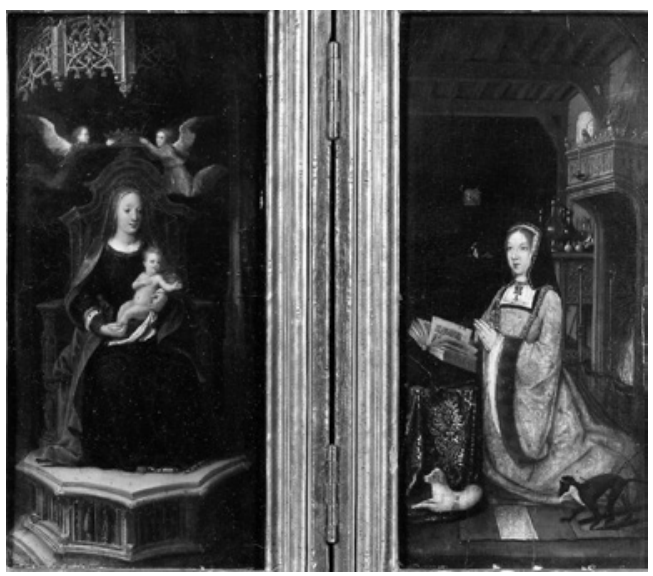

Austria was the daughter of

Maximilian I and Mary of Burgundy. In 1496, she married John II of Aragon, who died six months after their union. She then married Philibert II, Duke of Savoy, in 1501. He died accidentally in 1504, and Margaret decided then to wear mourning dress until her death in 1530 . In 1507, she became regent of the Netherlands. Her wealth and her taste for the arts made her one of the most famous patrons of her time. In this diptych, Margaret is portrayed as the Duchess of Savoy, as her appearance and her coat of arms indicate. One can thus conclude that the diptych was executed after 1501 and before 1507 when 
she became regent (see FALQUE 2012, 113). Margaret of Austria also appears in cat. 724 .

Identity of the sitter(s): Margaret of Austria

Provenance: unknown

Number of portrait(s): 1

Type of person(s): lay (woman alone)

Attitude of the sitter(s): hands clasped

Representation of the sitter(s): full-length

Gaze of the sitter(s): towards the scene

Object(s): yes (prie-dieu, book, dog)

Coat(s) of arms: no

Environment: domestic setting

Structuring of the pictorial space: distinct spaces

Patron saint(s): none

Gesture of the patron saint(s): not applicable

Type of religious scene: hieratic

Religious scene(s) depicted: the Virgin and Child

\section{Cat. 406-Type 3D}

Master of 1499

The Virgin and Child Enthroned with a Couple in Prayer (c. 1475-1500)

$71 \times 55 \mathrm{~cm}$

Paris, Musée du Louvre, inv. no. R.F. 2370 BIB L.: Corpus Paris III, no. 202 (with bibl.).

Identity of the sitter(s): unknown

Provenance: unknown

Number of portrait(s): 2

Type of person(s): lay (couple)

Attitude of the sitter(s): hands clasped

Representation of the sitter(s): full-length

Gaze of the sitter(s): towards the scene

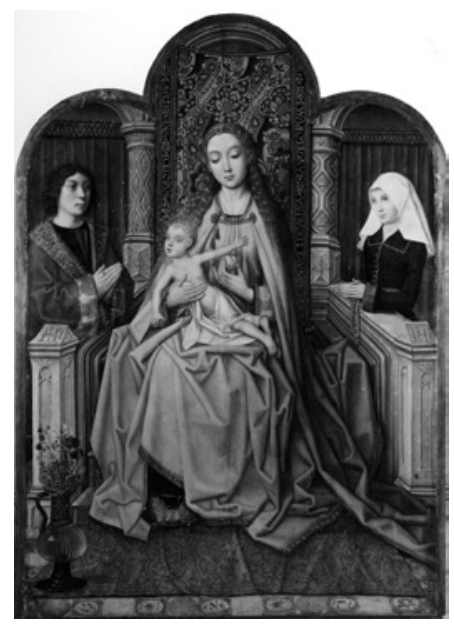

Object(s): no

Coat(s) of arms: no

Environment: architectural space with sacred connotation

Structuring of the pictorial space: not applicable

Patron saint(s): none

Gesture of the patron saint(s): not applicable

Type of religious scene: hieratic

Religious scene(s) depicted: the Virgin and Child 
Cat. 407-Type $3^{B}$

[Link to the Friedländer 3.o Database]

Master of 1518

The Virgin and Child with St. Anne and a Man in Prayer and Patron Saint

(c. 1500-1550)

$43 \times 33.5 \mathrm{~cm}$

Whereabouts unknown

BIBL.: FRIEDLÄNDER XI, no. 77 .

Identity of the sitter(s): unknown

Provenance: unknown

Number of portrait(s): 1

Type of person(s): religious (man alone: canon)

Attitude of the sitter(s): hands clasped

Representation of the sitter(s): half-length

Gaze of the sitter(s): into space

Object(s): no

Coat(s) of arms: no

Environment: architectural space with sacred connotation

Structuring of the pictorial space: not applicable

Patron saint(s): Augustine

Gesture of the patron saint(s): holding his/her attribute

Type of religious scene: hieratic

Religious scene(s) depicted: the Virgin and Child with St. Anne

Cat. 408-Type $2 \mathrm{~A}$

Master of 1518

Triptych of the Crucifixion with a Family in Prayer and Patron Saints (c. 1520)

$89 \times 69.8 \mathrm{~cm}$ (centre panel) and $89 \times 29.8 \mathrm{~cm}$ (wings)

Germany, private collection

BIB L.: MÜLLER HOFSTEDE 1991.

Identity of the sitter(s): unknown

Provenance: unknown

Number of portrait(s): 3

Type of person(s): mixed (family)

Attitude of the sitter(s): hands clasped

Representation of the sitter(s): full-length

Gaze of the sitter(s): towards the scene

Object(s): yes (prie-dieu, book)

Coat(s) of arms: yes

Environment: historical setting 
Structuring of the pictorial space: continuous space

Patron saint(s): James, Elizabeth of Hungary

Gesture of the patron saint(s): introducing

Type of religious scene: narrative

Religious scene(s) depicted: the Crucifixion, the Fountain of Life

\section{Cat. 409-Type $2 \mathrm{C}$}

Master of 1518

Triptych of the Feast in the House of Simon ('Triptych of the Abbey of Dielegem') (c. 1500-1550) $180 \times 150 \mathrm{~cm}$ (centre panel), $185 \times$ $70 \mathrm{~cm}$ (left wing) and $185 \times 71 \mathrm{~cm}$ (right wing)

Brussels, MRBAB, inv. no. 329 BIBL.: FRIEDLÄNDER XI, no. 72; WAUTERS 1909; BROUETTE 1974; VAN BELLINGEN 1986; GODFRIND-BORN 1995.

HISTORICAL INFORMATION: The triptych stems from the Dielegem abbey. In his Chorographia sacra brabantiae of 1659 , Sanderus locates the work in the refectory of the abbey. The abbot portrayed on the right wing has not been identified with certainty, but he must be an abbot from the early sixteenth century. According to Wauters, he is Jean de Tuegele, abbot from 1536 to 1538 , because of the motto cum moderamine inscribed on the drapery of the prie-dieu. This motto would be a speaking device: moderamem means brake (tuegele in Dutch). In 1974, Brouette noted a translation problem in Wauters' hypothesis: one must not read moderamen in the motto, but moderaminem. Brouette further suggested that the coat of arms was not that of a single person but of the abbey. According to Brouette, the abbot could be Corneille van der Goes, abbot from 1512 to 1536 . Corneille van der Goes came from Goes in Zeeland, and in this town, a church was dedicated to Mary Magdalen, who plays a central role in the iconography of the triptych.

Identity of the sitter(s): an abbot of Dielegem (Jean de Tuegele or Corneille van der Goes?)

Provenance: Premonstratensian abbey of Dielegem

Number of portrait(s): 1

Type of person(s): religious (man alone: Premonstatensian abbot) 
Attitude of the sitter(s): hands clasped

Representation of the sitter(s): full-length

Gaze of the sitter(s): towards the scene

Object(s): yes (prie-dieu, book, mitre, crosier)

Coat(s) of arms: yes

Environment: historical setting

Structuring of the pictorial space: distinct spaces

Patron saint(s): none

Gesture of the patron saint(s): not applicable

Type of religious scene: narrative

Religious scene(s) depicted: the Feast in the House of Simon, the Resurrection of Lazarus, the Rapture of Mary Magdalen, Noli me tangere

\section{Cat. 410-Type 6A}

Master of 1518

Two Wings. A Couple in Prayer with Patron

Saints (c. 1500-1550)

$70 \times 24 \mathrm{~cm}$ (each wing)

Oldenburg, Landesmuseum für Kunst und Kulturgeschichte, inv. no. GO 46

BIBL.: FRIEDLÄNDER XI, no. 84; Exh. cat.

Bruges 1969, no. 105 .

Identity of the sitter(s): unknown

Provenance: unknown

Number of portrait(s): 2

Type of person(s): lay (couple)

Attitude of the sitter(s): hands clasped

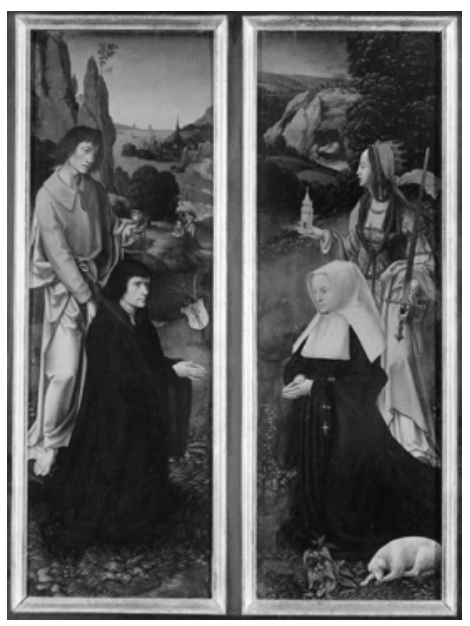

Representation of the sitter(s): full-length

Gaze of the sitter(s): indeterminate

Object(s): yes (dog)

Coat(s) of arms: yes

Environment: landscape, no sacred connotation (incomplete)

Structuring of the pictorial space: indeterminate

Patron saint(s): John the Evangelist, Barbara

Gesture of the patron saint(s): introducing, holding his/her attribute

Type of religious scene: indeterminate

Religious scene(s) depicted: St. James, St. John the Baptist 
Cat. 411-Type ${ }_{3} \mathrm{C}$

Master of 1518 (or anonymous Antwerp Master)

The Last Supperwith a Man in Prayer (1500-1525)

$68 \times 58 \mathrm{~cm}$

Brussels, MRBAB, inv. no. 3242

BIBL.: FRIEDLÄNDER XI, no. 97; Exh. cat.

Bruges 1969, no. 97; Exh. cat. Antwerp and Maastricht 2005, no. 88 (with bibl.).

Identity of the sitter(s): unknown

Provenance: unknown

Number of portrait(s): 1

Type of person(s): religious (man alone)

Attitude of the sitter(s): hands clasped

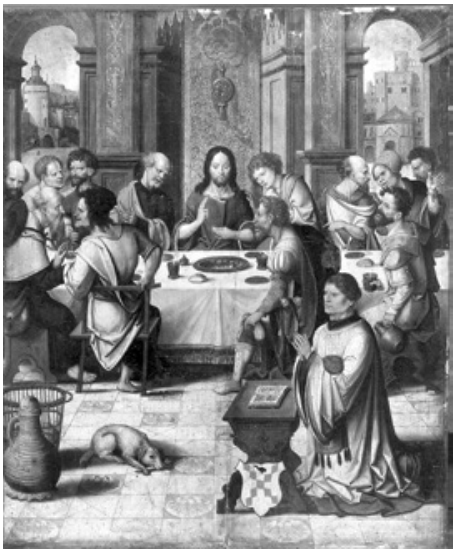

Representation of the sitter(s): full-length

Gaze of the sitter(s): into space

Object(s): yes (prie-dieu, book, dog)

Coat(s) of arms: yes

Environment: historical setting

Structuring of the pictorial space: not applicable

Patron saint(s): none

Gesture of the patron saint(s): not applicable

Type of religious scene: narrative

Religious scene(s) depicted: the Last supper

Cat. 412-Type 2A

Master of 1518 (or Jan/Joris Fraet?)

Triptych of the Adoration of the Magi with a Family in Prayer and Patron Saints (before 1522)

$114 \times 81.3 \mathrm{~cm}($ centre panel $)$ and $119 \times 37$ cm (wings)

Diest, church of St. Sulpicius and St. Dyonisius

BIBL.: PERIER-D'IETEREN 1976-77;

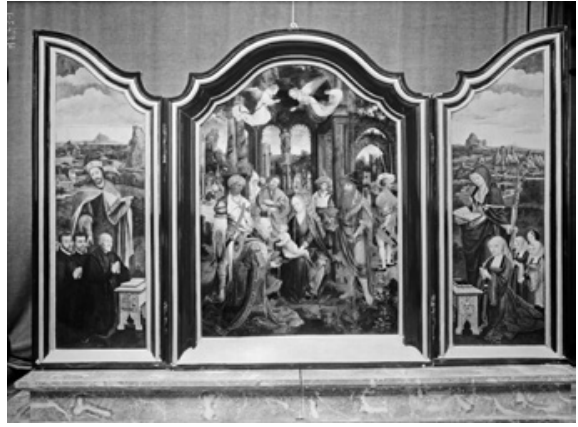

VAN DEN BERGEN-PANTENS 1976-77; Exh. cat. Antwerp and Maastricht 2005, no. 71 (with bibl.).

HISTORICAL INFORMATION: The triptych was commissioned by Hendrik van Zurpele $(\dagger 1522)$, alderman of Diest. He appears on the wings with his wife 
Marie Cants $(\dagger 1538)$, who came from Tienen, and their daughters. The triptych might have been destined for the church of the Béguinage of Diest: St. Begga, who presents Marie Cants on the right wing, was particularly venerated by the Diest beguines. In 1570, Daniël van Zurpele, the eldest son of Hendrik and Marie, replaced his father's portrait with his own effigy and added the two male portraits behind him.

Identity of the sitter(s): Hendrik van Zurpele, Marie Cants and their children Provenance: Diest, church of the Béguinage?

Number of portrait(s): $5(7)$

Type of person(s): lay (family with children)

Attitude of the sitter(s): hands clasped

Representation of the sitter(s): full-length

Gaze of the sitter(s): into space, towards the viewer

Object(s): yes (prie-dieu, book, rosary, small cross)

Coat(s) of arms: yes

Environment: historical setting

Structuring of the pictorial space: unified space with discontinuities

Patron saint(s): Henry of Uppsala, Begga

Gesture of the patron saint(s): indicating, holding his/her attribute

Type of religious scene: narrative

Religious scene(s) depicted: the Adoration of the Magi

\section{Cat. 413-Type 6A}

Master of Alkmaar

Fragment. Five Persons in Prayer (c. 1490-1510) $41.2 \times 28 \mathrm{~cm}$

Enschede, Rijksmuseum Twenthe, inv. no. 38 BIBL.: FRIEDLÄNDER X, supp. 158; Mus. cat. Enschede 1974-1976, no. 113 (with bibl.).

Identity of the sitter(s): unknown

Provenance: unknown

Number of portrait(s): 5

Type of person(s): lay (family)

Attitude of the sitter(s): hands clasped, hands held up

Representation of the sitter(s): full-length

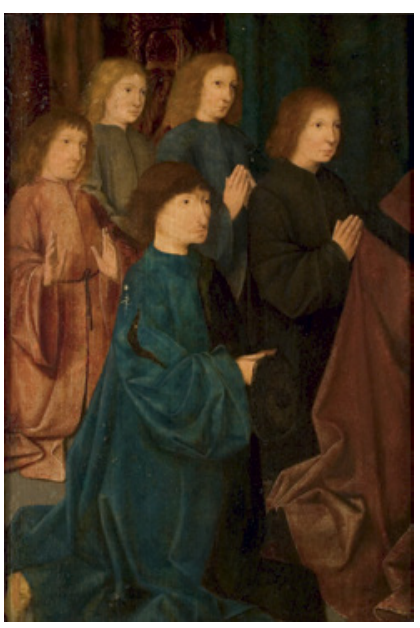

Gaze of the sitter(s): indeterminate

Object(s): yes (hat) 
Coat(s) of arms: no

Environment: indeterminate

Structuring of the pictorial space: indeterminate

Patron saint(s): none

Gesture of the patron saint(s): not applicable

Type of religious scene: indeterminate

Religious scene(s) depicted: none

\section{Cat. 414-Type 5}

Master of Alkmaar

Portraits of the Family van Naaldwijk in Prayer (c. 1490-1510)

$82 \times 56.5 \mathrm{~cm}$ (each panel)

Naaldwijk, Stadhuis, inv. no. 132-133-136 and Amsterdam, Rijksmuseum, inv. no. SK-C-57 BIBL.: FRIEDLÄNDER X, no. 59.I; Mus. cat. Amsterdam 1976, 629; Mus. cat. Amsterdam 2009 [online], https://www.rijksmuseum.nl/ $\mathrm{nl} /$ collectie/SK-C-57/catalogus-entry (with bibl.).

HISTORICAL INFORMATION: This set of six panels display the portraits of the Counts of Holland, from Hendrik I van Naaldwiijk (c.

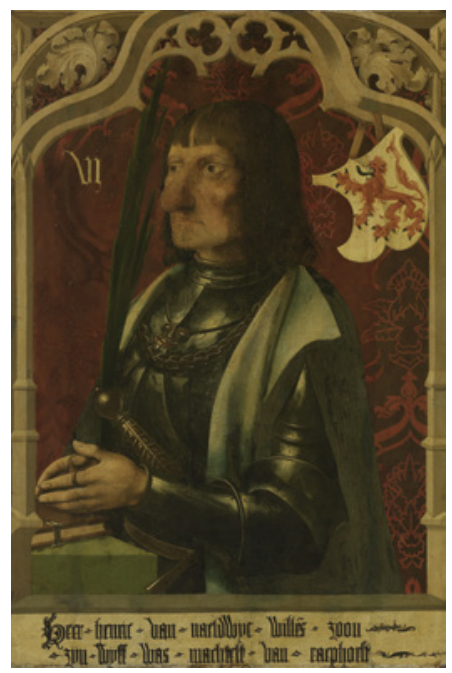
1305-149) up to Hendrik IV van Naaldwijk and his daughter Willeme $(† 1506)$, who was the last descendant of the lineage. The lower part of each painting contains an inscription in Dutch, identifying the sitter and giving the name of his/her spouse: 1. Hendricc van Naeldwijc heer willems zoon / zijn wijff was haeze van scalcwijc; 2. willem van Naeldwijc, hendrics zoon / zijn wijff was Sophie van teylingen. 3. Heer Hendric van Naeldwijk, willems zoon / zijn wijff was katrijn van heenvliet. 4. willem van naeldwijc, heer hendrics zoon / zijn wijff was willeme van egmond van de waterin. 5. heer henric van naeldwijc wille $[m]$ s zoon / zijn wijff was machtelt van raephorst. 6. willeme van naeldwijc, heer hendrics dochter / haer man was jan heer van montfoor.

Identity of the sitter(s): members of the van Naaldwijk family

Provenance: unknown

Number of portrait(s): 6 
Type of person(s): lay (family)

Attitude of the sitter(s): hands clasped

Representation of the sitter(s): half-length

Gaze of the sitter(s): into space, reading a book

Object(s): yes (prie-dieu, book, rosary, palm)

Coat(s) of arms: yes

Environment: neutral space (incomplete)

Structuring of the pictorial space: not applicable

Patron saint(s): none

Gesture of the patron saint(s): not applicable

Type of religious scene: indeterminate

Religious scene(s) depicted: none

\section{Cat. 415 -Type $3 \mathrm{C}$}

[RKD work no. 103077]

Master of Alkmaar

The Crucifixion with a Nun in Prayer (c. 1500-1510)

$29.9 \times 21 \mathrm{~cm}$

Private collection

BIB L.: NIESSEN 2010, 281-84.

Identity of the sitter(s): unknown

Provenance: unknown

Number of portrait(s): 1

Type of person(s): religious (woman alone: Poor Clare or Franciscan tertiary nun)

Attitude of the sitter(s): hands clasped

Representation of the sitter(s): full-length

Gaze of the sitter(s): towards the scene

Object(s): no

Coat(s) of arms: no

Environment: historical setting

Structuring of the pictorial space: not applicable

Patron saint(s): none

Gesture of the patron saint(s): not applicable

Type of religious scene: narrative

Religious scene(s) depicted: the Crucifixion 
Cat. 416-Type $3_{3}$ B

Master of Alkmaar

The Virgin and Child with St. Anne and a Priest with Patron Saint (c. 1490-1510)

$52 \times 36.8 \mathrm{~cm}$

United Kingdom, private collection

вIв L.: FRIEDLÄNDER X, SUpp. 159; HOOGEWERFF II, 36o-61.

Identity of the sitter(s): unknown

Provenance: unknown

Number of portrait(s): 1

Type of person(s): religious (man alone)

Attitude of the sitter(s): physical contact with the sacred person

Representation of the sitter(s): full-length

Gaze of the sitter(s): into space

Object(s): no

Coat(s) of arms: no

Environment: enclosed garden

Structuring of the pictorial space: not applicable

Patron saint(s): Joseph (?)

Gesture of the patron saint(s): introducing

Type of religious scene: hieratic

Religious scene(s) depicted: the Virgin and Child with St. Anne

Cat. 417-Type $3^{B}$

Master of Alkmaar

The Virgin and Child with St. Anne and two Nuns with Patron Saints (c. 1490-1510)

$60 \times 39 \mathrm{~cm}$

Brussels, MRBAB, inv. no. 6597

BIBL.: FRIEDLÄNDER X, no. 57; Mus. cat.

Brussels 1984, 335; NIESSEN 2010, 269-71 (with bibl.).

Identity of the sitter(s): unknown

Provenance: unknown

Number of portrait(s): 2

Type of person(s): religious (group: Poor

Clares or Franciscan tertiary nuns)

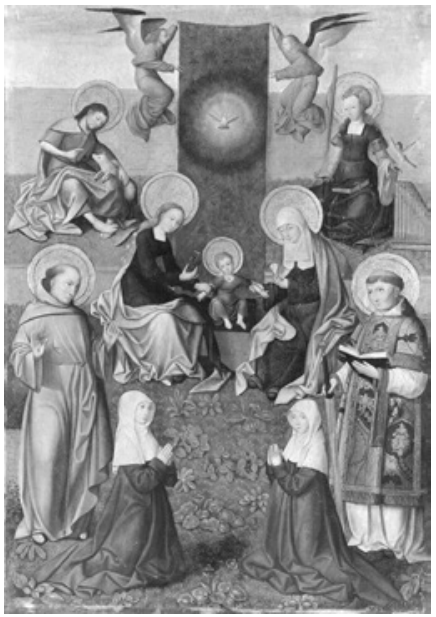

Attitude of the sitter(s): hands clasped

Representation of the sitter(s): full-length, small scale

Gaze of the sitter(s): into space 
Object(s): no

Coat(s) of arms: no

Environment: enclosed garden

Structuring of the pictorial space: not applicable

Patron saint(s): Francis, an unidentified saint

Gesture of the patron saint(s): holding his/her attribute

Type of religious scene: hieratic

Religious scene(s) depicted: the Virgin and Child with St. Anne, St. John the Baptist, St. Cecilia

Cat. 418-Type 6A

Master of Alkmaar

Two Wings. A Family in Prayer with Patron Saints (c. $1515^{-1520)}$

$102 \times 36 \mathrm{~cm}$ (each wing)

Amsterdam, Rijksmuseum, inv. nos. SK-A1188-A and SK-A-1188-B

BIBL.: FRIEDLÄNDER X, no. 53; Mus. cat. Amsterdam 1976, 629; Mus. cat. Amsterdam 2009 [online], https://www.rijksmuseum.nl/ $\mathrm{nl} /$ collectie/SK-A-1188-A/catalogus-entry (with bibl.); NIESSEN 2010, 284-89.

HISTORICAL INFORMATION: The persons portrayed are Willem Jelysz. van Soutelande $(\dagger$
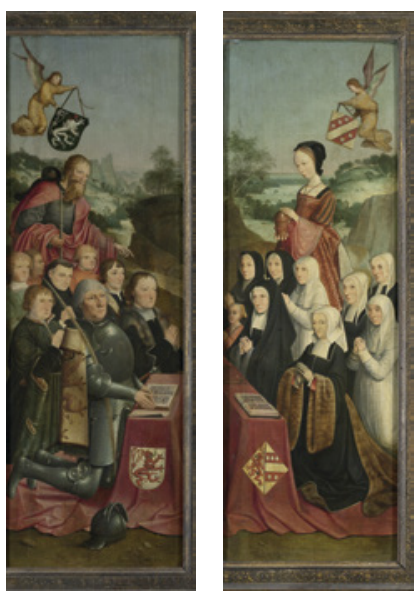
1515-1516), Kathrijn van der Graft († 1490-1491)

and their children. Willem Jelysz. was alderman and councillor of the orphanage of Haarlem. He is wearing the habit of the Brotherhood of the Jerusalem Pilgrims. The coats of arms held by the angels in the upper part of the wings are those of the Haarlem citizen Jacob de Wael and his wife Margriet van Waveren. Jacob de Wael was also a member of the brotherhood. It is possible that their portraits were located on the now lost centre panel.

Identity of the sitter(s): Willem Jelysz. van Soutelande, Kathrijn van der Graft Willemsdr. and their children

Provenance: unknown

Number of portrait(s): 17

Type of person(s): mixed (family)

Attitude of the sitter(s): hands clasped

Representation of the sitter(s): full-length

Gaze of the sitter(s): indeterminate 
Object(s): yes (prie-dieu, book, helmet)

Coat(s) of arms: yes

Environment: landscape, no sacred connotation (incomplete)

Structuring of the pictorial space: indeterminate

Patron saint(s): James, Mary Magdalen

Gesture of the patron saint(s): holding his/her attribute, indicating

Type of religious scene: indeterminate

Religious scene(s) depicted: none

Cat. 419-Type 6B

Master of Alkmaar (attributed to)

Portrait of a Man in Prayer (1500-1525)

$28.5 \times 22 \mathrm{~cm}$

Copenhagen, Statens Museum for Kunst, inv. no. KMSsp737

HISTORICAL INFORMATION: The sitter's habit indicates that he is a member of a brotherhood of Jerusalem pilgrims.

Identity of the sitter(s): unknown

Provenance: unknown

Number of portrait(s): 1

Type of person(s): lay (man alone)

Attitude of the sitter(s): hands clasped

Representation of the sitter(s): half-length

Gaze of the sitter(s): indeterminate

Object(s): yes (hat, palm)

Coat(s) of arms: no

Environment: neutral space (incomplete)

Structuring of the pictorial space: indeterminate

Patron saint(s): none

Gesture of the patron saint(s): not applicable

Type of religious scene: indeterminate

Religious scene(s) depicted: none 
Cat. 420-Type 6A

Master of Alkmaar (attributed to) (or Cornelis Buys)

Two Wings. Christ and Pontius Pilate and the Judgement of Pontius Pilate; The Man of Sorrows with a Man in Prayer and St. Martin (reverse) (c. 1500)

$87.5 \times 38 \mathrm{~cm}$ (each wing)

Boston, Museum of Fine Arts, inv. nos. 1980.356-357

вIB L.: HOOGEWERFF II, 374.

Identity of the sitter(s): unknown

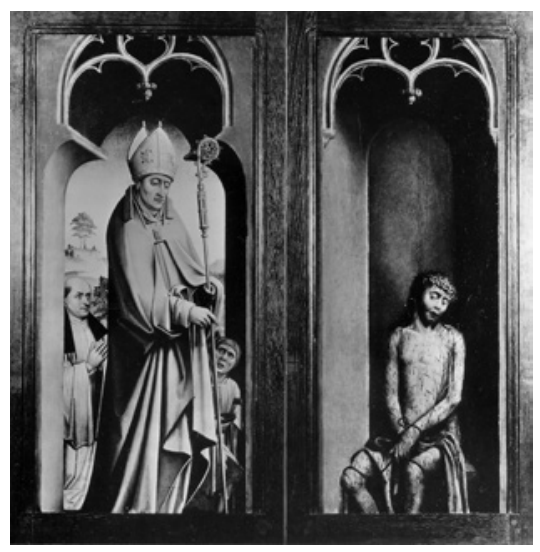

Provenance: unknown

Number of portrait(s): 1

Type of person(s): religious (man alone: canon)

Attitude of the sitter(s): hands clasped

Representation of the sitter(s): full-length

Gaze of the sitter(s): indeterminate

Object(s): no

Coat(s) of arms: no

Environment: landscape, no sacred connotation (incomplete)

Structuring of the pictorial space: indeterminate

Patron saint(s): none

Gesture of the patron saint(s): not applicable

Type of religious scene: hieratic

Religious scene(s) depicted: Christ and Pontius Pilate, the Judgement of Pontius Pilate, St. Martin, the Ecce Homo

Cat. 421-Type 6B

Master of Alkmaar (circle of) (or Cornelis Buys)

Portrait of a Man holding a Rosary (c. 1500)

$34 \times 22 \mathrm{~cm}$

's Heereberg, Huis Bergh

Identity of the sitter(s): unknown

Provenance: unknown 
Number of portrait(s): 1

Type of person(s): lay (man alone)

Attitude of the sitter(s): holding a rosary

Representation of the sitter(s): half-length

Gaze of the sitter(s): indeterminate

Object(s): yes (rosary)

Coat(s) of arms: no

Environment: neutral space (incomplete)

Structuring of the pictorial space: indeterminate

Patron saint(s): none

Gesture of the patron saint(s): not applicable

Type of religious scene: indeterminate

Religious scene(s) depicted: none

Cat. 422-Type $3^{\mathrm{D}}$

Master of Amiens

Au juste pois véritable balance and Pré ministrant pasture solitaire (1519 and 1520 )

$173 \times 97 \mathrm{~cm}$ and $162 \times 87 \mathrm{~cm}$

Amiens, Musée de Picardie, inv. nos. P 526-527.

BIBL.: FRIEDLÄNDER XI, 66; Exh. cat. Antwerp and Maastricht 2005, no. 27 (with bibl.); MAILLART 2011; Exh. cat. Paris 2017, no. 7 .

HISTORICAL INFORMATION: Commissioned in 1518 and 1519 , these works belong to a set of paintings ordered by the Brotherhood of the Puy-NotreDame in Amiens. Dedicated to the Virgin, this brotherhood organised a literary tournament each year. The competitors had to compose a verse on

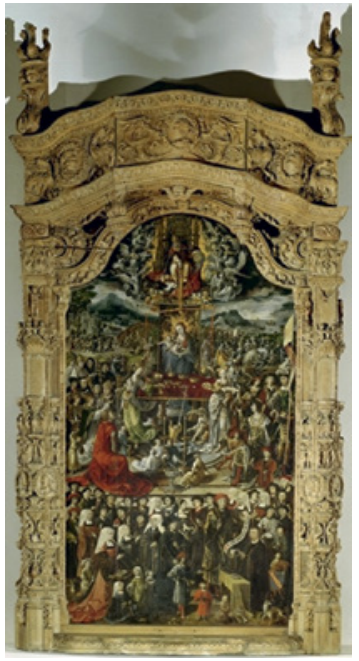
an allegorical truth about the Virgin. From $145^{1}$ onwards, the brotherhood commissioned a painting illustrating this verse. These paintings are two of the few brotherhood's works still preserved today. Indeed, most of the paintings of the Puy-Notre-Dame have been lost or destroyed, but a manuscript commissioned by Louise of Savoy contains a copy of each of them. The donor of the 1518 panel (and winner of the 1518 contest) dedicated to the verse 'Au juste pois véritable balance' was Antoine Picquet. He was councillor of the King Francis I and a lawyer in Amiens. He is depicted with his family. He is holding a banderole displaying the verse. In the crowd are depicted several 
contemporaries, including Francis I, Charles $\mathrm{V}$ and the pope Leon $\mathrm{x}$. The painting of 1519 was commissioned by Adrien Després.

Identity of the sitter(s): Antoine Picquet and his family, Adrien Després

Provenance: Amiens, cathedral of Our Lady, chapel of the Brotherhood of the Puy-Notre-Dame

Number of portrait(s): 5 and 1

Type of person(s): lay (family with children)

Attitude of the sitter(s): hands clasped, holding a banderole

Representation of the sitter(s): full-length

Gaze of the sitter(s): into space

Object(s): yes (banderole, prie-dieu, book)

Coat(s) of arms: yes

Environment: landscape with sacred connotation

Structuring of the pictorial space: not applicable

Patron saint(s): none

Gesture of the patron saint(s): not applicable

Type of religious scene: narrative

Religious scene(s) depicted: the Virgin

\section{Cat. 423-Type ${ }_{3} \mathrm{C}$}

Master of Delft

Triptych of the Crucifixion with a Monk in Prayer (c. 1510)

$98.2 \times 105 \mathrm{~cm}$ (centre panel), $102.2 \times 49.3 \mathrm{~cm}$ (left wing) and $102 \times 49.4 \mathrm{~cm}$ (right wing)

London, NG, inv. no. NG2922.1 BIBL.: FRIEDLÄNDER X, no.
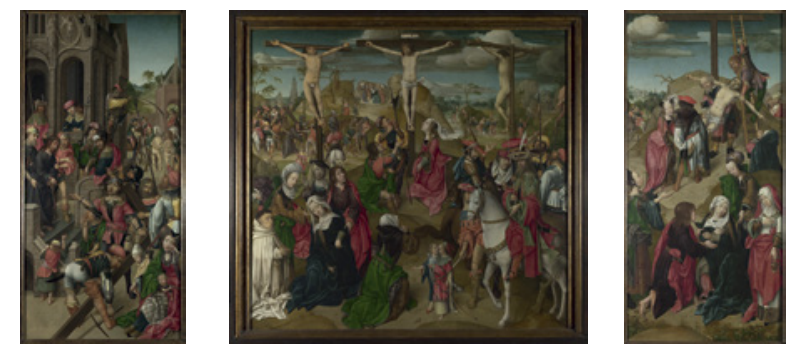

6o; HOOGEWERFF II, 394-96; CAMPBELL 1998, 322-33 (with bibl.).

HISTORICAL INFORMATION: The sitter wears the habit of the Premonstratensian Order. Since the tower of the Nieuwekerk of Delft (in its state between 1496 and 1536) appears in the landscape of the centre panel, Campbell suggests that the monk was living in the Premonstratensian abbey of Koningsveld, the only Premonstratensian monastery in the surroundings of Delft. This abbey of canonesses was dedicated to the Holy Cross, the Virgin and All Saints. The canonesses were placed under the authority of a prioress and a provoost. The monk might thus be one of the provoosts in activity in the early sixteenth century. In all likelihood, he is Herman van Rossum. This 
man was successively vicar of Beesd, s'Gravenzande and Schiedam, Provoost of Mariënschoot, Prior of Mariënweerd and Provoost of Koningsveld. In 1513, he left that position to become the abbot of the monastery of Mariënweerd.

Identity of the sitter(s): Herman van Rossum (?)

Provenance: Premonstratensian abbey of Koningsveld (?)

Number of portrait(s): 1

Type of person(s): religious (man alone: Premonstratensian monk)

Attitude of the sitter(s): hands clasped

Representation of the sitter(s): full-length

Gaze of the sitter(s): into space

Object(s): no

Coat(s) of arms: no

Environment: historical setting

Structuring of the pictorial space: fragmentation of the pictorial space

Patron saint(s): none

Gesture of the patron saint(s): not applicable

Type of religious scene: narrative

Religious scene(s) depicted: Christ bearing the cross, the Crucifixion, the Descent from the cross, St. Augustine, St. Peter, St. Mary Magdalen, the Virgin and Child

Cat. 424-Type 2A

Master of Delft

Triptych of the Virgin and Child with Saints, Sibyls and a Couple in Prayer (c. 1500-1510)

$84.5 \times 68 \mathrm{~cm}$ (centre panel) and $84.5 \times$ $30 \mathrm{~cm}$ (wings)

Amsterdam, Rijksmuseum, inv. no. SK-A-3141

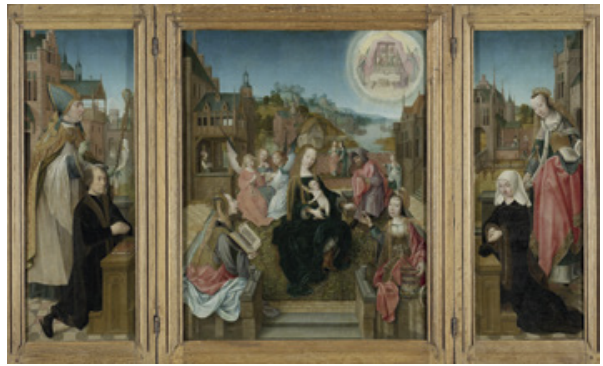

BIB L.: FRIEDLÄNDER X, no. 62; RINGBOM 1995, 87-116; Exh. cat. Rotterdam 1992, no. 54; Mus. cat. Amsterdam 2009 [online], https://www.rijksmuseum.nl/ $\mathrm{nl} /$ collectie/SK-A-3141/catalogus-entry (with bibl.).

Identity of the sitter(s): unknown

Provenance: unknown

Number of portrait(s): 2

Type of person(s): lay (couple)

Attitude of the sitter(s): hands clasped

Representation of the sitter(s): full-length 
Gaze of the sitter(s): into space, towards the scene

Object(s): yes (prie-dieu, book)

Coat(s) of arms: no

Environment: enclosed garden, architectural space with sacred connotation Structuring of the pictorial space: unified space with discontinuities

Patron saint(s): Martin, Cunera

Gesture of the patron saint(s): indicating, introducing

Type of religious scene: hieratic

Religious scene(s) depicted: the Virgin and Child with sybils, the Annunciation

\section{Cat. 425-Type $2 \mathrm{~A}$}

[RKD work no. 21104]

Master of Delft (workshop of)

Triptych of the Crucifixion with a Family in Prayer and Patron Saints (c. 1490-1520) $185 \times 107 \mathrm{~cm}$ (centre panel) and $185 \times 43 \mathrm{~cm}$ (wings)

Cologne, Wallraf-Richartz Museum, inv. no. WRM 477

вIB L.: FRIEDLÄNDER X, no. 61; Mus. cat. Cologne 1969, 75-76; BANGS 1999, 127-32.

HISTORICAL INFORMATION: The father of the family has been identified as Pieter Kievit. The coat of arms of the mother remains unknown. The Kiewits were a wealthy patrician family from Rotterdam. Pieter was the master of the city orphanage in 1536 and chief (boonheer) of one of Rotterdam's neighbourhoods in 1538. He died in 1542. One of his sons, Jan Pietersz., made an important political career in Rotterdam in the second half of the sixteenth century. According to Bangs, the triptych was destined for the church of St. Lawrence in Rotterdam, where it was hung above the familial tomb. However, he does not provide any evidence allowing us to confirm this assumption.

Identity of the sitter(s): Pieter Kievit and his family

Provenance: unknown

Number of portrait(s): 22

Type of person(s): mixed (family with children)

Attitude of the sitter(s): hands clasped

Representation of the sitter(s): full-length, children in small scale

Gaze of the sitter(s): into space, towards the scene

Object(s): yes (prie-dieu, book, rosary)

Coat(s) of arms: yes

Environment: architectural space, no sacred connotation

Structuring of the pictorial space: distinct spaces 
Patron saint(s): George, Mary Magdalen

Gesture of the patron saint(s): introducing, holding his/her attribute

Type of religious scene: narrative

Religious scene(s) depicted: the Crucifixion, the Virgin and Child with St. Anne, St. Christopher

Cat. 426-Type 2A

Master of Delft (workshop of)

Triptych of the Crucifixion with a Family in Prayer and Patron Saints (dated 1528 on the frame)

$61 \times 65 \mathrm{~cm}$ (centre panel) and $54 \times 25.5 \mathrm{~cm}$ (wings)

Oxford, St. Edmund Hall chapel

BIBL.: GRÖSSINGER 1992, no. 48.

Identity of the sitter(s): unknown

Provenance: unknown

Number of portrait(s): 17

Type of person(s): lay (family with children)

Attitude of the sitter(s): hands clasped, holding a rosary

Representation of the sitter(s): full-length, children in small scale

Gaze of the sitter(s): into space

Object(s): yes (prie-dieu, book, rosary, dog)

Coat(s) of arms: yes

Environment: historical setting

Structuring of the pictorial space: distinct spaces

Patron saint(s): Christopher, Mary Magdalen

Gesture of the patron saint(s): holding his/her attribute

Type of religious scene: narrative

Religious scene(s) depicted: the Crucifixion, the Annunciation

\section{Cat. 427-Type $2 B$}

[RKD work no. 43583]

Master of Delft and Master of Frankfurt

Triptych of the Virgin and Child with St. Anne ('Triptych of Dirck Dircksz. van Beesd') (1500-1525)

$93.5 \times 62 \mathrm{~cm}($ centre panel) and $75 \times 31 \mathrm{~cm}$ (wings)

Aachen, Suermondt-Ludwig-Museum, inv. no. GK $15^{26}$ 
BIBL.: FRIEDLÄNDER X, no. 63; GODDARD 1984, no. 70; VOGT 2002; Exh. cat. Roermond 2009, 196-97 (with bibl.).

HISTORICAL INFORMATION: The triptych shows the family of Dirck Dircksz. van Beesd on the wings. The predella contains the epitaph of the family members: $A n[n o]$ xiiij $[c]$. 86. was Dirick dir / icks . va[n] beest . anders . genaem $[t]$ / van . heemskerck . te ih $[e] r[u s a][[e] m$ en $[d e]$ op $[. .] /.[b]$ erch sinay. en starf. $a[n n o] . x v[c] . x l v . / d[e] . x l$ dach $v a[n]$. nove $[m]$ ber (on the left), $A[n n o] . x v$ [c] . xxxii. de .xii. de. da[ch]/In .julio . starf. geertruyt. /Vra[n]ck. va[n]. dyemens. docht [er] /Die. huijsvrouwe.va[n]. diri[ck]/Van. beet. ofte heemskerck. The frame of the predella also contains a Latin inscription: Obiijt a $[$ nno $]$... 9 mae $f$. theo [dorus] theodorici va $[n]$ beest . mo [na]ch[us] [pr]of[essus] do [mu] s. $h[$ uius $]$. se $[p] u l[t u]$ s $i[n] \operatorname{ter}[f r] a[t] r[e]$ s suos. According to this inscription, Dirck Dircksz. van Beesd died on 11 November 1545 and he made the pilgrimage to Jerusalem in 1486. During this trip, he visited the convent of St. Catherine on the Sinaï. His wife, Geertruid van Diemen, died on 12 July 1532. Their oldest son, Dirck, was a monk at the charterhouse of Bartholomeüsdal. His epitaph is written in Latin and states that he was buried in the charterhouse, with his brothers. The triptych might have been destined for Bartholomeüsdal, where the parents founded a mass.

Identity of the sitter(s): Dirck Dircksz. van Beesd and his family

Provenance: Delft, charterhouse of Bartholomeüsdal (?)

Number of portrait(s): 7

Type of person(s): mixed (family with children)

Attitude of the sitter(s): hands clasped, holding a book, hands held up

Representation of the sitter(s): full-length

Gaze of the sitter(s): towards the scene, reading a book

Object(s): yes (book, rosary, palm)

Coat(s) of arms: yes

Environment: landscape with sacred connotation

Structuring of the pictorial space: distinct spaces

Patron saint(s): John the Baptist, Mary Magdalen

Gesture of the patron saint(s): holding his/her attribute

Type of religious scene: hieratic

Religious scene(s) depicted: the Virgin and Child with St. Anne, St. Jerome in the wilderness 
Cat. 428-Type ${ }_{3} \mathrm{D}$

Master of Flémalle (Robert Campin?)

Maria in Sole with St. Peter, St. Augustine and a Man in Prayer (c. 1440)

$48 \times 21 \mathrm{~cm}$

Aix-en-Provence, Musée Granet, inv. no.

86o.I.296

BIB L.: FRIEDLÄNDER II, no. 66;

THÜRLEMANN 2002, no. III.F.4; IMAÏ 2005; Exh. cat. Frankfurt and Berlin 2009, no. 10 (with bibl.).

HISTORICAL INFORMATION: The coat of arms painted on the frame has not been identified. Nevertheless, two hypotheses about

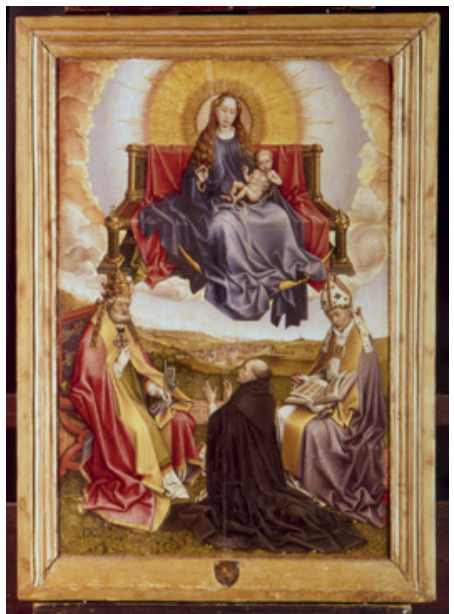
the sitter have been formulated: according to Hulin de Loo, the man is Pierre l'Escuyer, abbot of the Augustinian monastery of Eaucourt in the Artois region. Châtelet considers that the painting was commissioned by Pierre Assalbit to commemorate the cardinal Pierre Ameil, who died in Rome in 1401 and is portrayed in the painting.

Identity of the sitter(s): unknown

Provenance: unknown

Number of portrait(s): 1

Type of person(s): religious (man alone)

Attitude of the sitter(s): hands held up

Representation of the sitter(s): full-length

Gaze of the sitter(s): towards the scene

Object(s): no

Coat(s) of arms: yes (on the frame)

Environment: enclosed garden

Structuring of the pictorial space: religious scene in a cloud

Patron saint(s): none

Gesture of the patron saint(s): not applicable

Type of religious scene: hieratic

Religious scene(s) depicted: Maria in Sole, St. Peter, St. Augustine 
Cat. 429-Type $2 \mathrm{C}$

Master of Flémalle (Robert Campin?) Triptych of the Annunciation ('Mérode Triptych') (c. 1425)

$64.1 \times 63.2 \mathrm{~cm}$ (centre panel) and 64.5 $\times 27.3 \mathrm{~cm}$ (wings)

New York, MET, The Cloisters Collection, inv. no. 1956 (56.70)

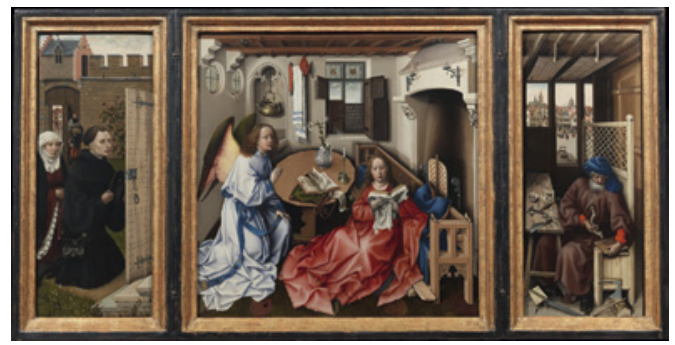
BIBL.: FRIEDLÄNDER II, no. 54; THÜRLEMANN 2002, 58-76, no. I.12 (with bibl.); Exh. cat. Frankfurt and Berlin 2009, no. 4 (with bibl.).

HISTORICAL INFORMATION: The coats of arms painted on the centre panel identify the male sitter as Pieter Engelbrechts. He came from a Mechelen family of merchants, with parents in Cologne. Between 1425 and 1428, Pieter married Marguerite Scrijnmakere, who came from the Cologne wealthy middle class. After her death, he married Heylwich Bille († 1466) and later, Aleydis de Kempenere. Scholars usually agree on the fact that the woman accompanying him in the triptych is his first wife.

Identity of the sitter(s): Pieter Engelbrechts and Marguerite Scrijnmakere (?)

Provenance: unknown

Number of portrait(s): 2

Type of person(s): lay (couple)

Attitude of the sitter(s): hands clasped, holding a hat

Representation of the sitter(s): full-length

Gaze of the sitter(s): into space, towards the scene

Object(s): yes (hat, rosary, purse)

Coat(s) of arms: yes

Environment: enclosed garden, historical setting (domestic setting)

Structuring of the pictorial space: continuous space

Patron saint(s): none

Gesture of the patron saint(s): not applicable

Type of religious scene: narrative

Religious scene(s) depicted: the Annunciation, St. Joseph 
Cat. 430-Type $2 \mathrm{C}$

Master of Flémalle (Robert Campin?)

Triptych of the Entombment ('Seilern Triptych') (c. 1415-1420)

$60 \times 48.9 \mathrm{~cm}($ centre panel $)$ and $60 \times$ $22.5 \mathrm{~cm}$ (wings)

London, Courtauld Institute of Art, (the

Princes Gate Collection, cat. no. 1).

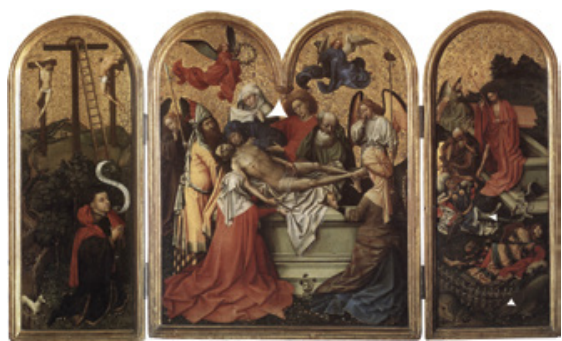

BIBL.: FRIEDLÄNDER II, add. 147;

THÜRLEMANN 2002, 28-37, no. I.3 (with bibl.); NYS 2003.

HISTORICAL INFORMATION: In 2003, Nys proposed to identify the portrayed man as Jehan le Kien, a middle-class man from Tournai, who owned a chapel dedicated to the Holy Sepulchre at the church of St. Piat. Although plausible and seductive, this hypothesis cannot be confirmed with any certainty.

Identity of the sitter(s): unknown (Jehan le Kien?)

Provenance: Tournai, church of St. Piat, chapel of the Holy Sepulchre (?)

Number of portrait(s): 1

Type of person(s): lay (man alone)

Attitude of the sitter(s): hands clasped

Representation of the sitter(s): full-length

Gaze of the sitter(s): towards the scene

Object(s): yes (dog, banderole)

Coat(s) of arms: no

Environment: historical setting

Structuring of the pictorial space: unified space with discontinuities

Patron saint(s): none

Gesture of the patron saint(s): not applicable

Type of religious scene: narrative

Religious scene(s) depicted: the Entombment, the Resurrection of Christ

Cat. 431-Type $2 \mathrm{C}$

Master of Flémalle (Robert Campin?) (copy after)

Triptych of the Descent of the Cross with a Man in Prayer (c. 1430 for the original and c. 1448-1465 for the copy)

$60 \times 60.5 \mathrm{~cm}($ centre panel) and $60 \times$

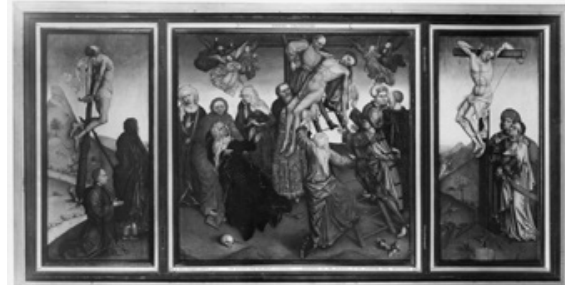
$26.5 \mathrm{~cm}$ (wings)

Liverpool, Walker Art Gallery, inv. no. 1178 
BIBL.: FRIEDLÄNDER II, no. 59a; Mus. cat. Liverpool 1963, 39, no. 1178; THÜRLEMANN 2002, 131-40, no. I.16 (with bibl.).

HISTORICAL INFORMATION: It is generally acknowledged that this triptych, which is a copy of the famous Descent of the Cross by the Master of Flémalle, was commissioned by Jan de Coninck between 1448 and 1465 for the Hospital of St. Julian in Bruges.

Identity of the sitter(s): Jan de Coninck (?)

Provenance: Bruges, Hospital of St. Julian (?)

Number of portrait(s): 1

Type of person(s): lay (man alone)

Attitude of the sitter(s): hands clasped

Representation of the sitter(s): full-length

Gaze of the sitter(s): towards the scene

Object(s): no

Coat(s) of arms: yes

Environment: historical setting

Structuring of the pictorial space: continuous space

Patron saint(s): none

Gesture of the patron saint(s): not applicable

Type of religious scene: narrative

Religious scene(s) depicted: the Crucifixion

Cat. 432-Type 6A

Master of Flémalle (Robert Campin?) (or workshop of Rogier van der Weyden) Two Wings. Heinrich Von Werl in Prayer with St. John the Baptist, St. Barbara Reading (c. 1434-1438) $101 \times 47 \mathrm{~cm}$ (each wing)

Madrid, Museo Nacional del Prado, inv. nos. 1352-1353

BIBL.: FRIEDLÄNDER II, no. 67; THÜRLEMANN 2002, no. III.B.4 (with bibl.); Exh. cat. Frankfurt and Berlin

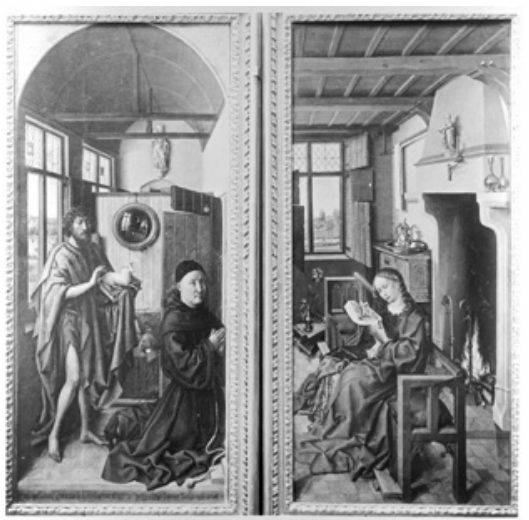
2009, no. 22 (with bibl.).

HISTORICAL INFORMATION: Heinrich von Werl has been identified by the inscription in the lower part of the left wing: Anno milleno e quater $X$ ter et octo hic feci effigiem d(ep)ingi minister Henricus Werlis magister coloniensis. Heinrich was a Franciscan friar. In 1430, he is mentioned as a student at the 
University of Cologne. Two years later, he gained the title of Minister for the Franciscans of the province of Cologne (which included the Low Countries). In 1462, he withdrew to the monastery of Osnabrück, where he died on 10 April 1463 .

Identity of the sitter(s): Heinrich von Werl

Provenance: unknown

Number of portrait(s): 1

Type of person(s): religious (man alone: Franciscan friar)

Attitude of the sitter(s): hands clasped

Representation of the sitter(s): full-length

Gaze of the sitter(s): indeterminate

Object(s): yes (hat)

Coat(s) of arms: no

Environment: domestic setting (incomplete)

Structuring of the pictorial space: indeterminate

Patron saint(s): John the Baptist

Gesture of the patron saint(s): holding his/her attribute

Type of religious scene: indeterminate

Religious scene(s) depicted: St. Barbara reading

Cat. 433-Type 6A

Master of Flémalle (Robert Campin?) (workshop of)

Portrait of a Man in Prayer (c. 1430-1435)

$31.8 \times 23.2 \mathrm{~cm}$

New York, MET, inv. no. 1950 50.145.35

BIBL.: AINSWORTH and CHRISTIANSEN 1998, 146-47 (with bibl.); THÜRLEMANN 2002, no. III.G.1; Exh. cat. Frankfurt and Berlin 2009, no. 19 (with bibl.).

Identity of the sitter(s): unknown

Provenance: unknown

Number of portrait(s): 1

Type of person(s): lay (man alone)

Attitude of the sitter(s): hands clasped

Representation of the sitter(s): half-length

Gaze of the sitter(s): indeterminate

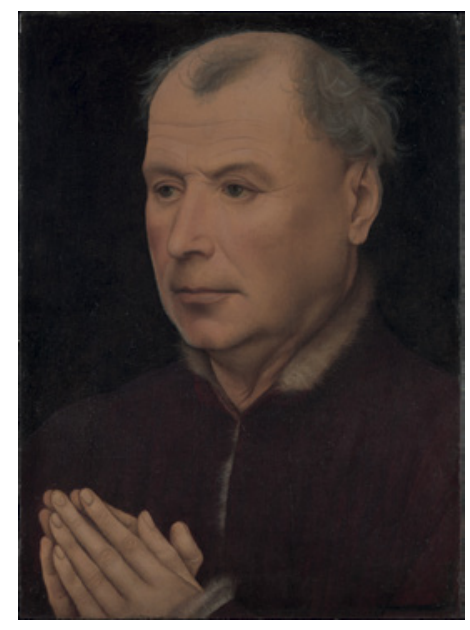


Object(s): no

Coat(s) of arms: no

Environment: neutral space (incomplete)

Structuring of the pictorial space: indeterminate

Patron saint(s): none

Gesture of the patron saint(s): not applicable

Type of religious scene: indeterminate

Religious scene(s) depicted: none

Cat. 434-Type 6A

[RKD work no. 38353]

Master of Frankfurt

One Wing. A Woman in Prayer with St. Roch (c. 1497)

$86.5 \times 27.5 \mathrm{~cm}$

The Netherlands, private collection

BIB L.: FRIEDLÄNDER VII, no. 156; GODDARD 1984, no. 123 (with bibl.).

Identity of the sitter(s): unknown

Provenance: unknown

Number of portrait(s): 1

Type of person(s): lay (woman alone)

Attitude of the sitter(s): hands clasped

Representation of the sitter(s): full-length

Gaze of the sitter(s): indeterminate

Object(s): no

Coat(s) of arms: no

Environment: landscape, no sacred connotation (incomplete)

Structuring of the pictorial space: indeterminate

Patron saint(s): Roch

Gesture of the patron saint(s): introducing

Type of religious scene: indeterminate

Religious scene(s) depicted: none

Cat. 435-Type $2 \mathrm{~A}$

Master of Frankfurt

Triptych of the Crucifixion ('Triptych of the Humbracht Family') (c. 1506)

$116 \times 77 \mathrm{~cm}$ (centre panel) and $119 \times 37 \mathrm{~cm}$ (wings) 
Frankfurt, Städelsches Kunstinstitut, inv. no. 715

BIB L.: FRIEDLÄNDER VII, no. 128; Goddard 1984, no. 101; Mus. cat. Frankfurt 1993, 368-92 (with bibl.).

HISTORICAL INFORMATION: The family portrayed in this triptych came from Frankfurt. The father, Klaus Humbracht (1440-1504), was a wealthy patrician of this city. He is accompanied by his wife, Greda Brun, his three sons (Klaus, Jakob and Johann) and his three daughters (Margarethe, Katheline and Anna). Johann is wearing the canonical habit. He entered the college of Our Lady in Frankfurt in 1504 and was admitted to the canonical chapter on 12 November of this year. His sister Anna wears the habit of the Penitent Sisters of Mary Magdalene. In 1503, Jakob moved to Antwerp, where he spent the rest of his life. In 1512, he married a certain Johanna van Apelteren. In all likelihood, he commissioned the triptych to the Master of Frankfurt, who was active in Antwerp at this time. The commission was probably made after 1504, the year Jakob's father passed away. Greta Brun was then already dead. For some unknown reason, the background landscape of the centre panel contains a depiction of the city of Utrecht, recognisable on the basis of the tower of the cathedral, the church of St. James, the Buurtoren and the Wittevrouwepoort.

Identity of the sitter(s): Humbracht family

Provenance: unknown

Number of portrait(s): 8

Type of person(s): mixed (family)

Attitude of the sitter(s): hands clasped

Representation of the sitter(s): full-length

Gaze of the sitter(s): towards the scene, towards the ground

Object(s): yes (rosary)

Coat(s) of arms: yes

Environment: historical setting

Structuring of the pictorial space: continuous space

Patron saint(s): Nicholas, Margaret

Gesture of the patron saint(s): holding his/her attribute

Type of religious scene: narrative

Religious scene(s) depicted: the Crucifixion, a gisant with a memento mori 
Cat. 436-Type $2 \mathrm{~A}$

Master of Frankfurt

Triptych of the Lamentation with a Couple in Prayer and Patron Saints (c. 1515)

$102 \times 70 \mathrm{~cm}$ (centre panel) and $102 \times 30 \mathrm{~cm}$ (wings)

Munich, Alte Pinakothek, inv. nos. 6o-62

BIBL.: FRIEDLÄNDER VII, no. 127; HOOGEWERFF III, 21-22; GODDARD 1984, no. 115 (with bibl.).

Identity of the sitter(s): unknown

Provenance: unknown

Number of portrait(s): 2

Type of person(s): lay (couple)

Attitude of the sitter(s): hands clasped, holding a rosary

Representation of the sitter(s): full-length

Gaze of the sitter(s): into space

Object(s): yes (prie-dieu, rosary)

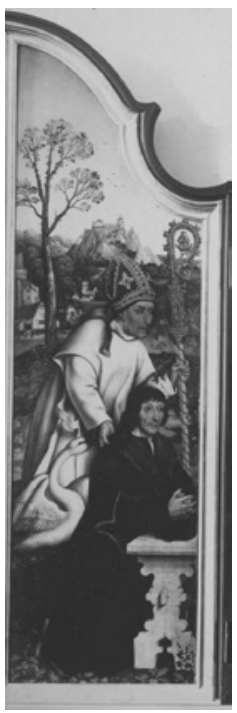

Coat(s) of arms: no

Environment: historical setting

Structuring of the pictorial space: unified space with discontinuities

Patron saint(s): Hugh of Lincoln, Catherine

Gesture of the patron saint(s): introducing, holding his/her attribute

Type of religious scene: narrative

Religious scene(s) depicted: the Lamentation

Cat. 437-Type 2B

Master of Frankfurt

Triptych of the Virgin and Child Enthroned with a Family in Prayer and Patron Saints (c. 1518)

$106 \times 65 \mathrm{~cm}$ (centre panel) and $106 \times$ $21 \mathrm{~cm}$ (wings)

Pistoia, Museo Civico

BIBL.: FRIEDLÄNDER VII, no. 132;

GODDARD 1984, no. 48 (with bibl.).

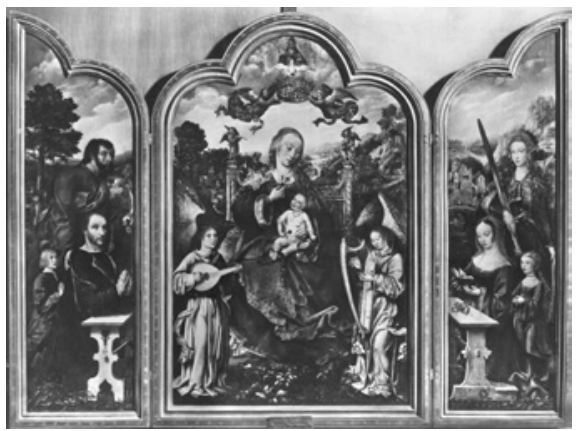

Identity of the sitter(s): unknown

Provenance: unknown 
Number of portrait(s): 4

Type of person(s): lay (family with children)

Attitude of the sitter(s): hands clasped, holding a book

Representation of the sitter(s): full-length

Gaze of the sitter(s): into space, towards the ground

Object(s): yes (prie-dieu, rosary, book)

Coat(s) of arms: no

Environment: landscape with sacred connotation

Structuring of the pictorial space: unified space with discontinuities

Patron saint(s): John the Baptist, Catherine

Gesture of the patron saint(s): introducing, holding his/her attribute

Type of religious scene: hieratic

Religious scene(s) depicted: the Virgin and Child, the Annunciation

\section{Cat. 438-Type 6A}

[RKD work no. 38335]

Master of Frankfurt

Two Wings. A Family in Prayer with Patron Saints (c. 1508)

$74.6 \times 44.2 \mathrm{~cm}$ (each wing)

Chicago, Chicago Art Institute, inv. no. 33.1046

BIBL.: FRIEDLÄNDER, no. 135; Goddard 1984, no. 38, no. 130 (with bibl.).

Identity of the sitter(s): unknown

Provenance: unknown

Number of portrait(s): 4

Type of person(s): lay (family with children)

Attitude of the sitter(s): hands clasped, holding a rosary

Representation of the sitter(s): full-length

Gaze of the sitter(s): indeterminate

Object(s): yes (prie-dieu, rosary, book, hat)

Coat(s) of arms: yes

Environment: landscape, no sacred connotation (incomplete)

Structuring of the pictorial space: indeterminate

Patron saint(s): Adrian, Elizabeth of Hungary

Gesture of the patron saint(s): holding his/her attribute

Type of religious scene: indeterminate

Religious scene(s) depicted: none 
Cat. 439-Type 6A

[RKD work no. 38278 ]

Master of Frankfurt

Two Wings. A Family in Prayer with Patron Saints (c. 1500-1510)

$87.5 \times 26 \mathrm{~cm}$ (each wing)

Manchester, City Art Gallery, inv. no. 1957.510

BIB L.: FRIEDLÄNDER VII, no. 134.

Identity of the sitter(s): unknown

Provenance: unknown

Number of portrait(s): 4

Type of person(s): lay (family with children)

Attitude of the sitter(s): hands clasped

Representation of the sitter(s): full-length

Gaze of the sitter(s): indeterminate

Object(s): yes (dog, rosary)

Coat(s) of arms: no

Environment: landscape, no sacred connotation (incomplete)

Structuring of the pictorial space: indeterminate

Patron saint(s): Catherine, Barbara

Gesture of the patron saint(s): introducing, holding his/her attribute

Type of religious scene: indeterminate

Religious scene(s) depicted: memento mori

Cat. 440-Type 6A

Master of Frankfurt

Two Wings. St. Andrew and a Man in Prayer; St. Hedwige (c. 1500)

$76 \times 24.5 \mathrm{~cm}$ (left wing) and $79 \times 25 \mathrm{~cm}$ (right wing)

Dresden, Gemäldegalerie Alte Meister Staatliche Kunstsammlungen Dresden, inv. nos. 807-808

BIBL.: FRIEDLÄNDER VII, no. 138; GODDARD 1984, no. 125 (with bibl.); Exh.

cat. Dresden 2005, no. 71 (with bibl.).

Identity of the sitter(s): unknown

Provenance: unknown

Number of portrait(s): 1

Type of person(s): lay (man alone)

Attitude of the sitter(s): hands clasped

Representation of the sitter(s): full-length 
Gaze of the sitter(s): indeterminate

Object(s): no

Coat(s) of arms: no

Environment: landscape, no sacred connotation (incomplete)

Structuring of the pictorial space: indeterminate

Patron saint(s): Andrew

Gesture of the patron saint(s): introducing

Type of religious scene: indeterminate

Religious scene(s) depicted: St. Hedwige

Cat. 441-Type $3^{\mathrm{D}}$

Master of Frankfurt (attributed to)

The Holy Kinship with a Nun in

Prayer (c. 1490-1515)

$78 \times 82 \mathrm{~cm}$ (left wing) and $77 \times$

$81.5 \mathrm{~cm}$ (right wing)

Houston, Sarah Campbell Blaffer
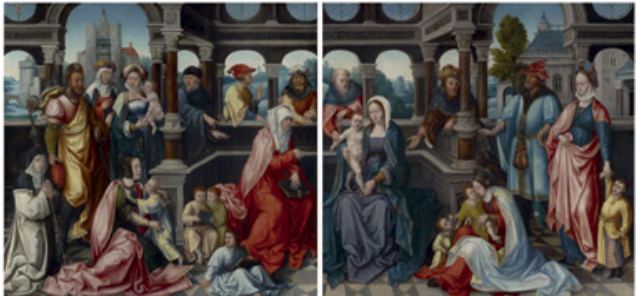

Foundation, inv. no. 1977.1

BIB L.: WRIGHT 1980; Mus. cat. Houston 1981, 30-32; GODDARD 1984, 166.

HISTORICAL INFORMATION: The coat of arms painted on the window in the upper left corner of the left panel has not been identified.

Identity of the sitter(s): unknown

Provenance: unknown

Number of portrait(s): 1

Type of person(s): religious (woman alone)

Attitude of the sitter(s): hands clasped

Representation of the sitter(s): full-length

Gaze of the sitter(s): into space

Object(s): no

Coat(s) of arms: yes

Environment: architectural space with sacred connotation

Structuring of the pictorial space: not applicable

Patron saint(s): none

Gesture of the patron saint(s): not applicable

Type of religious scene: hieratic

Religious scene(s) depicted: the Holy Kinship 
Cat. 442-Type 2A

Master of Frankfurt (follower of) (or Master of 1518)

Triptych of the Adoration of the Magi with a Couple in Prayer and Patron Saints (c. 1520$)$

$54 \times 30 \mathrm{~cm}$ (centre panel) and $54 \times 13.5 \mathrm{~cm}$ (wings)

Whereabouts unknown

BIB L.: SCHADE 2001, 292-93 (with bibl.).

Identity of the sitter(s): unknown

Provenance: unknown

Number of portrait(s): 2

Type of person(s): lay (couple)

Attitude of the sitter(s): hands clasped

Representation of the sitter(s): full-length

Gaze of the sitter(s): indeterminate

Object(s): yes (rosary)

Coat(s) of arms: no

Environment: historical setting

Structuring of the pictorial space: unified space with discontinuities

Patron saint(s): Peter, John the Baptist

Gesture of the patron saint(s): introducing

Type of religious scene: narrative

Religious scene(s) depicted: the Adoration of the Magi

\section{Cat. 443-Type ${ }_{3}$ B}

Master of Frankfurt (workshop of)

The Virgin and Child with Saints and a Man in Prayer (c. 1505)

$69 \times 55.2 \mathrm{~cm}$

Brisbane, Queensland Art Gallery

BIBL.: FRIEDLÄNDER VIII, no. 152; GODDARD 1984, no. 23 (with bibl.).

REMARK: Technical investigation

has revealed that the current portrait hides the original figure, who was a young woman. Oddly, only her head has been overpainted. The current

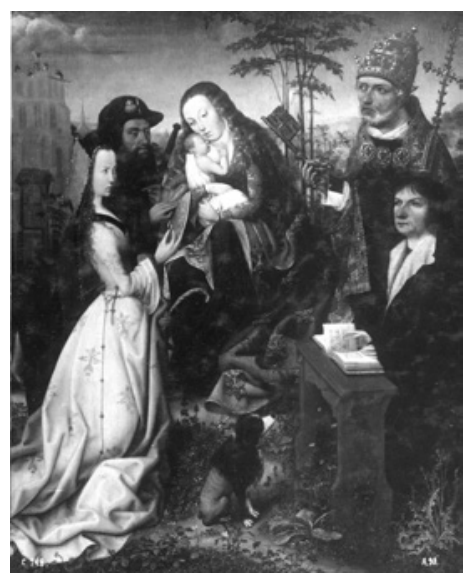
male portrait thus wears a dress. The identity of the patron saint has also been modified. St. Peter's key hides a horn, which enables the 
identification of the former saint as Cornelius. See http://www.zone4.com .au/2016/03/31/background/.

Identity of the sitter(s): unknown

Provenance: unknown

Number of portrait(s): 1

Type of person(s): lay (woman alone)

Attitude of the sitter(s): holding a book

Representation of the sitter(s): full-length

Gaze of the sitter(s): towards the scene

Object(s): yes (prie-dieu, book, dog)

Coat(s) of arms: no

Environment: enclosed garden

Structuring of the pictorial space: not applicable

Patron saint(s): Cornelius (now Peter)

Gesture of the patron saint(s): holding his/her attribute

Type of religious scene: hieratic

Religious scene(s) depicted: the Virgin and Child, St. James, St. Barbara

\section{Cat. 444-Type 6A}

Master of Hoogstraeten

Seven Panels from the Hoogstraeten Altarpiece (c. 1505)

$92 \times 31 \mathrm{~cm}$ (panels 1-2), $92 \times 64 \mathrm{~cm}$ (panel 3 ), $76 \times 60 \mathrm{~cm}$ (panel 4), $92 \times 65 \mathrm{~cm}$ (panel 5) and $103 \times 32 \mathrm{~cm}$ (panels 6-7)

Antwerp, KMSK, inv. nos. $383-389$

BIBL.: FRIEDLÄNDER VII, no. 103; Mus. cat. Antwerp 1985, 116-22; Exh. cat. Antwerp and Maastricht 2005, no. 9 (with bibl.).

HISTORICAL INFORMATION: These seven panels come from an altarpiece dedicated to the Seven Sorrows of the Virgin, which was placed on the high altar of the church of St. Catherine at Hoogstraeten. The seventh panel contains the portrait of a woman in prayer, who has been identified as Oda Stercke. Taking into account the fact that the high altar was

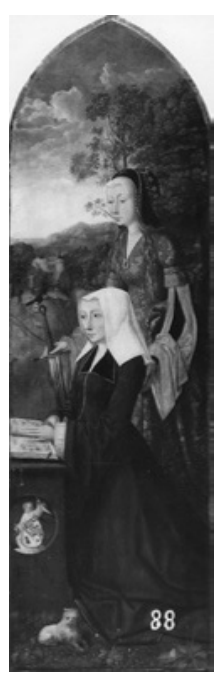
also dedicated to St. Peter and the Eleven Thousand Virgins of Cologne, the other panels of the altarpiece probably depicted these themes. One of them probably contained the portrait of Oda's husband, Peter van der Beke.

Identity of the sitter(s): Oda Stercke

Provenance: Hoogstraeten, church of St. Catherine, high altar 
Number of portrait(s): 1

Type of person(s): lay (woman alone)

Attitude of the sitter(s): hands clasped

Representation of the sitter(s): full-length

Gaze of the sitter(s): indeterminate

Object(s): yes (prie-dieu, book, dog)

Coat(s) of arms: yes

Environment: landscape, no sacred connotation (incomplete)

Structuring of the pictorial space: indeterminate

Patron saint(s): Catherine (?)

Gesture of the patron saint(s): introducing

Type of religious scene: indeterminate

Religious scene(s) depicted: the Presentation at the temple, Christ among the doctors, Christ bearing the cross, the Crucifixion, the Entombment, the Mater Dolorosa

\section{Cat. 445-Type 6A}

[R KD work no. 32249]

Master of Hoogstraeten (attributed to) (or circle of Ambrosius Benson)

Two Wings. A Couple in Prayer with Patron Saints (c. 1500-1515)

$42 \times 12.9 \mathrm{~cm}$ (each wing)

London, sale Sotheby's (11 December 2003), lot no. 113

Identity of the sitter(s): unknown

Provenance: unknown

Number of portrait(s): 2

Type of person(s): lay (couple)

Attitude of the sitter(s): hands clasped

Representation of the sitter(s): full-length

Gaze of the sitter(s): indeterminate

Object(s): yes (rosary)

Coat(s) of arms: yes (on the frame)

Environment: landscape, no sacred connotation (incomplete)

Structuring of the pictorial space: indeterminate

Patron saint(s): an unidentified saint, Anne

Gesture of the patron saint(s): introducing

Type of religious scene: indeterminate

Religious scene(s) depicted: none 
Cat. 446 - Type ${ }_{3} \mathrm{C}$

Master of San Lorenzo della Costa

Triptych of the Martyrdom of

St. Andrew (1499)

$150 \times 92 \mathrm{~cm}$ (each wing)

Santa Margherita Ligure, church of

San Lorenzo della Costa

BIB L.: BAUTIER 1931;

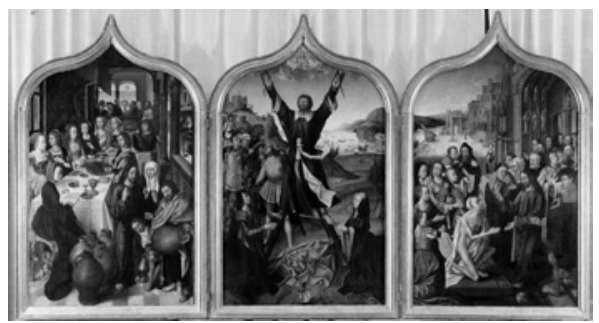

FRIEDLÄNDER VIb, supp. 246;

CAVELLI TRAVERSO 2003, no. 25.

HISTORICAL INFORMATION: The couple has been identified on the basis of the coats of arms and the inscription Andrea da Costa fecit firer Brugis 1499 on the reverse of the wings. Andrea da Costa was a member of the Genovese nobility who came to Flanders. He became a citizen of Bruges in 1483 and married Agnès Adornes in 1492. He was councillor of the Emperor Maximilian and ambassador at the court of France. He died on 14 April 1542; Agnès died on 15 January 1528. The triptych was destined to the St. Andrew's altar in the church of San Lorenzo della Costa in Santa Margherita Ligure.

Identity of the sitter(s): Andrea da Costa and Agnès Adornes

Provenance: Santa Margherita Ligure, church of San Lorenzo della Costa,

St. andrew's altar

Number of portrait(s): 2

Type of person(s): lay (couple)

Attitude of the sitter(s): hands clasped

Representation of the sitter(s): full-length

Gaze of the sitter(s): towards the scene

Object(s): no

Coat(s) of arms: yes

Environment: historical setting

Structuring of the pictorial space: not applicable

Patron saint(s): none

Gesture of the patron saint(s): not applicable

Type of religious scene: narrative

Religious scene(s) depicted: the Wedding at Cana, the Martyrdom of

St. Andrew, the Resurrection of Lazarus, Adam and Eve, the Death

Cat. 447-Type $3 \mathrm{~A}$

[RKD work no. 192076]

Master of the Amsterdam Death of the Virgin 
Christ on the Cross with Saints and a Group of People in Prayer (c. 1500) $29 \times 28 \mathrm{~cm}$

Previously Wassenaar, Hans Ludwig Larsen collection BIBL.: FRIEDLÄNDER X, supp. 175 .

REMARK: The collection of Hans Ludwig Larsen ( $\dagger$ 1937) was located in Wassenaar, in the Leiden region. After Larsen's death and following the political situation in Europe in the late 1930s, his wife and children moved to the United States and loaned a part of the collection to the Lakenhal Museum in Leiden. In 1943, these paintings were brought to the art dealer Van Marle \& Bignell in The Hague, where they were supposed to be sold on 25 January. However, a large number of them were bought on 14January by E. Göpel for the Führermuseum in Linz. On the basis of the Stichting Nederlandsch Kunstbezit (SNK), twelve of these paintings have been traced back and restituted to the descendants of the Larsen family. The present painting is not mentioned in the sale catalogue of 1943. Its trace has been lost.

Identity of the sitter(s): unknown

Provenance: unknown

Number of portrait(s): 4

Type of person(s): mixed (family with children)

Attitude of the sitter(s): hands clasped

Representation of the sitter(s): full-length

Gaze of the sitter(s): towards the scene

Object(s): yes (rosary)

Coat(s) of arms: no

Environment: historical setting

Structuring of the pictorial space: not applicable

Patron saint(s): Andrew, Francis, Barbara

Gesture of the patron saint(s): protecting, introducing

Type of religious scene: narrative

Religious scene(s) depicted: the Crucifixion, Christ crowned with thorns, Christ bearing the cross, the Descent from the cross, the Entombment

Cat. 448-Type 6A

[RKD work no. 16961]

Master of the Amsterdam Death of the Virgin

Fragment. Five Persons in Prayer with Two Saints (c. 1500)

$42.8 \times 31.8 \mathrm{~cm}$

New York, sale Sotheby's (22 May 1997), lot no. 118

BIBL.: FRIEDLÄNDER X, no. 150. 
Identity of the sitter(s): unknown

Provenance: unknown

Number of portrait(s): 5

Type of person(s): lay (group indeterminate)

Attitude of the sitter(s): hands clasped

Representation of the sitter(s): full-length

Gaze of the sitter(s): indeterminate

Object(s): no

Coat(s) of arms: no

Environment: landscape, no sacred connotation (incomplete)

Structuring of the pictorial space: indeterminate

Patron saint(s): Peter, a saint bishop

Gesture of the patron saint(s): protecting, holding his/her attribute

Type of religious scene: indeterminate

Religious scene(s) depicted: none

Cat. 449-Type 6A

Master of the Amsterdam Death of the Virgin

One Wing. The Assumption of the Virgin, the Intercession of

Christ and the Virgin (reverse) (c. 1500)

$124 \times 47 \mathrm{~cm}$

Antwerp, KMsk, inv. nos. 533-534

BIB L.: FRIEDLÄNDER X, no. 149; HOOGEWERFF I, 534-

24; Mus. cat. Antwerp 1985, 110-12; Mus. cat. Antwerp 1998, 488.

Identity of the sitter(s): unknown

Provenance: unknown

Number of portrait(s): 5

Type of person(s): religious (group: canons)

Attitude of the sitter(s): hands clasped

Representation of the sitter(s): full-length

Gaze of the sitter(s): indeterminate

Object(s): yes (hat, banderole)

Coat(s) of arms: no

Environment: historical setting

Structuring of the pictorial space: indeterminate

Patron saint(s): none

Gesture of the patron saint(s): not applicable

Type of religious scene: intercession

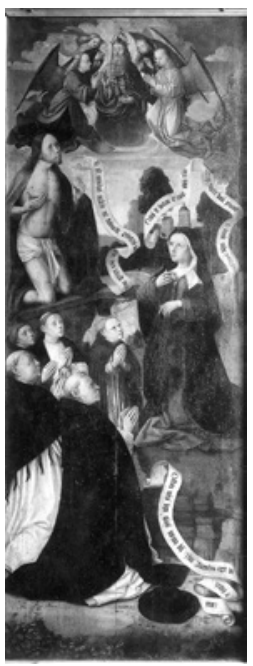


Religious scene(s) depicted: the Intercession of Christ and the Virgin, the Assumption of the Virgin

Cat. 450-Type 6B

[RKD work no. 20157]

Master of the Amsterdam Death of the Virgin

Portrait of a Woman in Prayer (c. 1500)

$24 \times 19.5 \mathrm{~cm}$

Previously Amsterdam, Boon-Van Leer collection

BIB L.: FRIEDLÄNDER X, no. 152; Exh. cat. Amsterdam 1958, no. 46.

Identity of the sitter(s): unknown

Provenance: unknown

Number of portrait(s): 1

Type of person(s): lay (woman alone)

Attitude of the sitter(s): hands clasped

Representation of the sitter(s): half-length

Gaze of the sitter(s): indeterminate

Object(s): no

Coat(s) of arms: no

Environment: neutral space (incomplete)

Structuring of the pictorial space: indeterminate

Patron saint(s): none

Gesture of the patron saint(s): not applicable

Type of religious scene: indeterminate

Religious scene(s) depicted: none

Cat. 451-Type $3^{\mathrm{A}}$

Master of the Amsterdam Death of the Virgin

The Agony in the Garden with a Couple in Prayer and Patron Saints (c. 1500)

$82.8 \times 72.8 \mathrm{~cm}$

Philadelphia, Philadelphia Museum of Art, inv. no. 751

вIB L.: FRIEDLÄNDER X, no. 147;

HOOGEWERFF I, 523-24; Mus. cat.

Philadelphia 1994, 80.

Identity of the sitter(s): unknown

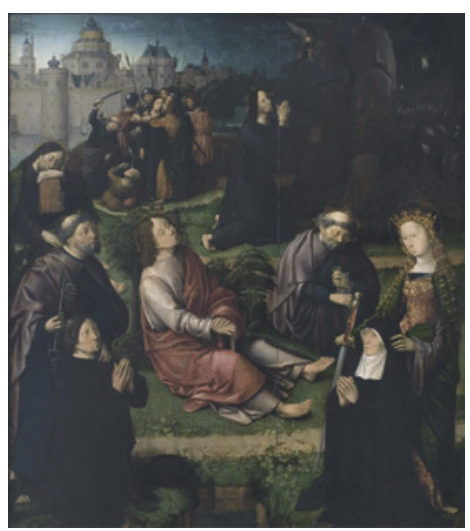


Provenance: unknown

Number of portrait(s): 2

Type of person(s): lay (couple)

Attitude of the sitter(s): hands clasped

Representation of the sitter(s): full-length

Gaze of the sitter(s): towards the scene

Object(s): yes (hat)

Coat(s) of arms: no

Environment: historical setting

Structuring of the pictorial space: not applicable

Patron saint(s): Peter, Catherine

Gesture of the patron saint(s): protecting

Type of religious scene: narrative

Religious scene(s) depicted: the Agony in the garden

Cat. 452-Type 6A

Master of the Amsterdam Death of the Virgin

Two Wings. The Last Supper with a Friar in Prayer; The Resurrection of Christ (c. 1485-1500)

$53 \times 65.5 \mathrm{~cm}$ (each wing)

Amsterdam, Rijksmuseum, inv. nos. SK-A-2129 and SK-A-2130

BIBL.: FRIEDLÄNDER X, no. 145;

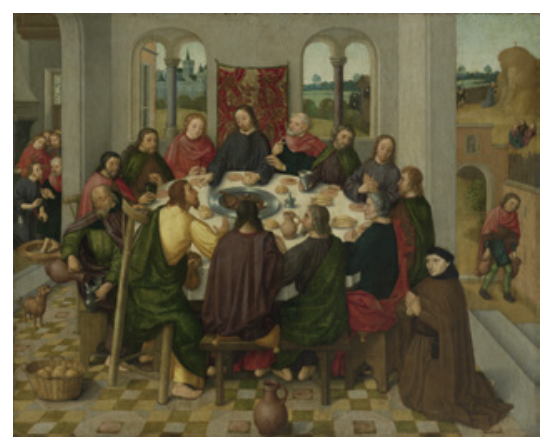
HOOGEWERFF I, 524-25; Mus.

cat. Amsterdam 1976, 630; Mus. cat. Amsterdam 2009 [online], https://www .rijksmuseum.nl/nl/collectie/SK-A-2129/catalogus-entry (with bibl.).

Identity of the sitter(s): unknown

Provenance: unknown

Number of portrait(s): 1

Type of person(s): religious (man alone: Franciscan friar)

Attitude of the sitter(s): hands clasped

Representation of the sitter(s): full-length

Gaze of the sitter(s): into space 
Object(s): no

Coat(s) of arms: no

Environment: historical setting

Structuring of the pictorial space: not applicable

Patron saint(s): none

Gesture of the patron saint(s): not applicable

Type of religious scene: narrative

Religious scene(s) depicted: the Last supper, the Resurrection of Christ

Cat. 453-Type 6A

[RKD work no. 257126]

Master of the Antwerp Adoration

One wing. St. Ambrose with a Man in Prayer (c. 1500-1510)

$73 \times 51 \mathrm{~cm}$

Pavia, Museo Civico Pinacoteca Malaspina, inv. no. P 117

BIB L.: ZATT 2011, no. 64 (with bibl.).

Identity of the sitter(s): unknown

Provenance: unknown

Number of portrait(s): 1

Type of person(s): religious (man alone: Benedictine or Augustinian monk)

Attitude of the sitter(s): hands clasped

Representation of the sitter(s): full-length

Gaze of the sitter(s): indeterminate

Object(s): no

Coat(s) of arms: no

Environment: landscape, no sacred connotation (incomplete)

Structuring of the pictorial space: indeterminate

Patron saint(s): Ambrose

Gesture of the patron saint(s): holding his/her attribute

Type of religious scene: indeterminate

Religious scene(s) depicted: none 
Cat. 454-Type 2A

Master of the Antwerp Adoration

Triptych of the Adoration of the

Magi with Saints and a Man in

Prayer (c. 1500-1510)

$29 \times 22 \mathrm{~cm}$ (centre panel) and 29

$\times 8 \mathrm{~cm}$ (wings)

Antwerp, KMSK, inv. nos.

208-209-2ogbis-210-21obis

BIB L.: FRIEDLÄNDER XI, no. 46;

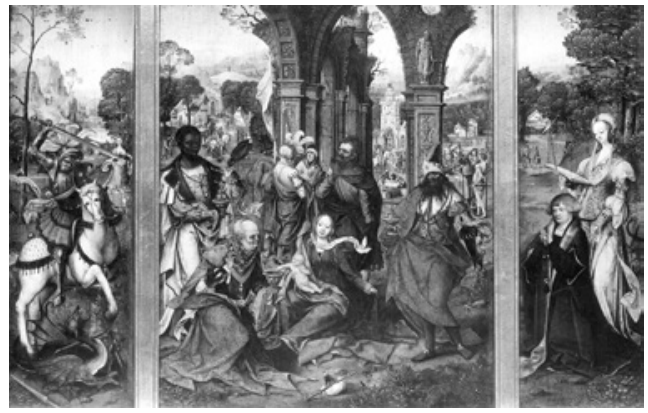

Mus. cat. Antwerp 1998, 489; Exh.

cat. Antwerp and Maastricht 2005, no. 68 (with bibl.).

Identity of the sitter(s): unknown

Provenance: unknown

Number of portrait(s): 1

Type of person(s): lay (man alone)

Attitude of the sitter(s): holding a rosary

Representation of the sitter(s): full-length

Gaze of the sitter(s): towards the scene

Object(s): yes (rosary)

Coat(s) of arms: no

Environment: historical setting

Structuring of the pictorial space: continuous space

Patron saint(s): Margaret

Gesture of the patron saint(s): introducing

Type of religious scene: narrative

Religious scene(s) depicted: the Adoration of the Magi, St. George fighting the dragon, the Annunciation

Cat. 455-Type 2 B

[RKD work no. 194341]

Master of the Antwerp Adoration

Triptych of the Holy Family with a Man in Prayer and Patron Saints (c. 1520-1530)

$69.5 \times 52.8 \mathrm{~cm}$ (centre panel), $69.5 \times 23.3 \mathrm{~cm}$ (right wing) and $69.4 \times 23.1 \mathrm{~cm}$

(left wing)

Private collection 
BIB L.: Sale cat. Van Ham (Cologne, 1-3 April 2004), no. 1220; Exh. cat. Antwerp and Maastricht 2005, no. 69 .

Identity of the sitter(s): unknown

Provenance: unknown

Number of portrait(s): 1

Type of person(s): lay (man alone)

Attitude of the sitter(s): hands clasped

Representation of the sitter(s): full-length

Gaze of the sitter(s): into space

Object(s): no

Coat(s) of arms: no

Environment: landscape, no sacred connotation

Structuring of the pictorial space: continuous space

Patron saint(s): James, Jerome

Gesture of the patron saint(s): introducing

Type of religious scene: hieratic

Religious scene(s) depicted: the Holy family, St. Onofrius

\section{Cat. 456 - Type 3 B}

Master of the Antwerp Triptych of the Virgin The Virgin and Child with a Man and St. Michael (c. 1500)

$82.5 \times 73.5 \mathrm{~cm}$

Berlin, Staatliche Museen zu Berlin, Gemäldegalerie, inv. no. $1631 \mathrm{~A}$ BIBL.: FRIEDLÄNDER V, no. 24; Mus. cat. Berlin 1996, no. 744; Exh. cat. Rotterdam 2009, 145-46.

Identity of the sitter(s): unknown

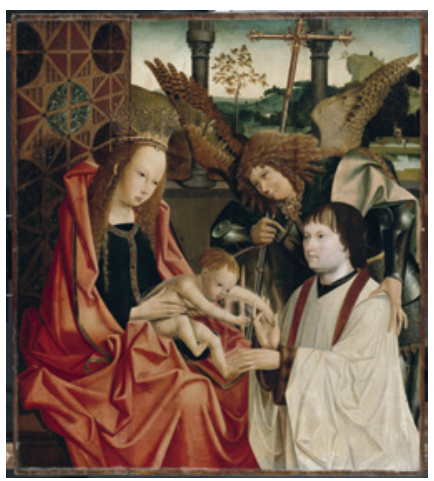

Provenance: unknown

Number of portrait(s): 1

Type of person(s): religious (man alone: priest)

Attitude of the sitter(s): physical contact with the sacred person

Representation of the sitter(s): half-length

Gaze of the sitter(s): towards the scene

Object(s): no 
Coat(s) of arms: no

Environment: architectural space with sacred connotation

Structuring of the pictorial space: not applicable

Patron saint(s): Michael

Gesture of the patron saint(s): protecting

Type of religious scene: hieratic

Religious scene(s) depicted: the Virgin and Child

\section{Cat. 457 - Type $3 \mathrm{C}$}

[RKD work no. 71726]

Master of the Antwerp Triptych of the Virgin (or follower of Geertgen tot Sint Jans)

The Assumption of the Virgin with a Couple in Prayer (c. 1510)

$115 \times 95 \mathrm{~cm}$

Bonn, Rheinisches Landesmuseum, inv. no. 1043

BIBL.: FRIEDLÄNDER V, no. 25; HOOGEWERFF II, 209-10; DUDOK VAN HEEL 1999; Exh. cat. Utrecht 1999-2000, 237.

HISTORICAL INFORMATION: The couple has been identified as Jan Dirksz. Sill and Liesbeth Huigensdr. A little child is depicted behind Liesbeth. This might be a child who died at a young age. Coming from Marken, the Sill family had been established in Amsterdam since 1450. Jan Dirksz. is mentioned as alderman of the city in 1511. From 1510 to 1520 , he also held the role of churchwarden of the church of Our Lady and of the Nieuwekerk. Between 1522 and 1528, he was kapelmeester of the Heilige Stedekapel. In 1513, he founded five weekly masses at the altar of the Seven Sorrows of the Virgin at the Nieuwekerk, where his parents were buried. He had planned to be buried there as well, with his wife.

Identity of the sitter(s): Jan Dirksz. Sill and Liesbeth Huigensdr.

Provenance: Amsterdam, Nieuwekerk (?)

Number of portrait(s): 2

Type of person(s): lay (family with children)

Attitude of the sitter(s): hands clasped, holding a rosary

Representation of the sitter(s): full-length, child in small scale

Gaze of the sitter(s): into space

Object(s): yes (rosary) 
Coat(s) of arms: yes

Environment: landscape with sacred connotation

Structuring of the pictorial space: religious scene in a cloud

Patron saint(s): none

Gesture of the patron saint(s): not applicable

Type of religious scene: narrative

Religious scene(s) depicted: the Assumption of the Virgin

Cat. 458-Type 6A

Master of the Baroncelli Portraits

Fragments. Portrait of Pierantonio Bandini Baroncelli and Maria Bonciani in Prayer (c. 1490-1500)

$55 \times 31 \mathrm{~cm}$ (each panel)

Florence, Galleria degli Uffizi, inv. nos. 1836 and 8405

BIBL.: FRIEDLÄNDER VIa, no. 137; MARTENS D. 1995 (with bibl.).

HISTORICAL INFORMATION: Pierantonio Baroncelli was the successor of Tommaso Portinari as director of the Bruges branch of the Medici bank from 1480 onwards. He married Maria Bonciani in 1489 and died in 1499.

Identity of the sitter(s): Pierantonio Bandini Baroncelli and Maria Bonciani Provenance: unknown

Number of portrait(s): 2

Type of person(s): lay (couple)

Attitude of the sitter(s): hands clasped, holding a book

Representation of the sitter(s): indeterminate

Gaze of the sitter(s): indeterminate

Object(s): yes (book)

Coat(s) of arms: yes

Environment: architectural space, no sacred connotation (incomplete)

Structuring of the pictorial space: indeterminate

Patron saint(s): none

Gesture of the patron saint(s): not applicable

Type of religious scene: indeterminate

Religious scene(s) depicted: none

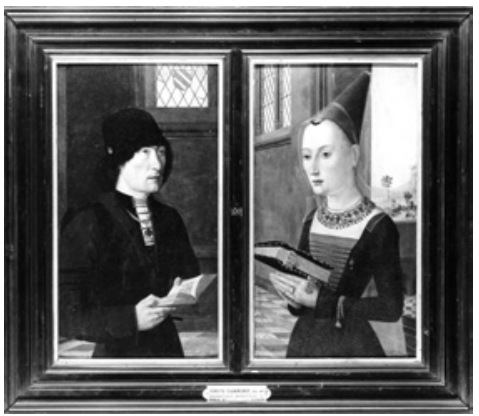


Cat. 459-Type 3D

Master of the Baroncelli Portraits

St. Catherine of Bologna with three Persons in Prayer (c. 1480-1490)

$91 \times 65 \mathrm{~cm}$

London, Courtauld Institute of Art, inv. no. 26 BIB L.:FRIEDLÄNDER VIa, no. 138; MARTENS D. 1995; KOSTER 1998.

HISTORICAL INFORMATION: The coat of arms painted on the curtain-rod in the background identifies the sitters as Giacomo Loiani and his two successive wives. The Genovese Loaini family maintained close relations with the Low Countries during the fifteenth century. As Martens has shown, the convent depicted in

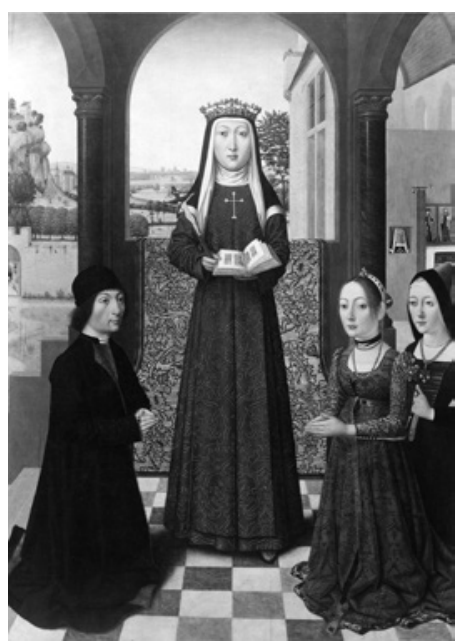
the work is the monastery of the Corpus Christi in Bologna, in which Catherine of Bologna lived until her death in 1463. After her death, her body was miraculously preserved and started to be the centre of a cult in Bologna. Around 1475, the body was placed in a tabernacle on wheels that could be observed from the church through a fenestrella. This fenced opening and the body of the saint are depicted on the centre panel, in the background.

Identity of the sitter(s): Giacomo di Giovanni Loiani and his two successive wives

Provenance: unknown

Number of portrait(s): 3

Type of person(s): lay (family)

Attitude of the sitter(s): hands clasped

Representation of the sitter(s): full-length

Gaze of the sitter(s): into space, towards the viewer

Object(s): no

Coat(s) of arms: yes

Environment: cloister

Structuring of the pictorial space: not applicable

Patron saint(s): none

Gesture of the patron saint(s): not applicable

Type of religious scene: hieratic

Religious scene(s) depicted: St. Catherine of Bologna 
Cat. 460-Type ${ }_{3} \mathrm{C}$

Master of the Baroncelli Portraits

The Descent of the Holy Ghost with a Couple in Prayer ('Rapaert Pentecost')

(c. 1490)

$102 \times 118.6 \mathrm{~cm}$

London, sale Christie's (7 December 2010), lot no. 8

BIBL.: FRIEDLÄNDER X, no. 14; MARTENS D. and MUND 2003 (with bibl.); Sale cat. Christie's

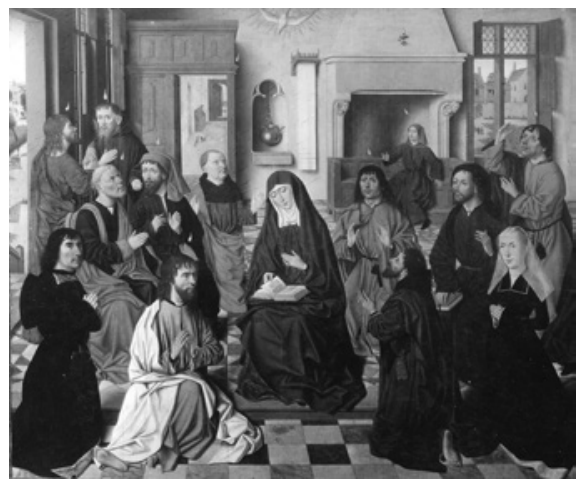
(London, 7 December 2010), no. 8.

REMARK: This panel is usually entitled the 'Rapaert Pentecost' because of the name of a previous owner. At the beginning of the seventeenth century, the panel was in the possession of the doctor Pieter Rapaert (1579-1635), who added a pair of wings with a portrait of himself, his wife Margriet de Badts and their children, around 1630 . The wings are nowadays preserved in a private collection. In 2012, the painting was exhibited at the TEFAF in Maastricht by Jean-Luc Baroni.

Identity of the sitter(s): unknown

Provenance: unknown

Number of portrait(s): 2

Type of person(s): lay (couple)

Attitude of the sitter(s): hands clasped

Representation of the sitter(s): full-length

Gaze of the sitter(s): into space

Object(s): no

Coat(s) of arms: no

Environment: historical setting

Structuring of the pictorial space: not applicable

Patron saint(s): none

Gesture of the patron saint(s): not applicable

Type of religious scene: narrative

Religious scene(s) depicted: the Descent of the Holy Spirit 
Cat. 461-Type $2 \mathrm{C}$

Master of the Baroncelli Portraits (attributed to)

Triptych of the Lamentation with a Couple in Prayer (c. 1480-1490)

Genoa, Palazzo Durazzo Pallavicini BIBL.: MARTENS D. 1995, 86; FRIEDLÄNDER V, no. $7 \mathrm{~d}$; FRIEDLÄNDER VIb, add. 265.

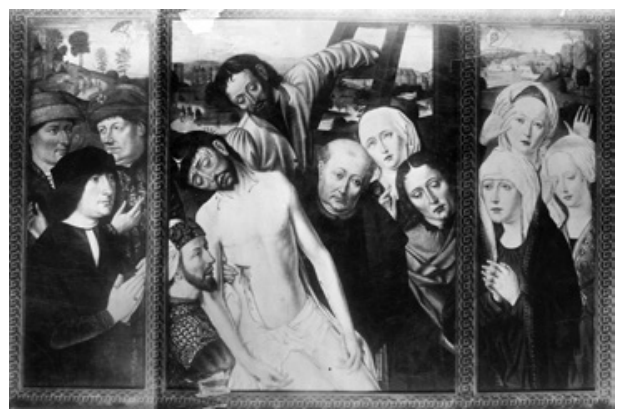

Identity of the sitter(s): unknown

Provenance: unknown

Number of portrait(s): 2

Type of person(s): lay (couple)

Attitude of the sitter(s): hands clasped

Representation of the sitter(s): half-length

Gaze of the sitter(s): towards the scene

Object(s): no

Coat(s) of arms: yes

Environment: historical setting

Structuring of the pictorial space: continuous space

Patron saint(s): none

Gesture of the patron saint(s): not applicable

Type of religious scene: narrative

Religious scene(s) depicted: none

Cat. 462 - Type 4 B

Master of the Brünswick Diptych Diptych of the Virgin and Child with St. Anne and a Monk in Prayer with St. Barbara (c. 1475-1500)

$35 \times 23 \mathrm{~cm}$ (each wing)

Brünswick, Herzog Anton UlrichMuseum, inv. no. 13

BIBL.: FRIEDLÄNDER V, no. 16; HOOGEWERFF II, 194-95; VAN LUTTERVELT 1951; SANDERS
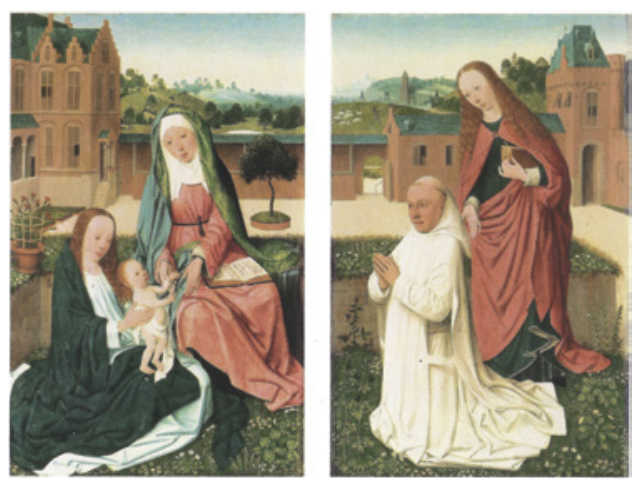
1990, 49-50; Exh. cat. Roermond 2009, 53-55. 
HistoricAl INFORMATION: Taking into account the presence of St. Bavo (patron saint of Haarlem) and the Virgin of the Visitation (the patron saint of Geertruidenberg), the Carthusian monk depicted in this diptych might be Hendrik van Haarlem. Hendrik was prior of the charterhouse of Amsterdam from 1484 to 1490 and of the charterhouse of Geertruidenberg from 1490 to 1499. He died on 16 April 1506.

Identity of the sitter(s): Hendrik van Haarlem (?)

Provenance: Charterhouse of Amsterdam or of Gertruidenberg (?)

Number of portrait(s): 1

Type of person(s): religious (man alone: Carthusian monk)

Attitude of the sitter(s): hands clasped

Representation of the sitter(s): full-length

Gaze of the sitter(s): towards the scene

Object(s): no

Coat(s) of arms: no

Environment: cloister

Structuring of the pictorial space: continuous space

Patron saint(s): Barbara

Gesture of the patron saint(s): introducing

Type of religious scene: hieratic

Religious scene(s) depicted: the Virgin and Child with St. Anne, St. Bavo

\section{Cat. 463-Type 2D}

Master of the Family of St. Anne Triptych of the Family of St. Anne with a Nun in Prayer (c. 1475-1500) $88 \times 94 \mathrm{~cm}($ centre panel) and $88 \times$ $39 \mathrm{~cm}$ (wings)

Ghent, MSK, inv. no. S-106 BIBL.: HULIN DE LOO 1939; Exh.

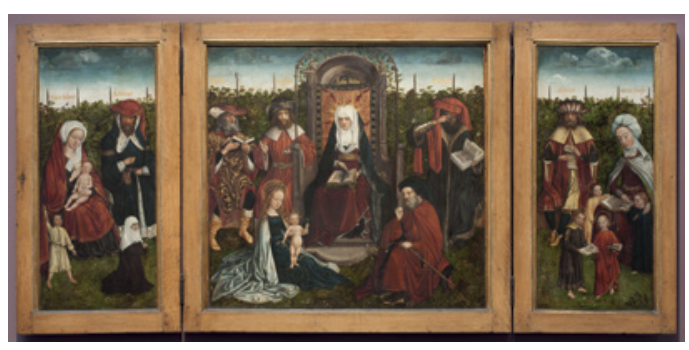
cat. Ghent 1975, no. 31; DHANENS 1987; DE PATOUL and VAN SCHOUTE 1994, 520-21.

Identity of the sitter(s): unknown

Provenance: unknown

Number of portrait(s): 1

Type of person(s): religious (woman alone)

Attitude of the sitter(s): hands clasped

Representation of the sitter(s): full-length, small scale

Gaze of the sitter(s): towards the scene 
Object(s): no

Coat(s) of arms: no

Environment: enclosed garden

Structuring of the pictorial space: continuous space

Patron saint(s): none

Gesture of the patron saint(s): not applicable

Type of religious scene: hieratic

Religious scene(s) depicted: the Family of St. Anne

\section{Cat. 464-Type 2B}

Master of the Family of St. Anne Triptych of the Family of St. Anne with two Persons in Prayer and Patron Saints (c. 1500-1510) $77 \times 58.5 \mathrm{~cm}$ (centre panel), $77 \times$ $28.7 \mathrm{~cm}$ (left wing) and $77 \times \mathbf{2 9 . 2}$ $\mathrm{cm}$ (right wing)

Ghent, Msk, inv. no. 19o6-B BIBL.: EECKHOUT 1974; Exh.

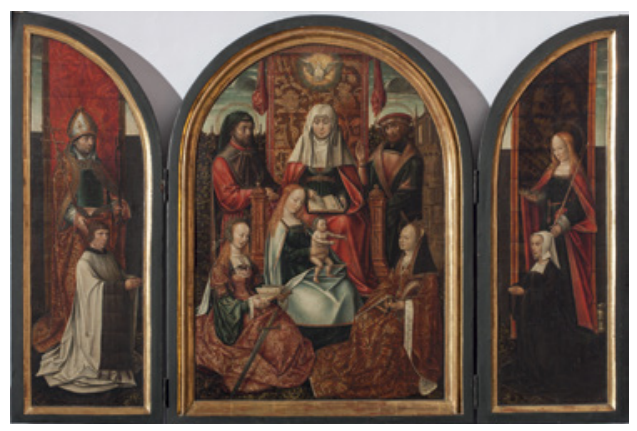
cat. Ghent 1975, no. 32 (with bibl.).

Identity of the sitter(s): unknown

Provenance: unknown

Number of portrait(s): 2

Type of person(s): mixed (group: canon, lay woman)

Attitude of the sitter(s): hands clasped

Representation of the sitter(s): full-length

Gaze of the sitter(s): into space

Object(s): no

Coat(s) of arms: no

Environment: enclosed garden

Structuring of the pictorial space: distinct spaces

Patron saint(s): Livinus of Ghent, Bridget of Sweden

Gesture of the patron saint(s): protecting

Type of religious scene: hieratic

Religious scene(s) depicted: the Family of St. Anne, St. Barbara, St. Catherine 
Cat. 465-Type $2 \mathrm{D}$

[RKD work no. 30224]

Master of the Female Half-Lengths

Triptych of the Virgin and Child with Two Persons in Prayer (1525-1550)

$12.8 \times 9.2 \mathrm{~cm}$ (centre panel) and $12.9 \times 3.7 \mathrm{~cm}$ (wings)

Cologne, Wallraf-Richartz Museum, inv. no. KGM A1063

BIB L.: FRIEDLÄNDER XII, no. 52; Mus. cat. Cologne 1969, 96; SCHADE 2001, 172-73 (with bibl.).

Identity of the sitter(s): unknown

Provenance: unknown

Number of portrait(s): 2

Type of person(s): religious (group)

Attitude of the sitter(s): hands clasped

Representation of the sitter(s): full-length

Gaze of the sitter(s): into space, towards the scene

Object(s): yes (prie-dieu, book)

Coat(s) of arms: no

Environment: ecclesial space

Structuring of the pictorial space: distinct spaces

Patron saint(s): none

Gesture of the patron saint(s): not applicable

Type of religious scene: hieratic

Religious scene(s) depicted: the Virgin and Child

Cat. 466-Type $3 \mathrm{D}$

Master of the Fountain of Life

The Fountain of Life ('Epitaph of Jan Clemensz.')

(before 1511)

$90.5 \times 73.5 \mathrm{~cm}$

Prague, Narodni Galerie, inv. no. DO-4131

BIBL.: Repertory Czechoslovakia, no. 34 (with bibl.); Mus. cat. Prague 1999, no. 83 (with bibl.); Exh. cat. Utrecht 1999-2000, 153 .

HISTORICAL INFORMATION: The inscription on the frame indicates that the panel is a memo-

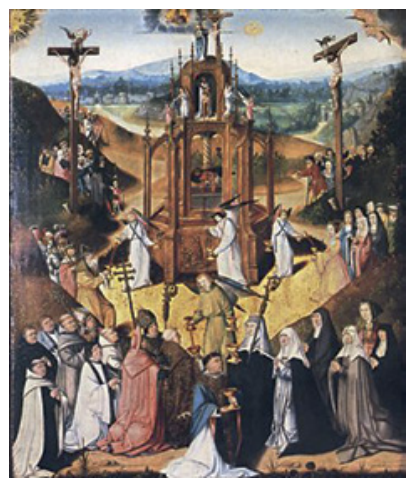
rial painting dedicated to Jan Clemensz., who passed away in 1511: Int iaer ons 
heren m. V. en. XI. Den XIIIden dach in iulo op S. Margarieten dach sterf heer / Ian Clemenssoen. Ons Pater was Bidt voir Zyn ziel. Amen. The term 'ons pater' suggests that he was the rector of the convent in which he was buried, as suggested by Truus van Bueren.

Identity of the sitter(s): Jan Clemensz.

Provenance: unknown

Number of portrait(s): 1

Type of person(s): religious (man alone: Carmelite monk)

Attitude of the sitter(s): hands clasped

Representation of the sitter(s): full-length

Gaze of the sitter(s): towards the scene

Object(s): no

Coat(s) of arms: no

Environment: landscape with sacred connotation

Structuring of the pictorial space: not applicable

Patron saint(s): none

Gesture of the patron saint(s): not applicable

Type of religious scene: hieratic

Religious scene(s) depicted: the Fountain of Life

\section{Cat. 467 -Type $3 \mathrm{C}$}

Master of the Fountain of Life

The Mass of St. Gregory with a Group of People in Prayer (c. 1510)

$90.5 \times 77 \mathrm{~cm}$

Kreuzlingen, Heinz Kisters collection

BIBL.: Exh. cat. Zurich and Cologne 1994, no. 98 (with bibl.); GORMANS and LENTES 2007, 124.

Identity of the sitter(s): unknown

Provenance: unknown

Number of portrait(s): 6

Type of person(s): mixed (unidentified group)

Attitude of the sitter(s): hands clasped

Representation of the sitter(s): full-length

Gaze of the sitter(s): into space, towards the scene 
Object(s): yes (hat)

Coat(s) of arms: no

Environment: historical setting

Structuring of the pictorial space: not applicable

Patron saint(s): none

Gesture of the patron saint(s): not applicable

Type of religious scene: narrative

Religious scene(s) depicted: the Mass of St. Gregory

\section{Cat. 468-Type ${ }_{3} \mathrm{C}$}

Master of the Fountain of Life

The Mass of St. Gregory with a Man in Prayer

(c. 1500-1510)

$92.1 \times 78.1 \mathrm{~cm}$

Utrecht, Museum Catharijneconvent, inv. no. RMCC s 194

BIBL.: Exh. cat. Utrecht 1999-2000, 155-56;

Mus. cat. Utrecht 2002, 64-65 (with bibl.).

Identity of the sitter(s): unknown

Provenance: unknown

Number of portrait(s): 1

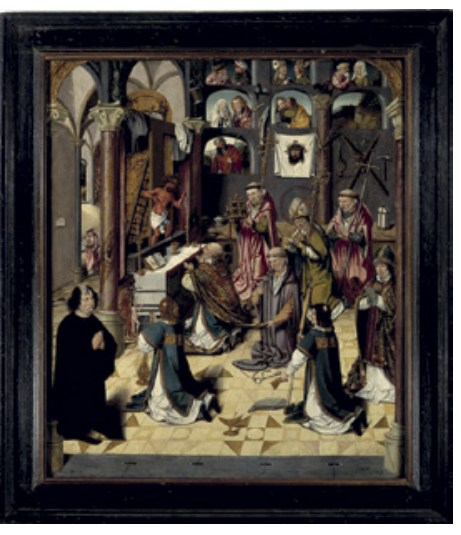

Type of person(s): lay (man alone)

Attitude of the sitter(s): hands clasped

Representation of the sitter(s): full-length

Gaze of the sitter(s): towards the scene

Object(s): no

Coat(s) of arms: no

Environment: historical setting

Structuring of the pictorial space: not applicable

Patron saint(s): none

Gesture of the patron saint(s): not applicable

Type of religious scene: narrative

Religious scene(s) depicted: none 
Cat. 469 -Type ${ }_{3} \mathrm{C}$

Master of the Fountain of Life

The Works of Mercy with a Family in

Prayer (c. 1510)

$65 \times 110 \mathrm{~cm}$

Enschede, Rijksmuseum Twenthe, inv. no. 39

BIBL.: Mus. cat. Enschede 19741976, no. 117 (with bibl.).

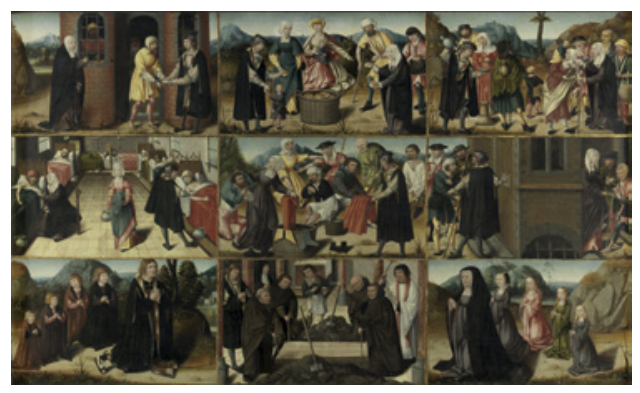

Identity of the sitter(s): unknown

Provenance: unknown

Number of portrait(s): 10

Type of person(s): lay (family with children)

Attitude of the sitter(s): hands clasped

Representation of the sitter(s): full-length

Gaze of the sitter(s): towards the scene

Object(s): no

Coat(s) of arms: no

Environment: landscape, no sacred connotation

Structuring of the pictorial space: fragmentation of the pictorial space

Patron saint(s): none

Gesture of the patron saint(s): not applicable

Type of religious scene: narrative

Religious scene(s) depicted: the Seven works of Mercy

Cat. 470-Type 6A

Master of the Guild of St. George

Fragment. Portrait of Jan van Mol in Prayer (c. 1490-1498)

$43 \times 18 \mathrm{~cm}$ (now reduced at $29.8 \mathrm{~cm} \times 18 \mathrm{~cm}$ )

London, Courtauld Institute of Art, inv. no. 18

BIBL.: FRIEDLÄNDER IV, no. 108; PERIER D'IETEREN

1971.

HISTORICAL INFORMATION: Jan van Mol was a magistrate in Mechelen in the early sixteenth century.

Identity of the sitter(s): Jan van Mol

Provenance: unknown

Number of portrait(s): 1

Type of person(s): lay (man alone)

Attitude of the sitter(s): hands clasped

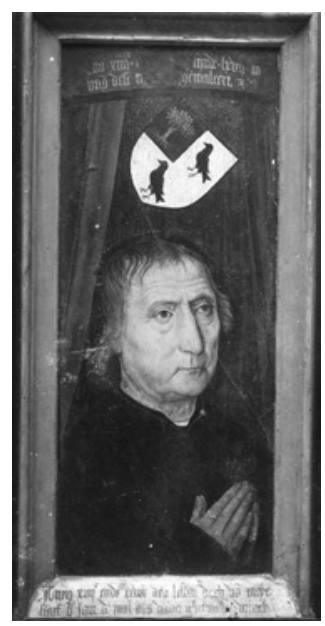


Representation of the sitter(s): indeterminate

Gaze of the sitter(s): indeterminate

Object(s): no

Coat(s) of arms: no

Environment: neutral space (incomplete)

Structuring of the pictorial space: indeterminate

Patron saint(s): none

Gesture of the patron saint(s): not applicable

Type of religious scene: indeterminate

Religious scene(s) depicted: none

Cat. 471-Type 6A

Master of the Guild of St. George

Fragment. Portrait of the Lord of Bricquegny in

Prayer (c. 1504)

$27.3 \times 18 \mathrm{~cm}$

Ghent, de Spiegelaere collection

BIBL.: PERIER D'IETEREN 1971.

HISTORICAL INFORMATION: The sitter is the Lord of Bricquegny who, from 1504 onwards, was clerk at the Grand conseil in Mechelen and then Ordinary Secretary of the Conseil, from 1508 onwards.

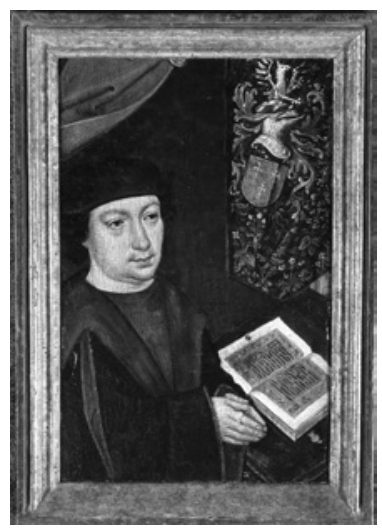

REMARK: The panel is a fragment from a larger work. The upper right part with the tapestry is an addition to the original fragment.

Identity of the sitter(s): Lord of Bricquegny

Provenance: unknown

Number of portrait(s): 1

Type of person(s): lay (man alone)

Attitude of the sitter(s): hands clasped

Representation of the sitter(s): indeterminate

Gaze of the sitter(s): indeterminate

Object(s): yes (prie-dieu, book)

Coat(s) of arms: yes

Environment: indeterminate

Structuring of the pictorial space: indeterminate

Patron saint(s): an unidentified saint

Gesture of the patron saint(s): protecting 
Type of religious scene: indeterminate

Religious scene(s) depicted: none

Cat. 472-Type $3^{B}$

Master of the Guild of St. George

The Members of the Guild of the Large Crossbow of Mechelen in Prayer before St. George (c. 1495-1498)

$105 \times 74 \mathrm{~cm}$

Antwerp, KMSK, inv. no. 818

BIBL.: FRIEDLÄNDER IV, no. 107;

Mus. cat. Antwerp 1985, 84-90 (with bibl.).

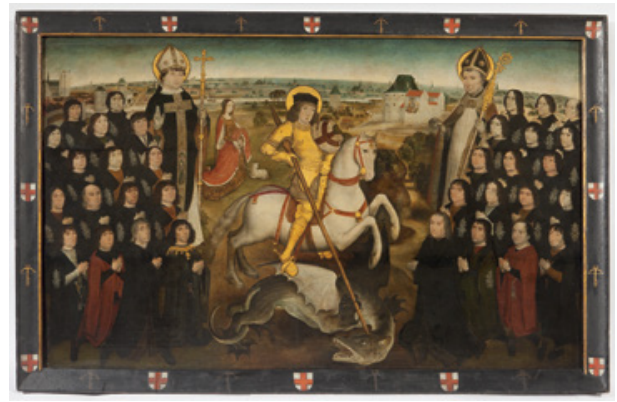

HISTORICAL INFORMATION: The painting shows the members of the Guild of the Large Crossbow of Mechelen in prayer in front of St. George, who is modelled on Philip the Fair. The princess in the background looks like Joanna of Castile, and the city in the background is Mechelen. The painting commemorates the members of the guild who fought with Charles the Bold in Neuss between 25 August 1474 and 18 June 1475. The man in the upper right corner holds in his hands the charter of privileges, accorded by the Duke of Burgundy to the people of Mechelen to thank them for their support during this fight.

Identity of the sitter(s): members of the Guild of the Large Crossbow of Mechelen

Provenance: Mechelen, house of the Guild of St. George

Number of portrait(s): 33

Type of person(s): lay (group: association)

Attitude of the sitter(s): hands clasped, holding a parchment

Representation of the sitter(s): full-length

Gaze of the sitter(s): into space, towards the scene

Object(s): no

Coat(s) of arms: yes (on the frame)

Environment: landscape, no sacred connotation

Structuring of the pictorial space: not applicable

Patron saint(s): saint bishops

Gesture of the patron saint(s): holding his/her attribute

Type of religious scene: hieratic

Religious scene(s) depicted: St. George 
Cat. 473-Type $2 B$

Master of the Guild of St. George

Triptych of the Holy Kinship with a Family in

Prayer and Patron Saints (c. 1450-1500)

$67.5 \times 104 \mathrm{~cm}$ (open)

Nantes, Musée départemental Dobrée, inv.

no. 896.1 .3807

BIBL.: MARTENS D. 2003.

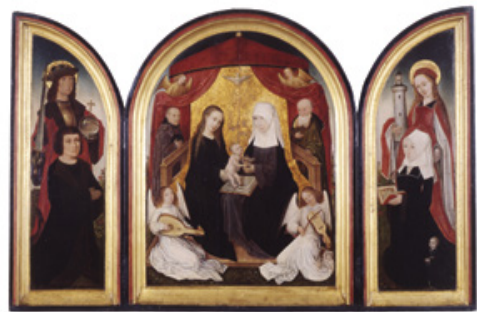

HISTORICAL INFORMATION: The depicted family has not been identified, but the attribution of the work to the Master of the Guild of St. George suggests that the family comes from Mechelen, where the artist was active. The presence of St. Clare and St. Francis could indicate a Franciscan location.

Identity of the sitter(s): unknown

Provenance: unknown

Number of portrait(s): 3

Type of person(s): lay (family with children)

Attitude of the sitter(s): hands clasped, holding a book

Representation of the sitter(s): full-length

Gaze of the sitter(s): into space

Object(s): yes (book)

Coat(s) of arms: no

Environment: landscape with sacred connotation

Structuring of the pictorial space: distinct spaces

Patron saint(s): Henry, Barbara

Gesture of the patron saint(s): holding his/her attribute, introducing

Type of religious scene: hieratic

Religious scene(s) depicted: the Holy kinship, St. Francis, St. Clare

Cat. 474-Type $1 B$

Master of the Holy Blood (or anonymous south Netherlandish master)

Polyptych of of the Seven Sorrows of the Virgin (c. 1520-1530)

$93 \times 402 \mathrm{~cm}$ (open)

Barcelona, Museu Frederic Marès, inv. no. MFM 1612 BIBL.: SANDALINAS LINARES et alii 2018 (with bibl.). 
REMARK: This polyptych has an unusual formar. The centre piece and the wings are convex. This characteristic is typical of pillar paintings but these usually don't have wings. Sandalinas Linares et alii 2018 suggest that this work "was designed to be fixed not on an independent pillar but to a helf-column attached to a wall" (124).

Identity of the sitter(s): unknown

Provenance: unknown

Number of portrait(s): 1

Type of person(s): religious (man alone: Carmelite monk)

Attitude of the sitter(s): hands clasped

Representation of the sitter(s): full-length

Gaze of the sitter(s): into space

Object(s): yes (hat)

Coat(s) of arms: no

Environment: neutral space

Structuring of the pictorial space: unified space with discontinuities, grisaille

Patron saint(s): John the Evangelist

Gesture of the patron saint(s): introducing

Type of religious scene: hieratic

Religious scene(s) depicted: the Seven Sorrows of the Virgin, the Ecce Homo, the Mater Dolorosa, St. Mary Magdalen, St. John the Baptist

Cat. 475 -Type $2 \mathrm{~A}$

[RKD work no. 17315]

Master of the Holy Blood

Triptych of the Adoration of the Magi with a Family in Prayer and Patron Saints

(c. 1500-1550)

$93.3 \times 65.3 \mathrm{~cm}$ (centre panel) and $93.3 \times 30 \mathrm{~cm}$ (wings)

London, sale Christie's (1o December 1993), lot no. 36

BIB L.: FRIEDLÄNDER IXb, no. 190.

Identity of the sitter(s): unknown

Provenance: unknown

Number of portrait(s): 4

Type of person(s): lay (family with children)

Attitude of the sitter(s): hands clasped 
Representation of the sitter(s): full-length, children in small scale

Gaze of the sitter(s): into space

Object(s): yes (prie-dieu, book, rosary)

Coat(s) of arms: no

Environment: historical setting

Structuring of the pictorial space: unified space with discontinuities

Patron saint(s): James, Catherine

Gesture of the patron saint(s): introducing

Type of religious scene: narrative

Religious scene(s) depicted: the Adoration of the Magi

Cat. 476 - Type $2 \mathrm{D}$

Master of the Holy Blood

Triptych of the Deipara Virgo with two

Friars in Prayer (c. 1500-1510)

$286.5 \times 223 \mathrm{~cm}$ (open)

Bruges, church of St. James

BIBL.: FRIEDLÄNDER IXb, no. 195;

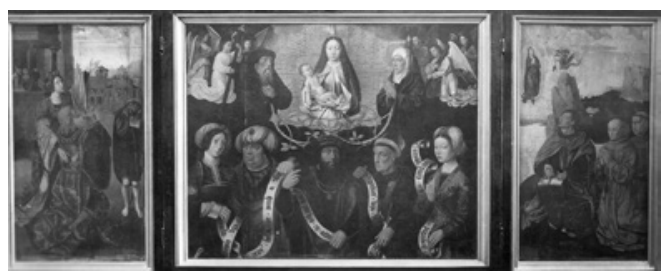

Exh. cat. Bruges 1998 (vol. 2), no. 31

(with bibl.).

Identity of the sitter(s): unknown

Provenance: Bruges, Franciscan church (?)

Number of portrait(s): 2

Type of person(s): religious (group: Franciscan friars)

Attitude of the sitter(s): hands clasped

Representation of the sitter(s): full-length

Gaze of the sitter(s): into space, towards the scene

Object(s): no

Coat(s) of arms: no

Environment: historical setting

Structuring of the pictorial space: distinct spaces

Patron saint(s): none

Gesture of the patron saint(s): not applicable

Type of religious scene: hieratic

Religious scene(s) depicted: August and the Tiburtine Sibyl, the Deipara

Virgo, St. John in Patmos 
Cat. 477 - Type 2 B

Master of the Holy Blood

Triptych of the Virgin and Child with Saints and a Couple in Prayer with Patron Saints (1509-1529)

$87.5 \times 66 \mathrm{~cm}$ (centre panel) and $88.5 \times 28 \mathrm{~cm}$ (wings)

Bruges, Groeningemuseum, inv. no. 91.8

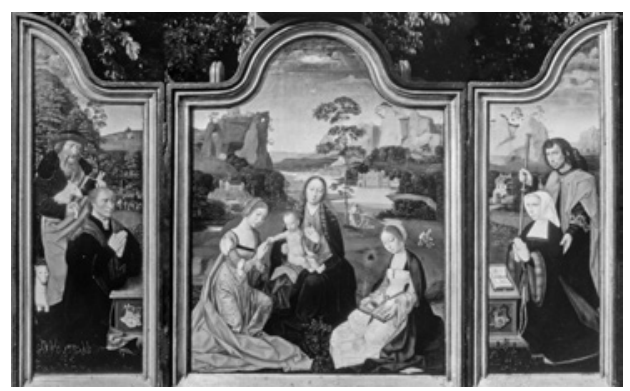

BIBL.: VAN DEN BERGEN-PANTENS 1976; DE VOS 1994, 242-44; Exh. cat. Bruges 1998 (vol. 2), no. 32 (with bibl.).

HISTORICAL INFORMATION: The portrayed persons are Joachim Christiaens and his wife Jossine Lampsins. The male portrait is nevertheless not original. It covers the portrait of Jan van Cattenbrouk, Jossine's first husband. After Jan's death in 1529, Jossine replaced his portrait with the one of her second husband. Coming from Templeuve, Joachim Christiaens is frequently mentioned in the accounts of the Provostship of St. Donatian in Bruges between 1535 and $155^{2}$. He was councillor of the city of Bruges and reneur (that is alderman of the 'Proosche', a part of the Provostship). This status allowed him to be buried with his wife in 1552, in the church of St. Donatian.

Identity of the sitter(s): Jan van Cattenbrouck (originally Joachim Christiaens) and Jossine Lamsins

Provenance: Bruges, church of St. Donatian (St. Michael's altar?)

Number of portrait(s): 2

Type of person(s): lay (couple)

Attitude of the sitter(s): hands clasped

Representation of the sitter(s): full-length

Gaze of the sitter(s): towards the scene

Object(s): yes (book, rosary, prie-dieu)

Coat(s) of arms: yes

Environment: landscape with sacred connotation

Structuring of the pictorial space: unified space with discontinuities

Patron saint(s): Joachim (previously John the Baptist), Josse

Gesture of the patron saint(s): introducing, holding his/her attribute

Type of religious scene: hieratic

Religious scene(s) depicted: the Virgin and Child with St. Catherine, St. Barbara, the Annunciation 
Cat. 478 -Type $2 B$

Master of the Holy Blood (attributed to) (centre panel) and Master of the Legend of the Magdalen (attributed to) (wings)

Triptych of the Virgin and Child with two Men in Prayer and Patron Saints (1500-1525) $44 \times 35 \mathrm{~cm}$ (centre panel) and

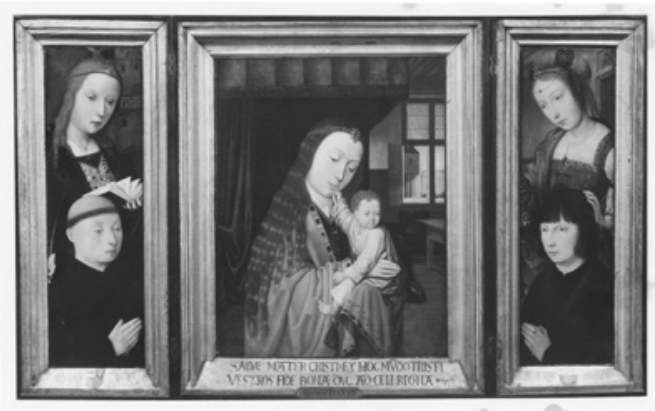
$47 \times 15 \mathrm{~cm}$ (wings)

Paris, sale Drouot (25 February 1939), lot no. 1

Identity of the sitter(s): unknown

Provenance: unknown

Number of portrait(s): 2

Type of person(s): mixed (unidentified group)

Attitude of the sitter(s): hands clasped

Representation of the sitter(s): half-length

Gaze of the sitter(s): into space

Object(s): no

Coat(s) of arms: no

Environment: domestic setting

Structuring of the pictorial space: unified space with discontinuities

Patron saint(s): Barbara, Mary Magdalen

Gesture of the patron saint(s): introducing, protecting

Type of religious scene: hieratic

Religious scene(s) depicted: the Virgin and Child

Cat. 479 - Type $3 \mathrm{C}$

Master of the Joseph Sequence (also known as Master of the Affligem Abbey) Triptych of the Affligem Abbey (c. 1495)

$144.5 \times 86 \mathrm{~cm}$ (left part of the centre panel), $144 \times 85 \mathrm{~cm}$ (right part of the centre panel), $148 \times 58.5$ (left part of the left inner wing), $147.5 \times 60 \mathrm{~cm}$ (right part of the left inner wing), $148 \times 59 \mathrm{~cm}$ (left part of the right inner wing), $148 \times 59 \mathrm{~cm}$ (right part of the right inner wing), $151 \times 118 \mathrm{~cm}$ (left outer wing) and $148 \times 120$ $\mathrm{cm}$ (right outer wing) 
Brussels, MRBAB, inv. nos. 344-345-347-348-349-350-351-352-353-354

BIBL.: FRIEDLÄNDER V, no. 80; PAUWELS 1994-1995; STROO et alii 2006, 26-67 (with bibl.); Exh. cat. Brussels 2013, no. 30.

HISTORICAL INFORMATION: This triptych dedicated to the Seven Sorrows of the Virgin comes from the church of the Benedictine abbey of Affligem. The Benedictine monk depicted on the panel of the Bearing of the cross is sometimes identified as Gijsbrecht van Marselaer, who had been ordained priest in 1460. After the death of the abbot Goossen Herdinckx in 1493, the monks of Affligem elected Van Marselaer as the new abbot of the community, but he refused this position and recommended that they choose Willem Michiels instead. It has been argued that the altarpiece was a commission of Willem, in order to express his gratitude towards Gijsbrecht. These are only hypotheses, which cannot be confirmed by any means.

REMARK: This now dismembered and partially preserved altarpiece was originally composed as a triptych. The work has been divided into ten elements, eight of them having been preserved. The missing pieces formed the right part of the centre panel and probably depicted the Descent from the cross.

Identity of the sitter(s): Gijsbrecht van Marselaer?

Provenance: Church of the Benedictine abbey of Affligem, choir of Our Lady

Number of portrait(s): 1

Type of person(s): religious (man alone: Benedictine monk)

Attitude of the sitter(s): hands clasped

Representation of the sitter(s): full-length

Gaze of the sitter(s): into space

Object(s): no

Coat(s) of arms: no

Environment: landscape, no sacred connotation

Structuring of the pictorial space: not applicable

Patron saint(s): none

Gesture of the patron saint(s): not applicable

Type of religious scene: narrative

Religious scene(s) depicted: the Presentation in the temple, Christ among the doctors, the Crucifixion, the Entombment, the Mourners at Christ's tomb, the Presentation of the Virgin in the temple, the Annunciation, the Nativity, the Adoration of the magi 
Cat. 480 - Type ${ }_{3} \mathrm{C}$

Master of the Legend of St. Barbara

Epitaph of Janne Colijns (c. 1490-1500)

$56 \times 54 \mathrm{~cm}$

Berlin, Staatliche Museen zu Berlin, Gemäldegalerie, inv. no. 2129

BIBL.: FRIEDLÄNDER IV, supp. 114; Exh. cat. Brussels 1994, 51-52; Mus. cat. Berlin 1996, no. 745; Exh. cat. Bonn and Essen 2005, 486 (with bibl.).

HISTORICAL INFORMATION: This painting is the epitaph of Janne Colijns,

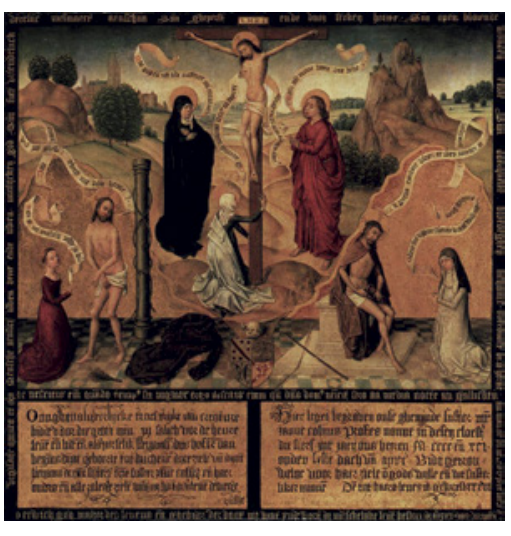
the prioress of the Augustinian Onze lieve Vrouw ter Rosen gheplant in Jericho Convent in Brussels, which belonged to the Congregation of Windesheim. Born in 1453-1454 into a noble family of Veurne (the church depicted in the background might be the church of St. Nicholas in that city), Janne entered the convent of Jherico in 1461. She took the habit in 1468-1469. Between 1481 and 1483 , she was appointed procurator, before being chosen as the prioress on 16 June 1486. Janne is also known for her activity as a scribe: she wrote several manuscripts for her convent and for people from the outside (including the prior of the Premonstratensian abbey of Grimbergen and the monastery of Groenendaal). She notably wrote a compilation of forty-four sermons delivered by Jan Storm between 1468 and 1474 (see STOOP 2013, 90-103). Janne Colijns passed away in April 1491, at the age of thirty-seven.

REMARK: the sitter is portrayed twice.

Identity of the sitter(s): Janne Colijns

Provenance: Brussels, Onze lieve Vrouw ter Rosen gheplant in Jericho Convent Number of portrait(s): 2 (twice the same person)

Type of person(s): religious (woman alone: Augustinian canoness)

Attitude of the sitter(s): hands clasped

Representation of the sitter(s): full-length

Gaze of the sitter(s): towards the scene

Object(s): yes (banderole)

Coat(s) of arms: yes

Environment: landscape with sacred connotation

Structuring of the pictorial space: not applicable

Patron saint(s): none

Gesture of the patron saint(s): not applicable

Type of religious scene: hieratic

Religious scene(s) depicted: the Crucifixion, the Ecce Homo, Christ at the Column 
Cat. 481-Type 6A

Master of the Legend of St. Barbara

Portrait of a Couple in Prayer (c. 1490-1500)

$40 \times 28 \mathrm{~cm}$

Banbury, Upton House, collection of the Viscount Bearsted (National Trust)

BIBL.: FRIEDLÄNDER, supp. 115; Exh. cat. Brussels 2013, no. 59 (with bibl.).

Identity of the sitter(s): unknown

Provenance: unknown

Number of portrait(s): 2

Type of person(s): lay (couple)

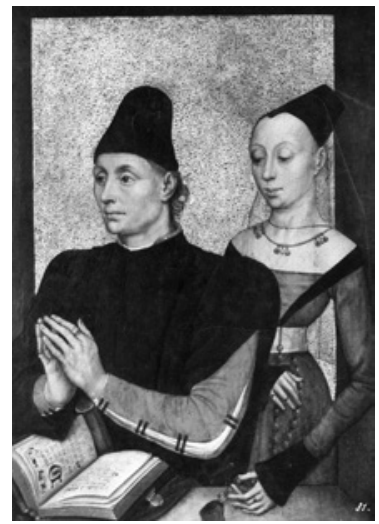

Attitude of the sitter(s): hands clasped, particular gesture

Representation of the sitter(s): half-length

Gaze of the sitter(s): indeterminate

Object(s): yes (book, rosary)

Coat(s) of arms: no

Environment: neutral space (incomplete)

Structuring of the pictorial space: indeterminate

Patron saint(s): none

Gesture of the patron saint(s): not applicable

Type of religious scene: indeterminate

Religious scene(s) depicted: none

\section{Cat. 482-Type $2 \mathrm{C}$}

Master of the Legend of St. Barbara

Triptych of the Adoration of the Magi with Members of a Guild in Prayer (c. 1480)

$92 \times 96 \mathrm{~cm}($ centre panel) and $90 \times 42 \mathrm{~cm}$ (wings)

Rome, Casa Colonna (centre panel) and New York, MET, inv. no. 32.100.56A (wings) BIBL.: FRIEDLÄNDER IV, no. 68, add. 152; GIBSON 1965; AINSWORTH and CHRISTIANSEN 1998, 120-22 (with bibl.). HISTORICAL INFORMATION: The sitters

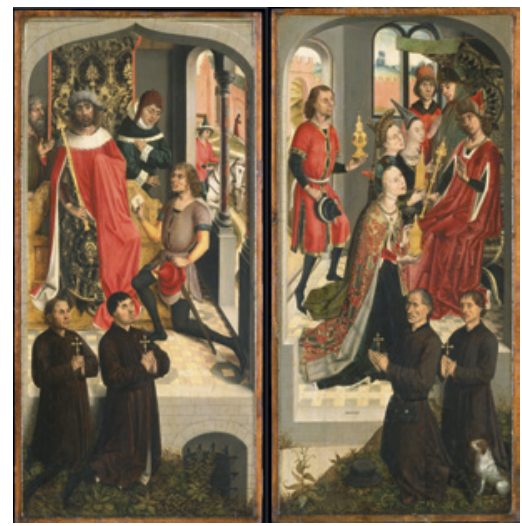
are all wearing the same clothes. They are probably members of a guild or a brotherhood. 
Identity of the sitter(s): unknown (members of a guild or a brotherhood)

Provenance: unknown

Number of portrait(s): 4

Type of person(s): lay (group: association)

Attitude of the sitter(s): holding a small cross

Representation of the sitter(s): full-length

Gaze of the sitter(s): towards the scene

Object(s): yes (dog, small cross)

Coat(s) of arms: no

Environment: historical setting

Structuring of the pictorial space: distinct spaces

Patron saint(s): none

Gesture of the patron saint(s): not applicable

Type of religious scene: narrative

Religious scene(s) depicted: the Adoration of the Magi, the Annunciation, Abner's Messenger before David (?), the Queen of Sheba Bringing Gifts to Solomon

\section{Cat. 483 - Type $2 B$}

[Link to the Friedländer 3.o Database]

Master of the Legend of St. Barbara

Triptych of the Holy Kinship with a Couple in Prayer and Patron Saints (c. 1490-1500)

$68 \times 27 \mathrm{~cm}$ (each wing), oil on wood and carved piece

Bamberg, Senger Bamberg Kunsthandel

BIBL.: FRIEDLÄNDER IV, no. 61.

Identity of the sitter(s): unknown

Provenance: unknown

Number of portrait(s): 2

Type of person(s): lay (couple)

Attitude of the sitter(s): hands clasped

Representation of the sitter(s): full-length

Gaze of the sitter(s): towards the scene

Object(s): no

Coat(s) of arms: yes

Environment: landscape, no sacred connotation

Structuring of the pictorial space: distinct spaces (different techniques: painting/sculpture)

Patron saint(s): Henry, James (?) 
Gesture of the patron saint(s): introducing, protecting

Type of religious scene: hieratic

Religious scene(s) depicted: the Holy kinship

Cat. 484-Type 3A

[RKD work no. 53084]

Master of the Legend of St. Catherine

The Marriage of the Virgin with a Man in Prayer (c. 1475-1500)

$45 \times 29 \mathrm{~cm}$

Madrid, Museo Nacional del Prado, inv. no. 2706

BIBL.: BERMEJO 1980, 160.

Identity of the sitter(s): unknown

Provenance: unknown

Number of portrait(s): 1

Type of person(s): lay (man alone)

Attitude of the sitter(s): hands clasped

Representation of the sitter(s): full-length

Gaze of the sitter(s): into space

Object(s): no

Coat(s) of arms: no

Environment: historical setting

Structuring of the pictorial space: not applicable

Patron saint(s): none

Gesture of the patron saint(s): not applicable

Type of religious scene: narrative

Religious scene(s) depicted: the Marriage of the Virgin, the Man of Sorrows

Cat. 485-Type $2 \mathrm{~A}$

Master of the Legend of St. Catherine Triptych of the Descent of the Cross with a Man in Prayer and Patron Saint (c. 1475-1500)

$129 \times 94 \mathrm{~cm}($ centre panel) and $129 \times$ $43 \mathrm{~cm}$ (wings)

Cologne, Wallraf-Richartz Museum (loan of the Franciscan monastery of Cologne), deposit no. 29

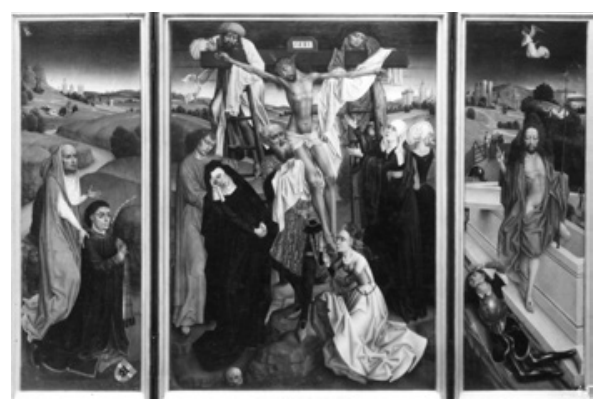


BIBL.: FRIEDLÄNDER IV, no. 51; Mus. cat. Cologne 1969, 81-82; STEYAERT 2016.

Identity of the sitter(s): unknown

Provenance: unknown

Number of portrait(s): 1

Type of person(s): religious (man alone: canon)

Attitude of the sitter(s): hands clasped

Representation of the sitter(s): full-length

Gaze of the sitter(s): towards the scene

Object(s): no

Coat(s) of arms: yes

Environment: historical setting

Structuring of the pictorial space: unified space with discontinuities

Patron saint(s): Jerome

Gesture of the patron saint(s): introducing

Type of religious scene: narrative

Religious scene(s) depicted: the Descent from the cross, the Resurrection of Christ, the Annunciation

\section{Cat. 486-Type $2 B$}

[Link to the Friedländer 3.o Database]

Master of the Legend of St. Catherine (after?)

Triptych of the Virgin and Child with Saints and a Man in Prayer (c. 1473-1481)

$87 \times 71 \mathrm{~cm}$ (centre panel) and $87 \times 32 \mathrm{~cm}$ (wings)

S'Heerenberg, Estate of the late Dr. J. H. Van Heck

BIBL.: FRIEDLÄNDER IV, no. 54a; MARTENS D. 1997; Exh. cat. Brussels 2013, no. 39 (with bibl.).

HISTORICAL INFORMATION: The patron saint Idelfonso suggests that the man depicted could be of Spanish origin, but his identity remains unknown

Identity of the sitter(s): unknown

Provenance: unknown

Number of portrait(s): 1

Type of person(s): lay (man alone)

Attitude of the sitter(s): hands clasped

Representation of the sitter(s): full-length

Gaze of the sitter(s): towards the scene

Object(s): yes (dog)

Coat(s) of arms: no 
Environment: ecclesial space

Structuring of the pictorial space: distinct spaces

Patron saint(s): Idelfonso

Gesture of the patron saint(s): holding his/her attribute

Type of religious scene: hieratic

Religious scene(s) depicted: the Virgin and Child with saints, the Mass of

St. Gregory, the Annunciation

Cat. 487-Type 6A

Master of the Legend of St.

Catherine and Master of the Legend of St. Barbara

Four Wings of the 'Job Altarpiece'

(c. 1485-1490)

$118 \times 87 \mathrm{~cm}$ (each panel)

Cologne, Wallraf-Richartz Museum, inv. nos. 409-412

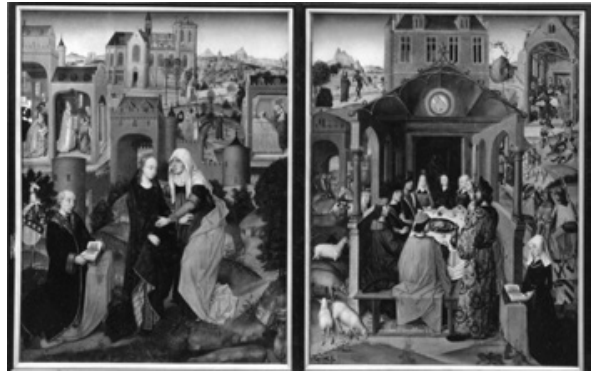

BIBL.: FRIEDLÄNDER IV, no. 69; HOOGEWERFF I, 488-89; Mus. cat. Cologne 1969, 82-86; Exh. cat. Leuven 2009, 348.

HISTORICAL INFORMATION: These panels contain the coat of arms of the da Villa family from Villastellone, a place in the surroundings of Torino. This family of bankers and merchants was composed of three branches in the fifteenth century. The branches of Claudio da Villa ( $†$ 1483-86) and of Domenico da Villa possessed the same coat of arms, but with distinct crownings (a dragon for Claudio's family and a unicorn for Domenico's). It has long been assumed that the persons depicted on these panels are Claudio da Villa and his wife Gentina Solaro. Nevertheless, the unicorn above the coats of arms suggests that they are Domenico's son Petrino and his wife. Indeed, in 1489, Petrino founded a chapel dedicated to Job in the church of St. Augustine of Chieri.

Identity of the sitter(s): Petrino da Villa and his wife

Provenance: Chieri, church of St. Augustine, St. Job's chapel (?)

Number of portrait(s): 2

Type of person(s): lay (couple)

Attitude of the sitter(s): hands clasped, holding a book

Representation of the sitter(s): full-length

Gaze of the sitter(s): indeterminate

Object(s): yes (prie-dieu, book) 
Coat(s) of arms: yes

Environment: historical setting

Structuring of the pictorial space: indeterminate

Patron saint(s): none

Gesture of the patron saint(s): not applicable

Type of religious scene: narrative

Religious scene(s) depicted: the Visitation, the Life of St. Peter, the Life of Job, St. Peter, Job, St. Mary Magdalen, the Virgin and Child

\section{Cat. 488-Type 1 -}

Master of the Legend of St. Godelieve Altarpiece of the Legend of St. Godelieve (c. 1475-1500)

$125.1 \times 311 \mathrm{~cm}($ open$)$ and $125.1 \times 160.7 \mathrm{~cm}$ (closed)

New York, MET, inv. no. 12.79

BIBL.: AINSWORTH and CHRISTIANSEN 1998, 125-28 (with bibl.).

HISTORICAL INFORMATION: This altar-

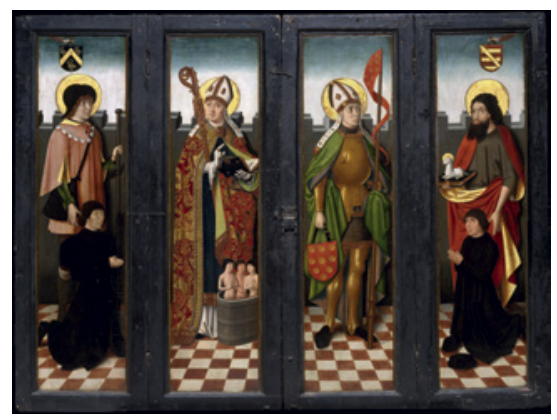

piece might be a commission of the Load Bearers' Guild in Bruges, whose patron saint was Godelieve, for their chapel in the church of Our Lady.

Identity of the sitter(s): Guild of the Load Bearers in Bruges (?)

Provenance: Bruges, church of Our Lady (?)

Number of portrait(s): 2

Type of person(s): lay (group: association)

Attitude of the sitter(s): hands clasped

Representation of the sitter(s): full-length

Gaze of the sitter(s): into space

Object(s): no

Coat(s) of arms: yes

Environment: architectural space with sacred connotation

Structuring of the pictorial space: continuous space

Patron saint(s): Josse, John the Baptist

Gesture of the patron saint(s): introducing

Type of religious scene: hieratic

Religious scene(s) depicted: the Legend of St. Godelieve, St. Nicholas, St. Quirinus 


\section{Cat. 489-Type $1 B$}

Master of the Legend of St. Lucy Altarpiece of the Virgin of the Black Heads Brotherhood (before 1493) $255 \times 166 \mathrm{~cm}$ (open) and $255 \times 75 \mathrm{~cm}$ (closed)

Tallinn, Niguliste Museum BIBL.: FRIEDLÄNDER VIb, add. 278; VERHAEGEN 1961; MÄND 2000; MÄND 2007 (with bibl.).

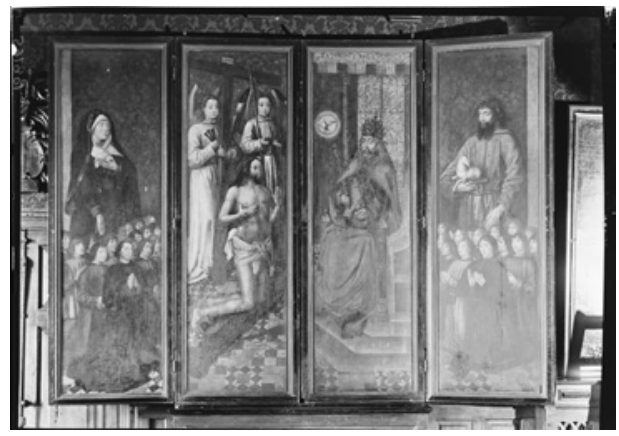

HISTORICAL INFORMATION: This triptych was commissioned by the Brotherhood of the Black Heads of Tallinn. This brotherhood was composed of unmarried and foreign merchants and was mostly active in Estonia and Latvia, with more than twenty houses. The account book of the brotherhood's altars for the period 1418-1517 contains an entry for the Carnival of 1493 stating that a member of the Great Guild (which was related to the brotherhood) and a town councillor brought from the West after transit through Lübeck an altarpiece destined for the Dominican church of St. Catherine in Tallinn. Half of the cost of the altarpiece's transportation was paid by the guild. According to Mänd, this mention can be related to the present altarpiece and the commission took place before 1488. The Black Heads of Tallinn founded at the beginning of the fifteenth century two altars at the Dominican church of St. Catherine: the first one was dedicated to the Virgin and the second to the Holy Trinity. Most probably, this triptych was destined for the first of these. Two wardens were in charge of the maintenance of these altars and these were usually members of the Great Guild, which did not have its own altar in the church and used the Balck heads' ones. It is thus possible that these wardens of the Great Guild are portrayed among the Black Heads. In 1524, because of the Reformation, the brotherhood's members decided to move the altarpiece to their house, where it stayed until World War II. The archives of the brotherhood mention several works of art that could be identified as the altarpiece of the Virgin, but none can be related to it with certainty (see MÄND 200o).

Identity of the sitter(s): Brotherhood of the Black Heads of Tallinn

Provenance: Tallin, Dominican church, chapel of the Black Heads

Brotherhood

Number of portrait(s): 30 
Type of person(s): lay (group: association)

Attitude of the sitter(s): hands clasped

Representation of the sitter(s): full-length, small scale

Gaze of the sitter(s): into space, towards the ground, towards the scene

Object(s): no

Coat(s) of arms: no

Environment: architectural space with sacred connotation

Structuring of the pictorial space: distinct spaces

Patron saint(s): John the Baptist

Gesture of the patron saint(s): interceding

Type of religious scene: intercession

Religious scene(s) depicted: the Virgin and Child, the Intercession of Christ, the Virgin, St. John the Baptist

\section{Cat. 490-Type 2A}

Master of the Legend of St. Lucy

Triptych of the Lamentation with a couple in Prayer and Patron saints (c. 1480-85) $176 \mathrm{~cm} \times 290 \mathrm{~cm}$ (open)

Private collection (on loan at the Groeningemuseum, Bruges)

Identity of the sitter(s): unknown

Provenance: unknown

Number of portrait(s): 2

Type of person(s): lay (couple)

Attitude of the sitter(s): hands clasped

Representation of the sitter(s): full-length

Gaze of the sitter(s): into space

Object(s): no

Coat(s) of arms: no

Environment: historical setting

Structuring of the pictorial space: continuous space

Patron saint(s): Dominic, Francis

Gesture of the patron saint(s): holding his/her attribute

Type of religious scene: narrative

Religious scene(s) depicted: the Lamentation, St. Dominic, St. Francis,

St. Anthony, St. Bernardin of Siena 
Cat. 491-Type 2A

Master of the Legend of St. Lucy

Triptych of the Lamentation with a Couple in Prayer and Patron Saints ('De Moore Triptych') (shortly before 1480)

$75 \times 61 \mathrm{~cm}($ centre panel) and $75 \times$ $27 \mathrm{~cm}$ (wings)

Lugano, Fundación Colección

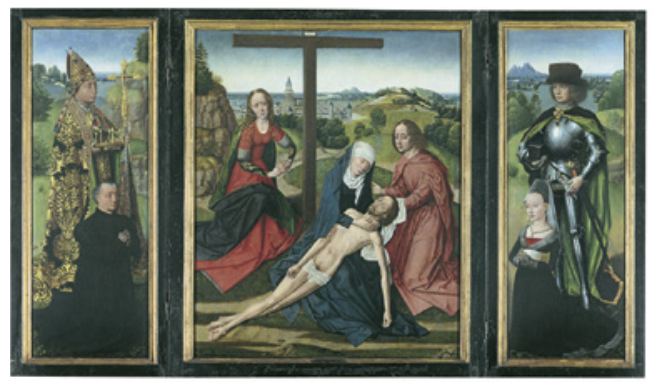

Thyssen-Bornemisza, inv. nos. 1930.67. (1, 2a, 2B, 3a, 3b)

BIBL.: FRIELÄNDER VIb, supp. 239; EISLER 1989, no. 11; MARTENS M. 1992a, 264-66.

Historical information: The triptych shows Donas de Moore and his wife Adrienne de Vos. They have been identified, on the basis of their coats of arms (now erased). Donas was a member of the high nobility of Bruges. He made a political career and held several important positions between 1447 and 1481, before being banned from the city because of his collaboration with Maximilian. Donas was the founder of the Moore Hospital. He was also a generous benefactor to his parish church of St. James, to which he donated stalls, a high altar and stained-glass windows. He founded with his wife the St. Donatian and St. Adrian's chapel. In all likelihood, the triptych was destined for this chapel, as suggested by the iconography. Donas de Moore passed away during his exile in Middelburg, on 9 September 1483. His wife arranged for his body to be brought back to Bruges. They were both buried under the high altar of the church.

Identity of the sitter(s): Donas de Moore and Adrienne de Vos

Provenance: Bruges, church of St. James, De Moore chapel (?)

Number of portrait(s): 2

Type of person(s): lay (couple)

Attitude of the sitter(s): hands clasped

Representation of the sitter(s): full-length

Gaze of the sitter(s): into space

Object(s): no

Coat(s) of arms: yes (erased during a restoration)

Environment: historical setting

Structuring of the pictorial space: unified space with discontinuities

Patron saint(s): Donatian, Adrian

Gesture of the patron saint(s): holding his/her attribute

Type of religious scene: narrative

Religious scene(s) depicted: the Lamentation 
Cat. 492-Type $2 B$

Master of the Legend of St. Lucy Triptych of the Virgin and Child Enthroned with Saints and a Man in Prayer (c. 1490-1500)

$80 \times 67.9 \mathrm{~cm}$ (centre panel) and 80 $\times 27.9 \mathrm{~cm}$ (wings)

Los Angeles, County Museum of Art, inv. nos. M. 69.54 a-c

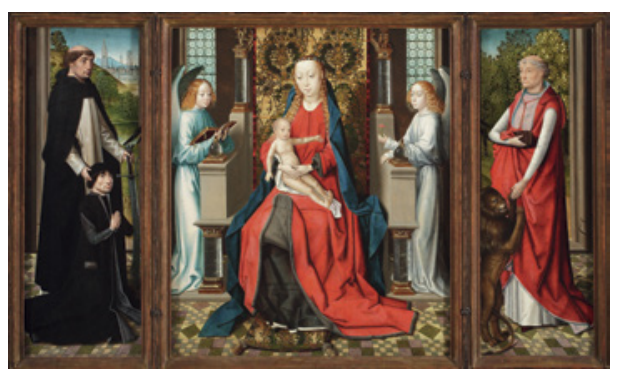

BIB L.: FRIEDLÄNDER VIa, no. 140; Corpus Los Angeles, 260-79 (with bibl.). Identity of the sitter(s): unknown

Provenance: unknown

Number of portrait(s): 1

Type of person(s): lay (man alone)

Attitude of the sitter(s): hands clasped

Representation of the sitter(s): full-length

Gaze of the sitter(s): into space

Object(s): no

Coat(s) of arms: no

Environment: architectural space with sacred connotation

Structuring of the pictorial space: continuous space

Patron saint(s): Peter Martyr

Gesture of the patron saint(s): protecting

Type of religious scene: hieratic

Religious scene(s) depicted: the Virgin and Child, St. Jerome

\section{Cat. 493-Type 6A}

[RKD work no. 105033]

Master of the Legend of St. Lucy

Two Wings. A Couple in Prayer with Patron Saints (c. 1490-1500)

$66 \times 22.5 \mathrm{~cm}$ (each wing)

Whereabouts unknown

BIBL.: FRIEDLÄNDER VIa, no. 143; MARTENS D. 2000, 67.

Identity of the sitter(s): unknown

Provenance: unknown

Number of portrait(s): 2

Type of person(s): lay (couple)

Attitude of the sitter(s): hands clasped

Representation of the sitter(s): full-length 
Gaze of the sitter(s): indeterminate

Object(s): yes (book)

Coat(s) of arms: no

Environment: landscape, no sacred connotation (incomplete)

Structuring of the pictorial space: indeterminate

Patron saint(s): Adrian, James

Gesture of the patron saint(s): introducing

Type of religious scene: indeterminate

Religious scene(s) depicted: none

\section{Cat. 494-Type $4 \mathrm{D}$}

Master of the Legend of St. Ursula

Diptych of Lodovico Portinari (c. 1479)

$51 \times 39.4 \mathrm{~cm}$ (left wing) and $41.4 \times 29.7 \mathrm{~cm}($ right wing)

Philadelphia, Philadelphia Museum of Art, inv. no. 1917 (right wing) and Cambridge, Harvard Art Museum, Fogg Museum, inv. no. 1943.07 (left wing)

BIB L.: FRIEDLÄNDER VIa, no. 122, 134; Corpus New England, no. 77; Exh. cat. Antwerp and Washington 2006, 9-10 (with bibl.).

HISTORICAL INFORMATION: The coat of arms

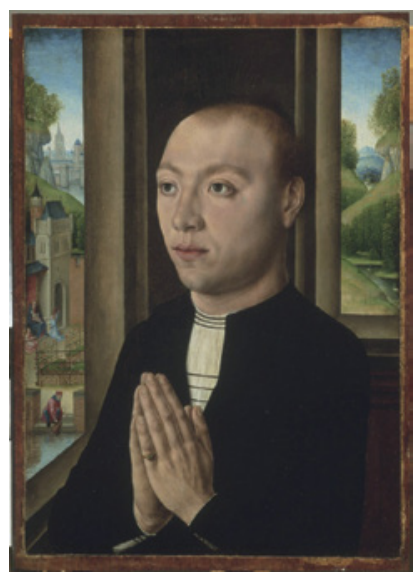
and the initials $L P$ on the reverse identify the sitter as Lodovico Portinari, who belonged to the Milanese branch of the Portinari family. He was the son of Pigello Portinari, Tommaso's brother (see cat. $5^{87}$ ).

Identity of the sitter(s): Lodovico Portinari

Provenance: unknown

Number of portrait(s): 1

Type of person(s): lay (man alone)

Attitude of the sitter(s): hands clasped

Representation of the sitter(s): half-length

Gaze of the sitter(s): into space

Object(s): no 
Coat(s) of arms: yes (on the reverse)

Environment: domestic setting

Structuring of the pictorial space: distinct spaces

Patron saint(s): none

Gesture of the patron saint(s): not applicable

Type of religious scene: hieratic

Religious scene(s) depicted: the Virgin and Child, the monogram of Christ

\section{Cat. 495-Type $4 \mathrm{D}$}

Master of the Legend of St. Ursula Diptych of the Virgin and Child with three Persons in Prayer (dated 1486 on the right wing) $28 \times 21 \mathrm{~cm}$ (each wing)

Antwerp, KMSK, inv. no.

5004-5004bis

\section{BIBL.: FRIEDLÄNDER VIa,}

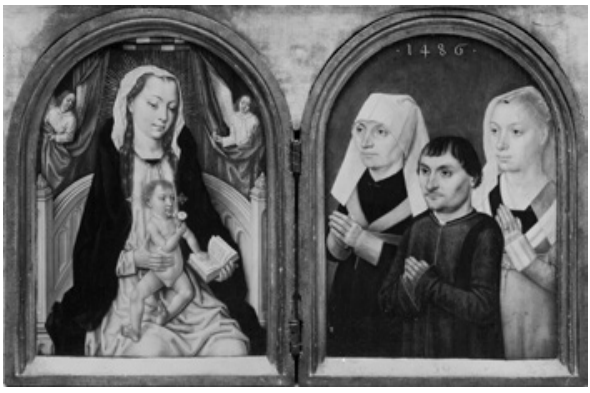

no. 116; Mus. cat. Antwerp 1985, 91-93; Mus. cat. Antwerp 1998, 500; Exh. cat. Antwerp and Washington 2006, no. 24 (with bibl.).

Identity of the sitter(s): unknown

Provenance: unknown

Number of portrait(s): 3

Type of person(s): lay (family)

Attitude of the sitter(s): hands clasped

Representation of the sitter(s): half-length

Gaze of the sitter(s): into space

Object(s): no

Coat(s) of arms: no

Environment: neutral space

Structuring of the pictorial space: distinct spaces

Patron saint(s): none

Gesture of the patron saint(s): not applicable

Type of religious scene: hieratic

Religious scene(s) depicted: the Virgin and Child 
Cat. 496-Type 6A

Master of the Legend of St. Ursula

Epitaph of Anna de Blasere (c. 1479)

$49.8 \times 34.3 \mathrm{~cm}$

New York, MET, inv. no. 1975.1.114

BIBL.: FRIEDLÄNDER VIa, no. 119; MARTENS M. 1992b; AINSWORTH and CHRISTIANSEN 1998, 176-78 (with bibl.). REMARK: The painting is preserved in its original frame, on which no trace of a hinge is observable. It has thus long been assumed that the painting was a single panel, and not the right wing of a diptych or a triptych as the absence of a religious scene

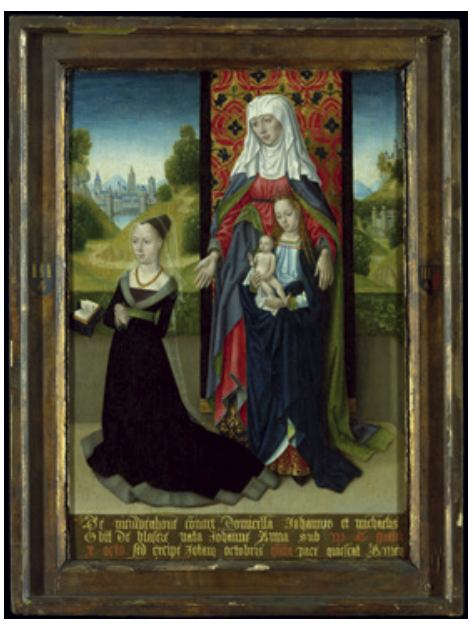
could suggest. According to Guy Bauman and Maximiliaan Martens, the work was destined for the chapel of the Van Nieuwenhove family at the church of Our Lady in Bruges, where it was integrated into a larger funerary setting. More recently, a radiograph of the panel and the frame was conducted and revealed traces of hinges on the left side of the frame. The panel was thus undoubtedly part of a diptych or a triptych.

Historical information: Anne de Blasere was the wife of Jan van Nieuwenhove, the brother of Maarten (see cat. 558). She died while giving birth at the age of twenty-one. As the inscription in the lower part of the panel indicates, the painting was her epitaph: De nieuwenhoue co $[n]$ iunx domicella Johannis et michaelis / Obit de blasere nata Johanne Anna sub.M.C.quater / $X \cdot o c t o \cdot s e d$ excipe iotam octobris.qui[n]ta.pace quiescat Amen. The panel and Anna's grave were located in the Van Nieuwenhove chapel in the church of Our Lady at Bruges.

Identity of the sitter(s): Anna de Blasere

Provenance: Bruges, church of Our Lady, Van Nieuwenhove chapel

Number of portrait(s): 1

Type of person(s): lay (woman alone)

Attitude of the sitter(s): hands clasped

Representation of the sitter(s): full-length

Gaze of the sitter(s): indeterminate

Object(s): yes (book)

Coat(s) of arms: yes

Environment: enclosed garden (incomplete)

Structuring of the pictorial space: indeterminate

Patron saint(s): Anne 
Gesture of the patron saint(s): introducing

Type of religious scene: indeterminate

Religious scene(s) depicted: none

Cat. 497-Type 6B

Master of the Legend of St. Ursula

Portrait of a Young Man in Prayer (1480)

$31.7 \times 21 \mathrm{~cm}$

New York, Rosenberg and Stiebel collection

BIB L.: Exh. cat. Bruges 1960, no. 5 .

Identity of the sitter(s): unknown

Provenance: unknown

Number of portrait(s): 1

Type of person(s): lay (man alone)

Attitude of the sitter(s): hands clasped

Representation of the sitter(s): half-length

Gaze of the sitter(s): indeterminate

Object(s): no

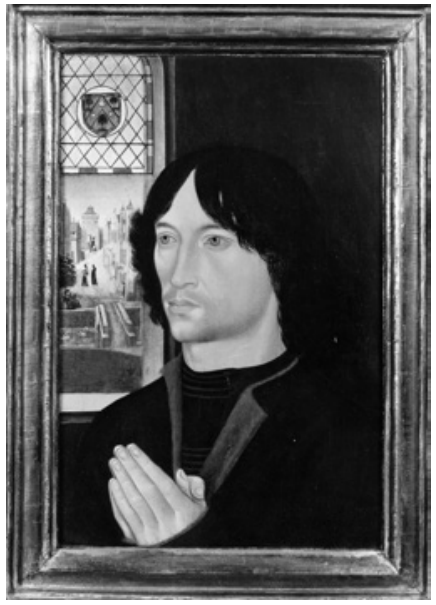

Coat(s) of arms: yes

Environment: domestic setting

Structuring of the pictorial space: indeterminate

Patron saint(s): none

Gesture of the patron saint(s): not applicable

Type of religious scene: indeterminate

Religious scene(s) depicted: memento mori

Cat. 498-Type $3^{D}$

Master of the Legend of St. Ursula

St. Michael Fighting the Demon with a Nun in Prayer

(c. 1450-1500)

$30 \times 19.5 \mathrm{~cm}$

Bruges, Our Lady of the Pottery

BIBL.: FRIEDLÄNDER VIb, add. 270; Exh. cat.

Bruges 1969, no. 4; Exh. cat. Bruges 1994, 205-06.

Identity of the sitter(s): unknown

Provenance: Bruges, Our Lady of the Pottery (?)

Number of portrait(s): 1

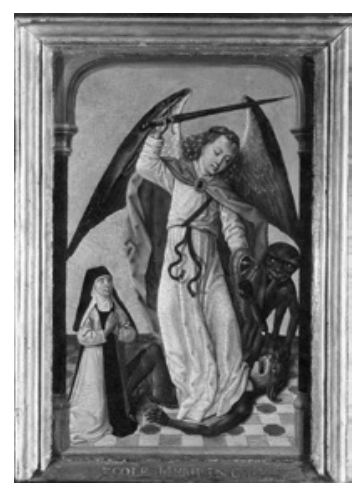

Type of person(s): religious (woman alone: Augustinian nun) 
Attitude of the sitter(s): hands clasped

Representation of the sitter(s): full-length, small scale

Gaze of the sitter(s): towards the scene

Object(s): no

Coat(s) of arms: no

Environment: architectural space, no sacred connotation

Structuring of the pictorial space: not applicable

Patron saint(s): none

Gesture of the patron saint(s): not applicable

Type of religious scene: hieratic

Religious scene(s) depicted: St. Michael fighting the demon

Cat. 499 - Type ${ }_{3} \mathrm{C}$

Master of the Legend of St. Ursula

The Christ on the Cross with a Man in Prayer

(c. 1475-1500)

$43 \times 33 \mathrm{~cm}$

Birmingham, Barber Institute of Fine Arts, inv. no. 60.8

BIBL.: FRIEDLÄNDER VIb, supp. 238; Exh.

cat. Nuremberg 1983, no. 488.

Identity of the sitter(s): unknown

Provenance: unknown

Number of portrait(s): 1

Type of person(s): lay (man alone)

Attitude of the sitter(s): hands clasped

Representation of the sitter(s): full-length

Gaze of the sitter(s): into space

Object(s): no

Coat(s) of arms: no

Environment: historical setting

Structuring of the pictorial space: not applicable

Patron saint(s): none

Gesture of the patron saint(s): not applicable

Type of religious scene: narrative

Religious scene(s) depicted: Christ on the cross 
Cat. 500-Type 2A

Master of the Legend of St. Ursula

Triptych of the Nativity with a Man in Prayer and Patron Saints (c. 1493-1499) $65 \times 52.8 \mathrm{~cm}$ (centre panel), $65.7 \times 24.5 \mathrm{~cm}$ (left wing) and $65 \times 24.2 \mathrm{~cm}$ (right wing) Detroit, Detroit Institute of Arts, inv. no. 59.122

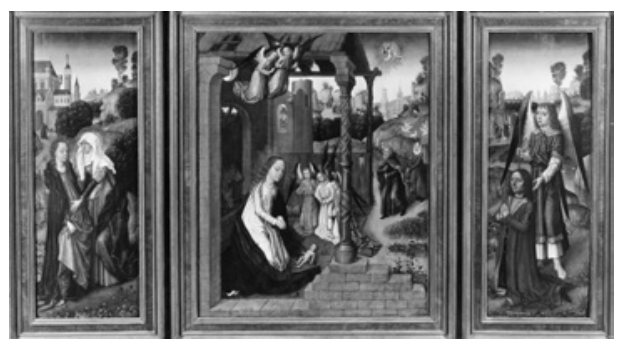

BIBL.: FRIEDLÄNDER VIa, no. 114; Exh. cat. Bruges 196o, no. 50; MARLIER 1964, 14, no. 5; FARIES et alii 1987.

Identity of the sitter(s): unknown

Provenance: unknown

Number of portrait(s): 1

Type of person(s): lay (man alone)

Attitude of the sitter(s): hands clasped

Representation of the sitter(s): full-length

Gaze of the sitter(s): towards the scene

Object(s): no

Coat(s) of arms: no

Environment: historical setting

Structuring of the pictorial space: unified space with discontinuities

Patron saint(s): Michael

Gesture of the patron saint(s): introducing

Type of religious scene: narrative

Religious scene(s) depicted: the Nativity, the Visitation

Cat. 501-Type $3 \mathrm{D}$

[R KD work no. 52453]

Master of the Legend of St. Ursula

Triptych of the Virgin and Child Enthroned with saints and a Man in Prayer (c. 1485-1490)

$44.5 \times 31 \mathrm{~cm}$ (centre panel) and $44.5 \times 13.5 \mathrm{~cm}$ (wings)

Dresden, Gemäldegalerie Alte Meister Staatliche Kunstsammlungen Dresden, inv. no. 3575

BIBL.: FRIEDLÄNDER VIa, no. 115; MARLIER 1964, 18, no. 3; SCHADE 2001, 142-43; Exh. cat. Dresden 2005, no. 70 (with bibl.). 
Identity of the sitter(s): unknown

Provenance: unknown

Number of portrait(s): 1

Type of person(s): religious (man alone)

Attitude of the sitter(s): hands crossed over the chest

Representation of the sitter(s): full-length, small scale

Gaze of the sitter(s): towards the scene

Object(s): no

Coat(s) of arms: no

Environment: architectural space with sacred connotation

Structuring of the pictorial space: not applicable

Patron saint(s): none

Gesture of the patron saint(s): not applicable

Type of religious scene: hieratic

Religious scene(s) depicted: the Virgin and Child, St. Catherine, St. Mary Magdalen, the Annunciation

Cat. 502-Type $2 B$

Master of the Legend of St. Ursula

Triptych of the Virgin and Child with a Man in Prayer and Patron Saint ('Pagagnotti Triptych') (c. 1485-1489)

$95 \times 28.5 \mathrm{~cm}$ (each wing)

Cherbourg, Musée Thomas Henry (centre panel) and New York, MET, inv. nos. 32.100.63 A-B (wings)

BIBL.: FRIEDLÄNDER VIa, no. 117; MARLIER 1964, no. 28;AINSWORTH and CHRISTIANSEN 1998, 122-24 (with bibl.).

HISTORICAL INFORMATION: The centre panel contains the coat of arms of the Pagagnotti family. The man on the left wing is Paolo Pagagnotti,

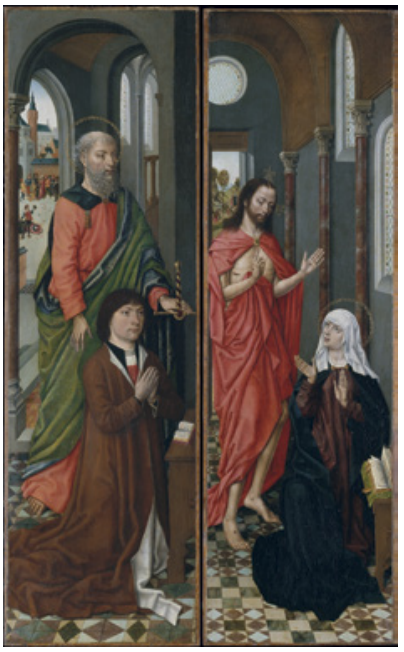
an Italian merchant, who commissioned the triptych in Bruges c. 1480.

Identity of the sitter(s): Paolo Pagagnotti

Provenance: unknown

Number of portrait(s): 1

Type of person(s): lay (man alone)

Attitude of the sitter(s): hands clasped 
Representation of the sitter(s): full-length

Gaze of the sitter(s): indeterminate

Object(s): yes (prie-dieu, book)

Coat(s) of arms: yes

Environment: architectural space with sacred connotation

Structuring of the pictorial space: distinct spaces

Patron saint(s): Paul

Gesture of the patron saint(s): introducing

Type of religious scene: hieratic

Religious scene(s) depicted: Christ appearing to his mother, the Virgin and child

\section{Cat. 503-Type 6A}

Master of the Legend of St. Ursula

Two Wings. A Family in Prayer with Patron Saints

(c. 1480-1490)

$50 \times 29 \mathrm{~cm}$

Amsterdam, Rijksmuseum, inv. no. SK-A-3326 (left wing) and whereabouts unknown (Amsterdam, sale L. Fournier, 24 June 1924) (right wing)

BIBL.: Mus. cat. Amsterdam 1976, 635; Mus. cat. Amsterdam 2009 [online], https://www.rijksmuseum .nl/nl/collectie/SK-A-3326/catalogus-entry (with bibl.).

Identity of the sitter(s): unknown

Provenance: unknown

Number of portrait(s): 8

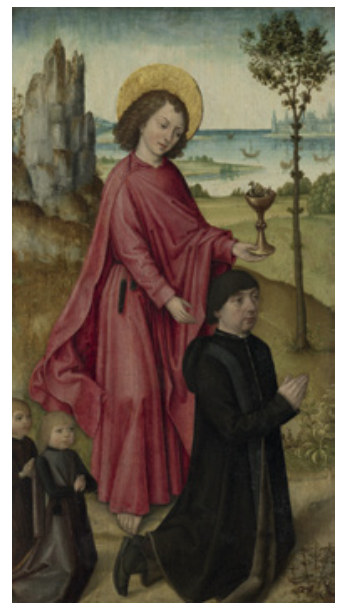

Type of person(s): lay (family with children)

Attitude of the sitter(s): hands clasped

Representation of the sitter(s): full-length

Gaze of the sitter(s): indeterminate

Object(s): yes (rosary, book)

Coat(s) of arms: no

Environment: landscape, no sacred connotation (incomplete)

Structuring of the pictorial space: indeterminate

Patron saint(s): John the Evangelist, Lidwina

Gesture of the patron saint(s): introducing

Type of religious scene: indeterminate

Religious scene(s) depicted: none 
Cat. 504-Type 6A

[RKD work no. 248005]

Master of the Legend of St. Ursula (attributed to)

The Holy Trinity with a Man in Prayer (c. 1490-1500)

$57.4 \times 40.1 \mathrm{~cm}$

Budapest, Szépmüvészeti Múzeum, inv. no. 3842

BIB L.: Mus. cat. Budapest 2000, 105; URBACH 2015 (vol. 2), no. 36 (with bibl.).

Identity of the sitter(s): unknown

Provenance: unknown

Number of portrait(s): 1

Type of person(s): lay (man alone)

Attitude of the sitter(s): hands clasped

Representation of the sitter(s): full-length

Gaze of the sitter(s): towards the scene

Object(s): no

Coat(s) of arms: no

Environment: landscape with sacred connotation (incomplete)

Structuring of the pictorial space: religious scene in a cloud

Patron saint(s): none

Gesture of the patron saint(s): not applicable

Type of religious scene: hieratic

Religious scene(s) depicted: the Holy Trinity

\section{Cat. 505-Type 3B}

Master of the Legend of St. Ursula (attributed to) The Virgin and Child with a Man in Prayer and St. Michael (c. 1450-1500)

$44.4 \times 34.2 \mathrm{~cm}$

London, sale Sotheby's (12 July 2001), lot no. 11

BIBL.: FRIEDLÄNDER VIb, Add. 271; Exh. cat. Bruges 1969, no. 5; Sale cat. Sotheby's (London, 12 July 2001), no. 11 (with bibl.).

Identity of the sitter(s): unknown

Provenance: unknown

Number of portrait(s): 1

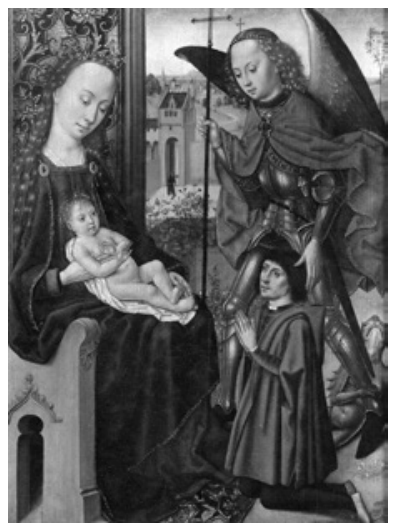

Type of person(s): lay (man alone)

Attitude of the sitter(s): hands clasped

Representation of the sitter(s): full-length, small scale

Gaze of the sitter(s): towards the scene 
Object(s): no

Coat(s) of arms: no

Environment: enclosed garden

Structuring of the pictorial space: not applicable

Patron saint(s): Michael

Gesture of the patron saint(s): introducing

Type of religious scene: hieratic

Religious scene(s) depicted: the Virgin and Child

Cat. 506-Type 6B

[RKD work no. 52516]

Master of the Legend of St. Ursula (or anonymous Bruges Master)

Portrait of a Young Man in Prayer (c. 1490-1500)

$24.3 \times 16 \mathrm{~cm}$

Providence, Rhode Island School of Design, Museum of Art, inv. no. 45.042

BIBL.: FRIEDLÄNDER VIb, supp. 137.

Identity of the sitter(s): unknown

Provenance: unknown

Number of portrait(s): 1

Type of person(s): lay (man alone)

Attitude of the sitter(s): hands clasped

Representation of the sitter(s): half-length

Gaze of the sitter(s): indeterminate

Object(s): no

Coat(s) of arms: no

Environment: neutral space (incomplete)

Structuring of the pictorial space: indeterminate

Patron saint(s): none

Gesture of the patron saint(s): not applicable

Type of religious scene: indeterminate

Religious scene(s) depicted: none

Cat. 507-Type 6A

[RKD work no. 49240]

Master of the Legend of the Magdalen

One Wing. A Couple in Prayer (c. 1490-1510)

$54 \times 27.3 \mathrm{~cm}$

Cambridge, Fitzwilliam Museum, inv. no. 2549 
BIB L.: Exh. cat. Cambridge 1993, no. 7.

Identity of the sitter(s): unknown

Provenance: unknown

Number of portrait(s): 2

Type of person(s): lay (couple)

Attitude of the sitter(s): hands clasped

Representation of the sitter(s): half-length

Gaze of the sitter(s): indeterminate

Object(s): no

Coat(s) of arms: no

Environment: landscape, no sacred connotation (incomplete)

Structuring of the pictorial space: indeterminate

Patron saint(s): none

Gesture of the patron saint(s): not applicable

Type of religious scene: indeterminate

Religious scene(s) depicted: none

Cat. 508-Type 6A

Master of the Legend of the Magdalen

One Wing. The Kiss of Judas with a Nun in Prayer

(c. 1480-1537)

$122 \times 66 \mathrm{~cm}$

London, Cyril Andrade collection

вIB L.: FRIEDLÄNDER XII, no. 16.

Identity of the sitter(s): unknown

Provenance: unknown

Number of portrait(s): 1

Type of person(s): religious (woman alon)

Attitude of the sitter(s): hands clasped

Representation of the sitter(s): full-length

Gaze of the sitter(s): indeterminate

Object(s): no

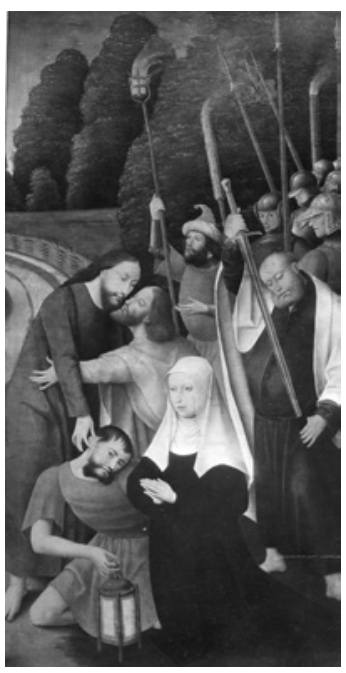

Coat(s) of arms: no

Environment: historical setting (incomplete)

Structuring of the pictorial space: indeterminate

Patron saint(s): none

Gesture of the patron saint(s): not applicable 
Type of religious scene: narrative

Religious scene(s) depicted: The Kiss of Judas

Cat. 509-Type 6B

Master of the Legend of the Magdalen

Portrait of a Man in Prayer (c. 1500)

$33.7 \times 23.4 \mathrm{~cm}$

Enschede, Rijksmuseum Twenthe, inv. no. 25

BIBL.: Mus. cat. Enschede 1974-1976, no. 118 (with bibl.).

Identity of the sitter(s): unknown

Provenance: unknown

Number of portrait(s): 1

Type of person(s): lay (man alone)

Attitude of the sitter(s): hands clasped

Representation of the sitter(s): half-length

Gaze of the sitter(s): indeterminate

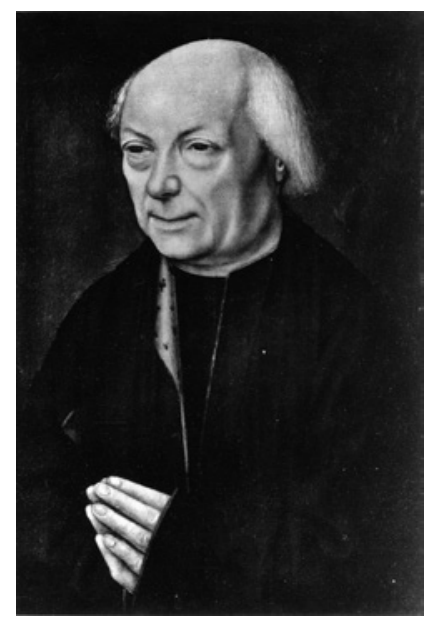

Object(s): no

Coat(s) of arms: no

Environment: neutral space (incomplete)

Structuring of the pictorial space: indeterminate

Patron saint(s): none

Gesture of the patron saint(s): not applicable

Type of religious scene: indeterminate

Religious scene(s) depicted: none

Cat. 510-Type 6A

[RKD work no. 48218]

Master of the Legend of the Magdalen

Portrait of a Man in Prayer (c. 1510-1520)

$37.1 \times 27.6 \mathrm{~cm}$

Philadelphia, Philadelphia Museum of Art, inv. no. 410

BIB L.: Mus. cat. Philadelphia 1913, no. 410; Mus. cat. Philadelphia 1994, 74.

Identity of the sitter(s): unknown

Provenance: unknown

Number of portrait(s): 1 
Type of person(s): lay (man alone)

Attitude of the sitter(s): hands clasped

Representation of the sitter(s): half-length

Gaze of the sitter(s): indeterminate

Object(s): no

Coat(s) of arms: no

Environment: neutral space (incomplete)

Structuring of the pictorial space: indeterminate

Patron saint(s): none

Gesture of the patron saint(s): not applicable

Type of religious scene: indeterminate

Religious scene(s) depicted: none

\section{Cat. 511-Type 6B}

[RKD work no. 49632]

Master of the Legend of the Magdalen

Portrait of a Man in Prayer with St. Paul (c. 1490-1510)

$35 \times 26 \mathrm{~cm}$

Berlin, sale Rudolph Lepke (22 March 1910), lot no. 37

Identity of the sitter(s): unknown

Provenance: unknown

Number of portrait(s): 1

Type of person(s): religious (man alone)

Attitude of the sitter(s): hands clasped

Representation of the sitter(s): indeterminate

Gaze of the sitter(s): indeterminate

Object(s): yes (banderole)

Coat(s) of arms: no

Environment: landscape, no sacred connotation (incomplete)

Structuring of the pictorial space: indeterminate

Patron saint(s): Paul

Gesture of the patron saint(s): protecting

Type of religious scene: indeterminate

Religious scene(s) depicted: the Virgin and Child with St. Anne 
Cat. 512-Type 6A

Master of the Legend of the Magdalen

Portrait of Katharina van der Stockt in Prayer (after 1520)

$34 \times 18.5 \mathrm{~cm}$

Münster, Landesmuseum für Kunst und Kulturgeschichte, inv. no. $15^{8}$

BIBL.: FRIEDLÄNDER XII, no. 15; Exh. cat. Bruges 1969, no. 75; Exh. cat. Brussels 2013, no. 91 (with bibl.). HISTORICAL INFORMATION: The inscription identifies the nun as Katharina van der Stockt. She is the granddaughter of the painter Vrancke van der Stockt. Katharina became a nun at the Hospital of St.

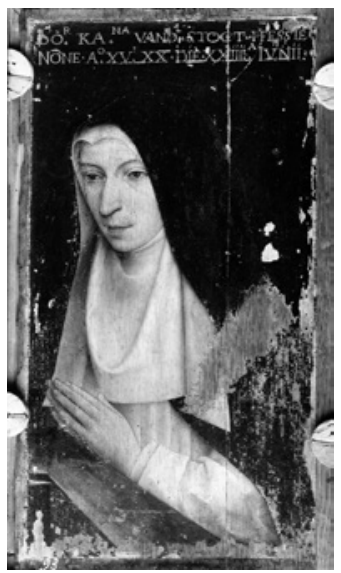

Elizabeth in Brussels on 24 June 1520. She might also appear in cat. $5^{28}$.

Identity of the sitter(s): Katharina van der Stockt

Provenance: unknown

Number of portrait(s): 1

Type of person(s): religious (woman alone: hospital nun)

Attitude of the sitter(s): hands clasped

Representation of the sitter(s): half-length

Gaze of the sitter(s): indeterminate

Object(s): yes (book)

Coat(s) of arms: no

Environment: neutral space (incomplete)

Structuring of the pictorial space: indeterminate

Patron saint(s): not applicable

Gesture of the patron saint(s): none

Type of religious scene: indeterminate

Religious scene(s) depicted: the Virgin of the Annunciation

\section{Cat. 513-Type 2B}

Master of the Legend of the Magdalen

Triptych of Our Lady of the Seven Sorrows with a Couple in Prayer ('Ashwellthorpe Triptych') (c. 1519) $82 \times 64 \mathrm{~cm}$ (centre panel) and 82 $\times 26 \mathrm{~cm}$ (wings)

Norfolk, Norwich Castle Museum

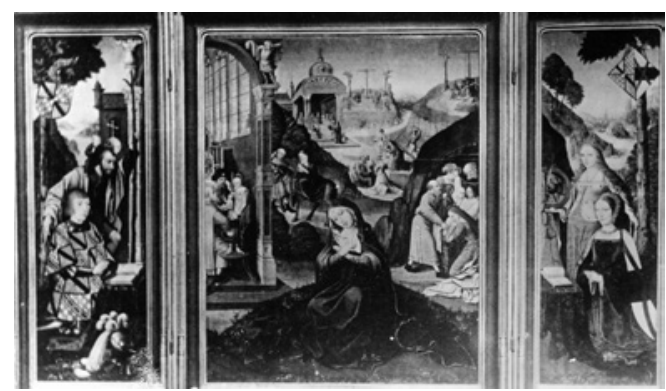
and Art Gallery, inv. no. NWHCM: 1983.46: F 
BIBL.: FRIEDLÄNDER XII, no. 9; MARTINDALE 1989 (with bibl.); DE VRIJ 2000, 20.

HISTORICAL INFORMATION: The coat of arms suspended above the man portrayed on the left wing belongs to the Knyvett family, from England. The depiction of St. Christopher enables us to identify the man as Christopher Knyvett, who worked in the service of the King of England: in 1512-1513, he travelled to the Low Countries, where he met Margaret of Austria and took part in a military campaign in Tournai, for which he received some land in 1515. From 1514 to 1520 , Christopher received a salary as a member of the royal house. The coat of arms of his wife is that of the Van Assche (or Van Grimberghen) family from Brabant. Several members of this family made a political career in the Low Countries. A description of the triptych, written c. 1700, mentions the presence of the date 1519 on the (now lost) frame.

Identity of the sitter(s): Christophe Knyvet of Ashwellthorpe and his wife

Provenance: unknown

Number of portrait(s): 2

Type of person(s): lay (couple)

Attitude of the sitter(s): hands clasped

Representation of the sitter(s): full-length

Gaze of the sitter(s): into space

Object(s): yes (prie-dieu, book, helmet)

Coat(s) of arms: yes

Environment: landscape with sacred connotation

Structuring of the pictorial space: unified space with discontinuities

Patron saint(s): Christopher, Catherine

Gesture of the patron saint(s): introducing

Type of religious scene: hieratic

Religious scene(s) depicted: the Virgin of the Seven Sorrows

Cat. 514-Type 2A

Master of the Legend of the Magdalen

Triptych of the Adoration of the Magi with a Couple in Prayer and Patron Saints (c. 1500-1550)

$75 \times 74 \mathrm{~cm}$ (centre panel) and $76.5 \times$ $31.5 \mathrm{~cm}$ (wings)

Oviedo, Museo de Bellas Artes de

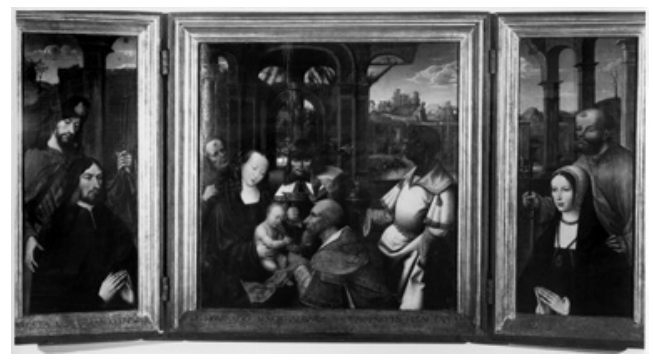
Asturias 
BIB L.: BERMEJO 1984; Exh. cat. Brussels 1985 (vol. 2), 478-79; Exh. cat. Leon and Palencia 1999, 192.

HISTORICAL INFORMATION: The inscription on the frame identifies the sitters as the Spaniards Alvaro de Carreno and his wife Maria Gonzales de Quiros: ESTRA OBRA MANDO FACER EL HONRADO SENOR DON ALBARO DE CARRENO EN BRUSELAS EN EL MES ... The triptych was destined for their chapel in the church of St. Tirso in Oviedo.

Identity of the sitter(s): Alvaro de Carreno and Maria Gonzales de Quiros

Provenance: Oviedo, church of St. Tirso

Number of portrait(s): 2

Type of person(s): lay (couple)

Attitude of the sitter(s): hands clasped

Representation of the sitter(s): half-length

Gaze of the sitter(s): into space

Object(s): no

Coat(s) of arms: no

Environment: historical setting

Structuring of the pictorial space: continuous space

Patron saint(s): James, Peter

Gesture of the patron saint(s): protecting

Type of religious scene: narrative

Religious scene(s) depicted: the Adoration of the Magi

Cat. 515-Type 2A

Master of the Legend of the Magdalen Triptych of the Annunciation with a Family in Prayer ('Du Quesnoy-Van der Tommen Triptych') (c. 1515-1520)

$80 \times 67.5 \mathrm{~cm}$ (centre panel) and $81.5 \times$ $28.5 \mathrm{~cm}$ (wings)

Brussels, MRBAB, inv. no. 1330

BIBL.: FRIEDLÄNDER XII, no. 1;

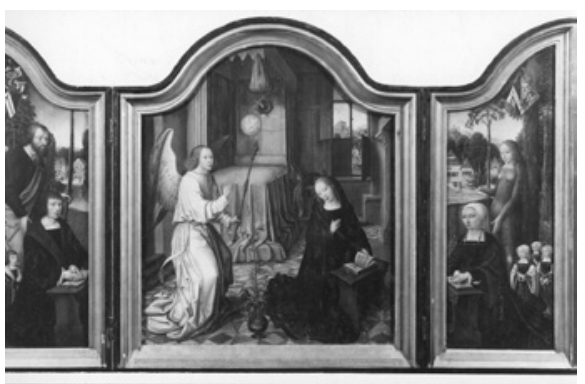

STROO et alii 2006, 104-26 (with bibl.).

Historical Information: The sitters are Simon Du Quesnoy (who died at least as early as 1522), his wife Maria van der Tommen and their children (including Jan, Marie, Isabelle and Jacques) from Brussels. The original location of the triptych remains unknown, although we know that Maria's parents and her son Jan were buried at the church of Sts Michael and Gudula, near the St. Barbara's altar. One can thus argue that the triptych was destined for this place. 
Identity of the sitter(s): Simon du Quesnoy, Mariavan der Tommen and their children

Provenance: Brussels, church of Sts Michael and Gudula (?)

Number of portrait(s): 8

Type of person(s): lay (family with children)

Attitude of the sitter(s): hands clasped

Representation of the sitter(s): full-length

Gaze of the sitter(s): towards the scene

Object(s): yes (prie-dieu, book, small cross)

Coat(s) of arms: yes

Environment: historical setting (domestic setting)

Structuring of the pictorial space: distinct spaces

Patron saint(s): Simon, Mary the Egyptian

Gesture of the patron saint(s): introducing

Type of religious scene: narrative

Religious scene(s) depicted: the Annunciation

\section{Cat. 516-Type $1 \mathrm{~A}$}

[RKD work no. 49206]

Master of the Legend of the Magdalen

Triptych of the Legend of the Magdalen (c. 1515-1520)

$122 \times 75 \mathrm{~cm}$ (fragment of the left wing), $122 \times 75 \mathrm{~cm}$ (fragment of the right wing), $87 \times 70 \mathrm{~cm}$ (fragment of the centre panel), $126 \times 115 \mathrm{~cm}$ (fragment of the centre panel) and $121 \times 75 \mathrm{~cm}$ (reverse of the wings)

Previously Berlin, Kaiser Friedrich Museum, now destroyed (fragment of the left wing), Philadelphia, Philadelphia Museum of Art, inv. no. 402 (fragment of the right wing), Budapest, Szépmüvészeti Múzeum, inv. no. 1338 (fragment of the centre panel), Copenhagen, Statens Museum for Kunst, inv. no. SP 717 (fragment of the centre panel), Schwerin, Staatliches Museum, inv. nos. Gig6 and G198 (reverse)

BIBL.: FRIEDLÄNDER XII, no. 10; TOMBU 1927; DE PATOUL 1974, 1-101; DE VRIJ 2000, 6-15; URBACH 2015 (vol. 2), no. 33 (with bibl.).

Identity of the sitter(s): unknown

Provenance: unknown

Number of portrait(s): 3

Type of person(s): lay (family) 
Attitude of the sitter(s): hands clasped

Representation of the sitter(s): full-length

Gaze of the sitter(s): into space

Object(s): yes (rosary)

Coat(s) of arms: no

Environment: historical setting

Structuring of the pictorial space: continuous space

Patron saint(s): Louis (?), Margaret

Gesture of the patron saint(s): holding his/her attribute

Type of religious scene: narrative

Religious scene(s) depicted: Life of St. Mary Magdalen

\section{Cat. 517-Type $1 \mathrm{D}$}

Master of the Legend of the Magdalen

Triptych of the Resurrection of Christ

(c. 1490-1510)

$87 \times 72 \mathrm{~cm}$ (centre panel) and $87 \times 30 \mathrm{~cm}$ (wings)

Zürich, Galerie Schulthess

BIBL.: FRIEDLÄNDER XII, no. 3 .

Identity of the sitter(s): unknown

Provenance: unknown

Number of portrait(s): 2

Type of person(s): lay (couple)

Attitude of the sitter(s): hands clasped

Representation of the sitter(s): half-length

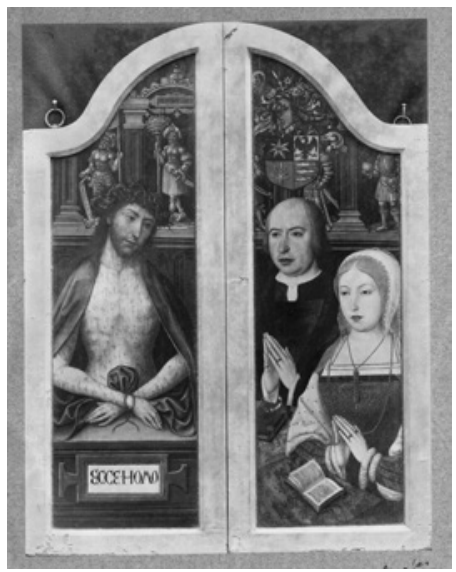

Gaze of the sitter(s): into space

Object(s): yes (book)

Coat(s) of arms: no

Environment: architectural space with sacred connotation

Structuring of the pictorial space: unified space with discontinuities

Patron saint(s): none

Gesture of the patron saint(s): not applicable

Type of religious scene: hieratic

Religious scene(s) depicted: the Supper at Emmaus, the Resurrection of

Christ, the Incredulity of St. Thomas, the Ecce Homo 
Cat. 518-Type 2B

Master of the Legend of the Magdalen Triptych of the Virgin and Child with a Nun in Prayer and Patron Saint (c. 1510-1520) $40 \times 29 \mathrm{~cm}$ (centre panel) and 41X $12 \mathrm{~cm}$ (wings)

Germany, private collection

BIBL.: FRIEDLÄNDER XII, no. 8; SCHADE 2001, 158-59 (with bibl.).

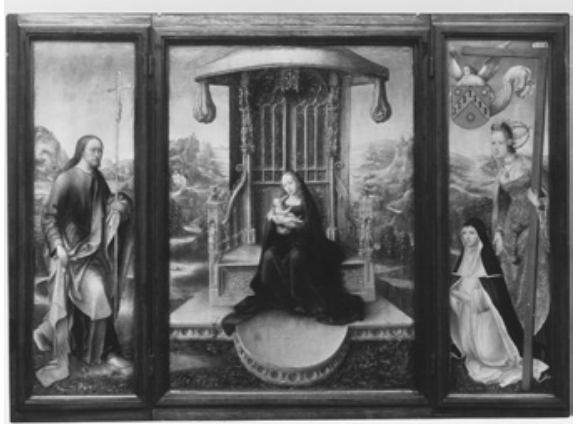

Identity of the sitter(s): unknown

Provenance: unknown

Number of portrait(s): 1

Type of person(s): religious (woman alone)

Attitude of the sitter(s): hands clasped

Representation of the sitter(s): full-length

Gaze of the sitter(s): towards the scene

Object(s): no

Coat(s) of arms: yes

Environment: landscape with sacred connotation

Structuring of the pictorial space: continuous space

Patron saint(s): Helen

Gesture of the patron saint(s): introducing

Type of religious scene: hieratic

Religious scene(s) depicted: the Virgin and Child, the Risen Christ

Cat. 519-Type 2B

Master of the Legend of the Magdalen Triptych of the Virgin and Child with St. Francis and a Couple in Prayer with Patron Saints (c. 1490-1510)

$5^{2} \times 90 \mathrm{~cm}$ (open)

Genoa, Galleria Durazzo Pallavicini

BIBL.：FRIEDLÄNDER XII, no. 6; BERMEJO 1984; SCHADE 2001, 422-23 (with bibl.).

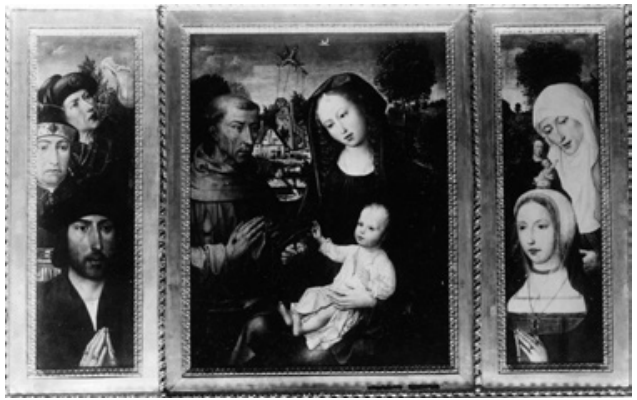

Identity of the sitter(s): unknown

Provenance: unknown

Number of portrait(s): 2 
Type of person(s): lay (couple)

Attitude of the sitter(s): hands clasped

Representation of the sitter(s): half-length

Gaze of the sitter(s): into space

Object(s): no

Coat(s) of arms: no

Environment: landscape, no sacred connotation

Structuring of the pictorial space: unified space with discontinuities

Patron saint(s): Cosmas, Damian, Anne

Gesture of the patron saint(s): protecting, holding his/her attribute

Type of religious scene: hieratic

Religious scene(s) depicted: the Virgin and Child, St. Francis

\section{Cat. 520-Type $2 \mathrm{~B}$}

Master of the Legend of the Magdalen

Triptych of the Virgin and Child with St. Francis and a Couple in Prayer with Patron Saints (dated 1533 on the frame)

Size unknown

London, sale Christie's (6 July 2011), lot no. 110

BIBL.: BERMEJO 1984; Sale cat. Christie's (London, 6 July 2011), no. 110; FALQUE 2012, 302.

HISTORICAL INFORMATION: The reverse of the wings of this recently reappeared triptych contains two coats of arms. According to Palasi, they belong to the Canizares family, who came from Asturias (see the Christie's sale catalogue). The original frame bears the date 1533 and the inscription guarnsair. This term is a variant of the Spanish verb guarnecer, which means 'to garnish' or 'to embellish'. In all likelihood, this inscription is an instruction for the painter in charge of the frame. The language suggests that the triptych was sent unfinished to Spain, where the final painting stages were accomplished.

Identity of the sitter(s): members of the Canizares family

Provenance: unknown

Number of portrait(s): 2

Type of person(s): lay (couple)

Attitude of the sitter(s): hands clasped

Representation of the sitter(s): half-length

Gaze of the sitter(s): into space

Object(s): no

Coat(s) of arms: yes (on the reverse)

Environment: landscape, no sacred connotation 
Structuring of the pictorial space: unified space with discontinuities

Patron saint(s): Jerome, Gregory the Great, Catherine

Gesture of the patron saint(s): protecting, holding his/her attribute

Type of religious scene: hieratic

Religious scene(s) depicted: the Virgin and Child with St. Francis, the Adoration of the Magi

\section{Cat. 521-Type 2B}

Master of the Legend of the Magdalen

Triptych of the Virgin and Child with two Women in Prayer and Patron Saints (c. 1500-1510)

$39 \times 24 \mathrm{~cm}$ (centre panel) and $39 \times 11 \mathrm{~cm}$ (wings)

Whereabouts unknown

BIBL.: FRIEDLÄNDER XII, no. 4; SCHADE 2001, 210-11.

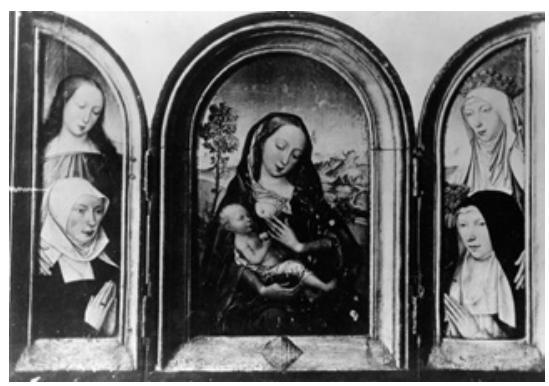

Identity of the sitter(s): unknown

Provenance: unknown

Number of portrait(s): 2

Type of person(s): mixed (unidentified group)

Attitude of the sitter(s): hands clasped

Representation of the sitter(s): half-length

Gaze of the sitter(s): into space

Object(s): no

Coat(s) of arms: yes

Environment: landscape, no sacred connotation

Structuring of the pictorial space: unified space with discontinuities

Patron saint(s): Margaret, Elizabeth of Hungary

Gesture of the patron saint(s): protecting

Type of religious scene: hieratic

Religious scene(s) depicted: the Virgin and Child, St. John the Baptist, St. Mary Magdalen

\section{Cat. 522-Type 6A}

[RKD work no. 49525]

Master of the Legend of the Magdalen

Two Wings. A Man Prayer with St. Anthony and St. Dominic (c. 1490-1510)

$36 \times 24 \mathrm{~cm}$ (each wing) 
Whereabouts unknown

BIBL.: FRIEDLÄNDER XII, no. 12.

Identity of the sitter(s): unknown

Provenance: unknown

Number of portrait(s): 1

Type of person(s): religious (man alone)

Attitude of the sitter(s): hands clasped

Representation of the sitter(s): half-length

Gaze of the sitter(s): indeterminate

Object(s): yes (crosier)

Coat(s) of arms: no

Environment: landscape, no sacred connotation (incomplete)

Structuring of the pictorial space: indeterminate

Patron saint(s): Paul

Gesture of the patron saint(s): protecting

Type of religious scene: indeterminate

Religious scene(s) depicted: the Annunciation, St. Dominic

\section{Cat. 523-Type 6C}

Master of the Legend of the Magdalen Two Wings. Portraits of Antoine

Molckmans, Catherine van der Merct and their Children with their Patron

Saints (c. 1500-1510)

$78.9 \times 48.2 \mathrm{~cm}$ (each wing)

London, sale Sotheby's (8 July 2015), lot no. 2

BIB L.: Sale cat. Sotheby's (London,

8 July 2015), no. 2.
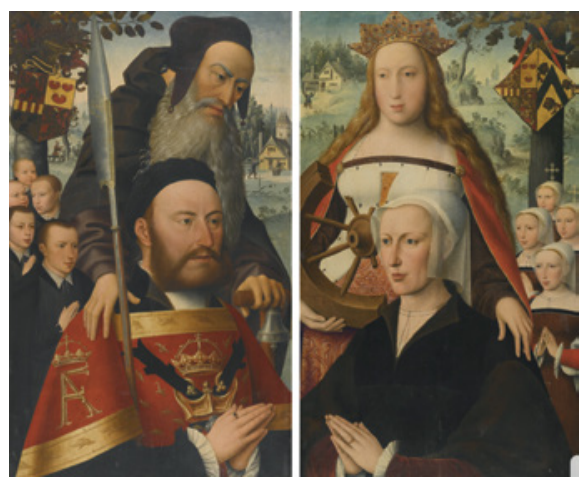

historical information: Antoine Molckmans and Catherine van der Merct have been identified, on the basis of their coats of arms. Antoine wears the ceremonial dress of the archero de corps (archer bodyguard); these were the Burgundian guards brought to Spain by Philip the Fair in the early sixteenth century. Other allusions to the duke are his coat of arms and the monogram $A F$, depicted on Antoine's tabard. As noted in the sale catalogue of 2015, this indicates that, like many other patrons of the painter, Antoine Molckmans gravitated within the Burgundian court in Brussels.

Identity of the sitter(s): Antoine Molckmans, Catherine van der Merct and their Children 
Provenance: unknown

Number of portrait(s): 11

Type of person(s): lay (family with children)

Attitude of the sitter(s): hands clasped

Representation of the sitter(s): half-length

Gaze of the sitter(s): indeterminate

Object(s): yes (halberd, small cross)

Coat(s) of arms: yes

Environment: landscape, no sacred connotation (incomplete)

Structuring of the pictorial space: indeterminate

Patron saint(s): Anthony, Catherine

Gesture of the patron saint(s): protecting

Type of religious scene: indeterminate

Religious scene(s) depicted: none

Cat. 524-Type 6A

[RKD work no. 49528]

Master of the Legend of the Magdalen

Two Wings. Portraits of Philippe Hannock and Maria Collisone with Patron Saints; Portraits of Charles de Clercq and Anne Hannock with Patron Saints (c. 1510)

$86 \times 47.5 \mathrm{~cm}$ (each wing)

Newark, Newark Museum, inv. no. 48.507 A-D

BIB L.: FRIEDLÄNDER XII, no. 13; DE VRIJ 2000, 18-19.

HISTORICAL INFORMATION: Friedländer identified the devotees on the right wing as Charles de Clercq and Anne Hannock and those on the left wing as Philippe Hannock and Maria Collisone. These families came from Mechelen.

Identity of the sitter(s): Charles de Clercq and Anne Hannock, Philippe Hannock and Maria Collisone

Provenance: unknown

Number of portrait(s): 4

Type of person(s): lay (family)

Attitude of the sitter(s): hands clasped, holding a small cross

Representation of the sitter(s): full-length

Gaze of the sitter(s): indeterminate

Object(s): yes (rosary, small cross)

Coat(s) of arms: yes

Environment: enclosed garden, architectural space, no sacred connotation (incomplete)

Structuring of the pictorial space: indeterminate 
Patron saint(s): Philip, Charlemagne

Gesture of the patron saint(s): introducing, holding his/her attribute

Type of religious scene: indeterminate

Religious scene(s) depicted: none

Cat. 525-Type $2 \mathrm{~A}$

Master of the Legend of the Magdalen (?) Triptych of the Lamentation with two Men in Prayer and Patron Saints (c. 1520-1530) $34.5 \times 25 \mathrm{~cm}$ (centre panel) and $35.5 \times 11$ $\mathrm{cm}$ (wings)

Whereabouts unknown

BIBL.: FRIEDLÄNDER XII, 90;

SCHADE 2001, 402-03 (with bibl.).

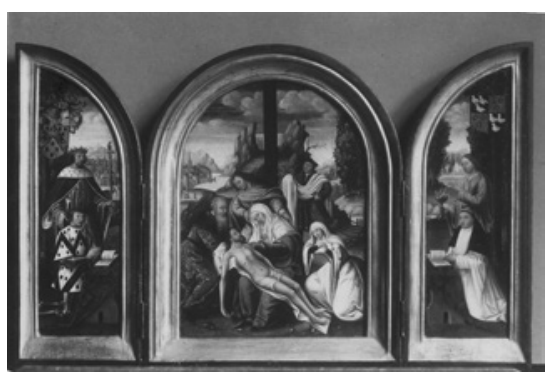

Identity of the sitter(s): unknown

Provenance: unknown

Number of portrait(s): 2

Type of person(s): mixed (unidentified group)

Attitude of the sitter(s): hands clasped

Representation of the sitter(s): full-length

Gaze of the sitter(s): towards the scene

Object(s): yes (prie-dieu, book)

Coat(s) of arms: yes

Environment: historical setting

Structuring of the pictorial space: unified space with discontinuities

Patron saint(s): Louis of Toulouse, John the Evangelist

Gesture of the patron saint(s): introducing, holding his/her attribute

Type of religious scene: narrative

Religious scene(s) depicted: the Lamentation

\section{Cat. 526-Type $2 B$}

Master of the Legend of the Magdalen (?)

Triptych of the Virgin and Child with a Family in Prayer and Patron Saints (c. 1520) $56 \times 44.5 \mathrm{~cm}$ (centre panel) and $58.5 \times 20 \mathrm{~cm}$ (wings)

Whereabouts unknown

BIBL.: SCHADE 2001, 164-65.

Identity of the sitter(s): unknown

Provenance: unknown 
Number of portrait(s): 12 at least

Type of person(s): lay (family with children)

Attitude of the sitter(s): hands clasped

Representation of the sitter(s): full-length

Gaze of the sitter(s): indeterminate

Object(s): no

Coat(s) of arms: no

Environment: landscape, no sacred connotation

Structuring of the pictorial space: unified space with discontinuities

Patron saint(s): Henry, Elizabeth of Hungary

Gesture of the patron saint(s): introducing, holding his/her attribute

Type of religious scene: hieratic

Religious scene(s) depicted: the Virgin and Child, St. Adrian, St. Mary

Magdalen

\section{Cat. 527-Type 6A}

[RKD work no. 49532]

Master of the Legend of the Magdalen (?)

Two wings. A couple in Prayer with Patron Saints (c. 1500-1525)

$55 \times 37 \mathrm{~cm}$ (each wing)

Mexico-City, Museo de San Carlos, inv. no. 54

BIB L.: DE VRIJ 2000, 19.

Identity of the sitter(s): unknown

Provenance: unknown

Number of portrait(s): 2

Type of person(s): lay (couple)

Attitude of the sitter(s): hands clasped, holding a book

Representation of the sitter(s): full-length

Gaze of the sitter(s): indeterminate

Object(s): yes (book)

Coat(s) of arms: no

Environment: landscape, no sacred connotation (incomplete)

Structuring of the pictorial space: indeterminate

Patron saint(s): Judocus, Elizabeth of Hungary

Gesture of the patron saint(s): introducing

Type of religious scene: indeterminate

Religious scene(s) depicted: none 
Cat. 528-Type 6A

[RKD work no. 34728]

Master of the Legend of the Magdalen (attributed to)

Fragment. Portrait of a Nun in Prayer (c. 1500-1550)

$25 \times 19 \mathrm{~cm}$

Vienna, sale Dorotheum (14 October 1997), lot no. 64

BIB L.: Sale cat. Dorotheum (Vienna, 14 October 1997), no. 64.

HISTORICAL INFORMATION: According to the Dorotheum sale catalogue, the nun is Katharina van der Stockt, as suggested by a comparison with another portrait by the Master of the Legend of the Magdalen (cat. 512).

Identity of the sitter(s): Katharina van der Stockt (?)

Provenance: unknown

Number of portrait(s): 1

Type of person(s): religious (woman alone: Augustinian canoness)

Attitude of the sitter(s): hands clasped

Representation of the sitter(s): full-length

Gaze of the sitter(s): indeterminate

Object(s): yes (small cross)

Coat(s) of arms: no

Environment: indeterminate

Structuring of the pictorial space: indeterminate

Patron saint(s): none

Gesture of the patron saint(s): not applicable

Type of religious scene: indeterminate

Religious scene(s) depicted: none

\section{Cat. 529-Type 2D}

Master of the Legend of the Magdalen (attributed to)

Triptych of the Virgin and Child with a Man in Prayer and his Patron Saint

(c. 1490-1510)

$50.5 \times 70.5 \mathrm{~cm}$ (open)

Burgos, cathedral of Our Lady

BIB L.: Exh. cat. Leuven 1959, no. 218.

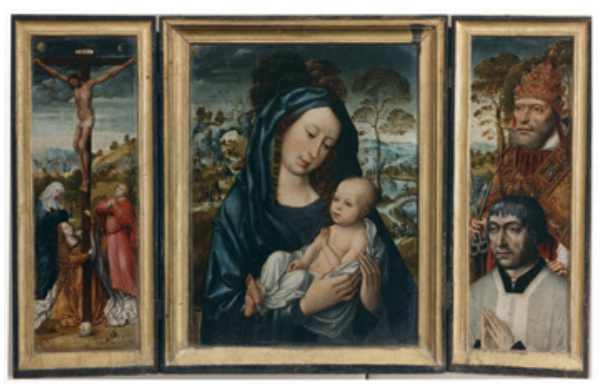

Identity of the sitter(s): unknown

Provenance: unknown 
Number of portrait(s): 1

Type of person(s): religious (man alone: priest)

Attitude of the sitter(s): hands clasped

Representation of the sitter(s): half-length

Gaze of the sitter(s): into space

Object(s): no

Coat(s) of arms: yes (on the outer wings)

Environment: landscape, no sacred connotation

Structuring of the pictorial space: unified space with discontinuities

Patron saint(s): Peter

Gesture of the patron saint(s): protecting

Type of religious scene: hieratic

Religious scene(s) depicted: the Crucifixion, the Agony in the garden, St. Michael fighting the dragon

Cat. 530-Type $2 B$

[RKD work no. 70931]

Master of the Legend of the Magdalen (attributed to)

Triptych of the Virgin and Child with Saints and a Priest in Prayer (c. 1490-1510)

$32.5 \times 20.5 \mathrm{~cm}$ (centre panel) and $42 \times 15 \mathrm{~cm}$ (wings)

London, sale Christie's (7 July 2000), lot no. 24 (centre panel) and London, sale Sotheby's (8 July 2009), lot nos. 33-44 (wings) (previously Sigmaringen, private collection)

BIBL.: FRIEDLÄNDER XII, no. 5; SCHADE 2001, 208-09 (with bibl.).

Identity of the sitter(s): unknown

Provenance: unknown

Number of portrait(s): 1

Type of person(s): religious (man alone)

Attitude of the sitter(s): hands clasped

Representation of the sitter(s): full-length

Gaze of the sitter(s): towards the scene

Object(s): no

Coat(s) of arms: no

Environment: landscape with sacred connotation

Structuring of the pictorial space: distinct spaces

Patron saint(s): William of Maleval

Gesture of the patron saint(s): introducing 
Type of religious scene: hieratic

Religious scene(s) depicted: the Virgin and Child, St. Catherine, St. Jerome, St. Agnes

Cat. 531-Type 2 B

Master of the Legend of the Magdalen (inner wings) and POURBUS, Pieter (outer wings)

Triptych of the Virgin and Child with a Couple in Prayer and Patron Saints ('Triptych Toison d'or') (c. 1505-1510) $87 \times 67 \mathrm{~cm}$ (centre panel) and $91 \times 29 \mathrm{~cm}$ (wings)

Amsterdam, Rijksmuseum, inv. nos. SK-A-962a-b (wings) and London, sale Christie's (9 July 1982) (centre panel) BIBL.: FRIEDLÄNDER XII, no. 11; Exh. cat. Bruges 1969, no. 68; PERIER

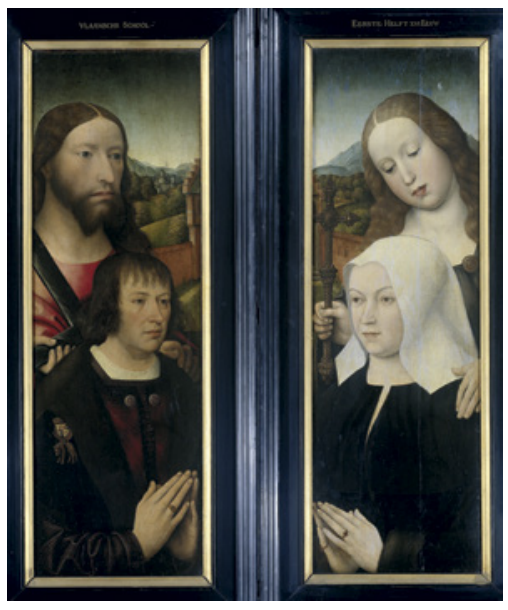
D'IETEREN 1975a; Mus. cat. Amsterdam 1976, 635; Mus. cat. Amsterdam 2009 [online], https://www.rijksmuseum.nl/nl/collectie/SK-A-962-B/catalogus-entry (with bibl.).

HistoricAl INFORMATION: The devotees are Thomas Isaacq and his wife. Thomas is wearing the insignia of the Order of the Golden Fleece and the coat of arms of Philip the Fair. His political career is well documented, on the basis of many archival documents dating from 1491 to 1539. In 1491, he was made Officer of Arms of the Golden Fleece, with the name 'Fusil'. In 1493, he was appointed third King of Arms of the Golden Fleece and was then named 'Toison d'or'. This explains the name given to the triptych. In 1505, Thomas took part in the embassy sent by Maximilian to the English court in order to negotiate the marriage between Margaret of Austria and the King Charles VII. In 1515, he was sent to the King of England to bring him a painting faict à la pourtraicture de Madame de Savoye by Pieter van Coninxloo. Thomas Isaacq died in 1540 and was buried at the church Notre-Dame-du-Sablon in Brussels.

Identity of the sitter(s): Thomas Isaacq and his wife

Provenance: unknown

Number of portrait(s): 2

Type of person(s): lay (couple) 
Attitude of the sitter(s): hands clasped

Representation of the sitter(s): half-length

Gaze of the sitter(s): towards the scene

Object(s): yes (collar of the Order of the Golden Fleece)

Coat(s) of arms: no

Environment: enclosed garden (incomplete)

Structuring of the pictorial space: unified space with discontinuities

Patron saint(s): Thomas, Margaret

Gesture of the patron saint(s): protecting

Type of religious scene: hieratic

Religious scene(s) depicted: the Virgin and Child

Cat. 532-Type 4D

Master of the Legend of the Magdalen and Anonymous French Master

Diptych of the Virgin and Child ('Diptych of Willem van Bibaut') (dated 1523 on the right wing)

$25 \times 14.5 \mathrm{~cm}$ (each wing)

Amsterdam, private collection

BIBL.: DE VRIJ 1998A; DE VRIJ 2000, 31-36; Exh. cat. Antwerp and Washington 2006, no. 23 (with bibl.); Exh. cat.

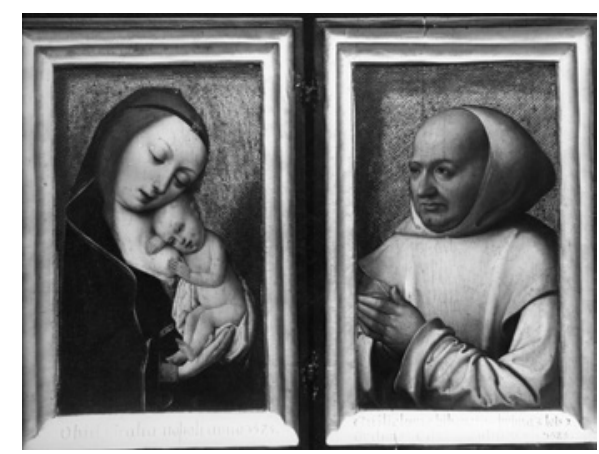

Roermond 2009, no. 30.

HISTORICAL INFORMATION: The inscription on the frame identifies the monk as Willem van Bibaut: GUILIELMIUS BIBAUCIUS PRIMAS TOTS ORDINIS CARTUSIENTIUM 1523. Born in Tielt c. 1484, Willem entered the Carthusian Order around 1500. He initially spent several years at the Charterhouse of Ghent, before being appointed prior of the Charterhouse of Geertruidenberg. In 1521, he became prior of the Grande Chartreuse and spent the rest of his life in this charterhouse. He died on 14 July 1535.

Identity of the sitter(s): Willem van Bibaut

Provenance: unknown

Number of portrait(s): 1

Type of person(s): religious (man alone: Carthusian monk)

Attitude of the sitter(s): hands clasped

Representation of the sitter(s): half-length 
Gaze of the sitter(s): towards the scene

Object(s): no

Coat(s) of arms: no

Environment: neutral space

Structuring of the pictorial space: continuous space

Patron saint(s): none

Gesture of the patron saint(s): not applicable

Type of religious scene: hieratic

Religious scene(s) depicted: the Virgin and Child, the Crucifix with symbols of the Passion

\section{Cat. 533-Type $1 \mathrm{~A}$}

[RKD work no. 114794]

Master of the Lille Adoration (attributed to) (or Dirck Vellert and Barthel Bruyn)

Triptych of the Ecce Homo with a Couple in Prayer and Patron Saints (c. $1520-1530)$

$102.2 \times 139.4 \mathrm{~cm}$ (open)

London, sale Christie's (10 December 2003), lot no. 19

BIB L.: FRIEDLÄNDER XII, 30; KONOWITZ 1995; Sale cat. Christie's (London, 10 December 2003), no. 19.

Identity of the sitter(s): unknown

Provenance: unknown

Number of portrait(s): 2

Type of person(s): lay (couple)

Attitude of the sitter(s): hands clasped

Representation of the sitter(s): full-length

Gaze of the sitter(s): into space

Object(s): no

Coat(s) of arms: no

Environment: landscape, no sacred connotation

Structuring of the pictorial space: distinct spaces

Patron saint(s): Jerome, Catherine

Gesture of the patron saint(s): protecting, holding his/her attribute

Type of religious scene: hieratic

Religious scene(s) depicted: the Ecce homo 
Cat. 534-Type 2A

Master of the Martyrdom of St. John Triptych of the Nativity with a Family in Prayer and Patron Saints (c. 1525) $54.5 \times 36.5 \mathrm{~cm}$ (centre panel) and 54.5 $\times 17 \mathrm{~cm}$ (wings)

Norwich Castle Museum, inv. no. 117.948

BIBL.: FRIEDLÄNDER XI, no. 63; SCHADE 2001, 270-71 (with bibl.).

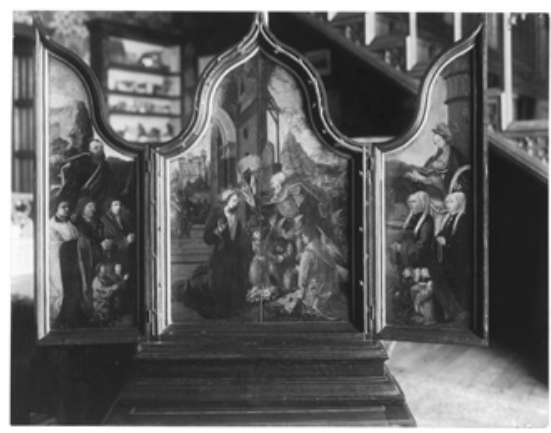

Identity of the sitter(s): unknown

Provenance: unknown

Number of portrait(s): 10

Type of person(s): mixed (family with children)

Attitude of the sitter(s): hands clasped, holding a rosary

Representation of the sitter(s): full-length

Gaze of the sitter(s): towards the scene

Object(s): yes (rosary)

Coat(s) of arms: no

Environment: historical setting

Structuring of the pictorial space: unified space with discontinuities

Patron saint(s): Peter, Barbara

Gesture of the patron saint(s): introducing, holding his/her attribute

Type of religious scene: narrative

Religious scene(s) depicted: the Nativity

\section{Cat. 535-Type 6A}

[Link to the Friedländer 3.o Database]

Master of the Morrison Triptych

Fragment. A Couple in Prayer with Patron Saints (c. 1500-1510)

$69.9 \times 48.2 \mathrm{~cm}$

New York, sale Christie's (25 January 2012), lot no. 7

BIB L.: FRIEDLÄNDER VII, add. 200; Sale cat. Christie's (New York, 25 January 2012), no. 7 .

Identity of the sitter(s): unknown

Provenance: unknown

Number of portrait(s): 2 
Type of person(s): lay (couple)

Attitude of the sitter(s): hands clasped

Representation of the sitter(s): indeterminate

Gaze of the sitter(s): indeterminate

Object(s): no

Coat(s) of arms: no

Environment: landscape, no sacred connotation (incomplete)

Structuring of the pictorial space: indeterminate

Patron saint(s): Francis, Catherine

Gesture of the patron saint(s): holding his/her attribute

Type of religious scene: indeterminate

Religious scene(s) depicted: none

\section{Cat. 536-Type ${ }_{3} \mathrm{C}$}

[RKD work no. 30110]

Master of the Orsoy Altarpiece

The Nativity and the Circumcision of Christ with a Man in Prayer (c. 1500)

$144 \times 153 \mathrm{~cm}$

Brussels, MRBAB, inv. no. 541

BIBL.: FRIEDLÄNDER IV, no. 105; STROO et alii 2006, 199-215 (with bibl.);

Exh. cat. Brussels 2013, no. 89 .

Identity of the sitter(s): unknown

Provenance: unknown

Number of portrait(s): 1

Type of person(s): religious (man alone: canon)

Attitude of the sitter(s): hands clasped

Representation of the sitter(s): full-length

Gaze of the sitter(s): towards the scene

Object(s): no

Coat(s) of arms: no

Environment: historical setting

Structuring of the pictorial space: not applicable

Patron saint(s): none

Gesture of the patron saint(s): not applicable

Type of religious scene: narrative

Religious scene(s) depicted: the Nativity, the Circumcision, St. Valerianus, St. Cecilia 
Cat. 537-Type $3^{B}$

Master of the Orsoy Altarpiece (attributed to)

The Fountain of Life with a Family in Prayer

(c. 1500)

$92 \times 76.5 \mathrm{~cm}$

Palermo, Tasca di Almerita collection

BIB L.: Repertory Sicily, 43-44 (with bibl.).

Identity of the sitter(s): unknown

Provenance: unknown

Number of portrait(s): 6

Type of person(s): lay (family)

Attitude of the sitter(s): hands clasped

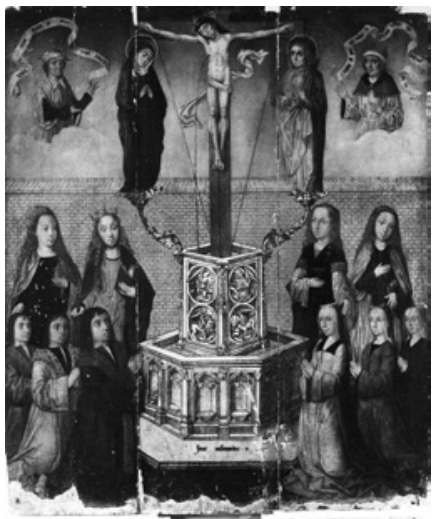

Representation of the sitter(s): full-length

Gaze of the sitter(s): into space, towards the scene

Object(s): no

Coat(s) of arms: no

Environment: enclosed garden

Structuring of the pictorial space: not applicable

Patron saint(s): Mary Magdalen, Catherine, Lucy, an unidentified saint

Gesture of the patron saint(s): introducing, holding his/her attribute

Type of religious scene: hieratic

Religious scene(s) depicted: the Fountain of Life

Cat. 538-Type 6B

Master of the Portraits of Princes

Portrait of a Young Man of the Fonseca Family in Prayer (c. 1490)

$39 \times 29.5 \mathrm{~cm}$, Rotterdam, Museum Boijmans van Beuningen, inv. no. 2311

BIBL.: FRIEDLÄNDER IV, pl. 104 A; Exh. cat. Bruges 1969, no. 61; PERIER D'IETEREN 1986; Exh. cat. Rotterdam 1994, no. 10 (with bibl.).

HISTORICAL INFORMATION: The original frame contains an inscription giving the age of the portrayed man (En lage de XXVI ans), the initials $C$ and $Y$, and a coat of arms

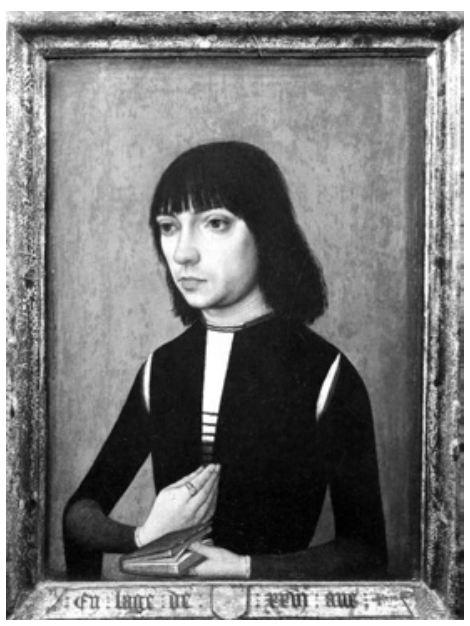
(which also appears on the reverse of the panel with the motto $A$ Dieu). The 
coat of arms belongs to the Spanish Fonseca family. The precise identity of the sitter unfortunately remains unknown.

Identity of the sitter(s): Member of the Fonseca family

Provenance: unknown

Number of portrait(s): 1

Type of person(s): lay (man alone)

Attitude of the sitter(s): holding a book, particular gesture

Representation of the sitter(s): half-length

Gaze of the sitter(s): indeterminate

Object(s): yes (book)

Coat(s) of arms: yes (on the frame and on the reverse)

Environment: neutral space (incomplete)

Structuring of the pictorial space: indeterminate

Patron saint(s): none

Gesture of the patron saint(s): not applicable

Type of religious scene: indeterminate

Religious scene(s) depicted: none

\section{Cat. 539-Type 6B}

Master of the Portraits of Princes (?)

Portrait of Lodewijk of Gruuthuse in Prayer

(c. 1480-1490)

$34.2 \times 22.8 \mathrm{~cm}$

Bruges, Groeningemuseum, inv. no. 0.1557

BIBL.: FRIEDLÄNDER IV, Add. 161; Exh. cat. Bruges 1969, no. 62; Exh. cat. Bruges, Bern and Vienna 2009, no. 19 (with bibl.). HISTORICAL INFORMATION: Lodewijk of Gruuthuse has been identified by his coat of arms and his motto (Plus est en vous) painted on the frame. Born in 1422, Lodewijk was Lord of Gruuthuse and Steenhuyse. He was

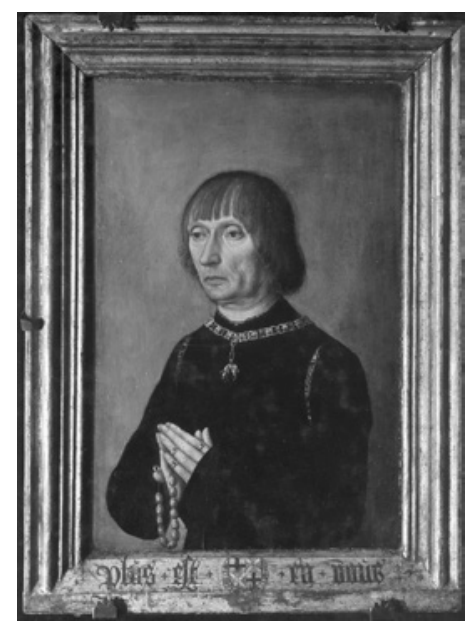
councillor and chamberlain of Philip the Good and Charles the Bold. From 1465 to 1477 , he acted as Governor of Holland, Zeeland and Friesland. During the struggle between Maximilian and the Flemish cities, he acted as an intermediary, which brought him disgrace. Lodewijk was a knight of the Order of the Golden Fleece and is famously renowned for his library.

Identity of the sitter(s): Lodewijk of Gruuthuse 
Provenance: unknown

Number of portrait(s): 1

Type of person(s): lay (man alone)

Attitude of the sitter(s): holding a rosary

Representation of the sitter(s): half-length

Gaze of the sitter(s): indeterminate

Object(s): yes (rosary, collar of the Order of the Golden Fleece)

Coat(s) of arms: yes

Environment: neutral space (incomplete)

Structuring of the pictorial space: indeterminate

Patron saint(s): none

Gesture of the patron saint(s): not applicable

Type of religious scene: indeterminate

Religious scene(s) depicted: none

Cat. 540-Type $3^{B}$

Master of the Spes nostra

Religious Allegory. Four Canons in Prayer before an Open Tomb and the Visitation

(c. 1500)

$88 \times 105 \mathrm{~cm}$

Amsterdam, Rijksmuseum, inv. no.

SK-A-2312

BIBL.: FRIEDLÄNDER X, no. 66.I; Mus. cat. Amsterdam 1976, 637; Exh. cat. Utrecht 1999-2000, 205-06; Exh. cat.

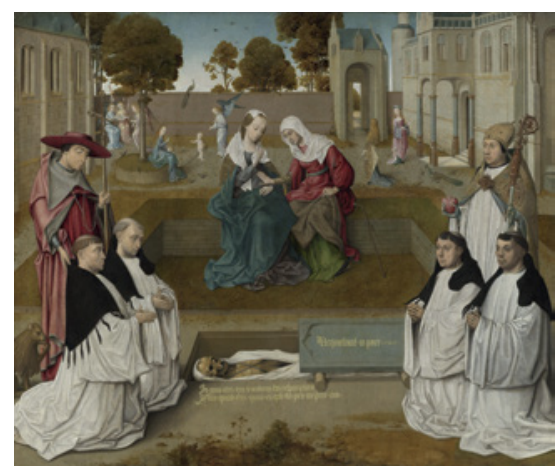

Rotterdam 1992, no. 53; Mus. cat. Amsterdam 2009 [online], https://www .rijksmuseum.nl/nl/collectie/SK-A-2312/catalogus-entry (with bibl.). HISTORICAL INFORMATION: The four men depicted in prayer are regular canons of the Augustinian Order. Their habit indicates that they belonged to the General Chapter of Sion. Several hypotheses have been formulated about their precise identity and the original location of the painting, but none of them has been confirmed with certainty. In 1952, Van Luttervelt suggested that the painting could come from the Augustinian Priory of Our Lady on Mount Sion, near Delft. Nevertheless, the numerous instances of damage inflicted upon the priory in the sixteenth century (a fire in 1544, the iconoclast crisis in 1566 and its destruction in 1572) have led others to reject this hypothesis. According to Bangs, the painting probably comes from the convent of Mariënpoel in Leiden and the four men are probably the four successive rectors (c. 1500): Johannes 
Crispiani, Gijsbert N., Gerard Dirksz. and Sebastian Fransz.. The regulars' Priory of Our Lady of the Visitation outside Haarlem and the Augustinian priory of Hieronymusdal in Oegstgeest near Leiden are also regularly mentioned as part of the potential provenance of the painting.

Identity of the sitter(s): unknown

Provenance: unknown

Number of portrait(s): 4

Type of person(s): religious (group: Augustinian canons)

Attitude of the sitter(s): hands clasped

Representation of the sitter(s): full-length

Gaze of the sitter(s): into space, towards the scene

Object(s): no

Coat(s) of arms: no

Environment: cloister

Structuring of the pictorial space: not applicable

Patron saint(s): Jerome, Augustine

Gesture of the patron saint(s): introducing, holding his/her attribute

Type of religious scene: hieratic

Religious scene(s) depicted: the Visitation

\section{Cat. 541-Type 3 B}

Master of the St. John Panels

The Virgin and Child with St. Anne and a

Family in Prayer with Patron Saints

(c. 1485-1495)

$54 \times 53.5 \mathrm{~cm}$

Amsterdam, Rijksmuseum, inv. no.

SK-A-4125

BIB L.: Mus. cat. Amsterdam 1976, 634;

Exh. cat. Utrecht 1999-2000, 92; Mus.

cat. Amsterdam 2009 [online], https://

www.rijksmuseum.nl/nl/collectie/SK-A4125/catalogus-entry (with bibl.).

Identity of the sitter(s): unknown

Provenance: unknown

Number of portrait(s): 16

Type of person(s): lay (family with children)

Attitude of the sitter(s): hands clasped, holding a book

Representation of the sitter(s): full-length, children in small scale 
Gaze of the sitter(s): towards the scene

Object(s): yes (book)

Coat(s) of arms: no

Environment: landscape with sacred connotation

Structuring of the pictorial space: not applicable

Patron saint(s): Francis, Lidwina

Gesture of the patron saint(s): introducing

Type of religious scene: hieratic

Religious scene(s) depicted: the Virgin and Child with St. Anne

Cat. 542-Type $3 \mathrm{~A}$

Master of the Turin Adoration

Triptych of the Adoration of the Magi with a Friar in Prayer and Patron Saint (c. 1490-1500)

$156.2 \times 214.3 \mathrm{~cm}$ (centre panel), $74 \times 99 \mathrm{~cm}$ (lower parts of the wings) and $79 \times 101 \mathrm{~cm}$ (upper parts of the wings)

Turin, Galleria Sabauda, inv. no. 309

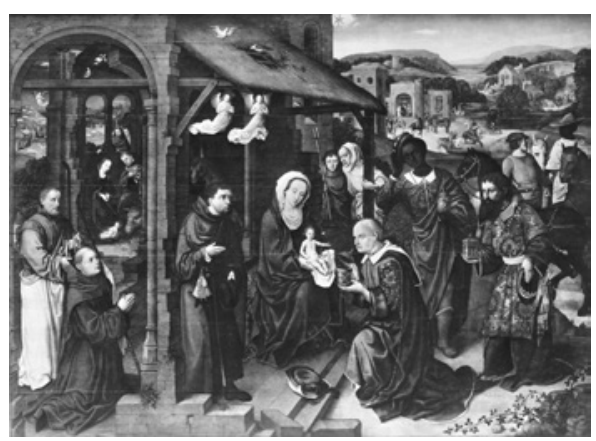
(centre panel), Genoa, Museo di Palazzo reale, inv. no. 945-946 (upper parts of the wings) and Strasbourg, Musée des Beaux-Arts, inv. no. 445-446 (lower parts of the wings)

BIBL.: FRIEDLÄNDER VIb, supp. 250; Corpus Turino, no. 20 (with bibl.); MARTENS D. 2010, 94-97; Exh. cat. Brussels 2013, no. 65 (with bibl.).

Identity of the sitter(s): unknown

Provenance: unknown

Number of portrait(s): 1

Type of person(s): religious (man alone: Franciscan friar)

Attitude of the sitter(s): hands clasped

Representation of the sitter(s): full-length

Gaze of the sitter(s): towards the scene

Object(s): no

Coat(s) of arms: no

Environment: historical setting

Structuring of the pictorial space: not applicable 
Patron saint(s): an unidentified saint

Gesture of the patron saint(s): introducing

Type of religious scene: narrative

Religious scene(s) depicted: the Adoration of the Magi, the Legend of St. Catherine, the Legend of St. Agnes, St. George, St. Cecilia, St. Sebastian, St. Ursula

\section{Cat. 543-Type 6B}

Master of the van Gelder Madonna (?)

Portrait of a Man in Prayer (c. 1490-1510)

$28.8 \times 20.9 \mathrm{~cm}$

Hartford, Wadsworth Atheneum, inv. no. 1941.155

BIBL.: Corpus New England, no. 65 (with bibl.); CUTTLER 1966, 168-69.

HISTORICAL INFORMATION: The coat of arms belongs to the humanist Hieronymus van Busleyden (c. 1470-1517) but its pictorial execution is weaker than the rest of the painting. It could thus be a later addition, and the identity of the sitter cannot

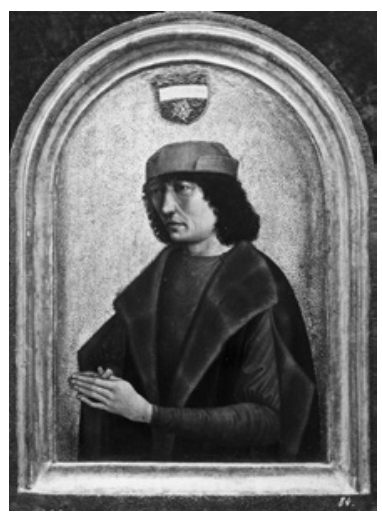
be confirmed with certainty.

Identity of the sitter(s): Hieronymus van Busleyden (?)

Provenance: unknown

Number of portrait(s): 1

Type of person(s): lay (man alone)

Attitude of the sitter(s): hands clasped

Representation of the sitter(s): half-length

Gaze of the sitter(s): indeterminate

Object(s): yes (hat)

Coat(s) of arms: yes

Environment: neutral space (incomplete)

Structuring of the pictorial space: indeterminate

Patron saint(s): none

Gesture of the patron saint(s): not applicable

Type of religious scene: indeterminate

Religious scene(s) depicted: none 
Cat. 544-Type 6B

Master of the View of Sainte-Gudule

Portrait of a Young Man Holding a Book (c. 1480)

$22.8 \times 14 \mathrm{~cm}$

London, NG, inv. no. NG2612

BIBL.: CAMPBELL 1998, 346-53 (with bibl.).

Identity of the sitter(s): unknown

Provenance: unknown

Number of portrait(s): 1

Type of person(s): lay (man alone)

Attitude of the sitter(s): holding a book

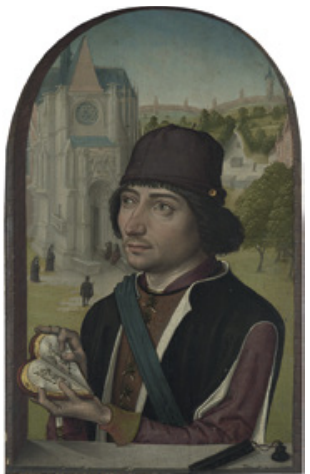

Representation of the sitter(s): half-length

Gaze of the sitter(s): indeterminate

Object(s): yes (book, inkwell, quill)

Coat(s) of arms: no

Environment: landscape with sacred connotation (incomplete)

Structuring of the pictorial space: indeterminate

Patron saint(s): none

Gesture of the patron saint(s): not applicable

Type of religious scene: indeterminate

Religious scene(s) depicted: none

Cat. 545-Type 6B

Master of the View of Sainte-Gudule

Portrait of a Young Man Holding a Book (c. 1480) $20.6 \times 12.6 \mathrm{~cm}$

New York, MET, inv. no. 50.145.27

BIBL.: AINSWORTH and CHRISTIANSEN 1998, 178-81 (with bibl.).

Identity of the sitter(s): unknown

Provenance: unknown

Number of portrait(s): 1

Type of person(s): lay (man alone)

Attitude of the sitter(s): holding a book

Representation of the sitter(s): half-length

Gaze of the sitter(s): indeterminate

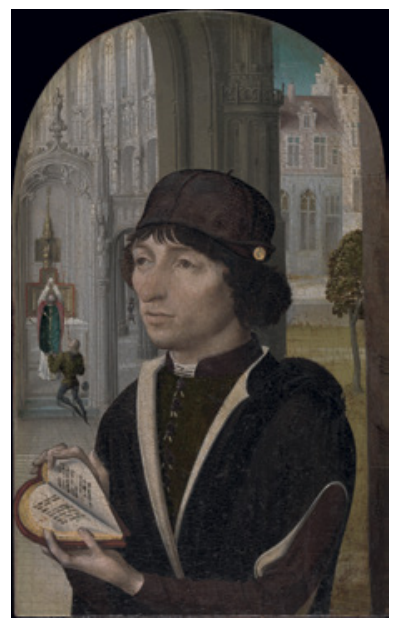

Object(s): yes (book) 
Coat(s) of arms: no

Environment: landscape with sacred connotation (incomplete)

Structuring of the pictorial space: indeterminate

Patron saint(s): none

Gesture of the patron saint(s): not applicable

Type of religious scene: indeterminate

Religious scene(s) depicted: none

\section{Cat. 546-Type $3_{3}$ B}

Master of the View of Sainte-Gudule

The Virgin and Child with a Woman in Prayer and St. Mary Magdalen (c. 1475-1500) $56 \times 49 \mathrm{~cm}$

Liège, Musée Grand Curtius, inv. no. A9 BIBL.: FRIEDLÄNDER IV, no. 73; LOZE 2004; Repertory Liège, no. 3 (with bibl.); Exh. cat. Leuven 2009, no. 46 (with bibl.).

Identity of the sitter(s): unknown

Provenance: unknown

Number of portrait(s): 1

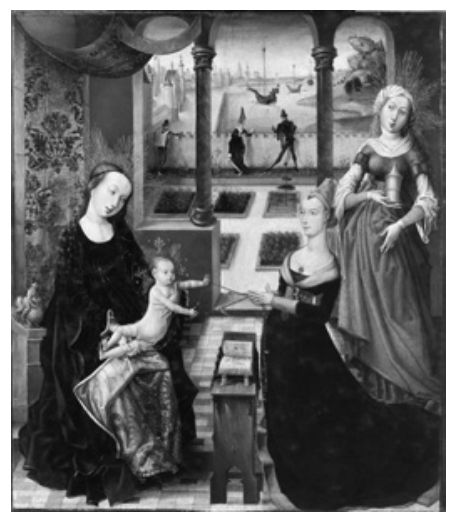

Type of person(s): lay (woman alone)

Attitude of the sitter(s): physical contact with the sacred person

Representation of the sitter(s): full-length

Gaze of the sitter(s): towards the scene

Object(s): yes (prie-dieu, book, rosary)

Coat(s) of arms: no

Environment: architectural space with sacred connotation

Structuring of the pictorial space: not applicable

Patron saint(s): Mary Magdalen

Gesture of the patron saint(s): holding his/her attribute

Type of religious scene: hieratic

Religious scene(s) depicted: the Virgin and Child 
Cat. 547-Type $2 \mathrm{C}$

Master of the View of Sainte-Gudule (attributed to)

Triptych of St. Anne (c. 1480)

$113 \times 84 \mathrm{~cm}($ centre panel $)$ and $113 \times 38$ $\mathrm{cm}$ (wings)

Paris, Musée de l'Histoire de la Médecine

BIBL.: FRIEDLÄNDER IV, no. 74; Exh.

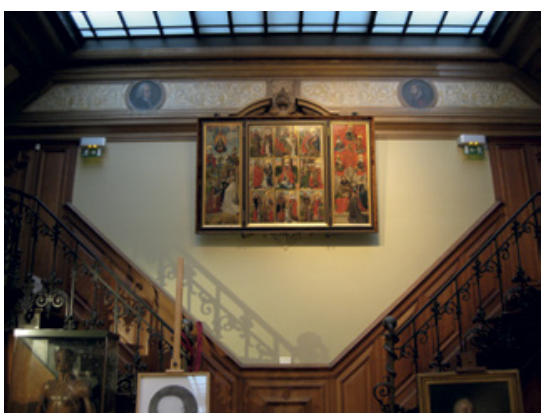

cat. Nijmegen 1985-1986, 117-20; Exh. cat. Brussels 2013, no. 80 (with bibl.). Identity of the sitter(s): unknown

Provenance: unknown

Number of portrait(s): 1

Type of person(s): religious (man alone: canon)

Attitude of the sitter(s): hands clasped

Representation of the sitter(s): full-length, small scale

Gaze of the sitter(s): towards the scene

Object(s): no

Coat(s) of arms: no

Environment: architectural space with sacred connotation

Structuring of the pictorial space: particular case

Patron saint(s): none

Gesture of the patron saint(s): not applicable

Type of religious scene: narrative

Religious scene(s) depicted: life and family of St. Anne

Cat. 548-Type 3D

Master of the Virgo inter Virgines

The Holy Trinity with the Virgin, St. John, St. Mary Magdalen and a Nun in Prayer (c. 1485-1495)

$146.1 \times 128.3 \mathrm{~cm}$

Zagreb, Jugoslavenska Akdemija, inv. no. $\mathrm{SG}_{71}$

BIBL.: FRIEDLÄNDER V, no. 62; HOOGEWERFF II, 272-74; Exh. cat. Rotterdam 1992, no. 49 (with bibl.).

Identity of the sitter(s): unknown

Provenance: unknown

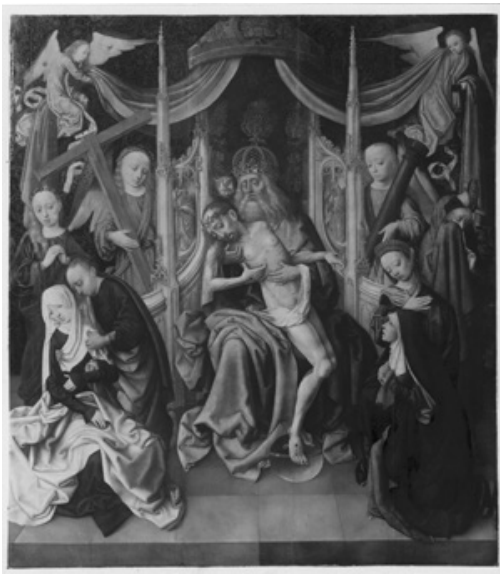

Number of portrait(s): 1 
Type of person(s): religious (woman alone)

Attitude of the sitter(s): hands clasped

Representation of the sitter(s): full-length

Gaze of the sitter(s): towards the scene

Object(s): no

Coat(s) of arms: no

Environment: architectural space with sacred connotation

Structuring of the pictorial space: not applicable

Patron saint(s): none

Gesture of the patron saint(s): not applicable

Type of religious scene: hieratic

Religious scene(s) depicted: the Holy Trinity, the Virgin, St. Mary Magdalen, St. John

Cat. 549-Type 6A

Master of the Virgo inter Virgines (attributed to) The Annunciation with the Duke of Alba in Prayer (c. 1500)

$94 \times 71 \mathrm{~cm}$

Madrid, collection of the Duke of Alba BIBL.: FRIEDLÄNDER V, add. 143; INIGUES 1925; CHÂTELET 1980, no. 136; BERMEJO 1982, 97-98 (with bibl.).

HISTORICAL INFORMATION: The portrayed man is don Fernando Alvarez de Toledo, first Duke of Alba. This panel was probably a wing

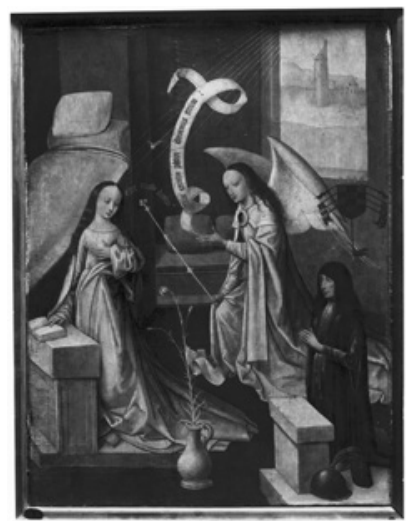
of an altarpiece from which another panel, depicting the Adoration of the Magi, is also preserved (Vienna, Kunsthistorisches Museum, inv. no. 6375) (see INIGUES 1925).

Identity of the sitter(s): Don Fernando Alvarez de Toledo

Provenance: unknown

Number of portrait(s): 1

Type of person(s): lay (man alone)

Attitude of the sitter(s): hands clasped

Representation of the sitter(s): full-length

Gaze of the sitter(s): indeterminate

Object(s): yes (prie-dieu, helmet)

Coat(s) of arms: yes

Environment: historical setting (domestic setting)

Structuring of the pictorial space: indeterminate 
Patron saint(s): none

Gesture of the patron saint(s): not applicable

Type of religious scene: narrative

Religious scene(s) depicted: the Annunciation, the Adoration of the Magi

Cat. 550-Type 6A

Master of the Virgo inter Virgines (attributed to) (or Master of the Legend of St. Catherine) Portrait of Hugo de Groot in Prayer (c.1490-1509) $37.5 \times 26 \mathrm{~cm}$

Chapel Hill, Ackland Art Centre, inv. no. 73.36.1 BIBL.: Exh. cat. Amsterdam 1958, no. 55; CHÄTELET 1980, no. 142; DE VRIJ 1999, 23-24 (with bibl.).

HistoricAl INFORMATION: Hugo de Groot (1451-1509) came from Delft, where he was priest at the Nieuwekerk. In addition, he was canon of the chapter of the court in The Hague and canon of the chapter of Geervliet. He was also councillor at the court of Holland. He has

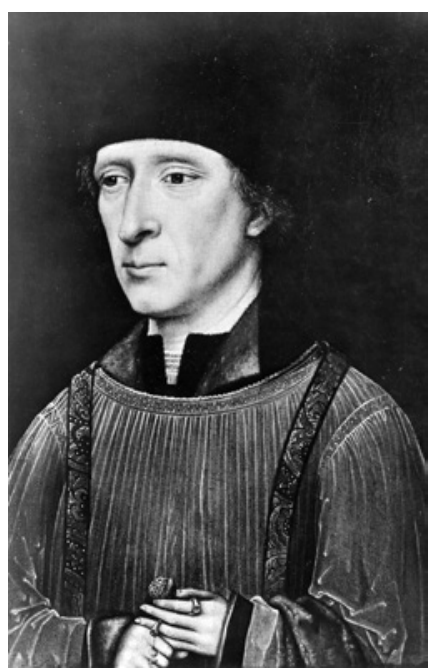
been identified, on the basis of the work of the archivist Oosterbaan, who discovered a copy of de Groot's epitaph in a seventeenth-century document. This text is identical to the one present on the reverse of this portrait: Hoc tumulo situs est Hugo cognomine Magnus, Optatus Delphis Pastor in aede nova, Consulis officio dignum quem Curia sumsit, Hagia Canonicum templa habuere pium, Quem Geervlietensis tenuit sacer ordo Decanum. Dic, Lector, superum sorte beatus eat 8 Mai 1509.

Identity of the sitter(s): Hugo de Groot

Provenance: unknown

Number of portrait(s): 1

Type of person(s): religious (man alone: canon)

Attitude of the sitter(s): holding a rosary

Representation of the sitter(s): half-length

Gaze of the sitter(s): indeterminate

Object(s): yes (rosary, flower)

Coat(s) of arms: no 
Environment: neutral space (incomplete)

Structuring of the pictorial space: indeterminate

Patron saint(s): none

Gesture of the patron saint(s): not applicable

Type of religious scene: indeterminate

Religious scene(s) depicted: none

\section{Cat. 551-Type $3^{\mathrm{A}}$}

[RKD work no. 20958]

Master of the Virgo inter Virgines (follower of)

Triptych of the Adoration of the Magi with Thomas Snoel in Prayer (c. 1500-1525)

$69 \times 61 \mathrm{~cm}$ (centre panel) and $69 \times 27.5 \mathrm{~cm}$ (wings)

Amersfoort, Stichting Armen de Pot

BIBL.: FRIEDLÄNDER V, no. 50; Exh. cat. Utrecht 1999-2000, 91, 273 (with bibl.).

HISTORICAL INFORMATION: The epitaph on the predella identifies the sitter as the priest Thomas Snoel. It also mentions that he died in $15^{26}$ and was buried in a church called Peterskerkhof (without any further details regarding the location of this church).

Identity of the sitter(s): Thomas Snoel

Provenance: unknown

Number of portrait(s): 1

Type of person(s): religious (man alone: priest)

Attitude of the sitter(s): hands clasped

Representation of the sitter(s): full-length

Gaze of the sitter(s): towards the scene

Object(s): no

Coat(s) of arms: no

Environment: historical setting

Structuring of the pictorial space: not applicable

Patron saint(s): Barbara

Gesture of the patron saint(s): introducing

Type of religious scene: narrative

Religious scene(s) depicted: the Lactation of St. Bernard, the Adoration of the Magi, St. Jerome in the wilderness 
Cat. 552-Type 2A

Master of the Von Grote Adoration

Triptych of the Lamentation with a Family in Prayer and Patron Saints (c. 1500-1510)

$90 \times 68.5 \mathrm{~cm}$ (centre panel) and $90 \times 30 \mathrm{~cm}$ (wings)

Vienna, Gemäldegalerie der Akademie des bildenden Künste, inv. nos. 567 and 570

BIBL.: FRIEDLÄNDER XI, no. 32; Exh. cat.

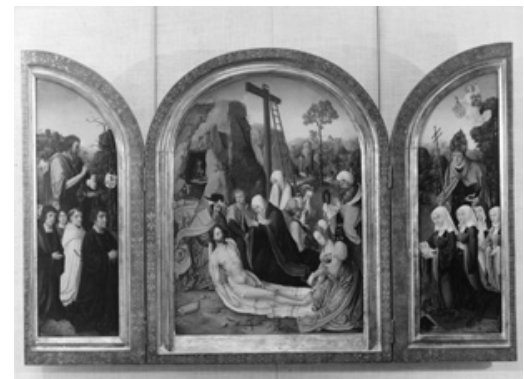

Bruges 1969, no. 94 (with bibl.).

Identity of the sitter(s): unknown

Provenance: unknown

Number of portrait(s): 10

Type of person(s): mixed (family)

Attitude of the sitter(s): hands clasped, holding a book

Representation of the sitter(s): full-length

Gaze of the sitter(s): into space, towards the scene, towards the ground

Object(s): yes (book)

Coat(s) of arms: yes

Environment: historical setting

Structuring of the pictorial space: unified space with discontinuities

Patron saint(s): John the Baptist, Cornelius

Gesture of the patron saint(s): holding his/her attribute

Type of religious scene: narrative

Religious scene(s) depicted: the Lamentation

\section{Cat. 553-Type 6A}

[RKD work no. 12442]

Master of the Von Grote Adoration

Two Wings. A Family in Prayer with Patron Saints (c. 1500-1520)

$85 \times 26.5 \mathrm{~cm}$ (each wing)

Luzern, sale Galerie Fischer (18 June 1996), lot no. 2002

Identity of the sitter(s): unknown

Provenance: unknown

Number of portrait(s): 5

Type of person(s): lay (family with children)

Attitude of the sitter(s): hands clasped

Representation of the sitter(s): full-length

Gaze of the sitter(s): indeterminate 
Object(s): yes (rosary, small cross)

Coat(s) of arms: no

Environment: landscape, no sacred connotation (incomplete)

Structuring of the pictorial space: indeterminate

Patron saint(s): Michael, Catherine

Gesture of the patron saint(s): holding his/her attribute

Type of religious scene: indeterminate

Religious scene(s) depicted: memento mori

\section{Cat. 554-Type 6A}

[Link to the Friedländer 3.o Database]

Master of the Von Grote Adoration

Two Wings. A Family in Prayer with Patron Saints (c. 1500-1510)

Size unknown

Whereabouts unknown

BIBL.: FRIEDLÄNDER XI, no. 31 .

Identity of the sitter(s): unknown

Provenance: unknown

Number of portrait(s): 13

Type of person(s): lay (family with children)

Attitude of the sitter(s): hands clasped

Representation of the sitter(s): full-length

Gaze of the sitter(s): indeterminate

Object(s): yes (rosary, small cross)

Coat(s) of arms: no

Environment: landscape, no sacred connotation (incomplete)

Structuring of the pictorial space: indeterminate

Patron saint(s): James, Catherine

Gesture of the patron saint(s): holding his/her attribute

Type of religious scene: indeterminate

Religious scene(s) depicted: none

Cat. 555-Type ${ }_{3} \mathrm{C}$

[RKD work no. 49961]

Master of the Von Grote Adoration (circle of)

The Crucifixion with a Family in Prayer (c. 1500-1520)

$99.6 \times 144.3 \mathrm{~cm}$

New York, sale Christie's (15 October 1998), lot no. 16 
Identity of the sitter(s): unknown

Provenance: unknown

Number of portrait(s): 10

Type of person(s): lay (family with children)

Attitude of the sitter(s): hands clasped

Representation of the sitter(s): full-length

Gaze of the sitter(s): into space, towards the ground, towards the scene

Object(s): yes (prie-dieu, book, rosary)

Coat(s) of arms: yes

Environment: historical setting

Structuring of the pictorial space: not applicable

Patron saint(s): none

Gesture of the patron saint(s): not applicable

Type of religious scene: narrative

Religious scene(s) depicted: the Crucifixion

Cat. 556-Type $2 \mathrm{~A}$

[Link to the Friedländer 3.o Database]

Master of the Von Grote Adoration (or anonymous Antwerp Master)

Triptych of the Adoration of the Magi with a Family in Prayer and Patron Saints (c. 1520$)$

$105.5 \times 71 \mathrm{~cm}$ (centre panel) and $105.5 \times 30.5 \mathrm{~cm}$ (wings)

Hampton Court, Royal Collections, inv. no. 1207

BIBL.: FRIEDLÄNDER XI, no. 39; CAMPBELL 1985, no. 2 (with bibl.).

Identity of the sitter(s): unknown

Provenance: unknown

Number of portrait(s): 5

Type of person(s): lay (family with children)

Attitude of the sitter(s): hands clasped

Representation of the sitter(s): full-length, children in small scale

Gaze of the sitter(s): towards the scene

Object(s): yes (prie-dieu, book)

Coat(s) of arms: no

Environment: historical setting

Structuring of the pictorial space: unified space with discontinuities

Patron saint(s): a saint bishop, James

Gesture of the patron saint(s): protecting

Type of religious scene: narrative

Religious scene(s) depicted: the Adoration of the Magi 
Cat. 557-Type 4 B

MEMLING, Hans

Diptych of Jean du Cellier (after 1482)

$25.2 \times 15.1 \mathrm{~cm}$ (left wing) and $25.8 \times 16 \mathrm{~cm}$ (right wing)

Paris, Musée du Louvre, inv. nos. RF 309 and RF 886.

BIBL.: FRIEDLÄNDER VIa, no. 15; MARTENS M. and VAN MIEGROET 1981-1984; DE VOS 1994, no. 62; Corpus Paris II, no. 182; LANE 2009, no. 61 (with
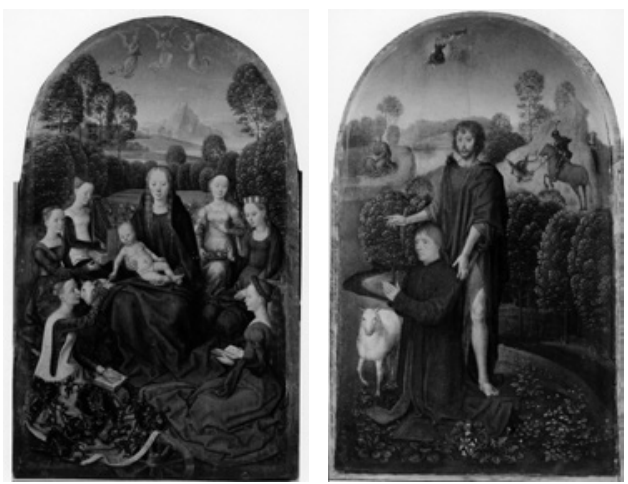
bibl.).

Historical INFORMATION: The sitter is Jean du Cellier, who was a spice merchant in Bruges. He is mentioned in the archives between 1473 and 1491. Shortly before 1482, he married Anne de Woestijne, the daughter of Pieter van Woestijne and Margaretha van Gruuthuse, Louis van Gruuthuse's sister. The coat of arms painted on the right wing is a later addition, but it is usually considered as having been copied from the coat of arms painted on the lost frame of the diptych. Taking into consideration the fact that the coat of arms of the Gruuthuse family are inserted at the centre of Jean's blazon, the diptych must have been executed after 1482. According to Weale, the presence of St. George and St. John the Evangelist in the background of the right wing alludes to Jean's father and brother, who were named Jan and Joris.

Identity of the sitter(s): Jean du Cellier

Provenance: unknown

Number of portrait(s): 1

Type of person(s): lay (man alone)

Attitude of the sitter(s): hands clasped

Representation of the sitter(s): full-length

Gaze of the sitter(s): towards the scene

Object(s): no

Coat(s) of arms: yes

Environment: enclosed garden

Structuring of the pictorial space: distinct spaces

Patron saint(s): John the Baptist

Gesture of the patron saint(s): protecting

Type of religious scene: hieratic

Religious scene(s) depicted: the Virgin and Child, St. Barbara, St. Catherine, St. Agnes, St. Cecilia, St. Lucy, St. Margaret, St. John in Patmos, St. George fighting the dragon 
Cat. 558 - Type $4 \mathrm{D}$

MEMLING, Hans

Diptych of Maarten van Nieuwenhove (dated 1487 on the frame)

$44 \times 33.5 \mathrm{~cm}$ (each wing)

Bruges, Sint-Janshospitaal, inv. no. O. SJ178. I.

BIBL.: FRIEDLÄNDER VIa, no.

14; DE VOS 1994, no. 78; Exh.
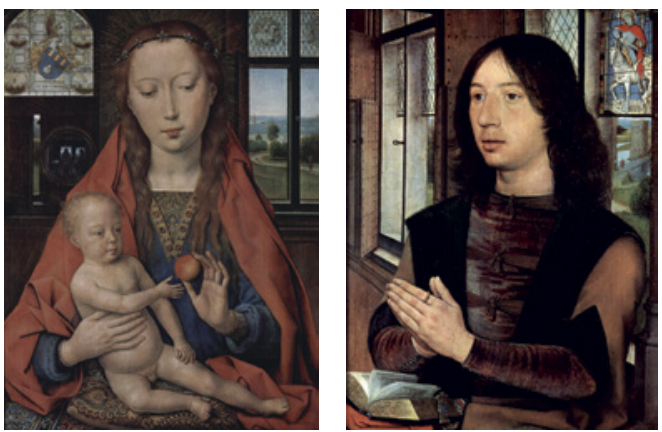

cat. Antwerp and Washington 2006, no. 26; LANE 2009, no. 14 (with bibl.). HISTORICAL INFORMATION: The inscription on the frame identifies the sitter as Maarten van Nieuwenhove, at the age of twenty-three: OC . OPVS . FIERI . FECIT . MARTINVS.DE.NEWENHOVEN . ANNO . DM 1487 et AN ${ }^{\circ}$. VERO . ETATIS . SVE :23. Maarten came from a wealthy family of Bruges. Many members of his family held political positions in the city and at the Burgundian court. When the diptych was commissioned, Maarten was destined for a brilliant political career. Indeed, he was appointed city councillor in 1492 and 1494, hoofdman in 1495 and 1498 and burgomaster in 1497. He died on 16 August 1500 , as stated on his tombstone, which was located in the family chapel in the church of Our Lady at Bruges.

Identity of the sitter(s): Maarten van Nieuwenhove

Provenance: unknown

Number of portrait(s): 1

Type of person(s): lay (man alone)

Attitude of the sitter(s): hands clasped

Representation of the sitter(s): half-length

Gaze of the sitter(s): into space

Object(s): yes (book)

Coat(s) of arms: yes

Environment: domestic setting

Structuring of the pictorial space: unified space with discontinuities

Patron saint(s): none

Gesture of the patron saint(s): not applicable

Type of religious scene: hieratic

Religious scene(s) depicted: the Virgin and Child 
Cat. 559-Type 4 B

MEMLING, Hans

Diptych of the Virgin and Child in a Rose-Garden with Angels, a Man in Prayer and St. George (c. 1490)

$43.3 \times 31.1 \mathrm{~cm}$ (each wing)

Munich, Alte Pinakothek, inv. nos. 680 and 1401

BIBL.: FRIEDLÄNDER VIa, no. 104;

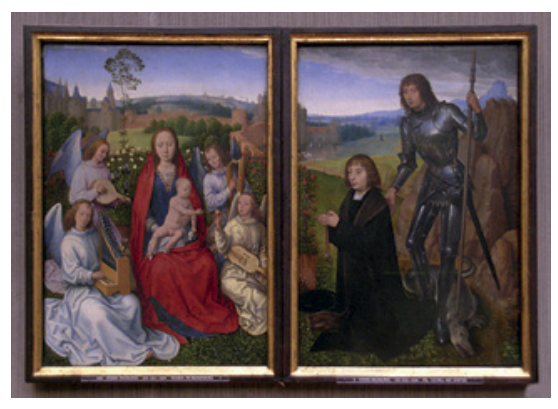

DE VOS 1994, no. 87; Mus. cat. Munich 2006, 328; LANE 2009, no. B9 (with bibl.).

Identity of the sitter(s): unknown

Provenance: unknown

Number of portrait(s): 1

Type of person(s): lay (man alone)

Attitude of the sitter(s): holding a rosary

Representation of the sitter(s): full-length

Gaze of the sitter(s): into space

Object(s): yes (rosary)

Coat(s) of arms: no

Environment: enclosed garden

Structuring of the pictorial space: unified space with discontinuities

Patron saint(s): George

Gesture of the patron saint(s): introducing

Type of religious scene: hieratic

Religious scene(s) depicted: the Virgin and Child, the Virgin and Child with St. Anne

Cat. 560 - Type $4 \mathrm{D}$

[RKD work no. 219270]

MEMLING, Hans

Diptych of the Virgin and Child with a Man in Prayer (c. 1480-1490)

$41.1 \times 33.2 \mathrm{~cm}$ (each wing)

Chicago, Chicago Art Institute, inv. nos. 1933.1050 and 1953.467

BIBL.: FRIEDLÄNDER VIa, no. 50, 92; DE VOS 1994, no. 55 (with bibl.); Mus.

cat. Chicago 2008, 250-59; LANE 2009, no. 20 (with bibl.).

Identity of the sitter(s): unknown

Provenance: unknown 
Number of portrait(s): 1

Type of person(s): lay (man alone)

Attitude of the sitter(s): hands clasped

Representation of the sitter(s): half-length

Gaze of the sitter(s): into space

Object(s): yes (book)

Coat(s) of arms: no

Environment: domestic setting

Structuring of the pictorial space: continuous space

Patron saint(s): none

Gesture of the patron saint(s): not applicable

Type of religious scene: hieratic

Religious scene(s) depicted: the Virgin and Child, St. Anthony

Cat. $5^{61}$-Type ${ }_{3} \mathrm{C}$

MEMLING, Hans

Panorama of the Advent and

Triumph of Christ (1480)

$81 \times 189 \mathrm{~cm}$

Munich, Alte Pinakothek, inv. no. WAF668

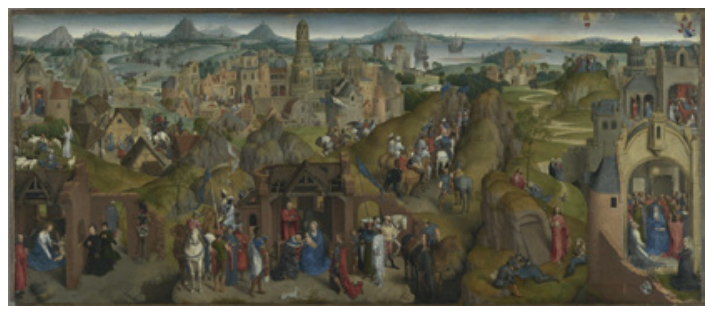

вIBL.: FRIEDLÄNDER VIa, no. 33; MARTENS M. 1992a, 227-32; DE VOS 1994, no. 38; Mus. cat. Munich 2006, 330-31; LANE 2009, no. 45 (with bibl.). HISTORICAL INFORMATION: The portrayed persons are Pieter Bultinc, Katelyne van Ryebeke and their son, Adriaan. Pieter was a merchant and a tanner, active in Bruges. The couple donated the panel to the chapel of the tanners' Guild of Bruges in 1480, as attested by an inscription on the frame, which is now lost but was transcribed in the seventeenth century. This chapel was located in the church of Our Lady. Pieter Bultinc belonged to this corporation and occupied several times the position of inspector. From 1477 to 1481 , he was also alderman of Bruges.

Identity of the sitter(s): Pieter Bultinc, Katelyne van Ryebeke and their son Adriaan

Provenance: Bruges, church of Our Lady, chapel of the tanners' Guild

Number of portrait(s): 3

Type of person(s): lay (family)

Attitude of the sitter(s): hands clasped, hands held up 
Representation of the sitter(s): full-length

Gaze of the sitter(s): into space, towards the scene

Object(s): no

Coat(s) of arms: yes

Environment: historical setting

Structuring of the pictorial space: fragmentation of the pictorial space

Patron saint(s): none

Gesture of the patron saint(s): not applicable

Type of religious scene: narrative

Religious scene(s) depicted: the Advent and Triumph of Christ

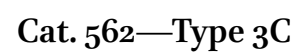

MEMLING, Hans

Panorama of the Passion (c. 1470-1471)

$56.7 \times 92.2 \mathrm{~cm}$

Turin, Galleria Sabauda, inv. no. 8

BIBL.: FRIEDLÄNDER VIa, no. 34; Corpus

Turino, no. 18; DE VOS 1994, no. 1; LANE 2009, no. 68 (with bibl.).

HistoricAl INFORMATION: Tomaso Portinari and his wife Maria Baroncelli have been identified by comparison with their portraits at the Metropolitan Museum (cat. 587). This panorama has been linked to a painting from the collection of Cosimo de' Medici, described by Vasari. The art historian located this painting in the Portinari chapel at the church Santa Maria Nuova in Florence. According to De Vos, the painting was a commission for the Portinari chapel in the church of St. James and it remained in Bruges until 1500-1510. Nuttal believes that it was destined for the Bruges church of the Franciscan Observants. Tommaso and Maria married in 1470 and had their first daughter in 1471. Since the girl is not depicted, the painting must be dated c. 1470-1471.

Identity of the sitter(s): Tommaso Portinari and Maria Baroncelli

Provenance: Florence, church Santa Maria Nuova (?)

Number of portrait(s): 2

Type of person(s): lay (couple)

Attitude of the sitter(s): hands clasped

Representation of the sitter(s): full-length

Gaze of the sitter(s): into space

Object(s): no 
Coat(s) of arms: no

Environment: historical setting

Structuring of the pictorial space: fragmentation of the pictorial space

Patron saint(s): none

Gesture of the patron saint(s): not applicable

Type of religious scene: narrative

Religious scene(s) depicted: the Passion

Cat. 563-Type 6B

[RKD work no. 27937]

MEMLING, Hans

Portrait of a Man of the Lespinette Family in Prayer (c. 1480)

$30 \times 22 \mathrm{~cm}$

The Hague, Mauritshuis, inv. no. 595

BIBL.: FRIEDLÄNDER VIa, no. 79; DE VOS 1994, no. 40; LANE 2009, no. 32 (with bibl.).

HISTORICAL INFORMATION: The coat of arms painted on the reverse of the panel indicates that the sitter is a member of the Lespinette family, who came from Franche-Comté.

Identity of the sitter(s): Member of the Lespinette family

Provenance: unknown

Number of portrait(s): 1

Type of person(s): lay (man alone)

Attitude of the sitter(s): hands clasped

Representation of the sitter(s): half-length

Gaze of the sitter(s): indeterminate

Object(s): no

Coat(s) of arms: yes (overpainted, on the reverse)

Environment: landscape, no sacred connotation (incomplete)

Structuring of the pictorial space: indeterminate

Patron saint(s): none

Gesture of the patron saint(s): not applicable

Type of religious scene: indeterminate

Religious scene(s) depicted: none 
Cat. 564-Type 6B

MEMLING, Hans

Portrait of a Young Man in Prayer (c. 1487)

$16 \times 12 \mathrm{~cm}$

Banbury, National Trust

BIBL.: FRIEDLÄNDER VIa, no. 87; DE VOS 1994, no. 80; LANE 2009, no. 3 (with bibl.).

Identity of the sitter(s): unknown

Provenance: unknown

Number of portrait(s): 1

Type of person(s): lay (man alone)

Attitude of the sitter(s): hands clasped

Representation of the sitter(s): half-length

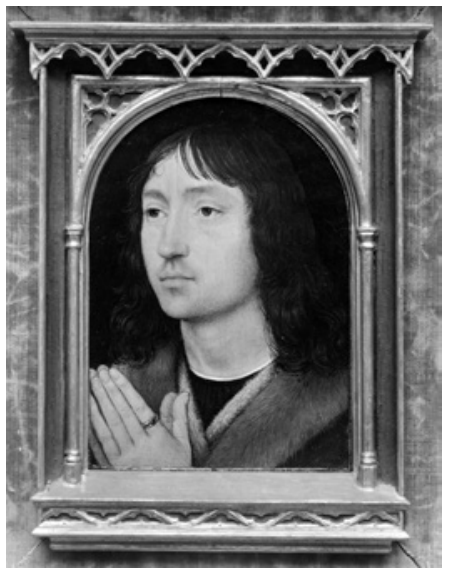

Gaze of the sitter(s): indeterminate

Object(s): no

Coat(s) of arms: no

Environment: neutral space (incomplete)

Structuring of the pictorial space: indeterminate

Patron saint(s): none

Gesture of the patron saint(s): not applicable

Type of religious scene: indeterminate

Religious scene(s) depicted: none

Cat. 565-Type 6B

MEMLING, Hans

Portrait of a Young Man in Prayer (c. 1480)

$39 \times 25.5 \mathrm{~cm}$

London, NG, inv. no. NG 2594

BIBL.: FRIEDLÄNDER VIa, no. 78; DE VOS 1994, no. 45; CAMPBELL 1998, 370-73; LANE 2009, no. 38 (with bibl.).

Identity of the sitter(s): unknown

Provenance: unknown

Number of portrait(s): 1

Type of person(s): lay (man alone)

Attitude of the sitter(s): hands clasped

Representation of the sitter(s): half-length

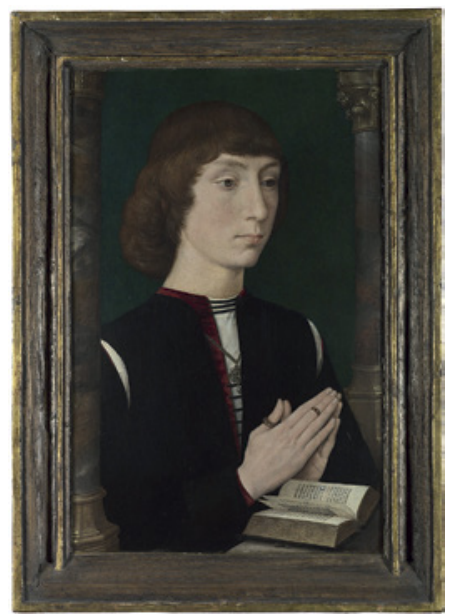


Gaze of the sitter(s): indeterminate

Object(s): yes (book)

Coat(s) of arms: no

Environment: neutral space (incomplete)

Structuring of the pictorial space: indeterminate

Patron saint(s): none

Gesture of the patron saint(s): not applicable

Type of religious scene: indeterminate

Religious scene(s) depicted: none

Cat. 566-Type 6B

MEMLING, Hans

Portrait of a Young Man in Prayer (c. 1485-1490) $29.2 \times 22.5 \mathrm{~cm}$

Madrid, Fundación Colección ThyssenBornemisza, inv. no. 1938.1

BIBL.: FRIEDLÄNDER VIb, supp. 232; EISLER 1989, no. 10; DE VOS 1994, no. 72; LANE 2009, no. 43 (with bibl.).

Identity of the sitter(s): unknown

Provenance: unknown

Number of portrait(s): 1

Type of person(s): lay (man alone)

Attitude of the sitter(s): hands clasped

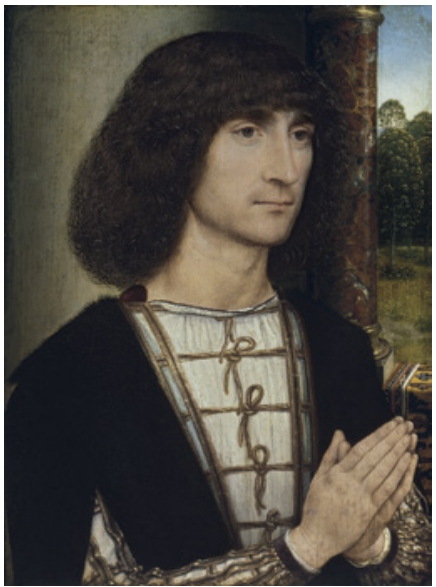

Representation of the sitter(s): half-length

Gaze of the sitter(s): indeterminate

Object(s): no

Coat(s) of arms: no

Environment: domestic setting

Structuring of the pictorial space: indeterminate

Patron saint(s): none

Gesture of the patron saint(s): not applicable

Type of religious scene: indeterminate

Religious scene(s) depicted: none (still life on the reverse) 
Cat. 567-Type 6B

MEMLING, Hans

Portrait of Gilles Joye in Prayer (dated 1472 on the frame)

$37.3 \times 29.2 \mathrm{~cm}$

Williamstown, Sterling and Francine Clark Art Institute, inv. no. 408

BIBL.: FRIEDLÄNDER VIa, no. 72; Corpus New England, no. 72; VAN MOLLE 1960; DE VOS 1994, no. 18; LANE 2009, no. 73 (with bibl.).

HISTORICAL INFORMATION: The famous composer and musician, Gilles Joye $\left(1425^{-1483}\right)$, has been identified by Van

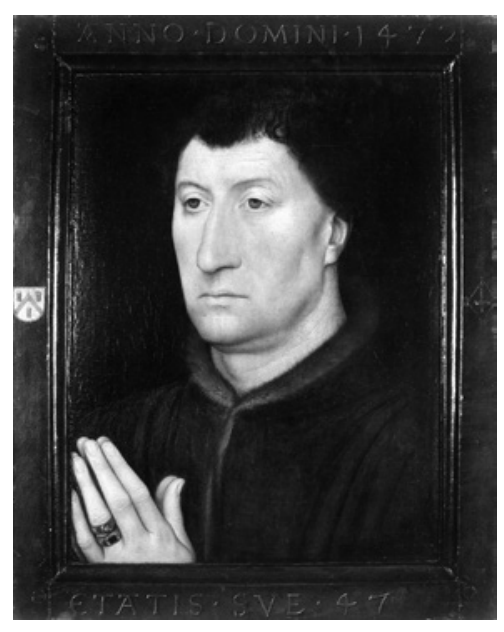
Molle, on the basis of the coat of arms. He was canon of the chapter of Our Lady in Clèves, from 1453 to 1460 , and then canon of St. Donatian in Bruges, from 1463 onwards. Between 1465 and 1469 , he also officiated as a priest at the Oudekerk in Delft. In 1462, he entered the musical chapel of Philip the Good, where he was initially cleric and then chaplain.

Identity of the sitter(s): Gilles Joye

Provenance: Bruges, church of St. Donatian

Number of portrait(s): 1

Type of person(s): religious (man alone: canon)

Attitude of the sitter(s): hands clasped

Representation of the sitter(s): half-length

Gaze of the sitter(s): indeterminate

Object(s): no

Coat(s) of arms: yes

Environment: neutral space (incomplete)

Structuring of the pictorial space: indeterminate

Patron saint(s): none

Gesture of the patron saint(s): not applicable

Type of religious scene: indeterminate

Religious scene(s) depicted: none 
Cat. 568-Type 6B

MEMLING, Hans

Portrait of Jacob Obrecht in Prayer (dated 1496) $50.8 \times 36.1 \mathrm{~cm}$

Fort Worth, Kimbell Art Museum, inv. no. KAM.1993.02

BIBL.: DE VOS 1994, no. 93; LANE 2009, no. $\mathrm{C} 1$ (with bibl.).

HISTORICAL INFORMATION: Jacob Obrecht was a famous composer. Son of Willem Obrecht, Trumpeter of the city of Ghent, he was born in 1458 or 1459. In 1484, he was appointed Choirmaster of the cathedral of Cambrai, but

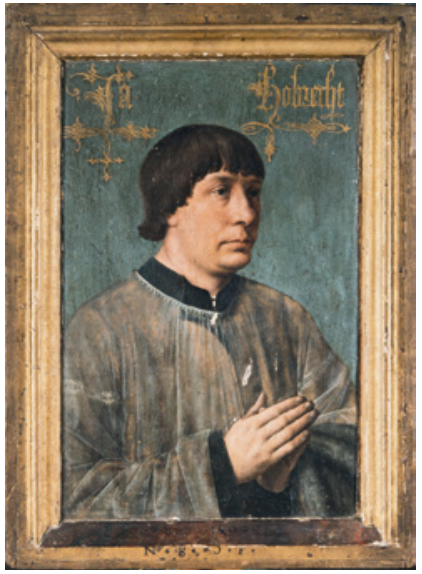
was later discharged for misbehaviour. He later occupied the same role at the church of St. Donatian in Bruges, where he is documented from 1485 to 1491. In 1487, Jacob moved to the court of Ferrara. From 1492 to 1496, he worked for the church of Our Lady in Antwerp before returning to Bruges in 1498 and then back to Ferrara in 1504, where he died from the plague in 1505 .

Identity of the sitter(s): Jacob Obrecht

Provenance: unknown

Number of portrait(s): 1

Type of person(s): religious (man alone: canon)

Attitude of the sitter(s): hands clasped

Representation of the sitter(s): half-length

Gaze of the sitter(s): indeterminate

Object(s): no

Coat(s) of arms: no

Environment: neutral space (incomplete)

Structuring of the pictorial space: indeterminate

Patron saint(s): none

Gesture of the patron saint(s): not applicable

Type of religious scene: indeterminate

Religious scene(s) depicted: none 
Cat. 569-Type ${ }_{3} \mathrm{C}$

MEMLING, Hans

The Lamentation with a Man in Prayer (c. 1475-1480)

$68 \times 53 \mathrm{~cm}$

Rome, Galleria Dorie Pamphili, appartamenti privati BIBL.: FRIEDLÄNDER VIa, no. 36; DE VOS 1994, no. 25; LANE 2009, no. 64 (with bibl.).

Identity of the sitter(s): unknown

Provenance: unknown

Number of portrait(s): 1

Type of person(s): lay (man alone)

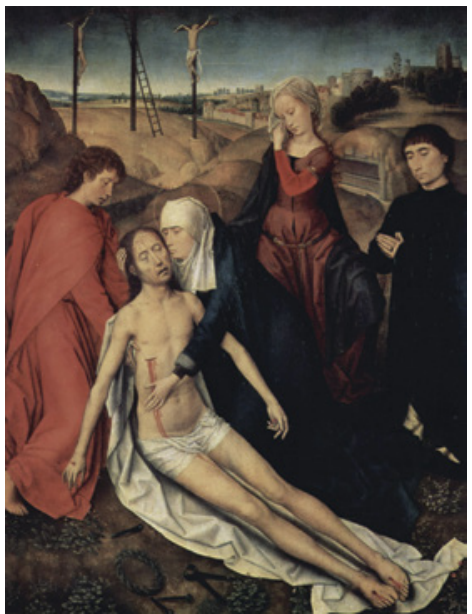

Attitude of the sitter(s): hands clasped

Representation of the sitter(s): full-length

Gaze of the sitter(s): towards the ground

Object(s): no

Coat(s) of arms: no

Environment: historical setting

Structuring of the pictorial space: not applicable

Patron saint(s): none

Gesture of the patron saint(s): not applicable

Type of religious scene: narrative

Religious scene(s) depicted: the Lamentation

Cat. 570-Type 5

[RKD work no. 116042]

MEMLING, Hans

The St. Ursula Shrine (before 1489)

$91.5 \times 99 \times 41.5 \mathrm{~cm}$

Bruges, Sint-Janshospitaal, inv. no. O.SJ176.I.

BIB L.: FRIEDLÄNDER VIa, no. 24; MARTENS D. 1994; DE VOS 1994, no. 83; LANE 2009, no. 13 (with bibl.).

HISTORICAL INFORMATION: The shrine was commissioned by the brothers and sisters of the Hospital of St. John in Bruges to replace the older shrine, which contained the relics of St. Ursula. The transfer of the relics took place on 21 October 1489, the day of the Feast of St. Ursula. Three of the four statuettes placed at the angles of the shrine represent the patron saints of the directors of 
the hospital at that time: St. John (Jan Floreins), St. James (Jacob de Ceuninc), and St. Agnes (Agnes Casembrod, the prioress). It is usually accepted that the two sisters depicted around the Virgin and Child on the gable end are the patrons of the shrine; they would be Jossine van Dudzele and Anna van den Moortele. De Vos nonetheless rejects this hypothesis and considers these figures as symbols of the religious community of the hospital.

Identity of the sitter(s): sisters of the Hospital of St. John in Bruges (Jossine van Dudzele and Anna van den Moortele?)

Provenance: Bruges, Hospital of St. John

Number of portrait(s): 4

Type of person(s): religious (group: hospital sisters)

Attitude of the sitter(s): hands clasped

Representation of the sitter(s): full-length

Gaze of the sitter(s): into space

Object(s): no

Coat(s) of arms: no

Environment: architectural space, no sacred connotation

Structuring of the pictorial space: not applicable

Patron saint(s): none

Gesture of the patron saint(s): not applicable

Type of religious scene: hieratic

Religious scene(s) depicted: the Life of St. Ursula, the Virgin and Child

Cat. 571 -Type $3 \mathrm{D}$

MEMLING, Hans

The Virgin and Child Enthroned with Saints and Angels and a Man in Prayer (after 1479)

$67 \times 72.1 \mathrm{~cm}$

New York, MET, inv. no. 14.40.634 BIBL.: FRIEDLÄNDER VIa, no. 65; DE VOS 1994, no. 35; AINSWORTH and CHRISTIANSEN 1998, 116-17; LANE 2009, no. 47 (with bibl.).

Identity of the sitter(s): unknown Provenance: unknown

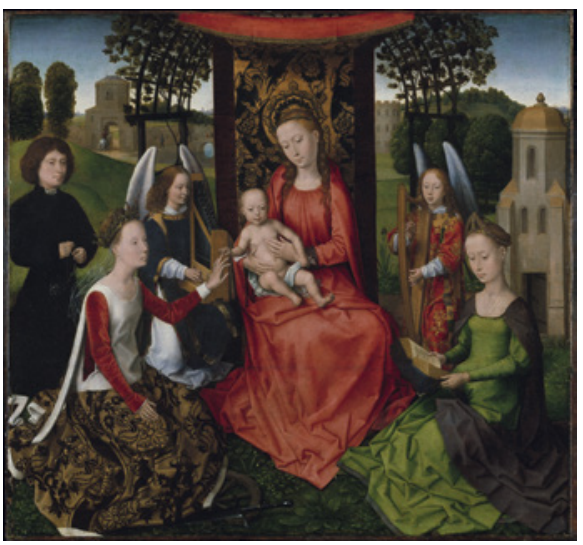

Number of portrait(s): 1 
Type of person(s): lay (man alone)

Attitude of the sitter(s): holding a rosary

Representation of the sitter(s): full-length

Gaze of the sitter(s): into space

Object(s): yes (rosary)

Coat(s) of arms: no

Environment: enclosed garden

Structuring of the pictorial space: not applicable

Patron saint(s): none

Gesture of the patron saint(s): not applicable

Type of religious scene: hieratic

Religious scene(s) depicted: the Virgin and Child, St. Catherine, St. Barbara

\section{Cat. $57^{2}$-Type $3^{B}$}

MEMLING, Hans

The Virgin and Child with a Family in Prayer and Patron Saints ('The Virgin of Jacob Floreins') (c. 149o)

$130.3 \times 160 \mathrm{~cm}$

Paris, Musée du Louvre, inv. no. RF 215

BIBL.: FRIEDLÄNDER VIa, no. 66; DE VOS 1994, no. 86; Corpus Paris II, no. 181; LANE 2009, no. 57 (with

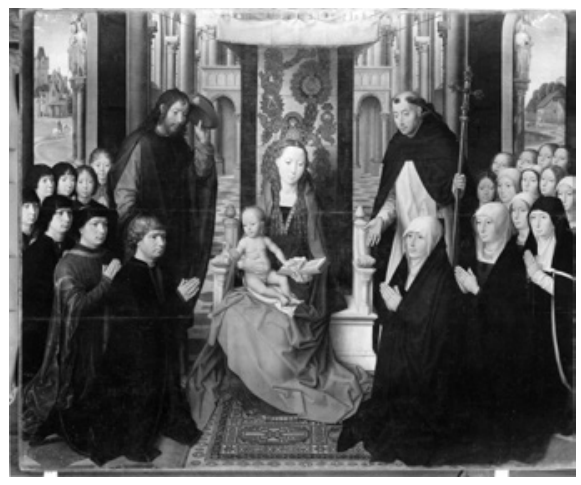
bibl.).

HistoriCAL INFORMATION: Weale identified the father of this family as Jacob Floreins, who was a spice merchant of Bruges, married to a woman from the Spanish Quintanadueña family. This identification is based on a mark on the rug in the centre of the composition, which Weale considered as a trade mark used by at least three members of the Floreins family. Unfortunately, he did not cite any source for this information. According to De Vos, this identification should be rejected.

Identity of the sitter(s): Jacob Floreins and his family (?)

Provenance: unknown

Number of portrait(s): 21

Type of person(s): mixed (family with children)

Attitude of the sitter(s): hands clasped 
Representation of the sitter(s): full-length

Gaze of the sitter(s): into space, towards the scene

Object(s): no

Coat(s) of arms: no

Environment: ecclesial space

Structuring of the pictorial space: not applicable

Patron saint(s): James, Dominic

Gesture of the patron saint(s): introducing

Type of religious scene: hieratic

Religious scene(s) depicted: the Virgin and Child

\section{Cat. 573-Type ${ }_{3}$ B}

MEMLING, Hans

The Virgin and Child with a Man in Prayer and St. Anthony (dated 1472)

$92.7 \times 53.6 \mathrm{~cm}$

Ottawa, National Gallery of Canada, inv. no. 6191 BIBL.: FRIEDLÄNDER VIa, no. 64; DE VOS 1994, no. 19; LANE 2009, no. 56 (with bibl.).

Identity of the sitter(s): unknown

Provenance: unknown

Number of portrait(s): 1

Type of person(s): lay (man alone)

Attitude of the sitter(s): hands clasped

Representation of the sitter(s): full-length

Gaze of the sitter(s): towards the scene

Object(s): yes (purse)

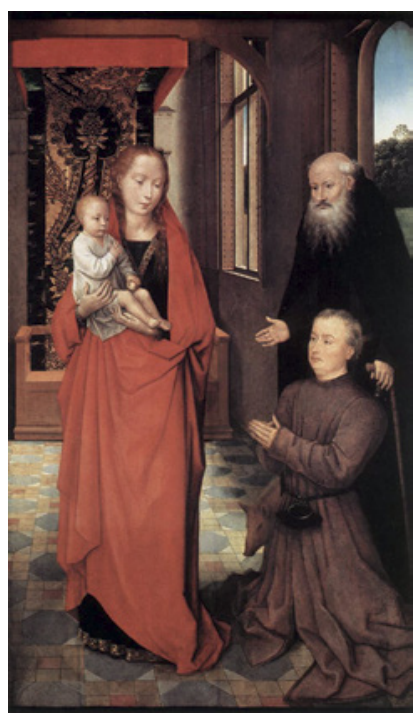

Coat(s) of arms: no

Environment: domestic setting

Structuring of the pictorial space: not applicable

Patron saint(s): Anthony

Gesture of the patron saint(s): introducing

Type of religious scene: hieratic

Religious scene(s) depicted: the Virgin and Child 
Cat. 574-Type $3^{B}$

MEMLING, Hans

The Virgin and Child with a Man in Prayer and

St. George (c. 1480-1485)

$55.6 \times 39.5 \mathrm{~cm}$

London, NG, inv. no. NG 686

BIBL.: FRIEDLÄNDER VIa, no. 63; DE VOS 1994, no. 51; CAMPBELL 1998, 354-58; LANE 2009, no. 36 (with bibl.).

Identity of the sitter(s): unknown

Provenance: unknown

Number of portrait(s): 1

Type of person(s): lay (man alone)

Attitude of the sitter(s): hands clasped

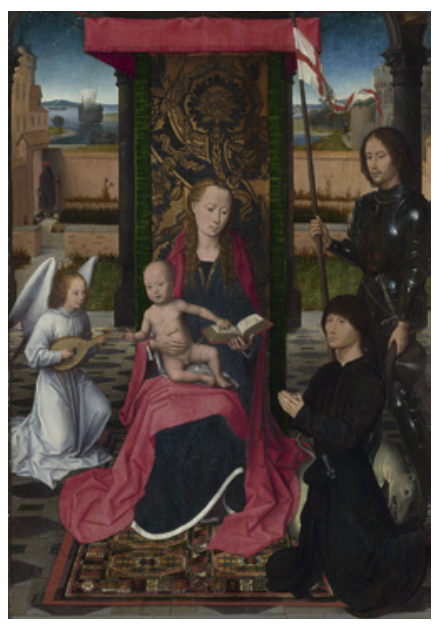

Representation of the sitter(s): full-length

Gaze of the sitter(s): into space

Object(s): yes (dagger, hat)

Coat(s) of arms: no

Environment: architectural space with sacred connotation

Structuring of the pictorial space: not applicable

Patron saint(s): George

Gesture of the patron saint(s): holding his/her attribute

Type of religious scene: hieratic

Religious scene(s) depicted: the Virgin and Child

\section{Cat. 575-Type 6A}

MEMLING, Hans

Three Fragments. The Virgin and Child and a Family in Prayer (c. 1490)

$43 \times 36 \mathrm{~cm}$ (panel with the Virgin and Child), $44.7 \times 32.4 \mathrm{~cm}$ (panel with the female portrait) and $44.5 \times 32 \mathrm{~cm}$ (panel with the male portrait)

Private collection (panel with the Virgin and Child) and Bucharest, Muzeul
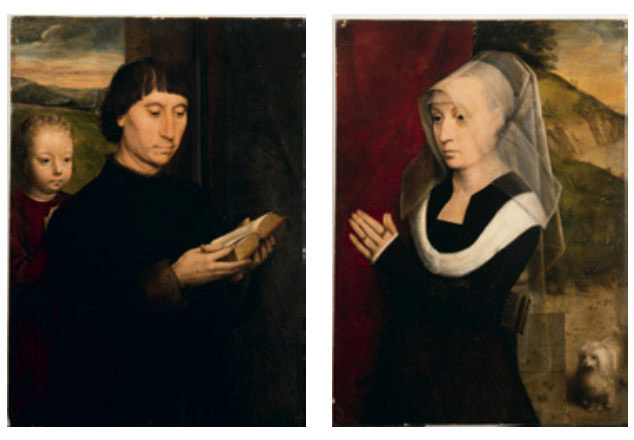
National de Arta, inv. no. 8.101 (panels with the portraits)

BIBL.: FRIEDLÄNDER VIa, no. 20; DE VOS 1994, no. 85; LANE 2009, no. 65 (with bibl.). 
Identity of the sitter(s): unknown

Provenance: unknown

Number of portrait(s): 3

Type of person(s): lay (family with children)

Attitude of the sitter(s): hands clasped, holding a book

Representation of the sitter(s): indeterminate

Gaze of the sitter(s): indeterminate

Object(s): yes (book, dog)

Coat(s) of arms: no

Environment: landscape, no sacred connotation (incomplete)

Structuring of the pictorial space: indeterminate

Patron saint(s): none

Gesture of the patron saint(s): not applicable

Type of religious scene: hieratic

Religious scene(s) depicted: the Virgin and Child

Cat. 576 - Type $2 B$

MEMLING, Hans

Triptych of St. Christopher ('Moreel Triptych') (dated 1484 on the frame) $141 \times 86.9 \mathrm{~cm}$ (centre panel) and $140.8 \times 86.8 \mathrm{~cm}$ (wings)

Bruges, Groeningemuseum, inv.

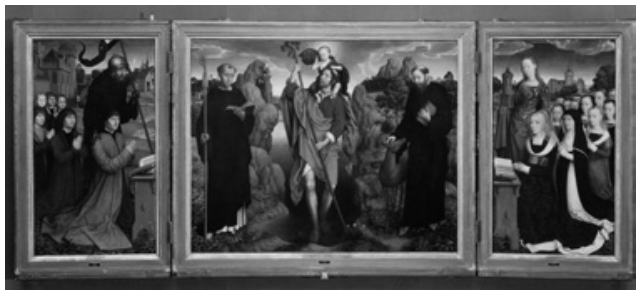
no. O.91.I.

BIBL.: FRIEDLÄNDER VIa, no. 12; Corpus Bruges I, no. 12; DE VOS 1994, no. 63; LANE 2009, no. 9 (with bibl.).

HISTORICAL INFORMATION: The triptych shows the family of Willem Moreel in prayer (see cat. 588). In 1485, Willem and Barbara gained authorisation to found a funerary chapel dedicated to St. Giles and St. Maurus in the church of St. James at Bruges. The triptych was destined for this chapel, as the date 1484 inscribed on the frame and the iconography strongly suggest.

Identity of the sitter(s): Willem Moreel, Barbara van Vlaenderberch and their children

Provenance: Bruges, church of St. James, St. Maur and St. Giles' altar

Number of portrait(s): 18

Type of person(s): lay (family with children)

Attitude of the sitter(s): hands clasped

Representation of the sitter(s): full-length

Gaze of the sitter(s): into space, towards the scene 
Object(s): yes (prie-dieu, book)

Coat(s) of arms: no

Environment: landscape, no sacred connotation

Structuring of the pictorial space: continuous space

Patron saint(s): William of Maleval, Barbara

Gesture of the patron saint(s): protecting, holding his/her attribute

Type of religious scene: hieratic

Religious scene(s) depicted: St. Christopher, St. Giles, St. George, St. John the Baptist, St. Maurus

Cat. 577 - Type ${ }_{3} \mathrm{C}$

MEMLING, Hans

Triptych of the Adoration of the Magi ('Triptych of Jan Floreins') (dated 1479 on the frame) $56.7 \times 67 \mathrm{~cm}$ (centre panel) and $56.7 \times 33.7 \mathrm{~cm}$ (wings)

Bruges, Sint-Janshospitaal, inv. no. O.SJ173.I

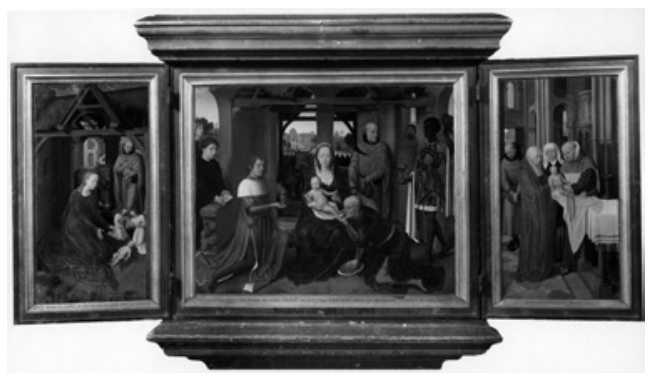

BIBL.: FRIEDLÄNDER VIa, no. 2; DE VOS 1994, no. 32; LANE 2009, no. 11 (with bibl.).

HISTORICAL INFORMATION: The inscription on the frame identifies the sitter as Jan Floreins: DIT . WERCK . DEDE . MAKEN . BROEDER . IAN . FLOREINS/ALIAS . VANDER . RIIST. . BROEDER . PROFFES . VANDE . HOSPITALE . VAN . SINT . IANS . IN . BRVGGHE . ANNO . MCCCCLXXIX ./ OPVS . IOHANIS . HEMLING:/. Jan Floreins, alias van der Rijst, is portrayed here at the age of thirty-six, as indicated by the inscription on the lower wall against which he is kneeling. He came from the Silly family and was born in 1443. He entered the Hospital of St. John in Bruges in 1472 as a brother. He then occupied the position of master from 1488 to 1497 . He died in 1504 or 1505 . The original location of the triptych remains unknown, but the inscription on the frame suggests that the work was meant to be seen (probably on a side-altar of the church of the hospital).

Identity of the sitter(s): Jan Floreins

Provenance: Bruges, Hospital of St. John

Number of portrait(s): 1

Type of person(s): religious (man alone: hospital brother)

Attitude of the sitter(s): holding a book

Representation of the sitter(s): full-length 
Gaze of the sitter(s): towards the ground

Object(s): yes (book)

Coat(s) of arms: yes (on the frame)

Environment: historical setting

Structuring of the pictorial space: not applicable

Patron saint(s): none

Gesture of the patron saint(s): not applicable

Type of religious scene: narrative

Religious scene(s) depicted: the Nativity, the Adoration of the Magi, the Presentation at the temple, St. John the Baptist, St. Veronica

Cat. 578 - Type $2 \mathrm{C}$

[R KD work no. 219444]

MEMLING, Hans

Triptych of the Crucifixion ('Greverade Triptych') (1491)

$221.5 \times 167 \mathrm{~cm}$ (centre panel) and $221.5 \times 83 \mathrm{~cm}$ (wings)

Lübeck, Sankt-Annen-Museum, inv. no. 1948/138

BIBL.: FRIEDLÄNDER VIa, no. 3; DE VOS 1994, no. 90; LANE 2009, no. 40 (with bibl.).

HISTORICAL INFORMATION: The identity of the man portrayed on the left wing cannot be established with certainty. He might be a member of the Greverade family from Lübeck, and more precisely Adolf Greverade. If this identification is correct, the triptych might have been commissioned to commemorate the foundation of the curacy of the Marian chapel of the cathedral of Lübeck, which belonged to the Greverade family.

Identity of the sitter(s): Adolf (?) Greverade

Provenance: Lübeck, cathedral, Greverade chapel

Number of portrait(s): 1

Type of person(s): lay (man alone)

Attitude of the sitter(s): hands clasped

Representation of the sitter(s): full-length

Gaze of the sitter(s): into space

Object(s): no

Coat(s) of arms: no

Environment: historical setting

Structuring of the pictorial space: continuous space

Patron saint(s): none

Gesture of the patron saint(s): not applicable

Type of religious scene: narrative 
Religious scene(s) depicted: the Passion of Christ, St. Giles, St. Blaise, St. Jerome, St. John the Baptist, the Annunciation

Cat. 579-Type 5

MEMLING, Hans

Triptych of the Crucifixion ('Triptych

of Jan Crabbe') (c. 1467-1470)

$78 \times 63 \mathrm{~cm}$ (centre panel), $83.3 \times 26.7$ $\mathrm{cm}$ (inner wings) and $83.3 \times 26.5 \mathrm{~cm}$ (outer wings)

Vicenza, Museo Civico, inv. no. A.297 (centre panel), New York, Pierpont Morgan Library (inner wings) and Bruges, Groeningemuseum, inv. no.
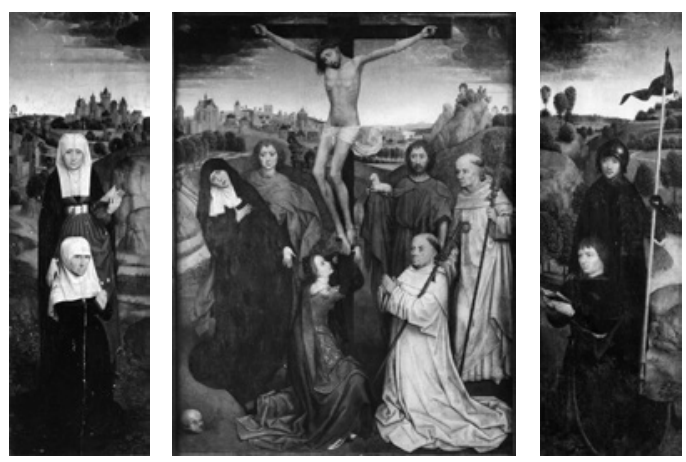
01254-1255 (outer wings)

BIB L.: FRIEDLÄNDER VIa, no. 4; Corpus Bruges I, no. 12a; DE VOS 1994, no. 5; GEIRNAERT 1997; LANE 2009, no. 54 (with bibl.).

HISTORICAL INFORMATION: The triptych shows Jan Crabbe, abbot of the Cistercian monastery of Ten Duinen in Koksijde (1457-1488), his mother Anna Willemz. and his half-brother Willem de Winter (son of Anna and Christoffel de Winter). Jan Crabbe most probably commissioned the triptych around 1468, with the plan of placing it in the chapel of the refuge house of Ten Duinen in Bruges, where he spent most of his time at the end of his life. As noticed by Noël Geirnaert, Jan Crabbe instituted a daily mass to be performed by a monk of the neighbouring Carmelite monastery, in honour of the Virgin, St. John the Baptist, St. John the Evangelist and St. Bernard, in the chapel of the refuge on 14July 1479. Taking into account the fact that all these saints are depicted in the triptych, the work was most probably destined for this chapel. Jan Crabbe was born in Hulst (Zeeland) between 1421 and 1426 and came from a wealthy family. He entered the Cistercian abbey of Ten Duinen as a novice in 1446. Before becoming abbot, he occupied the positions of Dijkgraaf of Polder Noordwatering and cellarer of the monastery. During his abbacy, Crabbe maintained close contact with the foreign bankers in Bruges and developed an interest in the Italian and humanistic culture of the time. From 1470 onwards, he began to commission manuscripts and acted as a patron of the arts. Besides this triptych, he commissioned stained-glass windows for the church of Hulst, goldsmith works and tapestries. Crabbe is also usually identified as the commissioner of Hugo van der Goes' Death of the Virgin (Bruges, Groeningemuseum), which he intended for Ten Duinen. Jan Crabbe also appears in cat. 19. 
Identity of the sitter(s): Jan Crabbe, Anna Willemz. and Willem de Winter Provenance: Koksijde, Cistercian abbey of Ten Duinen

Number of portrait(s): 3

Type of person(s): mixed (family)

Attitude of the sitter(s): hands clasped

Representation of the sitter(s): full-length

Gaze of the sitter(s): into space

Object(s): yes (book)

Coat(s) of arms: no

Environment: historical setting

Structuring of the pictorial space: unified space with discontinuities

Patron saint(s): Anne, John the Baptist, Bernard, William of Maleval

Gesture of the patron saint(s): introducing, holding his/her attribute

Type of religious scene: narrative

Religious scene(s) depicted: the Crucifixion, the Annunciation

Cat. 580 -Type $2 \mathrm{~A}$

[RKD work no. 37574]

MEMLING, Hans

Triptych of the Lamentation ('Triptych of Adriaan Reins') (dated 1480 on the frame)

$54 \times 46 \mathrm{~cm}$ (centre panel) and $44.5 \times 13.5 \mathrm{~cm}$ (wings)

Bruges, Sint-Janshospitaal, inv. no. O.SJ.177.I.

BIBL.: FRIEDLÄNDER VIa, no. 5; DE VOS 1994, no. 37; LANE 2009, no. 12 (with bibl.).

HISTORICAL INFORMATION: On the basis of the initials $A R$, painted on the frame, Weale identified the sitter as Adriaan Reins, who was brother of the Hospital of St. John in Bruges. Adriaan took his vows in 1479 and died before 1490. The original location of the triptych remains unknown. Taking into consideration the small size of the work, it might have been conceived as a work for personal devotion.

Identity of the sitter(s): Adriaan Reins

Provenance: Bruges, Hospital of St. John (?)

Number of portrait(s): 1

Type of person(s): religious (man alone: hospital brother)

Attitude of the sitter(s): hands clasped

Representation of the sitter(s): full-length

Gaze of the sitter(s): towards the scene

Object(s): no 
Coat(s) of arms: no

Environment: historical setting

Structuring of the pictorial space: continuous space

Patron saint(s): Adrian

Gesture of the patron saint(s): holding his/her attribute

Type of religious scene: narrative

Religious scene(s) depicted: the Lamentation, St. Barbara, St. Mary the Egyptian, St. Wilgeforte

Cat. 581-Type $1 \mathrm{D}$

MEMLING, Hans

Triptych of the Last Judgement ('Tani Triptych')

(c. 1467-1471)

$221 \times 161 \mathrm{~cm}$ (centre panel) and $223 \times 72 \mathrm{~cm}$ (wings)

Gdansk, Museum Narodowe, inv. no. SD/4131M BIBL.: FRIEDLÄNDER VIa, no. 8; Corpus Poland, no. 120; DE VOS 1994, no. 4; LANE 2009, no. 29 (with bibl.).

Historical information: Angelo Tani and his wife have been identified by Aby Warburg, on the basis of their coats of arms. Born in Florence in 1416, Tani was a banker

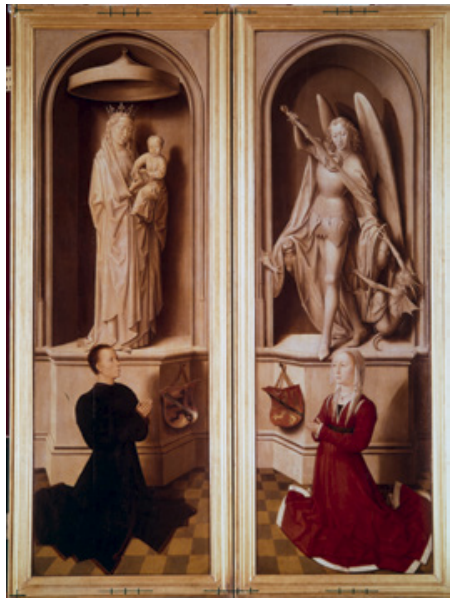

for the Medici bank. From 1446 onwards, he worked for the London branch of the bank, before becoming manager of the Bruges branch in 1455. In 146o, Tommaso Portinari replaced him in this position. Angelo Tani and Caterina Tanagli married in Florence in 1466 and had their first daughter in 1471. The triptych was thus executed between 1466 and 1471. Presumably, it was destined for the chapel of the Tani family, which was dedicated to St. Michael and located in the Badia Fiesolana in Fiesole. Completed in 1473 in Bruges, the triptych was transported by sea to Italy, in a galley leased by Tommaso Portinari and flying under the Burgundian flag. Soon after its departure, the galley was attacked by pirates working for the Hanseatic League and the triptych was brought to Gdansk, where it is still preserved today (on this unfortunate story, see Corpus Poland, 80-81, 85-87 and LANE 1991).

Identity of the sitter(s): Angelo Tani and Caterina Tanagli

Provenance: Gdansk (initially destined for the family chapel of Tani at the Badia Fiesolana in Fiesole)

Number of portrait(s): 2 
Type of person(s): lay (couple)

Attitude of the sitter(s): hands clasped

Representation of the sitter(s): full-length

Gaze of the sitter(s): into space, towards the scene

Object(s): no

Coat(s) of arms: yes

Environment: architectural space with sacred connotation

Structuring of the pictorial space: continuous space, grisaille

Patron saint(s): none

Gesture of the patron saint(s): not applicable

Type of religious scene: narrative

Religious scene(s) depicted: the Last Judgement, St. Michael, the Virgin and Child

Cat. 582-Type $1 \mathrm{~A}$

MEMLING, Hans

Triptych of the Two Saints John

(c. 1474-1479)

$173.6 \times 173.7 \mathrm{~cm}($ centre panel) and $176 \times$

$78.9 \mathrm{~cm}$ (wings)

Bruges, Sint-Janshospitaal, inv. no.

O. SJI175.I

BIB L.: FRIEDLÄNDER VIa, no. 11; DE

VOS 1994, no. 31; LANE 2009, no. 10 (with bibl.).
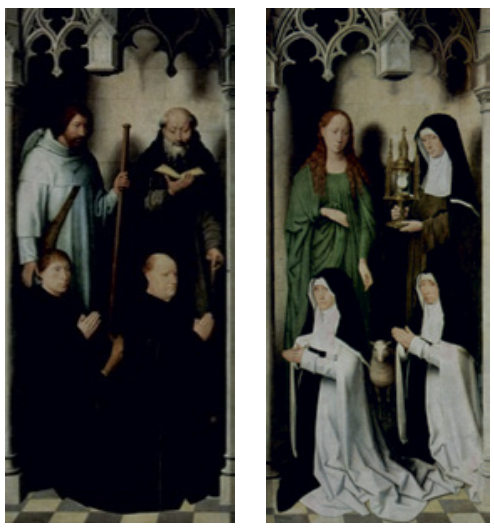

HISTORICAL INFORMATION: The triptych was commissioned around 1475 and was finished in 1479. It was destined for the high altar of the chapel of the Hospital of St. John in Bruges. This commission came from the two brothers and two sisters of the hospital, who are depicted on the reverse and who held important responsibilities within the community: Jacob Ceuninc (bursar from 1488-1490), Antheunis Seghers (master from 1461-1465 and 1469-1475, then bursar again from 1466-1468), Agnes Casembrod (prioress from 1459-1463 and from 1469-1489) and Clara van Hulsen (mentioned for the first time in the hospital in 1427 and deceased in 1479).

Identity of the sitter(s): Jacob de Ceunic, Antheunis Seghers, Agnes Casembrod, Clara van Hulsen

Provenance: Bruges, Hospital of St. John, high altar

Number of portrait(s): 4 
Type of person(s): religious (group: hospital brothers and sisters)

Attitude of the sitter(s): hands clasped

Representation of the sitter(s): full-length

Gaze of the sitter(s): into space

Object(s): no

Coat(s) of arms: no

Environment: niche

Structuring of the pictorial space: distinct spaces

Patron saint(s): James, Anthony, Clare, Agnes

Gesture of the patron saint(s): holding his/her attribute

Type of religious scene: hieratic

Religious scene(s) depicted: the Virgin and Child, St. Catherine, St. Barbara, St. John the Baptist, St. John the Evangelist, the Vision of St. John in Patmos, the Decollation of St. John the Baptist

Cat. 583 - Type $3^{B}$

MEMLING, Hans

Triptych of the Virgin and Child

Enthroned ('Triptych of John

Donne of Kidwelly') (c. 1480)

$72.3 \times 71.6 \mathrm{~cm}$ (centre panel) and

$72 \times 31.1 \mathrm{~cm}$ (wings)

London, NG, inv. no. NG 6275

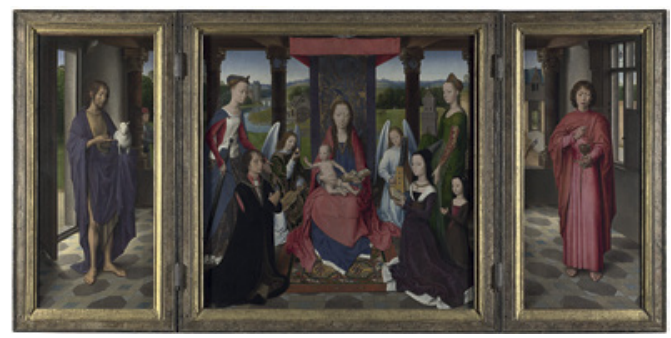

BIBL.: FRIEDLÄNDER VIa, no. 10; Corpus London III, no. 129; DE VOS 1994, no. 39; CAMPBELL 1998, 374-91; LANE 2009, no. 34 (with bibl.).

HISTORICAL INFORMATION: Coming from Wales, John Donne of Kidwelly was born in the 1420 in Picardy. He spent his whole career in the service of the House of York, as his father, Griffith Donne, had done before him. In 1461, Donne was made Usher of the Chamber, before being knighted in 1471. During his career, he was regularly sent to the Burgundian court, and he often resided in Calais. Sometime between 1462 and 1465, he married Elizabeth Hastings. They had at least four children, two girls and two boys. The little girl depicted next to her mother in the triptych is probably Anna, their oldest daughter. John Donne died in 1503 and was buried in the vicinity of King Edward Iv, in the St. George's chapel in Windsor. In the triptych, John and Elizabeth wear the collar of the House of York (recognisable by the suns and roses) to which the pendant of Edward IV, a lion, has been added. This indicates that the triptych dates from before 1483, the year Edward IV died, for this pendant was no longer worn after his death. 
Identity of the sitter(s): John Donne of Kidwelly and his family

Provenance: unknown

Number of portrait(s): 3

Type of person(s): lay (family)

Attitude of the sitter(s): hands clasped, holding a book

Representation of the sitter(s): full-length

Gaze of the sitter(s): into space

Object(s): yes (book)

Coat(s) of arms: yes

Environment: architectural space with sacred connotation

Structuring of the pictorial space: continuous space

Patron saint(s): Catherine, Barbara

Gesture of the patron saint(s): introducing

Type of religious scene: hieratic

Religious scene(s) depicted: the Virgin and Child, St. John the Baptist, St. John the Evangelist, St. Christopher, St. Anthony

Cat. 584 -Type $3 \mathrm{D}$

MEMLING, Hans

Triptych of the Virgin and Child Enthroned with a Man in Prayer and the Two Saints John (c. 1480-88)

$69 \times 47 \mathrm{~cm}$ (centre panel), $63.5 \times 18.8 \mathrm{~cm}$ (inner wings) and $69.9 \times 17.3 \mathrm{~cm}$ (outer wings)

Vienna, Kunsthistorisches Museum, inv. nos.

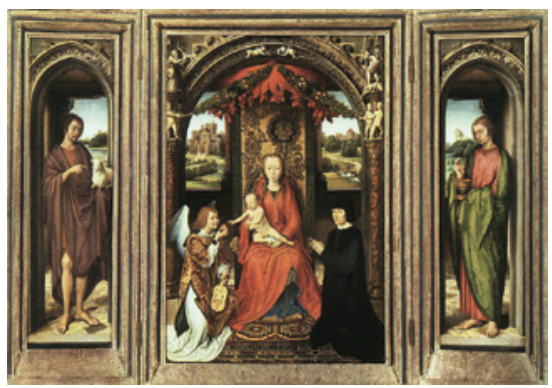

939-943-994

BIBL.: FRIEDLÄNDER VIa, no. 9; DE VOS 1994, no. 53; LANE 2009, no. 70 (with bibl.).

HISTORICAL INFORMATION: The current portrait is an overpainting that conceals the original portrait of Jan Crabbe, abbot of Ten Duinen (see cat. 579). The identity of the man currently visible in the triptych remains unknown.

Identity of the sitter(s): Jan Crabbe (overpainted)

Provenance: unknown

Number of portrait(s): 1

Type of person(s): religious (man alone: Cistercian abbot)

Attitude of the sitter(s): hands clasped

Representation of the sitter(s): full-length

Gaze of the sitter(s): into space 
Object(s): no

Coat(s) of arms: no

Environment: architectural space with sacred connotation

Structuring of the pictorial space: not applicable

Patron saint(s): none

Gesture of the patron saint(s): not applicable

Type of religious scene: hieratic

Religious scene(s) depicted: the Virgin and Child, St. John the Baptist, St. John the Evangelist

Cat. 585-Type $2 B$

MEMLING, Hans

Triptych of the Virgin and Child with St.Benedict ('Triptych of Benedetto Portinari') (1487)

$45.5 \times 34.5 \mathrm{~cm}$ (left wing), $41.5 \times$ $31.5 \mathrm{~cm}$ (centre panel) and $45 \times 34$ cm (right wing)

Berlin, Staatliche Museen zu Berlin, Gemäldegalerie, inv. no.
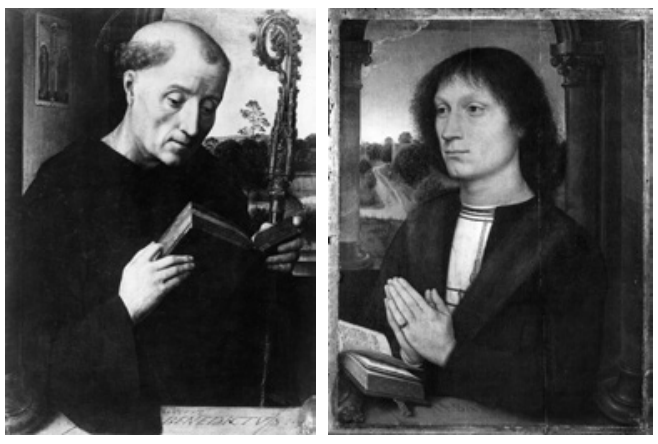

528B (centre panel) and Florence, Galleria degli Uffizi, inv. nos. 1100 and 1090 (wings)

BIBL.: FRIEDLÄNDER VIa, no. 23; DE VOS 1994, no. 79; VAN SCHOUTE and VEROUGSTRAETE 1996; LANE 2009, no. 23 (with bibl.).

Historical information: Born in 1466, Benedetto Portinari was the nephew of Tommaso Portinari (see cat. 587). From 1496 onwards, he was in charge of his uncle's business, together with his brother Folco.

Identity of the sitter(s): Benedetto Portinari

Provenance: unknown

Number of portrait(s): 1

Type of person(s): lay (man alone)

Attitude of the sitter(s): hands clasped

Representation of the sitter(s): half-length

Gaze of the sitter(s): into space

Object(s): yes (book)

Coat(s) of arms: no

Environment: architectural space with sacred connotation

Structuring of the pictorial space: continuous space

Patron saint(s): none 
Gesture of the patron saint(s): not applicable

Type of religious scene: hieratic

Religious scene(s) depicted: the Virgin and Child, St. Benedict

Cat. 586-Type 6A

MEMLING, Hans

Two Wings. A Member of the Rojas

Family in Prayer and a Young

Woman Reading (c. 1465-1467)

$106 \times 50.4 \mathrm{~cm}$ (left wing) and $36 \times$ $28.5 \mathrm{~cm}$ (right wing)

London, sale Sotheby's (10 July 2002), lot no. 8 (left wing) and Paris, private collection (right wing)
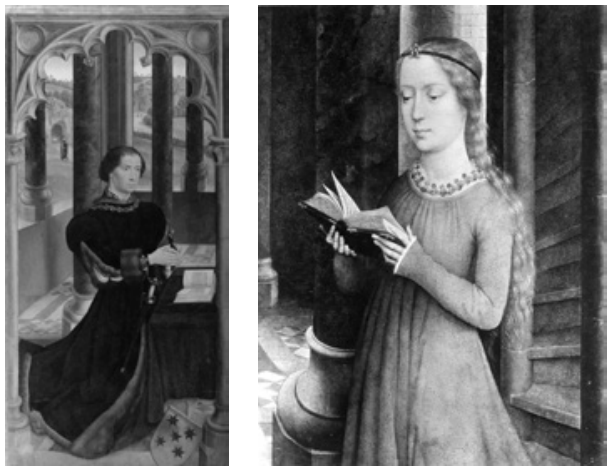

BIBL.: FRIEDLÄNDER VIb, supp. 228; DE VOS 1994, no. 2; PYPAERT 2008, no. 232; LANE 2009, no. B2 (with bibl.).

HISTORICAL INFORMATION: The man portrayed on the left wing is a member of the Rojas family, from Spain. According to Von Baldass, he is Francisco Rojas, who was ambassador of the Catholic Kings at the Burgundian court. De Vos believes that he is an older member of this family.

Identity of the sitter(s): member of the Rojas family (Francisco?)

Provenance: unknown

Number of portrait(s): 2

Type of person(s): lay (couple?)

Attitude of the sitter(s): hands clasped, holding a book

Representation of the sitter(s): full-length

Gaze of the sitter(s): indeterminate

Object(s): yes (books)

Coat(s) of arms: yes

Environment: architectural space, no sacred connotation (incomplete)

Structuring of the pictorial space: indeterminate

Patron saint(s): none

Gesture of the patron saint(s): not applicable

Type of religious scene: indeterminate

Religious scene(s) depicted: none 
Cat. 587 -Type $6 \mathrm{~A}$

MEMLING, Hans

Two Wings. Portraits of Tommaso

Portinari and Maria Baroncelli in Prayer (1470)

$44.1 \times 34 \mathrm{~cm}$ (each wing)

New York, MET, inv. nos. 14.40.626-627. BIBL.: FRIEDLÄNDER VIa, no. 69; DE VOS 1994, no. 9; LANE 2009,
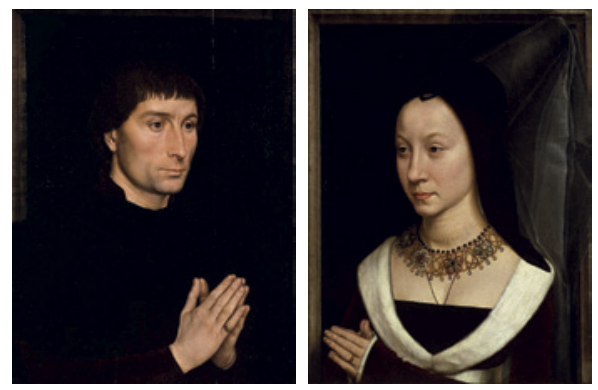
no. 50 (with bibl.).

HistoriCAl INFORMation: Tommaso Portinari (1428-1501) was a wealthy Florentine merchant. He belonged to the fifth generation of this famous family. He arrived in the Low Countries in 1440, at the age of twelve. In 1455, he started to work for the Bruges branch of the Medici bank and became its director in 1465, succeeding Angelo Tani (see cat. 581). He also made a political and diplomatic career. In 1464, Portinari was appointed councillor of the Duke Philip the Good. He married Maria Baroncelli in 1470 and their first son was born two years later. The death of Charles the Bold in 1477 marked the beginning of the financial decline of the Florentine banker, who definitely returned to Italy in 1497. These wings were probably part of a triptych dedicated to the Virgin and Child. We do not have any information about the original location or function of this triptych. Portinari and his wife also appear in cat. 562.

Identity of the sitter(s): Tommaso Portinari and Maria Baroncelli

Provenance: unknown

Number of portrait(s): 2

Type of person(s): lay (couple)

Attitude of the sitter(s): hands clasped

Representation of the sitter(s): half-length

Gaze of the sitter(s): indeterminate

Object(s): no

Coat(s) of arms: no

Environment: neutral space (incomplete)

Structuring of the pictorial space: indeterminate

Patron saint(s): none

Gesture of the patron saint(s): not applicable

Type of religious scene: indeterminate

Religious scene(s) depicted: none 
Cat. 588-Type 6A

MEMLING, Hans

Two Wings. Portraits of Willem Moreel and Barbara van Vlaenderberch in Prayer (c. 1472-1475)

$39.4 \times 29 \mathrm{~cm}$ (left wing) and $39.3 \times 29.5 \mathrm{~cm}$ (right wing)

Brussels, MRBAB, inv. nos. 1451-52

BIBL.: FRIEDLÄNDER VIa, no. 68; DE
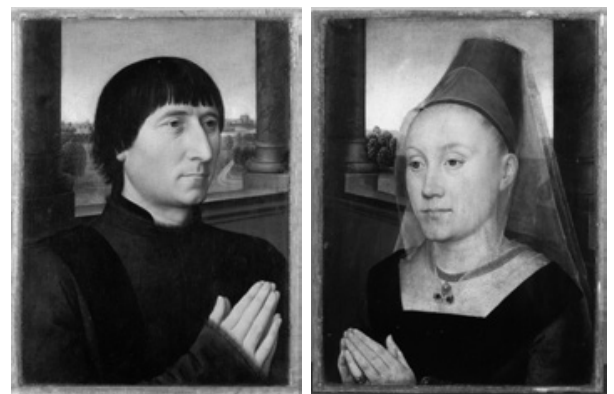

VOS 1994, no. 22; STROO et alii 1999, 20016; LANE 2009, no. 18 (with bibl.).

HISTORICAL INFORMATION: Willem Moreel and his wife Barbara van Vlaenderberch are identified by their coats of arms painted on the reverse of the panels. Lord of Oostcleychem, Willem was a merchant, who made a political career in Bruges. He was appointed burgomaster in 1478 and 1483, bailiff in 1488 and treasurer in 1489 . The couple is also portrayed with their children on Memling's Triptych of St. Christopher (cat. 576).

Identity of the sitter(s): Willem Moreel and Barbara van Vlaenderberch

Provenance: unknown

Number of portrait(s): 2

Type of person(s): lay (couple)

Attitude of the sitter(s): hands clasped

Representation of the sitter(s): half-length

Gaze of the sitter(s): indeterminate

Object(s): no

Coat(s) of arms: yes (on the reverse)

Environment: architectural space, no sacred connotation (incomplete)

Structuring of the pictorial space: indeterminate

Patron saint(s): none

Gesture of the patron saint(s): not applicable

Type of religious scene: indeterminate

Religious scene(s) depicted: none 
Cat. 589 - Type $3 \mathrm{D}$

MEMLING, Hans (after)

The Virgin and Child with Christiaan de Hondt in Prayer (c. 1485-1499)

$70 \times 47 \mathrm{~cm}$

Paris, Petit Palais

BIB L.: FRIEDLÄNDER VIa, no. 9d; Exh. cat. Bruges 1994, no. 86 (with bibl.).

HISTORICAL INFORMATION: On Christiaan de Hondt, see cat. 404.

Identity of the sitter(s): Christiaan de Hondt

Provenance: unknown

Number of portrait(s): 1

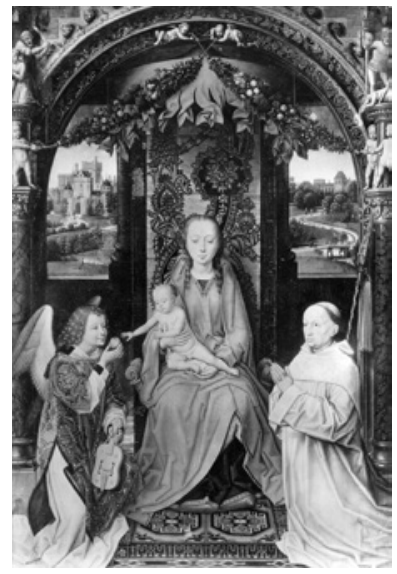

Type of person(s): religious (man alone:

Cistercian abbot)

Attitude of the sitter(s): hands clasped

Representation of the sitter(s): full-length

Gaze of the sitter(s): into space

Object(s): no

Coat(s) of arms: no

Environment: architectural space with sacred connotation

Structuring of the pictorial space: not applicable

Patron saint(s): none

Gesture of the patron saint(s): not applicable

Type of religious scene: hieratic

Religious scene(s) depicted: the Virgin and Child

Cat. 590-Type $2 B$

MEMLING, Hans (follower of)

Triptych of the Virgin and Child with a Couple in Prayer and Patron Saints

(c. 1490-1500)

$59.5 \times 39.8 \mathrm{~cm}$ (centre panel) and $59.5 \times 19.8 \mathrm{~cm}$ (wings)

London, sale Sotheby's (18 September 1997), lot no. 232

BIBL.: SCHADE 2001, 146-47.

Identity of the sitter(s): unknown

Provenance: unknown

Number of portrait(s): 2

Type of person(s): lay (couple)

Attitude of the sitter(s): hands clasped 
Representation of the sitter(s): full-length

Gaze of the sitter(s): into space

Object(s): no

Coat(s) of arms: no

Environment: landscape with sacred connotation

Structuring of the pictorial space: distinct spaces

Patron saint(s): Catherine, George

Gesture of the patron saint(s): introducing

Type of religious scene: hieratic

Religious scene(s) depicted: the Virgin and Child

Cat. 591-Type $2 \mathrm{~B}$

MEMLING, Hans (follower of)

Triptych of the Virgin and Child with a Man in Prayer and Patron Saint (c. 1475-1500)

$53.7 \times 35 \mathrm{~cm}$ (centre panel) and $52.8 \times 14.6 \mathrm{~cm}$ (wings)

Eindhoven, sale Sotheby's (4 December 2006), lot no. 460 (centre panel) and Chicago, Chicago Art Institute, inv. no. 33.1048 (wings)

BIBL.: FRIEDLÄNDER VI, 58, 135; MARTENS

D. 1991-1993, 245-48, Exh. cat. Bruges 1994, no. 78 .

Identity of the sitter(s): unknown

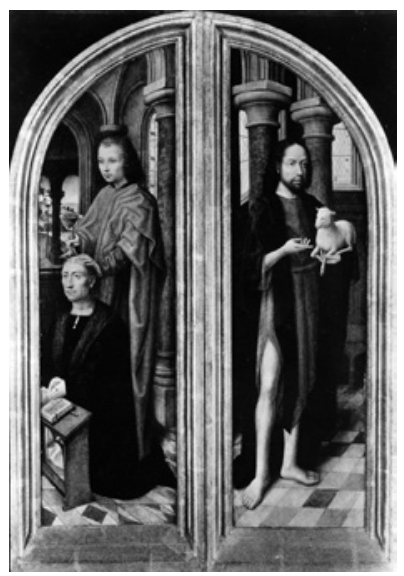

Provenance: unknown

Number of portrait(s): 1

Type of person(s): lay (man alone)

Attitude of the sitter(s): hands clasped

Representation of the sitter(s): full-length

Gaze of the sitter(s): into space

Object(s): yes (prie-dieu, book)

Coat(s) of arms: no

Environment: architectural space with sacred connotation

Structuring of the pictorial space: distinct spaces

Patron saint(s): John the Evangelist

Gesture of the patron saint(s): protecting

Type of religious scene: hieratic

Religious scene(s) depicted:John the Baptist, Virgin and Child 
Cat. 592-Type $4 \mathrm{C}$

MOSTAERT, Jan

Diptych of Mary of Burgundy (c. 1520)

$24 \times 16 \mathrm{~cm}$ (each wing)

Enschede, Rijksmuseum Twenthe, inv. no. 13 (left wing) and Madrid, Fundación Colección Thyssen-Bornemisza, inv. no. 1930.76 (right wing)

BIBL: FRIEDLÄNDER X, no.4; Exh. cat. Antwerp and Washington 2006, no. 28 (with bibl.).

HISTORICAL INFORMATION: Mary of Burgundy has been identified, on the basis of a comparison with another portrait, preserved

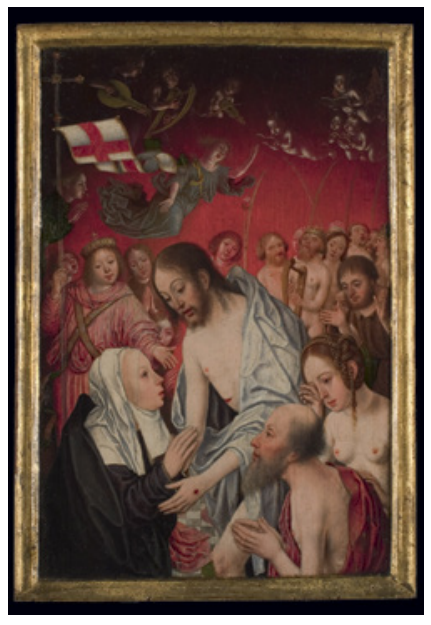
at the Gaasbeek Castle. Taking into account the fact that she died in 1520 , this diptych is a posthumous work, most probably commissioned by her daughter, Margaret of Austria (see cat. 405).

Identity of the sitter(s): Mary of Burgundy

Provenance: unknown

Number of portrait(s): 1

Type of person(s): lay (woman alone)

Attitude of the sitter(s): hands clasped

Representation of the sitter(s): half-length

Gaze of the sitter(s): towards the scene

Object(s): yes (prie-dieu, book)

Coat(s) of arms: no

Environment: architectural space with sacred connotation

Structuring of the pictorial space: continuous space

Patron saint(s): none

Gesture of the patron saint(s): not applicable

Type of religious scene: narrative

Religious scene(s) depicted: Christ in Limbo

Cat. 593-Type 6B

[RKD work no. 19727]

MOSTAERT, Jan

Portrait of a Man in Prayer (c. 1500-1550)

$92 \times 72 \mathrm{~cm}$ 
Liverpool, Walker Art Gallery, inv. no. $5^{1}$

BIB L.: FRIEDLÄNDER X, no. 38; Mus. cat. Liverpool 1963, 124, no. 1018.

Identity of the sitter(s): unknown

Provenance: unknown

Number of portrait(s): 1

Type of person(s): lay (man alone)

Attitude of the sitter(s): hands clasped

Representation of the sitter(s): half-length

Gaze of the sitter(s): indeterminate

Object(s): yes (gloves)

Coat(s) of arms: no

Environment: landscape with sacred connotation (incomplete)

Structuring of the pictorial space: indeterminate

Patron saint(s): none

Gesture of the patron saint(s): not applicable

Type of religious scene: indeterminate

Religious scene(s) depicted: St. Hubert

\section{Cat. 594-Type 6B}

[RKD work no. 20341]

MOSTAERT, Jan

Portrait of a Woman in Prayer (c. 1500-1550)

$62 \times 46 \mathrm{~cm}$

Würzburg, Marin von Wagner Museum

Identity of the sitter(s): Josine van Egmond

Provenance: unknown

Number of portrait(s): 1

Type of person(s): lay (woman alone)

Attitude of the sitter(s): holding a rosary

Representation of the sitter(s): half-length

Gaze of the sitter(s): indeterminate

Object(s): yes (rosary)

Coat(s) of arms: no

Environment: landscape, no sacred connotation (incomplete)

Structuring of the pictorial space: indeterminate 
Patron saint(s): none

Gesture of the patron saint(s): not applicable

Type of religious scene: indeterminate

Religious scene(s) depicted: none

Cat. 595-Type 6B

MOSTAERT, Jan

Portrait of Jacob Jansz. van der Meer in Prayer (c. 1490-1510)

$40.5 \times 27 \mathrm{~cm}$

Copenhagen, Statens Museum for Kunst, inv. no. KMS 4587

BIBL.: FRIEDLÄNDER X, no. 37; HOOGEWERFF II, 484; BOON 1966, 63.

Historical information: According to K. G. Boon, the sitter is Jacob Jansz. van der Meer. He has also been identified as such by Thierry de Bye

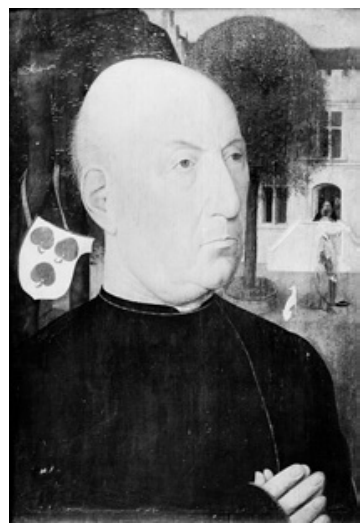

Dolleman. Jacob died on 23 June 1519.

Identity of the sitter(s): Jacob Jansz. van der Meer

Provenance: unknown

Number of portrait(s): 1

Type of person(s): lay (man alone)

Attitude of the sitter(s): hands clasped

Representation of the sitter(s): half-length

Gaze of the sitter(s): indeterminate

Object(s): no

Coat(s) of arms: yes

Environment: landscape, no sacred connotation (incomplete)

Structuring of the pictorial space: indeterminate

Patron saint(s): none

Gesture of the patron saint(s): not applicable

Type of religious scene: indeterminate

Religious scene(s) depicted: August and the Tiburtine Sibyl 
Cat. 596-Type $1 B$

MOSTAERT, Jan

Triptych of the Descent of the Cross ('Adrichem Triptych') (before 1520)

$134 \times 97.5 \mathrm{~cm}$ (centre panel), $140,5 \times 45.5 \mathrm{~cm}$ (left wing) and $139.5 \times 45 \mathrm{~cm}$ (right wing)

Brussels, MRBAB, inv. no. 3466

BIB L.: FRIEDLÄNDER X, no.1;HOOGEWERFF II, 470-76; Exh. cat. Utrecht 1999-2000, 73, 107; Exh. cat. Rotterdam 1992, no. 25 (with bibl.). HISTORICAL INFORMATION: Born in Alkmaar in 1475, Albrecht Adriaensz. van Adrichem was alderman of the city of Haarlem, where he died

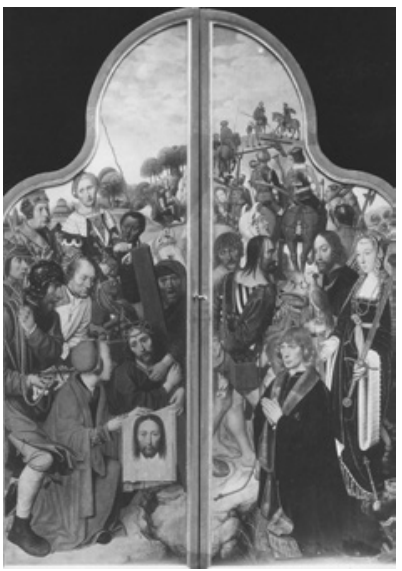
in 1555 . He is documented as regent of the Heilige-Geesthuis in 1514, as churchwarden of the church of St. Bavo from 1532 to 1535, and as master of the orphanage from 1542 to 1546 . Although Albrecht is portrayed alone, the coat of arms of his second wife, Barbara van der Laen, appears in the triptych. She died in 1513 and, in all likelihood, when Albrecht commissioned the work, he was already widowed. Around 1520, Albrecht married Elisabeth van Dorp, who appears next to him on a pair of wings, also executed by Mostaert (cat. 599).

Identity of the sitter(s): Albrecht Adriaensz. van Adrichem

Provenance: Haarlem, church of St. Bavo (?)

Number of portrait(s): 1

Type of person(s): lay (man alone)

Attitude of the sitter(s): hands clasped

Representation of the sitter(s): full-length

Gaze of the sitter(s): into space

Object(s): no

Coat(s) of arms: yes

Environment: historical setting

Structuring of the pictorial space: continuous space

Patron saint(s): Bavo, Catherine

Gesture of the patron saint(s): introducing, holding his/her attribute

Type of religious scene: narrative

Religious scene(s) depicted: the Descent from the cross, Christ crowned with thorns, the Ecce Homo, Christ bearing the cross 
Cat. 597 - Type 5

MOSTAERT, Jan

Triptych of the Last Judgement ('Van Noordwijk Triptych') (c. 1510-1520) $109 \times 71 \mathrm{~cm}($ centre panel) and $109 \times$ $35 \mathrm{~cm}$ (wings)

Bonn, Rheinisches Landesmuseum, inv. no. 168

BIBL:: FRIEDLÄNDER X, no. 3; HOOGEWERFF II, 480-84; VAN

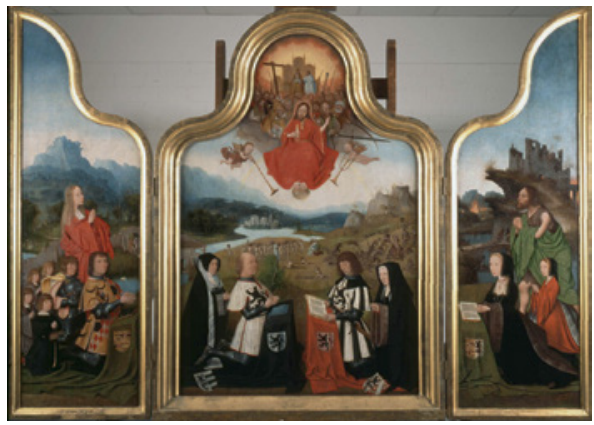

DER KLOOSTER 1963; Exh. cat. Utrecht 1999-2000, no. 80 (with bibl.). HISTORICAL INFORMATION: The triptych shows the family of Anna van Noordwijk van Obdam. Her grandparents, Daniël van Noordwijk ( $†$ 1466) and Agniese van Raaphorst ( $\dagger$ after 1485) and her parents, Jacob van Noordwijk $(\dagger 1503$ or 1504) and Aleid Jan Foeyendr. ( $† 1512)$ appear on the centre panel. Anna is portrayed on the right wing with her daughter, Adriana. The left wing is occupied by her husband, Gijsbrecht van Duivenvoorde, Lord of Den Bossche (whom she married in 1503) and his sons. The oldest boy, Arend van Almonde, came from her first marriage. The triptych might have been destined for the Dominican convent of Haarlem, with which the Van Raaphorst and the Van Noordwijk families had close ties. Several members of those families are indeed buried in the church and, more importantly, Anna van Noordwijk made an important gift to the Dominican convent in 1514.

Identity of the sitter(s): Anna van Noordwijk and her family

Provenance: Haarlem, church of the Dominican convent (?)

Number of portrait(s): 12

Type of person(s): lay (family with children)

Attitude of the sitter(s): hands clasped, holding a book

Representation of the sitter(s): full-length

Gaze of the sitter(s): towards the scene, reading a book, into space

Object(s): yes (prie-dieu, book)

Coat(s) of arms: yes

Environment: historical setting

Structuring of the pictorial space: continuous space

Patron saint(s): Mary, John the Baptist

Gesture of the patron saint(s): interceding

Type of religious scene: narrative

Religious scene(s) depicted: the Last Judgement 
Cat. 598-Type $3 \mathrm{~A}$

[R KD work no. 18729]

MOSTAERT, Jan

The Ecce Homo with a Man in Prayer and St.Jerome (c. 1515)

$55.5 \times 46 \mathrm{~cm}$

Saint Louis, Saint Louis Art Museum, inv. no. 207:1946

BIBL.: FRIEDLÄNDER X, add. 178.

Identity of the sitter(s): unknown

Provenance: unknown

Number of portrait(s): 1

Type of person(s): religious (man alone)

Attitude of the sitter(s): hands clasped

Representation of the sitter(s): full-length

Gaze of the sitter(s): into space

Object(s): no

Coat(s) of arms: no

Environment: historical setting

Structuring of the pictorial space: not applicable

Patron saint(s): Jerome

Gesture of the patron saint(s): introducing

Type of religious scene: narrative

Religious scene(s) depicted: the Ecce Homo

Cat. 599-Type 6A

MOSTAERT, Jan

Two Wings. Albrecht Adriaensz. van Adrichem and Elisabeth van Dorp in Prayer with Patron Saints (c. 1520-1522) $80 \times 38 \mathrm{~cm}$ (left wing) and $79.5 \times 37.8$ $\mathrm{cm}$ (right wing)

Brussels, MRBAB, inv. no. $2583^{-2584}$

BIBL.: FRIEDLÄNDER X, no. 5; HOOGEWERFF II, 479-80; Exh. cat. Rotterdam 1992, no. 25 (with bibl.).

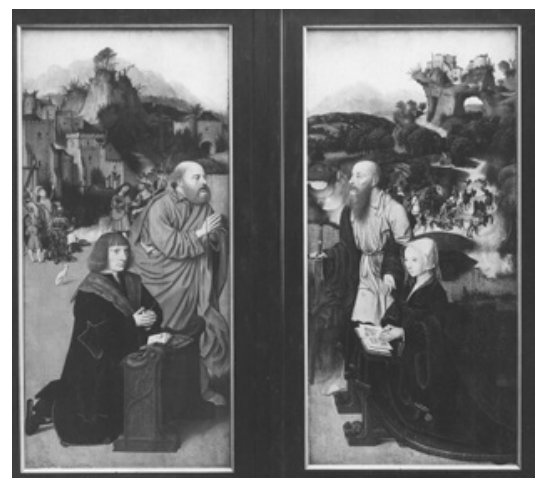
HISTORICAL INFORMATION: Albrecht

Adriaensz. van Adrichem has been identified, on the basis of his portrait in cat. 596. He is depicted with his third wife, Elisabeth van Dorp ( $†$ c. 1537), whom he married around 1520 . Elisabeth came from a noble family of Southern Holland. Albrecht and Elisabeth had two sons: Pieter, born in 1522 and Adriaen, born in 
1526. The two wings might come from an altarpiece destined for the St. Peter and St. Paul's altar at the Hofkapel in The Hague. Indeed, Elisabeth's father was buried in this chapel, and another member of the family, Arend Cornelisz. van Dorp, acted as a priest there at that time.

Identity of the sitter(s): Albrecht Adriaensz. van Adrichem and Elisabeth van Dorp

Provenance: The Hague, Hofkapel, St. Peter and St. Paul's altar (?)

Number of portrait(s): 2

Type of person(s): lay (couple)

Attitude of the sitter(s): hands clasped

Representation of the sitter(s): full-length

Gaze of the sitter(s): indeterminate

Object(s): yes (prie-dieu, book)

Coat(s) of arms: no

Environment: landscape with sacred connotation (incomplete)

Structuring of the pictorial space: indeterminate

Patron saint(s): Peter, Paul

Gesture of the patron saint(s): introducing, interceding

Type of religious scene: indeterminate

Religious scene(s) depicted: none

Cat. 6oo-Type ${ }_{3} \mathrm{C}$

MOSTAERT, Jan (after)

The Crucifixion with a Family in Prayer (c. 15001550)

Size unknown

Church of Oberbarnim

Identity of the sitter(s): unknown

Provenance: unknown

Number of portrait(s): 9

Type of person(s): lay (family with children)

Attitude of the sitter(s): hands clasped

Representation of the sitter(s): full-length

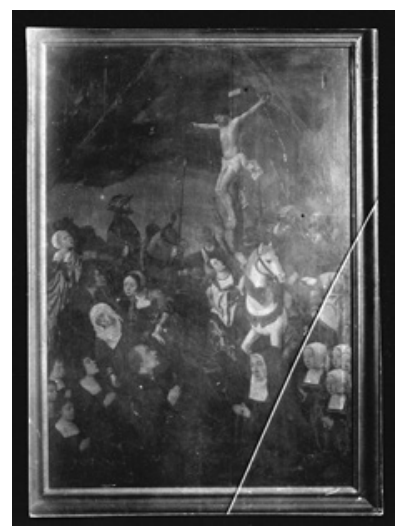

Gaze of the sitter(s): into space, towards the scene

Object(s): no

Coat(s) of arms: no

Environment: historical setting

Structuring of the pictorial space: not applicable 
Patron saint(s): none

Gesture of the patron saint(s): not applicable

Type of religious scene: narrative

Religious scene(s) depicted: the Crucifixion

Cat. 6o1-Type 6B

MOSTAERT, Jan (attributed to)

Two Wings. A Couple in Prayer

(c. 1500-1510)

$75.5 \times 57 \mathrm{~cm}$ (each wing)

Bruges, Adornes collection

Identity of the sitter(s): unknown

Provenance: unknown

Number of portrait(s): 2
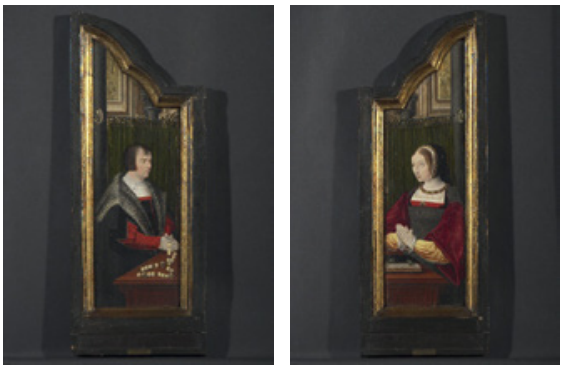

Type of person(s): lay (couple)

Attitude of the sitter(s): hands clasped, holding a rosary

Representation of the sitter(s): half-length

Gaze of the sitter(s): indeterminate

Object(s): yes (prie-dieu, book, rosary)

Coat(s) of arms: yes

Environment: ecclesial space

Structuring of the pictorial space: indeterminate

Patron saint(s): none

Gesture of the patron saint(s): not applicable

Type of religious scene: indeterminate

Religious scene(s) depicted: none

Cat. 6o2-Type 6A

MOSTAERT, Jan (circle of)

One Wing. A Man and his Sons in Prayer (c. 1520)

$42 \times 46.1 \mathrm{~cm}$

Oxford, Christ Church College, Gallery Collection, inv. no. JBS 233

BIB L.: Mus. cat. Oxford 1967, no. 233.

Identity of the sitter(s): unknown

Provenance: unknown

Number of portrait(s): 3

Type of person(s): lay (family with children)

Attitude of the sitter(s): hands clasped, holding a rosary 
Representation of the sitter(s): full-length

Gaze of the sitter(s): indeterminate

Object(s): yes (prie-dieu, rosary, hat)

Coat(s) of arms: no

Environment: landscape, no sacred connotation (incomplete)

Structuring of the pictorial space: indeterminate

Patron saint(s): none

Gesture of the patron saint(s): not applicable

Type of religious scene: indeterminate

Religious scene(s) depicted: none

Cat. 6o3-Type $2 \mathrm{~A}$

MOSTAERT, Jan and GEERTGEN tot Sint Jans (after)

Triptych of the Lamentation with a Couple in Prayer and Patron Saints (c. 1515-1520)

$72.5 \times 57.5 \mathrm{~cm}$ (centre panel) and $72.5 \times 21.5 \mathrm{~cm}$ (wings)

Haarlem, Frans Hals Museum (in

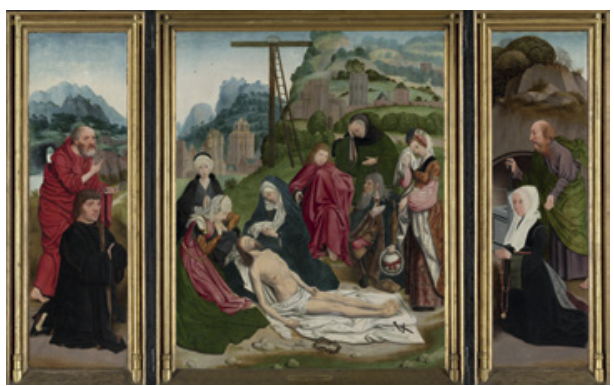
loan of the Rijksmuseum, Amsterdam), inv. no. SK-A-2123

вIB L.: FRIEDLÄNDER X, no. 2; SNYDER 1971; Mus. cat. Haarlem 2006, 45051; Mus. cat. Amsterdam 2009 [online], https://www.rijksmuseum.nl/nl/collec tie/SK-A-2123/catalogus-entry (with bibl.).

HISTORICAL INFORMATION: The reverse of the wings presents a coat of arms and a date $(15(7 ?) 7)$, added at a later date, probably in the course of the sixteenth century. According to Snyder, the coat of arms belonged to the Speyart van Woerden family, in the seventeenth century. This has led some scholars to suggest that the sitters could be Willem Pieterz. and Bella Borwoudtsdr., who are said to have had ties with Speyart van Woerden. However, there is no proof allowing us to confirm this hypothesis. De Bye Dolleman argues that this coat of arms bears a resemblance to that of the Van Huesen family from Haarlem.

Identity of the sitter(s): Willem Pietersz. and Bela Borwoutsdr. (?)

Provenance: unknown

Number of portrait(s): 2

Type of person(s): lay (couple)

Attitude of the sitter(s): holding a hat, holding a rosary

Representation of the sitter(s): full-length

Gaze of the sitter(s): towards the scene 
Object(s): yes (rosary, hat)

Coat(s) of arms: yes (added later)

Environment: historical setting

Structuring of the pictorial space: distinct spaces

Patron saint(s): Peter, Paul

Gesture of the patron saint(s): indicating, introducing

Type of religious scene: narrative

Religious scene(s) depicted: the Lamentation

Cat. 6o4-Type $3^{D}$

PATINIER, Joachim (follower of) (or follower of Joos van Cleve)

The Virgin and Child with a Nun in Prayer (c. 1530)

$33.5 \times 24.1 \mathrm{~cm}$

London, NG, inv. no. NG 945

BIB L.: CAMPBELL 2014, 234-37.

Identity of the sitter(s): unknown

Provenance: unknown

Number of portrait(s): 1

Type of person(s): religious (woman alone: Augustinian canoness)

Attitude of the sitter(s): hands clasped

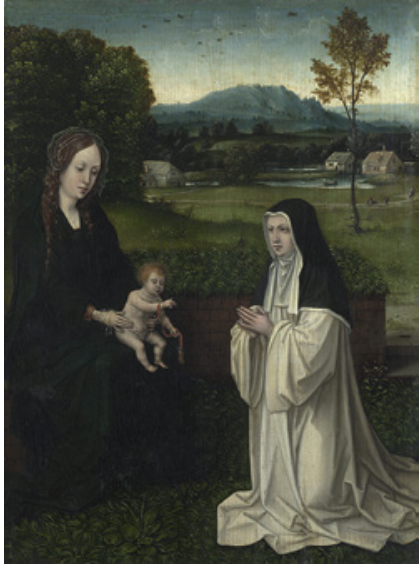

Representation of the sitter(s): full-length

Gaze of the sitter(s): towards the scene

Object(s): no

Coat(s) of arms: no

Environment: enclosed garden

Structuring of the pictorial space: not applicable

Patron saint(s): none

Gesture of the patron saint(s): not applicable

Type of religious scene: hieratic

Religious scene(s) depicted: the Virgin and Child

Cat. 6o5-Type ${ }_{3}$ B

[Link to the Friedländer 3.o Database]

PROVOOST, Jan (or circle of the Master of the Holy Blood)

A Man in Prayer with St. Andrew before an Apparition of the Virgin and Child

(c. 1500-1550) 


\section{$32.5 \times 27 \mathrm{~cm}$}

Brussels, Belfius Bank art Collection

BIB L.: FRIEDLÄNDER IXb, no. 163; KNUST 2007, no. C.I.24 (with bibl.).

HISTORICAL INFORMATION: According to the unpublished catalogue of the Belfius Bank art collection, the sitter is Jean Asset. He was the abbot of the Benedictine abbey of St. Andrew in Bruges from 1524 to 1554 . He played an important role in the reform of the monastery and the restoration of the conventual church, before leaving for the monastery of Anchin, where he died on 22 or 23 March 1555 (see the Monasticon belge. Tome III. Flandre occidentale, vol. 1 (Liège: 1960), 114).

Identity of the sitter(s): unknown

Provenance: unknown

Number of portrait(s): 1

Type of person(s): religious (man alone: Benedictine abbot)

Attitude of the sitter(s): hands clasped

Representation of the sitter(s): half-length

Gaze of the sitter(s): into space

Object(s): yes (prie-dieu, book, crosier)

Coat(s) of arms: yes

Environment: indeterminate

Structuring of the pictorial space: religious scene in a cloud

Patron saint(s): Andrew

Gesture of the patron saint(s): holding his/her attribute

Type of religious scene: hieratic

Religious scene(s) depicted: the Virgin and Child

Cat. 6o6-Type $4 \mathrm{D}$

PROVOOST, Jan

Diptych of a Franciscan Friar (dated 1522 on the frame)

$50 \times 40.2 \mathrm{~cm}$ (each wing)

Bruges, Sint-Janshospitaal, inv. no. OsJ $19 \mathrm{I}$

BIB L.: Exh. cat. Bruges 1998 (vol. 2), no. 22; SCHERER 2003; Exh. cat. Antwerp and Washington 2006, no.

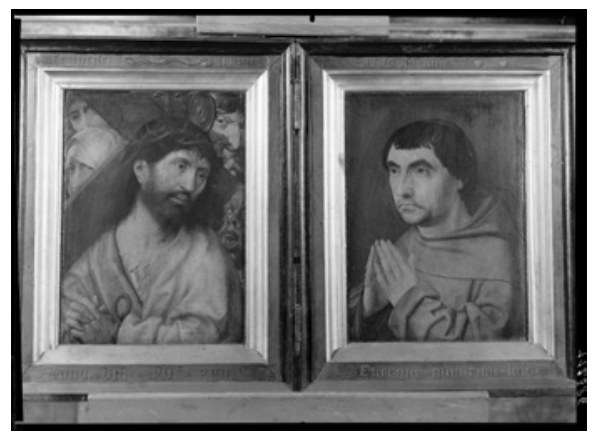
31; KNUST 2007, no. A23 (with bibl.). Identity of the sitter(s): unknown Provenance: unknown 
Number of portrait(s): 1

Type of person(s): religious (man alone: Franciscan friar)

Attitude of the sitter(s): hands clasped

Representation of the sitter(s): half-length

Gaze of the sitter(s): towards the scene

Object(s): no

Coat(s) of arms: no

Environment: neutral space

Structuring of the pictorial space: distinct spaces

Patron saint(s): none

Gesture of the patron saint(s): not applicable

Type of religious scene: hieratic

Religious scene(s) depicted: Christ bearing the cross, memento mori

Cat. 6o7-Type ${ }_{3}$ B

PROVOOST, Jan

The Virgin and Child Enthroned with St. Jerome, St. John the Baptist and a Carthusian Monk in Prayer (c. 1500-1510)

$75.5 \times 65 \mathrm{~cm}$

The Hague, Mauritshuis (in loan of the Rijksmuseum, Amsterdam), inv. no. SK-A-2569 BIBL.: FRIEDLÄNDER IXb, no. 178; KNUST 2007, no. A4; Exh. cat. Roermond 2009, no. 34; Mus. cat. Amsterdam 2009 [online], https://

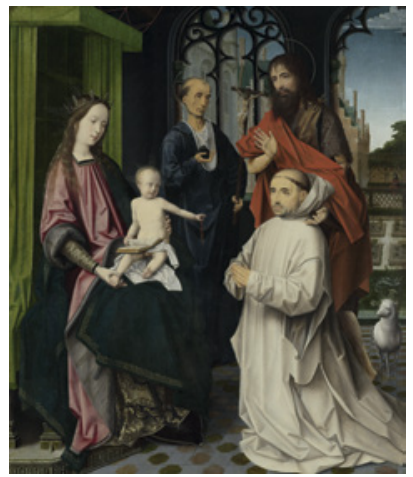
www.rijksmuseum.nl/nl/collectie/SK-A-2569/catalogus-entry (with bibl.).

Identity of the sitter(s): unknown

Provenance: unknown

Number of portrait(s): 1

Type of person(s): religious (man alone: Carthusian monk)

Attitude of the sitter(s): hands clasped

Representation of the sitter(s): full-length

Gaze of the sitter(s): into space

Object(s): no

Coat(s) of arms: no 
Environment: architectural space with sacred connotation

Structuring of the pictorial space: not applicable

Patron saint(s): John the Baptist

Gesture of the patron saint(s): introducing

Type of religious scene: hieratic

Religious scene(s) depicted: the Virgin and Child, St. Jerome

Cat. 6o8-Type $3^{B}$

PROVOOST, Jan

Triptych of the Virgin and Child Enthroned with Saints and a Family in Prayer (c. 1500-1520)

$154.5 \times 142.5 \mathrm{~cm}($ centre panel) and $154.5 \times$ $62 \mathrm{~cm}$ (wings)

Lisbon, Museu Nacional de Arte Antiga, inv. no. 697

BIBL.: FRIEDLÄNDER IXb, no. 123;

KNUST 2007, no. B2 (with bibl.).

Identity of the sitter(s): unknown

Provenance: unknown

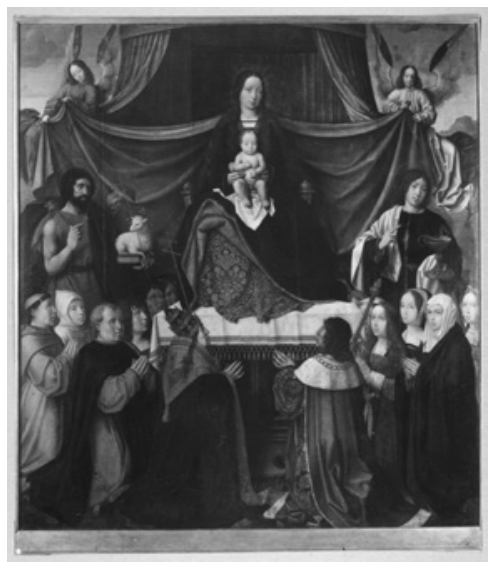

Number of portrait(s): 10

Type of person(s): mixed (family)

Attitude of the sitter(s): hands clasped

Representation of the sitter(s): full-length

Gaze of the sitter(s): into space, towards the scene, towards the viewer

Object(s): no

Coat(s) of arms: no

Environment: landscape with sacred connotation

Structuring of the pictorial space: not applicable

Patron saint(s): John the Baptist, John the Evangelist

Gesture of the patron saint(s): holding his/her attribute

Type of religious scene: hieratic

Religious scene(s) depicted: the Virgin and Child, St. Sebastian, St. Christopher, St. Paul, St. Peter 
Cat. 6o9-Type $2 B$

PROVOOST, Jan

Triptych of the Virgin and Child Enthroned with

St. Bernard, St. Benedict and Couple in Prayer

with Patron Saints (c. 1500-1520)

$75 \times 56.5 \mathrm{~cm}$ (centre panel) and $76 \times 23.5 \mathrm{~cm}$ (wings)

Hampton Court, Royal Collections

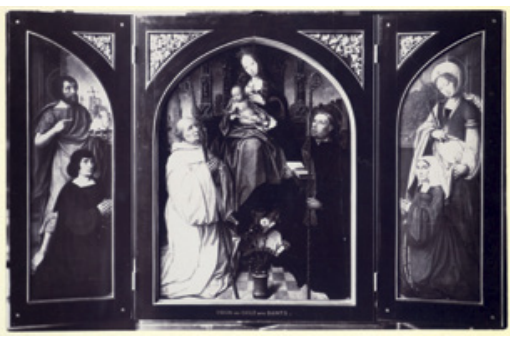

BIBL.: FRIEDLÄNDER IXb, no. 121; CAMPBELL 1985, no. 71; KNUST 2007, no. A21 (with bibl.).

Identity of the sitter(s): unknown

Provenance: unknown

Number of portrait(s): 2

Type of person(s): lay (couple)

Attitude of the sitter(s): hands clasped

Representation of the sitter(s): full-length

Gaze of the sitter(s): towards the scene

Object(s): yes (rosary)

Coat(s) of arms: no

Environment: architectural space with sacred connotation

Structuring of the pictorial space: distinct spaces

Patron saint(s): John the Baptist, Lucy

Gesture of the patron saint(s): protecting, holding his/her attribute

Type of religious scene: hieratic

Religious scene(s) depicted: the Virgin and Child, St. Bernard, St. Benedict,

Death and the Miser

Cat. 610-Type $3^{\mathrm{D}}$

PROVOOST, Jan

Triptych of the Virgin and Child with Saints and a Man in Prayer (c. 1500-1520)

$94.2 \times 67 \mathrm{~cm}$ (centre panel), $28.2 \times 94.5 \mathrm{~cm}$ (left wing) and $25.7 \times 94.5 \mathrm{~cm}$ (right wing)

Dublin, National Gallery of Ireland, inv. no. 4315

BIBL.: Mus. cat. Dublin 1987, 71-73; KNUST 2007, no. C.II.54 (with bibl.).

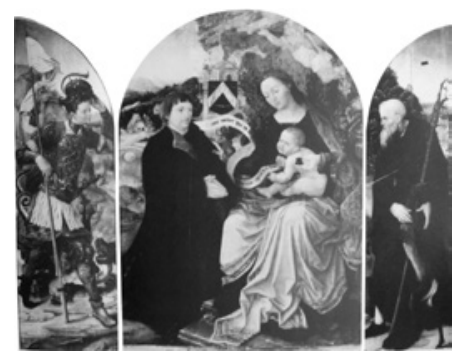

HISTORICAL INFORMATION: The coat of arms located next to the sitter was added at a later date and belonged to the Post family.

Identity of the sitter(s): unknown 
Provenance: unknown

Number of portrait(s): 1

Type of person(s): lay (man alone)

Attitude of the sitter(s): hands clasped

Representation of the sitter(s): full-length

Gaze of the sitter(s): towards the scene

Object(s): no

Coat(s) of arms: yes (later addition)

Environment: landscape with sacred connotation

Structuring of the pictorial space: not applicable

Patron saint(s): none

Gesture of the patron saint(s): not applicable

Type of religious scene: hieratic

Religious scene(s) depicted: the Virgin and Child, St. George, St. Giles

Cat. 611-Type 2D

PROVOOST, Jan

Triptych of the Virgin and Child with

St. Anne ('Van der Burch Triptych')

(c. 1490-1500)

$46.3 \times 37.2 \mathrm{~cm}$ (centre panel) and $46.3 \times 15.5 \mathrm{~cm}$ (wings)

Belgium, private collection

BIBL.: PERIER D'IETEREN 1985a;

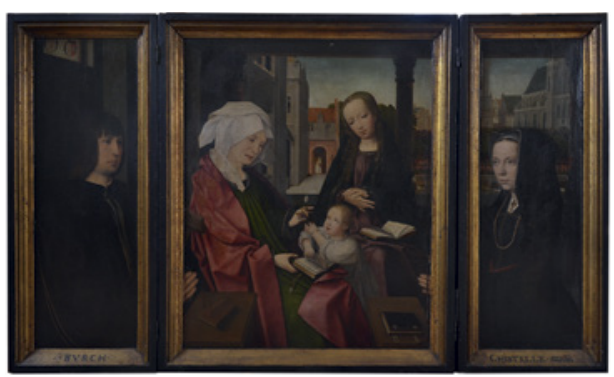

KNUST 2007, no. C.II.56 (with bibl.).

HISTORICAL INFORMATION: The sitters are Pieter van der Burch and his wife, who was a member of the Lense Family. They married in 1493. That same year, Pieter left the lordship of Veurne to become a citizen of Bruges. He was alderman of the city of Bruges between 1497 and 1501. The small size of the triptych suggests it was meant for personal devotion.

Identity of the sitter(s): Pieter van der Burch and his wife

Provenance: unknown

Number of portrait(s): 2

Type of person(s): lay (couple)

Attitude of the sitter(s): hands clasped

Representation of the sitter(s): half-length

Gaze of the sitter(s): into space, towards the scene

Object(s): yes (prie-dieu, book)

Coat(s) of arms: yes 
Environment: domestic setting

Structuring of the pictorial space: continuous space

Patron saint(s): none

Gesture of the patron saint(s): not applicable

Type of religious scene: hieratic

Religious scene(s) depicted: the Virgin and Child with St. Anne

Cat. 612-Type 6A

PROVOOST, Jan

Two Wings. A Couple in Prayer (c. 1500-1520)

$49.2 \times 16 \mathrm{~cm}$ (each wing)

Private collection

вIB L.: KNUST 2007, no. C.II.96.

Identity of the sitter(s): unknown

Provenance: unknown

Number of portrait(s): 2

Type of person(s): lay (couple)

Attitude of the sitter(s): holding a book, holding a rosary

Representation of the sitter(s): half-length

Gaze of the sitter(s): indeterminate

Object(s): yes (book, rosary)

Coat(s) of arms: no

Environment: domestic setting

Structuring of the pictorial space: indeterminate

Patron saint(s): none

Gesture of the patron saint(s): not applicable

Type of religious scene: indeterminate

Religious scene(s) depicted: none

Cat. 613-Type 6A

PROVOOST, Jan

Two Wings. A Family in Prayer with

Patron Saints (c. 1500-1550)

$59 \times 21 \mathrm{~cm}$ (each wing)

Philadelphia, Philadelphia Museum of Art, inv. no. 355

BIBL.: FRIEDLÄNDER IXb, no. 134; Mus. cat. Philadelphia 1994, 88; KNUST 2007, no. C.I.6 (with bibl.).

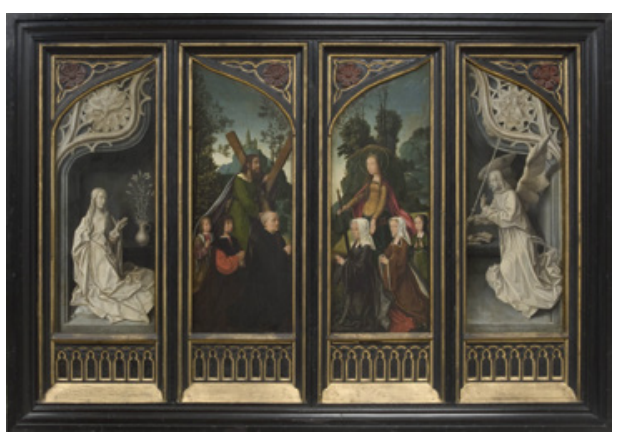


Identity of the sitter(s): unknown

Provenance: unknown

Number of portrait(s): 6

Type of person(s): lay (family with children)

Attitude of the sitter(s): hands clasped

Representation of the sitter(s): full-length

Gaze of the sitter(s): indeterminate

Object(s): no

Coat(s) of arms: no

Environment: landscape, no sacred connotation (incomplete)

Structuring of the pictorial space: indeterminate

Patron saint(s): Andrew, Catherine

Gesture of the patron saint(s): introducing

Type of religious scene: indeterminate

Religious scene(s) depicted: none

Cat. 614-Type 6A

PROVOOST, Jan

Two Wings. A Couple in Prayer with Patron

Saints (c. 1515-1521)

$120 \times 79 \mathrm{~cm}$ (each wing)

Bruges, Groeningemuseum, inv. no. O.218 BIBL.: FRIEDLÄNDER IXb, no. 132; Exh. cat. Bruges 1998 (vol. 2), no. 21; KNUST 2007, no. A19 (with bibl.).

Identity of the sitter(s): unknown
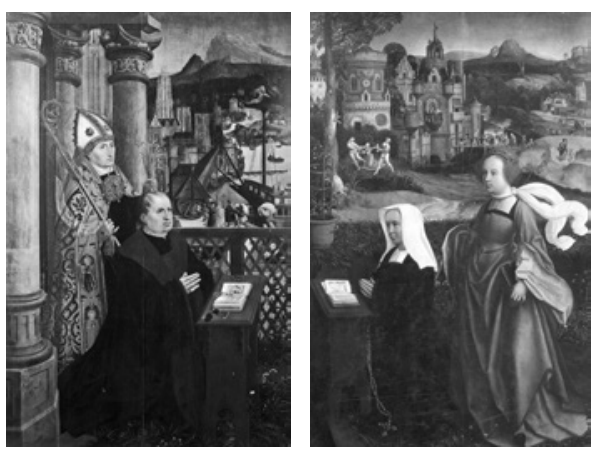

Provenance: Bruges, Dominican convent (before 1796)

Number of portrait(s): 2

Type of person(s): lay (couple)

Attitude of the sitter(s): hands clasped

Representation of the sitter(s): full-length

Gaze of the sitter(s): indeterminate

Object(s): yes (prie-dieu, book)

Coat(s) of arms: no

Environment: architectural space, no sacred connotation (incomplete)

Structuring of the pictorial space: indeterminate

Patron saint(s): Nicholas, Godelieve

Gesture of the patron saint(s): holding his/her attribute

Type of religious scene: indeterminate

Religious scene(s) depicted: Death and the Miser 
Cat. 615-Type 6A

[RKD work no. 63474]

PROVOOST, Jan (attributed to)

Fragment. A Family in Prayer (c. 1500-1520)

Size unknown

Whereabouts unknown

Identity of the sitter(s): unknown

Provenance: unknown

Number of portrait(s): 12 (at least)

Type of person(s): lay (family)

Attitude of the sitter(s): hands clasped

Representation of the sitter(s): full-length, children in small scale

Gaze of the sitter(s): indeterminate

Object(s): yes (banderole)

Coat(s) of arms: no

Environment: architectural space, no sacred connotation (incomplete)

Structuring of the pictorial space: indeterminate

Patron saint(s): none

Gesture of the patron saint(s): not applicable

Type of religious scene: indeterminate

Religious scene(s) depicted: none

Cat. 616-Type 6A

PROVOOST, Jan (attributed to)

Fragments. Portrait of a Couple in Prayer, St. Peter and St. Elizabeth of Hungary (c. 1500-1525)

$54.1 \times 46.8 \mathrm{~cm}$ (left wing) and $53.5 \times 46 \mathrm{~cm}$ (right wing)

Philadelphia, Philadelphia Museum of Art, inv. no. 273 (left wing) Etand Castagnolo, collection Thyssen-Bornemisza, inv. no. 336 (right wing)

BIBL.: FRIDLÄNDER IXb, no. 181, 182, 137; EISLER 1989, no. 20; Exh. cat. Bruges 1998

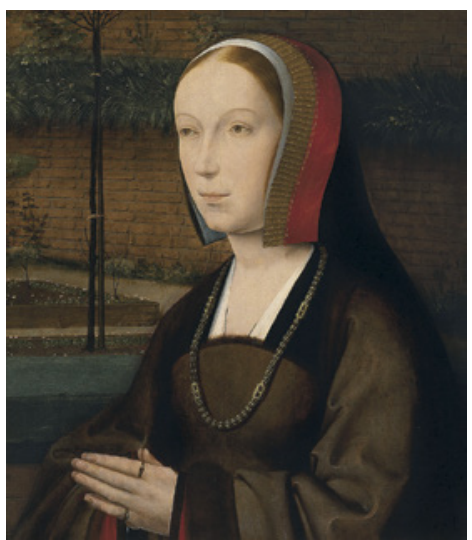
(vol. 2), no. 26; CAVELLI TRAVERSO 2003, no. 53; KNUST 2007, no. A2o (with bibl.). 
Identity of the sitter(s): unknown

Provenance: unknown

Number of portrait(s): 2

Type of person(s): lay (couple)

Attitude of the sitter(s): hands clasped

Representation of the sitter(s): indeterminate

Gaze of the sitter(s): indeterminate

Object(s): no

Coat(s) of arms: no

Environment: enclosed garden (incomplete)

Structuring of the pictorial space: indeterminate

Patron saint(s): Peter, Elizabeth of Hungary

Gesture of the patron saint(s): indeterminate

Type of religious scene: indeterminate

Religious scene(s) depicted: none

Cat. 617-Type 6B

[RKD work no. 192409]

PROVOOST, Jan (attributed to)

Portrait of a Man in Prayer (c. 1500-1525)

$42.5 \times 33.9 \mathrm{~cm}$

London, sale Christie's (22 April 2005), lot no. 101

Identity of the sitter(s): unknown

Provenance: unknown

Number of portrait(s): 1

Type of person(s): lay (man alone)

Attitude of the sitter(s): hands clasped

Representation of the sitter(s): half-length

Gaze of the sitter(s): indeterminate

Object(s): no

Coat(s) of arms: no

Environment: landscape, no sacred connotation (incomplete)

Structuring of the pictorial space: indeterminate

Patron saint(s): none

Gesture of the patron saint(s): not applicable

Type of religious scene: indeterminate

Religious scene(s) depicted: none 
Cat. 618-Type 6A

[R KD work no. 41730]

PROVOOST, Jan (workshop or circle of)

One Wing. A Man in Prayer with Patron Saint (c. 1500-1530)

$57 \times 43 \mathrm{~cm}$

Valenciennes, Musée des Beaux-Arts, inv. no. P 46.1.139

BIBL.: Repertory Nord-Pas-de-Calais I, no. 35 (with bibl.); KNUST 2007, no. C.II.83.

Identity of the sitter(s): unknown

Provenance: unknown

Number of portrait(s): 1

Type of person(s): religious (man alone: canon)

Attitude of the sitter(s): hands clasped

Representation of the sitter(s): full-length

Gaze of the sitter(s): indeterminate

Object(s): yes (palm)

Coat(s) of arms: no

Environment: enclosed garden (incomplete)

Structuring of the pictorial space: indeterminate

Patron saint(s): John the Baptist

Gesture of the patron saint(s): introducing

Type of religious scene: indeterminate

Religious scene(s) depicted: a gisant

Cat. 619-Type 2A

PROVOOST, Jan and POURBUS Pieter (follower of)

Triptych of the Legends of St. Anthony and St. Bonaventura ('Riebeke-Parmentier Triptych') (dated 1521 on the frame) $191 \times 140 \mathrm{~cm}($ centre panel $)$ and $187 \times 62.5$ cm (wings)

Brussels, MRBAB, inv. no. 2588

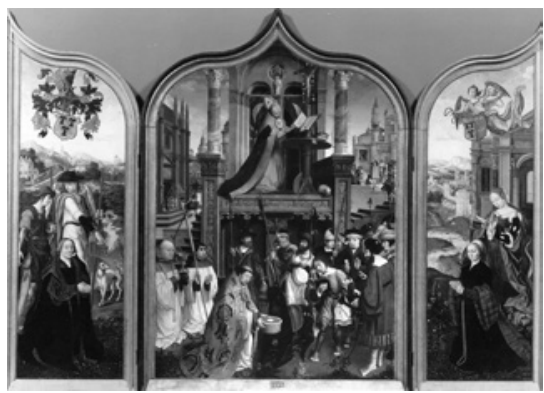

BIB L.: FRIEDLÄNDER IXb, no. 160; Mus. cat. Brussels 1984, 234; KNUST 2007, no. A22 (with bibl.).

HISTORICAL INFORMATION: Adam van Riebeke was born in 1439 and died in 1542. He was treasurer and alderman of the city of Bruges. His wife, Margaretha Parmentier, died after 1554 . 
Identity of the sitter(s): Adam van Riebeke and Margaretha Parmentier

Provenance: unknown

Number of portrait(s): 2

Type of person(s): lay (couple)

Attitude of the sitter(s): hands clasped

Representation of the sitter(s): full-length

Gaze of the sitter(s): into space

Object(s): no

Coat(s) of arms: yes

Environment: historical setting

Structuring of the pictorial space: unified space with discontinuities

Patron saint(s): Tobias, Margaret

Gesture of the patron saint(s): indicating, holding his/her attribute

Type of religious scene: narrative

Religious scene(s) depicted: episodes from the Lives of St. Anthony of Padua and St. Bonaventura

\section{Cat. 620-Type 6A}

PROVOOST, Jan

Two Wings. Portrait of a family in Prayer

(c. 1500-1550)

$97 \times 42 \mathrm{~cm}$ (each wing)

Whereabouts unknown

Identity of the sitter(s): unknown

Provenance: unknown

Number of portrait(s): 8

Type of person(s): lay (family with children)
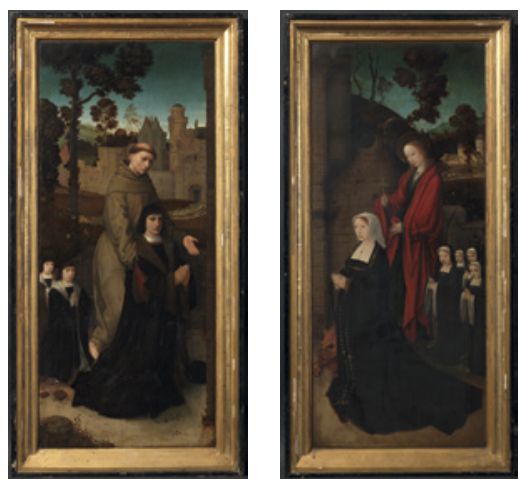

Attitude of the sitter(s): hands

clasped

Representation of the sitter(s): full-length

Gaze of the sitter(s): indeterminate

Object(s): yes (rosary)

Coat(s) of arms: no

Environment: landscape, no sacred connotation (incomplete)

Structuring of the pictorial space: indeterminate

Patron saint(s): Francis, Margaret

Gesture of the patron saint(s): presenting, holding his/her attributes 
Type of religious scene: indeterminate

Religious scene(s) depicted: the Annunciation

Cat. 621-Type 6A

[RKD work no. 249315]

PSEUDO-HEEMSKERCK

A Couple in Prayer before a Crucifix (c. 1550)

$69.3 \times 61.8 \mathrm{~cm}$

Dessau, Staatliche Galerie

BIBL.: BRUYN 1983 .

REMARK: The central section of the current work, showing a crucifix, is a later addition. In all likelihood, this panel was formerly two wings of a triptych. Once the centre panel was lost, the wings were probably joined together in order to form one single work. Other works of the corpus present similar additions (cat. 44 and 332).

Identity of the sitter(s): unknown

Provenance: unknown

Number of portrait(s): 2

Type of person(s): lay (couple)

Attitude of the sitter(s): hands clasped, holding a rosary

Representation of the sitter(s): half-length

Gaze of the sitter(s): into space

Object(s): yes (rosary)

Coat(s) of arms: no

Environment: landscape, no sacred connotation (incomplete)

Structuring of the pictorial space: indeterminate

Patron saint(s): Christopher, Catherine

Gesture of the patron saint(s): protecting

Type of religious scene: indeterminate

Religious scene(s) depicted: none 
Cat. 622-Type $4 \mathrm{D}$

SITTOW, Michel

Diptych of Don Diego de Guevara (c. 1515-1518)

$33.1 \times 25.6 \mathrm{~cm}$ (left wing) and $33.6 \times 23.7 \mathrm{~cm}$ (right wing)

Berlin, Staatliche Museen zu Berlin, Gemäldegalerie, inv. no. 1722 (left wing) and Washington, National Gallery of Art, inv. no. 1937.1.46 (right wing)

BIB L.: Mus. cat. Washington 1986, 228-36; Exh. cat. Antwerp and Washington 2006, no. 34 (with bibl.).

HISTORICAL INFORMATION: The sitter is usu-

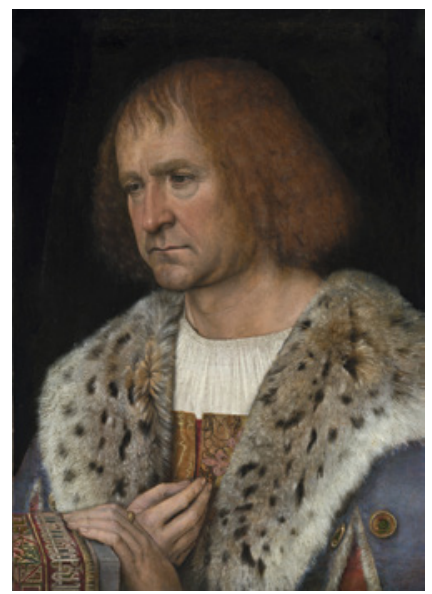
ally identified as Don Diego de Guevara, on the basis of archival sources. In the 1548 and 1554 inventories of Mencia de Mendoza, wife of Hendrik III of Nassau, a work depicting the Virgin and Child, with Diego de Guevara wearing a fur robe, is described. It is highly plausible that this work is Sittow's diptych. Don Diego de Guevara came from Santander in the North of Spain and arrived in the Low Countries in the late fifteenth century. He held important positions within the Burgundian administration: in 1501, he was made Maitre d'hôtel of Philip the Fair. He joined the duke and his wife Joanna of Castile for a trip to Spain in 1506, in his role of Premier maître d'hôtel of Joanna. In the following years, he led several diplomatic missions to Spain and England. In 1517, he was appointed Contador Mayor de Cuentas for Castile, and Clavaria (warden) of the Order of Calatrava. He died in $15^{20}$ or $15^{21}$. Don Diego de Guevara is wellknown for having offered Van Eyck's Arnolfini Portrait to Margaret of Austria. In the diptych, Diego is wearing the insignia of the Order of Calatrava, which seems to have been added at a later date.

Identity of the sitter(s): Diego de Guevara

Provenance: unknown

Number of portrait(s): 1

Type of person(s): lay (man alone)

Attitude of the sitter(s): particular gesture

Representation of the sitter(s): half-length

Gaze of the sitter(s): towards the scene

Object(s): no

Coat(s) of arms: no 
Environment: neutral space

Structuring of the pictorial space: continuous space

Patron saint(s): none

Gesture of the patron saint(s): not applicable

Type of religious scene: hieratic

Religious scene(s) depicted: the Virgin and Child

Cat. 623-Type 6B

SITTOW, Michel (follower of)

Portrait of a Man in Prayer (after 1515-1518)

$33.8 \times 23.5 \mathrm{~cm}$

London, sale Sotheby's (6 December 2012), lot no. 101

BIBL.: Sale cat. Sotheby's (London, 6 December 2012), no. 101

REMARK: This painting is a copy of the right wing of the Diptych of Don Diego de Guevara (cat. 622), but with another portrait.

Identity of the sitter(s): unknown

Provenance: unknown

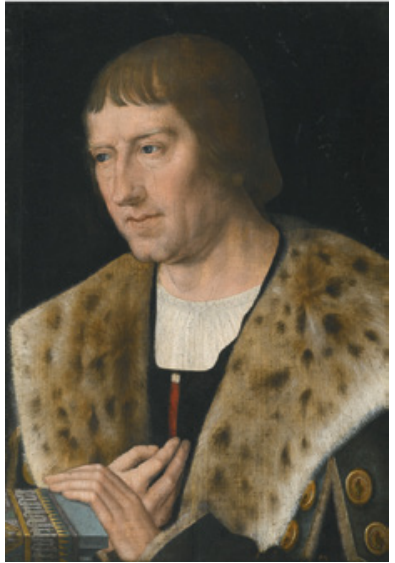

Number of portrait(s): 1

Type of person(s): lay (man alone)

Attitude of the sitter(s): particular gesture

Representation of the sitter(s): half-length

Gaze of the sitter(s): indeterminate

Object(s): no

Coat(s) of arms: no

Environment: neutral space (incomplete)

Structuring of the pictorial space: indeterminate

Patron saint(s): none

Gesture of the patron saint(s): not applicable

Type of religious scene: indeterminate

Religious scene(s) depicted: none

Cat. 624-Type $3^{A}$

[RKD work no. 51941]

VAN CLEVE, Joos

Altarpiece of the Lamentation (c. 1520-1525) 
$75 \times 146 \mathrm{~cm}$ (predella), $145 \times 206 \mathrm{~cm}$ (centre panel) and $45 \times 206 \mathrm{~cm}$ (lunette)

Paris, Musée du Louvre, inv. no. 1996

BIB L.: FRIEDLÄNDER IXa, no. 19; Exh. cat. Paris 1991, 45-76; HAND 2004, no. 73; Exh. cat. Aachen 2011, no. 11 (with bibl.); LEEFLANG 2015, 141-43.

HISTORICAL INFORMATION: Niccolo Bellogio was a nobleman, who made an important political career in Genoa. He is depicted with his wife Francischetta. The altarpiece was destined for the family chapel he founded in 1520 at Santa Maria della Pace. He died in 1537 and was buried in this chapel.

Identity of the sitter(s): Niccolo and Franchischetta Bellogio

Provenance: Genoa, church Santa Maria della Pace, Bellogio chapel

Number of portrait(s): 2

Type of person(s): lay (couple)

Attitude of the sitter(s): hands clasped, holding a book

Representation of the sitter(s): full-length

Gaze of the sitter(s): into space, towards the scene

Object(s): yes (rosary, book)

Coat(s) of arms: no

Environment: historical setting

Structuring of the pictorial space: not applicable

Patron saint(s): Nicholas of Tolentino, Clare

Gesture of the patron saint(s): indicating, introducing

Type of religious scene: narrative

Religious scene(s) depicted: the Lamentation, St. Francis receiving the stigmata, the Last supper

Cat. 625-Type 2A

VAN CLEVE, Joos

Triptych of the Adoration of the Magi with a Family in Prayer and Patron Saints (c. 1520)

$71.5 \times 69 \mathrm{~cm}($ centre panel $)$ and 71.5

$\times 31.5 \mathrm{~cm}$ (wings)

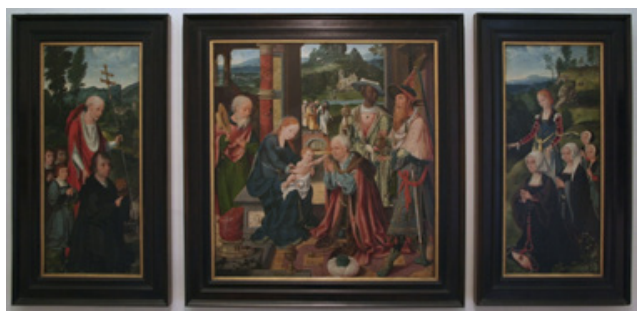

Prague, Narodni Galerie, inv. no. Do-37

BIBL.: FRIEDLÄNDER IXa, no. 7; Mus. cat. Prague 1999, no. 14; KOTKOVA 1999; HAND 2004, no. 18; Exh. cat. Aachen 2011, no. 4 (with bibl.); LEEFLANG 2015, 131-34.

Identity of the sitter(s): unknown

Provenance: unknown

Number of portrait(s): 8 
Type of person(s): lay (family with children)

Attitude of the sitter(s): hands clasped, holding a hat

Representation of the sitter(s): full-length

Gaze of the sitter(s): towards the scene

Object(s): yes (rosary, hat, small cross)

Coat(s) of arms: no

Environment: historical setting

Structuring of the pictorial space: unified space with discontinuities

Patron saint(s): Jerome, Lucy

Gesture of the patron saint(s): introducing, indicating

Type of religious scene: narrative

Religious scene(s) depicted: the Adoration of the Magi, the Virgin and Child with St. Anne, St. Catherine

Cat. 626-Type 2A

VAN CLEVE, Joos

Triptych of the Adoration of the Magi with Stefano Raggi and Patron Saint (c. 1520-1525)

$160 \times 136 \mathrm{~cm}$ (centre panel) and $160 \times$ $65 \mathrm{~cm}$ (wings)

Genoa, church of St. Donatian

BIBL.: FRIEDLÄNDER IXa, no. 9; CAVELLI TRAVERSO 2003, no. 4;

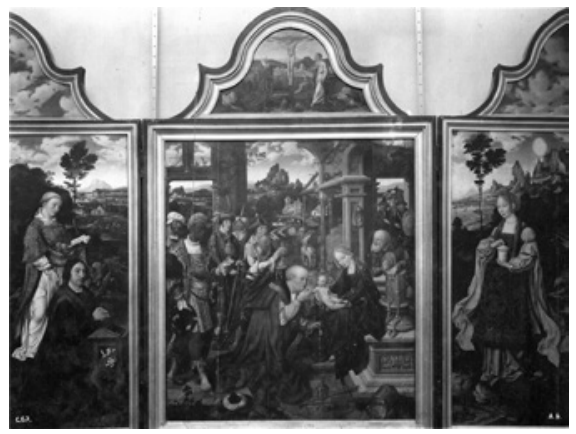

HAND 2004, no. 69; Exh. cat. Aachen 2011, 66-67 (with bibl.); LEEFLANG 2015, 135-39.

HISTORICAL INFORMATION: This triptych was commissioned by Stefano Fieschi Raggi, a wealthy merchant of Genoa, who also made a political career. In 1500, Stefano was made member of the Great Council of the city. In 1517, he became a member of the Council of elders (Anziano) and married Maria Maddalena Giustinianni. The name of his wife could explain the presence of St. Mary Magdalen in the triptych. Stefano travelled to Bruges with his uncle Lorenzo in 1507, for commercial reasons. As attested by the two wills he wrote between 1544 and 1557, the triptych was destined for his family chapel at the church of St. Donatian in Genoa.

Identity of the sitter(s): Stefano Raggi

Provenance: Genoa, church of St. Donatian, Raggi chapel

Number of portrait(s): 1

Type of person(s): lay (man alone) 
Attitude of the sitter(s): hands clasped

Representation of the sitter(s): full-length

Gaze of the sitter(s): into space

Object(s): yes (prie-dieu, book)

Coat(s) of arms: yes

Environment: historical setting

Structuring of the pictorial space: unified space with discontinuities

Patron saint(s): Stephen

Gesture of the patron saint(s): introducing

Type of religious scene: narrative

Religious scene(s) depicted: the Adoration of the Magi, St. Mary Magdalen, the Annunciation

\section{Cat. 627-Type 2A}

VAN CLEVE, Joos

Triptych of the Crucifixion with a Family in Prayer and Patron Saints (1518)

$91 \times 5^{8} \mathrm{~cm}$ (centre panel) and $89 \times 25 \mathrm{~cm}$ (wings)

Naples, Museo Nazionale di Capodimonte, inv. no. 844.89

BIBL.: FRIEDLÄNDER IXa, no. 11; Mus.

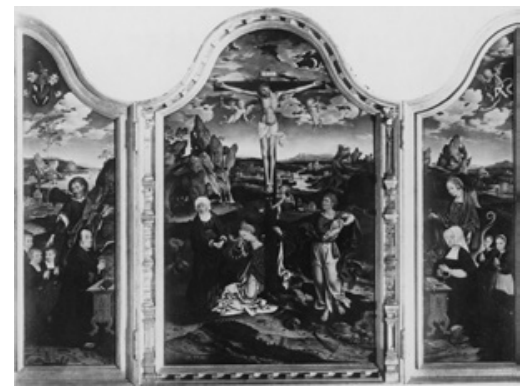

cat. Naples 1964, 47-48; HAND 2004, no. 10; Exh. cat. Aachen 2011, no. 3 (with bibl.); LEEFLANG 2015, 122-26.

HISTORICAL INFORMATION: The coats of arms painted on the wings are those of Marcus von Kirch and his wife Margriete Schats, who came from Mechelen. They are depicted with their children. The couple's respective ages (forty-five for him and twenty-five for her), are inscribed on their prie-dieu. Marcus was born on 16 July 1473 in Lindau, near Lake Constance. In 1494, he is documented as a participant in the fair of Bergen-op-Zoom. Between 1500 and 1514, he appears on several occasions in the Antwerp archives. He married Margriete Schats in 1513. According to Leeflang, the triptych might have been destined for a private chapel in a church of Mechelen or for their own house.

Identity of the sitter(s): Marcus von Kirch, Margriete Schats and their children

Provenance: unknown

Number of portrait(s): 7

Type of person(s): lay (family with children)

Attitude of the sitter(s): hands clasped, holding a rosary 
Representation of the sitter(s): full-length

Gaze of the sitter(s): towards the scene

Object(s): yes (prie-dieu, book, rosary, gloves)

Coat(s) of arms: yes

Environment: historical setting

Structuring of the pictorial space: continuous space

Patron saint(s): Mark, Margaret

Gesture of the patron saint(s): indicating, introducing

Type of religious scene: narrative

Religious scene(s) depicted: the Crucifixion, the Annunciation

Cat. 628-Type 2A

VAN CLEVE, Joos

Triptych of the Death

of the Virgin with two

Couples in Prayer and

Patron Saints (dated 1515)

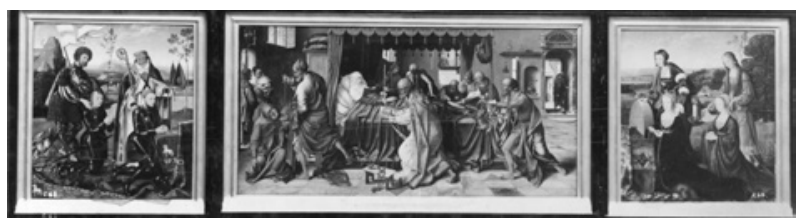

$63 \times 123 \mathrm{~cm}$ (centre panel) and $63 \times 57 \mathrm{~cm}$ (wings)

Cologne, Wallraf-Richartz Museum, inv. no. WRM 430

BIB L.: FRIEDLÄNDER IXa, no. 16; Mus. cat. Cologne 1969, 21-27; HAND 2004, no. 7; Exh. cat. Aachen 2011, 31-34 (with bibl.); LEEFLANG 2015, 95-101.

HistoriCAL INFORMATION: In 1515, Nicaise Hackeney ( $\dagger$ 1518) commissioned this triptych for the chapel of his family residence in the Neumarkt of Cologne, which he acquired in 1507. He is depicted with his brother George and their respective wives, Christina Hardenrath and Sibilla van Merle. Nicaise Hackeney was a wealthy patrician of Cologne, whose father, Casyn Hackeney, was a jeweller and creditor of the Habsburgs. Nicaise is mentioned in 1479 as a craftsman, then in 1483 as magister artium and in 1494 as a clerk. From 1490 onwards, he also worked for the Habsburgs and became an intimate of Maximilian I. In 1499, Nicaise was appointed Royal Treasurer. In c. 1523, Georg Hackeney commissioned to Van Cleve a copy of this triptych (cat. 629), which he instructed was to be destined to the church Sankt Marien im Kapitol of Cologne.

Identity of the sitter(s): Nicaise and Georg Hackeney, Christina Hardenrath and Sibilla van Merle

Provenance: Cologne, Neumarkt, Hackeney chapel

Number of portrait(s): 4

Type of person(s): lay (family)

Attitude of the sitter(s): hands clasped, holding a book 
Representation of the sitter(s): full-length

Gaze of the sitter(s): into space

Object(s): yes (prie-dieu, book, helmet, small cross)

Coat(s) of arms: yes

Environment: historical setting

Structuring of the pictorial space: distinct spaces

Patron saint(s): Nicasius, George, Christina, Gudula

Gesture of the patron saint(s): introducing, protecting

Type of religious scene: narrative

Religious scene(s) depicted: the Death of the Virgin, St. Sebastian, St. Roch

Cat. 629-Type 2A

VAN CLEVE, Joos

Triptych of the Death of the Virgin with two Couples in Prayer and Patron Saints (c. $1515^{-1518}$ or c. 1523$)$ $127 \times 154 \mathrm{~cm}$ (centre panel) and $127 \times 70 \mathrm{~cm}$ (wings)

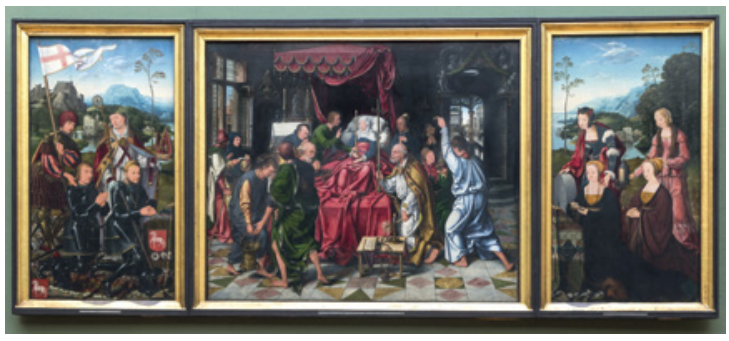

Munich, Alte Pinakothek, inv. nos. $15^{0-152}$

BIB L.: FRIEDLÄNDER IXa, no. 17; HAND 2004, no. 47; Mus. cat. Munich 2006, 305; Exh. cat. Aachen 2011, 51-53 (with bibl.); LEEFLANG 2015, 95-101.

HISTORICAL INFORMATION: This triptych was commissioned by Georg Hackeney for the 'Rood' altar of the church Sankt Marien im Kapitol in Cologne. It is a copy of the triptych commissioned by his brother, Nicaise, ten years earlier (cat. 628).

Identity of the sitter(s): Nicaise and Georg Hackeney, Christina Hardenrath and Sibilla van Merle

Provenance: Cologne, church Sankt Marien im Kapitol

Number of portrait(s): 4

Type of person(s): lay (family)

Attitude of the sitter(s): hands clasped, holding a book

Representation of the sitter(s): full-length

Gaze of the sitter(s): into space

Object(s): yes (prie-dieu, helmet, book, small cross)

Coat(s) of arms: yes

Environment: historical setting

Structuring of the pictorial space: distinct spaces

Patron saint(s): Nicasius, George, Christina, Gudula 
Gesture of the patron saint(s): introducing, protecting

Type of religious scene: narrative

Religious scene(s) depicted: the Death of the Virgin, St. Sebastian, St. Roch

Cat. 630-Type 2A

VAN CLEVE, Joos

Triptych of the Descent of the Cross with

a Couple in Prayer and Patron Saints (c. 1520)

$106.7 \times 71.1 \mathrm{~cm}$ (centre panel) and $109.2 \times$ $31.8 \mathrm{~cm}$ (wings)

Edinburgh, National Gallery of Scotland, inv. no. NG 1252

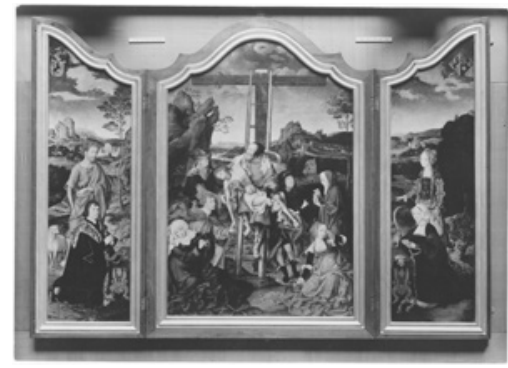

BIB L.: FRIEDLÄNDER IXa, no. 14; Mus. cat. Edinburgh 1997, 74; HAND 2004, no. 42; Exh. cat. Aachen 2011, 47 (with bibl.); LEEFLANG 2015, 126-31.

Historical INFORMation: The man portrayed on the left wing is Jan Pels, an Antwerp merchant born around 1480 and deceased in 1536 . His wife, Digna de Herde, is the daughter of Jan Herde, who was burgomaster of Antwerp.

Identity of the sitter(s): Jan Perls and Digna de Herde

Provenance: unknown

Number of portrait(s): 2

Type of person(s): lay (couple)

Attitude of the sitter(s): hands clasped, holding a book

Representation of the sitter(s): full-length

Gaze of the sitter(s): into space

Object(s): yes (prie-dieu, book, gloves, rosary)

Coat(s) of arms: yes

Environment: historical setting

Structuring of the pictorial space: continuous space

Patron saint(s): John the Baptist, Margaret

Gesture of the patron saint(s): indicating, holding his/her attribute

Type of religious scene: narrative

Religious scene(s) depicted: the Descent from the cross 
Cat. 631-Type $2 B$

VAN CLEVE, Joos

Triptych of the Holy Family with a Couple in Prayer and Patron Saints (c. 1528)

$94.5 \times 70 \mathrm{~cm}($ centre panel) and $94.5 \times 30$ $\mathrm{cm}$ (wings)

Vienna, Kunsthistorisches Museum, inv. no. 938

BIBL.: FRIEDLÄNDER IXa, no. 18;
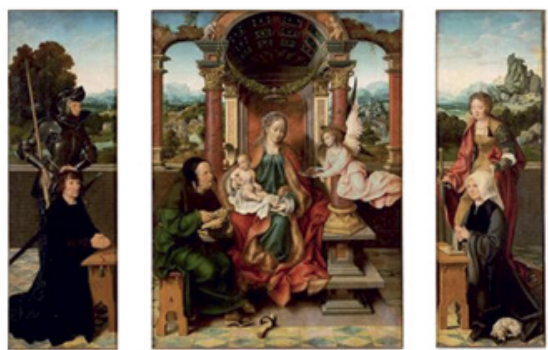

HAND 1978, 173, 304-05, no. 66; HAND 2004, no. 72; Exh. cat. Aachen 2011, 62-63 (with bibl.).

Identity of the sitter(s): unknown

Provenance: unknown

Number of portrait(s): 2

Type of person(s): lay (couple)

Attitude of the sitter(s): hands clasped

Representation of the sitter(s): full-length

Gaze of the sitter(s): towards the scene

Object(s): yes (prie-dieu, rosary, book, dog)

Coat(s) of arms: no

Environment: architectural space with sacred connotation

Structuring of the pictorial space: continuous space

Patron saint(s): Adrian (or George?), Catherine

Gesture of the patron saint(s): protecting

Type of religious scene: hieratic

Religious scene(s) depicted: the Holy family, St. Sebastian, St. Christopher

Cat. 632-Type $3^{B}$

VAN CLEVE, Joos

Triptych of the Virgin and Child with a Family in Prayer ('Cerezo Altarpiece')

$141 \times 136 \mathrm{~cm}$ (centre panel) and $144 \times 59 \mathrm{~cm}$ (wings)

Agaete (Gran Canaria), Ermita de Nuestra Senora de las Nieves and Nuestra Senora de la Concepcion

в Iв L.: LEEFLANG 2015, 143-50 (with bibl.).

HISTORICAL INFORMATION: This now dismembered triptych was commissioned by Antón Cerezo, a sugar merchant coming from Genoa and active in 
Gran Canaria, and his wife, Sancha Díaz de Zorita. They are portrayed with their son, Francisco Palomar. Dating from 11 October 1535, Antón's will mentions two paintings that could be related to this triptych. The first one was commissioned in Flanders and was destined for the high altar of the church of Our Lady of the Conception in Agaete (Gran Canaria). The second was a triptych described in terms very similar to those of another document, dating from 1532. This second archival document stipulates that the Cerezo couple was then planning to build a monastery of the Mercederian Order (Nuestra Senora de Merced) with a chapel dedicated to Our Lady of the Snow, in which they wanted to place an altarpiece of the Virgin with St. Anthony, St. Christoph and St. Francis on the wings. In all likelihood, the now preserved Cerezo altarpiece is one of these two paintings, the other one now being lost. The triptych is now divided into five pieces (the wings and three panels originally forming the centre panel). The dismemberment is a result of a Gran Canaria tradition of a procession during which the panel of the Virgin was transported in the streets of Agaete every 5 August.

Identity of the sitter(s): Antón Cerezo, Sancha Díaz de Zorita and their son Francisco Palomar

Provenance: Agaete (Gran Canaria), church of Our Lady of the Conception or monastery of the Mercederian Order

Number of portrait(s): 3

Type of person(s): lay (family with children)

Attitude of the sitter(s): hands clasped

Representation of the sitter(s): full-length

Gaze of the sitter(s): into space, towards the scene

Object(s): yes (rosary)

Coat(s) of arms: no

Environment: architectural space with sacred connotation

Structuring of the pictorial space: distinct spaces

Patron saint(s): none

Gesture of the patron saint(s): not applicable

Type of religious scene: hieratic

Religious scene(s) depicted: the Virgin and Child, St. Anthony, St. Jerome 
Cat. 633-Type 6A

VAN CLEVE, Joos

Two wings. A couple in Prayer (c. 1525)

$89 \times 25 \mathrm{~cm}$ (each wing)

Raveningham, collection of sir Edmond Bacon BIBL.: FRIEDLÄNDER IXa, no. 23; HAND 1978, no. 51; Exh. cat. Aachen 2011, no. 9 (with bibl.). Identity of the sitter(s): unknown

Provenance: unknown

Number of portrait(s): 2

Type of person(s): lay (couple)

Attitude of the sitter(s): hands clasped

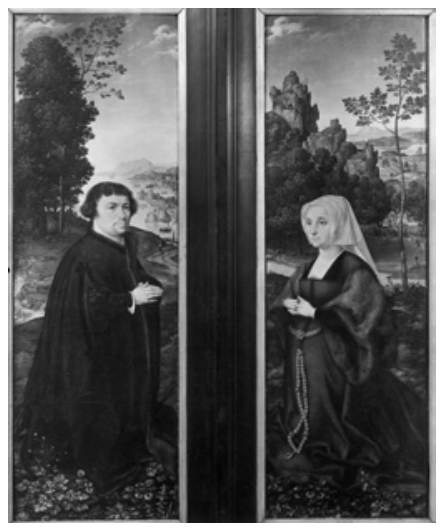

Representation of the sitter(s): full-length

Gaze of the sitter(s): indeterminate

Object(s): yes (rosary)

Coat(s) of arms: no

Environment: landscape, no sacred connotation (incomplete)

Structuring of the pictorial space: indeterminate

Patron saint(s): none

Gesture of the patron saint(s): not applicable

Type of religious scene: indeterminate

Religious scene(s) depicted: none

Cat. 634-Type $2 \mathrm{C}$

VAN CLEVE, Joos (attributed to)

Triptych of the Crucifixion with a Couple in Prayer (c. 1525)

$114 \times 82 \mathrm{~cm}$ (centre panel) and $117 \times 36$ $\mathrm{cm}$ (wings)

Tokyo, National Museum of Western Art, inv. no. P $1976-3$

BIBL.: FRIEDLÄNDER IXa, no. 13;

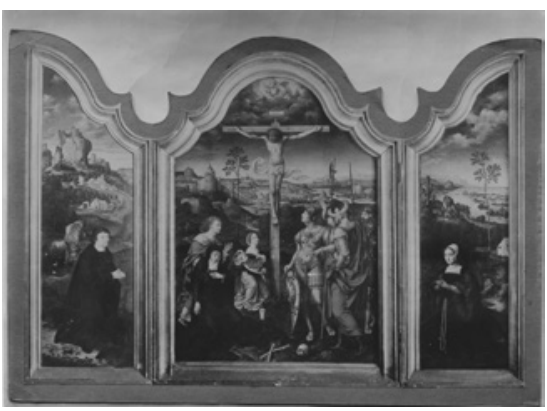
HAND 1978, no. 74; Mus. cat. Tokyo 1998, no. 10; HAND 2004, no. 57 (with bibl.).

Identity of the sitter(s): unknown

Provenance: unknown 
Number of portrait(s): 2

Type of person(s): lay (couple)

Attitude of the sitter(s): hands clasped

Representation of the sitter(s): full-length

Gaze of the sitter(s): into space, towards the scene

Object(s): yes (rosary)

Coat(s) of arms: no

Environment: historical setting

Structuring of the pictorial space: continuous space

Patron saint(s): none

Gesture of the patron saint(s): not applicable

Type of religious scene: narrative

Religious scene(s) depicted: the Crucifixion

Cat. 635-Type 6A

[RKD work no. 41273]

VAN CLEVE, Joos (attributed to)

Two wings. A couple in Prayer (c. 1500-1550)

$103 \times 37 \mathrm{~cm}$ (each wing)

Whereabouts unknown

Identity of the sitter(s): unknown

Provenance: unknown

Number of portrait(s): 2

Type of person(s): lay (couple)

Attitude of the sitter(s): hands clasped

Representation of the sitter(s): full-length

Gaze of the sitter(s): into space

Object(s): yes (prie-dieu, book)

Coat(s) of arms: no

Environment: landscape, no sacred connotation (incomplete)

Structuring of the pictorial space: indeterminate

Patron saint(s): none

Gesture of the patron saint(s): not applicable

Type of religious scene: indeterminate

Religious scene(s) depicted: none 
Cat. 636-Type $1 \mathrm{D}$

VAN CLEVE, Joos (circle of)

Triptych of the Holy Family (c. 1520-1530)

$105 \times 71 \mathrm{~cm}$ (centre panel) and $105 \times 31 \mathrm{~cm}$ (wings)

New York, sale Sotheby's (28 January 2000), lot no. 22

BI B L.: Sale cat. Sotheby's (New York, 28 January 2000), lot no. 22.

Identity of the sitter(s): unknown

Provenance: unknown

Number of portrait(s): 1

Type of person(s): lay (man alone)

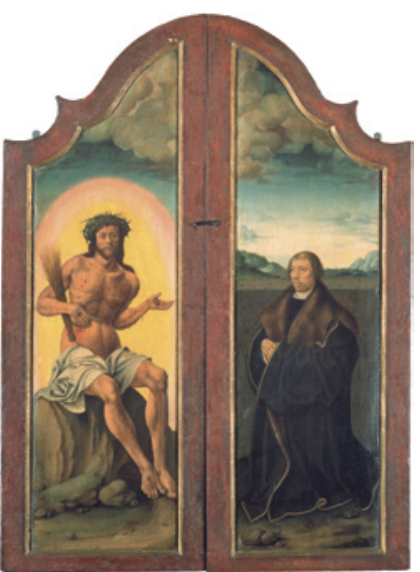

Attitude of the sitter(s): hands clasped

Representation of the sitter(s): full-length

Gaze of the sitter(s): into space

Object(s): no

Coat(s) of arms: no

Environment: enclosed garden

Structuring of the pictorial space: distinct spaces, religious scene in a cloud Patron saint(s): none

Gesture of the patron saint(s): not applicable

Type of religious scene: hieratic

Religious scene(s) depicted: the Holy family, St. Barbara, St. Catherine, the Man of sorrows

\section{Cat. 637-Type 5}

VAN CLEVE, Joos (follower of)

Triptych of the Adoration of the Magi with a Nun and a Man in Prayer and Patron Saints (c. 1525-1550)

Size unknown

Utrecht, private collection

Identity of the sitter(s): unknown Provenance: unknown

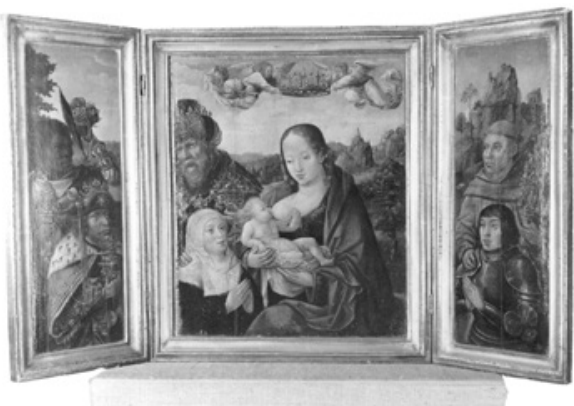

Number of portrait(s): 2

Type of person(s): mixed (unidentified group)

Attitude of the sitter(s): hands clasped 
Representation of the sitter(s): half-length

Gaze of the sitter(s): towards the scene

Object(s): no

Coat(s) of arms: no

Environment: landscape, no sacred connotation (incomplete)

Structuring of the pictorial space: continuous space

Patron saint(s): a magi, Francis

Gesture of the patron saint(s): protecting

Type of religious scene: hieratic

Religious scene(s) depicted: the Adoration of the Magi

Cat. 638-Type $2 \mathrm{~A}$

VAN CLEVE, Joos (workshop of) and anonymous North Netherlandish Master Triptych of the Christ Appearing to his Mother with a Family in Prayer and Patron Saints (c. 1530)

$90 \times 67 \mathrm{~cm}$ (centre panel) and $90 \times 27 \mathrm{~cm}$ (wings)

Welshpool, St. Mary

BIBL.: GRÖSSINGER 1992, no. 72.

Identity of the sitter(s): unknown

Provenance: unknown

Number of portrait(s): 8

Type of person(s): mixed (family with children)

Attitude of the sitter(s): hands clasped

Representation of the sitter(s): full-length

Gaze of the sitter(s): towards the scene

Object(s): yes (rosary, small cross, hat, purse)

Coat(s) of arms: yes

Environment: historical setting

Structuring of the pictorial space: distinct spaces

Patron saint(s): Paul, Mary Magdalen

Gesture of the patron saint(s): holding his/her attribute

Type of religious scene: narrative

Religious scene(s) depicted: Christ appearing to his mother 
Cat. 639-Type $3 \mathrm{~A}$

VAN CLEVE, Joos and PATINIER, Joachim (follower of)

Triptych of the Crucifixion with a Man in Prayer (c. 1520)

$98.4 \times 74.3 \mathrm{~cm}$ (centre panel) and 101 $\times 32.7 \mathrm{~cm}$ (wings)

NewYork, MET, inv. nos. 41.19o-.20a-c BIBL.: FRIEDLÄNDER IXa, no. 12;

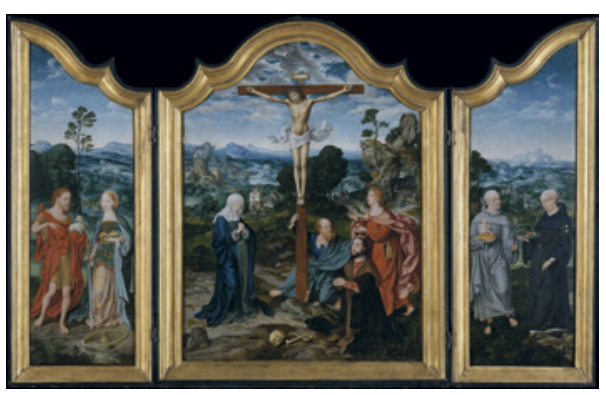
AINSWORTH and CHRISTIANSEN 1998, 356-59; HAND 2004, no. 40 (with bibl.).

Identity of the sitter(s): unknown

Provenance: unknown

Number of portrait(s): 1

Type of person(s): lay (man alone)

Attitude of the sitter(s): hands clasped

Representation of the sitter(s): full-length

Gaze of the sitter(s): towards the scene

Object(s): yes (hat)

Coat(s) of arms: no

Environment: historical setting

Structuring of the pictorial space: not applicable

Patron saint(s): Peter (?)

Gesture of the patron saint(s): protecting

Type of religious scene: narrative

Religious scene(s) depicted: the Crucifixion, St. John the Baptist, St. Catherine, St. Antony of Padua, St. Nicholas of Tolentino

Cat. 640-Type $3^{B}$

VAN CONINXLOO, Jan II

A Friar in Prayer with Mary Magdalen and Mary the Egyptian before the Fountain of Life (c. 1500-1550)

$26.2 \times 35.6 \mathrm{~cm}$

New York, sale Sotheby's (11 January 1996)

Identity of the sitter(s): unknown

Provenance: unknown

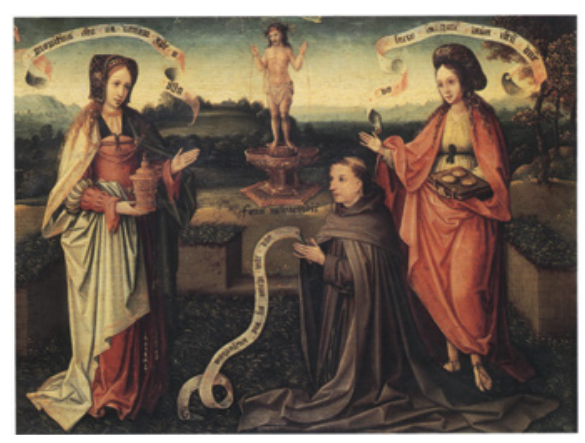


Number of portrait(s): 1

Type of person(s): religious (man alone: Franciscan friar)

Attitude of the sitter(s): holding a banderole

Representation of the sitter(s): full-length

Gaze of the sitter(s): into space

Object(s): yes (banderole)

Coat(s) of arms: no

Environment: enclosed garden

Structuring of the pictorial space: not applicable

Patron saint(s): Mary the Egyptian

Gesture of the patron saint(s): holding his/her attribute

Type of religious scene: hieratic

Religious scene(s) depicted: the Fountain of Life, St. Mary Magdalen

\section{Cat. 641-Type 6A}

VAN CONINXLOO, Jan II

Fragments. The Presentation at the Temple and the Christ Appearing to his Mother; A Couple in Prayer and Patron Saints (reverse) (c. 1530)

$88.5 \times 92.5 \mathrm{~cm}$

Rouen, Musée des Beaux-Arts, inv. nos. S.R. $37 \mathrm{a}-37 \mathrm{~b}-38 \mathrm{a}-38 \mathrm{~b}$

BIBL.: FRIEDLÄNDER VIII, pl. 133A, 88; MAQUET-TOMBU 1943a, 156; ENGELLAU-GULLANDER 1992, no. 2 (with bibl.).

HISTORICAL INFORMATION: These two panels were probably parts of the predella of a large altarpiece. The panel depicting the Presentation at the temple is signed by the painter. During the French Revolution, the panels were recorded among the goods of the convent Notre-Dame des Anges in Rouen. Unfortunately, we do not have any information about the sitters.

Identity of the sitter(s): unknown

Provenance: unknown

Number of portrait(s): 2

Type of person(s): lay (couple)

Attitude of the sitter(s): hands clasped

Representation of the sitter(s): full-length

Gaze of the sitter(s): indeterminate

Object(s): yes (hat, book)

Coat(s) of arms: no

Environment: ecclesial space (incomplete)

Structuring of the pictorial space: indeterminate

Patron saint(s): John the Baptist, Catherine 
Gesture of the patron saint(s): introducing

Type of religious scene: indeterminate

Religious scene(s) depicted: the Circumcision, Christ taking leave of his mother

\section{Cat. 642-Type 5}

VAN CONINXLOO, Jan II

Altarpiece of the Infancy and the Passion of Christ (Jäder Altarpiece') (dated 1514) $125 \times 49 \mathrm{~cm}$ (panels of the predella)

Jäder, church

BIBL.: FRIEDLÄNDER VIII, 88; ENGELLAU-GULLANDER 1992, no. 1, no. 45; D'HAINAUT-ZVENY 2005, 210-11.

HISTORICAL INFORMATION: According to several scholars, the Stockholm Cathedral is the original location of this altarpiece. They base their hypothesis on the fact that the work was transferred by the Chancellor of Sweden, Axel Oxenstierna, from the cathedral to the church of Jäder in 1566. The altarpiece might have been destined for the St. Andrew's chapel, which housed an altar dedicated to the Virgin. This hypothesis is not unanimously accepted because the iconography of the altarpiece is not totally related to the Virgin. EngellauGullander proposes that the group of devotees portrayed on the predella are members of the Penitential Order of Mary Magdalene. This order was created in Germany at the instigation of the pope and put under the direction of the Dominicans. Its objective was to address the issue of prostitution. According to Engellau-Gullander, the altarpiece was destined for a German chapel dedicated to John the Baptist and Mary Magdalen. Nevertheless, she does not mention any concrete proof in support of her hypothesis.

Identity of the sitter(s): unknown

Provenance: unknown

Number of portrait(s): 21

Type of person(s): lay (family)

Attitude of the sitter(s): hands clasped

Representation of the sitter(s): full-length

Gaze of the sitter(s): towards the scene, towards the ground

Object(s): no

Coat(s) of arms: no

Environment: landscape with sacred connotation

Structuring of the pictorial space: distinct spaces

Patron saint(s): none

Gesture of the patron saint(s): not applicable 
Type of religious scene: intercession

Religious scene(s) depicted: the Virgin immaculate, the Mass of St. Gregory, the Baptism of Christ, the Decollation of St. John the Baptist, Christ at Simon's house, the Intercession of Mary Magdalen, St. John the Baptist, Christ and Mary interceding, God the Father, Christ bearing the cross, the Lamentation, the Birth of the Virgin, the Flight into Egypt, Christ among the doctors, the Arrest of Christ, Christ in front of Pontius Pilate, The Entry of Christ at Jerusalem

Cat. 643-Type $1 B$

VAN CONINXLOO, Jan II

Triptych of St. Anne (dated 1546)

$149 \times 162 \mathrm{~cm}$ (centre panel),

$115 \times 74 \mathrm{~cm}$ (right wing) and

$114.5 \times 74 \mathrm{~cm}$ (left wing)

Brussels, MRBAB, inv. no. 338

BIB L.: FRIEDLÄNDER VIII, 88;

MAQUET-TOMBU 1943b;

ENGELLAU-GULLANDER 1992,

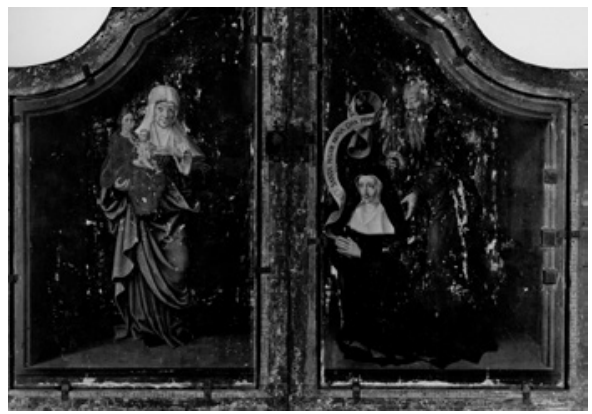

no. 3; VAN DER PLOEG 1998.

HISTORICAL INFORMATION: The fragmentary inscription on the reverse of the wings allowed van der Ploeg to identify the nun as Anthonine de Locquenghien: DESE [TAF]ELE [HEEFT] DOEN MAKE IOFFROWE AN[THO]NINE [V] A LO $[K E] N C H E M$ RELEGIOSE DES CLOSTERS GROOTE B[IGAERD]$D E A\left[^{\circ}\right]$ 1546. A nun bearing this name is mentioned in the Necrologium of the Benedictine abbey of Voorst. She died on 12 February 1594. The triptych was destined for St. Anne's altar in the abbey church of Voorst. It presents the same compositional structure as cat. 645 .

Identity of the sitter(s): Anthonine de Locquenghien

Provenance: Benedictine abbey of Voorst, St. Anne's altar

Number of portrait(s): 1

Type of person(s): religious (woman alone: Benedictine nun)

Attitude of the sitter(s): hands clasped

Representation of the sitter(s): full-length

Gaze of the sitter(s): towards the scene 
Object(s): yes (banderole)

Coat(s) of arms: no

Environment: niche

Structuring of the pictorial space: continuous space

Patron saint(s): Anthony

Gesture of the patron saint(s): introducing

Type of religious scene: hieratic

Religious scene(s) depicted: the Family of St. Anne, the Death of St. Anne, the Virgin and Child with St. Anne, Joachim's Sacrifice, St. Anthony

Cat. 644-Type $3 \mathrm{D}$

VAN CONINXLOO, Jan II (attributed to)

The Virgin and Child with St. Anne and a Nun in

Prayer (c. 1500-1550)

$36 \times 27 \mathrm{~cm}$

Whereabouts unknown

Identity of the sitter(s): unknown

Provenance: unknown

Number of portrait(s): 1

Type of person(s): religious (woman alone:

Augustinian canoness)

Attitude of the sitter(s): physical contact with the sacred person

Representation of the sitter(s): full-length

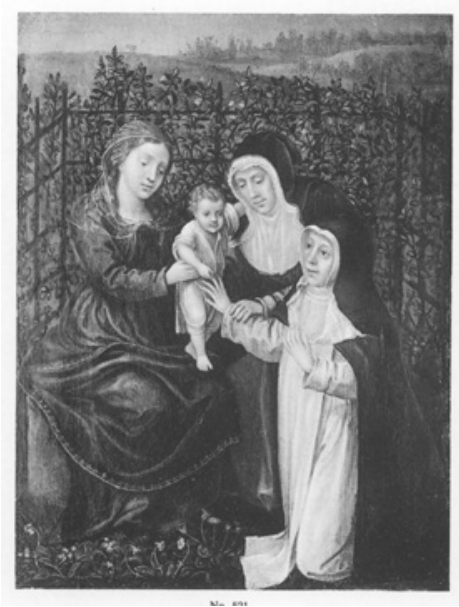

Gaze of the sitter(s): towards the scene

Object(s): no

Coat(s) of arms: no

Environment: enclosed garden

Structuring of the pictorial space: not applicable

Patron saint(s): none

Gesture of the patron saint(s): not applicable

Type of religious scene: hieratic

Religious scene(s) depicted: the Virgin and Child with St. Anne 
Cat. 645-Type $1 B$

VAN CONINXLOO, Jan II (workshop of)

Triptych of St. Benedict (c. 1545)

$135 \times 334.5 \mathrm{~cm}$ (open)

Brussels, MRBAB, inv. no. 36

BIBL.: MAQUET-TOMBU 1943b;

ENGELLAU-GULLANDER 1992, no. 14; VAN DER PLOEG 1998,

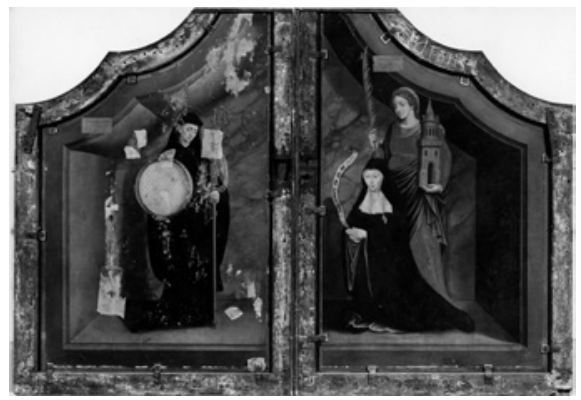
116-18.

HISTORICAL INFORMATION: The reverse of the wings presents a fragmentary inscription similar to that of Van Coninxloo's Triptych of St. Anne (cat. 643): Dese tafele heeft doe [ $n]$ [maeken] ionffrouw [Berbele] $\left.\operatorname{vr}[]^{\prime}\right][$ de]es [c]l[o]e[s]t[er] $v a[n]$ den grooten byga $[$ erden $]\left[A^{\prime} c ̧\right] l . v \ldots$. This inscription is not legible enough to guarantee that the triptych also comes from the abbey of Voorst, but the similarities with the Triptych of St. Anne make that probability very high. The nun was probably named Barbara, for she is presented by St. Barbara. Van der Ploeg lists several nuns called Barbara, Barbe or Berbel at Voorst, but none of these can be linked with certainty to the portrait.

Identity of the sitter(s): unknown (Benedictine nun from Voorst named Barbara)

Provenance: Benedictine abbey of Voorst

Number of portrait(s): 1

Type of person(s): religious (woman alone: Benedictine nun)

Attitude of the sitter(s): holding a banderole

Representation of the sitter(s): full-length

Gaze of the sitter(s): into space

Object(s): yes (banderole)

Coat(s) of arms: no

Environment: niche

Structuring of the pictorial space: continuous space

Patron saint(s): Barbara

Gesture of the patron saint(s): holding his/her attribute

Type of religious scene: hieratic

Religious scene(s) depicted: the Legend of St. Benedict 
Cat. 646-Type $1 \mathrm{D}$

VAN DEN BOSSCHE, Aert

Triptych of St. Crispian and St. Crispinian (c. 1490$)$

$95.5 \times 187.1 \mathrm{~cm}$ (centre panel), $97.8 \times 39.2 \mathrm{~cm}$ (right outer wings) and $98 \times 37.5 \mathrm{~cm}$ (right inner wings)

Brussels, Musée de la Ville de Bruxelles, inv. nos. K/1977/1-2 (right inner wings), Moscow, Pouchkine Museum, inv. nos. 4074-4075 (right outer wings), Warsaw, Muzeum Narodowe, inv. no. Wil. $15^{21}$ (centre panel)

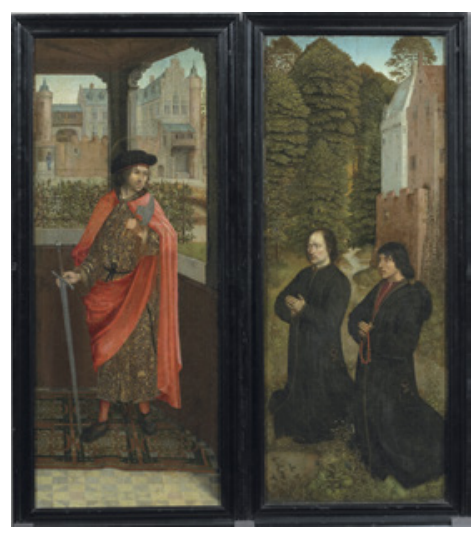

BIBL.: Corpus Poland, no. 113; BONENFANT-FEYTMANS 1991; DE VOS 1991; Exh. cat. Lille 2005, 94-99 (with bibl.); Exh. cat. Brussels 2013, no. 53 . HistoriCAL INFORMATION: In 1991, Bonnefant-Feytmans discovered several archival documents that shed light on the history of this triptych. It was commissioned to Aert van den Bossche in 1490 by the Brussels cobblers' Guild, whose patron saints were St. Crispian and St. Crispinian. At this time, the association was divided between a corporation (which was in charge of the finances) and a brotherhood, which commissioned the triptych. Nevertheless, the brotherhood maintained contentious relations with the corporation, and this situation impacted on the execution of the triptych. A solution was found in 1491, when the decision was taken to add the portraits of the four jurors of the corporation onto the wings of the triptych. The account books of the corporation mention the names of these four men: Jan van der Scaffenen, Joes de Block, Jan van der Groeten and Jan Mercx.

Identity of the sitter(s): Jan van der Scaffenen, Joes de Block, Jan van der Groeten and Jan Mercx

Provenance: Brussels, church of the Friars Minor, then church of St. Nicholas from 1500 onwards

Number of portrait(s): 2 (initially 4 ?)

Type of person(s): lay (group: association)

Attitude of the sitter(s): hands clasped

Representation of the sitter(s): full-length

Gaze of the sitter(s): into space

Object(s): yes (rosary)

Coat(s) of arms: no 
Environment: landscape, no sacred connotation (incomplete)

Structuring of the pictorial space: distinct spaces

Patron saint(s): none

Gesture of the patron saint(s): not applicable

Type of religious scene: narrative

Religious scene(s) depicted: the Legend of St. Crispian and St. Crispinian

Cat. 647- Type

VAN DER GOES Hugo and anonymous

Bruges Master

Triptych of the Virgin and Child ('Triptych of Willem van Overbeke') (c. 1485-1490) $21 \times 14 \mathrm{~cm}$ (centre panel) and $30 \times 11.5$ cm (wings)

Frankfurt, Städelsches Kunstinstitut, inv. no. 111

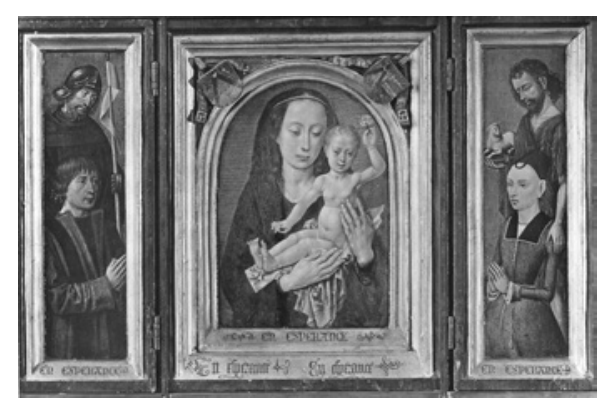

BIBL.: FRIEDLÄNDER IV, no. 5; Mus. cat. Frankfurt 1993, 164-81 (with bibl.);

SEDLACEK 1997; DHANENS 1998, 171-72.

HISTORICAL INFORMATION: The sitters are Willem van Overbeke $(\dagger 1529)$ and his wife Johanna de Keysere $(\dagger 1517)$. Willem was secretary of the Grand conseil in Mechelen. He married Johanna in 1478. The couple is also portrayed in cat. 211.

Identity of the sitter(s): Willem van Overbeke and Johanna de Keysere

Provenance: unknown

Number of portrait(s): 2

Type of person(s): lay (couple)

Attitude of the sitter(s): hands clasped

Representation of the sitter(s): half-length, small scale

Gaze of the sitter(s): towards the scene

Object(s): no

Coat(s) of arms: yes

Environment: neutral space

Structuring of the pictorial space: continuous space

Patron saint(s): William of Maleval, John the Baptist

Gesture of the patron saint(s): holding his/her attribute, protecting

Type of religious scene: hieratic

Religious scene(s) depicted: the Virgin and Child, the Annunciation 
Cat. 648-Type 6A

VAN DER GOES, Hugo

Fragment. A Man in Prayer with Patron Saint (c. 1480-1500)

$32.2 \times 2.5 \mathrm{~cm}$

Baltimore, Walters Art Museum, inv. no. 37.296

BIBL.: DHANENS 1998, 329-31.

Identity of the sitter(s): unknown

Provenance: unknown

Number of portrait(s): 1

Type of person(s): lay (man alone)

Attitude of the sitter(s): hands clasped

Representation of the sitter(s): indeterminate

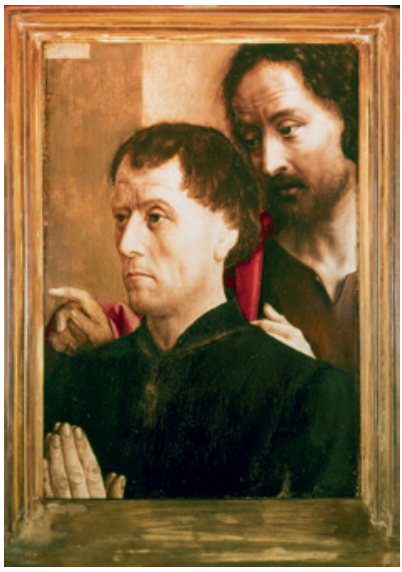

Gaze of the sitter(s): indeterminate

Object(s): no

Coat(s) of arms: no

Environment: indeterminate

Structuring of the pictorial space: indeterminate

Patron saint(s): an unidentified saint (John the Baptist?)

Gesture of the patron saint(s): indicating

Type of religious scene: indeterminate

Religious scene(s) depicted: none

Cat. 649-Type 6B

VAN DER GOES, Hugo

Portrait of a Man in Prayer (c. 1475)

$31.8 \times 26.7 \mathrm{~cm}$

New York, MET, inv. no. 29.100.15

BIB L.: FRIEDLÄNDER IV, supp.110; AINSWORTH

and CHRISTIANSEN 1998, 170-71 (with bibl.).

Identity of the sitter(s): unknown

Provenance: unknown

Number of portrait(s): 1

Type of person(s): lay (man alone)

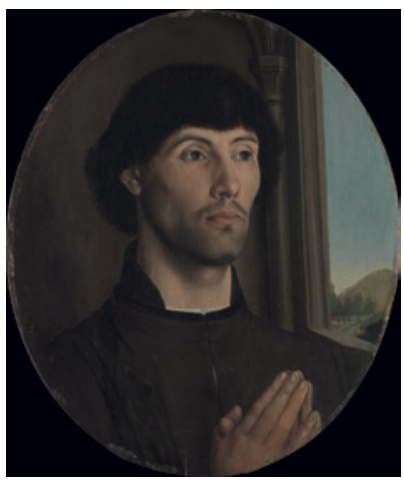

Attitude of the sitter(s): hands clasped

Representation of the sitter(s): full-length

Gaze of the sitter(s): indeterminate 
Object(s): no

Coat(s) of arms: no

Environment: domestic setting

Structuring of the pictorial space: indeterminate

Patron saint(s): none

Gesture of the patron saint(s): not applicable

Type of religious scene: indeterminate

Religious scene(s) depicted: none

Cat. 650-Type 2A

VAN DER GOES, Hugo

Triptych of the Adoration of the Shepherd ('Portinari Triptych') (c. 1473-1475)

$249 \times 300 \mathrm{~cm}$ (centre panel) and $249 \times 137 \mathrm{~cm}$ (wings)

Florence, Galleria degli Uffizi, inv. no. 1525

вIBL.: FRIEDLÄNDER IV, no. 10; DHANENS 1998, 250-301; WOLFTHAL 2007; FRANKE 2007-2008; KOSTER 2008, 39-77, 107-36.

HistoriCAL Information: The triptych shows Tommaso Portinari with his wife Maria Baroncelli and their three children (on the Portinari family, see cat. 587). The little girl portrayed behind her mother is Margerita, born in 1471. The two sons are Antonio, born in 1472, and Pigello, born between 1474 and 1476 . Scholars usually assume that the triptych was destined for the church of the Santa Maria Nuova Hospital. Tommaso was indeed one of its benefactors and founded a chaplaincy there on 4 August 1472. Nevertheless, Franke recently cast doubt upon this hypothesis and proposed that the triptych was destined for the chapel that Tommaso founded in 1474, at the church of St. James in Bruges and in which he planned to be buried with his wife.

Identity of the sitter(s): Tommaso Portinari, Maria Baroncelli and their children

Provenance: Florence, Santa Maria Nuova Hospital or Bruges, church of St. James

Number of portrait(s): 5

Type of person(s): lay (family with children)

Attitude of the sitter(s): hands clasped

Representation of the sitter(s): full-length, small scale

Gaze of the sitter(s): towards the scene

Object(s): no 
Coat(s) of arms: no

Environment: historical setting

Structuring of the pictorial space: unified space with discontinuities

Patron saint(s): Thomas, Anthony, Margaret, Mary Magdalen

Gesture of the patron saint(s): holding his/her attribute, introducing

Type of religious scene: narrative

Religious scene(s) depicted: the Nativity, the Annunciation

\section{Cat. 651-Type 6A}

\section{VAN DER GOES, Hugo}

Wings of the 'Bonkill Altarpiece'

(c. 1473-1482)

$216 \times 115 \mathrm{~cm}$ (each wing)

Edinburgh, National Gallery of Scotland (in loan of the Royal Collections of Hampton Court) BIBL.: FRIEDLÄNDER IV, no. 12; CAMPBELL 1985, no. 30-31 (with bibl.); DHANENS 1998, 302-25.

HISTORICAL INFORMATION: On
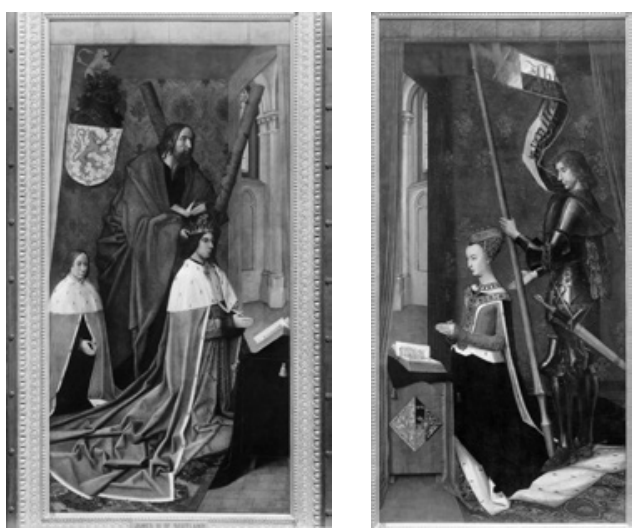

the basis of the coats of arms depicted, the sitters have been identified as James III, King of Scotland, his wife Margaret of Denmark and their oldest son James (born in 1473). The cleric portrayed on the other side of the wings is Edward Bonkill. He is probably the commissioner of the work. He was the Provoost of the collegiate church of Edinburgh. He came from a family of merchants and had ties with the Low Countries. This would explain why he commissioned the work to Hugo van der Goes. The cleric died in 1469. In all likelihood, these wings come from a triptych destined for the Trinity College in Edinburgh. This college was founded by Mary of Guelders, James III's daughter.

Identity of the sitter(s): James III of Scotland, Margaret of Denmark, their son and Sir Edward Bonkill

Provenance: Edinburgh, church of the Holy Trinity (?)

Number of portrait(s): 4

Type of person(s): mixed (unidentified group)

Attitude of the sitter(s): hands clasped

Representation of the sitter(s): full-length

Gaze of the sitter(s): indeterminate

Object(s): yes (prie-dieu, book)

Coat(s) of arms: yes 
Environment: ecclesial space

Structuring of the pictorial space: indeterminate

Patron saint(s): Andrew, Canute or George

Gesture of the patron saint(s): introducing, holding his/her attribute

Type of religious scene: indeterminate

Religious scene(s) depicted: the Holy Trinity

Cat. 652-Type 2A

VAN DER GOES, Hugo (attributed to)

Triptych of the Adoration of the Magi with a Man in Prayer and Patron Saint (c. 1480-1500) $26 \times 23 \mathrm{~cm}$ (centre panel) and $28 \times 10 \mathrm{~cm}$ (wings)

Vaduz, collection of the Regierenden

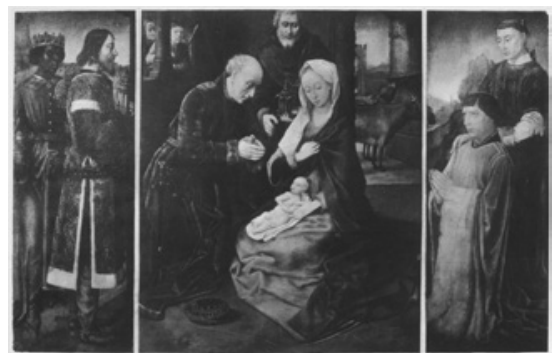

Fürsten von Lichtenstein, inv. nos. G. 735-737

BIBL.: FRIEDLÄNDER IV, no. 9; DHANENS 1998, 216; SCHADE 2001, 272-73 (with bibl.).

Identity of the sitter(s): unknown

Provenance: unknown

Number of portrait(s): 1

Type of person(s): religious (man alone)

Attitude of the sitter(s): hands clasped

Representation of the sitter(s): full-length

Gaze of the sitter(s): towards the scene

Object(s): no

Coat(s) of arms: no

Environment: historical setting

Structuring of the pictorial space: distinct spaces

Patron saint(s): Stephen

Gesture of the patron saint(s): protecting

Type of religious scene: narrative

Religious scene(s) depicted: the Adoration of the Magi, the Annunciation 
Cat. 653 - Type $3 \mathrm{D}$

VAN DER GOES, Hugo (workshop of)

The Virgin and Child with St. Anne and a

Franciscan Friar in Prayer (c. 1475)

$32.8 \times 38.8 \mathrm{~cm}$

Brussels, MRBAB, inv. no. 2748

BIBL.: STROO et alii 1999, 220-33 (with bibl.).

Identity of the sitter(s): unknown

Provenance: unknown

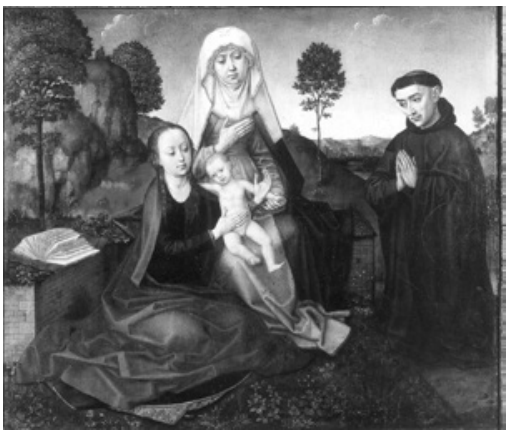

Number of portrait(s): 1

Type of person(s): religious (man alone: Franciscan friar)

Attitude of the sitter(s): hands clasped

Representation of the sitter(s): full-length

Gaze of the sitter(s): towards the scene

Object(s): no

Coat(s) of arms: no

Environment: enclosed garden

Structuring of the pictorial space: not applicable

Patron saint(s): none

Gesture of the patron saint(s): not applicable

Type of religious scene: hieratic

Religious scene(s) depicted: the Virgin and Child with St. Anne

Cat. 654-Type 6A

VAN DER STOCKT, Vrancke

One Wing. A Man in Prayer with St.John the Baptist (c. 1470)

$45.7 \times 20.8 \mathrm{~cm}$

Oberlin, Allen Memorial Art Museum, inv. no. AMAM 1942.12

BIBL.: FRIEDLÄNDER II, pl. 140; HARBISON 1973.

Identity of the sitter(s): unknown

Provenance: unknown

Number of portrait(s): 1

Type of person(s): lay (man alone)

Attitude of the sitter(s): hands clasped 
Representation of the sitter(s): full-length

Gaze of the sitter(s): indeterminate

Object(s): yes (prie-dieu, book)

Coat(s) of arms: no

Environment: landscape with sacred connotation (incomplete)

Structuring of the pictorial space: indeterminate

Patron saint(s): John the Baptist

Gesture of the patron saint(s): introducing

Type of religious scene: indeterminate

Religious scene(s) depicted: none

Cat. 655-Type 6A

VAN DER STOCKT, Vrancke

One Wing. A Woman in Prayer with St. Margaret (1450-1500)

$40.4 \times 20 \mathrm{~cm}$

Rochester, Rochester Memorial Art Gallery, inv. no. 44.15

BIB L.: FRIEDLÄNDER II, pl. 140.

Identity of the sitter(s): unknown

Provenance: unknown

Number of portrait(s): 1

Type of person(s): lay (woman alone)

Attitude of the sitter(s): hands clasped

Representation of the sitter(s): full-length

Gaze of the sitter(s): indeterminate

Object(s): yes (prie-dieu, book)

Coat(s) of arms: no

Environment: domestic setting

Structuring of the pictorial space: indeterminate

Patron saint(s): Margaret

Gesture of the patron saint(s): introducing

Type of religious scene: indeterminate

Religious scene(s) depicted: none 
Cat. 656 -Type ${ }_{3} \mathrm{C}$

VAN DER STOCKT, Vrancke (workshop of) The Annunciation with a Nun in Prayer (c. 1490-1500) $29.4 \times 28.8 \mathrm{~cm}$

London, sale Sotheby's (30 April 2014), lot no. 703

BIBL.: Sale cat. Sotheby's (London, 30 April 2014), no. 703 .

HISTORICAL INFORMATION: The coat of arms painted on the upper part of the panel

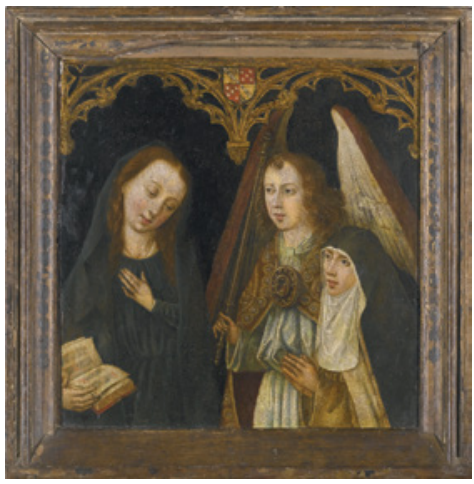
belongs to Don Diego de Guevara (see cat. 622). The identity of the sitter remains unknown and it is thus impossible to establish a link between her and de Guevara.

Identity of the sitter(s): unknown

Provenance: unknown

Number of portrait(s): 1

Type of person(s): religious (woman alone)

Attitude of the sitter(s): hands clasped

Representation of the sitter(s): half-length

Gaze of the sitter(s): towards the scene

Object(s): no

Coat(s) of arms: yes

Environment: neutral space

Structuring of the pictorial space: not applicable

Patron saint(s): none

Gesture of the patron saint(s): not applicable

Type of religious scene: narrative

Religious scene(s) depicted: none

\section{Cat. 657-Type $1 \mathrm{~B}$}

[Link to the sale catalogue]

VAN DER WEYDEN, Goswyn

Polyptych of the Legend of St. Dymphna (c. 1503-1505)

$300 \times 350 \mathrm{~cm}$ (open)

London, sale Sotheby's (8 December 2010), lot no. 4

BIBL.: FRIEDLÄNDER XI, 22; PASSEMIERS 1987, 112-25, no. 1; Sale cat. Sotheby's (London, 8 December 2010), no. 4; Exh. cat. Brussels 2013, no. 99 (with bibl.). 
HISTORICAL INFORMATION: The altarpiece is a commission made in 1505 by Arnold Streyters, Abbot of the Premonstratensian abbey of Tongerloo. He is depicted in the company of his chamberlain Wilhem Sapeel, who is identified by an inscription. The altarpiece was destined for St. Dymphna's chapel in the abbey church of Tongerloo. It was dismembered while the abbot Van der Achter was in charge of the abbey (1724-1745). The altarpiece was originally composed of eight panels, one of which is now lost.

Identity of the sitter(s): Arnold Streyers and Wilhem Sapeel

Provenance: Premonstratensian abbey of Tongerloo, St. Dymphna's chapel

Number of portrait(s): 2

Type of person(s): religious (group: Premonstratensian abbot and monk)

Attitude of the sitter(s): holding a book

Representation of the sitter(s): full-length

Gaze of the sitter(s): towards the scene

Object(s): yes (book)

Coat(s) of arms: yes

Environment: niche

Structuring of the pictorial space: continuous space, grisaille

Patron saint(s): an unidentified saint

Gesture of the patron saint(s): holding his/her attribute

Type of religious scene: narrative

Religious scene(s) depicted: the Legend of St. Dymphna, St. Dymphna, St. Lucy

Cat. $65^{8}$ - Type $3^{D}$

VAN DER WEYDEN, Goswyn

The Virgin and Child with three Persons in Prayer ('The Kalmthout Donation') (c. 1511)

$153 \times 153 \mathrm{~cm}$

Berlin, Staatliche Museen zu Berlin, Gemäldegalerie, inv. no. $5^{26}$

BIBL.: FRIEDLÄNDER XI, pl. 24; PASSEMIERS 1987, 137-53, no. 3 (with bibl.); Mus. cat. Berlin 1996, no. 864 .

HISTORICAL INFORMATION: This panel is a memorial work commissioned by the abbey of Tongerloo. It commemorates the donation of the domain of Kalmthout to the abbey by the Brabant family in the twelfth century. The kneeling figures are thus not actual portraits. The clods of earth that they hold in their hands symbolise this gift.

Identity of the sitter(s): Berner van Rijsbergen and his wife, Arnufus of Brabant 
Provenance: Premonstratensian abbey of Tongerloo

Number of portrait(s): 3

Type of person(s): lay (family)

Attitude of the sitter(s): particular gesture

Representation of the sitter(s): full-length

Gaze of the sitter(s): into space, towards the scene

Object(s): yes (shrubs)

Coat(s) of arms: yes

Environment: landscape with sacred connotation

Structuring of the pictorial space: not applicable

Patron saint(s): none

Gesture of the patron saint(s): not applicable

Type of religious scene: hieratic

Religious scene(s) depicted: the Virgin and Child

Cat. 659-Type $2 B$

VAN DER WEYDEN, Goswyn

Triptych of Antonius Tsgrooten (1507)

$33.7 \times 25.2 \mathrm{~cm}$ (centre panel), $41.8 \times$

$16.3 \mathrm{~cm}$ (left wing) and $41.8 \times 16.9 \mathrm{~cm}$ (right wing)

Antwerp, KMSK, inv. no. 5091

BIBL.: Mus. cat. Antwerp 1985, 14650; PASSEMIERS 1987, 127-35, no. 2;

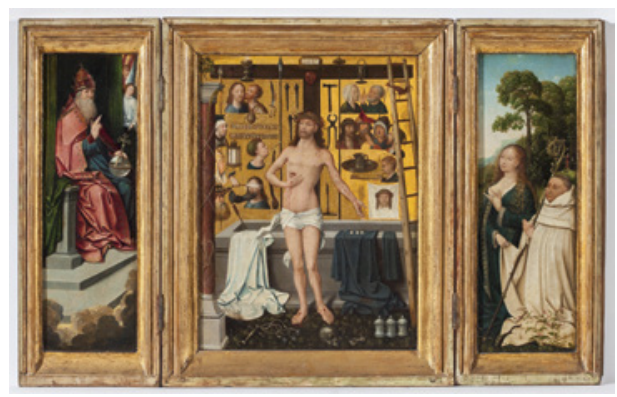

Exh. cat. Antwerp and Maastricht 2005, no. 7 (with bibl.). HISTORICAL INFORMATION: The triptych includes the portrait of Antonius Tsgrooten, abbot of Tongerloo (see cat. 401).

Identity of the sitter(s): Antonius Tsgrooten

Provenance: Premonstratensian abbey of Tongerloo (?)

Number of portrait(s): 1

Type of person(s): religious (man alone: Premonstratensian abbot)

Attitude of the sitter(s): hands clasped

Representation of the sitter(s): full-length

Gaze of the sitter(s): towards the scene

Object(s): yes (crosier)

Coat(s) of arms: yes

Environment: landscape with sacred connotation

Structuring of the pictorial space: distinct spaces

Patron saint(s): none 
Gesture of the patron saint(s): not applicable

Type of religious scene: intercession

Religious scene(s) depicted: the Intercession of Christ and the Virgin

\section{Cat. 66o-Type $1 A$}

VAN DER WEYDEN, Goswyn

Triptych of the Marriage of the Virgin ('Colibrant

Triptych') (dated 1516)

$212 \times 176 \mathrm{~cm}$ (open)

Lier, church of St. Gummarus

BIBL.: FRIEDLÄNDER XI, pl. 26; STOCKMANS

1908; PASSEMIERS 1987, 184-97, no. 7 .

HISTORICAL INFORMATION: The sitters are Jean-Baptiste Colibrant, Josina Meyngaert and their children, Joris, Jan and Josina (daughter

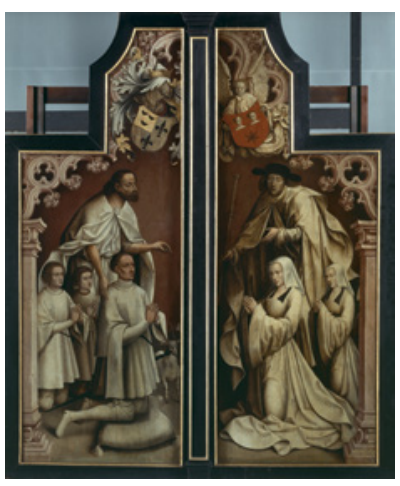
from Josina's first marriage). Son of Jan Colibrant and Jeanne van Heffene, Jean-Baptiste held several political positions in Lier. The triptych was destined for the Colibrant chapel in the church of St. Gummarus in Lier. The chapel had been founded in 1480 by Jean-Baptiste's brother, Joris Colibrant. The triptych is dated 1516 and thus could not have been commissioned either by JeanBaptiste, who died shortly before 1490, or by his oldest son Joris, who died during a pilgrimage to the Holy Land on 12 August 1511 . Before undertaking this journey, Joris settled his affairs and designated his cousin Frans as the executor of his goods and of his will. A municipal act of Antwerp, dating from 15 January 1515 also reveals that Frans founded two weekly masses in honour of the Seven Sorrows of the Virgin and of Joseph at the altar of the Colibrant chapel in Lier. Taking into account this fact and the date on the triptych, one can assume that Frans commissioned the triptych and founded the masses in his role of executor of Joris' will. In taking these actions, Frans was therefore executing the last will of his cousin.

Identity of the sitter(s): Colibrant family

Provenance: Lier, church of St. Gummarus, Colibrant chapel

Number of portrait(s): 5

Type of person(s): lay (family with children)

Attitude of the sitter(s): hands clasped 
Representation of the sitter(s): full-length

Gaze of the sitter(s): towards the centre

Object(s): no

Coat(s) of arms: yes

Environment: niche

Structuring of the pictorial space: distinct spaces, grisaille

Patron saint(s): John the Baptist, Josse

Gesture of the patron saint(s): introducing

Type of religious scene: narrative

Religious scene(s) depicted: the Presentation at the temple, the Marriage of the Virgin, the Annunciation

\section{Cat. 661-Type 2B}

\section{VAN DER WEYDEN, Goswyn}

Triptych of the Virgin and Child Enthroned with Saints and a Couple in Prayer with Patron Saints (c. 1515-1525)

$86 \times 73 \mathrm{~cm}$ (centre panel) and $86 \times 27 \mathrm{~cm}$ (wings)

Whereabouts unknown (previously New York, collection of Robert Hoe) BIB L.: FRIEDLÄNDER XI, pl. 28; PASSEMIERS 1987, 215-18, no. 11.

Identity of the sitter(s): unknown

Provenance: unknown

Number of portrait(s): 2

Type of person(s): lay (couple)

Attitude of the sitter(s): hands clasped

Representation of the sitter(s): full-length

Gaze of the sitter(s): towards the scene

Object(s): yes (rosary)

Coat(s) of arms: no

Environment: architectural space with sacred connotation

Structuring of the pictorial space: unified space with discontinuities

Patron saint(s): John the Baptist, Catherine

Gesture of the patron saint(s): protecting, introducing

Type of religious scene: hieratic

Religious scene(s) depicted: the Virgin and Child, St. Barbara, St. Catherine 
Cat. 662-Type 6A

VAN DER WEYDEN, Goswyn

Two Wings. Frans Colibrant and Elisabeth Biers in

Prayer (c. 1511)

$100 \times 33 \mathrm{~cm}$ (each wing)

Brussels, MRBAB, inv. no. 404

BIBL.: PASSEMIERS 1987, 204-07, no. 9; STROO et alii 2001, 336-47 (with bibl.).

REMARK: The extract from the prayer Obsecro te on the parchment held by the man suggests that the now lost centre panel showed a Virgin and Child.

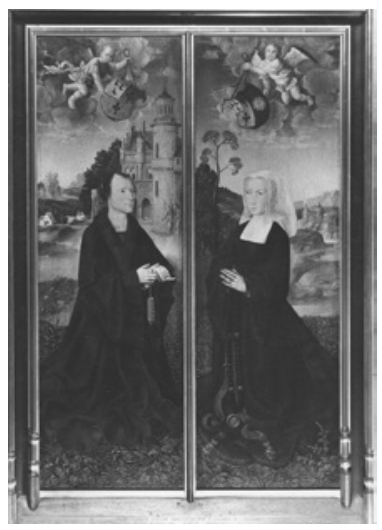

HISTORICAL INFORMATION: The persons portrayed are Frans Colibrant and his wife, Elisabeth Biers. Frans came from a wealthy and powerful family from Antwerp. He is mentioned for the first time in 1507 , in the Antwerp schepenbrieven. In 1510, he became secretary of the city of Antwerp and held this position until his death in 1520 . François and Elisabeth had three children: Willem (who became alderman in 1538), Ursula (who entered the convent of Steynaert in 1531) and Constantia.

Identity of the sitter(s): Frans Colibrant and Elisabeth Biers

Provenance: unknown

Number of portrait(s): 2

Type of person(s): lay (couple)

Attitude of the sitter(s): hands clasped, holding a parchment

Representation of the sitter(s): full-length

Gaze of the sitter(s): indeterminate

Object(s): yes (rosary, parchment)

Coat(s) of arms: yes

Environment: landscape, no sacred connotation (incomplete)

Structuring of the pictorial space: indeterminate

Patron saint(s): none

Gesture of the patron saint(s): not applicable

Type of religious scene: indeterminate

Religious scene(s) depicted: St. Francis, St. Elizabeth of Hungary 
Cat. 663-Type 2A

VAN DER WEYDEN, Goswyn (attributed to)

Triptych of the Crucifixion with a Family in Prayer and Patron Saints (c. 1515-1525) $109 \times 85 \mathrm{~cm}$ (centre panel) and $109 \times 37 \mathrm{~cm}$ (wings)

West Palm Beach, Norton Gallery and School of Art

BIB L.: PASSEMIERS 1987, 224-27, no. 13.

Identity of the sitter(s): unknown

Provenance: Burgos, church of St. Lawrence

Number of portrait(s): 4

Type of person(s): lay (family with children)

Attitude of the sitter(s): hands clasped

Representation of the sitter(s): full-length

Gaze of the sitter(s): towards the scene, towards the ground

Object(s): no

Coat(s) of arms: no

Environment: historical setting

Structuring of the pictorial space: continuous space

Patron saint(s): John the Baptist, Catherine

Gesture of the patron saint(s): introducing, holding his/her attribute

Type of religious scene: narrative

Religious scene(s) depicted: the Crucifixion

Cat. 664-Type $1 \mathrm{D}$

VAN DER WEYDEN, Rogier

Altarpiece of the Last Judgement ('Beaune Altarpiece') (c. 1443-1450)

$212 \times 499.2 \mathrm{~cm}$ (open)

Beaune, Hôtel-Dieu

BIBL.: FRIEDLÄNDER II, no. 14; Corpus Beaune, no. 135; DE VOS 1999, no. 17 (with bibl.).

HISTORICAL INFORMATION: The Beaune Altarpiece is a well-documented

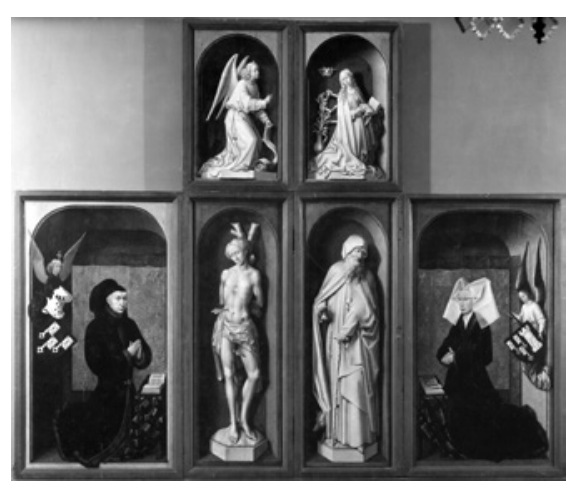


work. It was commissioned by the chancellor Nicolas Rolin and his wife Guigone de Salins for the Hôtel-Dieu, which they founded in Beaune in 1443. The altarpiece was destined for the chapel of the Grande salle des pôvres, which was dedicated in 1451. Nicolas Rolin was born in Autun before 1380 and came from a middle-class family. He studied Law and became a lawyer in Dijon and Paris, before being appointed at the court of John the Fearless in 1408. Around 1410-1411 he married Guigone, daughter of Etienne de Salins-la-Tour and Louise de Ryse. In 1419, Rolin was made Advisor of the Council of State at the Burgundian court and he succeeded Jean de Thoisy as Chancellor of Burgundy at the end of the year 1422. He held this position for thirty-five years. Rolin also appears in cat. 693 .

Identity of the sitter(s): Nicolas Rolin and Guigone de Salins

Provenance: Beaune, Hôtel Dieu, chapel of the Grande salle des pôvres

Number of portrait(s): 2

Type of person(s): lay (couple)

Attitude of the sitter(s): hands clasped

Representation of the sitter(s): full-length

Gaze of the sitter(s): into space

Object(s): yes (prie-dieu, book)

Coat(s) of arms: yes

Environment: niche

Structuring of the pictorial space: distinct spaces, grisaille

Patron saint(s): none

Gesture of the patron saint(s): not applicable

Type of religious scene: hieratic

Religious scene(s) depicted: the Last Judgement, the Annunciation, St. Sebastian, St. Anthony

\section{Cat. 665-Type $4 \mathrm{D}$}

VAN DER WEYDEN, Rogier

Diptych of Jean de Froimont (c. 146o)

$49 \times 31.5 \mathrm{~cm}$ (left wing) and $49 \times 31 \mathrm{~cm}$ (right wing)

Caen, Musée des Beaux-Arts, inv. no. M91 (left wing) and Brussels, MRBAB, inv. no. 4279 (right wing)

BIBL.: FRIEDLÄNDER II, no. 30-31; STROO and SYFER D'OLNE 1996, 123-30; DE VOS 1999, no. 33; VANWIJNSBERGHE 2003; Exh. cat. Antwerp and Washington 2006, no. 38 (with bibl.); Exh. cat. Brussels 2013, no. 3 .

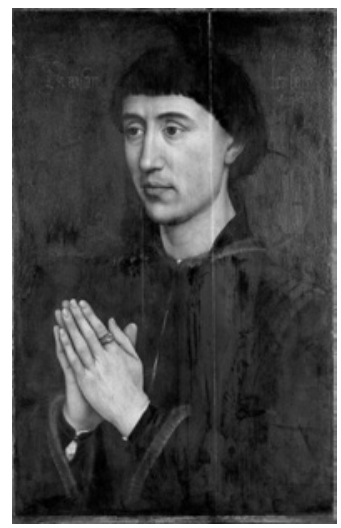


HISTORICAL INFORMATION: Born in Mons c. 1430-1435, Jean de Froimont held the position of clerk at the court of Mons from the beginning of the 1450s, before becoming greffier in 1462-1463 and councillor in 1467. On the basis of these positions, he made several diplomatic trips outside the city of Mons and regularly acted as an intermediary between the Duke and the Court of Mons. He thus moved in ducal circles and had many contacts with Philippe de Croy (see cat. 667), who was then Grand bailli of Hainault. Jean de Froimont married Jeanne de le Croix, who was the daughter of two members of the local upper class, Jean de le Croix and Jeanne Laurent. As several archival documents discovered by Vanwijnsberghe indicate, Jean de Froimont was an aristocrat from Mons, who slowly rose to the top of the political hierarchy of Mons.

Identity of the sitter(s): Jean de Froimont

Provenance: unknown

Number of portrait(s): 1

Type of person(s): lay (man alone)

Attitude of the sitter(s): hands clasped

Representation of the sitter(s): half-length

Gaze of the sitter(s): towards the scene

Object(s): no

Coat(s) of arms: no

Environment: neutral space

Structuring of the pictorial space: continuous space

Patron saint(s): none

Gesture of the patron saint(s): not applicable

Type of religious scene: hieratic

Religious scene(s) depicted: the Virgin and Child, St. Lawrence

Cat. 666-Type ${ }_{4} \mathrm{D}$

VAN DER WEYDEN, Rogier

Diptych of Jean Gros (c. 1455-1460)

$38.5 \times 28.6 \mathrm{~cm}$ (right wing) and $36 \times 27 \mathrm{~cm}$ (left wing)

Tournai, Musée des Beaux-Arts, inv. no. 421 (left wing) and Chicago, Chicago Art Institute, inv. no. 33.1051 (right wing)

BIBL.: FRIEDLÄNDER II, nos. 28-29; DE VOS 1999, no. 25; Mus. cat. Chicago 2008, 302-10; Exh. cat. Antwerp and Washington 2006, no. 37; Exh. cat. Leuven 2009, no. 20a-b (with bibl.).

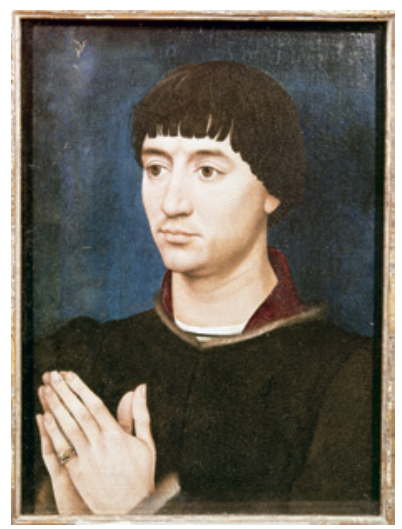


HISTORICAL INFORMATION: Jean Gros was born around 1434. He was made secretary to Philip the Good in 1450. He was also Audiencier of the Count of Charolais, the future Charles the Bold, and Governor-general of all finances under the reign of the latter. He married Guye de Messey, the daughter of Guillaume de Messey and Jeanne Hugonet, in 1472. Guye was also the sister of the chancellor Guillaume Hugonet. At some point, Jean's career turned bad. He was accused of misappropriation of funds, together with the chancellor Hugonet. He was imprisoned several times but was ultimately never found guilty. He was also jailed for his opposition to the autonomous rights and privileges of the cities of Flanders. At the beginning of the 1470s, probably because of his political problems, Jean and his wife moved to Bruges, where they bought a house in the Ezelstraat, near the church of St. James. They founded a chapel and an oratory in their parish church. It is possible that Jean placed the diptych in this oratory. In 1477, Jean was made Treasurer of the Order of the Golden Fleece. He died in Dijon in 1484.

Identity of the sitter(s): Jean Gros

Provenance: unknown

Number of portrait(s): 1

Type of person(s): lay (man alone)

Attitude of the sitter(s): hands clasped

Representation of the sitter(s): half-length

Gaze of the sitter(s): towards the scene

Object(s): no

Coat(s) of arms: yes

Environment: neutral space

Structuring of the pictorial space: continuous space

Patron saint(s): none

Gesture of the patron saint(s): not applicable

Type of religious scene: hieratic

Religious scene(s) depicted: the Virgin and Child 
Cat. $66_{7}$-Type $4 \mathrm{D}$

VAN DER WEYDEN, Rogier

Diptych of Philippe de Crö̈ (c. 1450-1460)

$49 \times 30 \mathrm{~cm}$ (left wing) and $49 \times 31 \mathrm{~cm}$ (right wing)

Antwerp, KMSK, inv. no. 254 (right wing) and San

Marino, Henry E. Huntington Library and Art Gallery, inv. no. 26.105 (left wing)

BIB L.: FRIEDLÄNDER II, no. 39-40; DE VOS 1999, no. 27, no. 32; Exh. cat. Antwerp and Washington 2006, no. 39; Exh. cat. Leuven 2009, no. 19a-b (with bibl.); Corpus Los Angeles, 169-89.

historical information: Philippe de Crö̈ came from the powerful Croÿ family from Picardy. As a member of the high nobility, he occupied

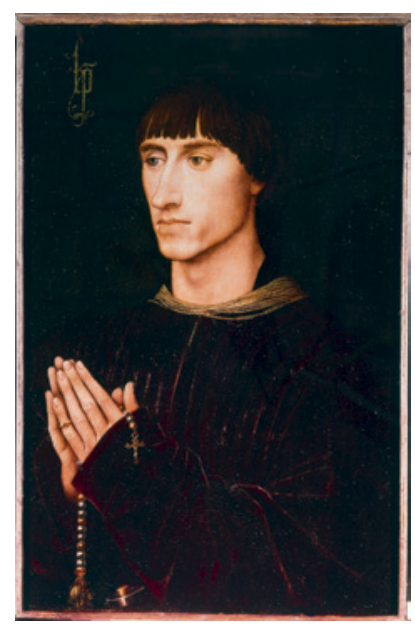
a high position within the Burgundian court under the reigns of Philip the Good, Charles the Bold and Maximilian of Austria. Philippe married Walburga de Meurs, daughter of the Count Vincenz de Meurs in 1454. At this time, he was conferred the title of Lord of Sempy, a title he held until 1461, when his mother died, and he was then conferred the title of Lord of Quiévrain. On the reverse of his portrait, his coat of arms is accompanied by his first title, indicating that the diptych was executed before 1461. From 1456 to 1465 , Philippe was Grand bailli and Captain general of Hainault. In $145^{8}$, he was appointed chamberlain to Philip the Good. He was made knight of the Golden Fleece in 1473. Philippe de Croÿ died at the house of Olivier de la Marche between 11 and 15 September 1482.

Identity of the sitter(s): Philippe de Crö̈

Provenance: unknown

Number of portrait(s): 1

Type of person(s): lay (man alone)

Attitude of the sitter(s): holding a rosary

Representation of the sitter(s): half-length

Gaze of the sitter(s): towards the scene

Object(s): yes (rosary)

Coat(s) of arms: yes

Environment: neutral space

Structuring of the pictorial space: distinct spaces

Patron saint(s): none

Gesture of the patron saint(s): not applicable

Type of religious scene: hieratic

Religious scene(s) depicted: the Virgin and Child 
Cat. 668-Type 6B

VAN DER WEYDEN, Rogier

Portrait of Jean, Duke of Clèves, in Prayer (c. 1450-1460)

$49 \times 31 \mathrm{~cm}$

Paris, Musée du Louvre, inv. no. 20223

BIB L.: FRIEDLÄNDER II, no. 126a; Corpus Paris III, no. 194 (with bibl.); DE VOS 1999, no. A2.

HISTORICAL INFORMATION: The identification of the sitter as Jean, Duke of Clèves has been made possible on the basis of an inscription apposed on the reverse and dated back to the nineteenth century. The identification can be verified with the other known portraits of

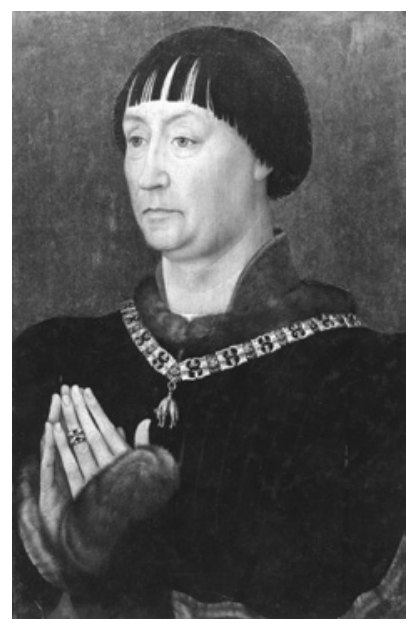
the duke (and notably a panorama of the city of Clèves from the seventeenth century, on which the six successive dukes are depicted). This panel was most probably the right wing of a diptych similar to cat. 664, 666 and 667 .

Identity of the sitter(s): Jean, Duke of Clèves

Provenance: unknown

Number of portrait(s): 1

Type of person(s): lay (man alone)

Attitude of the sitter(s): hands clasped

Representation of the sitter(s): half-length

Gaze of the sitter(s): indeterminate

Object(s): yes (collar of the Order of the Golden Fleece)

Coat(s) of arms: no

Environment: neutral space (incomplete)

Structuring of the pictorial space: indeterminate

Patron saint(s): none

Gesture of the patron saint(s): not applicable

Type of religious scene: indeterminate

Religious scene(s) depicted: none 
Cat. 669-Type 3 B

VAN DER WEYDEN, Rogier

The Holy Family with St. Paul and a Man in Prayer

(c. 1450)

$57 \times 47 \mathrm{~cm}$

New York, MET, inv. no. 32.100.44

BIBL.: FRIEDLÄNDER II, no. 40a; AINSWORTH and CHRISTIANSEN 1998, 404.

Identity of the sitter(s): unknown

Provenance: unknown

Number of portrait(s): 1

Type of person(s): lay (man alone)

Attitude of the sitter(s): particular gesture

Representation of the sitter(s): full-length

Gaze of the sitter(s): into space

Object(s): yes (gloves)

Coat(s) of arms: no

Environment: landscape, no sacred connotation

Structuring of the pictorial space: not applicable

Patron saint(s): Paul

Gesture of the patron saint(s): introducing

Type of religious scene: hieratic

Religious scene(s) depicted: the Holy Family

Cat. 670 -Type ${ }_{3} \mathrm{C}$

VAN DER WEYDEN, Rogier

Triptych of the Adoration of the Magi ('Triptych of St. Colomba') (c. 1450)

$138 \times 153 \mathrm{~cm}$ (centre panel) and $138 \times 70 \mathrm{~cm}$ (wings)

Munich, Alte Pinakothek, inv. no. WAF.1189 BIB L.: FRIEDLÄNDER II, no. 49; DE VOS 1999, no. 21; Mus. cat. Munich 2006, 342-44 (with bibl.).

HISTORICAL INFORMATION: In an inven-

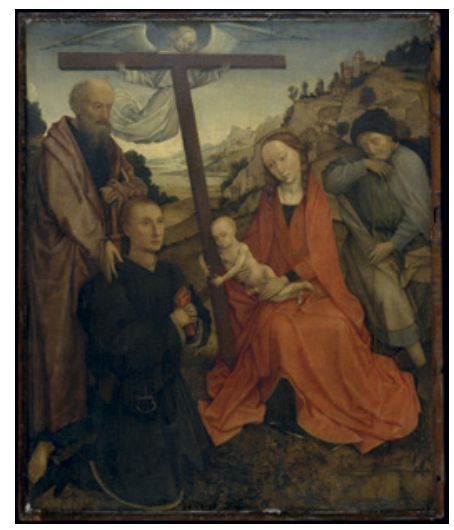
tory of 1801 , the triptych is mentioned as being displayed in the Wasservas chapel in the church of St. Colomba in Cologne. The sitter depicted on the centre 
panel is certainly not a member of this family, for the chapel was founded after the death of Rogier van der Weyden and the completion of the triptych. Scholars usually assume that the sitter is, in fact, Johan Dasse and that the triptych was commissioned by his wife in 1450 , while Van der Weyden was passing by Cologne during his trip to Rome. The triptych would have been destined for the Marian altar of the chapel, founded by Johan's wife in 1458, in memory of her late husband. At a later date, Johan's daughter married Johann Rinck, who replaced the altar founded by his mother-in-law in a Marian chapel. He nevertheless left in place the Rogerian triptych. This explains why the sitter is sometimes identified with Rinck.

Identity of the sitter(s): Johan Dasse (?)

Provenance: Cologne, church of St. Colomba

Number of portrait(s): 1

Type of person(s): lay (man alone)

Attitude of the sitter(s): hands clasped

Representation of the sitter(s): full-length

Gaze of the sitter(s): towards the scene

Object(s): no

Coat(s) of arms: no

Environment: historical setting

Structuring of the pictorial space: not applicable

Patron saint(s): none

Gesture of the patron saint(s): not applicable

Type of religious scene: narrative

Religious scene(s) depicted: the Annunciation, the Nativity, the Presentation at the temple

Cat. 671 -Type ${ }_{3} \mathrm{C}$

VAN DER WEYDEN, Rogier

Triptych of the Crucifixion with a Couple in Prayer (c. 1443-1445)

$96 \times 69 \mathrm{~cm}($ centre panel) and $101 \times$ $35 \mathrm{~cm}$ (wings)

Vienna, Kunsthistorisches Museum, inv. no. 901

BIBL.: FRIEDLÄNDER II, no. 11; DE VOS 1999, no. 13 (with bibl.).

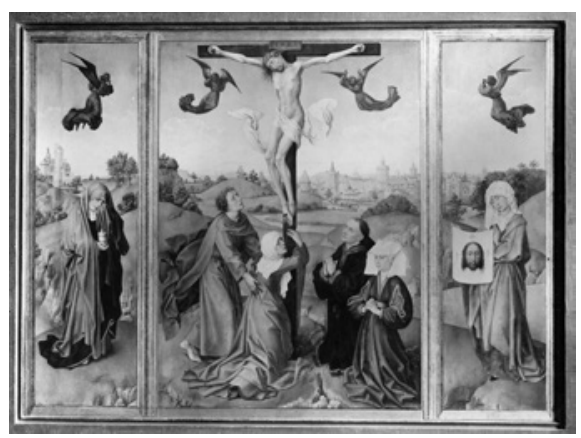

Identity of the sitter(s): unknown

Provenance: unknown 
Number of portrait(s): 2

Type of person(s): lay (couple)

Attitude of the sitter(s): hands clasped

Representation of the sitter(s): full-length

Gaze of the sitter(s): into space, towards the scene

Object(s): no

Coat(s) of arms: no

Environment: historical setting

Structuring of the pictorial space: not applicable

Patron saint(s): none

Gesture of the patron saint(s): not applicable

Type of religious scene: narrative

Religious scene(s) depicted: the Crucifixion, St. Mary Magdalen, St. Veronica

Cat. $672-$ Type $3 \mathrm{C}$

VAN DER WEYDEN, Rogier

Triptych of the Nativity ('Triptych of Pieter Bladelin') (c. 1445)

$91 \times 89 \mathrm{~cm}$ (centre panel) and $91 \times 40 \mathrm{~cm}$ (wings)

Berlin, Staatliche Museen zu Berlin, Gemäldegalerie, inv.

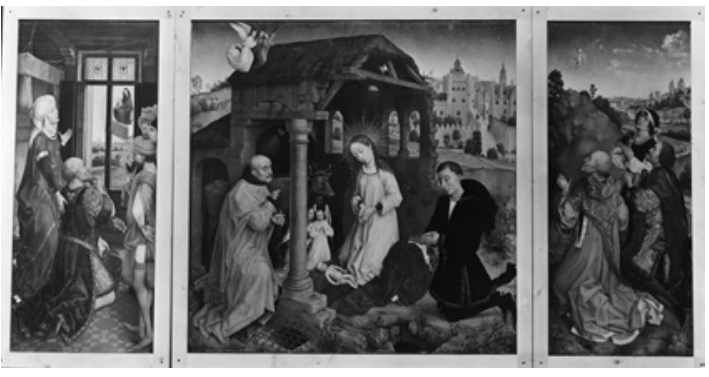
no. 535

BIB L.: FRIEDLÄNDER II, no. 38; DE VOS 1999, no. 15; Exh. cat. Frankfurt and Berlin 2009, no. 33 (with bibl.).

HISTORICAL INFORMATION: The sitter is usually identified as Pieter Bladelin and the castle depicted in the background of the centre panel is usually identified as the Middelburg castle, on the basis of a copy of the triptych held at the house of the priest of Middelburg (in Flanders) during the seventeenth century. In 1981, Elisabeth Dhanens discovered that this seventeenth-century copy of the triptych had been made in 1630-1631 by Jan Ricx, while the original was located in the Bruges residence of the Countess of Iseghem, Lady of Middelburg. Born in Bruges around 1410, Pieter Bladelin began his career as Treasurer of the city of Bruges. He held this position from 1436 to 1440, before entering into the service of Philip the Good. In 1444, he was made Treasurer of the Order of the Golden Fleece. Bladelin is well-known for having founded the small Flemish city of Middelburg: in 1433 he bought land from the abbey of Middelburg and later received from the duke the right to found a 
seigneury. He built a castle in 1448 , before starting the construction of the city itself (with a collegiate church and a hospital), in 1452. The original location of the triptych remains unknown. It could be the Bruges residence of Bladelin, his castle or the collegiate church in Middelburg. The identification of the sitter as Pieter Bladelin has nevertheless been called into question in Exh. cat. Frankfurt and Berlin 2009.

Identity of the sitter(s): Pieter Bladelin

Provenance: unknown

Number of portrait(s): 1

Type of person(s): lay (man alone)

Attitude of the sitter(s): hands clasped

Representation of the sitter(s): full-length

Gaze of the sitter(s): towards the ground

Object(s): no

Coat(s) of arms: no

Environment: historical setting

Structuring of the pictorial space: not applicable

Patron saint(s): none

Gesture of the patron saint(s): not applicable

Type of religious scene: narrative

Religious scene(s) depicted: the Nativity, August and the Tiburtine sibyl, the Annunciation to the magi, the Annunciation

Cat. 673 -Type $3 \mathrm{~A}$

VAN DER WEYDEN, Rogier (after)

The Lamentation with Saints and a Man in Prayer (c. 1470)

$55.5 \times 42.5 \mathrm{~cm}$

Palermo, collection of Nicola Leotta

BIB L.: CAMPBELL 1998, 442-45.

Identity of the sitter(s): unknown

Provenance: unknown

Number of portrait(s): 1

Type of person(s): lay (man alone)

Attitude of the sitter(s): hands clasped

Representation of the sitter(s): full-length

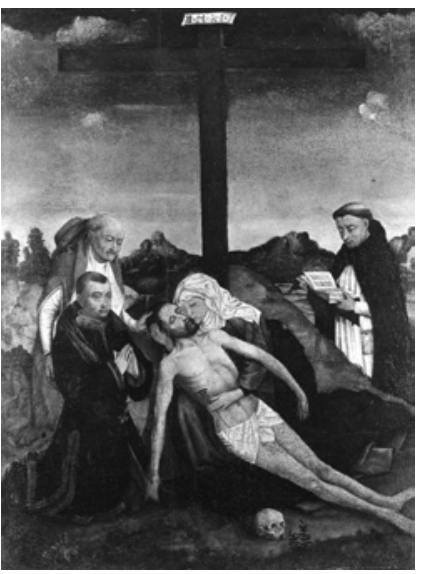

Gaze of the sitter(s): into space

Object(s): no

Coat(s) of arms: no 
Environment: historical setting

Structuring of the pictorial space: not applicable

Patron saint(s): Jerome

Gesture of the patron saint(s): interceding

Type of religious scene: narrative

Religious scene(s) depicted: the Lamentation, St. Dominic

Cat. 674-Type 2A

VAN DER WEYDEN, Rogier (after)

Triptych of the Descent of the Cross ('Edelheer Triptych') (dated 1443) $100 \times 110 \mathrm{~cm}$ (centre panel) and $100 \times 45 \mathrm{~cm}$ (wings)

Leuven, church of St. Peter

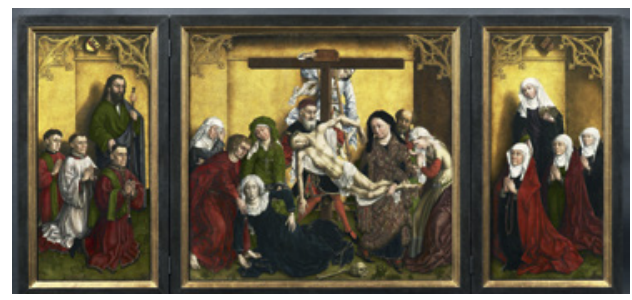

BIBL.: FRIEDLÄNDER II, no. 3e; Corpus Leuven, no. 187; Exh. cat. Leuven 2009, no. 68 (with bibl.); DUBOIS et alii 2012.

HISTORICAL INFORMATION: The coats of arms and the inscription on the reverse identify the sitters as Willem Edelheer, Adelaïde Cappuyns and their children: dese tafel heeft vereert heren Willem Edelheere / ende Alyt syn werdinne int iaer ons heeren mcccc en xli[ii?]. Willem and Adelaïde married before 10 June 1414 and had five children: Willem (who became a priest in 1431 and died in 1473), Jacob ( $†$ 1482), Catherine ( $†$ before 1452), Adelaïde and Lewis (who died at a young age, before 1435 , and is not depicted in the triptych). Willem Edelheer was the illegitimate son of a priest and belonged to the middle class of Leuven. He died on 17 October 1439. In his will, he requested the foundation of a chaplaincy in honour of the Holy Spirit, the Virgin and St. James in a chapel of the church of St. Peter, which was then under construction. The triptych (bearing the date 1443) was destined for this chapel and was most probably commissioned by his oldest son.

Identity of the sitter(s): Willem Edelheer, Adelaïde Cappuyns and their children

Provenance: Leuven, church of St. Peter, Edelheer chapel

Number of portrait(s): 6

Type of person(s): lay (family)

Attitude of the sitter(s): hands clasped

Representation of the sitter(s): full-length

Gaze of the sitter(s): into space, towards the scene

Object(s): yes (rosary)

Coat(s) of arms: yes 
Environment: neutral space

Structuring of the pictorial space: continuous space

Patron saint(s): James, Adelaïde

Gesture of the patron saint(s): protecting

Type of religious scene: narrative

Religious scene(s) depicted: the Descent from the cross, the Holy Trinity, St. John supporting the Virgin

Cat. 675-Type 2A

VAN DER WEYDEN, Rogier (after)

Triptych of the Descent of the Cross with a Family in Prayer and Patron

Saints (c. 1530)

$126 \times 94 \mathrm{~cm}$ (centre panel) and

$126 \times 48 \mathrm{~cm}$ (wings)

Cologne, sale Lempertz

(15 November 2003), lot no. 1108

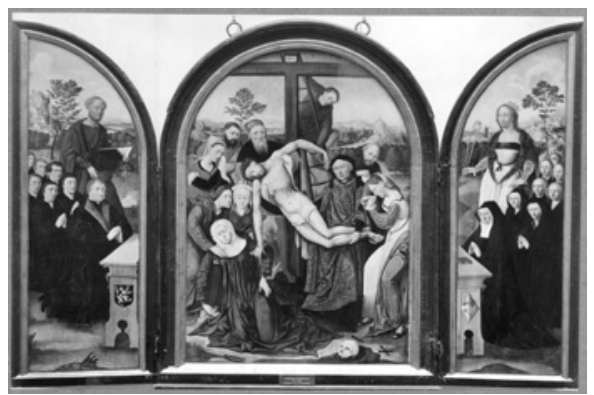

Identity of the sitter(s): unknown

Provenance: unknown

Number of portrait(s): 14 (at least)

Type of person(s): mixed (family)

Attitude of the sitter(s): hands clasped

Representation of the sitter(s): full-length

Gaze of the sitter(s): into space, towards the scene

Object(s): yes (prie-dieu, book)

Coat(s) of arms: yes (on the prie-dieu and on the reverse)

Environment: historical setting

Structuring of the pictorial space: continuous space

Patron saint(s): Peter, Agatha

Gesture of the patron saint(s): introducing, holding his/her attribute

Type of religious scene: narrative

Religious scene(s) depicted: the Descent from the cross 
Cat. 676 -Type $3 \mathrm{~A}$

VAN DER WEYDEN, Rogier (and workshop)

The Lamentation with a Man in Prayer and Patron Saints (c. 1460-1464)

$78 \times 129 \mathrm{~cm}$

The Hague, Mauritshuis, inv. no. 264

BIBL.: FRIEDLÄNDER II, no. 46;

DE VOS 1999, no. C5, 101, 161, 403-04;

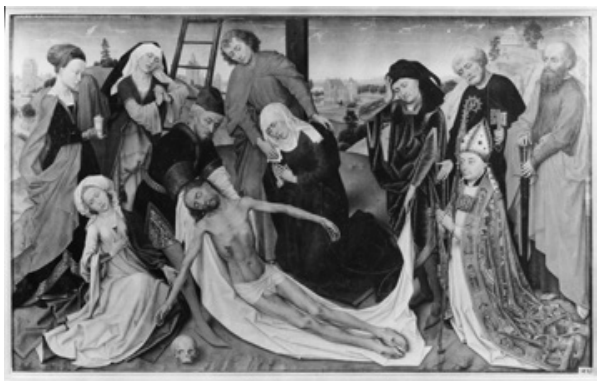

Exh. cat. Leuven, 2009, no. 76 (with bibl.).

HISTORICAL INFORMATION: The identity of the sitter remains uncertain, although he is usually identified as Jean Chevrot, Bishop of Tournai, based on a comparison with the bishop's portrait in the Chroniques de Hainaut and in Van der Weyden's Altarpiece of the Seven Sacraments (Antwerp, KMSK). Panofsky nevertheless identified the portrayed prelate as Pierre de Ranchicourt, Bishop of Arras, while Châtelet proposed that he was Philippe Courault, Abbot of St. Peter in Ghent. Jean Chevrot came from a wealthy family of Poligny and he made a brilliant political and ecclesiastical career. He first studied Law in Paris and then worked for the Duke of Burgundy, Philip the Good. In 1433, he presided over the Grand conseil, before becoming Bishop of Tournai. During his whole career, he was one of the closest collaborators of Philip the Good. He died in Lille in 1458.

Identity of the sitter(s): Jean Chevrot (?)

Provenance: unknown

Number of portrait(s): 1

Type of person(s): religious (man alone: bishop)

Attitude of the sitter(s): hands clasped

Representation of the sitter(s): full-length

Gaze of the sitter(s): towards the scene

Object(s): no

Coat(s) of arms: no

Environment: historical setting

Structuring of the pictorial space: not applicable

Patron saint(s): Peter, Paul

Gesture of the patron saint(s): introducing

Type of religious scene: narrative

Religious scene(s) depicted: the Lamentation 
Cat. 677 -Type $4 \mathrm{~B}$

VAN DER WEYDEN, Rogier (circle of)

Diptych of Jeanne de France (1450-1500)

$34 \times 22.5 \mathrm{~cm}$ (each wing)

Chantilly, Musée Condé, inv. no. 107

BIBL.: FRIEDLÄNDER II, no. 88; Corpus

Institut de France, no. 158 (with bibl.).

HISTORICAL INFORMATION: Born around

1435, Jeanne de France was the fourth

daughter of Charles VII, King of France. She

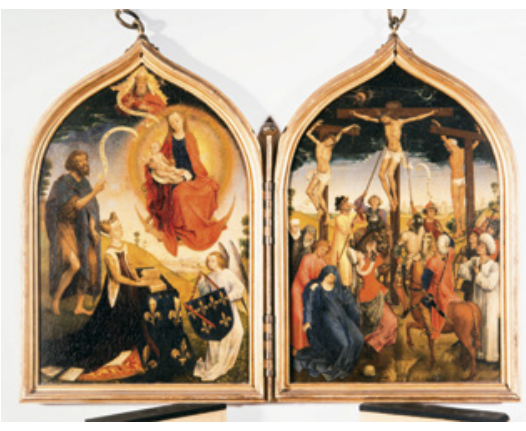

married the Duke of Bourbon, Jean II and died without any children in 1482. She is the daughter of Charlotte of Savoy, who is portrayed in a diptych very similar to this one (cat. 216).

Identity of the sitter(s): Jeanne de France

Provenance: unknown

Number of portrait(s): 1

Type of person(s): lay (woman alone)

Attitude of the sitter(s): hands clasped

Representation of the sitter(s): full-length

Gaze of the sitter(s): towards the scene

Object(s): yes (prie-dieu, book)

Coat(s) of arms: yes

Environment: landscape with sacred connotation, historical setting

Structuring of the pictorial space: distinct spaces

Patron saint(s): John the Baptist

Gesture of the patron saint(s): not applicable

Type of religious scene: hieratic

Religious scene(s) depicted: the Virgin and Child, the Crucifixion

Cat. 678-Type 6A

VAN DER WEYDEN, Rogier (circle of)

Fragments. A Man in Prayer with Patron Saint and the Virgin of the Annunciation (c. 1430-1500)

$68.3 \times 41.3 \mathrm{~cm}$ (panel with the portrait) and $68.3 \times 26.5$ $\mathrm{cm}$ (panel with the Virgin)

Petworth House, Egremont Collection (National Trust) BIBL.: FRIEDLÄNDER II, supp. 129; BILLINGE 2012.

Identity of the sitter(s): unknown

Provenance: unknown

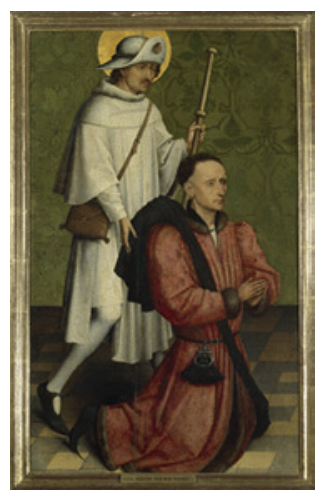


Number of portrait(s): 1

Type of person(s): lay (man alone)

Attitude of the sitter(s): hands clasped

Representation of the sitter(s): full-length

Gaze of the sitter(s): indeterminate

Object(s): no

Coat(s) of arms: no

Environment: neutral space (incomplete)

Structuring of the pictorial space: indeterminate

Patron saint(s): James

Gesture of the patron saint(s): protecting

Type of religious scene: indeterminate

Religious scene(s) depicted: the Virgin of the Annunciation

\section{Cat. 679 - Type ${ }_{3} \mathrm{C}$}

[R KD work no. 4703]

VAN DER WEYDEN, Rogier (circle of)

The Crucifixion with a Man in Prayer (c. 1475-1500)

$36.8 \times 36.2 \mathrm{~cm}$

Poughkeepsie, Frances Lehman Loeb Art Center, inv. no. 1995.10

BIBL.: FRIEDLÄNDER II, no. 92; Sale cat. Sotheby's (New York, 12 January 1995), no. 10 (with bibl.).

REMARK: A technical investigation of the panel indicated that the portrait was not planned as part of the original composition and was added at a later stage of the realisation of the work (see the online catalogue of the museum:

http://emuseum.vassar.edu/view/objects/asitem/search@/o?t:state:flow=facc 88e5-6d3b-42fe-8419-916a85bf651a).

HISTORICAL INFORMATION: The man portrayed on the left is identified by an inscription ( fr. amelius. de emael). Nothing is known about him.

Identity of the sitter(s): Amelius de Emael (?)

Provenance: unknown

Number of portrait(s): 1

Type of person(s): religious (man alone)

Attitude of the sitter(s): hands clasped

Representation of the sitter(s): full-length

Gaze of the sitter(s): towards the scene

Object(s): no

Coat(s) of arms: no

Environment: landscape with sacred connotation 
Structuring of the pictorial space: not applicable

Patron saint(s): none

Gesture of the patron saint(s): not applicable

Type of religious scene: narrative

Religious scene(s) depicted: the Crucifixion

Cat. 680-Type 2A VAN DER WEYDEN, Rogier (follower of) Altarpiece of the Passion ('Ambierlé Altarpiece') (1466) $220 \times 280 \mathrm{~cm}$ (closed) and $220 \times 560 \mathrm{~cm}$ (open), oil on wood and carved piece Ambierlé, church of the priory BIBL.: FRIEDLÄNDER II, no. 105; DUPONT 1938; SCHLUMBERGER 1965; DE VAIVRE 1987; DE VRIJ 1998b; Exh. cat. Brussels 2013, no. 8 (with bibl.). historical INFormation: The devotees are Michel de Chaugy, his wife Laurette de Jaucourt and his parents, Jean de Chaugy and Guillaumette de Montagu. The altarpiece was commissioned by Michel, as attested by the inscription below the portraits: Ceste table en ce lieu présent donna pour fair à Dieu present messi Michiel de Chagy conseillé chambellain aussy et le premier maistre dhoste du noble prince dont nest tel Philippe bon duc de Bourgonge en l'an que leglise tesmoigne. The text is unfortunately incomplete, but a document from 1665 gives the end of this inscription: Mil quatre cent soixante six Dieu voile qu'en sa gloire sit. Michel de Chaugy was a member of the Burgundian nobility. He was councillor, chamberlain and Premier maître d'hôtel of Philip the Good. In 1463, he was made Gruyer d'Auxois, and then Bailiff of Mâcon. After the death of Philip the Good, Michel entered into the service of Charles the Bold. He was notably in charge of the payments to the artists who produced the decoration for the marriage of the duke and Margaret of York. He would thus had several opportunities to commission this altarpiece to Flemish artists (see JACOBS 1998, 195). Michel died in 1479 without any children. His will, written in 1476 , stipulates that the altarpiece had to be displayed on the high altar of the church of Ambierlé.

Identity of the sitter(s): Michel de Chaugy and his family

Provenance: Ambierlé, priory church

Number of portrait(s): 4 
Type of person(s): lay (family)

Attitude of the sitter(s): hands clasped, holding a book

Representation of the sitter(s): full-length

Gaze of the sitter(s): into space

Object(s): yes (prie-dieu, book, sword)

Coat(s) of arms: yes

Environment: landscape, no sacred connotation

Structuring of the pictorial space: distinct spaces (different techniques: painting/sculpture)

Patron saint(s): John the Baptist, Lawrence, George, Michael

Gesture of the patron saint(s): introducing, holding his/her attribute

Type of religious scene: narrative

Religious scene(s) depicted: scenes of the Passion, the Annunciation, St. Anne, St. Catherine, St. Margaret, St. Martin

\section{Cat. 681-Type 3 B}

[Link to the Friedländer 3.o Database]

VAN DER WEYDEN, Rogier (follower of)

Epitaph of Johanna van Horne and her Family (shortly after 1461)

$87 \times 94 \mathrm{~cm}$

Berlin, Staatliche Museen zu Berlin, Gemäldegalerie (destroyed in 1945)

BIBL.: FRIEDLÄNDER II, no. 121c; GEURTS 1968, 109; DE VOS 1999, $35^{8}$.

HISTORICAL INFORMATION: The coats of arms and the inscription on the frame identify the sitters as Jacob I van Horne (1420-1488), Johanna van Meurs $(\dagger 1461)$ and their children. They belonged to the high nobility of Holland. Jacob was Lord of Horne and Count of Horne from 1450 onwards. The couple is depicted with eight children, but only seven of them are known: Willem (1449-1453), Jacob II, Count of Horne (c. 1450-1502), Jan (1458-1505), Bishop of Liège from 1482 onwards, Maria, Margaretha (1461-1518), Frederik ( $\dagger 1487)$ and Walburga. Horne was a little city in Limbourg. According to Geurts, the castle depicted in the background on the left is the castle of Horne, and the one on the right is the castle of Weert.

Identity of the sitter(s): Johanna van Horne and her family

Provenance: unknown

Number of portrait(s): 10

Type of person(s): mixed (family)

Attitude of the sitter(s): hands clasped

Representation of the sitter(s): full-length

Gaze of the sitter(s): towards the scene 
Object(s): yes (book)

Coat(s) of arms: yes

Environment: enclosed garden

Structuring of the pictorial space: not applicable

Patron saint(s): Jerome, Elizabeth of Hungary

Gesture of the patron saint(s): introducing

Type of religious scene: hieratic

Religious scene(s) depicted: the Virgin and Child

Cat. 682-Type 6A

[RKD work no. 69649]

VAN DER WEYDEN, Rogier (follower of)

One Wing. A Man in Prayer with St. Augustine (1450-1500)

$80.5 \times 28.5 \mathrm{~cm}$

Paris, sale Piasa (17 December 2008), lot no. 4

BI B L.: Sale cat. Piasa (Paris, 17 December 2008), no. 4 (with bibl.).

Identity of the sitter(s): unknown

Provenance: unknown

Number of portrait(s): 1

Type of person(s): lay (man alone)

Attitude of the sitter(s): holding a book

Representation of the sitter(s): full-length

Gaze of the sitter(s): indeterminate

Object(s): yes (book)

Coat(s) of arms: no

Environment: landscape, no sacred connotation (incomplete)

Structuring of the pictorial space: indeterminate

Patron saint(s): Augustine

Gesture of the patron saint(s): holding his/her attribute

Type of religious scene: indeterminate

Religious scene(s) depicted: none 
Cat. 683 - Type $3 \mathrm{C}$

VAN DER WEYDEN, Rogier (follower of)

The Lamentation with a Man in Prayer (c. 1470)

$47 \times 35 \mathrm{~cm}$

Madrid, Museo Nacional del Prado, inv. no. 2540 BIBL.: FRIEDLÄNDER II, no. 2od; BERMEJO 1980, 111-12; DE VOS 1999, no. B12 (with bibl.).

Identity of the sitter(s): unknown

Provenance: unknown

Number of portrait(s): 1

Type of person(s): lay (man alone)

Attitude of the sitter(s): hands clasped

Representation of the sitter(s): full-length

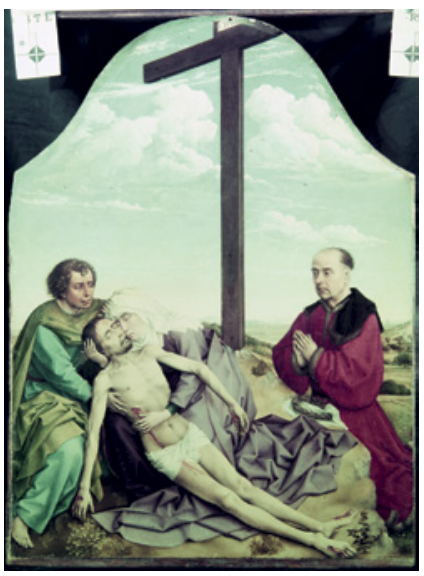

Gaze of the sitter(s): towards the scene

Object(s): no

Coat(s) of arms: no

Environment: historical setting

Structuring of the pictorial space: not applicable

Patron saint(s): none

Gesture of the patron saint(s): not applicable

Type of religious scene: narrative

Religious scene(s) depicted: the Lamentation

Cat. 684-Type $3 \mathrm{D}$

VAN DER WEYDEN, Rogier (follower of)

The Virgin and Child with a Man in Prayer

(c. 1500-1510)

$48.5 \times 42.5 \mathrm{~cm}$

Tongeren, Stedelijk Museum

BIBL.: ULRIX-CLOSSET 1962.

Identity of the sitter(s): unknown

Provenance: unknown

Number of portrait(s): 1

Type of person(s): lay (man alone)

Attitude of the sitter(s): hands clasped

Representation of the sitter(s): half-

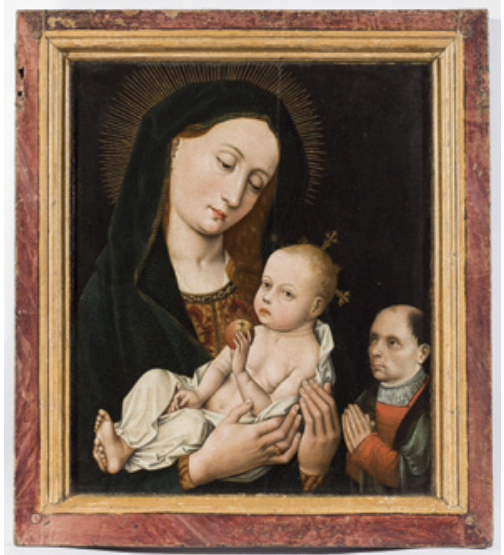

length, small scale

Gaze of the sitter(s): towards the scene 
Object(s): no

Coat(s) of arms: no

Environment: neutral space

Structuring of the pictorial space: not applicable

Patron saint(s): none

Gesture of the patron saint(s): not applicable

Type of religious scene: hieratic

Religious scene(s) depicted: the Virgin and Child

\section{Cat. 685 - Type ${ }_{3} \mathrm{C}$}

VAN DER WEYDEN, Rogier

(follower of)

Triptych of the Crucifixion ('Sforza

Triptych') (c. 146o)

$54 \times 46 \mathrm{~cm}$ (centre panel) and

$54 \times 19.5 \mathrm{~cm}$ (wings)

Brussels, MRBAB, inv. no. 515

BIBL.: FRIEDLÄNDER II, no. 93;

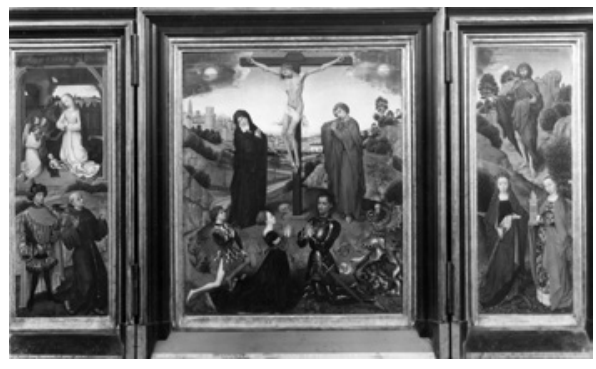

STROO et SYFER D'OLNE 1996, 130-51 (with bibl.); Exh. cat. Brussels 2013, no. 5 .

HISTORICAL INFORMATION: The coat of arms on the centre panel is that of the Sforza family. The man on the right is the condottiere Alessandro Sforza (1409-1473), who was also a bibliophile and a poet. The identity of the two other persons has led to some discussions. It is now assumed that they are Alessandro's son, Costanzo Sforza (1447-1483) and his daughter, Battista Sforza (1446-1472). The condottiere probably commissioned the triptych in 1458, during a journey he made through France and the Low Countries, in the service of his brother, the Duke of Milan.

Identity of the sitter(s): Alessandro Sforza and two members of his family

Provenance: unknown

Number of portrait(s): 3

Type of person(s): lay (family)

Attitude of the sitter(s): hands clasped, particular gesture

Representation of the sitter(s): full-length

Gaze of the sitter(s): into space, towards the scene

Object(s): yes (hat, sword)

Coat(s) of arms: yes

Environment: historical setting

Structuring of the pictorial space: not applicable 
Patron saint(s): none

Gesture of the patron saint(s): not applicable

Type of religious scene: narrative

Religious scene(s) depicted: the Crucifixion, the Nativity, St. Bavo, St. Francis, St. John the Baptist, St. Catherine, St. Barbara, St. Jerome, St. George

Cat. 686-Type ${ }_{2} \mathrm{C}$

VAN DER WEYDEN, Rogier

(follower of)

Triptych of the Crucifixion with a Man in Prayer ('Abegg Triptych')

(c. 1438-1440)

$103 \times 31.1 \mathrm{~cm}$ (centre panel) and

$103 \times 70 \mathrm{~cm}$ (wings)

Bern, Kunstmuseum, Abegg Stiftung,
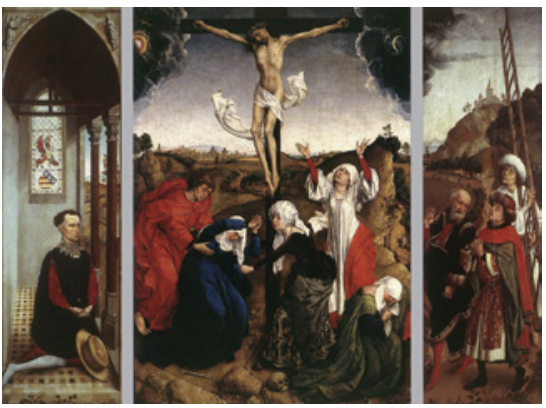

inv. no. 14.2.63

вIBL.: FRIEDLÄNDER II, supp. 131; DHANENS 1984, 73-93; DE VOS 1999, no. 10; Exh. cat. Frankfurt and Berlin 2009, no. 31 (with bibl.).

HISTORICAL INFORMATION: The stained-glass window on the left wing presents a coat of arms similar to that of the da Villa family (see cat. 487). Many members of this lineage commissioned Flemish artworks destined for foundations in Flanders or in Chieri, where they came from. Hulin de Loo proposed in an unpublished paper from 1936 that the young man depicted here is Oberto da Villa. More recently, Campbell has demonstrated that the coat of arms does not belong to this family. The man wears the collar of the Order of the Porcupine, but he has not been identified.

Identity of the sitter(s): unknown

Provenance: unknown

Number of portrait(s): 1

Type of person(s): lay (man alone)

Attitude of the sitter(s): particular gesture

Representation of the sitter(s): full-length

Gaze of the sitter(s): towards the scene

Object(s): yes (hat)

Coat(s) of arms: yes

Environment: architectural space, no sacred connotation

Structuring of the pictorial space: unified space with discontinuities

Patron saint(s): none 
Gesture of the patron saint(s): not applicable

Type of religious scene: narrative

Religious scene(s) depicted: the Crucifixion

Cat. 687 -Type $3 \mathrm{~A}$

VAN DER WEYDEN, Rogier (or workshop)

The Lamentation with Saints and a Man in Prayer (c. 1470)

$37 \times 46.5 \mathrm{~cm}$

London, NG, inv. no. NG 6265

BIBL.: FRIEDLÄNDER II, no. 20;

CAMPBELL 1998, 440-46; DE VOS 1999, 370-71 (with bibl.).

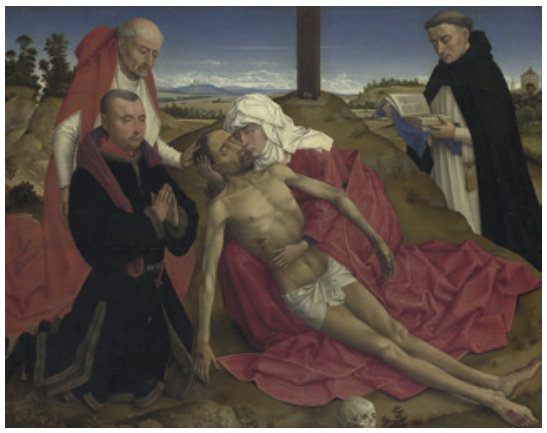

Identity of the sitter(s): unknown

(Girolamo Vento?)

Provenance: unknown

Number of portrait(s): 1

Type of person(s): lay (man alone)

Attitude of the sitter(s): hands clasped

Representation of the sitter(s): full-length

Gaze of the sitter(s): into space

Object(s): no

Coat(s) of arms: no

Environment: historical setting

Structuring of the pictorial space: not applicable

Patron saint(s): Jerome

Gesture of the patron saint(s): interceding

Type of religious scene: narrative

Religious scene(s) depicted: the Lamentation, St. Dominic

Cat. 688-Type 6A

VAN DER WEYDEN, Rogier (workshop of)

Fragment or Wing. Portrait of a Couple in Prayer (c. 1470)

$18.2 \times 12 \mathrm{~cm}$

New York, Acevado collection, lot no. 11

BIB L.: Exh. cat. Leuven 2009, no. 1 (with bibl.). 
HISTORICAL INFORMATION: The face of the man bears some similarities with Rogier van der Weyden's portrait in the Recueil d'Arras (fol. 276) and in Dominique Lampson's Pictorium aliquot Germaniae inferioris effigies (1572). In Lampson's work, the engraved portrait is oriented in the same direction as in this panel. It thus appears possible that this painted portrait served as a model for the engraving. If the sitter is Van der Weyden, the woman could be his mother Agnès de Waterlos or his widow Elisabeth Goffaert († 1477). Dendrochronological analysis gives $1463^{-1477}$ as a likely date of execution. The painting could thus have been commissioned by Elisabeth around 1470. If this were the case, Rogier's portrait would be a posthumous one.

Identity of the sitter(s): Rogier van der Weyden and Elisabeth Goffaert (?)

Provenance: unknown

Number of portrait(s): 2

Type of person(s): lay (couple)

Attitude of the sitter(s): hands clasped, holding a rosary

Representation of the sitter(s): half-length

Gaze of the sitter(s): indeterminate

Object(s): yes (rosary)

Coat(s) of arms: no

Environment: neutral space (incomplete)

Structuring of the pictorial space: indeterminate

Patron saint(s): none

Gesture of the patron saint(s): not applicable

Type of religious scene: indeterminate

Religious scene(s) depicted: none

Cat. 689-Type 6A

VAN DER WEYDEN, Rogier (workshop of)

Portrait of a Man in Prayer (c. 1460)

$20 \times 15.2 \mathrm{~cm}$

Banbury, Upton House (National Trust), inv. no. 171

BIB L.: Exh. cat. Leuven 2009, no. 23 (with bibl.).

Identity of the sitter(s): unknown

Provenance: unknown

Number of portrait(s): 1

Type of person(s): lay (man alone)

Attitude of the sitter(s): hands clasped

Representation of the sitter(s): half-length

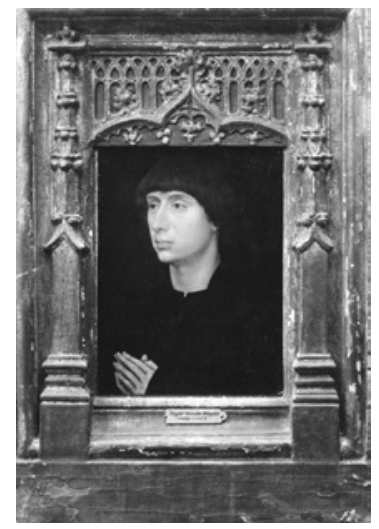


Gaze of the sitter(s): indeterminate

Object(s): no

Coat(s) of arms: no

Environment: neutral space (incomplete)

Structuring of the pictorial space: indeterminate

Patron saint(s): none

Gesture of the patron saint(s): not applicable

Type of religious scene: indeterminate

Religious scene(s) depicted: none

Cat. 69o-Type ${ }_{3} \mathrm{C}$

VAN DER WEYDEN, Rogier (workshop of)

The Nativity with a Woman in Prayer (c. 1460)

$43.5 \times 35 \mathrm{~cm}$

Germany, Marks-Thomée collection

BIB L.: Exh. cat. Frankfurt and Berlin 2009, no. 34.

REMARK: This panel is a copy of the centre panel of the Bladelin Triptych (cat. 672).

Identity of the sitter(s): unknown

Provenance: unknown

Number of portrait(s): 1

Type of person(s): lay (woman alone)

Attitude of the sitter(s): hands clasped

Representation of the sitter(s): full-length

Gaze of the sitter(s): towards the scene

Object(s): no

Coat(s) of arms: no

Environment: historical setting

Structuring of the pictorial space: not applicable

Patron saint(s): none

Gesture of the patron saint(s): not applicable

Type of religious scene: narrative

Religious scene(s) depicted: the Nativity 
Cat. 691-Type $2 \mathrm{C}$

VAN DER WEYDEN, Rogier (workshop of)

Triptych of the Annunciation with a Man in Prayer

(c. 1435-1440)

$87 \times 91.5 \mathrm{~cm}$ (centre panel) and $89 \times 36 \mathrm{~cm}$ (wings)

Paris, Musée du Louvre, inv. no. 1982 (centre panel) and Turin, Galleria Sabauda, inv. nos. 312 and 320 (wings)

BIBL.: FRIEDLÄNDER II, no. 6; Corpus Turino, no. 19; DE VOS 1999, no. 7; Exh. cat. Leuven 2009, no. 27a-b-c (with bibl.); Exh. cat. Frankfurt and

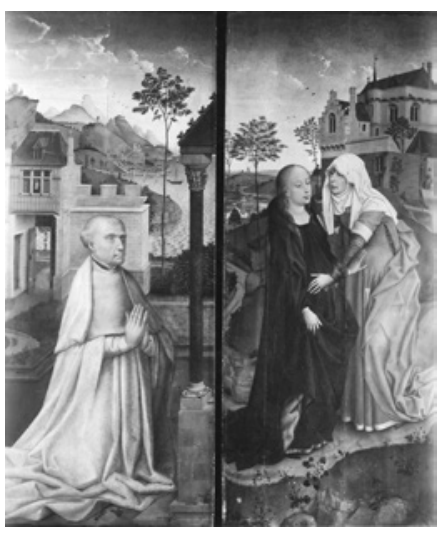
Berlin 2009, no. 26 (with bibl.).

HISTORICAL INFORMATION: The current portrait is an overpainting that hides the original one. A piece of wood corresponding to the man's face has been sawn off and replaced by another panel on which the new face has been painted, while the whole body and the coat of arms (initially hung on a tree) have been overpainted. This coat of arms was that of the da Villa family from Piedmont. The clothes of the first sitter match with the fashion c. 1435. He could thus be Domenico da Villa (1390-1471/2), who lived in Brussels and was the father of Petrino da Villa (cf. cat. 487). In the early sixteenth century, the triptych was in Italy, as attested by a copy executed by an artist from Piedmont. Identity of the sitter(s): unknown

Provenance: unknown

Number of portrait(s): 1 (previously 2 )

Type of person(s): religious (man alone)

Attitude of the sitter(s): hands clasped

Representation of the sitter(s): full-length

Gaze of the sitter(s): towards the scene

Object(s): no

Coat(s) of arms: yes (overpainted)

Environment: landscape with sacred connotation (incomplete)

Structuring of the pictorial space: distinct spaces

Patron saint(s): none

Gesture of the patron saint(s): not applicable

Type of religious scene: narrative

Religious scene(s) depicted: the Annunciation, the Visitation 
Cat. 692-Type $3^{B}$

VAN EYCK, Jan

The Virgin and Child with Canon Joris van der Paele (c. 1434-1436)

$112.1 \times 157.8 \mathrm{~cm}$

Bruges, Groeningemuseum, inv. no. 0.161.I

BIBL.: FRIEDLÄNDER I, pl. 23-25; Corpus Bruges I, no. 9; DHANENS 1980, 212-31; ROTHSTEIN 1999 (with bibl.).

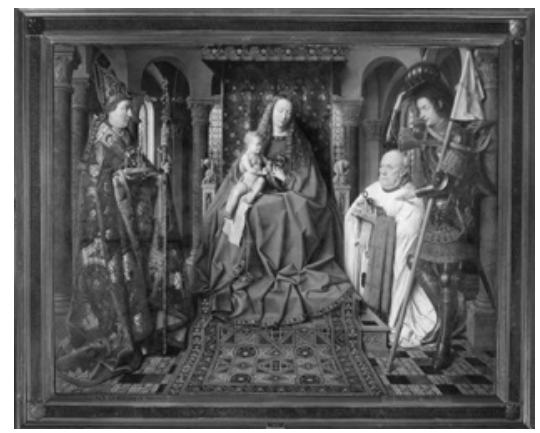

HISTORICAL INFORMATION: The inscription on the frame gives the name of the sitter and the occasion of the commission: Hoc op (us) fecit fieri mag(iste) $r$ Georgi(us) de Pala hui(us) ecclesie canoni(ci) p(er) Iohanne(m) de Eyck pictore $(m)$. Et fundavit hic duas capell(an)ias de i(n) $g($ re)mio chori domini $M$ CCCC . XXXIIII . (com)pl(evit) au(tem) 1436. The sitter is Joris van der Paele, canon of the chapter of St. Donatian in Bruges. The text states that he founded two chaplaincies in 1434 and that the work was finished in 1436. Joris van der Paele first made a career at the papal chancery, before returning to Bruges around 1420, where he became a canon. At the time of his first foundation in 1434, he was exempted from attending liturgical services because of his fragile health and his age. It is usually assumed that the canon kept the Eyckian painting in his house for a few years, before installing it in the Bruges cathedral as his memorial work. Joris died in 1443.

Identity of the sitter(s): Joris van der Paele

Provenance: Bruges, house of Joris van der Paele or church of St. Donatian

(?)

Number of portrait(s): 1

Type of person(s): religious (man alone: canon)

Attitude of the sitter(s): holding a book

Representation of the sitter(s): full-length

Gaze of the sitter(s): into space

Object(s): yes (book, spectacles)

Coat(s) of arms: no

Environment: ecclesial space

Structuring of the pictorial space: not applicable

Patron saint(s): George

Gesture of the patron saint(s): introducing

Type of religious scene: hieratic

Religious scene(s) depicted: the Virgin and Child, St. Donatian 
Cat. 693-Type $3 \mathrm{D}$

VAN EYCK, Jan

The Virgin of Chancellor Rolin (c. 1436-1441) $66 \times 62 \mathrm{~cm}$

Paris, Musée du Louvre, inv. no. 1271 BIBL.: FRIEDLÄNDER I, pl. 51; Corpus Paris II, no. 175 (with bibl.); GELFAND 2009 .

HISTORICAL INFORMATION: The painting shows Nicolas Rolin (see cat. 664). The work was probably destined for St. Sebastian's chapel at the church Notre-

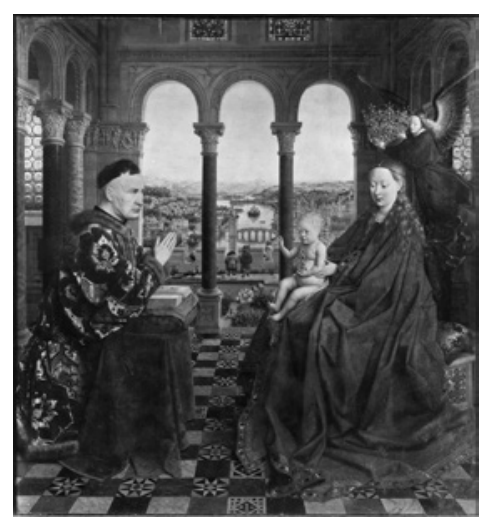
Dame-du-Chastel in Autun.

Identity of the sitter(s): Nicolas Rolin

Provenance: Autun, church Notre-Dame-du-Chastel (St. Sebastian's chapel?)

Number of portrait(s): 1

Type of person(s): lay (man alone)

Attitude of the sitter(s): hands clasped

Representation of the sitter(s): full-length

Gaze of the sitter(s): towards the scene

Object(s): yes (prie-dieu, book, purse)

Coat(s) of arms: no

Environment: architectural space with sacred connotation

Structuring of the pictorial space: not applicable

Patron saint(s): none

Gesture of the patron saint(s): not applicable

Type of religious scene: hieratic

Religious scene(s) depicted: the Virgin and Child

Cat. 694-Type 2 B

VAN EYCK, Jan

Triptych of the Virgin and Child ('Dresden Triptych') (dated 1437 on the frame)

$33.1 \times 27.5 \mathrm{~cm}$ (centre panel) and $33.1 \times 13.6$ $\mathrm{cm}$ (wings)

Dresden, Staatliche Kunstsammlungen, inv. no. 799

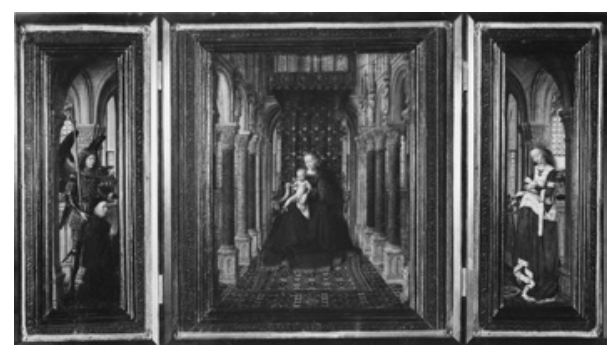


BIBL.: FRIEDLÄNDER I, pl. 54-55; DHANENS 1980, 242-51, 385-86; NEIDHARDT and SCHÖLZEL 200o; STREETON 2011 (with bibl.). HISTORICAL INFORMATION: The identity of the sitter has raised much debate and cannot be established with any certainty. The original frames present the date 1437 and two coats of arms; the one on the right is unknown and the one on the left is that of the Giustiniani family. The Genovese and Venetian branches of this family were commercially active in the Low Countries during the second quarter of the fifteenth century. The sitter was initially identified as Michele Giustiniani, but an archival document from Genoa indicates that Michele asked to settled in the Italian city in 1430 . He does not appear in any Bruges document from around 1437 onwards. Recently, Streeton has discovered an account book of the Bruges branch of the Borromei bank, containing many transactions executed in 1438 for a certain Raffaello Giustiniani 'from Bruges'. Following this source, this man appears to be one of the best clients of the bank and he was probably the Giustiniani agent in Bruges. Raffaello could thus be the commissioner of this triptych, either for himself or for another member of the family. Nonetheless, there is no evidence allowing us to confirm this hypothesis.

Identity of the sitter(s): member of the Giustiniani family (?)

Provenance: unknown

Number of portrait(s): 1

Type of person(s): lay (man alone)

Attitude of the sitter(s): hands clasped

Representation of the sitter(s): full-length

Gaze of the sitter(s): into space

Object(s): no

Coat(s) of arms: yes

Environment: ecclesial space

Structuring of the pictorial space: continuous space

Patron saint(s): Michael

Gesture of the patron saint(s): introducing

Type of religious scene: hieratic

Religious scene(s) depicted: the Virgin and Child, St. Catherine, the Annunciation 
Cat. 695-Type ${ }_{3}$ B

VAN EYCK, Jan (and workshop)

The Virgin and Child with St. Barbara and St. Elizabeth ('The Virgin of Jan $\left.V^{\prime}{ }^{\prime}\right)($ c. 1441-1443)

$47.4 \times 61.3 \mathrm{~cm}$

New York, Frick Collection, inv. no. 54.1.161

BIBL.: FRIEDLÄNDER I, pl. 53; Exh. cat. New York 1994, no. 2 (with bibl.);

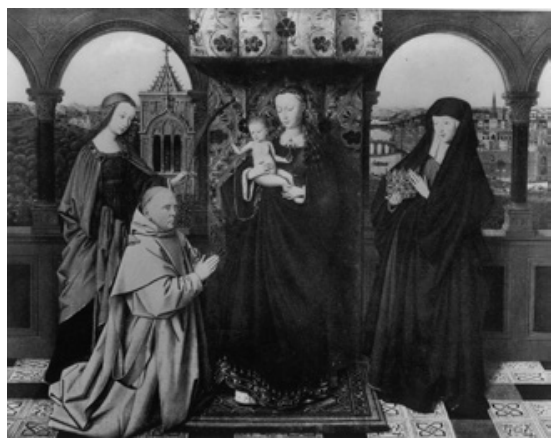
SUGIYAMA 2016.

HISTORICAL INFORMATION: In 1938, Scholtens discovered several archival documents revealing the monk's identity and the circumstances of the commission of this painting: on 3 September 1443, the Bishop of Bruges, Martinus de Mayo, consecrated three altarpieces-one of them being this Eyckian painting - offered to the charterhouse of Bruges (also known as Genadedal or Val-de-Grâce) by Jan Vos, who was at this time the prior of the monastery. Jan Vos is the sitter for this painting. During his visit, the bishop attached indulgences to these paintings, on the condition that they would stay within the Order. Initially a member of the Teutonic Order, Jan Vos spent most of his life in the Order of St. Bruno. On 19 August 1431, he is mentioned as Procurator of the Utrecht house of the Teutonic Order. He then entered the charterhouse of Nieuwlicht, in the neighbourhood of Utrecht, where he lived for a few years as a brother, before being appointed Prior of the charterhouse of Genadedal in Bruges in 1441. At the very beginning of his stay in Bruges, Jan Vos commissioned this painting for the church of the charterhouse. In 1450, he returned to Nieuwlicht, where he also became prior. Leaving Bruges, he took the Eyckian painting with him and placed it in the church of his new monastery, on the altar dedicated to St. Barbara, which was founded in 1446. Jan Vos held the title of Prior of Nieuwlicht until 1458, and he died in 1462. The Carthusian monk also appears in cat. 282.

Identity of the sitter(s): Jan Vos

Provenance: Bruges, charterhouse of Genadedal

Number of portrait(s): 1

Type of person(s): religious (man alone: Carthusian monk)

Attitude of the sitter(s): hands clasped

Representation of the sitter(s): full-length

Gaze of the sitter(s): into space 
Object(s): no

Coat(s) of arms: no

Environment: architectural space with sacred connotation

Structuring of the pictorial space: not applicable

Patron saint(s): Barbara

Gesture of the patron saint(s): protecting

Type of religious scene: hieratic

Religious scene(s) depicted: the Virgin and Child, St. Elizabeth of Hungary

Cat. 696-Type ${ }_{3} \mathrm{D}$

VAN EYCK, Jan (copy after)

Triptych of the Virgin and Child ('Van Maelbeke Triptych') (before 1441 for the original)

$177.2 \times 99.7 \mathrm{~cm}($ centre panel $)$ and $177.2 \times$ $41 \mathrm{~cm}$ (wings)

Bruges, Groeningemuseum, inv. no. 2007. GROoo01.I-0003.I

BIBL.: FRIEDLÄNDER I, pl. 58-59;

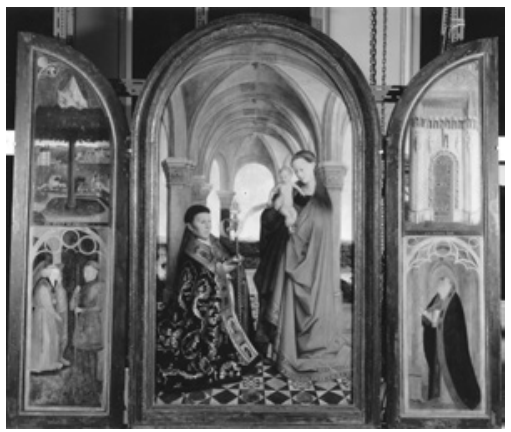
JONES 1995; JONES 2006 (with bibl.). HISTORICAL INFORMATION: The triptych is a copy of a lost work by Jan van Eyck, which had been commissioned by Nicholas van Maelbeke, the Provoost of the church of St. Martin at Ieper. The painting was meant to be Nicholas' epitaph. In the seventeenth century, the triptych was still located in the choir of the church at Ieper. The canon Petrus Wijts then commissioned a copy of the triptych, with his own portrait instead of Nicholas'. As shown by Jones, Wijts was willing to revive an old-fashioned and traditional way of representation and to pay tribute to a famous painting.

Identity of the sitter(s): Nicholas van Maelbeke

Provenance: Ieper, church of St. Martin

Number of portrait(s): 1

Type of person(s): religious (man alone: priest)

Attitude of the sitter(s): hands clasped

Representation of the sitter(s): full-length

Gaze of the sitter(s): into space

Object(s): yes (book, crosier)

Coat(s) of arms: no

Environment: architectural space with sacred connotation

Structuring of the pictorial space: not applicable 
Patron saint(s): none

Gesture of the patron saint(s): not applicable

Type of religious scene: hieratic

Religious scene(s) depicted: the Virgin and Child

Cat. 697-Type 2A

VAN EYCK, Jan (follower of)

Triptych of the Crucifxion with Two

Women in Prayer and Patron Saints

(c. 1500)

$74 \times 116 \mathrm{~cm}$ (open)

Whereabouts unknown

Identity of the sitter(s): unknown

Provenance: unknown

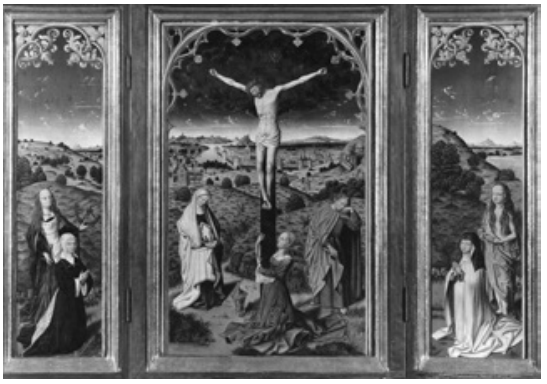

Number of portrait(s): 2

Type of person(s): mixed (unidentified group)

Attitude of the sitter(s): hands clasped

Representation of the sitter(s): full-length

Gaze of the sitter(s): indeterminate

Object(s): no

Coat(s) of arms: no

Environment: historical setting

Structuring of the pictorial space: continuous space

Patron saint(s): Catherine, Mary the Egyptian

Gesture of the patron saint(s): introducing, holding his/her attribute

Type of religious scene: narrative

Religious scene(s) depicted: the Crucifixion, the Annunciation

Cat. 698-Type $3 \mathrm{D}$

[RKD work no. 56301]

VAN EYCK, Jan (follower of)

St. Peter with a Canon in Prayer (c. 1475-1500)

$31 \times 21 \mathrm{~cm}$

Private collection

Identity of the sitter(s): unknown

Provenance: unknown

Number of portrait(s): 1

Type of person(s): religious (man alone: canon) 
Attitude of the sitter(s): holding a book

Representation of the sitter(s): full-length

Gaze of the sitter(s): towards the scene

Object(s): yes (book)

Coat(s) of arms: no

Environment: architectural space with sacred connotation

Structuring of the pictorial space: not applicable

Patron saint(s): none

Gesture of the patron saint(s): not applicable

Type of religious scene: hieratic

Religious scene(s) depicted: St. Peter enthroned

Cat. 699-Type $3^{B}$

VAN EYCK, Jan (workshop or follower of)

Portrait of a Man in Prayer (c. 1435)

$26.4 \times 19.5 \mathrm{~cm}$

Leipzig, Museum der bildenden Künste, inv. no. $5^{11}$

BIBL.: FRIEDLÄNDER I, no. 50a; Mus. cat. Leipzig 2012 (with bibl.).

Identity of the sitter(s): unknown

Provenance: unknown

Number of portrait(s): 1

Type of person(s): lay (man alone)

Attitude of the sitter(s): hands clasped

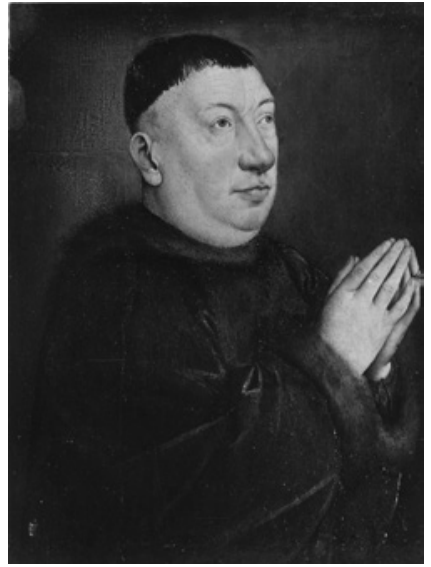

Representation of the sitter(s): half-length

Gaze of the sitter(s): indeterminate

Object(s): no

Coat(s) of arms: no

Environment: neutral space (incomplete)

Structuring of the pictorial space: indeterminate

Patron saint(s): none

Gesture of the patron saint(s): not applicable

Type of religious scene: indeterminate

Religious scene(s) depicted: none 
Cat. 70o-Type $1 \mathrm{D}$

VAN EYCK, Jan and Hubert

Polyptych of the Adoration of the Mystic Lamb ('Ghent Altarpiece') (achieved in 1432)

$375 \times 260 \mathrm{~cm}$ (closed) and $375 \times 520 \mathrm{~cm}$ (open)

Ghent, St. Bavo's Cathedral

BIBL.: FRIEDLÄNDER I, pl. 1-16; DHANENS 1965; DHANENS 1980, 74-117. HISTORICAL INFORMATION: This altarpiece was commissioned by Joos Vijd $(\dagger$ 1439) and his wife Elisabeth Borluut $(\dagger$ 1443). Lord of Pamele and Ledeberg, Joos Vijd belonged to the upper class of

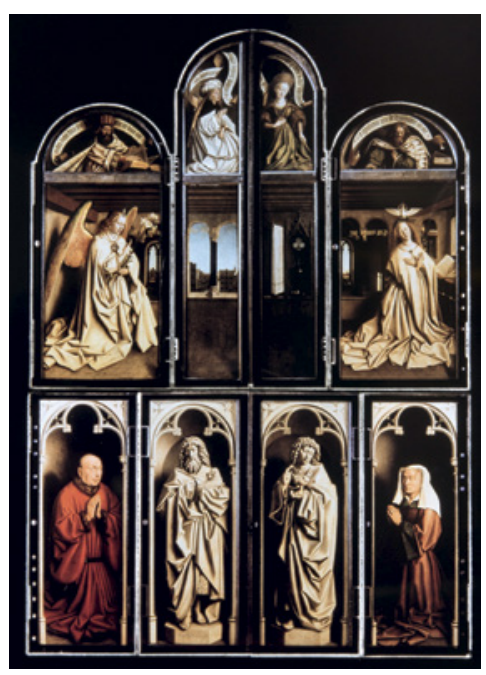
Ghent. He was elected alderman of the city several times and burgomaster in 1433-1434. The commission of this altarpiece took place within a vast foundation programme for the church of St. John the Baptist. The work was destined for the family chapel of Joos Vijd and was finished in 1432, as stipulated by the dedicatory inscription: Pictor hubertus eeyck. maior quo nemo repertus / Incepit - pondus. que johannes arte secundus / Frater perfecit . judoci vyd prece fretus / Versu sexta mai. vos collocat acta tueri. The act of foundation was registered on 13 May 1435 and provided for a daily mass in honour of God, the Virgin and all saints and in memory of the founders and their ancestors.

Identity of the sitter(s): Joos Vijd and Elisabeth Borluut

Provenance: Ghent, church of St. John the Baptist (current St. Bavo's

Cathedral), Vijd chapel

Number of portrait(s): 2

Type of person(s): lay (couple)

Attitude of the sitter(s): hands clasped

Representation of the sitter(s): full-length

Gaze of the sitter(s): into space

Object(s): no

Coat(s) of arms: no

Environment: niche

Structuring of the pictorial space: distinct spaces, grisaille 
Patron saint(s): none

Gesture of the patron saint(s): not applicable

Type of religious scene: hieratic

Religious scene(s) depicted: the Annunciation, St. John the Baptist, St. John the Evangelist, the Adoration of the Lamb, Prophets and sybils, God the Father with the Virgin Mary and St. John the Baptist, Musician angels

Cat. 701-Type ${ }_{3} \mathrm{C}$

VAN HEEMSKERCK, Maarten

The Crucifixion with a Canon in Prayer (dated 1543)

$335 \times 270 \mathrm{~cm}$

Ghent, MSK, inv. no. $\mathrm{S}_{52}$

BIBL.: GROSSHANS 1980, 158; Exh. cat. Amsterdam 1986, 71.

Identity of the sitter(s): unknown

Provenance: Ghent, convent of the Rich Clares (?)

Number of portrait(s): 1

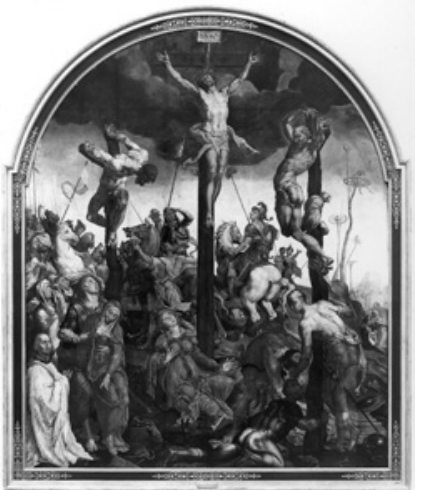

Type of person(s): religious (man alone: canon)

Attitude of the sitter(s): hands clasped

Representation of the sitter(s): full-length

Gaze of the sitter(s): towards the viewer

Object(s): no

Coat(s) of arms: no

Environment: historical setting

Structuring of the pictorial space: not applicable

Patron saint(s): none

Gesture of the patron saint(s): not applicable

Type of religious scene: narrative

Religious scene(s) depicted: the Crucifixion 
Cat. 702-Type $3 \mathrm{D}$

VAN HEEMSKERCK, Maarten

The Man of Sorrows with Two Women in Prayer (c. 1550)

$55 \times 84 \mathrm{~cm}$

Private collection

BIBL.: FRIEDLÄNDER XIII, no. 204; GROSSHANS 1980, no. 72 (with bibl.).

Identity of the sitter(s): unknown

Provenance: unknown

Number of portrait(s): 2

Type of person(s): lay (group indeterminate)

Attitude of the sitter(s): hands clasped

Representation of the sitter(s): half-length

Gaze of the sitter(s): towards the scene

Object(s): yes (rosary)

Coat(s) of arms: yes

Environment: neutral space

Structuring of the pictorial space: not applicable

Patron saint(s): none

Gesture of the patron saint(s): not applicable

Type of religious scene: hieratic

Religious scene(s) depicted: the Man of Sorrows

Cat. 703-Type $2 \mathrm{C}$

VAN HEEMSKERCK, Maarten

Triptych of the Crucifixion and the Life of St. Lawrence (1540 for centre panel and 1542 for the wings)

$570 \times 405 \mathrm{~cm}$ (centre panel) and $570 \times 200$ cm (wings)

Linköping, cathedral

BIBL.: GROSSHANS 1980, 133-48; VELDMAN 1996; HELMUS 2010, 221-38.

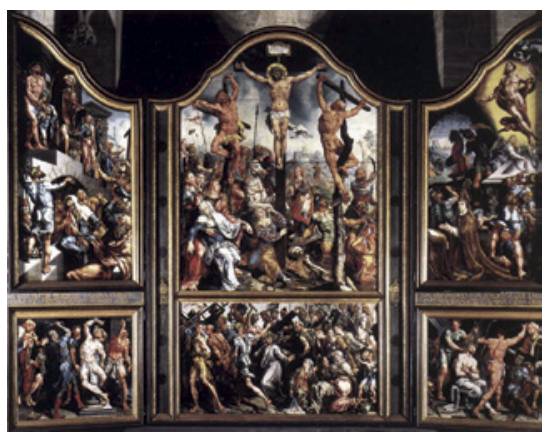
HISTORICAL INFORMATION: This imposing triptych was destined for the high altar of the church of St. Lawrence in Alkmaar. Its commission is very well documented, for three contracts signed by Maarten van Heemskerck and 
his patrons are preserved. The commission was made at the suggestion of the parish priest, Hieronymus Jansz. and the kerkmeester Dirck van Teylingen. Dating from 25 August 1538, the first contract was signed at the house of Hieronymus Jansz., in the presence of the witnesses Jorden van Foreest, Ijf Simonz., Ijsbrant Pietersz. and Dirck van Teylingen. This first contract concerned the production of the centre panel, to be delivered two years later. On 18 November 1539, the second contract, which concerned the inner wings, was signed at the house of Hieronymus Jansz., in the presence of the glass-maker Simon Auwelz. Finally, on 12 March 1541, the last contract was signed at the house of Dirck van Teylingen, with Hieronymus Jansz., the kerkmeesters, Jorden van Foreest and Simon Jansz., and the painter Cornelis Buys. Taking into account the high cost of this commission, the patrons appealed to the generosity of several benefactors. Among these were several kerkmeesters of Alkmaar, as well as the Bishop of Utrecht, Joris van Egmond. In exchange for Joris's financial help, the artist painted the portrait of the bishop on the inner right wing of the altarpiece. Dirck van Teylingen, Hieronymus Jansz. and Maarten van Heemskerck also appear on the outer wings: they are standing, wearing dark clothes, looking at the viewers among the protagonists of the scene. Luckily, the altarpiece survived the wave of iconoclasm of 1566 . Nevertheless, after the seizure of the city by the troops of Willem van Oranje in 1572, the church of St. Lawrence was reformed and its works of art were removed. Van Heemskerck's altarpiece was thus sold to Sweden in 1582 . Since then, it has been located in the cathedral of Linköping.

Identity of the sitter(s): Joris van Egmond

Provenance: Alkmaar, church of St. Lawrence, high altar

Number of portrait(s): 1

Type of person(s): religious (man alone: bishop)

Attitude of the sitter(s): hands clasped

Representation of the sitter(s): full-length

Gaze of the sitter(s): towards the scene

Object(s): yes (prie-dieu, book)

Coat(s) of arms: no

Environment: historical setting

Structuring of the pictorial space: distinct spaces

Patron saint(s): none

Gesture of the patron saint(s): not applicable

Type of religious scene: narrative

Religious scene(s) depicted: the Passion, the Life of St. Lawrence 
Cat. 704-Type $2 \mathrm{C}$

VAN HEEMSKERCK, Maarten

Triptych of the Crucifixion with a Family in Prayer (1549)

$100.5 \times 58.5 \mathrm{~cm}$ (centre panel) and $100.5 \times 28 \mathrm{~cm}$ (wings)

Saint Petersburg, Hermitage Museum, inv. no. 415

BIBL.: Exh. cat. Amsterdam 1986, no. 137-38.

REMARK: A panel showing Moses and
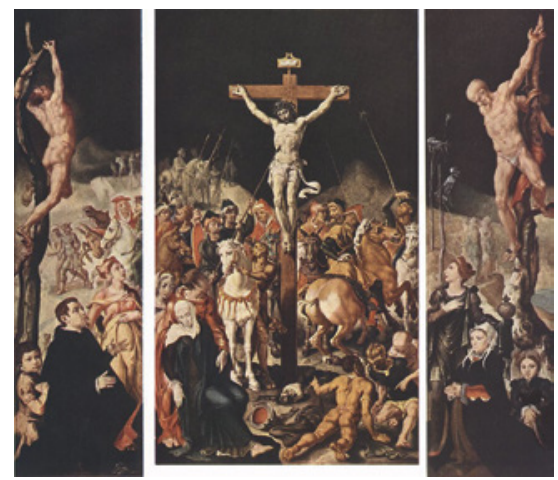

the brazen serpent in grisaille (Amsterdam, private collection) was formerly the outer wing of the triptych. This panel includes the following inscription: MARTINUS HEEMSKERCK inventor 1549.

Identity of the sitter(s): unknown

Provenance: unknown

Number of portrait(s): 4

Type of person(s): lay (family with children)

Attitude of the sitter(s): hands clasped, hands held up, particular gesture

Representation of the sitter(s): full-length

Gaze of the sitter(s): towards the scene, towards the viewer

Object(s): no

Coat(s) of arms: no

Environment: historical setting

Structuring of the pictorial space: continuous space

Patron saint(s): none

Gesture of the patron saint(s): not applicable

Type of religious scene: narrative

Religious scene(s) depicted: the Crucifixion, Moses and the brazen serpent

Cat. 705-Type 2A

VAN HEEMSKERCK, Maarten

Triptych of the Ecce Homo ('Van Drenkwaerdt Triptych') (dated 1544 on the frame)

$162 \times 89 \mathrm{~cm}$ (centre panel) and $171 \times 5^{1}$ cm (wings)

Warsaw, Muzeum Narodowe, inv. no. 188233

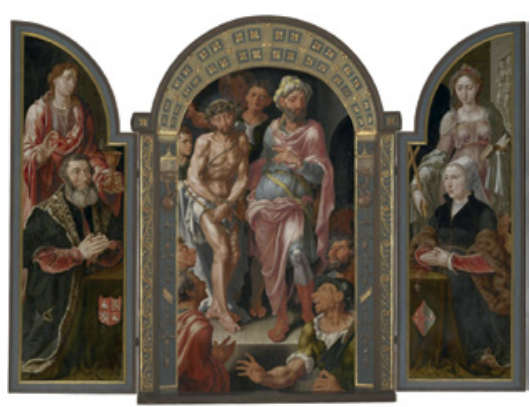


BIB L.: Exh. cat. Amsterdam 1986, no. 135; WOOLLETT et alii 2012 (with bibl.). HISTORICAL INFORMATION: The triptych was commissioned by Jan van Drenckwaerdt, for the altar of his chapel in the church of the Augustinian monastery of Dordrecht. He is depicted with Margaretha van Baardwijk, whom he married in 1519. Both of them came from wealthy patrician families of Dordrecht. They did not have any children. Like his father, Jan played an important role in the political life of Dordrecht. In 1516, he was made schout (bailiff) of Dordrecht by Charles v and he held this position until his death in 1549. He was also a member of the Brotherhood of St. Anthony, which gathered members from the wealthiest and most powerful families of the city. The triptych contains Jan's motto (ESPOIR/CONFORT/DRENCKWAIRT) and the date 1544. Taking into account the fact that Margaretha died in 1542, the triptych was most probably meant as a memorial work. The couple was buried in the chapel, in close vicinity of the triptych.

Identity of the sitter(s): Jan van Drenckwaerdt and Margaretha van Baardwijk

Provenance: Dordrecht, church of St. Augustine

Number of portrait(s): 2

Type of person(s): lay (couple)

Attitude of the sitter(s): hands clasped

Representation of the sitter(s): full-length

Gaze of the sitter(s): into space

Object(s): yes (prie-dieu)

Coat(s) of arms: yes

Environment: architectural space, no sacred connotation

Structuring of the pictorial space: distinct spaces

Patron saint(s): John the Evangelist, Margaret

Gesture of the patron saint(s): holding his/her attribute

Type of religious scene: narrative

Religious scene(s) depicted: the Ecce Homo

Cat. 706-Type $2 \mathrm{C}$

VAN HEEMSKERCK, Maarten

Triptych of the Entombment with a Family in Prayer (c. 1540-1545)

$88 \times 79 \mathrm{~cm}$ (centre panel) and $80.5 \times 35 \mathrm{~cm}$ (wings)

Vienna, Kunsthistorisches Museum, inv. nos. 6950-51 (wings) and Rotterdam, Museum Boijmans van Beuningen, inv. no. 1291 (centre panel)

BIB L.: GROSSHANS 1980, 155-58; Exh. cat. Rotterdam 1994, no. 87 (with bibl.); Exh. cat. Utrecht 1999-2000, 117-18. 
Identity of the sitter(s): unknown

Provenance: unknown

Number of portrait(s): 6

Type of person(s): lay (family)

Attitude of the sitter(s): hands clasped, holding rosary, particular gesture

Representation of the sitter(s): half-length

Gaze of the sitter(s): towards the scene, towards the viewer

Object(s): yes (book, prie-dieu, rosary)

Coat(s) of arms: yes

Environment: historical setting

Structuring of the pictorial space: unified space with discontinuities

Patron saint(s): none

Gesture of the patron saint(s): not applicable

Type of religious scene: narrative

Religious scene(s) depicted: the Entombment

\section{Cat. 707-Type 6A}

[RKD work no. 48420]

VAN HEEMSKERCK, Maarten

Two Wings. A Canon in Prayer with Mary Magdalen; St. John and the Virgin (c. 1540)

$125.7 \times 47.8 \mathrm{~cm}$ (each wing)

London, NG, inv. nos. NG 6508.1-2

BIBL.: DUNKERTON et alii 1999, 46-47; GROSSHANS 1980, 109; CAMPBELL 2014, 388-96 (with bibl.).

HISTORICAL INFORMATION: The two coats of arms painted on the reverse of the wings cannot be identified. As Campbell notes, they could have been executed with mistakes. If this is the case, they could belong to the Hamal and the Kersbeke families, and the sitter could be a canon, whose father was a Hamal and whose mother was a Kersbeke. Campbell found two canons with a father from the Hamal family, but their mother's name is unknown. The first is Arnout de Hamale (canon of the collegiate church of St. Gertrude at Mons) and the second is Johannes de Hamalia (canon of the collegiate church of St. Saviour at Harelbeke).

Identity of the sitter(s): unknown

Provenance: unknown

Number of portrait(s): 1

Type of person(s): religious (man alone: canon)

Attitude of the sitter(s): hands clasped 
Representation of the sitter(s): full-length

Gaze of the sitter(s): indeterminate

Object(s): no

Coat(s) of arms: yes (on the reverse)

Environment: celestial space (incomplete)

Structuring of the pictorial space: indeterminate

Patron saint(s): Mary Magdalen

Gesture of the patron saint(s): protecting

Type of religious scene: indeterminate

Religious scene(s) depicted: St. John supporting the Virgin, two saints bishops

\section{Cat. 7o8-Type 6A}

VAN HEEMSKERCK, Maarten

Two Wings. A Family in Prayer (c. 1545)

$68 \times 27 \mathrm{~cm}$ (each wing)

Strasbourg, Musée municipal, inv. no. 90 BIBL.: PLOMP and VAN BUEREN 1999; WOOLLETT et alii 2012, 12.

HISTORICAL INFORMATION: Jacob de Vries and his wife, Machteld van Meerdervoort have been recently identified, on the basis of their coats of

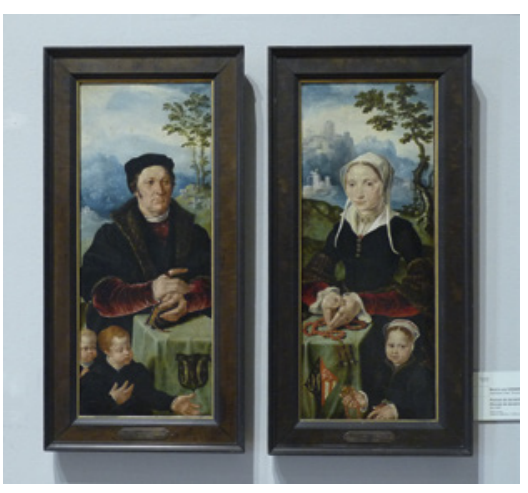
arms. They are portrayed with their children. Jacob was secretary of the city of Dordrecht. He died between 11 July 1543 and 3 September 1547.

Identity of the sitter(s): Jacob de Vries, Machteld van Meerdervoort and their children

Provenance: unknown

Number of portrait(s): 5

Type of person(s): lay (family with children)

Attitude of the sitter(s): holding a book, holding a rosary, particular gesture Representation of the sitter(s): half-length

Gaze of the sitter(s): towards the viewer, indeterminate

Object(s): yes (prie-dieu, book, rosary)

Coat(s) of arms: yes

Environment: landscape, no sacred connotation (incomplete)

Structuring of the pictorial space: indeterminate

Patron saint(s): none

Gesture of the patron saint(s): not applicable 
Type of religious scene: indeterminate

Religious scene(s) depicted: none

Cat. 709-Type 6A

[RKD work no. 8584]

VAN HEEMSKERCK, Maarten (circle of)

Two Wings. A Family in Prayer (c. 1550)

$59 \times 46 \mathrm{~cm}$ (each wing)

Stockholm, sale Stockholms Auktionsverk (6 June 1996), lot no. 189

Identity of the sitter(s): unknown

Provenance: unknown

Number of portrait(s): 8

Type of person(s): lay (family)

Attitude of the sitter(s): hands clasped, particular gesture

Representation of the sitter(s): full-length

Gaze of the sitter(s): indeterminate

Object(s): yes (prie-dieu, book, rosary)

Coat(s) of arms: no

Environment: indeterminate

Structuring of the pictorial space: indeterminate

Patron saint(s): none

Gesture of the patron saint(s): not applicable

Type of religious scene: indeterminate

Religious scene(s) depicted: none

Cat. 710-Type 2A

VAN HEMESSEN, Jan

Triptych of the Last Judgement ('Rockox

Triptych') (c. 1536-1537)

$98.5 \times 97.5 \mathrm{~cm}$ (centre panel) and 98.5

$\times 48.5 \mathrm{~cm}$ (wings)

Antwerp, church of St. James

BIBL.: FRIEDLÄNDER XII, no. 175;

WALLEN 1971, no. 17; WALLEN 1983, 84-86.

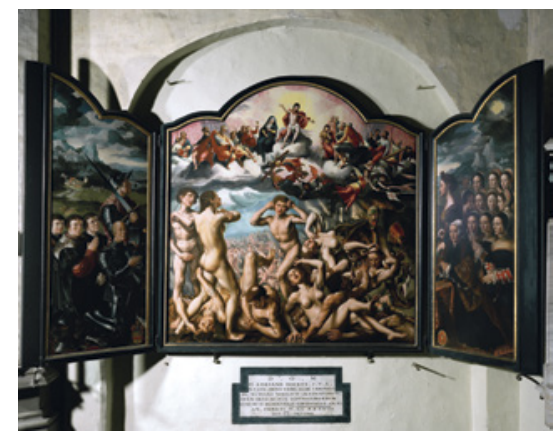

HISTORICAL INFORMATION: The triptych was commissioned by Adriaen Rockox, around 1536-1537, and was destined for the Rockox chapel in the church of St. James at Antwerp, where it is still preserved today. The patron, 
who belonged to one of the wealthiest families of Antwerp, appears with his wife Catharina van Overhoff and their children. Their sons are named Jan, Nicholas and Adriaen. One of their daughters, Anna, is portrayed in profile. She died in 1535, at the age of twenty-five. Her portrait is thus posthumous.

Identity of the sitter(s): Adriaen Rockox, Catharina van Overhoff and their children

Provenance: Antwerp, church of St. James, Rockox chapel

Number of portrait(s): 15

Type of person(s): lay (family)

Attitude of the sitter(s): hands clasped

Representation of the sitter(s): full-length

Gaze of the sitter(s): into space, towards the scene

Object(s): yes (prie-dieu, book, helmet)

Coat(s) of arms: yes

Environment: historical setting

Structuring of the pictorial space: distinct spaces

Patron saint(s): Adrian, Catherine

Gesture of the patron saint(s): holding his/her attribute

Type of religious scene: narrative

Religious scene(s) depicted: the Last Judgement, Christ and the Virgin as intercessors

Cat. 711-Type $3^{D}$

VAN LATHEM, Lieven (follower of)

The Virgin and Child with Saints and a Couple in Prayer (c. 1490-1500)

$18.5 \times 15 \mathrm{~cm}$

Baden Baden, Bilgrey collection

Identity of the sitter(s): unknown

Provenance: unknown

Number of portrait(s): 2

Type of person(s): lay (couple)

Attitude of the sitter(s): hands clasped

Representation of the sitter(s): full-length, small scale

Gaze of the sitter(s): into space

Object(s): no

Coat(s) of arms: no

Environment: enclosed garden 
Structuring of the pictorial space: not applicable

Patron saint(s): none

Gesture of the patron saint(s): not applicable

Type of religious scene: hieratic

Religious scene(s) depicted: the Virgin and Child, St. Francis, St. John, the Virgin and Child with St. Anne, St. Catherine, St. Barbara, a saint bishop, an unidentified saint

\section{Cat. 712-Type $3 \mathrm{D}$}

VAN LATHEM, Lieven (follower of)

The Virgin and Child with Saints and a Man in Prayer (c. 1500)

$27.1 \times 20.4 \mathrm{~cm}$

London, NG, inv. no. NG 1939

вIB L.: CAMPBELL 1998, 293-99 (with bibl.). HISTORICAL INFORMATION: The identification of the sitter has caused some problems. His collar indicates that he is a knight of the Order of the Golden Fleece. The Burgundian emblem (flint, steel and sparks), painted above the window, suggests that he is a Duke

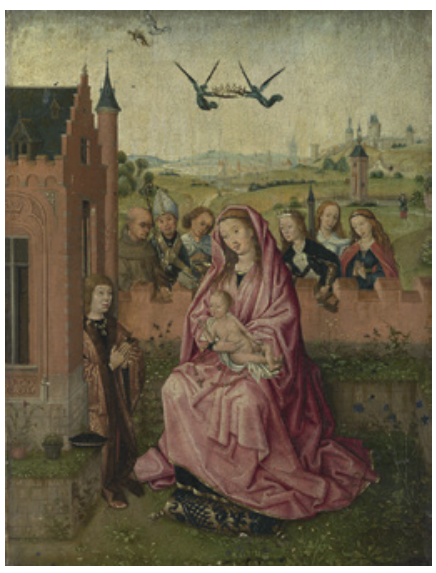
of Burgundy. The fashion of his clothes (around 1500) suggests that he is Philip the Fair. Nevertheless, the coat of arms (visible in the underdrawing only) is not that of Philip the Fair, but of the Clugny family. Taking into account the fact that no member of the Clugny family ever became a member of the Order of the Golden Fleece, Campbell suggests that the painting was begun for a member of that family and was eventually finished for Philip the Fair.

Identity of the sitter(s): Philip the Fair (originally a member of the Clugny Family?)

Provenance: unknown

Number of portrait(s): 1

Type of person(s): lay (man alone)

Attitude of the sitter(s): hands clasped

Representation of the sitter(s): full-length

Gaze of the sitter(s): towards the scene

Object(s): yes (hat, collar of the Order of the Golden Fleece)

Coat(s) of arms: no 
Environment: enclosed garden

Structuring of the pictorial space: not applicable

Patron saint(s): none

Gesture of the patron saint(s): not applicable

Type of religious scene: hieratic

Religious scene(s) depicted: the Virgin and Child, St. Francis, St. Lazarus, St. John, St. Catherine, St. Barbara, St. Margaret

Cat. 713-Type 2A

VAN LEYDEN, Aertgen (circle of)

Triptych of the Resurrection of Christ with a Couple in Prayer and Patron Saints (c. 1500-1550) $116.1 \times 76.5$ (centre panel) and $113.3 \times$ $30.5 \mathrm{~cm}$ (wings)

Kansas City, Nelson-Atkins Museum of Art, inv. no. 38.4 A

BIBL.: Mus. cat. Kansas City 2005,

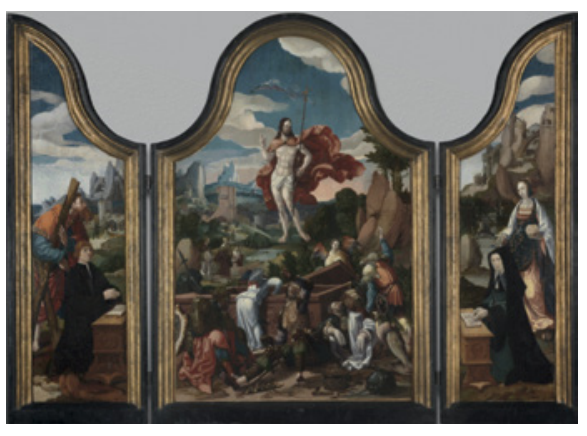

no. 19; Exh. cat. Leiden 2011, no. 125a (with bibl.).

Identity of the sitter(s): unknown

Provenance: unknown

Number of portrait(s): 2

Type of person(s): lay (couple)

Attitude of the sitter(s): hands clasped, holding a book

Representation of the sitter(s): full-length

Gaze of the sitter(s): into space, towards the viewer

Object(s): yes (prie-dieu, book)

Coat(s) of arms: no

Environment: historical setting

Structuring of the pictorial space: continuous space

Patron saint(s): Andrew, Mary Magdalen

Gesture of the patron saint(s): introducing, holding his/her attribute

Type of religious scene: narrative

Religious scene(s) depicted: the Resurrection of Christ 
Cat. 714-Type 6A

VAN ORLEY, Bernard

One Wing. A Man in Prayer with St. Michael

(c. 1500-1550)

$146 \times 84 \mathrm{~cm}$

Munich, Alte Pinakothek, inv. no. WAF 744

BIB L.: FRIEDLÄNDER VIII, no. 122.

Identity of the sitter(s): unknown

Provenance: unknown

Number of portrait(s): 1

Type of person(s): lay (man alone)

Attitude of the sitter(s): hands clasped

Representation of the sitter(s): full-length

Gaze of the sitter(s): indeterminate

Object(s): no

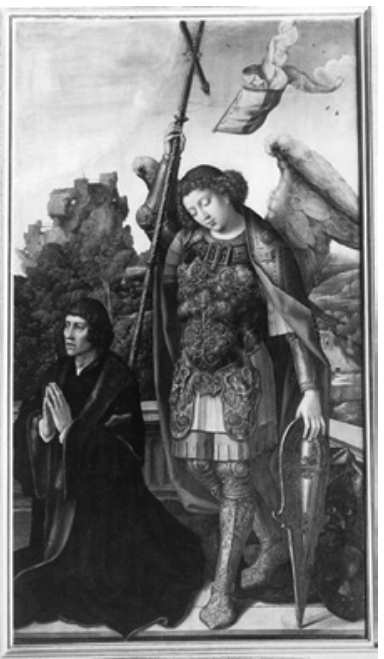

Coat(s) of arms: no

Environment: landscape, no sacred connotation (incomplete)

Structuring of the pictorial space: indeterminate

Patron saint(s): Michael

Gesture of the patron saint(s): holding his/her attribute

Type of religious scene: indeterminate

Religious scene(s) depicted: none

\section{Cat. 715-Type 6B}

VAN ORLEY, Bernard

Portrait of Marie Haneton in Prayer (c. 1522)

$72.4 \times 54.6 \mathrm{~cm}$

Edinburgh, National Gallery of Scotland, inv. no. 1895

BIBL.: FRIEDLÄNDER VIII, no. $15^{2}$.

HISTORICAL INFORMATION: The young woman has been identified as Marie Haneton, on the basis of her coat of arms painted on the reverse. Her blazon is accompanied by that of her husband,

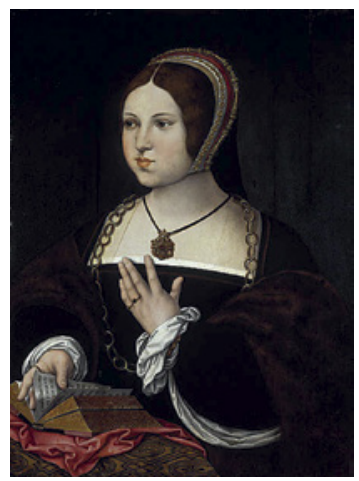
Lambert du Briaerd, and an inscription stating her name, and the date of her death (22 August 1525). She was then nineteen years old. Marie is the daughter of Philippe Haneton and Marguerite Numan (see cat. 718). 
Identity of the sitter(s): Marie Haneton

Provenance: unknown

Number of portrait(s): 1

Type of person(s): lay (woman alone)

Attitude of the sitter(s): particular gesture

Representation of the sitter(s): half-length

Gaze of the sitter(s): indeterminate

Object(s): yes (book)

Coat(s) of arms: yes (on the reverse)

Environment: neutral space (incomplete)

Structuring of the pictorial space: indeterminate

Patron saint(s): none

Gesture of the patron saint(s): not applicable

Type of religious scene: indeterminate

Religious scene(s) depicted: none

Cat. 716-Type $3 \mathrm{C}$

VAN ORLEY, Bernard

The Lamentation with a Woman in Prayer (c. 1500-1550)

Size unknown

Whereabouts unknown

BIBL.: FRIEDLÄNDER VIII, no. 116.

Identity of the sitter(s): unknown

Provenance: unknown

Number of portrait(s): 1

Type of person(s): lay (woman alone)

Attitude of the sitter(s): hands clasped

Representation of the sitter(s): full-length

Gaze of the sitter(s): towards the scene

Object(s): no

Coat(s) of arms: no

Environment: historical setting

Structuring of the pictorial space: not applicable

Patron saint(s): none

Gesture of the patron saint(s): not applicable

Type of religious scene: narrative

Religious scene(s) depicted: the Lamentation

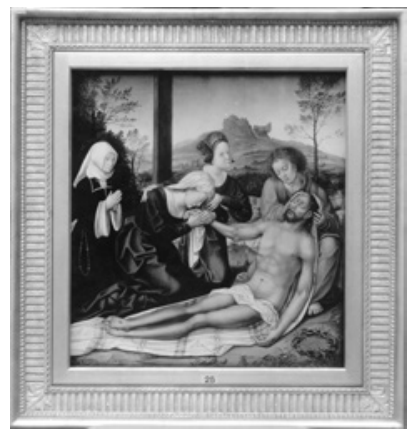


Cat. 717-Type $3 \mathrm{C}$

[Link to the Friedländer 3.o Database]

VAN ORLEY, Bernard

The Lamentation with a Woman in Prayer (c. 1500-1550)

Size unknown

Whereabouts unknown

BIBL.: FRIEDLÄNDER VIII, no. 117.

Identity of the sitter(s): unknown

Provenance: unknown

Number of portrait(s): 1

Type of person(s): lay (woman alone)

Attitude of the sitter(s): hands clasped

Representation of the sitter(s): full-length

Gaze of the sitter(s): towards the scene

Object(s): yes (prie-dieu, book)

Coat(s) of arms: yes

Environment: historical setting

Structuring of the pictorial space: not applicable

Patron saint(s): none

Gesture of the patron saint(s): not applicable

Type of religious scene: narrative

Religious scene(s) depicted: the Lamentation

Cat. 718-Type 2A

VAN ORLEY, Bernard

Triptych of the Lamentation ('Haneton

Triptych') (c. 1500-1522)

$87 \times 108.5 \mathrm{~cm}$ (centre panel) and $87 \times$ $48 \mathrm{~cm}$ (wings)

Brussels, MRBAB, inv. no. $35^{8}$

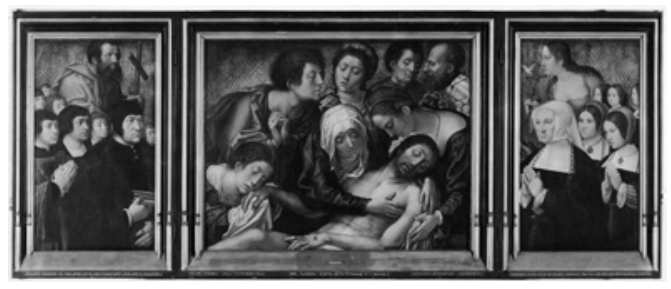

BIB L.: FRIEDLÄNDER VIII, no. 86; FARMER 1981, 167-70; Mus. cat. Brussels 1984, 218; GALAND 2013, 236-61 (with bibl.).

Historical INFORMATION: Philippe Haneton started his political career at the Grand conseil of Mechelen, as secretary of the Audiencier Gerard Numan. Later, he married Numan's daughter, Marguerite, with whom he had twelve children. His union with Marguerite Numan allowed him to enter the highest sphere of the Habsburgian administration. In 1494, Philippe was made secretary to the Grand conseil, before being appointed Audiencier and first secretary 
of the Netherlands, in 1499. In 1506, he was appointed Guardian of the charters of Flanders and, from 1519 onwards, he was Treasurer of the Order of the Golden Fleece. Philippe also made a diplomatic career. He joined in the negotiations for the marriage of Charles $\mathrm{V}$ and Claude of France. In 1505, he was also appointed executor of Philip the Fair's will. Philippe Haneton died in 1522 and was buried in the chapel of the Holy Sacrament at the collegiate church of Sts Michael and Gudula. Marguerite Numan died in 1531 and was buried next to her husband. In 1763, G. P. Mensaert saw the Haneton Triptych in the entrance of the choir of the Blessed Sacrament chapel. The triptych was thus the memorial work of the couple. Their daughter Marie is also portrayed in cat. 715 .

Identity of the sitter(s): Philippe Haneton, Marguerite Numan and their children

Provenance: Brussels, church of Sts Michaels and Gudula, Blessed Sacrament chapel

Number of portrait(s): 14

Type of person(s): mixed (family with children)

Attitude of the sitter(s): hands clasped, holding a book

Representation of the sitter(s): half-length

Gaze of the sitter(s): towards the scene

Object(s): yes (book)

Coat(s) of arms: no

Environment: neutral space

Structuring of the pictorial space: continuous space

Patron saint(s): Philip, Margaret

Gesture of the patron saint(s): holding his/her attribute

Type of religious scene: narrative

Religious scene(s) depicted: the Lamentation, the Annunciation

Cat. 719-Type 1D

VAN ORLEY, Bernard

Triptych of the Legends of St. Thomas and St. Matthias (c. 1512)

$140 \times 880 \mathrm{~cm}$ (centre panel) and $80 \mathrm{~cm}$ $\times 138.5 \mathrm{~cm}$ (wings)

Vienna, Kunsthistorisches Museum, inv. no. 992 (centre panel) and Brussels, мRBAB, inv. nos $1435^{-1436}$ (wings)

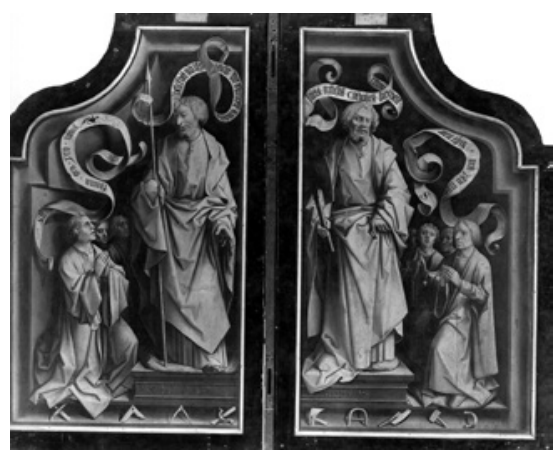


BIBL.: FRIEDLÄNDER VIII, no. 82; FARMER 1981, 50-6o; HENDRIKMAN 1999; GALAND 2013, 146-71 (with bibl.).

HISTORICAL INFORMATION: The identification of the portrayed persons has provoked much discussion. It has long been assumed that they were members of the Brussels masons and carpenters' Guild. Nevertheless, in 1988, Janssens discovered archival documents of the church Notre-Dame-du-Sablon refuting this hypothesis. On the basis of a close identification of the tools painted in the lower part of the outer wings, he identified the sitters as members of the Brussels joiners and coopers' Guild. In all likelihood, the triptych was destined for Notre-Dame-du-Sablon. Indeed, in the late fifteenth century, a bishop consecrated all the altars of the church, and one of them was dedicated to St. Thomas and St. Matthias. Between 1623 and 1628, the traveller DubuissonAubenay located the altarpiece in this church and described it: "au costé droit et sous la ['] il y a une chapelle où y a, sur l'autel de St. Matthieu et St...., une Histoire des deus saints où y a des temples et perspectives excellentes." See HALKIN 1946, 62.

Identity of the sitter(s): Guild of the Brussels joiners and coopers

Provenance: Brussels, church Notre-Dame-du-Sablon, altar of the joiners and coopers' Guild

Number of portrait(s): 7

Type of person(s): lay (group: association)

Attitude of the sitter(s): hands clasped

Representation of the sitter(s): full-length

Gaze of the sitter(s): towards the scene

Object(s): yes (banderole, tools)

Coat(s) of arms: yes

Environment: niche

Structuring of the pictorial space: continuous space, grisaille

Patron saint(s): none

Gesture of the patron saint(s): not applicable

Type of religious scene: hieratic

Religious scene(s) depicted: the Legends of St. Thomas and St. Matthias 
Cat. 720-Type 6A

VAN ORLEY, Bernard

Two Wings. Episodes of the Legend of St.

John the Baptist (c. 1514)

$65 \times 76 \mathrm{~cm}$ (each panel)

New York, MET, inv. no. 2001.216.3 and private collection

BIBL.: FRIEDLÄNDER VIII, no. 92; Mus. cat. Kansas City 2005, 20712 (with bibl.); Sale cat. Sotheby's (London, 9 July 2008), no. 7; GALAND

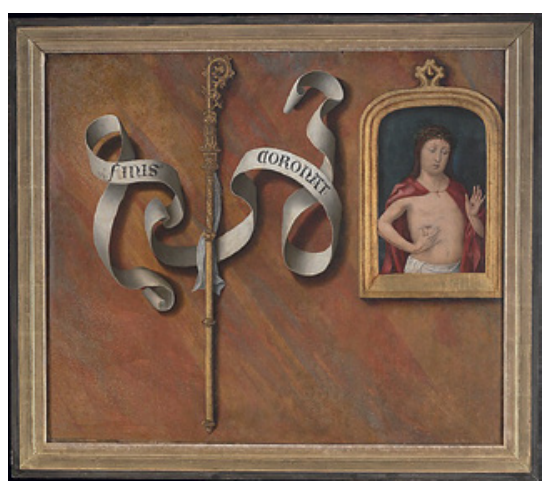
2013, 51-52.

HISTORICAL INFORMATION: These panels come from an altarpiece, dedicated to St. John the Baptist and commissioned by Jacques Coëne for the church of the Benedictine monastery of Marchiennes (on Jacques Coëne, see cat. 234, cat. 721 and cat. 741). In 1515, the abbot founded five altars in the church, dedicated to St. Andrew, St. John the Baptist, St. Sebastian, St. Nicaise and St. Martin. The altarpiece from which the panels come was probably destined for one of these altars. The reverse of the panels shows a crosier, a banderole with the abbot's motto (FINIS CORONAT) and Jacques' own portrait within a fictive frame.

Identity of the sitter(s): Jacques Coëne

Provenance: Benedictine abbey of Marchiennes, abbey church

Number of portrait(s): 1

Type of person(s): religious (man alone: Benedictine abbot)

Attitude of the sitter(s): hands clasped

Representation of the sitter(s): half-length

Gaze of the sitter(s): indeterminate

Object(s): no

Coat(s) of arms: yes

Environment: framed

Structuring of the pictorial space: indeterminate

Patron saint(s): none

Gesture of the patron saint(s): not applicable

Type of religious scene: narrative

Religious scene(s) depicted: the Beheading of St. John the Baptist, the Birth of St. John the Baptist, the Man of Sorrows in a fictive frame 
Cat. 721-Type 6A

VAN ORLEY, Bernard

Two Wings. Episodes of the Legend of St. Martin (c. 1514)

$69.2 \times 75.6 \mathrm{~cm}$ (left panel) and $69 \times$ $75 \mathrm{~cm}$ (right panel)

Kansas City, Nelson-Atkins Museum of Art, inv. no. inv. no. 53-59 and London, sale Sotheby's (7 July 2010), lot no. 3

BIBL.: FRIEDLÄNDER VIII, no. 92;

Mus. cat. Kansas City 2005, no. 15

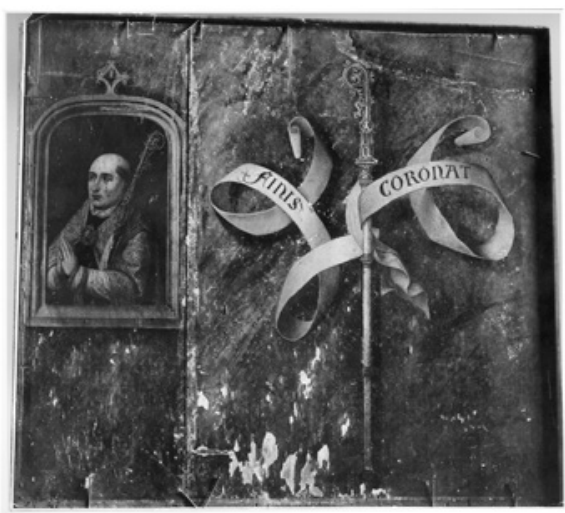
(with bibl.); Sale cat. Sotheby's (London, 7 July 2010), no. 3; GALAND 2013, 51. HISTORICAL INFORMATION: These panels come from an altarpiece dedicated to St. Martin and commissioned by Jacques Coëne for the church of the Benedictine monastery of Marchiennes (on Jacques Coëne, see cat. 234, cat. 720 and cat. 741). The reverse of one of the panels shows a crosier, a banderole with the abbot's motto (FINIS CORONAT) and his portrait within a fictive frame. In 1515, the abbot founded five altars dedicated to St. Andrew, St. John the Baptist, St. Sebastian, St. Nicaise and St. Martin within the abbey church. The altarpiece from which these panels come was probably destined for one of these altars.

Identity of the sitter(s): Jacques Coëne (?)

Provenance: Benedictine abbey of Marchiennes, abbey church

Number of portrait(s): 1

Type of person(s): religious (man alone: Benedictine abbot)

Attitude of the sitter(s): hands clasped

Representation of the sitter(s): half-length

Gaze of the sitter(s): indeterminate

Object(s): yes (crosier)

Coat(s) of arms: yes

Environment: framed

Structuring of the pictorial space: indeterminate

Patron saint(s): none

Gesture of the patron saint(s): not applicable

Type of religious scene: narrative

Religious scene(s) depicted: St. Martin adoring the Virgin and Child with St. Peter, St. Agnes, St. Mary Magdalen and St. Anthony (?), the Knighting of St. Martin by the Emperor Constantine, the Virgin and Child in a fictive frame 
Cat. 722-Type 6A

VAN ORLEY, Bernard

Two Wings. St. Helena before the Pope

in Rome; Charlemagne Depositing the Passion Relics at the Cathedral of Aachen (reverse: Carrying of the Cross; a Canon in Prayer) (c. 1510-1520) $103.4 \times 95.5 \mathrm{~cm}$ (each wing)

Brussels, MRBAB, inv. no. 4999 (left wing) and Turin, Galleria Sabauda, inv.

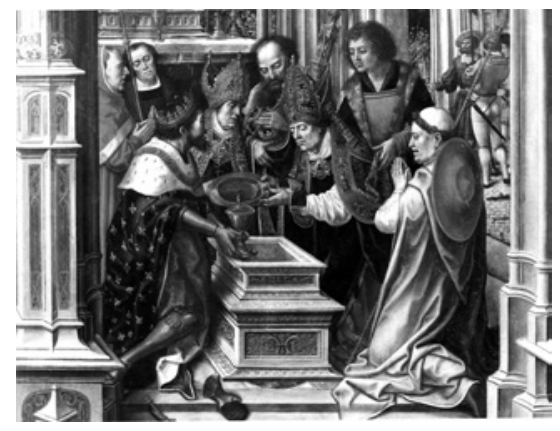
no. 317 (right wing)

BIBL.: FRIEDLÄNDER VIII, no. 99; GALAND 2013, 172-97 (with bibl.). HISTORICAL INFORMATION: The Turin panel was cleaned in 2010 and it revealed the portrait of a canon kneeling at a prie-dieu in front of the Bearing of the cross. The prie-dieu was covered by a cloth with an inscription: Dni Petri Du Viez (...) canonici (qda) huius (...) (see GALAND 2013, 179). One can thus deduce that the canon was called Pieter or Pierre. However, the state of preservation of the coat of arms painted on the prie-dieu does not allow any identification. It has long been assumed that this panel comes from an altarpiece commissioned in 1515 by the Brotherhood of the Holy Cross at Veurne. Galand has nonetheless demonstrated that this hypothesis is not valid.

Identity of the sitter(s): unknown

Provenance: unknown

Number of portrait(s): 1

Type of person(s): religious (man alone: canon)

Attitude of the sitter(s): hands clasped

Representation of the sitter(s): full-length

Gaze of the sitter(s): towards the scene

Object(s): yes (prie-dieu, book)

Coat(s) of arms: yes

Environment: neutral space (incomplete)

Structuring of the pictorial space: continuous space

Patron saint(s): none

Gesture of the patron saint(s): not applicable

Type of religious scene: narrative

Religious scene(s) depicted: Christ bearing the cross, St. Helena before the pope in Rome, Charlemagne depositing the Passion relics at the cathedral of Aachen 
Cat. 723-Type 6A

VAN ORLEY, Bernard

Two Wings. The Ascension of Christ, the Descent of the Holy Spirit (c. 1525-1530)

$95.3 \times 110 \mathrm{~cm}$ (each wing)

Raleigh, North Carolina Museum of Art, inv. nos. 52.9.89-9o

BIBL.: FARMER 1981, 254-55; BRUIJNEN 2000-2001, 101-04.

Identity of the sitter(s): unknown

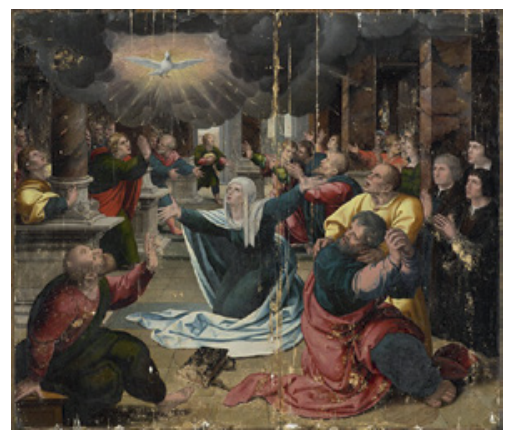

Provenance: unknown

Number of portrait(s): 6

Type of person(s): mixed (unidentified group)

Attitude of the sitter(s): hands clasped

Representation of the sitter(s): full-length

Gaze of the sitter(s): indeterminate

Object(s): no

Coat(s) of arms: no

Environment: historical setting

Structuring of the pictorial space: indeterminate

Patron saint(s): none

Gesture of the patron saint(s): not applicable

Type of religious scene: narrative

Religious scene(s) depicted: the Descent of the Holy Spirit, the Ascension

\section{Cat. 724 -Type $4 \mathrm{D}$}

[Link to the Friedländer 3.o Database]

VAN ORLEY, Bernard (after)

Diptych of Margaret of Austria (c. 1518)

$24 \times 18 \mathrm{~cm}$

Ottawa, National Gallery of Canada (right wing), inv. no. 28531

BIBL.: FRIEDLÄNDER VIII, no. 133, (133); PEARSON 2001-2002; PEARSON 2005, 162-91; Exh. cat. Mechelen 2005, no. 104 (with bibl.).

HISTORICAL INFORMATION: Margaret of Austria (see cat. 405) is portrayed as the Regent of the Low Countries and as a widow, in accordance with her official portraits. This diptych is a copy from a lost work of Bernard van Orley, usually dated around 1518 . 
Identity of the sitter(s): Margaret of Austria

Provenance: unknown

Number of portrait(s): 1

Type of person(s): lay (woman alone)

Attitude of the sitter(s): particular gesture

Representation of the sitter(s): half-length

Gaze of the sitter(s): towards the scene

Object(s): yes (book)

Coat(s) of arms: no

Environment: domestic setting

Structuring of the pictorial space: continuous space

Patron saint(s): none

Gesture of the patron saint(s): not applicable

Type of religious scene: hieratic

Religious scene(s) depicted: the Virgin and Child

Cat. 725-Type 3 A

[Link to the Friedländer 3.o Database]

VAN ORLEY, Bernard (after)

Triptych of the Crucifixion with a Man in Prayer and Patron Saint (c. 1500-1550)

$64 \times 45.5 \mathrm{~cm}$ (centre panel) and $65 \times 18.5 \mathrm{~cm}$ (wings)

Madrid, Museo Arqueologico Nacional, inv. no. 51.978

BIB L.: FRIEDLÄNDER VIII, no. 88a; Repertory Spain I, no. 12 (with bibl.).

Identity of the sitter(s): unknown

Provenance: unknown

Number of portrait(s): 1

Type of person(s): lay (man alone)

Attitude of the sitter(s): hands clasped

Representation of the sitter(s): full-length

Gaze of the sitter(s): towards the scene

Object(s): yes (banderole)

Coat(s) of arms: yes (on the reverse)

Environment: historical setting

Structuring of the pictorial space: not applicable

Patron saint(s): an angel

Gesture of the patron saint(s): introducing

Type of religious scene: narrative

Religious scene(s) depicted: the Crucifixion, Christ bearing the cross, the Descent from the cross 
Cat. 726-Type $1 B$

VAN ORLEY, Bernard (and workshop) Polyptych of the Life and Death of the Virgin (dated 1520)

$120 \mathrm{~cm} \times 332 \mathrm{~cm}$ (open)

Brussels, Musée du Centre public d'aide sociale (CPAS)

BIBL.: FRIEDLÄNDER VIII, no. 84; Mus. cat. Brussels 1950, 29, 37-39; FARMER 1981, 99, 245-48 (with bibl.); Exh. cat. Brussels 1994, no. 100.

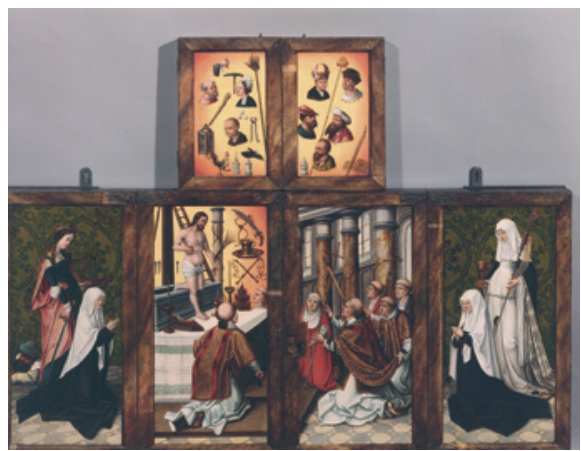

HistoricAl INFORMATION: Archival sources testify that this polyptych comes from the infirmary of the Grand Béguinage in Brussels, also known as the Béguinage Notre-Dame-de-la-Vigne. The dedication of the béguinage explains the theme of the polyptych, focused on the Virgin. On the basis of the archives and the patron saints, the two beguines have been identified as Catherine Smets, the mistress of the infirmary, and Gertrude Suetrocx, the mistress of the cellar.

Identity of the sitter(s): Catherine Smets and Gertrude Suetrocx

Provenance: Brussels, Grand Béguinage

Number of portrait(s): 2

Type of person(s): religious (group: Beguines)

Attitude of the sitter(s): hands clasped

Representation of the sitter(s): full-length

Gaze of the sitter(s): towards the ground

Object(s): no

Coat(s) of arms: no

Environment: architectural space with sacred connotation

Structuring of the pictorial space: unified space with discontinuities

Patron saint(s): Catherine, Gertrude

Gesture of the patron saint(s): holding his/her attribute

Type of religious scene: narrative

Religious scene(s) depicted: the Life and Death of the Virgin, the Mass of St. Gregory 
Cat. 727-Type 6A

[RKD work no. 35990]

VAN ORLEY, Bernard (circle of)

Fragment. A Monk in Prayer with Patron Saint (c. 1515-1525)

$108.5 \times 81 \mathrm{~cm}$

s'Heerenberg, Huis Bergh, inv. no. 0211-0070

Identity of the sitter(s): unknown

Provenance: unknown

Number of portrait(s): 1

Type of person(s): religious (man alone: Carmelite monk)

Attitude of the sitter(s): holding a book

Representation of the sitter(s): full-length

Gaze of the sitter(s): indeterminate

Object(s): yes (book)

Coat(s) of arms: no

Environment: niche

Structuring of the pictorial space: indeterminate

Patron saint(s): an unidentified saint

Gesture of the patron saint(s): holding his/her attribute

Type of religious scene: indeterminate

Religious scene(s) depicted: none

Cat. 728-Type 5

VAN ORLEY, Bernard (circle of)

Triptych of the Crucifixion with

Three Men in Prayer (c. 1500-1550)

$140 \times 130 \mathrm{~cm}$ (centre panel) and

$143 \times 57 \mathrm{~cm}$ (wings)

Cologne sale Lempertz

(22 November 2008), lot no. 1328

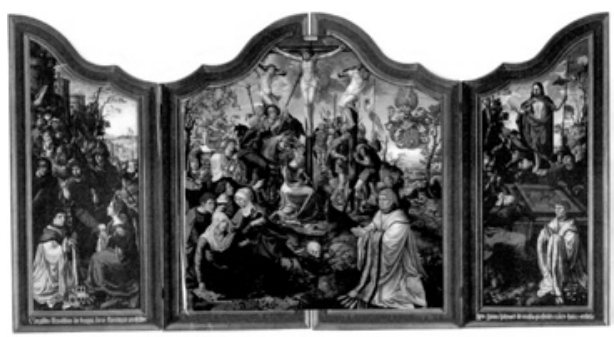

(centre panel) and Cologne, Priesterseminar (wings)

BIB L.: Sale cat. Lempertz (Vienna, 22 November 2008), no. 1328.

HISTORICAL INFORMATION: The reconstruction of this triptych is proposed in the catalogue of the Lempertz sale of 2008. Now held at the Seminary of Cologne, the wings come from the church of St. Maria ad Gradus in Cologne, which was destroyed in 1817. They bear inscriptions that identify the sitters: Arnold von Tongern, canon of St. Maria ad Gradus, professor of theology and rector of the University of Cologne from $15^{20}$ to 1525 , is depicted on the left wing. Johannes Hilpoet von Neuss, also a canon of St. Maria ad Gradus, 
is depicted on the right wing. The canon portrayed on the centre panel has not been identified. The coat of arms painted above him seems to be a later addition.

Identity of the sitter(s): Arnold von Tongern, Johannes Hilpoet von Neuss and an unknown man

Provenance: Cologne, church of St. Maria ad Gradus

Number of portrait(s): 3

Type of person(s): religious (group: canons)

Attitude of the sitter(s): hands clasped

Representation of the sitter(s): full-length

Gaze of the sitter(s): into space

Object(s): no

Coat(s) of arms: no

Environment: historical setting

Structuring of the pictorial space: not applicable

Patron saint(s): none

Gesture of the patron saint(s): not applicable

Type of religious scene: narrative

Religious scene(s) depicted: the Crucifixion

Cat. 729-Type $3 \mathrm{~A}$

VAN ORLEY, Bernard (circle of) (or anonymous South Netherlandish Master)

The Lamentation with a Family in Prayer and Patron Saints (c. 1525)

$111 \times 142.5 \mathrm{~cm}$

Brussels, MRBAB, inv. no. 333

BIBL.: GALAND 2013, 374-85 (with bibl.).

Identity of the sitter(s): unknown

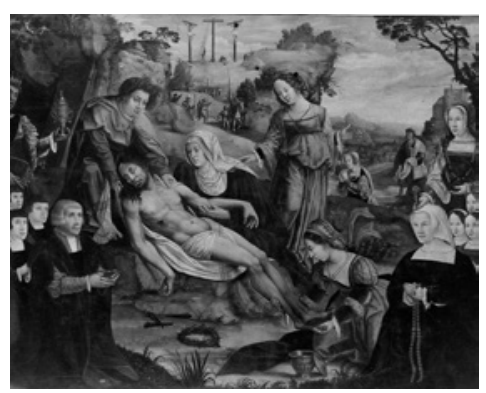

Provenance: unknown

Number of portrait(s): 8

Type of person(s): lay (family)

Attitude of the sitter(s): hands clasped, holding a book, holding a rosary

Representation of the sitter(s): full-length

Gaze of the sitter(s): into space

Object(s): yes (rosary, book)

Coat(s) of arms: no

Environment: historical setting

Structuring of the pictorial space: not applicable 
Patron saint(s): Caspar (?), Catherine

Gesture of the patron saint(s): holding his/her attribute

Type of religious scene: narrative

Religious scene(s) depicted: the Lamentation

Cat. 730-Type $3^{B}$

VAN ORLEY, Bernard (follower of)

The Virgin and Child with St. Francis and Hernán Gómez Dávila in Prayer

(c. 1500-1550)

$60 \times 78 \mathrm{~cm}$

Madrid, Museo Nacional del Prado, inv. no. P1934

BIB L.: FRIEDLÄNDER VIII, no. 132a;

Mus. cat. Madrid 1991, no. 943 .

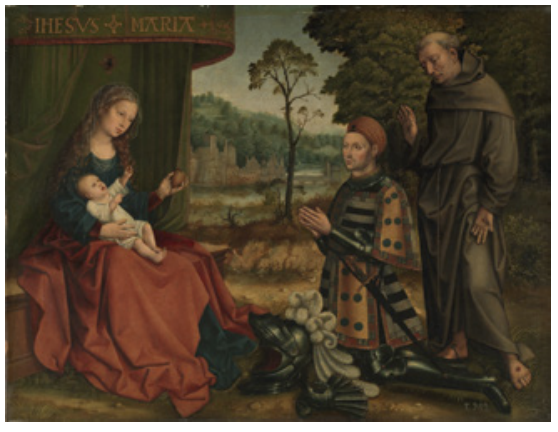

HISTORICAL INFORMATION: According to the entry for the painting in the museum catalogue, published in 1873, the work comes from the chapel of the Dávila family, in the convent of St. Francis in Avila. The sitter is also identified as Hernán Gómez Dávila, who was buried in this chapel. The identification has since been reaffirmed.

Identity of the sitter(s): Hernán Gómez Dávila

Provenance: Avila, convent of St. Francis, Dávila chapel

Number of portrait(s): 1

Type of person(s): lay (man alone)

Attitude of the sitter(s): hands clasped

Representation of the sitter(s): full-length

Gaze of the sitter(s): towards the scene

Object(s): yes (helmet, sword, gloves)

Coat(s) of arms: no

Environment: landscape with sacred connotation

Structuring of the pictorial space: not applicable

Patron saint(s): Francis

Gesture of the patron saint(s): holding his/her attribute

Type of religious scene: hieratic

Religious scene(s) depicted: the Virgin and Child 
Cat. 731-Type 6A

VAN OUWATER, Albrecht (attributed to)

Fragment. A Man in Prayer (c. 146o)

$9.8 \times 8.9 \mathrm{~cm}$

New York, MET, inv. no. 17.190.22

BIBL.: FRIEDLÄNDER III, no. 10; AINSWORTH and CHRISTIANSEN 1998, 158-59 (with bibl.).

Identity of the sitter(s): unknown

Provenance: unknown

Number of portrait(s): 1

Type of person(s): indeterminate

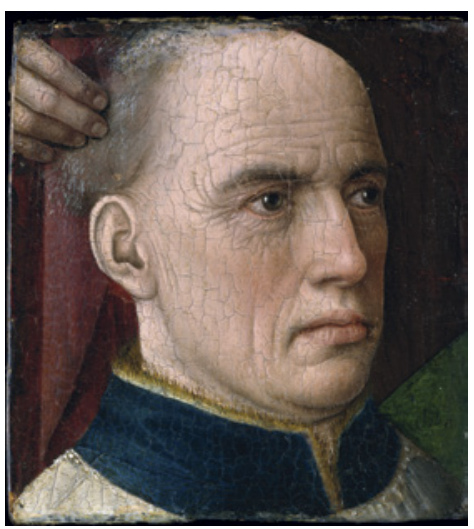

Attitude of the sitter(s): indeterminate

Representation of the sitter(s): indeterminate

Gaze of the sitter(s): indeterminate

Object(s): indeterminate

Coat(s) of arms: indeterminate

Environment: indeterminate

Structuring of the pictorial space: indeterminate

Patron saint(s): an unidentified saint

Gesture of the patron saint(s): indeterminate

Type of religious scene: indeterminate

Religious scene(s) depicted: none

Cat. $73^{2}$-Type $4 \mathrm{D}$

VAN SCOREL, Jan

Diptych of the Virgin and Child with a Man in Prayer

(c. 1527-1530)

$65 \times 44 \mathrm{~cm}$ (each wing)

Berlin, Staatliche Museen zu Berlin, Gemäldegalerie, inv. no. 644B (left wing) and Tambov, Kartinaja Galeria, inv. no. 13 (right wing)

BIBL.:FRIEDLÄNDERXII, no. 362; HOOGEWERFF IV, 163-64; Exh. cat. Antwerp and Washington 2006, no. 33 (with bibl.).

Identity of the sitter(s): unknown

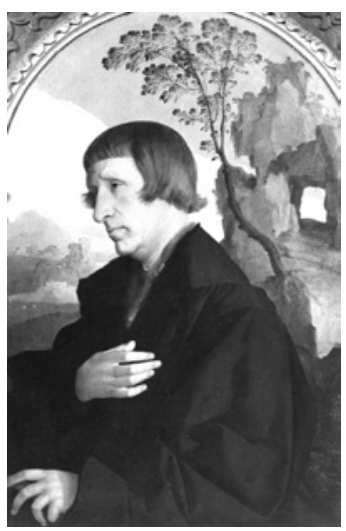

Provenance: unknown

Number of portrait(s): 1

Type of person(s): lay (man alone) 
Attitude of the sitter(s): particular gesture

Representation of the sitter(s): half-length

Gaze of the sitter(s): towards the scene

Object(s): no

Coat(s) of arms: no

Environment: landscape with sacred connotation

Structuring of the pictorial space: continuous space

Patron saint(s): none

Gesture of the patron saint(s): not applicable

Type of religious scene: hieratic

Religious scene(s) depicted: the Virgin and Child, Lucretia

Cat. 733-Type 6B

[RKD work no. 24381]

VAN SCOREL, Jan

Portrait of Isabelle van Grijpskerke in Prayer (c. 1550)

$65.5 \times 51.5 \mathrm{~cm}$

Delft, Museum Prinsenhof

BIBL.: HOOGEWERFF IV, 178-80.

HISTORICAL INFORMATION: Isabella Nicolaesdr. van Grijpskerke was the mother superior of the St. Aechten convent in Delft between 1537 and 1557, the year of her death. She was the sister of the poet Johannes Secundus.

Identity of the sitter(s): Isabella Nicolaesdr. van Grijpskerke

Provenance: unknown

Number of portrait(s): 1

Type of person(s): religious (woman alone)

Attitude of the sitter(s): holding a rosary

Representation of the sitter(s): half-length

Gaze of the sitter(s): indeterminate

Object(s): yes (rosary)

Coat(s) of arms: no

Environment: neutral space (incomplete)

Structuring of the pictorial space: indeterminate

Patron saint(s): none

Gesture of the patron saint(s): not applicable

Type of religious scene: indeterminate

Religious scene(s) depicted: none 
Cat. 734 -Type ${ }_{3} \mathrm{C}$

VAN SCOREL, Jan

The Lamentation with a Canon in Prayer (c. 1535) $166.5 \times 138 \mathrm{~cm}$

Utrecht, Centraal Museum, inv. no. 175

BIBL.: FRIEDLÄNDER XII, no. 323; Exh. cat. Utrecht and Douai 1977, no. 49; Exh. cat. Amsterdam 1986, no. 108; Mus. cat. Utrecht 2011, no. 25 (with bibl.).

HISTORICAL INFORMATION: This panel has been linked to the description in a 1646 chronicle

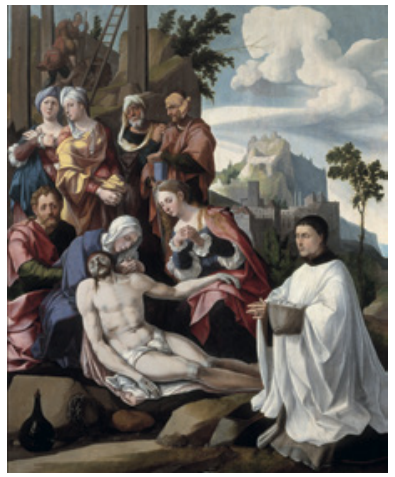
of a painting, executed by Jan van Scorel and depicting the Lamentation (a painting in which de Heer Jesus Christus vanden kruyce wierdt ghenomen). In the seventeenth century, this painting was placed on the altar of the St. Peter and St. Paul's chapel at the church of St.John (Janskerk) in s'Hertogenbosch. As stated by Faries in the museum catalogue (2011), this link between the actual painting and the description of the chronicle cannot be established with any certainty.

Identity of the sitter(s): unknown

Provenance: s'Hertogenbosch, church of St. John, St. Peter and St. Paul's chapel (?)

Number of portrait(s): 1

Type of person(s): religious (man alone: canon)

Attitude of the sitter(s): hands clasped

Representation of the sitter(s): full-length

Gaze of the sitter(s): towards the scene

Object(s): no

Coat(s) of arms: no

Environment: historical setting

Structuring of the pictorial space: not applicable

Patron saint(s): none

Gesture of the patron saint(s): not applicable

Type of religious scene: narrative

Religious scene(s) depicted: the Lamentation 


\section{Cat. 735-Type $1 B$}

[RKD work no. 8274]

Van Scorel, Jan

Triptych of the Entry in Jerusalem ('Lokhorst Triptych') (c. 1526)

$79 \times 146.8 \mathrm{~cm}$ (centre panel), $81.3 \times 65.5 \mathrm{~cm}$ (right wing) and $81.5 \times 65.6 \mathrm{~cm}$ (left wing)

Utrecht, Centraal Museum, inv. nos. 6o78a and 7991

BIBL.: FRIEDLÄNDER XII, no. 296, supp. 416; Exh. cat. Amsterdam 1986, no. 61; Mus. cat. Utrecht 2011, no. 22 (with bibl.).

HISTORICAL INFORMATION: The triptych is dated from $1526-1527$. The inscriptions on its outer wings and Karel van Mander's description make this a well-documented work. The triptych was the memorial painting of Herman van Lokhorst, as indicated by the inscriptions: Qve lavisse pedes tersisse vnxisseq[ve] sacros o mvlier, lachrimis crinibvs atq[ve] rosa // Diceris, officio redimens tva crimina pvlchro //Me[m] braq[ve] sic $D[$ omi] ni contvmvlanda notans // Decano Lochorst pete femina $s[$ an $] c[t]$ a qvietem Sacrv $[m]$ qvi magno fu $[n] d a t$ amore tibi. // Esset Wernervs svbita nisi morte peremptvs Tvtata $h v[n] c$ virt [vs] imperiosa foret. Obiit Herman [n]vs VIII idvs // Augvsti M CCCC XXVIII // Obiit III Cal. Octob M CCCC I (=) (left wing); Ghisbertus lochorst iaceo scolasticus antro si bene qvid servi nu[n]c bona messis erit. // Hern[n]nus de Lochorst sacri Salvatoris templi traiecten[sis] decanvs atq[ve] nvperhvivs sacre svmme edis // canonicvs amoris ac pietatis stvdio erga agnatos in medio ecclesie sepvltos statvam // pictvramq[ve] restavrari cvravit an $[n]$ o post virginevm partvm MD XXVI. an[n]o Christi M CCCC L IIII (right wing). The triptych was destined for the cathedral of Utrecht. In 1526, Jan van Scorel was living in Utrecht, at Herman van Lokhorst's house. Herman was the Dean of the church of St. Saviour and a canon of the cathedral of Utrecht. He died in 1527. He commissioned the triptych shortly before his death, in order to place it above his parents' grave, where he also wanted to be buried. Three ancestors of Herman van Lokhorst are depicted next to him: Herman and Werner van Lokhorst appear on the left outer wing and Gysbert van Lokhorst on the right outer wing. The third person has not been identified. It could be Jacob or Gerrit van Lokhorst. One can notice that St. Cornelius is modelled on the pope Adrian vi on the inner left wing. Identity of the sitter(s): Herman van Lokhorst and his ancestries (Herman, Gysbert and Werner Lokhorst)

Provenance: Utrecht, cathedral

Number of portrait(s): 6

Type of person(s): mixed (family) 
Attitude of the sitter(s): hands clasped

Representation of the sitter(s): full-length

Gaze of the sitter(s): into space

Object(s): no

Coat(s) of arms: no

Environment: celestial space

Structuring of the pictorial space: continuous space, religious scene in a cloud

Patron saint(s): John the Baptist, Thomas or Matthew, John the Evangelist, Anne, a saint bishop

Gesture of the patron saint(s): introducing

Type of religious scene: narrative

Religious scene(s) depicted: the Entry in Jerusalem, St. Agnes, St. Cornelius, St. Anthony, St. Sebastian, St. Christopher, St. Gertrude, the Coronation of the Virgin

Cat. 736-Type 6A

[RKD work no. 236589]

VAN SCOREL, Jan

Two Wings. A Family in Prayer (c. 1500-1550)

$88.5 \times 26.5 \mathrm{~cm}$ (each wing)

Zürich, sale Koller (27 March 2009), lot no. 3005

Identity of the sitter(s): unknown

Provenance: unknown

Number of portrait(s): 10

Type of person(s): lay (family with children)

Attitude of the sitter(s): hands clasped, particular gesture

Representation of the sitter(s): half-length

Gaze of the sitter(s): indeterminate, towards the viewer

Object(s): yes (crucifix)

Coat(s) of arms: yes

Environment: architectural space, no sacred connotation (incomplete)

Structuring of the pictorial space: indeterminate

Patron saint(s): none

Gesture of the patron saint(s): not applicable

Type of religious scene: indeterminate

Religious scene(s) depicted: Adam and Eve 
Cat. 737 - Type $3^{B}$

VAN SCOREL, Jan (after)

Epitaph of Pieter van Suchtelen (after 1539)

$100 \times 82 \mathrm{~cm}$

Zutphen, Stedelijk Museum, inv. no. P 1756

BIBL.: DOORNINK-HOOGENRAAD 1965;

Exh. cat. Nijmegen 1975-1976, no. 7; Mus. cat. Zutphen 1991, 83; Exh. cat. Kevelaer 2000-2001, no. III-104 (with bibl.).

HISTORICAL INFORMATION: Pieter van Suchtelen was born in 1487 and died around 1522. He was the son of Johan van Suchtelen

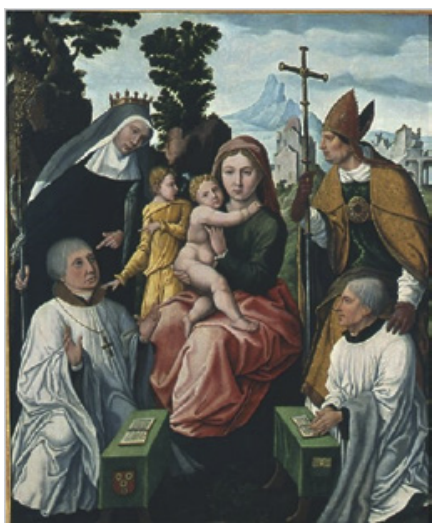
and Gertken ter Stege. He was a canon and then Dean of the chapter of St. Walburgis in Zutphen. He is portrayed on the left and has been identified by his coat of arms. The identity of the other canon remains unknown. He might be Johannes ten Oever. For a complete biography of Suchtelen, see GROUSTRA 2006.

Identity of the sitter(s): Pieter van Suchtelen and Johannes ten Oever (?)

Provenance: Zutphen, church of St. Walburgis (?)

Number of portrait(s): 2

Type of person(s): religious (group: canons)

Attitude of the sitter(s): holding a book, hands held up

Representation of the sitter(s): full-length

Gaze of the sitter(s): towards the scene

Object(s): yes (prie-dieu, book)

Coat(s) of arms: yes

Environment: landscape, no sacred connotation

Structuring of the pictorial space: not applicable

Patron saint(s): Walburga, an unidentified saint

Gesture of the patron saint(s): introducing

Type of religious scene: hieratic

Religious scene(s) depicted: the Virgin and Child 
Cat. 738 -Type $3 \mathrm{D}$

VAN SCOREL, Jan (attributed to)

The Virgin and Child with a Couple in

Prayer (c. 1530)

$55.5 \times 76.2 \mathrm{~cm}$

Madrid, Fundación Colección Thyssen-

Bornemisza, inv. no. 1930.104

BIBL.: FRIEDLÄNDER XII, no. 329b;

EISLER 1989, no. 41; Exh. cat. Utrecht 2000, no. B-2 (with bibl.).

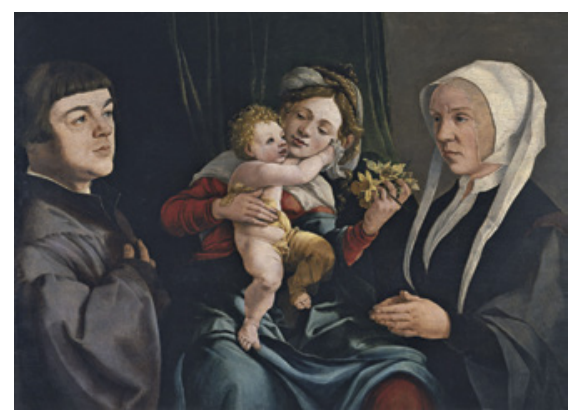

Identity of the sitter(s): unknown

Provenance: unknown

Number of portrait(s): 2

Type of person(s): lay (couple)

Attitude of the sitter(s): hands clasped, particular gesture

Representation of the sitter(s): half-length

Gaze of the sitter(s): into space, towards the scene

Object(s): no

Coat(s) of arms: no

Environment: neutral space

Structuring of the pictorial space: not applicable

Patron saint(s): none

Gesture of the patron saint(s): not applicable

Type of religious scene: hieratic

Religious scene(s) depicted: the Virgin and Child

Cat. 739-Type 2 B

[RKD work no. 19756]

VAN SCOREL, Jan (attributed to)

Triptych of the Virgin and Child with St. Anne and a Couple in Prayer with Patron

Saints (c. 1530)

$89 \times 58.2 \mathrm{~cm}$ (centre panel) and $88.5 \times 22.7 \mathrm{~cm}$ (wings)

Belgium, collection of E. Loncke

BIBL.: Sale cat. Sotheby's (London, 8 July 1999), no. 47 (with bibl.); Exh. cat. Utrecht 2000, no. A4.

HISTORICAL INFORMATION: The coats of arms painted on the outer wings have not been identified with certainty. They could be those of one of the following families: the Van Berchems, the Berthouts, the Van Helmonds or the Van Mechelens. 
Identity of the sitter(s): unknown

Provenance: unknown

Number of portrait(s): 2

Type of person(s): lay (couple)

Attitude of the sitter(s): hands clasped

Representation of the sitter(s): half-length

Gaze of the sitter(s): into space

Object(s): no

Coat(s) of arms: yes (on the reverse)

Environment: landscape with sacred connotation

Structuring of the pictorial space: continuous space

Patron saint(s): unidentified saints

Gesture of the patron saint(s): introducing, holding his/her attribute

Type of religious scene: hieratic

Religious scene(s) depicted: the Virgin and Child

\section{Cat. 740-Type $1 \mathrm{D}$}

VAN SCOREL, Jan (workshop of?)

Triptych of the Crucifixion (c. 1527-1529)

$130 \times 166 \mathrm{~cm}$ (centre panel) and $130 \times 48 \mathrm{~cm}$ (wings)

Utrecht, Museum Catharijneconvent, inv. no. ABM S 331

BIBL.: Exh. cat. Utrecht 1955, no. 29; Exh. cat. Utrecht and Douai 1977, no.45; Mus. cat. Utrecht 2002, 85-87 (with bibl.).

Identity of the sitter(s): unknown
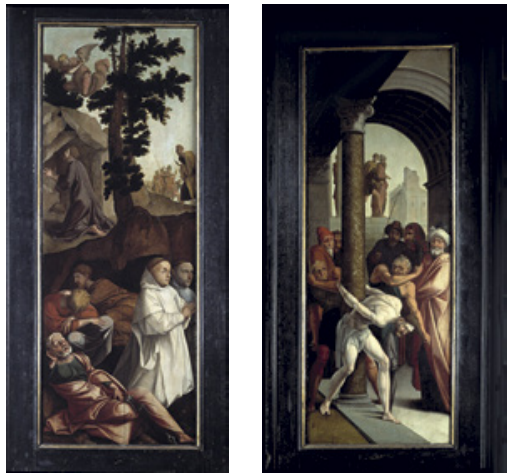

Provenance: Utrecht, charterhouse of Nieuwlicht (?)

Number of portrait(s): 2

Type of person(s): religious (group: Carthusian monks)

Attitude of the sitter(s): hands clasped

Representation of the sitter(s): full-length

Gaze of the sitter(s): into space

Object(s): no

Coat(s) of arms: no

Environment: historical setting

Structuring of the pictorial space: distinct spaces

Patron saint(s): none

Gesture of the patron saint(s): not applicable 
Type of religious scene: narrative

Religious scene(s) depicted: the Crucifixion, the Flagellation

\section{Cat. 741-Type 6A}

VAN SCOREL, Jan (workshop of)

One Wing. St. Ursula and the Eleven Thousand Virgins; Portrait of Jacques Coëne in Prayer (reverse) (dated 1539)

$193 \times 77 \mathrm{~cm}$

Douai, Musée de la Chartreuse, inv. no. 2856

BIB L.: Exh. cat. Utrecht and Douai 1977, no. 32.

HISTORICAL INFORMATION: On Jacques Coëne, see cat. 234. He also appears in cat. 720 and cat. 721 .

Identity of the sitter(s): Jacques Coëne

Provenance: Benedictine abbey of Marchiennes (?)

Number of portrait(s): 1

Type of person(s): religious (man alone: Benedictine abbot)

Attitude of the sitter(s): hands clasped

Representation of the sitter(s): half-length

Gaze of the sitter(s): towards the viewer

Object(s): no

Coat(s) of arms: no

Environment: framed

Structuring of the pictorial space: indeterminate

Patron saint(s): none

Gesture of the patron saint(s): not applicable

Type of religious scene: indeterminate

Religious scene(s) depicted: St. Ursula and the eleven thousand virgins

\section{Cat. 742-Type $2 B$}

[R KD work no. 27510]

VAN SCOREL, Jan (workshop of)

Triptych of the Holy Family ('Stoop Triptych') (c. 1523-1537)

$76 \times 69.5 \mathrm{~cm}$ (centre panel) and $76 \times 27 \mathrm{~cm}$ (wings)

The Netherlands, private collection

BIB L.: FRIEDLÄNDER XII, no. 297; HOOGEWERFF IV, 129; Exh. cat. Utrecht 1999-2000, 94, 275; Exh. cat. Utrecht 2000, no. B-3 (with bibl.).

Historical INFORMATION: The sitters are Willem Stoop Adriaensz., Adrianna Gerritsdr. van Roon and their children. This family was established 
in Dordrecht, where Willem was alderman and burgomaster. He died in 1537. According to Hoogewerff, the triptych was a memorial work destined for the Grote Kerk of Dordrecht, but he did not cite his sources for this assertion.

Identity of the sitter(s): Willem Adriaansz. Stoop, Adriana Gerritsdr. Roon and their children

Provenance: unknown

Number of portrait(s): 19

Type of person(s): mixed (family)

Attitude of the sitter(s): hands clasped

Representation of the sitter(s): full-length

Gaze of the sitter(s): towards the scene

Object(s): yes (prie-dieu, book)

Coat(s) of arms: yes

Environment: landscape, no sacred connotation

Structuring of the pictorial space: distinct spaces

Patron saint(s): John the Baptist, Mary Magdalen

Gesture of the patron saint(s): holding his/her attribute

Type of religious scene: hieratic

Religious scene(s) depicted: the Holy Family

\section{Cat. 743-Type 6A}

VAN UTRECHT, Jacob

The Dead Christ with a Couple in

Prayer (c. 1525)

$54.5 \times 175.5 \mathrm{~cm}$

Enschede, Rijksmuseum Twenthe,

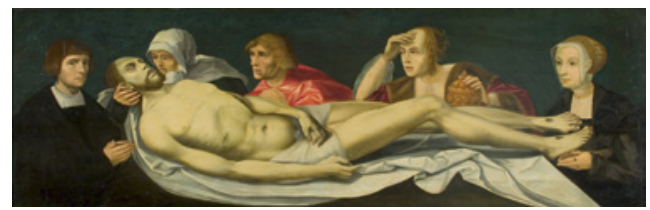

inv. no. 45

BIB L.: Mus. cat. Enschede, no. 97 (with bibl.).

Identity of the sitter(s): unknown

Provenance: unknown

Number of portrait(s): 2

Type of person(s): lay (couple)

Attitude of the sitter(s): hands clasped

Representation of the sitter(s): half-length

Gaze of the sitter(s): into space

Object(s): no

Coat(s) of arms: no

Environment: neutral space

Structuring of the pictorial space: not applicable

Patron saint(s): none 
Gesture of the patron saint(s): not applicable

Type of religious scene: hieratic

Religious scene(s) depicted: the Dead Christ

Cat. 744-Type ${ }_{3} \mathrm{C}$

VAN UTRECHT, Jacob

The Nativity with a Man in prayer (c. 1515)

$62.9 \times 47.8 \mathrm{~cm}$

London, sale Christie's (4 December 2013), lot no. 119

BIB L.: Sale cat. Christie's (London, 4 December 2013), no. 119.

Identity of the sitter(s): unknown

Provenance: unknown

Number of portrait(s): 2

Type of person(s): lay (couple)

Attitude of the sitter(s): hands clasped

Representation of the sitter(s): full-length

Gaze of the sitter(s): towards the scene

Object(s): no

Coat(s) of arms: no

Environment: historical setting

Structuring of the pictorial space: not applicable

Patron saint(s): none

Gesture of the patron saint(s): not applicable

Type of religious scene: narrative

Religious scene(s) depicted: the Nativity

Cat. 745-Type 2A

VAN UTRECHT, Jacob

Triptych of the Annunciation with a

Couple in Prayer and Patron Saints

(c. 1525)

$136 \times 94 \mathrm{~cm}$ (centre panel)

London, sale Christie's (5 July 2011),

lot no. 5

BIBL.: HOOGEWERFF III, 66-70;

Sale cat. Christie's (London, 5 July

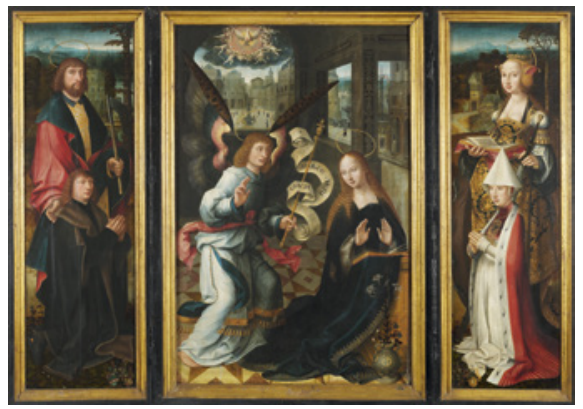
2011), no. 5 .

HistoriCAL INFORMATION: The sitters are Herman Plönnies and Ida Greverade. They were wealthy patricians of Lübeck. Herman made a political 
career in this town. According to Hoogewerff, who nevertheless did not cite any sources, the triptych was their memorial work.

Identity of the sitter(s): Herman Plönnies and Ida Greverade

Provenance: unknown

Number of portrait(s): 2

Type of person(s): lay (couple)

Attitude of the sitter(s): hands clasped

Representation of the sitter(s): full-length

Gaze of the sitter(s): towards the viewer

Object(s): no

Coat(s) of arms: yes

Environment: historical setting

Structuring of the pictorial space: distinct spaces

Patron saint(s): Matthew, Catherine

Gesture of the patron saint(s): introducing, holding his/her attribute

Type of religious scene: narrative

Religious scene(s) depicted: the Annunciation, St. Christopher, St. Anthony

Cat. 746-Type $2 \mathrm{C}$

VANDERCOUTHEREN, Jan

Altarpiece of St. Stephen (1522)

$113 \times 470 \mathrm{~cm}$ (open), oil on wood and carved piece

Korbeek-Dijle, church of St. Bartholomew BIBL.: PERIER D'IETEREN and GESCHEKONING 2000, 125-32.

HISTORICAL INFORMATION: The archives

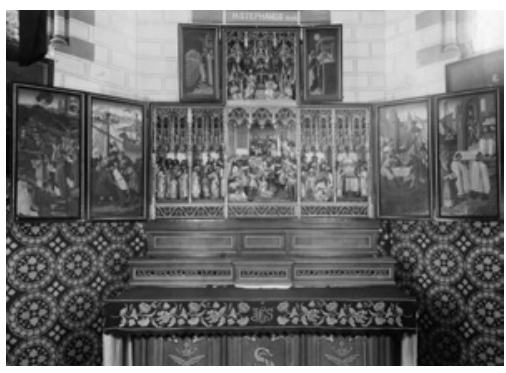

of Leuven retain two documents related to the commission and the delivery of this altarpiece to the church of St. Bartholomew at Korbeek-Dijle. The contract, dating from 28 July 1522, states that the altarpiece had been commissioned by the churchwardens and the priest, Egide Stevens, to the painter Jan Vandercoutheren. The name of the sculptor who executed the centre piece is not mentioned. Vandercoutheren had to deliver the work fourteen days before Christmas. A second document, dating from 5 August 1522, invites the painter and three members of his family to fulfil the contract. The priest depicted on the left wing has thus been identified as Egide Stevens.

Identity of the sitter(s): Egide Stevens

Provenance: Korbeek-Dijle, church of St. Bartholomew

Number of portrait(s): 1 
Type of person(s): religious (man alone: priest)

Attitude of the sitter(s): hands clasped

Representation of the sitter(s): full-length

Gaze of the sitter(s): into space

Object(s): no

Coat(s) of arms: no

Environment: historical setting

Structuring of the pictorial space: distinct spaces (different techniques: painting/sculpture)

Patron saint(s): none

Gesture of the patron saint(s): not applicable

Type of religious scene: narrative

Religious scene(s) depicted: the Life of St. Stephen

\section{Cat. 747}

VERMEYEN, Jan

Diptych (?) of Erard de la Marck (c. 1530)

$64 \times 54.5 \mathrm{~cm}$ (right wing) and $63.5 \times 54 \mathrm{~cm}$ (left wing)

Haarlem, Frans Hals Museum, inv. no. 683 (left wing) and Amsterdam Rijksmuseum, inv. no. SK-A-4069 (right wing)

BIBL.: FRIEDLÄNDER XII, no. 390, supp. 417; Exh. cat. Antwerp and Washington 2006, no. 35; BAGLEY-YOUNG 2008; Mus. cat. Amsterdam 2009 [online], https:// www.rijksmuseum.nl/nl/collectie/SK-A-

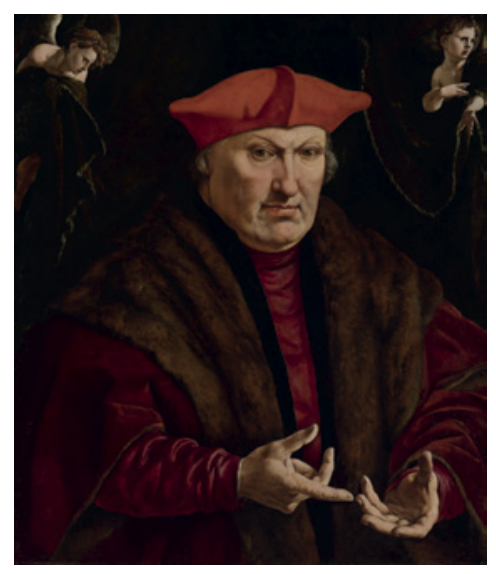
4069/catalogus-entry (with bibl.).

HistoriCAL INFORMATION: Erard de la Marck (1472-1538) was the son of Robert de la Marck and Jeanne de Saulcy. He was the Prince-bishop of Liège from 1505 until his death in 1538 . He started his ecclesiastical career as a canon of the chapter of St. Lambert in Liège. He was then elected Bishop of Chartres in 1507, Archbishop of Valence in $15^{20}$ and cardinal in 1521. After a long period of coalition with the kingdom of France, he allied with Charles v in 1518 and became one of the privileged councillors of Margaret of Austria.

REMARK: There is much debate about this alleged Diptych of the Virgin and Child with Erard de la Marck. Many scholars assume that the two panels belong together, while others consider they do not form a united work. I opt and argue 
for this second option, notably taking into consideration the attitude of the sitter (see FALQUE 2012, 119-21).

Identity of the sitter(s): Erard de la Marck

Provenance: unknown

Number of portrait(s): 1

Type of person(s): religious (man alone: bishop)

Attitude of the sitter(s): particular gesture

Representation of the sitter(s): half-length

Gaze of the sitter(s): towards the viewer

Object(s): no

Coat(s) of arms: no

Environment: neutral space (incomplete)

Structuring of the pictorial space: indeterminate

Patron saint(s): none

Gesture of the patron saint(s): not applicable

Type of religious scene: indeterminate

Religious scene(s) depicted: none

Cat. 748 - Type $2 \mathrm{C}$

VERMEYEN, Jan

Triptych of the Raising of Lazarus

('Micault Triptych') (c. 1547-1549)

$145 \times 125 \mathrm{~cm}$ (centre panel) and

$151 \times 57 \mathrm{~cm}$ (wings)

Brussels, MRBAB, inv. no.

$679-385$

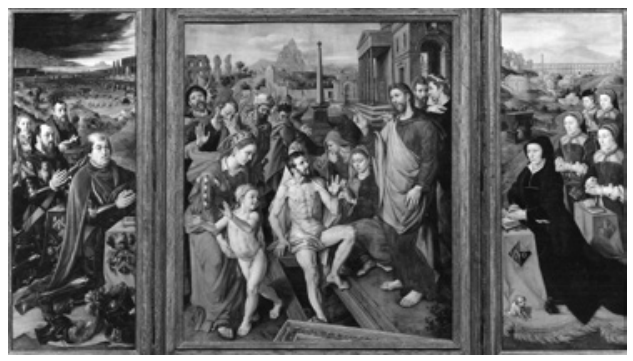

BIBL.: FRIEDLÄNDER XII, no. 388; VAN DEN BERGEN-PANTENS 1973; Mus. cat. Brussels 1984, 312; HORN 1989, 24, 29, 30, 35-37, 38, 82, 94-95 (with bibl.).

HISTORICAL INFORMATION: Jan Micault and his family have been identified, on the basis of their coats of arms. Jan Micault is mentioned in 1499, in the Comptes de la recette générale des finances, as working for Simon Longin. In 1506, he was made Argentier of Philip the Fair, and in 1507, he became Receveur général des finances of Charles v. He held this position until 1535. In 1522, he was made Treasurer of the Order of the Golden Fleece, before being knighted in 1524. He died in 1539 and was buried in the family chapel at the church of Sts Michael and Gudula. He married Livina Cats van Welle († 1547), with whom he had three sons and four daughters. Taking into consideration certain biographical elements, Christiane Van den Bergen dates the triptych to around 
1547-1549. Its original location was the St. Lazarus' altar in the chapel of the Holy Sacrament at the church of Sts Michael and Gudula. This altar was destroyed in 1622, during the construction of the tombstones of the Archdukes Albert and Isabella. Jan Micault and Livina Cats also appear in cat. 85 and cat. 341 .

Identity of the sitter(s):Jan Micault, Livina Cats van Welle, and their children Provenance: Brussels, church of Sts Michael and Gudula, chapel of the Blessed Sacrament

Number of portrait(s): 9

Type of person(s): lay (family with children)

Attitude of the sitter(s): hands clasped, holding a book

Representation of the sitter(s): full-length

Gaze of the sitter(s): towards the scene

Object(s): yes (prie-dieu, book, dog, hat, small cross)

Coat(s) of arms: yes

Environment: historical setting

Structuring of the pictorial space: distinct spaces

Patron saint(s): none

Gesture of the patron saint(s): not applicable

Type of religious scene: narrative

Religious scene(s) depicted: the Resurrection of Lazarus, the Annunciation

Cat. add. 1-Type $2 \mathrm{C}$

Anonymous Antwerp Master

Triptych of St. Luke Painting the Virgin with a Monk in Prayer (c. 1520-1530)

$44.1 \times 33 \mathrm{~cm}$ (centre panel), $44.2 \times 16.4$ $\mathrm{cm}$ (left wing) and $44 \times 16.1 \mathrm{~cm}$ (right wing)

Antwerp, the Phoebus Foundation

Identity of the sitter(s): unknown

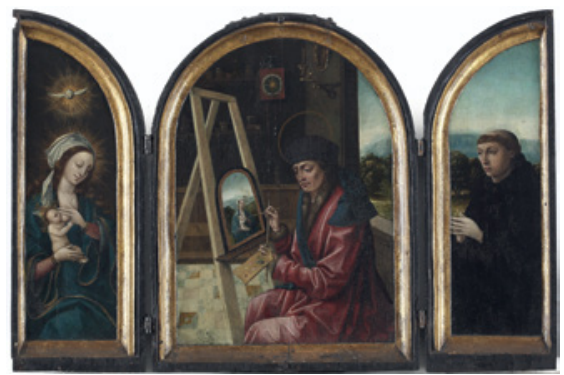

Provenance: unknown

Number of portrait(s): 1

Type of person(s): religious (man alone)

Attitude of the sitter(s): hands clasped

Representation of the sitter(s): half-length

Gaze of the sitter(s): towards the scene

Object(s): no

Coat(s) of arms: no 
Environment: indeterminate landscape (incomplete)

Structuring of the pictorial space: distinct spaces

Patron saint(s): none

Gesture of the patron saint(s): not applicable

Type of religious scene: narrative

Religious scene(s) depicted: St. Luke painting the Virgin

Cat. add. 2-Type $3^{B}$

Anonymous South Netherlandish Master

The Virgin and Child with Josse vanden Damme in Prayer and Patron saint (1484)

$74.5 \times 57.8 \mathrm{~cm}$

Cassel, Musée départemental de Flandre, inv. no. C.2009.2.1

HISTORICAL INFORMATION: The sitter has been identified as Josse vanden Damme (d. 16 May 1484), on the basis of the inscription in the lower part of the composition (Hier is begraven Joos Van den Damme, Galoicts Zone die stard in't Jaer duyst vierhondert viere ende tachtentich den sestiensten Dach van Meye. God hebbe zyn ziele Amen). According to the online information of the museum (which acquired the painting in 2009), the work was produced in Dendermonde, where the sitter lived, and was destined for a side-chapel of the church of Our Lady.

Identity of the sitter(s): Josse vanden Damme

Provenance: Dendermonde, church of Our Lady (?)

Number of portrait(s): 1

Type of person(s): lay (man alone)

Attitude of the sitter(s): hands clasped

Representation of the sitter(s): full-length

Gaze of the sitter(s): eyes closed

Object(s): no

Coat(s) of arms: yes

Environment: landscape with sacred connotation

Structuring of the pictorial space: not applicable

Patron saint(s): Barbara

Gesture of the patron saint(s): holding his/her attribute

Type of religious scene: hieratic

Religious scene(s) depicted: the Virgin and Child 
Cat. add. 3-Type 6A

DAVID, Gerard (circle of)

One wing. A Woman in Prayer with St. Anthony (c. 1500)

$88 \times 37 \mathrm{~cm}$

London, Victoria \& Albert Museum, inv. no. 528-1870

BIB L.: Mus. cat. London 1973, no. 81.

Identity of the sitter(s): unknown

Provenance: unknown

Number of portrait(s): 1

Type of person(s): religious (woman alone)

Attitude of the sitter(s): hands clasped

Representation of the sitter(s): half-length

Gaze of the sitter(s): indeterminate

Object(s): no

Coat(s) of arms: no

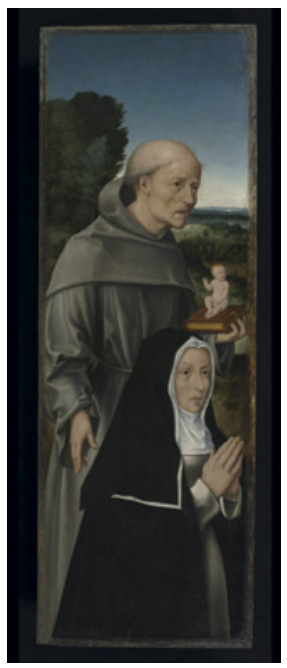

Environment: landscape with sacred connotation (incomplete)

Structuring of the pictorial space: indeterminate

Patron saint(s): Anthony

Gesture of the patron saint(s): Holding his/her attribute

Type of religious scene: indeterminate

Religious scene(s) depicted: none

Cat. add. 4-Type 6A

Master of 1518

One Wing. A Man in Prayer with the Prophet Daniel (c. 1515-1525)

$73.7 \times 68.6 \mathrm{~cm}$

New York, sale Christie's (27 April 2017), lot no. 101

Identity of the sitter(s): unknown

Provenance: unknown

Number of portrait(s): 1

Type of person(s): lay (man alone)

Attitude of the sitter(s): hands clasped

Representation of the sitter(s): full-length

Gaze of the sitter(s): indeterminate

Object(s): yes (prie-dieu, book)

Coat(s) of arms: yes 
Environment: indeterminate landscape (incomplete)

Structuring of the pictorial space: indeterminate

Patron saint(s): Daniel

Gesture of the patron saint(s): presenting

Type of religious scene: indeterminate

Religious scene(s) depicted: none

Cat. add. 5-Type $1 B$

Master of the Legend of St. Godelieve

Triptych of the Lamentation ('Van der Straeten Triptych') (c. 1490)

$97 \times 63.5 \mathrm{~cm}$ (centre panel) and $97 \times 24 \mathrm{~cm}$ (wings)

Bruges, Church of Our Lady

BIBL.: HAVERKAMP-BEGEMANN 1955, 187-92; MARTENS D. 1992, 151-53.

HISTORICAL INFORMATION: The sitters have been identified by James Weale as Josse van der Straeten, Margaretha van Rye and their children, on the basis of the coats of arms painted on the reverse. A Bruges citizen who held the position of alderman

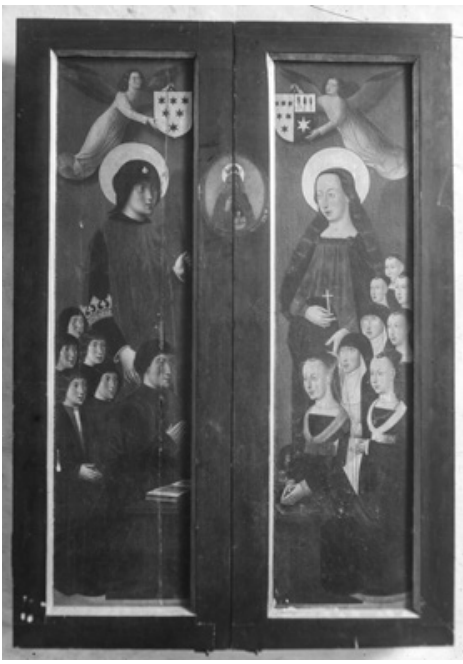
of the city several times, Josse died on 2 August 1490 and was buried in the church of Our Lady. He also twice occupied the position of kerkmeester of the same church. Margaretha died on 13 October 1502 and was buried in the church of the convent of the Poor Clares in Bruges. In the triptych, two of their daughters wear the Dominican habit. It is possible that the triptych was destined for the chapel in which Joos was buried in the church of Our Lady.

Identity of the sitter(s): Josse van der Straeten, Margaretha van Rye and their children

Provenance: Bruges, church of Our Lady (?)

Number of portrait(s): 14

Type of person(s): mixed (family with children)

Attitude of the sitter(s): hands clasped

Representation of the sitter(s): full-length

Gaze of the sitter(s): into space

Object(s): yes (prie-dieu, book, small cross)

Coat(s) of arms: yes

Environment: neutral space 
Structuring of the pictorial space: continuous space, religious scene in a cloud

Patron saint(s): Joos, Margaret

Gesture of the patron saint(s): holding his/her attribute

Type of religious scene: hieratic

Religious scene(s) depicted: the Trinity, the Lamentation

Cat. add. 6-Type 6A

Master of the Von Grote Adoration

Two Wings. A Family in Prayer with Patron Saints (c. 1500-1520)

$82.6 \times 30.9 \mathrm{~cm}$ (each wing)

London, sale Christie's (6 July 2018), lot no. 103

BIBL.: FRIEDLÄNDER XI, no. 31 .

Identity of the sitter(s): unknown

Provenance: unknown

Number of portrait(s): 13

Type of person(s): lay (family with children)

Attitude of the sitter(s): hands clasped

Representation of the sitter(s): full-length

Gaze of the sitter(s): indeterminate

Object(s): yes (rosary, small cross)

Coat(s) of arms: no

Environment: indeterminate landscape (incomplete)

Structuring of the pictorial space: indeterminate

Patron saint(s): Anthony, Catherine

Gesture of the patron saint(s): holding his/her attributes

Type of religious scene: not applicable

Religious scene(s) depicted: none 
Ingrid Falque - 9789004409736

Downloaded from Brill.com04/26/2023 02:23:27PM via free access 


\title{
Bibliography to the Catalogue
}

\author{
Reference Works
}

[Corpus Antwerp]

Mund, Hélène, Stroo, Cyriel and Goetghebeur, Nicole (with the collaboration of Hans Van Nieuwdorp), The Mayer van den Bergh Museum. Corpus of Fifteenth-Century Painting in the Southern Netherlands and the Principality of Liège, 20 (Brussels: 2003). [Corpus Beaune]

Veronée-Verhaegen, Nicole, L'Hôtel-Dieu de Beaune. Les Primitifs flamands. I. Corpus de la peinture des Pays-Bas méridionaux au quinzième siècle, 13 (Brussels: 1973).

[Corpus Bruges I]

Base-Dondeyne, M. and De Vos, Dirk, Musée communal des Beaux-Arts (Musée Groeninge) Bruges. Les Primitifs flamands. I. Corpus de la peinture des Pays-Bas méridionaux au quinzième siècle, 1 (Brussels: 1983).

[Corpus Dijon]

Comblen-Sonkes, Micheline (with the collaboration of Nicole Veronée-Verhaegen), Le Musée des Beaux-Arts de Dijon. Les Primitifs flamands. I. Corpus de la peinture des Pays-Bas méridionaux au quinzième siècle, 14 (Brussels: 1986).

[Corpus Granada]

Van Schoute, Roger, La chapelle royale de Grenade. Les Primitifs flamands. I. Corpus de la peinture des Pays-Bas méridionaux au quinzième siècle, 6 (Brussels: 1963).

[Corpus Institut de France]

Comblen-Sonkes, Micheline, Les musées de l'Institut de France. Musées JacquemartAndré et Marmottan à Paris, Musée Condé à Chantilly. Les Primitifs flamands. I. Corpus de la peinture des Pays-Bas méridionaux au quinzième siècle, 15 (Brussels: 1988).

[Corpus Leningrad]

Loewinson-Lessing, Vladimir and Nicouline, Nicolas, Le Musée de l'Ermitage. Leningrad. Les Primitifs flamands. I. Corpus de la peinture des Pays-Bas méridionaux au quinzième siècle, 8 (Brussels: 1965).

[Corpus Lille]

Châtelet, Albert and Goetghebeur, Nicole, Le Musée des Beaux-Arts de Lille. Corpus de la peinture du $X V^{e}$ siècle dans les Pays-Bas méridionaux et la Principauté de Liège, 21 (Brussels: 2006).

[Corpus Lisbon]

Lievens-De Waegh, Marie Léopoldine, Le Musée national d'art ancien et le Musée national des carreaux de faïnce de Lisbonne. Les Primitifs flamands. I. Corpus de la peinture des Pays-Bas méridionaux au quinzième siècle, 16 (Brussels: 1991). 
[Corpus London I]

Davies, Martin, The National Gallery London. I. Les Primitifs flamands. I. Corpus de la peinture des anciens Pays-Bas méridionaux au XV siècle, 3 (Antwerp: 1953).

[Corpus London II]

Davies, Martin, The National Gallery London. II. Les Primitifs flamands. I. Corpus de la peinture des anciens Pays-Bas méridionaux au XV siècle, 3 (Antwerp: 1954).

[Corpus London III]

Davies, Martin, The National Gallery London. III. Les Primitifs flamands. I. Corpus de la peinture des anciens Pays-Bas méridionaux au XVe siècle (Brussels: 1971).

[Corpus Leuven]

Comblen-Sonkes, Micheline, The Collegiate Church of Saint Peter Louvain. Corpus of Fifteenth-Century Painting in the Southern Netherlands and the Principality of Liège, 18 (Brussels: 1996).

[Corpus Los Angeles]

Wolfthal, Diane and Metzger, Catherine, Los Angeles Museums. Corpus of Early Netherlandish Painting, 22 (Brussels: 2014).

[Corpus Paris I]

Adhémar, Hélène, Le Musée national du Louvre. I. Les Primitifs flamands. I. Corpus de la peinture des anciens Pays-Bas méridionaux au XV siècle, 5 (Brussels: 1962).

[Corpus Paris II]

Comblen-Sonkes, Micheline and Lorentz, Philippe, Musée du Louvre. Paris. II. Corpus de la peinture des anciens Pays-Bas méridionaux et de la Principauté de Liège au quinzième siècle, 17 (Brussels: 1962).

[Corpus Paris III]

Comblen-Sonkes, Micheline and Lorentz, Philippe, Musée du Louvre. Paris. III. Corpus de la peinture des anciens Pays-Bas méridionaux et de la Principauté de Liège au quinzième siècle, 19 (Brussels: 2001).

[Corpus Melbourne]

Hoff, Ursula and Davie, Martin, The National Gallery of Victoria. Melbourne. Les Primitifs flamands. I. Corpus de la peinture des Pays-Bas méridionaux au quinzième siècle, 12 (Brussels: 1971).

[Corpus New England]

Eisler, Colin, New England Museums. Les Primitifs flamands. I. Corpus de la peinture des Pays-Bas méridionaux au quinzième siècle, 4 (Brussels: 1961).

[Corpus Palencia]

Vandevivere, Ignace, La cathédrale de Palencia et l'église paroissiale de Cervara de Pisuerga. I. Les Primitifs flamands. I. Corpus de la peinture des Pays-Bas méridionaux au quinzième siècle, 10 (Brussels: 1967). 
[Corpus Poland]

Bialostocki, Jan, Les musées de Pologne (Gdansk, Krakow, Warszawa). Les Primitifs flamands. I. Corpus de la peinture des Pays-Bas méridionaux au XVe siècle, 9 (Brussels: 1966).

[Corpus Turino]

Aru, C. and De Geradon, Et., La Galerie Sabauda de Turin. Les Primitifs flamands. I. Corpus de la peinture des Pays-Bas méridionaux au quinzième siècle, 5 (Antwerp: 1952).

[Corpus Urbino]

Lavalleye, Jacques, Le palais ducal d'Urbin. Les Primitifs flamands. I. Corpus de la peinture des Pays-Bas méridionaux au quinzième siècle, 7 (Brussels: 1964).

[FRIEDLÄNDER I-XIV (1st edition)]

Friedländer, Max J., Die altniederländische Malerei, 14 vols (Berlin and Leiden: 1924-1937).

[FRIEDLÄNDER I-XIV]

Friedländer, Max J., Early Netherlandish Painting, 14 vols (Leiden and Brussels: 1967-1976)

\section{[HOOGEWERFF I-V]}

Hoogewerff, Godefridus Johannes, De Noord-Nederlandsche Schilderkunst, 5 vols (The Hague: 1936-1947).

[Repertory Spain I]

Lavalleye, Jacques, Collections d'Espagne. I. Les Primitifs flamands. II. Répertoire des peintures flamandes des quinzième et seizième siècles, 1 (Antwerp: 1953).

[Repertory Spain II]

Lavalleye, Jacques, Collections d'Espagne. II. Les Primitifs flamands. II. Répertoire des peintures flamandes des quinzième et seizième siècles, 1 (Antwerp: 1958).

[Repertory Liège]

Allart, Dominique, Collections publiques de Liège. Les Primitifs flamands. II. Répertoire des peintures flamandes des quinzième et seizième siècles, 6 (Brussels: 2008).

[Repertory Nord-Pas-de-Calais]

Heck, Christian, Collections du Nord-Pas-de-Calais. La peinture de Flandre et de France du Nord au XVe et au début du XVI $I^{e}$ siècle. Les Primitifs flamands. II. Répertoire des peintures flamandes des quinzième et seizième siècles, 5, 2 vols (Brussels: 2005).

[Repertory Sicily]

Uyttebrouck, A., Collections d'Italie. I. Sicile. Les Primitifs flamands. II. Répertoire des peintures flamandes des quinzième et seizième siècles (Brussels: 1967).

[Repertory Czechoslovakia]

Vackova, Jarmila (with the collaboration of Micheline Comblen-Sonkes), Collections de Tchécoslovaquie. Les Primitifs flamands. II. Répertoire des peintures flamandes des quinzième et seizième siècles (Brussels: 1985). 


\section{Museums Catalogues}

[Mus. cat. Amsterdam 1976]

van Thiel, Pieter J. J., All the Paintings of the Rijksmuseum in Amsterdam (Amsterdam: 1976).

[Mus. cat. Amsterdam 2009 (online)]

Filedt Kok, Jan Piet (ed.), Early Netherlandish Paintings in the Rijksmuseum, Amsterdam (Amsterdam: 2009). https://www.rijksmuseum.nl/en/collection-catalogues/early -netherlandish-paintings.

[Mus. cat. Antwerp 1978]

De Coo, Jozef, Museum Mayer van den Bergh. Catalogus ı. Schilderijen, verluchte handschriften, tekeningen (Antwerp: 1978).

[Mus. cat. Antwerp 1985]

Vandenbroeck, Paul, Catalogus schilderkunst $14^{e}-15^{e}$ eeuw. Koninklijk Museum voor Schone Kunsten Antwerpen (Antwerp: 1985).

[Mus. cat. Antwerp 1998]

Vandamme, Erik, Catalogus schilderkunst oude meesters. Koninklijk Museum voor Schone Kunsten-Antwerpen (Antwerp: 1988).

[Mus. cat. Berlin 1996]

Bock, Henning, Gemäldegalerie Berlin. Gesamtverzeichnis (Berlin: 1996).

[Mus. cat. Bonn 1927]

Provinzialmuseum in Bonn. Katalog der Gemäldegalerie (Bonn: 1927).

[Mus. cat. Brussels 1950]

Le patrimoine artistique de l'Assistance publique de Bruxelles (Brussels: 1950).

[Mus. cat. Brussels 1984]

Musées royaux des Beaux-Arts de Belgique. Département d'art Ancien. Catalogue inventaire de la peinture ancienne (Brussels: 1984).

[Mus. cat. Budapest 200o]

Ember, Ildiko and Urbach, Szusza (eds.), Museum of Fine Arts Budapest. Old Masters' Gallery. Early Netherlandish, Dutch and Flemish Paintings (Summary catalogue. 2) (Budapest: 2000).

[Mus. cat. Chicago 2008]

Wolff, Martha (ed.), Northern European and Spanish Paintings Before 1600 in the Art Institute of Chicago: A Catalogue of the Collection (New Haven: 2008).

[Mus. cat. Cleveland 1978]

Handbook of the Cleveland Museum of Art (Cleveland: 1978).

[Mus. cat. Cologne 1969]

Hiller, Irmgard and Vey, Horst, Katalog des deutschen und niederländischen Gemälde bis $155^{\circ}$ (mit Ausnahme der kölner Malerei) im Wallraf-Richartz-Museum und im Kunstgewerbemuseum der Stadt Köln (Cologne: 1969). 
[Mus. cat. Copenhagen 1951]

Catalogue of Old Foreign Paintings (Copenhagen: 1951).

[Mus. cat. Dublin 1987]

Vogelaar, Christiaan, Netherlandish Fifteenth and Sixteenth Century Paintings in the National Gallery of Ireland. A Complete Catalogue (Dublin: 1987).

[Mus. cat. Edinburgh 1997]

The National Gallery of Scotland. Concise Catalogue of Paintings (Edinburgh: 1997).

[Mus. cat. Enschede 1974-1976]

ter Kuile, Onno, Catalogus van de schilderijen, Enschede (Rijksmuseum Twenthe)

(Enschede: 1974-1976).

[Mus. cat. Frankfurt 1957]

Prinz, Wolfram, Gemälde des historischen Museums Frankfurt am Main (Frankfurt: 1957).

[Mus. cat. Frankfurt 1993]

Sander, Jochen, Niederländische Gemälde im Städel 1400-1550 (Frankfurt: 1993).

[Mus. cat. Haarlem 2006]

Köhler, Neeltje (ed.), Painting in Haarlem, 1500-1850. The Collection of the Frans Hals Museum (Ghent: 2006).

[Mus. cat. Hannover 1992]

Wolfson, Michael, Die deutschen und niederländischen Gemälde bis 1550 (Hannover: 1992).

[Mus. cat. Houston 1981]

Wright, Christopher, A Golden Age of Painting. Dutch, Flemish, German Paintings, Sixteenth-Seventeenth Centuries from the Collection of the Sarah Blaffer Foundation (San Antonio: 1981).

[Mus. cat. Kansas City 2005]

Dunbar, Burton L. (ed.), The Collection of the Nelson-Atkins Museum of Art. German and Netherlandish Paintings. 1450-1600 (Kansas City: 2005).

[Mus. cat. Leiden 1983]

Stedelijk Museum de Lakenhal. Catalogus van schilderijen en tekeningen (Leiden: 1983).

[Mus. cat. Leipzig 2012]

Nicolaisen, Jan and Beck, Rüdiger, Niederländische Malerei, 1430-180o: Museum der bildenden Künste Leipzig (Seemann: 2012).

[Mus. cat. Liverpool 1963]

Foreign Schools. Catalogue. Text (Liverpool: 1963).

[Mus. cat. London 1973]

Kauffmann, C. M., Catalogue of Foreign Painting, I. Before 1800 (London: 1973).

[Mus. cat. Maastricht 1958]

Catalogus van schilderijen en beeldhouwwerken (Maastricht: 1958). 
[Mus. cat. Madrid 1991]

Museo del Prado. Inventario general de pinturas. II. El Museum de la Trinidad (Madrid: 1991).

[Mus. cat. Munich 2006]

Schawe, Martin, Alte Pinakothek. Altdeutsche und altniederländische Malerei (Munich: 2006).

[Mus. cat. Münster 1986]

Pieper, Paul, Die deutschen, niederländischen und italienischen Tafelbilder bis um 1530 (Münster: 1986).

[Mus. cat. Naples 1964]

Notizie su Capodimonte. Catalogo delle Gallerie e del Museo (Naples: 1964).

[Mus. cat. Ottawa 1987]

Laskin, Myron and Pantazzi, Michael (eds.), Catalogue of European and American Painting, Sculpture and Decorative Arts (Ottawa: 1987).

[Mus. cat. Oxford 1967]

Shaw, J. Byam, Paintings by Old Masters at Christ Church Oxford (London: 1967).

[Mus. cat. Philadelphia 1913]

Valentiner, W. R., Flemish and Dutch Paintings, Philadelphia (John G.Johnson Collection) (Philadelphia: 1913).

[Mus. cat. Philadelphia 1994]

Paintings from Europe and the Americas in the Philadelphia Museum of Art (Philadelphia: 1994).

[Mus. cat. Prague 1999]

Kotkova, Olga, The National Gallery in Prague. Netherlandish Painting 1480-1600. Illustrated Summary catalogue I/1 (Prague: 1999).

[Mus. cat. Stuttgart 1992]

Rettich, Edeltraud, Klapproth, Rädiger and Ewald, Gerhard, Alte Meister. Staatsgalerie Stuttgart (Stuttgart: 1992).

[Mus. cat. Tokyo 1998]

Masterpieces of the National Museum of Western Art (Tokyo: 1998).

[Mus. cat. Toledo 1976]

Catalogue of European Paintings (Toledo: 1976).

[Mus. cat. Utrecht 1999]

Helmus, Liesbeth M., De verzamelingen van het Centraal Museum Utrecht. Schilderkunst tot 1850 (Utrecht: 1999).

[Mus. cat. Utrecht 2002]

Dijkstra, Jeeltje, Dirkse, P. P. W. M. and Smits, A. E. A. M., De schilderijen van Museum Catharijneconvent (Utrecht: 2002).

[Mus. cat. Utrecht 2011]

Helmus, Liesbeth M. and Faries, Molly (eds.), Catalogue of Paintings, 1363-160o. Centraal Museum Utrecht (Utrecht: 2011). 
[Mus. cat. Warsaw 1967]

Malarstwo Europejskie, Muzeum Narodowe w Warszawie (Warsaw: 1967).

[Mus. cat. Washington 1986]

Hand, John Oliver and Wolff, Martha, Early Netherlandish Painting. The Collection of the National Gallery of Art. Systematic Catalogue (Cambridge: 1986).

[Mus. cat. Zutphen 1991]

Reinders, Carin, Stedelijk Museum Zutphen. Een keuze uit de collectie (Zutphen: 1991).

\section{Exhibitions Catalogues}

[Exh. cat. Aachen 2011]

van den Brink, Peter (ed.), Joos van Cleve. Leonardo des Nordens [exh. cat., SuermondtLudwig-Museum, Aachen] (Stuttgart: 2011).

[Exh. cat. Alkmaar 2014]

Meuwissen, Daantje (ed.),Jacob Cornelisz van Oostsanen (ca. 1475-1533): de Renaissance in Amsterdam en Alkmaar [exh. cat., Amsterdam Museum, Amsterdam; Stedelijk Museum Alkmaar and Sint Laurenskerk, Alkmaar] (Zwolle: 2014).

[Exh. cat. Amsterdam 1958]

Middeleeuwse kunst der noordelijke Nederlanden [exh. cat., Rijksmuseum, Amsterdam] (Amsterdam: 1958).

[Exh. cat. Amsterdam 1986]

Filedt Kok, Jan Piet, Haselma-Kubes, Willy and Kloek, Wouter Th. (eds.), Kunst voor de beeldenstorm. Noordnederlandse kunst 1525-1580 [exh. cat., Rijksmuseum, Amsterdam] (The Hague: 1986).

[Exh. cat. Antwerp 1993]

Van Nieuwdorp, Hans (ed.), Les retables anversois. $X V^{e}-X V I^{e}$ siècles [exh. cat., Onze-

Lieve-Vrouw Kathedraal, Antwerp] (Antwerp: 1993).

[Exh. cat. Antwerp and Maastricht 2005]

van den Brink, Peter and Martens, Maximiliaan P. J. (eds.), ExtravagAnt! A Forgotten

Chapter of Antwerp Painting. 1500-1530 [exh. cat., Koninklijk Museum voor Schone

Kunsten, Antwerp; Bonnefantenmuseum, Maastricht] (Antwerp: 2005).

[Exh. cat. Antwerp and Washington 2006]

Hand, John Oliver, Metzger, Catherine A. and Spronk, Ron (eds.), Prayers and Portraits.

Unfolding the Netherlandish Diptych [exh. cat., Koninklijk Museum voor Schone Kunsten, Antwerp; National Gallery, Washington] (New Haven: 2006).

[Exh. cat. Bonn and Essen 2005]

Krone und Schleier. Kunst aus mittelalterlichen Frauenklöstern [exh. cat., Kunst- und Ausstellungshalle der Bundesrepublik Deutschland, Bonn; Ruhrlandmuseum Essen] (Munich: 2005). 
[Exh. cat. Bourg-en-Bresse 1981]

Van Orley et les artistes à la cour de Marguerite d'Autriche [exh. cat., Musée de l'Ain,

Bourg-en-Bresse] (Bourg-en-Bresse: 1981).

[Exh. cat. Bruges 1960]

Le siècle des Primitifs flamands [exh. cat., Groeningemuseum, Bruges] (Bruges: 1960).

[Exh. cat. Bruges 1962]

La toison d'or. Cinq siècles d'art et d'histoire [exh. cat., Groeningemuseum, Bruges]

(Bruges: 1962).

[Exh. cat. Bruges 1969]

Primitifs flamands anonymes. Maîtres aux noms d'emprunt des Pays-Bas méridionaux $d u X V^{e}$ et du début du XVI siècle [exh. cat., Groeningemuseum, Bruges] (Bruges: 1969).

[Exh. cat. Bruges 1994]

De Vos, Dirk (ed.), Hans Memling [exh. cat., Groeningemuseum, Bruges] (Bruges: 1994). [Exh. cat. Bruges 1998]

Martens, Maximiliaan P. J. (ed.), Bruges et la Renaissance. De Memling à Pourbus [exh. cat., Memlingsmuseum, Bruges], 2 vols. (Ghent: 1998).

[Exh. cat. Bruges 2002]

Borchert, Till-Holger (ed.), Le Siècle de Van Eyck, 1430-1530 : Le Monde méditerranéen et les Primitifs flamands [exh. cat., Groeningemuseum, Bruges] (Ghent: 2002).

[Exh. cat. Bruges and Rotterdam 1965]

Pauwels, Henri, Hoetink, Hendrick and Herzog, Sadja (eds.) Jan Gossaert genaamd Mabuse. Jean Gossaert dit Mabuse [exh. cat., Groeningemuseum, Bruges; Museum Boijmans van Beuningen, Rotterdam] (Rotterdam: 1965).

[Exh. cat. Bruges, Bern and Vienna 2009]

Borchert, Till-Holger, Marti, Susan and Keck, Gabriele (eds.), Splendeurs de la cour de Bourgogne: Charles le Téméraire (1433-1477) [exh. cat., Groeningemuseum, Bruges; Kunsthistorisches Museum, Vienna] (Antwerp: 2009).

[Exh. cat. Brussels 1985]

Duvosquel, Jean-Marie and Vandevivere, Ignace (eds.), Splendeurs d'Espagne et les villes belges 1500-1700 [exh. cat., Palais des Beaux-Arts, Brussels], 2 vols. (Brussels: 1985).

[Exh. cat. Brussels 1994]

Vandenbroeck, Paul (ed.), Le jardin clos de l'âme. L'imaginaire des religieuses dans les Pays-Bas du Sud, depuis le XIII e siècle [exh. cat., Palais des Beaux-Arts, Brussels] (Brussels: 1994).

[Exh. cat. Brussels 1996]

Allard, Dominique (ed.), S.O.S. oude schilderijen. Redding en behoud van 20 werken op paneel. S.O.S peintures anciennes. Sauvegarde de 20 ouvres sur panneau [exh. cat., Musée d'Art ancien, Brussels] (Brussels: 1996). 
[Exh. cat. Brussels 2013]

Bücken, Véronique and Steyaert, Griet (eds.), L'héritage de Rogier van der Weyden: la peinture à Bruxelles, 1450-1520 [exh. cat., Musées royaux des Beaux-Arts de Belgique, Brussels] (Tielt: 2013).

[Exh. cat. Cambridge 1993]

Arnould, Alain and Massing, Jean-Michel (eds.), Splendours of Flanders. Late Medieval Art in Cambridge Collections [exh. cat., the Fitzwilliam Museum, Cambridge] (Cambridge: 1993).

[Exh. cat. Cassel 2013]

Vézilier-Dussart, Sandrine (ed.), Splendeurs du maniérisme en Flandre. 1500-1575 [exh. cat., Musée départemental de Flandre, Cassel] (Cassel: 1993).

[Exh. cat. Den Bosch 1990]

Koldeweij, Jos (ed.), In Buscoducis 1450-1629. Kunst uit de Bourgondische tijd te 's-Hertogenbosch. De cultuurvan late middeleeuwen en renaissance [exh. cat., Noordbrabants Museum, Den Bosch] (Den Bosch: 1990).

[Exh. cat. Dresden 2005]

Ketelsen, Thomas and Neidhardt, Uta (eds.), Das Geheimnis des Jan van Eyck. Die frühen niederländischen Zeichnungen und Gemälde in Dresden [exh. cat., Staatliche Kunstsammlingen, Dresden] (Dresden: 2005).

[Exh. cat. Frankfurt and Berlin 2009]

Kemperdick, Stephan and Sander, Jochen (eds.), Der Meister von Flémalle und Rogier van der Weyden [exh. cat., Städel Museum Frankfurt; Gemäldegalerie der Staatlichen Museen zu Berlin, Berlin] (Ostfildern: 2009).

[Exh. cat. Ghent 1975]

Gent. Duizend jaar kunst en cultuur [exh. cat., Museum voor Schone Kunsten, Ghent] (Ghent: 1975).

[Exh cat. Kevelaer 2000-2001]

van der Coelen, Peter and Plötz, Robert (eds.), De Gouden Eeuw van Gelre. Kunst en cultuur in het oude hertogdom [exh. cat., Niederrheinisches Museum für Volkskunde und Kulturgeschichte, Kevelaer] (Geldern: 2000-2001).

[Exh. cat. Leiden 2011]

Vogelaar, Chistiaan, Filedt Kok, Jan Piet, Leeflang, Micha and Veldman, Ilda (eds.), Lucas de Leyden en de Renaissance [exh. cat., Museum de Lakenhal, Leiden] (Antwerp: 2011).

[Exh. cat. Leon and Palencia 1999]

Fernandez Pardo, Francisco (ed.), Las tablas flamencas en la Ruta Jacobea [exh. cat., Sala culturel Gaudí, Leon; Salas culturales Caja España, Palencia] (Logroño: 1999). [Exh. cat. Leuven 1975]

Dirk Bouts en zijn tijd [exh. cat., Sint-Pieterskerk, Leuven] (Leuven: 1975). 
[Exh. cat. Leuven 1998]

Smeyers, Maurits (ed.), Dirk Bouts (ca. 1410-1475). Een Vlaams primitief te Leuven [exh. cat., Sint-Pieterskerk and Predikherenkerk, Leuven] (Leuven: 1998).

[Exh. cat. Leuven 2009]

Campbell, Lorne and van der Stock, Jan (eds.), Rogiervan der Weyden. 140o-1464. Maître des passions [exh. cat., M Museum, Leuven] (Leuven: 2009).

[Exh. cat. Lille 2005]

Gombert, Florence and Martens, Didier (eds.), Le Maître au feuillage brodé. Primitifs flamands : secrets d'atelier [exh. cat., Palais des Beaux-Arts, Lille] (Paris: 2005).

[Exh. cat. London and Los Angeles 2003]

Kren, Thomas and McKendrick, Scot (eds.), Illuminating the Renaissance. The Triumph of Flemish Manuscript Painting in Europe [exh. cat., Royal Academy of Arts, London; The J. Paul Getty Museum, Los Angeles] (Los Angeles: 2003).

[Exh. cat. Mechelen 1998]

8oo jaar Onze-Lieve-Vrouwegasthuis. Uit het erfgoed van de Mechelse gasthuiszusters en het OCMW [exh. cat., Stedelijk Museum Hof van Busleyden, Mechelen] (Mechelen: 1998).

[Exh. cat. Mechelen 2005]

Eichberger, Dagmar (ed.), Women of Distinction. Margaret of York and Margaret of Austria [exh. cat., Lamot, Mechelen] (Leuven: 2005).

[Exh. cat. Namur 2001]

Toussaint, Jacques (ed.), Art en Namurois. La sculpture 1400-1550 [exh. cat., Musée des arts anciens du Namurois and Musée Diocésain, Namur] (Namur: 2001).

[Exh. cat. Namur 2010]

Dialogue avec l'invisible. L'art aux sources de l'Europe. OEuvres d'exception issues de la Communautéfrançaise (VIII ${ }^{e}-X V I I^{\mathrm{e}}$ siècle) [exh. cat., Musée provincial des Arts anciens de Namur, Namur] (Namur: 2010).

[Exh. cat. New York 1994]

Ainsworth, Maryan W. (ed.), Petrus Christus [exh. cat., The Metropolitan Museum of Art, New York] (Ghent: 1994).

[Exh. cat. Nijmegen 1975-1976]

Lemmens, Gerard Th. M. (ed.), Het drieluik van de familie Kanis en de Schilderkunst in Gelre omstreeks 1530 [exh. cat., Museum Commanderie van Sint-Jan, Nijmegen] (Nijmegen: 1975-1976).

[Exh. cat. Nurmberg 1983]

Löcher, Kurt (ed.), Martin Luther und die Reformation in Deutschland [exh. cat., Germanisches Nationalmuseum, Nurmberg] (Frankfurt: 1983).

[Exh. cat. Oostzaan 200o]

de Kruijff, Jan Dirk (ed.), Jacob Cornelisz van Oostsanen, geboren te Oostzaan ca. 14701530 [exh. cat., Grote kerk, Oostzaan] (Oostzaan: 2000). 
[Exh. cat. Oud-Zuilen 1996]

Op stand aan de wand. Vijf eeuwen familieportretten in Slot Zuylen Slot Zuylen [exh. cat., Stichtse Vecht, Oud-Zuilen] (Oud-Zuilen: 1996).

[Exh. cat. Paris 1991]

Scaillierez, Cécile (ed.), Joos van Cleve au Louvre [exh. cat., Musée du Louvre, Paris] (Paris: 1991).

[Exh. cat. Paris 2017]

Scaillierez, Cécile (ed.), François Ier et l'art des Pays-Bas [exh. cat., Musée du Louvre, Paris] (Paris: 2017).

[Exh. cat. Roermond 2009]

Pansters, Krijn (ed.), Het geheim van de stilte. De besloten wereld van de Roermondse kartuizers [exh. cat., Voormalige kartuizerklooster 'O.L. Vrouw van Bethlehem', Roermond] (Zwolle: 2009).

[Exh. cat. Rotterdam 1994]

Giltaij, J. and Lammertse, Friso, Van Eyck to Bruegel. Dutch and Flemish Painting in the Collection of the Museum Boijmans van Beunigen [exh. cat., Museum Boijmans van Beuningen, Rotterdam] (Rotterdam: 1994).

[Exh. cat. Rotterdam 2012]

Kemperdick, Stephan and Lammertse, Friso (eds.), De weg naar Van Eyck [exh. cat., Museum Boijmans van Beuningen, Rotterdam] (Rotterdam: 2012).

[Exh. cat. The Hague 1945]

Nederlandsche kunst van de XVde en XVIde eeuw Koninklijk Kabinet van Schilderijen Mauritshuis [exh. cat., Mauritshuis, The Hague] (The Hague: 1945).

[Exh. cat. Tongeren 1981]

Schatten en schenkers van de O.-L.-Vrouwkerkvan Tongeren [exh. cat., Provinciaal GalloRomeins Museum, Tongeren] (Tongeren: 1981).

[Exh. cat. Uden 1992]

Heilige Anne, Grote moeder. De cultus van de Heilige Moeder Anna en haar familie in de

Nederlanden en aangrenzende streken [exh. cat., Museum voor Religieuze Kunsten, Uden] (Nijmegen: 1992).

[Exh. cat. Utrecht 1955]

Jan van Scorel [exh. cat., Centraal Museum] (Utrecht: 1955).

[Exh. cat. Utrecht 1999-200o]

van Bueren, Truus (ed.), Leven na de dood. Gedenken in de late Middeleeuwen [exh. cat.,

Catharijneconvent, Utrecht] (Turnhout: 1999-200o).

[Exh. cat. Utrecht 200o]

Faries, Molly and Helmus, Liesbeth (eds.), De Madonna's van Jan van Scorel (1495-1562)

[exh. cat., Centraal Museum, Utrecht] (Utrecht: 2000). 
[Exh. cat. Utrecht and Den Bosch 1993]

van den Boogert, Bob and Kerkhoff, Jacqueline (eds.), Maria van Hongarije. Koningin tussen keizers en kunstenaars. 1505-1558 [exh. cat., Catharijneconvent, Utrecht; Noordbrabants Museum, Den Bosch] (Zwolle: 1993).

[Exh. cat. Utrecht and Douai 1977]

Jan van Scorel d'Utrecht. Retables et tableaux de son atelier vers 1540. Documents et examens scientifiques [exh. cat., Centraal Museum, Utrecht; Musée de la Chartreuse, Douai] (Douai: 1977).

[Exh. cat. Zurich and Cologne 1994]

Jezler, Peter (ed.), Himmel, Hölle, Fegefeuer. Das Jenseits im Mittelalter [exh. cat., Schweizerisches Landesmuseum, Zurich; Wallraf-Richartz-Museum, Cologne] (Munich: 1994).

\section{Sales Catalogues}

[Sale cat. Christie's (Amsterdam, 8 November 1999)]

Old Masters Pictures (sale no. 2437) (Amsterdam, Christie's: 8 November 1999).

[Sale cat. Christie's (London, 10 December 2003)]

Old Masters Pictures (sale no. 6837) (London, Christie's: 10 December 2003).

[Sale cat. Christie's (London, 7 July 2006)]

Old Masters Pictures. Day Sale (sale no. 7254) (London, Christie's: 7 July 2006).

[Sale cat. Christie's (London, 7 December 2010)]

Old Masters \& 19th Century Art. Evening Sale (sale no. 7887) (London, Christie's: 7 December 2010).

[Sale cat. Christie's (London, 5 July 2011)]

Old Master \& British Paintings. Evening Sale (sale no. 7980) (London, Christie's: 5 July 2011).

[Sale cat. Christie's (London, 6 July 2011)]

Old Master \& British Paintings (sale no. 7981) (London, Christie's: 6 July 2011).

[Sale cat. Christie's (London, 3 July 2012)]

Old Master \& British Paintings. Evening Sale (sale no. 5602) (London, Christie's: 3 July 2012).

[Sale cat. Christie's (London, 5 December 2012)]

Old Master \& British Paintings. Day Sale (sale no. 5965) (London, Christie's: 5 December 2012).

[Sale cat. Christie's (London, 4 December 2013)]

Old Master \& British Paintings. Day Sale (sale no. 1165) (London, Christie's: 4 December 2013). 
[Sale cat. Christie's (London, 30 April 2014)]

Old Master \& British Paintings (sale no. 14030) (London, Christie's: 30 April 2014).

[Sale cat. Christie's (New York, 25 January 2012)]

Old Master Paintings. Part I (sale no. 2534) (New York, Christie's: 25 January 2012).

[Sale cat. Christie's (New York, 6 April 2006)]

Important Old Master Paintings, Part I (sale no. 1620) (New York, Christie's: 6 April 2006).

[Sale cat. Cornette de Saint Cyr (Paris, 25 October 2013)]

Collection d'un grand amateur et divers (Paris, Cornette de Saint Cyr: 25 October 2013).

[Sale cat. Dorotheum (Vienna, 14 October 1997)]

Alte Meister (Vienna, Dorotheum: 14 October 1997).

[Sale cat. Lempertz (Vienna, 22 November 2008)]

Alte Kunst. Old Masters (sale no. 929) (Vienna, Lempertz: 22 November 2008).

[Sale cat. Piasa (Paris, 17 December 2008)]

Importants tableaux anciens (Paris, Piasa: 17 December 2008).

[Sale cat. Servarts (Brussels, 16 May 2006)]

Beaux-Arts. Art \& Antique Auctioneer (Brussels, Servarts: 16 May 2006).

[Sale cat. Sotheby's (Amsterdam, 14 May 2002)]

Old Master Paintings (sale no. AMo845) (Amsterdam, Sotheby's: 14 May 2002).

[Sale cat. Sotheby's (Amsterdam, 18 May 2010)]

Old Master Paintings (sale no. AM109o) (Amsterdam, Sotheby's: 18 May 2010).

[Sale cat. Sotheby's (London, 8 July 1999)]

Old Master Paintings (sale no. Log161) (London, Sotheby's: 8 July 1999).

[Sale cat. Sotheby's (London, 12 July 2001)]

Old Master Paintings. Part I (sale no. Lo1121) (London, Sotheby's: 12 July 2001).

[Sale cat. Sotheby's (London, 7 December 2006)]

Old Master Painting (sale no. 6034) (London, Sotheby's: 7 December 2006).

[Sale cat. Sotheby's (London, 8 June 2007)]

Important Old Master Paintings and European Works of Art Including Property of the Albright-Knox Art Gallery (New York, Sotheby's: 8 June 2007).

[Sale cat. Sotheby's (London, 9 July 2008)]

Old Master Paintings. Evening Sale (London, Sotheby's: 9 July 2008).

[Sale cat. Sotheby's (London, 7 July 2010)]

Old Master and British Paintings. Evening Sale (sale no. L10033) (London, Sotheby's: 7 July 2010).

[Sale cat. Sotheby's (London, 8 December 2010)]

Old Master \& British Paintings Evening Sale (sale no. L1oo36) (London, Sotheby's: 8

December 2010). 
[Sale cat. Sotheby's (London, 6 December 2012)]

Old Master \& British Paintings. Day Sale (sale no. 12037) (London, Sotheby's: 6 December 2012).

[Sale cat. Sotheby's (London, 8 July 2015)]

Old Master \& British Paintings. Evening Sale (sale no. 15033) (London, Sotheby's: 8 July 2015).

[Sale cat. Sotheby's (London, 9 December 2015)]

Old Master \& British Paintings. Evening Sale (London, Sotheby's: 9 December 2015).

[Sale cat. Sotheby's (New York, 12 January 1995)]

Important Old Master Paintings. The Property of the New-York Historical Society (sale no. 6653) (New York, Sotheby's: 12 January 1995).

[Sale cat. Sotheby's (New York, 28 January 2000)]

Old Masters 2000 (sale no. 7425) (New York, Sotheby's: 28 January 200o).

[Sale cat. Sotheby's (New York, 28 January 2011)]

Old Master \& 19th Century European Art (sale no. No8715) (New York, Sotheby's: 28 January 2000).

[Sale cat. Sotheby's (New York, 6 June 2013)]

Old Master Paintings (sale no. Nogoo3) (New York, Sotheby's: 6 June 2013).

[Sale cat. Van Ham (Cologne, 1-3 April 2004)]

Alte Kunst (sale no. 231) (Cologne, Van Ham Kunstauktionen: 1-3 April 2004).

\section{Works and Articles}

[AINSWORTH 2010]

Ainsworth, Maryan W. (with contributions by Stijn Alsteens, Nadine Orenstein et alii), Man, Myth and Sensual Pleasures: Jan Gossart's Renaissance. The Complete Works (New York: 2010).

[AINSWORTH and CHRISTIANSEN 1998]

Ainsworth, Maryan W. and Christiansen, Keith (eds.), From Van Eyck to Bruegel. Early Netherlandish Painting in The Metropolitan Museum of Art (New York: 1998).

[BAGLEY-YOUNG 2008]

Bagley-Young, Abigail, “Jan Cornelisz. Vermeyen's Cardinal Erard de la Marck and Holy Family: A Diptych Reunited," Burlington Magazine 150 (2008), 76-82.

[BANGS 1999]

Bangs, Jérémy Dupertuis, "The Master of Alkmaar and Hand X. The Haarlem Painters of the Van Waterlant Family," Wallraf-Richartz Jahrbuch 6o (1999), 65-162.

[BERMEJO 1980]

Bermejo Martinez, Elisa, La pintura de los primitivos flamencos en España, vol. 1 (Madrid: 1980). 


\section{[BERMEJO 1982]}

Bermejo Martinez, Elisa, La pintura de los primitivos flamencos en España, vol. 2 (Madrid: 1982).

[BERMEJO 1984]

Bermejo Martinez, Elisa, "Algunas obras ineditas del Maestro de la leyenda de la Magdalena," in Liber amicorum Herman Liebaers, ed. Frans Vanwijngaerden (Brussels: 1984), 393-409.

[BILLINGE 2012]

Billinge, Rachel, "The Technical Examination of Two Rogerian Panels from the Collection of the National Trust at Petworth House," in Rogier van der Weyden in Context. Proceedings of Symposium XVII, Leuven, November 20og, ed. Lorne Campbell, Jan Van der Stock, Catherine Reynolds and Lieve Watteuw (Leuven: 2012), 207-14.

[BONENFANT-FEYTMANS 1991]

Bonenfant-Feytmans, Anne-Marie, "Aert Van den Bossche, peintre du polyptyque des saints Crépin et Crépinien," Annales d'Histoire de l'Art et d'Archéologie 13 (1991), $43-58$.

\section{[BOON 1966]}

Boon, K. G., "Geertgen tot Sint Jans of Mostaert," Oud Holland 81 (1966), 61-71.

[BORN et alii 2014]

Born, Annick, Buylaert, Frederik, De Clercq, Wim, Dumolyn, Jan, Lievois, Daniël, Lobkova, Nadya, Martens, Maximiliaan P. J. and van Vaerenbergh, Jeroen, "The Van Pottelsberghe-Van Steelant Memorial by Gerard Horenbout: Lordship, Piety and Mortality in Early Sixteenth-Century Flanders," Zeitschrift für Kunstgeschichte 77 (2014), 491-516.

[BRINE 2006]

Piety and Purgatory: Wall-Mounted Memorials from the Southern Netherlands, c. 13801520 (PhD. Diss., Courtauld Institute of Art: 2006).

[BRINE 2008]

Brine, Douglas, "Evidence for the Forms and Usage of Early Netherlandish Memorial Paintings," Journal of the Warburg and Courtauld Institutes 71 (2008), 139-68.

[BROUETTE 1974]

Brouette, Émile, "Un portrait de Corneille van der Goes, abbé de Dielegem (1512-36) et de Middelbourg (1536-39)," Analecta Praemonstratensia 50/1-4 (1974), 253-60.

[BRUIJNEN 2001-2002]

Bruijnen, Yvette, "The Master of Saint Michael: A Newly Established Group of Paintings by an Artist in the Orbit of Bernard van Orley," Oud Holland 115 (2001-2002), 79-110. [BRUYERE 2010]

Bruyère, Paul, “La 'Vierge au papillon' du Trésor de la cathédrale de Liège (ca. 1459), fruit d'une réflexion théologique originale," Publication du Centre européen d'études bourguignonnes (XIV ${ }^{e}-X V I^{e} s$.) $5^{0}(2010), 303^{-27}$. 


\section{[BRUYERE 2012]}

Bruyère, Paul, “Le martyre de saint Lambert du 'Diptyque Palude' et les cérémonies de 1489 à la cathédrale de Liège," Le Moyen Âge 118 (2012), 329-68.

[BRUYN 1983]

Bruyn, Joshua, "Over de betekenis van het werk van Jan van Scorel omstreeks 1530 voor oudere en jongere tijdgenoten (2)," Oud Holland 97 (1983), 217-23.

[BRUYN 1998]

Bruyn, Joos, "Van vroom kleinood tot nondescript specimen: het Portret van een monnik door Dieric Bouts of uit zijn atelier," Jaarboek van het Koninklijk Museum voor Schone Kunsten Antwerpen (1998), 69-84.

[BRUYN 2009]

Bruyn, Joshua, "Een gedachtenisvenster voor Claes van Ruyven en Geertgen tot Sint Jans' Johannespaneel te Wenen," Oud Holland 122 (2009), 81-119.

[BUYLE and VANTHILLO 200o]

Buyle, Marjan and Vanthillo, Christine (eds.), Retables flamands et brabançons dans les monuments belges (Brussels: 2000).

[CALVO et alii 2005]

Calvo, Anne, Afonso, J. F., Aguiar, M., Nodal, C., Carballo, C. and Bravo, L., "Estudios sobre el Triptico de Pentecostàs, de la Iglesia de Sao Pedro de Miragaia, Porto," in I Congreso del GE-IIC, Museu Nacional d'Art de Catalunya, vol. 1 (Barcelona: 2005), 399-407.

[CAMPBELL 1985]

Campbell, Lorne, The Early Flemish Pictures in the Collection of her Majesty the Queen (Cambridge: 1985).

[CAMPBELL 1998]

Campbell, Lorne, The National Gallery of London. The Fifteenth Century Netherlandish School, (London: 1998).

[CAMPBELL 2014]

Campbell, Lorne, National Gallery Catalogues: The Sixteenth Century Netherlandish Paintings with French Paintings before 1600 (London: 2014).

[CARROLL 1987]

Carroll, Jane L., The Paintings of Jacob Cornelis van Oostsanen (1472?-1533), (PhD. Diss., University of North Carolina: 1987).

[CAVELLI TRAVERSO 2003]

Cavelli Traverso, Carla, Primitivi fiamminghi in Liguria (Genoa: 2003).

[CHÂTELET 1980]

Châtelet, Albert, Les Primitifs hollandais. La peinture dans les Pays-Bas du Nord au XV siècle (Paris: 1980).

[CIULISOVA 2009a]

Ciulisová, Ingrid, "Memory and Witness: 'Translated Images'," Revue belge d'archéologie et d'histoire de l'art 78 (2009), 3-13. 


\section{[CIULISOVA 2009b]}

Ciulisová, Ingrid, "Two Donors with Saint John the Baptist and Saint Barbara (SaintMartin Cathedral, Bratislava)," in Underdrawing and Technology in Painting. Symposium XVI. Bruges, September 21st, 22nd and 23rd, 2006. The Quest for the Original, ed. Hélène Verougstraete and Colombe Janssens de Bisthoven (Leuven: 2009), 42-47.

[COENEN et alii 1984-85]

Coenen, Hubert, Kockaert, Léopold, Vynkier, Jozef and Waregne-Reyes, Carmen, "Le triptyque des saintes Agathe et Apolline de Turnhout. Approche iconographique et historique. Examen technologique et traitement," Bulletin de l'Institut royal du Patrimoine artistique 20 (1984-1985), 43-69.

[COOLS 2001]

Cools, Hans, "Les frères Henri, Jean, Antoine et Corneille de Glymes-Bergen : les Quatre Fils Aymo, des Pays-Bas Bourguignons," in Publication du Centre européen d'Études bourguignonnes (XIV ${ }^{e}-X V I^{e} s$. 41 (2001), 275-301.

[CORDONNIER 1994]

Cordonnier, Aude, Musée de l'Hospice Comtesse. Miroir de Lille et des Pays-Bas, XIII $X X^{e}$ (Tournai: 1994).

[COUTO 1955]

Couto, João, "O triptico da deposiçao da cruz proveniente da Ilha da Madeira," Boletim do Museu Nacional de Arte Antiga 3 (1955), 1-3.

[CUTTLER 1966]

Cuttler, Charles D., "The Master of the Dijon Diptych. An Addendum to the New England Museum Corpus," Bulletin de l'Institut royal du Patrimoine artistique 9 (1966), 165-69.

[D'HAENENS 1984]

D'Haenens, Albert, L'Europe de la mer du Nord et de la Baltique. Le monde de la Hanse (Paris: 1984).

[D'HAINAUT-ZVENY 2005]

D'Hainaut-Zvény, Brigitte (ed.), Miroirs du sacré. Les retables sculptés à Bruxelles. $X V^{e_{-}}$ XVI ${ }^{e}$ siècles. Production, formes et usages (Brussels: 2005).

[DE BOSQUE 1975]

De Bosque, André, Quentin Metsys (Brussels: 1975).

[DE MEYERE et alii 1995]

De Meyere, J. A. L., Smit, J. G. and Volkers-de Ruiter, A. A., "De memorietafel Van Schayck kunsthistorisch, genealogisch en heraldisch bekeken," Flehite. Tijdschrift voor verleden en heden van Oost Utrecht 25/1-2 (1995), 4-13.

[DE MOOR 1981]

de Moor, Geertruida, “Adriana van Roon (ca. 1450-1527) en Dirk Pietersz. Spangert (ca. 1465-1549), schenkers van het drieluikje met Het laatste avondmaal, toegeschreven 
aan Jacob Cornelisz. van Oostsanen," Bulletin van het Rijksmuseum 28 (1981), 63-78, $55^{-116 .}$

[DE PATOUL 1974]

De Patoul, Brigitte, Le Maître de la Légende de sainte Marie-Madeleine : étude du triptyque de la Légende de sainte Marie-Madeleine, comparaison avec les tableaux de scènes attribuées au maître et conservés dans les collections publiques de Belgique, (master's thesis, Université catholique de Louvain: 1974).

[DE PATOUL and VAN SCHOUTE 1994]

De Patoul, Brigitte, and Van Schoute, Roger (eds.), Les Primitifs flamands et leur temps (Tournai: 1994).

[DE TERVARENT 1941]

de Tervarent, Guy, Les énigmes de l'art du Moyen Âge. Deuxième série. Art flamand (Paris: 1941).

[DE VAIVRE 1987]

de Vaivre, Jean-Bernard, “Le polyptyque d'Ambierlé," Bulletin monumental 145 (1987), $113^{-14}$.

[DE VOS 1970]

De Vos, Dirk, “Brugs Meester van 1473. Triptiek van Jan de Witte," Openbaar Kunstbezit in Vlaanderen 8 (1970), 21a-21b.

[DE VOS 1989-1991]

De Vos, Dirk, "Enkele minder bekende anonieme brugse schilders uit het einde van de 15 de en het begin van de 16de eeuw," Bulletin des Musées royaux des Beaux-Arts de Belgique 38-40 (1989-1991), 187-203.

[DE VOS 1991]

De Vos, Dirk, "À propos du retable des saints Crépin et Crépinien. Les deux volets méconnus du musée des Beaux-Arts de Moscou," Annales d'Histoire de l'Art et d'Archéologie 13 (1991), 33-42.

[DE VOS 1994]

De Vos, Dirk, Hans Memling. L'œuvre complet (Antwerp: 1994).

[DE VOS 1999]

De Vos, Dirk, Rogier Van der Weyden. L'ouvre complet (Antwerp: 1999).

[DE VRIJ 1998a]

de Vrij, Marc R., "The Master of Willem van Bibaut, his OEuvre, his Alleged Origin and his Place in the Studio," Pantheon $5^{6}$ (1998), 186-91.

[DE VRIJ 1998b]

de Vrij, Marc R., "Vrancke van der Stockt en het retabel van Ambierlé," Jaarboekvan het

Koninklijk Museum voor Schone Kunsten Antwerpen (1998), 209-31.

[DE VRIJ 1999]

de Vrij, Marc R., De Meester van de Virgo inter Virgines (Amsterdam: 1999). 
[DE VRIJ 2000]

de Vrij, Marc R., De Meestervan de Magdalena-Legende (Amsterdam: 200o).

[DEFOER 2011]

Defoer, Henri L. M., "The Triptych of the Pauw-Sas Family from the Utrecht Charterhouse," in Living Memoria. Studies in Medieval and Early Modern Memorial Culture in Honour of Truus van Bueren, ed. Rolf de Weijert, Kim Ragetli, Arnoud-Jan Bijsterveld and Jeanette van Arenthals (Hilversum: 2011), 321-32.

[DENEFFE and POSTEC 2004-2005]

Deneffe, Dominique and Postec, Marie, "La Sainte Anne trinitaire de Neerlanden. Histoire et description. Traitement de restauration et étude matérielle," Bulletin de l'Institut royal du Patrimoine artistique 31 (2004-2005), 65-90.

[DHANENS 1965]

Dhanens, Elisabeth, Inventaris van het kunstpatrimonium van Oostvlaanderen. VI. Het retabel van het Lam Gods in de Sint-Baafskathedraal te Gent (Ghent: 1965).

[DHANENS 1980]

Dhanens, Elisabeth, Hubert et Jan van Eyck (Antwerp: 1980).

[DHANENS 1984]

Dhanens, Elisabeth, "Tussen de van Eycks en Hugo van der Goes," Mededelingen van de Koninklijke Academie voor Wetenschappen, Letteren en Schone Kunsten van België. Klasse der Schone Kunsten 45 (1984), 1-98.

[DHANENS 1987]

Dhanens, Elisabeth, "Een Maagschap van de H. Anna in het derde kwart van de 15de eeuw?," Academia Analecta. Mededelingen van de Koninklijke Academie voor Wetenschappen, Letteren en Schone Kunsten van Belgïe. Klasse der Schone Kunsten 48 (1987), 113-21.

[DHANENS 1998]

Dhanens, Elisabeth, Hugo van der Goes (Antwerp: 1998).

[DIDIER 1967]

Didie, Robert, "Les retables de Ternant," in Congrès d'archéologie du Nivernais (Paris: 1967), 258-76.

[DOORNINK-HOOGENRAAD 1965]

Doornink-Hoogenraad, M. M., "Petrus van Suchtelen en zijn memorietafel," Gelders Oudheidkundig contactbericht 28 (1965), 1-6.

[DUBOIS et alii 2012]

Dubois, Hélène, Currie, Christina and Vandekerchove, Véronique, “The Edelheere Triptych': The Earliest Copy of Rogier van der Weyden's 'Descent from the Cross'. History, Examination and Conservation Treatment," in Rogier van der Weyden in Context. Papers Presented at the Seventeenth Symposium for the Study of Underdrawing and Technology in Painting held in Leuven, 22-24 October 20og, ed. Lorne Campbell, Jan Van der Stock, Catherine Reynolds and Lieve Watteeuw (Leuven: 2012), 195-206. 


\section{[DUDOK VAN HEEL 1995]}

Dudok van Heel, S. A. C., "Een bordt van de drie coningen daer haer vaders figuer in staet'. Een vroeg portret van de familie Bas," Amstelodamum 82/4 (1995), 97-105.

[DUDOK VAN HEEL 1996]

Dudok van Heel, S. A. C., "Twee figuren te veel. De familie Cat en hun memorietafel uit 1517," Jaarboek Centraal Bureau voor Genealogie 50 (1996), 199-223.

[DUDOK VAN HEEL 1999]

Dudok van Heel, S. A. C., "Jan Dirckszn Sill en de zesde kapel van de Nieuwe Kerk," Amstelodamum 86 (1999), 161-69.

[DÜLBERG 1990]

Dülberg, Angelica, Privatporträts: Geschichte und Ikonologie einer Gattung im 15. und 16. Jahrhundert (Berlin: 1990).

[DUNKERTON et alii 1999]

Dunkerton, Jill, Foister, Susan, Gordon, Dillian and Penny, Nicholas, Giotto to Dürer: Early Renaissance Painting in the National Gallery (London: 1991).

[DUPONT 1938]

Dupont, Jacques, "Le retable d'Ambierlé," Gazette des Beaux-Arts 2 (1938), 276-88.

[DUQUENNE 2009]

Duquenne, Xavier, "Peeter Scheyfve et Agnès de Gramme, donateurs du triptyque de l'Adoration des mages de Jérôme Bosch (vers 1494) conservé au Prado," in Underdrawing and Technology in Painting. Symposium XVI. Bruges, September 21st, 22nd and 23rd, 2006. The Quest for the Original, ed. Hélène Verougstraete and Colombe Janssens de Bisthoven (Leuven: 2009), 27-33.

[EECKHOUT 1974]

Eeckhout, Paul, "Un triptyque gantois du XV e siècle acquis par les amis du Musée de Gand," L'antiquaire. Gazette nationale 13 (1974).

[EECKHOUT 1985-1988]

Eeckhout, Paul, "Les trois diptyques du Maître de 1499," Bulletin des Musées royaux des Beaux-Arts de Belgique 34-37 (1985-1988), 49-63.

[EICHBERGER 2002]

Eichberger, Dagmar, Leben mit Kunst. Wirken durch Kunst. Sammelwesen und Hofkunst unter Margarete von Österreich, Regentin der Niederlande (Turnhout: 2002).

[EISLER 1977]

Eisler, Colin, Painting from the Samuel H. Kress Collection. European Schools Excluding Italian (Oxford: 1977).

[EISLER 1989]

Eisler, Colin, The Thyssen-Bornemisza Collection. Early Netherlandish Painting (London: 1989).

[ENGELLAU-GULLANDER 1992]

Engellau-Gullander, Cecilia, Jan II van Coninxlo, a Brussels Master of the First Half of the 16th Century (PhD. Diss., University of Stockholm: 1992). 


\section{[EWING 1984]}

Ewing, Dan, “A Rediscovered Holy Kindred by Jan de Beer," Jaarboek van het Koninklijk Museum voor Schone Kunsten Antwerpen (1984), 85-102.

[EWING 2016]

Ewing, Dan, Jan de Beer. Gothic Renewal in Renaissance Antwerp (Turnhout: 2016). [FALQUE 2011]

Falque, Ingrid, "Entre traditions flamande et ibérique. Les œuvres religieuses flamandes comportant des portraits d'Espagnols (1400-1550)," Publication du Centre européen d'Études bourguignonnes (XIV ${ }^{e}-X V I^{e} s$.) 51 (2011), 275-301.

[FALQUE 2012]

Falque, Ingrid, "Ung petit tableau fermant a deux fuilletz. Notes sur l'évolution formelle et les voies de diffusion du diptyque à portrait dévotionnel dans les anciens PaysBas aux XVe et XVI ${ }^{\mathrm{e}}$ siècles," Le Moyen Âge 117/1 (2012), 89-127.

[FARIES et alii 1987]

Faries, Molly, Heller, B. and Levine, D., "The Recently Discovered Underdrawings of the Master of the Saint Ursula Legend's Triptych of the Nativity," Bulletin of the Detroit Institute of Arts 62 (1987), 4-19.

[FARMER 1981]

Farmer, John D., Bernard van Orley of Brussels (PhD. Diss., Princeton University: 1981). [FILEDT KOK et alii 1975]

Filedt Kok, Jan Piet, Eikemeier, Peter and Asperen de Boer, J. R. J., "Das Diptychon des Lucas van Leiden von 1522. Versuch einer Rekonstruktion,” Nederlands Kunsthistorisch Jaarboek 26 (1975), 229-58.

[FILEDT KOK et alii 2014]

Filedt Kok, Jan Piet, Gibson, Walter and Bruijnen, Yvette, Cornelis Engebrechtsz: A Sixteenth-Century Leiden Artist and his Workshop (Turnhout: 2014).

[FRANKE 2007-2008]

Franke, Susanne, "Between Status and Spiritual Salvation: The Portinari Triptych and Tommaso Portinari's Concern for His Memoria," Simiolus: Netherlands Quarterly for the History of Art 33 (2007-2008), 123-44.

[FRIEDRICHS 1970]

Friedrichs, H. F., Die Reichsfreiherren von Ritter zu Groenesteyn und ihre Vorfahren. II. Das Utrechter Geschlecht de Ridder (Neustad: 1970).

[GALAND 2013]

Galand, Alexandre, The Flemish Primitives VI: The Bernard Van Orley Group. Catalogue of Early Netherlandish Painting: Royal Museums of Fine Arts of Belgium (Turnhout: 2013).

[GAUTHIER 1968]

Gauthier, Marthe, Ternant (Nièvre). Son histoire et ses triptyques (Bourbon-Lancy: 1968). 


\section{[GEIRNAERT 1997]}

Geirnaert, Noël, "Le Triptyque de la Crucifixion de Hans Memling pour Jean Crabbe, abbé de l'abbaye des Dunes (1457-1488). Témoignage des documents contemporains," in Memling Studies. Proceedings of the International Colloquium (Bruges, 10-12 novembre 1994), ed. Hélène Verougstraete, Roger Van Schoute and Maurits Smeyers (Louvain-la-Neuve: 1997), 25-30.

[GELFAND 1994]

Gelfand, Laura D., Fifteenth-Century Netherlandish Devotional Portrait Diptychs: Origins and Functions (PhD. Diss., Case Western Reserve University: 1994).

[GELFAND 2009]

Gelfand, Laura D., "Piety, Nobility and Posterity: Wealth and the Ruin of Nicolas Rolin's Reputation," Journal of Historians of Netherlandish Art 1/1 (2009), DOI: 10.5092/ jhna.2009.1.1.3.

[GENAILLE 1961]

Genaille, Robert, "Reconstitution d'un triptyque de Bellegambe," Bulletin de la Societé de l'Histoire de l'Art français (1961), 7-20.

[GENAILLE 1963]

Genaille, Robert, “Le Retable de Varsovie. La ‘Déploration' de Jean Bellegambe," Bulletin du Musée National de Varsovie 4 (1963), 37-49.

[GENAILLE 1976]

Genaille, Robert, “L'œuvre de Jean Bellegambe," Gazette des Beaux-Arts 87 (1976), 7-28. [GEURTS 1968]

Geurts, P. A. M., "De graaf van Horne Filips van Montmorency. 1524-1568," Spiegel der historie 3 (1968), 105-44.

[GIBSON 1965]

Gibson, Walter S., "A New Identification for a Panel by the St. Barbara Master", The Art Bulletin 47/4 (1965), 504-06.

[GIBSON 1970]

Gibson, Walter S., "The Master of the Douai Carrying of the Cross," Oud Holland 85 (1970), 111-15.

[GIBSON 1977]

Gibson, Walter S., The Paintings of Cornelisz Engebrechtsz. (New York: 1977).

[GODDARD 1984]

Goddard, Stephen H., The Master of Frankfurt and his Shop (Brussels: 1984).

[GODFRIND-BORN 1995]

Godfrind-Born, Annick, "Le style et le rôle du dessin sous-jacent dans la genèse du triptyque de Marie-Madeleine attribué au Maître de 1518," Le dessin sous-jacent dans la peinture. Colloque X. Le dessin sous-jacent dans le processus de création (5-7 septembre 1993), ed. Roger Van Schoute and Hélène Verougstraete (Louvain-la-Neuve: 1995), 121-32. 
[GORMANS and LENTES 2007]

Gormans, Andrea and Lentes, Thomas (eds.), Das Bilder Erscheinung. Die Gregormesse im Mittelalter, Kultbild. Visualität und Religion in der Vormoderne (Berlin: 2007).

[GROSSHANS 1980]

Grosshans, Rainald, Maerten van Heemskerck. Die Gemälde (Berlin: 1980).

[GRÖSSINGER 1992]

Grössinger, Christa, North-European Panel Paintings: A Catalogue of Netherlandish and German Paintings before 1600 in English Churches and Colleges (London: 1992).

[GROUSTRA 2006]

Groustra, Aafje H., “Ter eeuwige herinneringen'. De kapittelheren van de SintWalburgiskerk te Zutphen," in Lebü̈nus en Walburgis biijen. Deventer en Zutphen als historische centra van kerkelijk leven (Delft: 2006), 135-164.

[GUISLAIN-WITTERMANN et alii 1980-1981]

Guislain-Wittermann, Régine, Comblen-Sonkes, Micheline, Kockaert, Léopold, Van den Bergen-Pantens, Christine, "Un triptyque de la Vierge aux anges annonciateurs de la Passion. Etat des observations technologiques et historiques et du traitement," Bulletin de l'Institut royal du Patrimoine artistique 18 (1980-1981), 191-217.

[HAAK 1958]

Haak, B., "Het portret van Pompejus Occo door Dirck Jacoobsz," Bulletin van het Rijksmuseum 8 (1958), 27-37.

[HALKIN 1946]

Halkin, Léon, "L'itinéraire de Belgique de Dubuisson-Aubenay (1623-1628)," in Revue belge d'archéologie et d'histoire de l'art, 16 (1946), 47-76.

[HAND 1978]

Hand, John Oliver, Joos van Cleve: The Early and Mature Paintings (PhD. Diss., Princeton University: 1978).

[HAND 2004]

Hand, John Oliver, Joos van Cleve: The Complete Paintings (New Haven: 2004).

[HARBISON 1973]

Harbison, Craig, "A Late 15th Century Flemish Panel Attributed to Vrancke van der Stockt," Allen Memorial Art Museum Bulletin 30/2 (1973), 52-62.

[HARRISON 1994]

Harrison, Jefferson C., "Jan Gossaert's Madonna and Child: A Newly Proposed Mabuse Triptych," Chrysler Museum Journal 1 (1994), 2-13.

[HAVERKAMP-BEGEMANN 1955]

Haverkamp-Begemann, Egbert, "De Meester van de Godelieve-Legende, een brugs schilder uit het einde van de XVde eeuw," Bulletin de Musées royaux des Beaux-Arts de Belgique (= Miscellanea Erwin Panofsky) 1955, 185-98. 


\section{[HEINS 2008]}

Heins, Pascal, “La 'Vierge au papillon' du Trésor de la cathédrale de Liège. Etude d'une 'Bildepitaph,' Bulletin de la Classe des Arts. Académie royale de Belgique 19 (2008), $215^{-73}$.

[HEISE and VOGELER 2008]

Heinse, Brigitte and Vogeler, Hildegard, Die Altäre des St. Annen Museums (Lübeck: 2008).

[HELLER 1976]

Heller, Elisabeth, Das altniederländische Stifterbild (Munich: 1976).

[HELMUS 2010]

Helmus, Liesbeth M., Schilderen in opdracht. Noord-Nederlandse contracten voor altaarstukken 1485-1570 (Utrecht: 2010).

[HENDERIKS 2011]

Henderiks, Valentine, Albrecht Bouts (1451/55-1549) (Turnhout: 2011). [HENDRIKMAN 1999]

Hendrikman, Lars, "Bernard van Orley's Washington Diptych, Art Historical and Technical Observations," in Le dessin sous-jacent et la technologie dans la peinture. Colloque XII. La peinture dans les anciens Pays-Bas au $16^{e}$ siècle. Pratiques d'atelier, infrarouges et autres méthodes d'investigation (11-13 septembre 1997), ed. Roger Van Schoute and Hélène Verougstraete (Louvain-la-Neuve: 1999), 63-72.

[HENDRIKMAN 2005]

Hendrikman, Lars, "Portraits and Politics. Evolution in the Depiction of King Christian II of Denmark During his Reign and Exile (1513-1531)," in Trade, Diplomacy and Cultural Exchange. Continuity and Change in the North Sea Area and the Baltic, ca. 1350-1750, ed. Hanno Brand (Hilversum: 2005), 186-210.

[HERMAND 2002]

Hermand, Xavier, "La réforme de l'abbaye de Saint-Trond et les réseaux monastiques au début du XVIe siècle," Revue bénédictine 112 (2002), 323-78.

[HOOGSTEDE et alii 2016]

Hoogstede, Luuk, Spronk, Ron, Erdmann, Robert G., Klein Gotink, Rik, Ilsink, Matthijjs, Koldeweij, Jos, Nap, Hanneke and Veldhuizen, Daan, Hieronymus Bosch, Painter and Draughtsman. Technical Studies (Brussels: 2016).

[HORN 1989]

Horn, Hendrick J., Jan Cornelisz. Vermeyen: Painter of Charles V and his Conquest of Tunis (Doornspijk: 1989).

[HULIN DE LOO 1939]

Hulin de Loo, Georges, "Comment j'ai trouvé Horenbaut," Annuaire des Musées royaux des Beaux-Arts de Belgique 2 (1939), 3-21. 


\section{[ILSINK et alii 2016]}

Ilsink, Matthijs, Koldeweij, Jos, Spronk, Ron, Hoogstede, Luuk, Erdman, Robert G., Gotink, Rik Klein, Nap, Hanneke and Veldhuizen, Daan, Hieronymus Bosch. Painter and Draughtsman: Catalogue Raisonné (Brussels: 2016).

[IMAÏ 2005]

Imaï, Sumiko, "La Virgo in sole de Robert Campin : mémorial personnel et document théologique," Annales d'Histoire de l'Art et d'Archéologie 27 (2005), 49-64.

[INIGUES 1925]

Iñigues, Angulo, "El maestro de la Virgo inter virgines. La tabla del primer conde de Alba," Archivo espanol de Arte y arqueologia 1 (1925), 193-96.

[JACOBS 1998]

Jacobs, Lynn F., Early Netherlandish Carved Altarpieces, 1380-1550. Medieval Tastes and Mass Marketing (Cambridge: 1998).

[JANSSENS DE BISTHOVEN 1984]

Janssens de Bisthoven, Boudewijn, "De graven van Vlaanderen en de abten van de Duinenabdij. De grisailles bewaard in het Grootseminarie van Brugge," in De Duinenabdij en het Grootseminarie te Brugge. Bewoners/Gebouwen/ Kunstpatrimonium, ed. Aldebert Denaux and Eric Vanden Berghe (Tielt: 1984), 287-335.

[JONES 1995]

Jones, Susan Frances, "The Virgin of Nicholas van Maelbeke and the Followers of Jan van Eyck," in Petrus Christus in Renaissance Bruges. An Interdisplinary Approach, ed. Ainsworth, Maryan W. (New York: 1995), 85-96.

[JONES 2006]

Jones, Susan Frances, "New Evidence for the Date, Function and Historical Significance of Jan van Eyck's Van Maelbeke Virgin," Burlington Magazine 148 (2006), 73-81.

[JOURNET 1963]

Journet, René, "Deux retables du XV e siècle à Ternant (Nièvres)," Annales littéraires de l'Université de Besançon 49 (1963), 5-45.

[KAGAN et alii 2002]

Kagan, Judith, Gerard, Aubert and Gerard-Bendele, Anne, "Le retable de la Passion de Ternant," in Retables brabançons des XV et XVI siècles. Actes du colloque organisé par le Musée du Louvre les 18 et 19 mai 2001, ed. Sophie Guillot de Suduiraut (Paris: 2002), 229-72.

[KASL 1999]

Kasl, Ronda, The Making of Hispano-Flemish Style: Art, Commerce, and Politics in Fifteenth-Century Castile (Turnhout: 2014).

[KNUST 2007]

Knust, Cornelia, Vorbild der Gerechtigkeit.Jan Provosts Gerichtsbild in Brügge, mit einem Katalog seiner Werke (Göttingen: 2007). 


\section{[KOCKEROLS 2004]}

Kockerols, Hadrien, Monuments funéraires en pays mosan. 4. Arrondissement de Liège: tombes et épitaphes, 1000-1800 (Malonne: 2004).

[KONOWITZ 1995]

Konowitz, Ellen, "Dirk Vellert and the Master of the Lille Adoration: Some Antwerp Mannerist Paintings Reconsidered," Oud Holland 109 (1995), 177-90.

[KOOPSTRA 2016]

Koopstra, Anna, Inventing Realities, Picturing Salvation: Making, Meaning and Patronage of the Paintings of Jean Bellegambe (c. 1470-1535/36) (PhD. Diss., Courtauld Institute of Art: 2016).

[KOSTER 1998]

Koster, Margaret L., "Reconsidering St Catherine of Bologna with Three Donors by the Baroncelli Master of Bruges," Simiolus: Netherlands Quarterly for the History of Art 26 (1998), 4-17.

[KOSTER 2003]

Koster, Margaret L., "New Documentation for the Portinari Altarpiece," The Burlington Magazine 145 (2003), 164-79.

[KOSTER 2008]

Koster, Margaret L., Hugo Van Der Goes and the Procedures of Art and Salvation (Turnhout: 2008).

[KOTKOVA 1999]

Kotkova, Olga, "Joos van Cleve, Triptych with the Adoration of the Magi in the National Gallery in Prague: an Example of Workshop Practice," in La peinture dans les PaysBas au ${ }_{16} 6^{e}$ siècle : pratiques d'atelier : infrarouges et autres méthodes d'investigation, ed. Roger Van Schoute and Hélène Verougstraete (Louvain-la-Neuve: 1999), 89-97.

[KYZOUROVA et alii 2010]

Kyzourová, Ivana, Necasková, Milena and Stehlíková, Dana, Geertgen tot Sint Jans: triptych s Klaněním tř́ králů: ze sbírek Pražského hradu (Prague: 2010).

[LANE 1970]

Lane, Barbara G., "Petrus Christus: A Reconstructed Triptych with an Italian Motif," The Art Bulletin $5^{2}$ (1970), 390-93.

[LANE 2009]

Lane, Barbara G., Hans Memling. Master Painter in Fifteenth-Century Bruges (London: 2009).

[LEEFLANG 2015]

Leeflang, Micha, Joos van Cleve. A Sixteenth-Century Antwerp Artist and his Workshop (Turnhout: 2015).

[LEEFLANG and MARTENS M. 2000]

Leeflang, Micha and Martens, Maximiliaan P. J., "Een vijftiende-eeuws Stichterspaneel gereconstueerd," in 200 jaar verzamelen. Collectieboek Museum voor Schone Kunsten 
Gent, ed. Arnout Balis, Robert Hoozee, Martens, Maximiliaan P. J. and Paul Van Haute (Ghent: 2000), 37-39.

[LIEBURG et alii 1996]

Lieburg, F. A., Okkema, J. C. and Schmitz, H., De Laurens in het midden. Uit de geschiedenis van de Grote kerk van Rotterdam (Rotterdam: 1996).

[LOZE 2004]

Loze, Pierre, "À propos du Maître de la Vue de Sainte-Gudule. Hypothèse sur ses commanditaires et la représentation d'une demeure seigneuriale dans plusieurs de ses œuvres," Annales d'Histoire de l'Art et d'Archéologie 26 (2004), 51-72.

[MADOU 2002]

Madou, Mireille, "Die bliscap is sonder eynde hier boven in hemelrijck," in Als ich can. Liber Amicorum in Memory of Professor Dr. Maurits Smeyers, ed. Bert Cardon, Jan Van der Stock, Dominique Vanwijnsberghe (Leuven: 2002), 843-6o.

[MAILLART 2011]

Maillart, François-Xavier, La confrérie du Puy Notre-Dame d'Amiens et sa production artistique et littéraire de 1389 à 1525 (Amiens: 2011).

[MAJERUS 1997]

Majérus, Pascal, Ces femmes qu'on dit béguines ... Guide des béguinages de Belgique. Bibliographie et sources d'archives (Brussels: 1997).

[MAQUET-TOMBU 1943a]

Maquet-Tombu, Jeanne, "Bernard van Orley et son entourage," Société royale d'archéologie de Bruxelles (1943), 145-66.

[MAQUET-TOMBU 1943b]

Maquet-Tombu, Jeanne, "Les Van Coninxloo et les abbayes bénédictines," Apollo 23 (1943), 16-21.

[MARCH 1948]

March, Maria J., "Tres tablas del Palau de Barcelona atribuibles a Mabuse," Boletin de la Sociedad Española de Excursiones 52 (1948), 289-301.

[MARIJNISSEN 1961]

Marijnissen, Roger H., "Het retabel van Averbode uit de verzamelingen van het Museum Vleeshuis. Onderzoek en behandeling," Tijdschrift der stad Antwerpen 7 (1961), 6-15. [MARIJNISSEN 1985]

Marijnissen, Roger H., Tableaux, authentiques, maquillés, faux: l'expertise des tableaux et les méthodes de laboratoire (Brussels: 1985).

[MARLIER 1957]

Marlier, Georges, Ambrosius Benson et la peinture à Bruges au temps de Charles-Quint (Damme: 1957).

[MARLIER 1964]

Marlier, Georges, “Le Maître de la Légende de sainte Ursule," Jaarboekvan het Koninklijk Museum voor Schone Kunsten (1964), 5-42. 
[MARLIER 1966]

Marlier, Georges, La Renaissance flamande. Pierre Coecke d'Alost (Brussels: 1966).

[MARTENS D. 1990]

Martens, Didier, "Une Crucifixion flamande et sa descendance au XVI ${ }^{\mathrm{e}}$ siècle. Lecture d'une séquence de copies," Jaarboek van het Koninklijk Museum voor Schone Kunsten Antwerpen (1990), 237-70.

[MARTENS D. 1991-1993]

Martens, Didier, "Un imitateur de Hans Memling : Le Maître du Triptyque Verbeek," Aachener Kunstblätter 59 (1991-1993), 239-57.

[MARTENS D. 1992]

Martens, Didier, "Le triptyque de Bientina. Motifs et sources," Gazette des Beaux-Arts 134 (1992), 149-64.

[MARTENS D. 1994]

Martens, Didier, "Observations sur la châsse de sainte Ursule de Hans Memling: sa structure, ses commanditaires et ses sources," Annales d'Histoire de l'Art et d’Archéologie 16 (1994), 79-98.

[MARTENS D. 1995]

Martens, Didier, "Le Maître des Portraits Baroncelli : un élève de Petrus Christus ?," Gentse Bijdragen tot de Kunstgeschiedenis en Oudheidkunde 30 (1995), 71-105.

[MARTENS D. 1997]

Martens, Didier, "Les deux triptyques jumeaux du Maître de la Légende de sainte Catherine : analyse des sources et chronologie relative," Revue belge d'archéologie et d'histoire de l'art 66 (1997), 35-73.

[MARTENS D. 1998a]

Martens, Didier, "La 'Sainte anne trinitaire au chartreux' de Poznan : primitif hollandais ou primitif flamand?," Annales de la Société Royale d'Archéologie de Bruxelles 62 (1998), 65-102.

[MARTENS D. 1998b]

Martens, Didier, "Nouvelles recherches sur la 'Madone au trône arqué' attribuée à Dirck Bouts," Jahrbuch der Berliner Museen 40 (1998), 45-70.

[MARTENS D. 2000]

Martens, Didier, "Un disciple tardif de Rogier de la Pasture : Maître Johannes (alias Johannes Hoesacker?)," Oud Holland 114 (2000), 79-106.

[MARTENS D. 2003]

Martens, Didier, "Un triptyque du Maître malinois de la Gilde de saint Georges au Musée Dobrée de Nantes," Acta historiae artium Academiae Scientiarum Hungaricae 44 (2003), 171-81.

[MARTENS D. 2007a]

Martens, Didier, "Une œuvre hispano-flamande du groupe au Feuillage brodé : le triptyque de Zumaia (Gipuzkoa)," in Le Maître au feuillage brodé. Démarches d'artistes et méthodes d'attribution d'œuvres à un peintre anonyme des anciens Pays-Bas duXV 
siècle. Colloque organisé par le Palais des Beaux-Arts de Lille les 23 et 24 juin 2005, ed. Florence Gombert and Didier Martens (Lille: 2007), 69-86.

[MARTENS D. 2007b]

Martens, Didier, "Iconoclasmes et malentendus. Une image méconnue du Sacrilège de Cambron," Zeitschrifte für Kunstgeschichte 70 (2007), 215-36.

[MARTENS D. 2010]

Martens, Didier, Peinture flamande et goût ibérique aux XV $V^{\text {ème }}$ et XVI ème siècles (Brussels: 2010).

[MARTENS D. and MUND 2003]

Martens, Didier and Mund, Hélène, "Autour de la Pentecôte Rapaert du Maître des Portraits Baroncelli : modèles et traditions dans la peinture brugeoise à l'aube des Temps modernes," Jahrbuch der berliner Museen 45 (2003), 7-37.

[MARTENS M. 1992a]

Martens, Maximiliaan P. J., Artistic Patronage in Bruges Institutions. c. 1440-1482 (PhD. Diss., University of California: 1992).

[MARTENS M. 1992b]

Martens, Maximiliaan P. J., "The Epitaph of Anna van Nieuwenhove," The Metropolitan Museum Journal 27 (1992), 37-42.

[MARTENS M. 2000]

Martens, Maximiliaan P. J., "De portretten van Lieven van Pottelsberghe en Livina van Steelant," in 200 jaar verzamelen: collectieboek Museum voor Schone Kunsten Gent, ed. Arnout Balis, Robert Hoozee, Maximiliaan P. J. Martens and Paul Van Haute (Ghent and Amsterdam: 2000), 52-56.

[MARTENS M. and VAN MIEGROET 1981-1984]

Martens, Maximiliaan P. J. and van Miegroet, Jan, "Nieuwe inzichten omtrent de omstreden du Cellier-diptiek, toegeschreven aan Hans Memling," Gentse Bijdragen tot de Kunstgeschiedenis 26 (1981-1984), 59-88.

[MARTINDALE 1989]

Martindale, Andrew, "The Ashwellthorpe Triptych," in Early Tudor England: Proceedings of the 1987 Harlaxton Symposium, ed. Daniel Willams (Woodbridge: 1989), 107-23.

[MÄND 2000]

Mänd, Anu, "Über den Marienaltar der Revaler Schwarzenhäupter und seine Ikonographie," in Eesti kunstuisidemed Madalmaadega 15.-17. Sajandil. Püha Lucia Legendi meistri Maartja altar 500 aastat Tallinas. Konverents 25.-26. September 1995. Die Kunstbeziehungen Estlands mit den Niederlanden in den 15.-17. Jahrhunderten. Der Marienaltar des Meisters der Lucialegende 500 Jahre in Tallinn. Konferenz am 25.26. September 1995 (Tallinn: 2000), 228-38.

[MÄND 2007]

Mänd, Anu, "The Altarpiece of the Virgin Mary of the Confraternity of the Black Heads in Tallinn: Dating, Donors, and the Double Intercession," Acta Historiae Artium Balticae 2 (2007), 35-53. 
[MÄND and NURKSE 2013]

Mänd, Anu and Nurkse, Alar, "Family Ties and the Commissioning of Art: On the Donors and Overpaintings of the Netherlandish Passion Altarpiece," Kunstiteaduslikke Uurimusi / Studies on Art and Architecture 22/3-4 (2013), 115-48.

[MEUWISSEN and VAN LEERDAM 2011]

Meuwissen, Daantje and van Leerdam, Andrea, "The Last Judgement with Christian II of Denmark and Isabella of Austria. A Memorial Piece from the Workshop of Jacob Cornelisz. van Oostsanen?," in Living Memoria. Studies in Medieval and Early Modern Memorial Culture in Honour of Truus van Bueren, ed. Rolf de Weijert, Kim Ragetli, Arnoud-Jan Bijsterveld and Jeanette van Harenthals (Hilversum: 2011), 333-45.

[MOLHUYSEN and BLOK 1914]

Molhuysen, P. C. and Blok, P. J. (ed.), Nieuw Nederlandsch biografisch woordenboek, vol. 3 (Leiden: 1914).

[MÜLLER HOFSTEDE 1991]

Müller Hofstede, Justus, "Jan van Dornickes Kreuzigungsaltar. Ein Meisterwerk der Antwerpener Malerei vor Pieter Bruegel D. Ä," Wallraf-Richartz Jahrbuch $5^{2}$ (1991), $151-61$.

[NEIDHARDT and SCHÖLZEL 200o]

Neidhardt, Uta and Schölzel, Christoph, "Jan van Eyck's Dresden Triptych," in Investigating Jan van Eyck, ed. Susan Foister, Sue Jones and Delphine Cool (Turnhout: 2000), 25-39.

[NICOULINE 1987]

Nicouline, Nicolas, Peintures néerlandaises des $X V^{e}$ et $X V I^{e}$ siècles dans les musées de l'Union soviétique (Leningrad: 1987).

[NIESSEN 2010]

Niessen, Judith, “De Meester van Alkmaar en zijn werkplaats, een heroverweging," Oud Holland 123 (2010), 260-304.

[NYS 2001]

Nys, Ludovic, Les tableaux votifs tournaisiens en pierre: 1350-1475 (Brussels: 2001).

[NYS 2003]

Nys, Ludovic, "Le Triptyque Seilern: une nouvelle hypothèse," La Revue de l'art 139/1 (2003), 5-20.

[PACULLY 1897]

Pacully, Emil, "Le retable d'Oporto," Gazette des Beaux-Arts 39 (1897), 196-204.

[PASSEMIERS 1987]

Passemiers, Gérard, Goossen van der Weyden (1465-1538/1545). Peintre de l'école anversoise (Brussels: 1987).

[PAUWELS 1959]

Pauwels, Henri, "Een kruisiging met stichters van Joos van Wassenhove," Revue belge d'archéologie et d'histoire de l'art 28 (1959), 43-51. 


\section{[PEARSON 2000]}

Pearson, Andrea, "Personal Worship, Gender, and the Devotional Portrait Diptych.

Gender in Early Modern Europe," Sixteenth Century Journal 31/1 (2001), 99-122.

[PEARSON 2001]

Pearson, Andrea, "Nuns, Images, and the Ideals of Women's Monasticism: Two Paintings

from the Cistercian Convent of Flines," Renaissance Quarterly 54/4 (2001), 356-402.

[PEARSON 2001-2002]

Pearson, Andrea, "Margaret of Austria's Devotional Portrait Diptychs," Woman's Art Journal 22/2 (2001-2002), 19-25.

[PEARSON 2005]

Pearson, Andrea, Envisioning Gender in Burgundian Devotional Art, 1350-1530. Experience, Authority, Resistance (Aldershot: 2005).

[PEARSON 2017]

Pearson, Andrea, "Sensory Piety as Social Intervention in a Mechelen Besloten Hofje," Journal of Historians of Netherlandish Art 9/2 (2017), DOI: 10.5092/jhna.2017.9.2.1.

[PELINCK 1959]

Pelinck, E., "Drie Hollandse memorietafels uit de 16de eeuw en hun stichters

(Boshuysen, Berendrecht, Booth)," Jaarboek van het Centraal Bureau voor Genealogie 13 (1959), 99-104.

\section{[PERIER D'IETEREN 1971]}

Périer d'Ieteren, Catheline, "Le portrait d'un seigneur de Bricquegny dû au Maître de la gilde de Saint-Georges," Revue belge d'archéologie et d'histoire de l'art 40 (1971), $39-53$.

[PERIER D'IETEREN 1975a]

Périer d'Ieteren, Catheline, "Contribution à l'étude des volets du triptyque dit de Toison d'or attribués au Maître de la Légende de sainte Marie-Madeleine," Oud Holland 89 (1975), 129-41.

[PERIER D'IETEREN 1975b]

Périer d'Ieteren, Catheline, "Précisions iconographiques et historiques sur la série de la Légende de Saint Rombaut," Handelingen van het Koninklijke Kring voor Oudheidkunde Letteren en Kunst van Mechelen 79 (1975), 113-32.

[PERIER D'IETEREN 1975c]

Périer d'Ieteren, Catheline, "Le Maître de la gilde de Saint Georges: catalogue critique de cinq des panneaux de la Légende de saint Rombaut," Jaarboek van het Koninklijk Museum voor Schone Kunsten Antwerpen (1975), 153-200.

[PERIER D'IETEREN 1976]

Périer d'Ieteren, Catheline, "Deux panneaux de la Légende de saint Rombaut de Malines conservés à Dublin," Jaarboek van het Koninklijk Museum voor Schone Kunsten Antwerpen (1976), 83-108. 


\section{[PERIER D'IETEREN 1976-77]}

Périer d'Ieteren, Catheline, "Un triptyque maniériste anversois conservé à Diest. Contribution à l'étude du poncif et problème des volets," Bulletin de l'Institut royal du Patrimoine artistique 16 (1976-77), 96-113.

[PERIER D'IETEREN 1985a]

Périer d'Ieteren, Catheline, "Une œuvre inédite de Jean Provost. Le triptyque Van der Burch et ses rapports avec le diptyque du Fogg Museum," La Revue de l'art 67 (1985), $66-76$.

[PERIER D'IETEREN 1985b]

Périer d'Ieteren, Catheline, Colyn de Coter et la technique picturale des peintres flamands du XV $V^{e}$ siècle (Brussels: 1985).

[PERIER D'IETEREN 1986]

Périer d'Ieteren, Catheline, "Une œuvre retrouvée du Maître des Portraits princiers," Annales d'Histoire de l'Art et d'Archéologie 8 (1986), 43-58.

[PERIER D'IETEREN 2005]

Périer d'Ieteren, Catheline, Thierry Bouts. L'ouvre complet (Brussels: 2005).

[PERIER D'IETEREN and GESCHE-KONING 2000]

Périer d'Ieteren, Catheline and Gesche-Koning, Nicole, Guide bruxellois des retables

(Brussels: 2000).

[PLOMP and VAN BUEREN 1999]

Plomp, Nico and van Bueren, Truus, "Luiken met gebedsportretten van Maarten van Heemskerck," Genealogie. Kwartaalblad van het Centraal Bureau voor Genealogie 5 (1999), 88-91.

[PYPAERT 2008]

Pypaert, Jean-Luc, "Early Netherlandish Painting XV? Joseph Van der Veken," in Autour de la Madeleine Renders. Un aspect de l'histoire des collections, de la restauration et de la contrefaçon en Belgique dans la première moitié du vingtième siècle, ed. Dominique Vanwijnsberghe (Turnhout: 2008), 197-282.

[RENSON 2001]

Renson, Marianne, "Genealogical Information Concerning the BronchorstBosschuysen Triptych," in Hieromynus Bosch. New Insights Into his Life and Work, ed. Jos Koldeweij, Bernard Vermet and Barbara van Kooij (Rotterdam: 2001), 93-95. [RIMMELE 2014]

Rimmele, Marius, "Klapp-Effekte. Medienspezifika als künstmerisch Herausforderung am Beispiel von Colijn de Coters Brüsseler Kreuzabnahme-Triptychon," WallrafRichartz-Jahrbuch 75 (2015), 131-64.

[RINGBOM 1995]

Ringbom, Sixten, Les images de dévotion. $X I I^{e}-X V^{e}$ siècles (Paris: 1995).

[ROBIJNS DE SCHEIDAUER 1955]

Robijns de Scheidauer, Louis, "Les Grands-Aumôniers d'Anvers," L'intermédiaire des généalogistes 57 (1955), 113-25. 


\section{[ROTHSTEIN 1999]}

Rothstein, Bret, "Vision and Devotion in Jan van Eyck's Virgin and Child with Canon Joris Van der Paele," Word and Image 15 /3 (1999), 262-76.

[SANDALINAS LINARES et alii 2018]

Sandalinas Linares, Carmen, Fransen, Bart and Van Eyck, Elisabeth, "The Polyptych of the Seven Sorrows of the Virgin in the Museu Frederic Marés. An Unusual Altarpiece," in Technical Studies of Paintings: Problems of Attribution (15th17th Centuries). Papers Presented at the Nineteenth Symposium for the Study of Underdrawing and Technology in Painting held in Bruges, 11-13 September 2014, ed. Anne Dubois, Jacqueline Couvert and Till-Holger Borchert (Leuven: 2018), 122-36.

[SANDERS 1990]

Sanders, Johannes G. M., Waterland als woestijn. Geschiedenis van het kartuizersklooster 'Het Hollandse Huis' bij Geerttruidenberg. 1336-1595 (Hilversum: 1990).

[SCHADE 2001]

Schade, Karl, Ad excitandum devotionis affectum. Kleine Triptychen in der altniederländischen Malerei (Weimar: 2001).

[SCHERER 2003]

Scherer, Annette, "Fromme Rätsel. Beobachtungen zum Diptychon eines Franziskaners von Jan Provost," in Im Zeichen des Christkinds: privates Bild und Frömmigkeit im Spätmittelalter, ed. Frank Matthias Kammel (Nuremberg: 2003), 78-86.

[SCHLUMBERGER 1965]

Schlumberger, Eveline, "L'admirable retable d'Ambierlé rétabli à sa place originelle," Connaissance des arts 1 (1965), 22-28.

[SCHMIDT C. 1986]

Schmidt, Cornelis, Om de eer van de familie. Het geslacht Teding van Berkhout 1500-1950. Een sociologische benadering (Amsterdam: 1986).

[SCHOLTENS 1958]

Scholtens, H. J. J., "Het te Napels bewaarde Kersttafereel van Jacob Cornelisz. van Oostsanen," Oud Holland 73 (1958), 198-210.

[SEDLACEK 1997]

Sedlacek, Ingrid, "En espérence. Zu dem Marien-Triptychon mit der Mitteltafel des Hugo van der Goes im Frankfurter Städel," Wallraf-Richartz-Jahrbuch $5^{8}$ (1997), 15-30.

[SILVER 1984]

Silver, Larry, The Paintings of Quinten Massys with Catalogue Raisonné (Oxford: 1984).

[SILVER 2006]

Silver, Larry, Bosch (Paris: 2006).

[SIP 1963]

Sip, Jaromîr, Geertgen tot Sint Jans: die Anbetung der heiligen drei Könige (Prague: 1963). 


\section{[SNYDER 1971]}

Snyder, James E., "The Early Haarlem School of Painting, Part III: The Problem of Geertgen tot Sint Jans and Jan Mostaert," The Art Bulletin 53/4 (1971), 445-58.

[STERLING 1978]

Sterling, Charles, "Carnet savoyard," Revue du Louvre 28 (1978), 333-42.

[STEYAERT 2016]

Steyaert, Griet, “'A Deposition Including Two Men on two Ladders': Carel van Mander's Description of Rogier's Deposition and the Deposition by the Master of the Legend of Saint Catherine," in Rogier van der Weyden y España. Actas del congreso internacional, Proceedings of the International Symposium, Madrid, Museo Nacional del Prado, mayo de 2015, ed. Lorne Campbell and José Juan Pérez Preciado (Madrid: 2016), 57-65.

[STOCKMANS 1908]

Stockmans, J. B., "De Triptiek-Colibrant en haren schenker," Bulletin de l'Académie royale d'archéologie de Belgique 1 (1908), 290-312.

[STOOP 2013]

Stoop, Patricia, Schrijven in commissie. De zusters uit het Brusselse klooster Jericho en de preken van hun biechtvaders (ca. 1456-1510) (Hilversum: 2013).

[STREETON 2011]

Streeton, Noëlle L. W., "Jan van Eyck's Dresden Triptych: New Evidence for the Giustiniani of Genoa in the Borromei Ledger for Bruges," Journal of Historians of Netherlandish Art 3/1 (2011), DoI: 10.5092/jhna.2011.3.1.1.

[STROO 2009]

Stroo, Cyriel (ed.), Pre-Eyckian Panel Painting in the Low Countries. I. Catalogue (Brussels: 2009).

[STROO and SYFER D'OLNE 1996]

Stroo, Cyriel and Syfer-d'Olne, Pascale, The Flemish Primitives. I. The Master of Flémalle and Rogier van der Weyden Groups. Catalogue of Early Netherlandish Painting in the Royal Museums of Fine Arts of Belgium (Brussels: 1996).

[STROO et alii 1999]

Stroo, Cyriel, Syfer-d'Olne, Pascale, Dubois, Anne, and Slachmuylders, Roel, The Flemish Primitives. II. The Dirk Bouts, Petrus Christus, Hans Memling and Hugo van der Goes Groups. Catalogue of Early Netherlandish Painting in the Royal Museums of Fine Arts of Belgium (Brussels: 1999).

[STROO et alii 2001]

Stroo, Cyriel, Syfer-d'Olne, Pascale, Dubois, Anne, Slachmuylders, Roel, and Toussaint, Nathalie, The Flemish Primitives. III. The Hieronymus Bosch, Albrecht Bouts, Gerard David, Colijn de Coter and Goossen van der Weyden Groups. Catalogue of Early Netherlandish Painting in the Royal Museums of Fine Arts of Belgium (Brussels: 2001). 


\section{[STROO et alii 2006]}

Stroo, Cyriel, Syfer-d'Olne, Pascale, Dubois, Anne, Slachmuylders, Roel, Fransen, Bart and Peters, Famke, The Flemish Primitives. IV. Masters with Provisional Names. Catalogue of Early Netherlandish Painting in the Royal Museums of Fine Arts of Belgium (Turnhout: 2006).

[SUGIYAMA 2016]

Sugiyama, Miyako, "An Image for 'All Truly Penitent'. Reconsidering the Function of the Madonna of Jan Vos by Jan van Eyck and His Workshop," Medieval Low Countries 3 (2016), 97-121.

[TESTA 1986]

Testa, Judith A., "A Note of the Relationship of Manuscript Illuminations and Panel Painting: Simon Bening's Beata Rosarium and the Diptych of Chrétien de Hondt," Jaarboek van het Koninklijk Museum voor Schone Kunsten Antwerpen (1986), 19-30.

[THÜRLEMANN 2002]

Thürlemann, Felix, Robert Campin. A Monographic Study with Critical Catalogue (Munich: 2002).

[TOMBU 1927]

Tombu, Jeanne, “Un triptyque du Maître de la Légende de Marie-Madeleine," Gazette des Beaux-Arts 69 (1927), 299-310.

[TOMBU and LEFFEVRE 1930]

Tombu, Jeanne and Lefèvre, Placide, "Un diptyque de l'Église Saint-Nicolas à Bruxelles," Annales de la Société royale d'Archéologie de Bruxelles 35 (1930), 175-78.

[ULRIX-CLOSSET 1962]

Ulrix-Closset, Marguerite, "La Vierge au donateur du musée de l'hôpital civil de Tongres," Bulletin du Crédit communal de Belgique (1962), 1-7.

[UNVEFEHRT 1975]

Unvefehrt, Gerd, "Zu einigen Halbfigurenbildern Hieronymus Boschs und seines Kreises," Jaarboek van het Koninklijk Museum voor Schone Kunsten Antwerpen (1975), 101-52.

[URBACH 2015]

Urbach, Susan, Early Netherlandish Paintings. Old Masters' Gallery Catalogues, Szépmúvészeti Múzeum Budapest, 2 vols (London: 2015).

[VAN BELLINGEN 1986]

Van Bellingen, S., “De Meester van 1518," Brabantse Folklore 251 (1986), 236-41.

[VAN BRUAENE 2004 (online)]

Van Bruaene, Anne-Laure, Repertorium van rederijkerskamers in de Zuidelijke Nederlanden en Luik 1400-1650 (2004), [online] http://www.dbnl.org/titels.titel .php?id=bruaoo2repeo1. 


\section{[VAN BUEREN 1989]}

van Bueren, Truus, "Gegevens over enkele epitafen uit het Sint Jansklooster te Haarlem,"

Oud Holland 103 (1989), 121-51.

[VAN BUEREN 1993]

van Bueren, Truus, Tot lof van Haarlem. Het beleid van de stad Haarlem ten aanzien van de kunstwerken uit de geconfisqueerde geestelije instellingen (Hilversum: 1993).

[VAN CAMP 1952]

Van Camp, Gaston, "Iconographie de la trinité dans un triptyque flamand de ca. 1500," Revue belge d'archéologie et d'histoire de l'art 21 (1952), 55-58.

[VAN DEN BERGEN-PANTENS 1967]

Van den Bergen-Pantens, Christiane, "Un tableau votif de Philippe de Hinckaert (1505)," Le Parchemin 121-122 (1967), 213-17.

[VAN DEN BERGEN-PANTENS 1969]

Van den Bergen-Pantens, Christiane, "Iconographie d'une alliance: les Wouters et les Beste," Le Parchemin 140 (1969), 389-401.

[VAN DEN BERGEN-PANTENS 1973]

Van den Bergen-Pantens, Christiane, "Le triptyque Micault de J. C. Vermeyen. Étude historique," Bulletin des Musées royaux des Beaux-Arts de Belgique 22/3-4 (1973), 33-57.

[VAN DEN BERGEN-PANTENS 1976-77]

Van den Bergen-Pantens, Christiane, "Un triptyque maniériste anversois conservé à Diest. Contribution à l'identification des premiers donateurs," Bulletin de l'Institut royal du Patrimoine artistique 16 (1976-1977), 114-29.

[VAN DEN BERGEN-PANTENS 1976]

Van den Bergen-Pantens, Christiane, "Une œuvre inédite du Maître du Saint-Sang," Handelingen van het Genootschap voor Geschiedenis Société d'émulation te Brugge 113 (1976), 229-46.

[VAN DEN BERGEN-PANTENS 2001]

Van den Bergen-Pantens, Christiane, "Étude et datation du Triptyque de saint Hippolyte (Cathédrale Saint-Sauveur à Bruges). Apport des archives," in Bouts Studies. Proceedings of the International Colloquium (Leuven, 26-28 November 1998), ed. Bert Cardon, Maurits Smeyers, Roger Van Schoute and Hélène Verougstraete (Leuven: 2001), 11-18.

[VAN DER KLOOSTER 1963]

van der Klooster, L. J., “Drie opmerkingen over Jan Mostaerts z.g. Alckemade triptiek,” Jaarboek van het Centraal Bureau voor Genealogie 17 (1963), 137-42.

[VAN DER PLOEG 1998]

van der Ploeg, Frank, "Jan II van Coninxloo en zijn werkzaamheden voor het benedictinessenklooster van Groot-Bijgaarden bij Brussel," Oud Holland 112 (1998), 104-26. 


\section{[VAN DER VELDEN 2006]}

van der Velden, Hugo, "Diptych Altarpiece and the Principle of Dextrality," in Essays in

Context. Unfolding the Netherlandish Diptych, ed. John Oliver Hand and Ron Spronk

(Cambridge: 2006), 124-55.

[VAN DIJCK 1998]

van Dijck, G. C. M., "Peter van Os ontmaskerd. Het drieluik van Boston," Brabantse Leeuw 47/2 (1998), 116-24.

[VAN LUTTERVELT 1947]

van Luttervelt, Raymond, "Twee utrechtse primitieven (Johannes van Huemen?)," Oud Holland 62 (1947), 107-22.

[VAN LUTTERVELT 1951]

van Luttervelt, Raymond, "Schilderijen met karthuizers uit de late 15de en de vroege 16de eeuw," Oud Holland 66 (1951), 75-92.

[VAN MIEGROET 1989]

van Miegroet, Hans J., Gerard David (Antwerp: 1989).

[VAN MOLLE 1960]

van Molle, Frans, Identification d'un portrait de Gilles Joye attribué à Memling (Brussels: 1960).

[VAN ROEY 1954-1960]

Van Roey, J., "Een onbekende Antwerpse Schilder; Jan van Wueluwe (ca. 1485-14 october 1550)," Jaarboek van het Koninklijk Museum voor Schone Kunsten Antwerpen (1954-1960), 65-72.

[VAN SCHOUTE and VEROUGSTRAETE 1996]

Van Schoute, Roger and Verougstraete, Hélène, "À propos du triptyque (?) de Benedetto Portinari de Hans Memling," Art\&Fact. Mélanges Pierre Colman 15 (1995), 65-66.

[VAN SUCHTELEN et alii 1997]

van Suchtelen, Ariane, Bruijnen, Yvette and Buijsen, Edwin, Art on Wings. Celebrating the Reunification of a Triptych by Gerard David (The Hague: 1997).

[VAN WAMEL 2016]

van Wamel, Marieke, "The Patron in the Picture. Bosch and his Donor Portraits," in Jheronimus Bosch: His Life and his Work. Proceedings of the 4 th International Jheronimus Bosch Conference, 14-16 April 2016, ed. Jo Timmermans, Ron Spronk, Jos Koldeweij et alii (Den Bosch: 2016), 408-23.

[VAN WEZEL 2003]

van Wezel, Gerard (ed.), De Onze-Lieve-Vrouwekerk en de grafkapel voor Oranje-Nassau te Breda (Zeist: 2003).

[VANWIJNSBERGHE 2003]

Vanwijnsberghe, Dominique, "Lidentification du portrait 'Froimont' de Rogier van der Weyden," Revue de l'art 139 (2003), 21-36. 


\section{[VELDMAN 1996]}

Veldman, Ilda M., "Een monument in de Alkmaarse geschiedenis. Het Laurentiusdrieluik van Maarten van Heemskerck," in Glans en glorie van de Grote Kerk. Het interieur van de Alkmaarse Sint Laurens, ed. Leo Noordegraaf (Hilversum: 1996), $203-26$.

\section{[VERHAEGEN 1961]}

Verhaegen, Nicole, "Un important retable du Maître de la Légende de sainte Lucie conservé à Tallin," Bulletin de l'Institut royal du Patrimoine artistique 4 (1961), 142-54.

[VEROUGSTRAETE and VAN SCHOUTE 1989]

Verougstraete, Hélène and Van Schoute, Roger, Cadres et supports dans la peinture flamande aux $X V^{e}$ et $X V I^{e}$ siècles (Heure-le-Romain: 1989).

[VOGT 2002]

Vogt, Christine, Meister von Frankfurt-Meister von Delft. Das Annentriptychon der Delfter Familie van Beest im Suermondt-Ludwig-Museum Aachen (Aachen: 2002).

[VON SONNENBURG 1994]

von Sonnenburg, Hubert, "A Case of Recurring Deception," The Metropolitan Museum of Art Bulletin 51 (1993-1994), 9-19.

[VRANCKX 1999]

Vranckx, Jochen, Het drieluik van de Heilige Drievuldigheid in de Sint-Servatiuskerk van Berg. Een integrale benadering (master's thesis, Katholieke Universiteit Leuven: 1999).

[WALLEN 1971]

Wallen, Burr, "The Portraits of Jan Sanders van Hemessen," Oud Holland 86 (1971), $70-87$.

[WALLEN 1983]

Wallen, Burr, J. S. Van Hemessen. An Antwerp Painter Between Reform and Counter Reform (Ann Arbor: 1983).

[WAUTERS 1909]

Wauters, A. J., "Corneille van Coninxloo et le Triptyque de l'abbé de Tuegele au Musée de Bruxelles," Revue de Belgique 55 (1909), 99-113.

[WEALE 1910]

Weale, James H., "Portraits of Archbishop John Carondelet," The Burlington Magazine for Connoisseurs 16/84 (1910), 341-43.

[WEIDEMA and KOOPSTRA 2012]

Weidema, Sytske and Koopstra, Anna, Jan Gossart. The Documentary Evidence (London: 2012).

[WERA 1951]

Wéra, Martine, "Contribution à l'étude d'Albert Bouts," Revue belge d'archéologie et d'histoire de l'art 20 (1951), 139-44. 


\section{[WOLFF-THOMSEN 1997]}

Wolff-Thomsen, Ulrike, "Jan Joest von Kalkar. Ein niederländischer Maler um 1500," Bielefeld (1997), 386-89.

[WOLFTHAL 2007]

Wolfthal, Diane, "Florentine Bankers, Flemish Friars and the Patronage of the Portinari Altarpiece," in Cultural Exchange Between the Low Countries and Italy (1400-160o), ed. Ingrid Alexander-Skipes (Turnhout: 2007), 1-22.

[WOLLESWINKEL 1993]

Wolleswinkel, E. J., "De portretcollectie Pauw van Wieldrecht op 'Broekhuizen' te Leersum (I)," Jaarboek van het Centraal Bureau voor Geneaologie 47 (1993), 147-74.

[WOLLESWINKEL 1994]

Wolleswinkel, E. J., "De portretcollectie Pauw van Wieldrecht op 'Broekhuizen' te Leersum (II)," Jaarboek van het Centraal Bureau voor Geneaologie 48 (1994), 108-37. [WOOLLETT et alii 2012]

Woollett, Anne T., Szafran, Yvonne and Phenix, Alan, Drama and Devotion. Heemskerck's Ecce Homo Altarpiece from Warsaw (Los Angeles: 2012).

[WRIGHT 1980]

Wright, "The Dutch Masters. Paintings from the Sarah Campbell Blaffer Collection," The Connoisseur 204 (1980), 176-83.

[ZATTI 2011]

Zatti, Susanna, La Pinacoteca Malaspina (Pavia: 2011). [ZDANOV 2015]

Zdanov, Sacha, "Le Triptyque De la Coste Adornes : étude historique, technique et stylistique," Annales d'Histoire de l'Art et d'Archéologie 37 (2015), 47-72. 


\section{Photographic Credits}

Alain Marchandisse: Figs. 31, 160.

Alte Pinakothek, Munich: Figs. 272, 350, 390, 436, 559, 561, 629, 714.

Amsterdam Museum, Amsterdam: Fig. 309.

Barnes Foundation, Merion: Figs. 20, 124, 219.

bpk, Berlin: Fig. 456.

Collectie Gelderland: Fig. 737 .

County Museum of Art, Los Angeles: Fig. 492.

Fundación Colección Thyssen-Bornemisza, Madrid: Figs. 242, 491, 566, 738.

Ingrid Falque: Figs. 547, 611.

KIK-IRPA, Brussels: Figs. 1, 9, 13, 17, 19, 21, 22, 25, 30, 34, 35, 37, 38, 41, 46, 47, 48, 49, 50, 51, 52, 53, 54, 58, 71, 103, 107, 109, 110, 111, 117, 120, 121, 122, 128, 129, 134, 135, 136, 139, 140, 141, 143, 146, 147, 149, 152, 153, 156, 157, 158, 159, 163, 174, 176, 179, 180, 183, 192, 194, 197, 204, 206, 212, 213, 215, 216, 223, 231, 234, 237, 238, 256, 258, 259, 260, 262, 264, 266, 268, 270, 271, 275, 278, 282, 284, 289, 294, 298, 306, 310, 320, 321, 324, 326, 327, 328, 330, 334, 338, 339, 341, 351, 353, $357,359,360,364,365,371,376,377,381,383,394,396,397,399,401,402$, 403, 404, 405, 406, 409, 410, 411, 412, 417, 420, 428, 431, 432, 435, 437, 443, 444, 446, 449, 454, 458, 459, 460, 461, 463, 464, 470, 471, 472, 476, 477, 481, $485,487,489,495,497,498,499,500,505,508,509,512,513,514,515,519$, $5^{21,} 529,532,537,538,539,542,543,546,55^{0}, 55^{2}, 557,562,564,567,568$, $572,575,576,577,579,581,585,586,588,589,591,596,599,601,606,614$, $619,620,626,627,628,633,643,645,646,647,648,650,651,653,659,660$, $662,663,664,665,666,667,668,670,671,672,673,674,676,677,683,684$, $685,689,691,692,693,694,695,696,697,699,700,701,710,712,718,719$, $722,726,729,732,746,748$, add. 5 .

Lasalle University Art Museum, Philadelphia: Fig. 217.

Lempertz: Fig. 728.

Metropolitan Museum of Art, New York: Figs. 148, 229, 230, 273, 276, 329, 349, 429, 433, 482, 488, 496, 502, 545, 571, 587, 639, 649, 669, 720, 731.

Musée Dobrée, Nantes: Fig. 473.

Musée de l'Ain, Bourg-en-Bresse: Fig. 336.

Museo Nacional del Prado, Madrid: Fig. 730.

Museum Frederic Marès, Barcelone: Fig. 474.

Museum Rotterdam, Rotterdam: Fig. 91.

National Gallery, London: Figs. 214, 224, 281, 322, 323, 325, 335, 358, 396, 398, 423, $544,565,574,583,604,687,707,712$.

National Gallery of Art, Washington: Figs. 274, 283, 622. 
Nelson-Atkins Museum of Art, Kansas City: Fig. 713.

Norton Gallery and School of Art, West Palm Beach: Fig. 663.

National Trust Images: Fig. 678.

Philadelphia Museum of Art, Philadelphia: Figs. 5, 125, 250, 261, 451, 494, 613, 616.

Rijksmuseum, Amsterdam: Figs. 15, 36, 45, 6o, 69, 94, 95, 279, 285, 303, 354, 414, $418,424,45^{2}, 503,531,540,541,603,607,747$.

Rijksmuseum Twenthe, Enschede: Figs. 56, 413, 469, 592, 743.

R KD, The Hague: Figs. 42, 65, 74, 76, 106, 108, 114, 123, 142, 151, 168, 181, 201, 203, 221, 225, 246, 247, 252, 254, 267, 288, 292, 300, 308, 311, 345, 346, 372, 373, $382,387,478,517,518,525,534,548,549,600,608,609,630,634,636,637$, $640,644,652,675,716,721$.

Sarah Campbell Blaffer Foundation, Houston: Fig. 441.

Sotheby's: Figs. 3, 6, 23, 523, 623 .

Statens Museum for Kunst, Copenhagen: Figs. 280, 361, 419, 595 .

Stedelijk Museum de Lakenhal: Figs. 83, 342, 343, 344.

Victoria \& Albert Museum, London: Fig. add. 3.

Wallraf-Richartz Museum, Cologne: Fig. 173.

Walters Art Gallery, Baltimore: Fig. 162.

Wikimedia commons: Figs. 14, 18, 32, 57, 64, 68, 82, 161, 182, 227, 232, 233, 239, 251, 255, 265, 287, 290, 291, 293, 299, 304, 312, 348, 355, 362, 366, 367, 379, $384,385,388,422,462,466,468,480,558,559,569,573,582,584,597,625$, $629,631,680,686,703,704,705,708,715,723,734,740,745$. 